\title{
Intervalência Metálica e Interações Eletrônicas em Sistemas Complexos Poliaza-Heterocíclicos
}

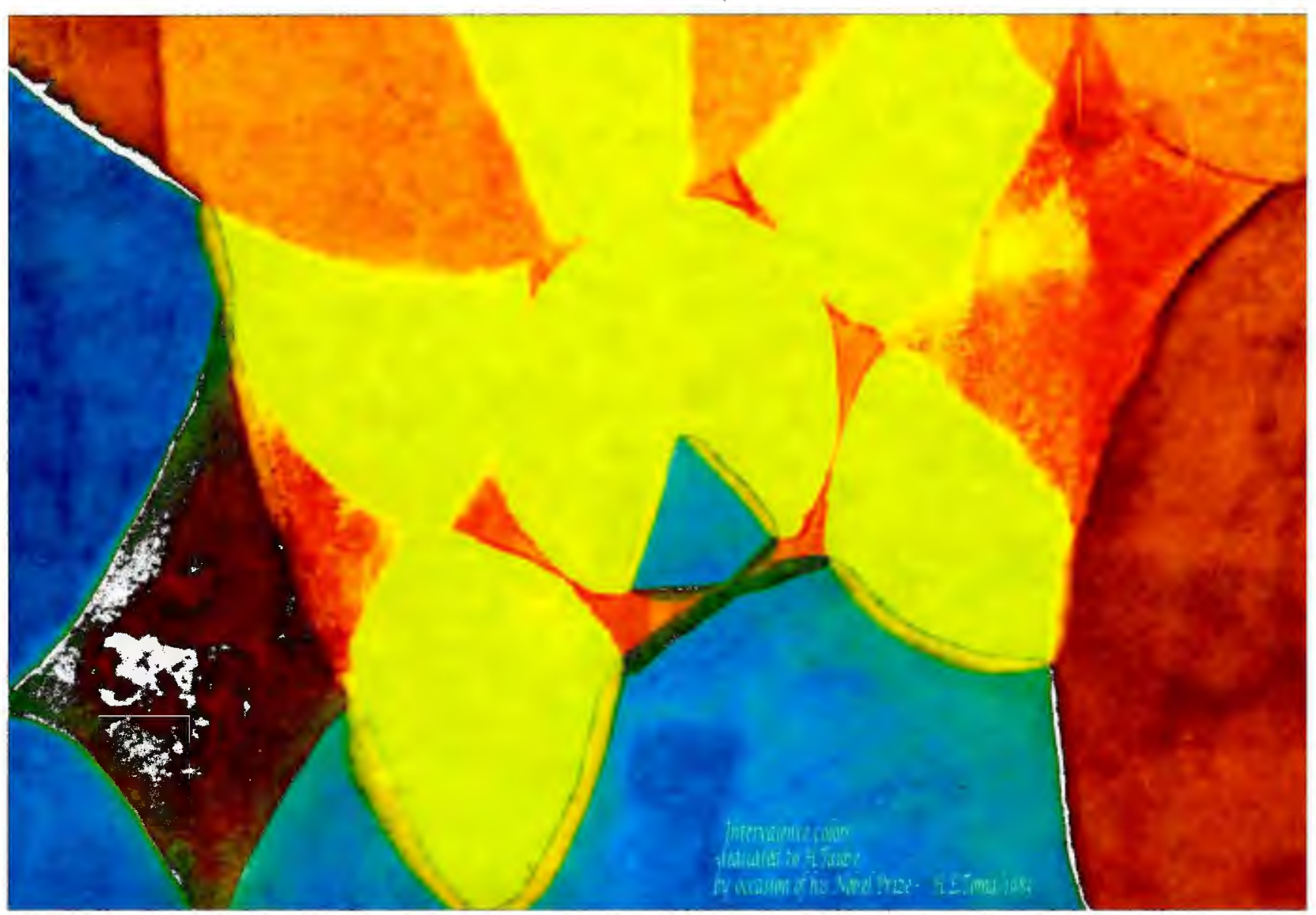

\section{Reginaldo C. Rocha}

10 - USP

2000 
Créditos pela gravura da capa frontal

Tema: "Intervalence Colors"

Obra de Henrique E. Toma, 1983

\footnotetext{
Pintura sobre papel utilizando "tintas"

preparadas a partir de soluções coloridas

de complexos de valência mista:

amarelo $\rightarrow \mathrm{Zn}_{3}\left[\mathrm{Fe}(\mathrm{CN})_{5}(\mathrm{pyCN})\right]_{2}$

azul $\rightarrow \mathrm{Fec}_{4}\left[\mathrm{Fe}(\mathrm{CN})_{6}\right]_{3}$ (azul da Prússia)

marrom $\rightarrow \mathrm{Cu}_{3}\left[\mathrm{Fe}(\mathrm{CN})_{5}(\mathrm{pyCN})\right]_{2}$

verde $\rightarrow \mathrm{Fe}\left[\mathrm{Fe}(\mathrm{CN})_{5}(\mathrm{pyCN})\right]$

vermelho $\rightarrow \mathrm{Ni}_{3}\left[\mathrm{Fe}(\mathrm{CN})_{5}(\mathrm{pyCN})\right]_{2}$
}

Um tributo a HENRY TAUBE

em reconhecimento à importância de sua contribuição no campo da química de valência mista. 


\title{
UNIVERSIDADE DE SÃO PAULO INSTITUTO DE QUÍMICA
}

Intervalência Metálica e Interações Eletrônicas em Sistemas Complexos Poliaza-Heterocíclicos

\section{Reginaldo César Rocha}

\author{
Tese de Doutoramento
}

Orientador: Prof. Dr. Henrique E. Toma

São Paulo

$01 / 12 / 2000$ 


\section{DEDALUS - Acervo - CQ}

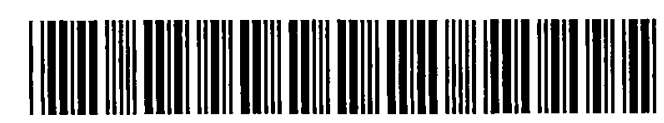

30100003729

Ficha Catalográfica

Elaborada pela Divisão de Biblioteca e

Documentação do Conjunto das Químicas da USP.

\section{Rocha, Reginaldo César}

R672i lntervalência metálica e interaçðes eletrônicas em sistemas complexos poliaza-heterocíclicos / Reginaldo César Rocha. -São Paulo, 2000. 140p.

Tese (doutorado) - Instituto de Quimica da Universidade de Sao Paulo. Departamento de Química Fundamental. Orientador: Toma, Henrique Eisi

1. Composto de coordenação : Química inorgânica 2. Rutênio: Química inorgânica 3. Ferro: Quimica inorgânica 4. Eletroquímica 5. Espectroscopia I. T. Il. Toma, Henrique Eisi, orientador. 


\section{Întervalência Metálica e Interações Eletrônicas em Sistemas Complexos Poliaza- Heterocíclicos".}

\section{REGINALDO CÉSAR ROCHA}

Tese de Doutorado submetida ao Instituto de Quimica da Unioersidade de Sấo Paulo como parte dos requisitos necessários à obtençăo do grau de Doutor em Ciências - भ́'rea: Química 9norgânica.

\section{Aprovada por:}

Prof. Dr. HENRIQUE EISI TOMA
IQ - USP
(Orientador e Presidente)

\footnotetext{
Profa. Dra. NEYDE YUKIE MURAKAMI IHA

IQ - USP

Prof. Dr. GIANLUCA CAMILLO AZZELLINI

IQ - USP

Prof. Dr. ALZIR AZEVEDO BATISTA

UFSC

Prof. Dr. LUIS ANTONIO ANDRADE DE OLIVEIRA

IQ - UNESP - Araraquara 
In memorian

"The best way to have a good idea is to have lots of ideas."

\section{Linus C. PAUling, 1901-1994}

(Cientista, professor e humanitário)

Prêmio Nobel de Química - 1954

Prêmio Nobel da Paz - 1962

Ao Prof. Dr. Henrique E. Toma,

pela sua inestimável contribuição à

Química Inorgânica na Terra Brasilis 


\section{Agradecimentos}

Ao Prof. Dr. Henrique E. Toma, pela acolhida no Laboratório de Química Inorgânica e pela orientação.

À Dra. Francisca N. Rein, pelos trabalhos em colaboração e, acima de tudo, pela amizade.

Ao Prof. Dr. Koiti Araki, pelo acompanhamento durante a iniciação científica.

Aos atuais colegas Dra. Anamaria, Fábio, Dr. Fauze, Gregoire, Herbert, Hiroshi, Dra. Izilda, Luís Fernando, Makoto, Marcelo, Dr. Pellegrino, Sergio, Sheila, Sofia, e Vagner, e aos colegas que outrora integraram o grupo, pela contribuição, companheirismo e momentos de descontração.

A todos os colegas do B2T, por toda ajuda prestada e pela agradável convivência.

Aos professores do Instituto de Química da USP, pelos conhecimentos transmitidos e, em especial, aos do B2T - Drs. Ana Maria da C. Ferreira, Denise de O. Silva, Gianluca C. Azzellini, Neyde Y. M. Iha, Vera R. L. Constantino e Viktoria K. L. Osório - pelos conselhos e motivação.

Às funcionátias do B2T - Alzilene, Cida e Ivone - pelo auxilio e pela agradável convivência.

Aos professores que ministraram os cursos de pós-graduação e aos que supervisionaram as atividades de monitoria durante o mesmo período - Drs. Ana Maria C. Ferreira, Fernando R. Ornellas, Hentique E. Toma, Hermi F. Brito, Neyde Y. M. Iha, Paulo S. Santos, Vera R. L. Constantino, Viktoria K. L. Osorio - pelos ensinamentos e contribuição profissional.

Aos meus amigos e à minha familia, dos quais nunca me faltou estímulo, incentivo e apoio.

A todos aqueles anônimos que sempre contribuem direta ou indiretamente para as grandes realizações.

Ao Conselho Nacional de Desenvolvimento Científico e Tecnológico (CNPq) e à Fundação de Amparo à Pesquisa do Estado de São Paulo (FAPESP), pelas bolsas concedidas.

Ao Instituto de Química da Universidade de São Paulo pelo apoio institucional e pelas facilidades oferecidas. 


\section{Índice}

Nomes e Fórmulas de Compostos ……..................................................................................ii

Lista de Abreviaturas .................................................................................................................

Simbologia e Unidades Métricas .......................................................................................

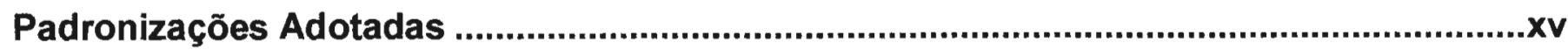

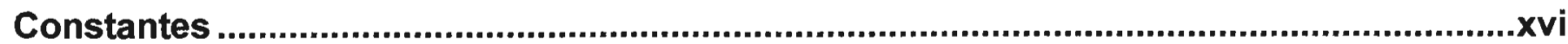

Conversores e Equivalências Úteis......................................................................................

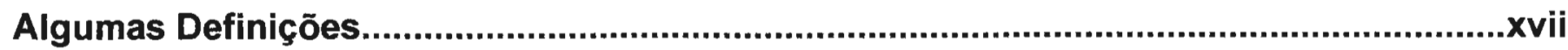

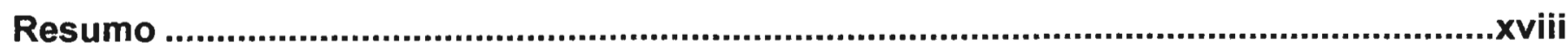

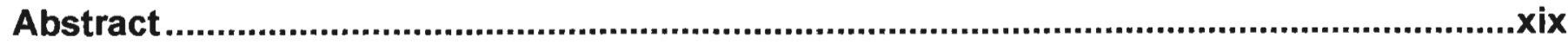

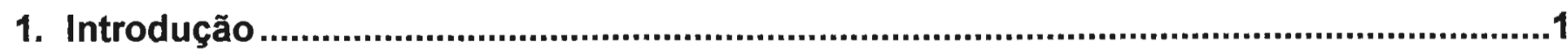

1.1. Transferência de elétrons ................................................................................................ 1

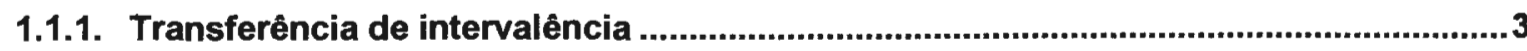

1.2. Sistemas de valência mista .............................................................................................. 4

1.2.1. Tipos e classificação de sistemas de valência mista ........................................................5

1.2.2. Reação de comproporcionamento ..................................................................................6

1.2.3. Acoplamento eletrônico e deslocalizaçăo.........................................................................

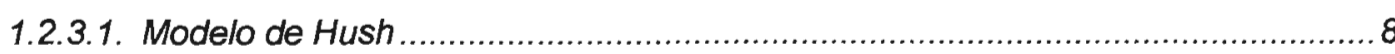

1.2.3.2. Algumas relaçס̃es de Marcus-Hush .............................................................. 9

1.2.4. Critérios de distinção entre classe II e classe III.........................................................11

1.2.5. Uma breve visão da química de valência mista atual.....................................................11

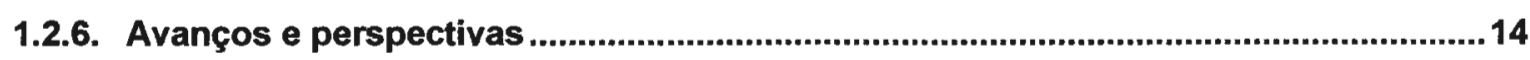

1.3. Eletrônica molecular................................................................................................................. 15

1.3.1. Dispositivos moleculares.............................................................................................15

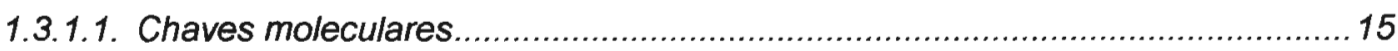

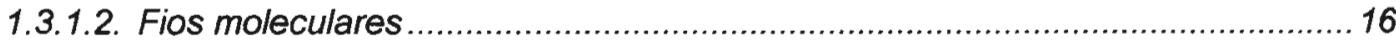


1.4. Reações redox próton-acopladas (PCET)................................................................. 18

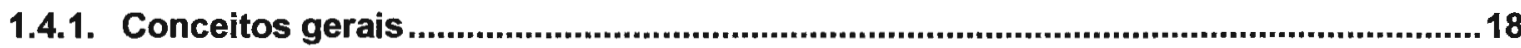

1.5. Isomeria de ligaçăo............................................................................................................. 20

1.5.1. Alguns exemplos de isômeros de ligação.....................................................................21

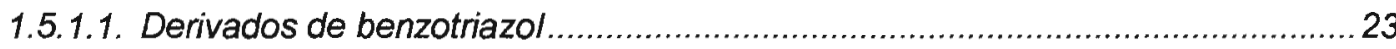

1.6. Os ligantes benzotriazol e benzoimidazol .................................................................. 24

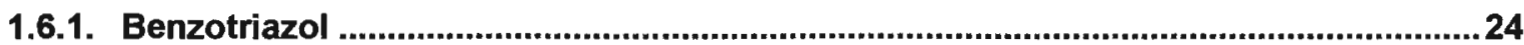

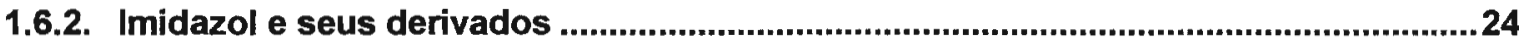

1.7. Complexos derivados de rutênio e ferro .................................................................... 25

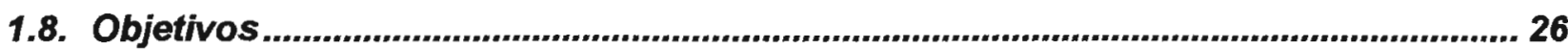

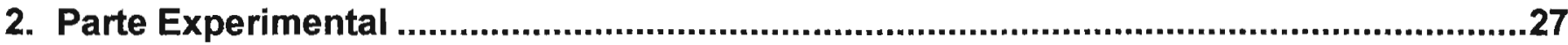

2.1. Síntese e preparação dos compostos............................................................................ 27

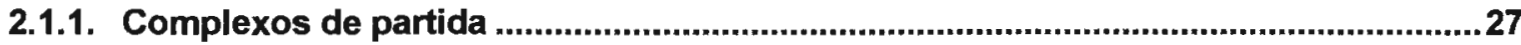

2.1.2. Ligantes $\mathrm{N}$-heterocíclicos (benzotriazol e benzoimidazol) ........................................27

2.1.3. Complexos mononucleares ............................................................................................27

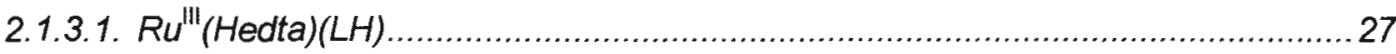

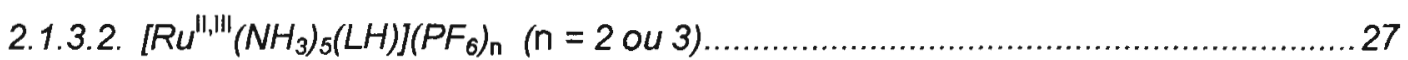

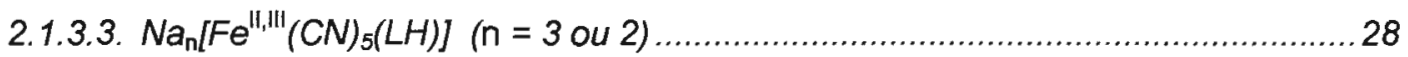

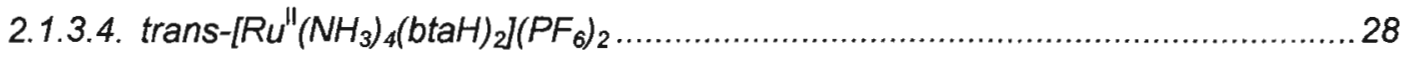

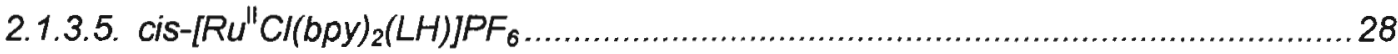

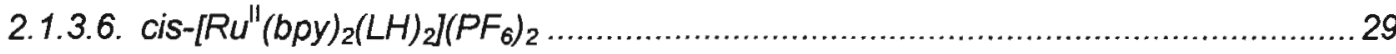

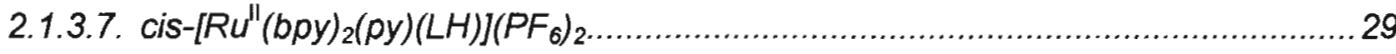

2.1.4. Complexos binucleares simétricos.................................................................................... 29

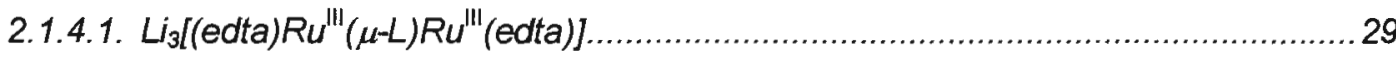

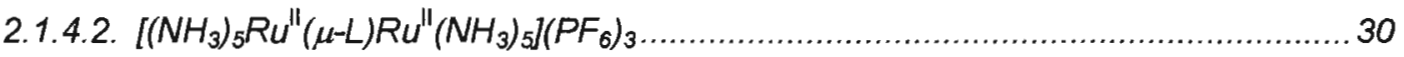

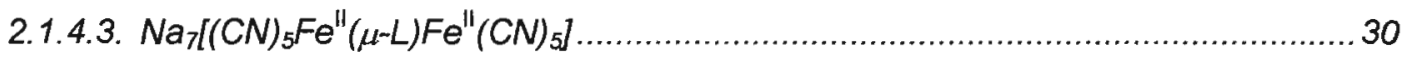

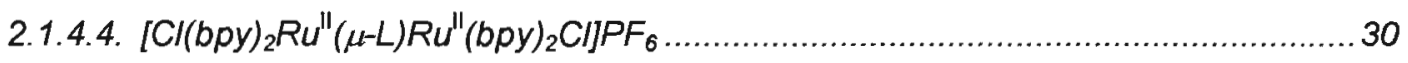

2.1.5. Complexos binucleares assimétricos............................................................................... 30 
2.1.5.1. [(edta)Ru $\left.u^{I I I}(\mu-L) R u^{I I, I I I}\left(N H_{3}\right)_{5}\right]\left(P F_{6}\right)_{n}(n=0$ ou 1) 30

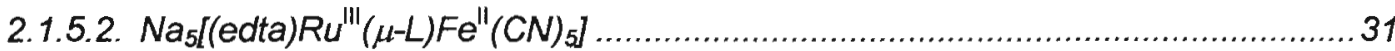

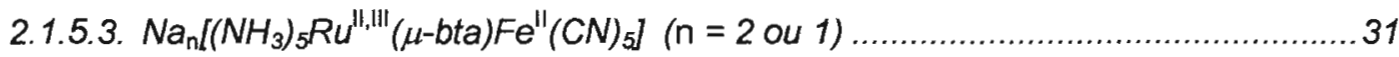

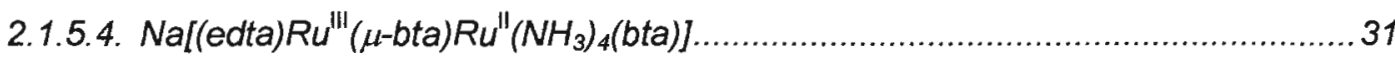

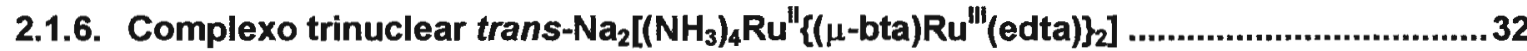

2.1.7. Preparação de alguns sais..................................................................................32

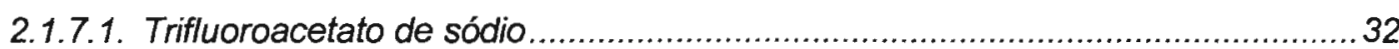

2.1.7.2. Perclorato de tetraetilamónio ..................................................... 32

2.1.8. Preparação de soluçð̋es dos complexos................................................................32

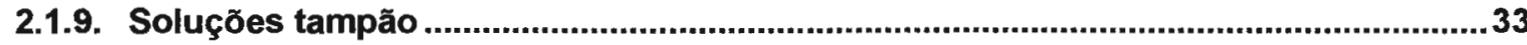

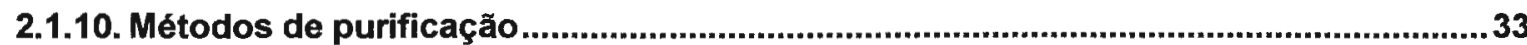

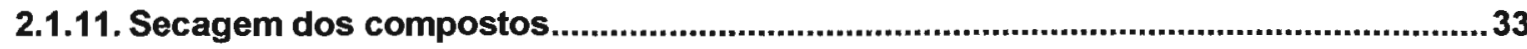

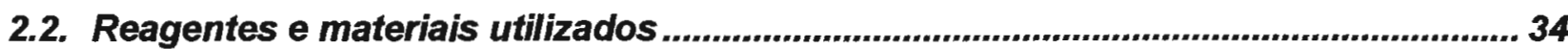

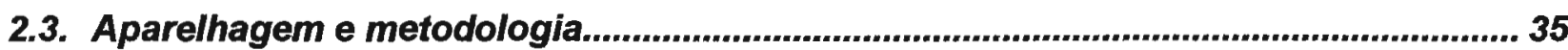

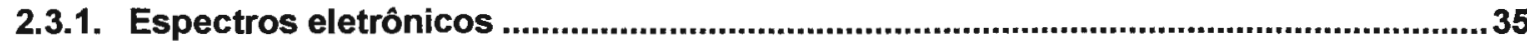

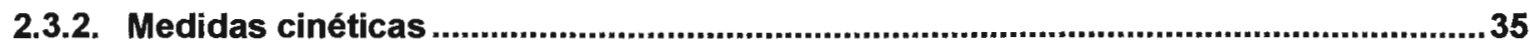

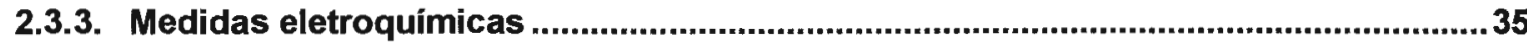

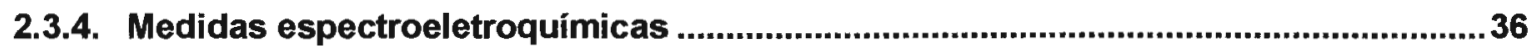

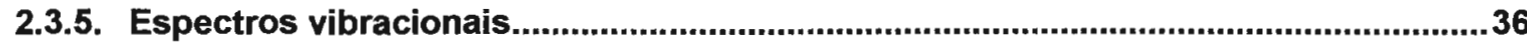

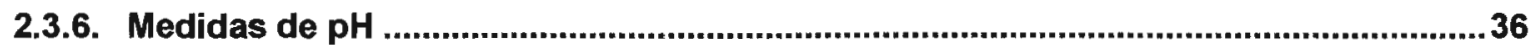

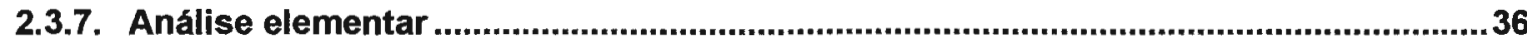

2.3.8. Cálculos quânticos e modelagem molecular ...........................................................37

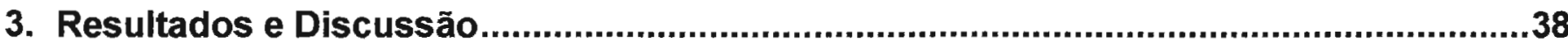

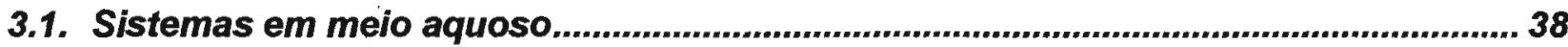

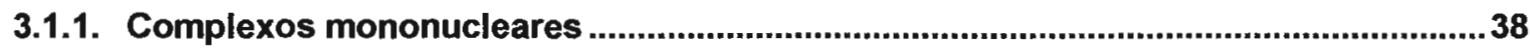

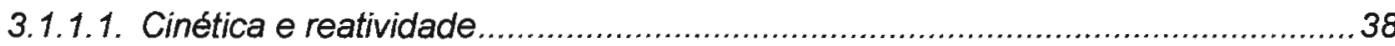

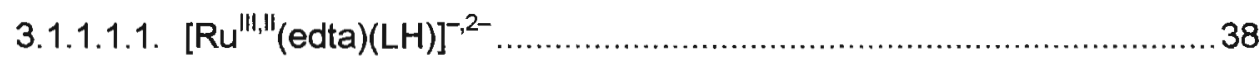

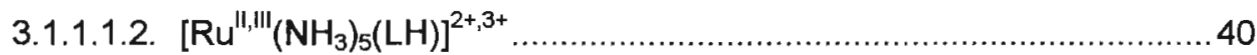

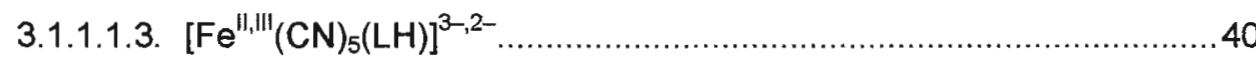


3.1.1.2. Isomeria de ligação 41

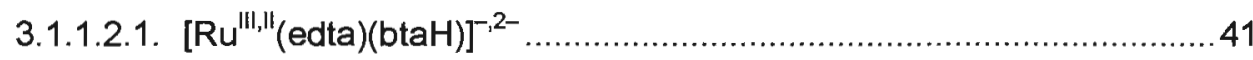

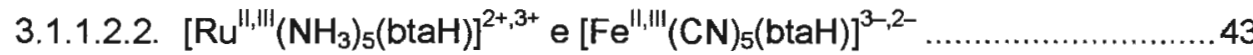

3.1.1.3. Eletroquímica e espectroeletroquímica ......................................... 43

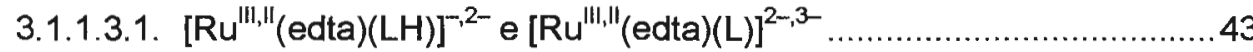

3.1.1.3.2. $\left[\mathrm{Ru}^{\mathrm{II}, \mathrm{Ill}}\left(\mathrm{NH}_{3}\right)_{5}(\mathrm{bimH})\right]^{2+, 3+}$ e $\left[\mathrm{Ru}^{\mathrm{II}, \mathrm{III}}\left(\mathrm{NH}_{3}\right)_{5}(\mathrm{bim})\right]^{+, 2+} \ldots \ldots \ldots \ldots \ldots \ldots \ldots \ldots . . \ldots 5$

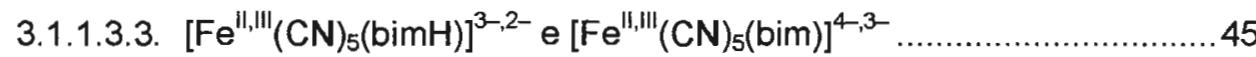

3.1.1.3.4. Comparação dos espectros eletrônicos .................................46

3.1.1.4. Reações de transferência de elétrons próton-acopladas (PCET) ....................47

3.1.1.4.1. Comparação geral .................................................... 49

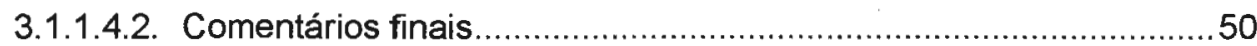

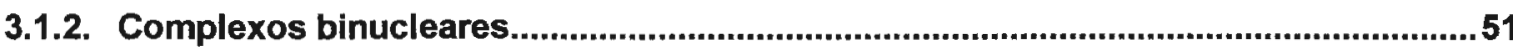

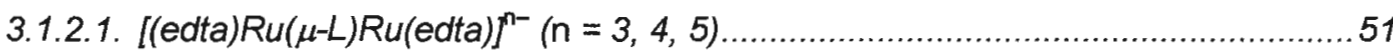

3.1.2.1.1. Eletroquímica e espectroeletroquimica .............................. 51

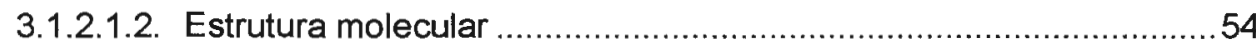

3.1.2.1.3. Propriedades de intervalência ......................................... 54

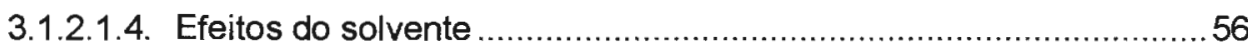

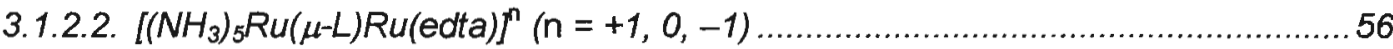

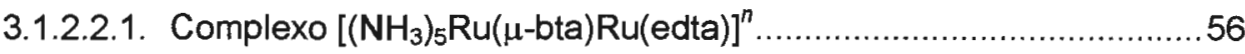

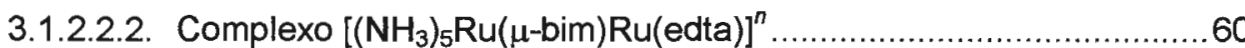

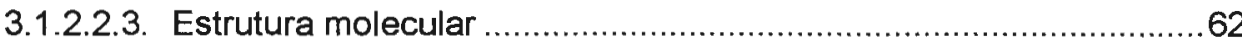

3.1.2.2.4. Propriedades de intervalência ............................................63

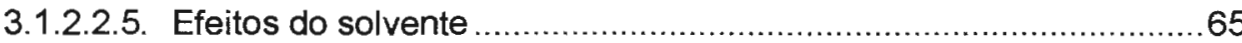

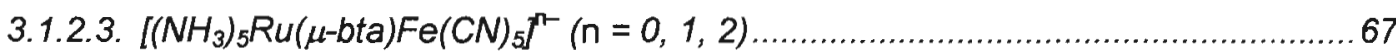

3.1.2.3.1. Propriedades redox e termodinâmicas .................................67

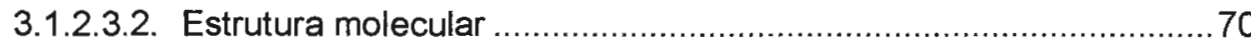

3.1.2.3.3. Propriedades de valência mista .......................................... 71

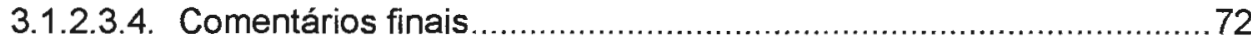

3.1.2.3.5. Comparação geral de uma série .......................................... 73 


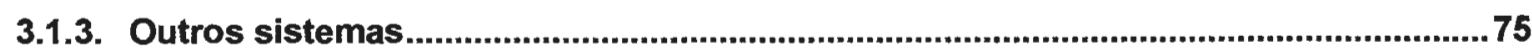

3.1.3.1. Complexo binuclear $\left\{\{(\text { edta }) R u\}_{2}(\mu \text {-bta })\right\}^{4}$ : "molecular switching" .....................75

3.1.3.1.1. Propriedades eletroquímicas ......................................................75

3.1.3.1.2. Propriedades espectroeletroquímicas ......................................76

3.1.3.1.3. Reatividade, estrutura e propriedades gerais ................................78

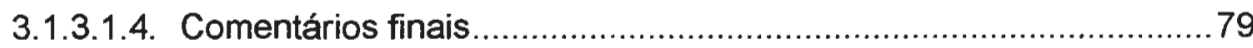

3.1.3.2. Complexo trinuclear $\mathrm{Na}_{2}\left[\left(\mathrm{NH}_{3}\right)_{4} R u\{(\text { bta }) R u(e d t a)\}_{2}\right]$ : "molecular wires" ..............81

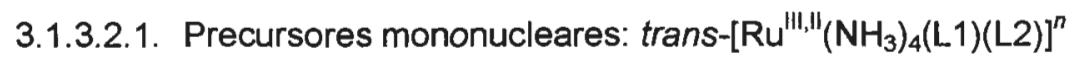

$$
\left(\mathrm{L}_{1}=\mathrm{btaH} / \mathrm{bta}^{-} ; \mathrm{L} 2=\mathrm{btaH} / \mathrm{bta}^{-} ; n=3,2,1,0\right) \text {. }
$$

3.1.3.2.2. Precursor binuclear: trans-[(L)Ru( $\left(\mathrm{NH}_{3}\right)_{4}(\mu-b t a) \mathrm{Ru}($ edta $\left.)\right]^{n-}$

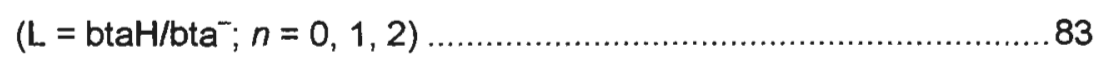

3.1.3.2.3. Complexo trans-[($\left.\left(\mathrm{NH}_{3}\right)_{4} \mathrm{Ru}\{(\mathrm{bta}) \mathrm{Ru}(\mathrm{edta})\}_{2}\right]^{n-}(n=1,2,4) \ldots \ldots \ldots \ldots . . .86$

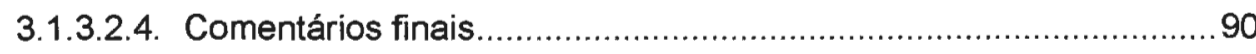

3.2. Sistemas em meio orgânico .................................................................................. 92

3.2.1. Síntese e purificação dos compostos............................................................................92

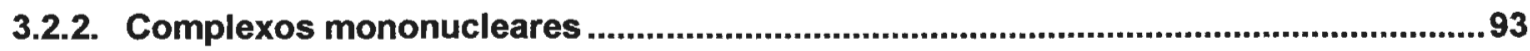

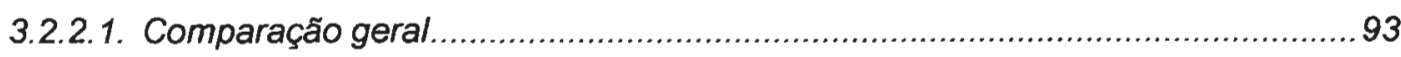

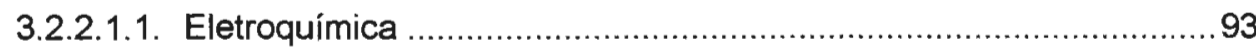

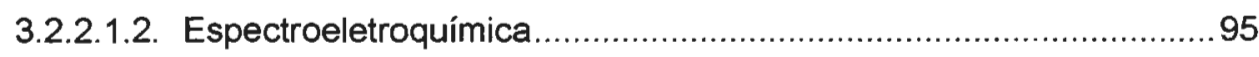

3.2.2.1.3. Correlação das propriedades eletrônicas e redox ............................99

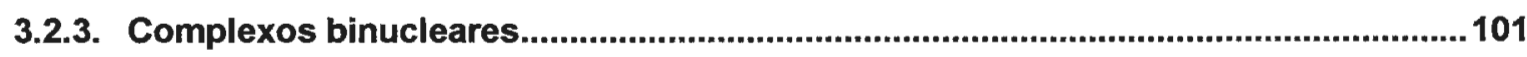

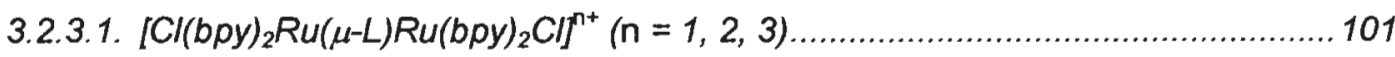

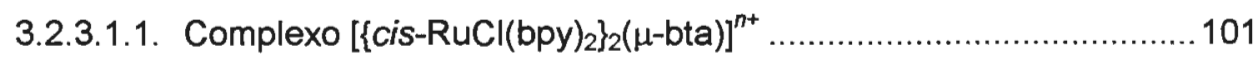

3.2.3.1.2. Complexo $\left[\{\text { cis-RuCl(bpy })_{2}\right\}_{2}(\mu \text {-bim) }]^{n+\ldots \ldots \ldots \ldots \ldots \ldots \ldots \ldots \ldots \ldots \ldots \ldots} 102$

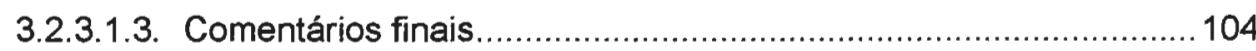

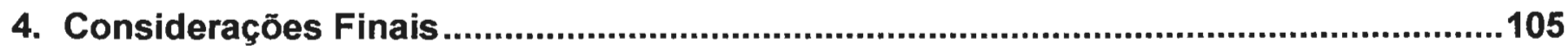

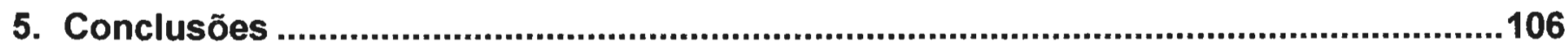


6. Apêndices. 108

6.1. A base do formalismo de Hush 108

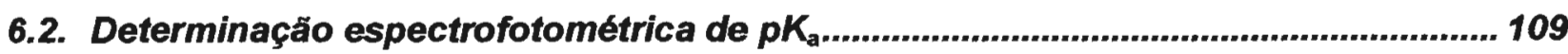

6.3. Ciclo termodinåmico: avaliaçăo de $K_{\text {eq }}$........................................................................................ 110

6.4. Material suplementar 111

6.4.1. Parâmetros ácido-base, redox e termodinâmicos para complexos

de ferro e rutênio de partida em química de solução aquosa

6.4.2. Constantes de dissociação ácida e espectros eletrônicos

dos ligantes de partida. 112

6.4.3. Dados eletroquímicos e espectrais para alguns complexos

de rutênio-polipiridina de partida ou substituídos em meio orgânico 112

6.4.3.1. Complexos de partida

6.4.3.1.1. cis- $\mathrm{RuCl}_{2}(\mathrm{bpy})_{2}$

6.4.3.1.2. $\operatorname{cis}-\left[\mathrm{RuCl}(\mathrm{bpy})_{2}(\mathrm{py})\right]^{+}$

6.4.3.2. Complexos cis- $\left[R u C l(b p y)_{2}(L H)\right]^{n+}(n=0,1,2)$

6.4.3.2.1. $\mathrm{LH}=\mathrm{btaH}$

6.4.3.2.2. $\mathrm{LH}=\mathrm{bimH}$

6.4.3.3. Complexos cis- $\left[R u(b p y)_{2}(L H)_{2}\right]^{n+}(n=1,2,3)$

6.4.3.3.1. $\mathrm{LH}=\mathrm{btaH}$ 115

6.4.3.3.2. $\mathrm{LH}=\mathrm{bimH}$ 116

6.4.3.4. Complexos cis- $\left[R u(b p y)_{2}(p y)(L H)\right]^{n^{+}}(n=1,2,3)$. 116

6.4.3.4.1. $\mathrm{LH}=\mathrm{btaH}$ 116

6.4.3.4.2. $\mathrm{LH}=\mathrm{bimH}$

6.4.4. Parâmetros de intervalência de uma série de complexos de valência mista 118

6.5. Cálculo das constantes de velocidade de transferência de elétrons para uma série de sistemas de valência mista. 


\section{Nomes e Fórmulas de Compostos}

Nome $^{a}$

Aqua(etilenodiaminotetraacetato)rutenato(III)

Pentaaminclororutênio(III)

Aminpentacianoferrato(II)

Trans-tetraamindiclororutênio(III)

Cis-bis(2,2'-bipiridina)diclororutênio(II)
Fórmula

$\mathrm{Ru}(\mathrm{Hedta})\left(\mathrm{H}_{2} \mathrm{O}\right)$

$\left[\mathrm{RuCl}\left(\mathrm{NH}_{3}\right)_{5}\right]^{2+}$

$\left[\mathrm{Fe}(\mathrm{CN})_{5}\left(\mathrm{NH}_{3}\right)\right]^{3-}$

trans-[RuCl$\left.{ }_{2}\left(\mathrm{NH}_{3}\right)_{4}\right]^{+}$

cis- $\mathrm{RuCl}_{2}(\mathrm{bpy})_{2}$
Fórmula estrutural<smiles>O=C1CN2CCN(CC(=O)O2)[C@@](O)(C(=O)O)C(=O)O1</smiles><smiles></smiles><smiles>CCCCCCC#N</smiles><smiles></smiles>

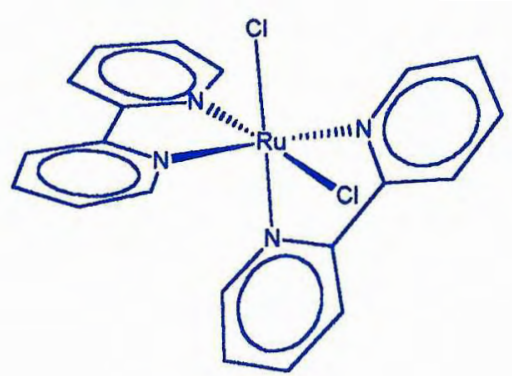

a Os nomes dos compostos de coordenação utilizados nesta tese foram baseados na nomenclatura de química inorgânica da IUPAC (International Union of Pure and Applied Chemistry) de $1990^{1}$ e traduzidos para a língua portuguesa conforme normas previamente estabelecidas. ${ }^{2}$ 


\section{Nome}

Aminopirazina

Benzoimidazol

Benzonitrila

1,2-Bis(4-piridil)etano

1,2-Bis(4-piridil)etileno

2,2'-Bipiridina

4,4'-Bipiridina

4,4'-bpy

bpy
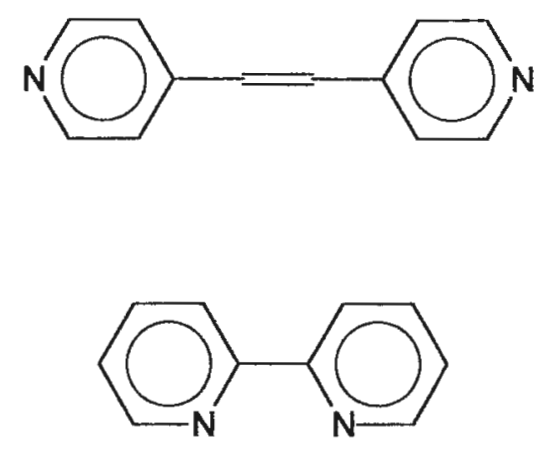

bn

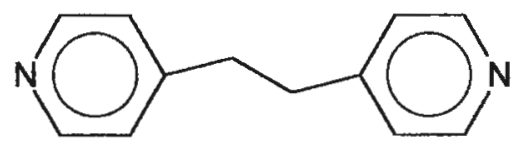

bpe

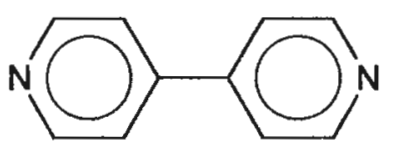

btaH

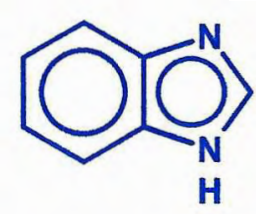

\section{Fórmula estrutural ${ }^{\mathrm{b}}$}<smiles>Nc1cnccn1</smiles>

H 


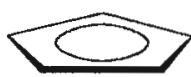

Dimetilacetamida

dma

Dimetilformamida

dmf

Dimetilsulfóxido

dmso

Ácido desoxirribonucléico

DNA

4,4'-Dipiridilamina

dpa

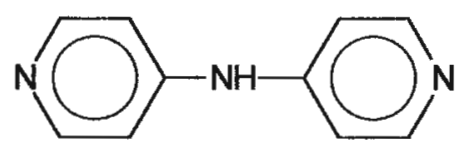

Etanol

etOH

Formamida

fma

Ácido acético

Hac

Ácido etilenodiaminotetraacético

$\mathrm{H}_{4}$ edta

Histidina

his<smiles>NC(Cc1cnc[nH]1)C(=O)O</smiles>

Ácido 3-hidroxipicolínico

$\mathrm{H}_{2}$ hpic<smiles>O=C(O)c1ncccc1O</smiles>

Ácido 2-mercaptonicotínico

$\mathrm{H}_{2}$ mnic<smiles>O=C(O)c1cccnc1S</smiles>

Ácido trifluoroacético

Htfa

Imidazol

$\mathrm{imH}$<smiles>c1c[nH]cn1</smiles> 
Isonicotinamida (4-piridinacarboxamida)

isn

Acetonitrila

Metanol

Nitrobenzeno

Nitrometano

2-(2-piridil)benzoimidazol

pbimH

Propilenocarbonato

Ácido 1,4-piperazinadietanossulfônico

p-Toluenossulfonato

Piridina

3-Cianopiridina

3-pyCN

pc

pipes

pts

py
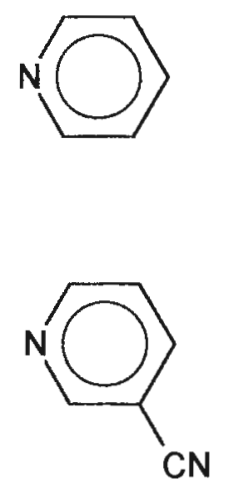

4-pyCN

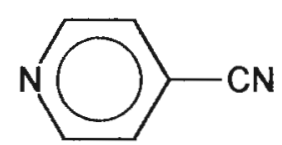

pym

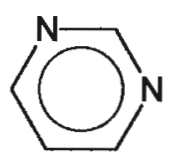

pySH
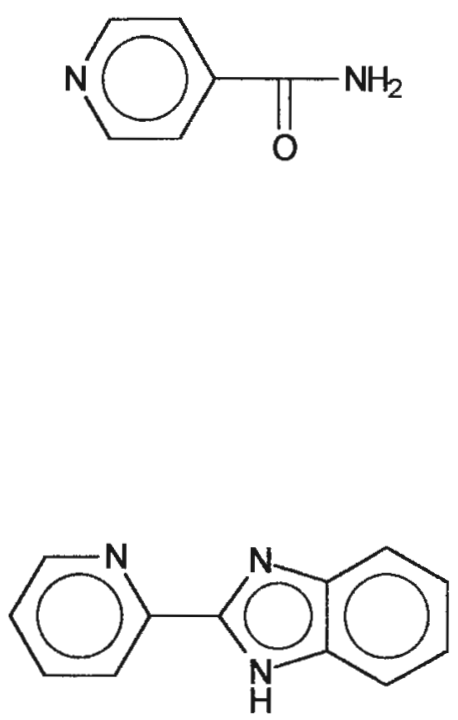

$\mathrm{CN}$

Pirimidina

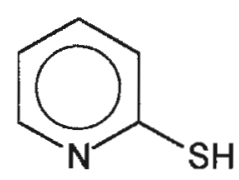


Pirazina

4-terc-Butilpiridina

tbpy

tea

Tetraetilamônio

2,2':6',2"-Terpiridina

terpy

tpyp

1H-Tetrazol

trz

tz

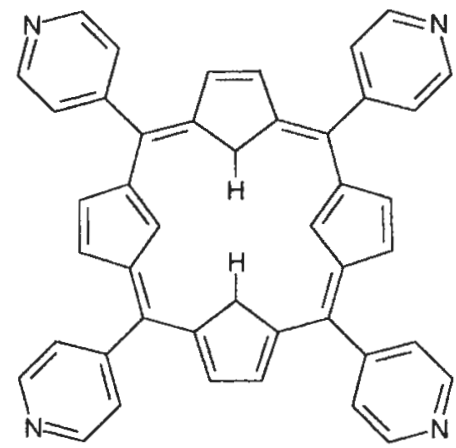<smiles>c1nnn[nH]1</smiles><smiles>c1nc[nH]n1</smiles><smiles>c1ccc(-c2cccc(-c3ccccn3)n2)nc1</smiles>

$\mathrm{H}$

$\mathrm{H}$ 


\section{Lista de Abreviaturas}

Nome

Centro aceitador de elétron(s) em uma reação redox

Transferência de carga

Centro doador de elétron(s) em uma reação redox

Voltametria de pulso diferencial

Eletrodo de calomelano saturado

Eletrodo padrão de hidrogênio

Ressonância paramagnética eletrônica

Equação

Equivalente químico ${ }^{\mathrm{a}}$

Esquema

Transferência de elétrons

Figura

Espectroscopia no infravermelho por transformada de Fourier

Orbital molecular ocupado de maior energia

Infravermelho

Transferência de intervalência

Transferência de carga de intervalência

Ligante de ponte (ou ligante-ponte) ${ }^{b}$

Ligante ionizável (ligante ácido)

Transferência de carga ligante-metal

\section{Abreviatura}

A

CT

D

DPV

ECS

EPH

EPR

Eq.

equiv

Esq.

ET

Fig.

FTIR

HOMO

IR

IT

IVCT

$L_{b}$

LH

LMCT

Quantidade (em massa) de um composto que reage totalmente com outra substância

b Na maioria dos casos, o ligante-ponte será representado simplesmente por $\mathrm{L}$. 
Orbital molecular não-ocupado de menor energia

Transferência de carga metal-ligante

Massa molar

Transferência de carga metal-metal

Orbital molecular (ou orbitais moleculares)

MO

Infravermelho próximo

NIR

Estado do produto (ou simplesmente produto)

$\mathbf{P}$

Transferência de elétrons próton-acoplada

PCET

(ou reação redox dependente do $\mathrm{pH}$ )

Por exemplo

p. ex.

Ponto de fusão

P.F.

Coordenadas nucleares ou de reação

$\boldsymbol{Q}$

Estado do reagente (ou simplesmente reagente)

$\mathbf{R}$

Referência ou referências (literatura)

ref.

Ressonância magnética nuclear

RMN

Espalhamento Raman intensificado pela superfície

SERS

Ombro

sh

Orbital molecular semipreenchido

SOMO

(ocupado por 1 elétron)

Microscopia de varredura por tunelamento

STM

Ultravioleta

UV

Vide (do latim videre: veja) ${ }^{a}$

v.

Voltametria cíclica (ou voltamograma cíclico)

VC

Visivel

Vis

Valência mista

VM

Versus (do latim vertere: contra)

vs.

\footnotetext{
a American Heritage Dictionary, $4^{a}$ ed., Houghton Mifflin Co., 2000.
} 


\section{Simbologia e Unidades Métricas}

\section{Grandeza}

Absorção óptica

Coeficiente de deslocalização

Caminho óptico de uma amostra absorvente

Concentração

Distância geométrica metal-metal

Constante difusional da espécie oxidada

Constante difusional da espécie reduzida

Largura de meia-banda

Potencial de redução padrão

Potencial redox ou de meia-onda

Potencial de onda anódica

Potencial de onda catódica

Energia de absorção óptica

Absortividade molar (em $\lambda_{\text {máx }}$ )

Constante dielétrica óptica

Constante dielétrica estática

Constante de força de ligação ou vibracional

Força do oscilador

Energia de ressonância ou de acoplamento eletrônico

Índice de refração

Corrente de pico anódico

Corrente de pico catódico

\author{
Símbolo
}

\section{Unidade}

adimensional

adimensional

$\mathrm{cm}$

$\mathrm{mol} \mathrm{dm} \mathrm{m}^{-3}$

ångström / $\AA\left(10^{-10} \mathrm{~m}\right)$

$D_{\text {ox }}$

$\mathrm{cm}^{2} \mathrm{~s}^{-1}$

$\mathrm{cm}^{2} \mathrm{~s}^{-1}$

$\Delta \bar{v}_{1 / 2}$

$\mathrm{cm}^{-1}\left(10^{2} \mathrm{~m}^{-1}\right)$

$E^{\circ}$

volt / V

$E_{1 / 2}$

volt / V

$E_{\mathrm{a}}$

volt / V

$E_{\mathrm{c}}$

volt / V

$E_{\text {op }}$

$\mathrm{cm}^{-1}\left(10^{2} \mathrm{~m}^{-1}\right)$

$\varepsilon_{\text {máx }}$

$\mathrm{mol}^{-1} \mathrm{dm}^{3} \mathrm{~cm}^{-1}\left(0,1 \mathrm{~m}^{2} \mathrm{~mol}^{-1}\right)$

$\varepsilon_{\text {op }}$

adimensional

$\varepsilon_{\mathrm{s}}$ adimensional

$\mathrm{N} \mathrm{m}^{-1}\left(\mathrm{~kg} \mathrm{~s}^{-2}\right)$

$\boldsymbol{f}_{\mathrm{osc}}$

adimensional

$H_{\mathrm{ab}}$

$\mathrm{cm}^{-1}\left(10^{2} \mathrm{~m}^{-1}\right)$

adimensional

$\eta$

$\boldsymbol{i}_{\mathbf{a}}$

microampère / $\mu \mathrm{A}\left(10^{-6} \mathrm{~A}\right)$

$i_{c}$ microampère $/ \mu \mathrm{A}\left(10^{-6} \mathrm{~A}\right)$

a Esta lista encontra-se ordenada alfabeticamente pela simbologia das grandezas associadas.

b V. definição posterior no item Algumas Definiçốes. 
Constante de equilíbrio

Constante $K$ para uma dissociação ácida simples

Constante $K$ para a reação de comproporcionamento

Constante cinética

Constante cinética de dissociação

Constante cinética de formação

Energia de reorganização

Energia reorganizacional de esfera interna

Energia reorganizacional de esfera externa

Comprimento de onda de absorção máxima

Massa

Momento de transição

Momento de dipolo elétrico

Quantidade de matéria

Freqüência

Número de onda

Carga

Temperatura

Tempo

Velocidade de varredura de potencial

Volume

$$
\text { K }
$$$$
K_{a}
$$

$K_{c}$

$\boldsymbol{k}$

$\boldsymbol{k}_{\mathrm{d}}$

$k_{t}$

$\lambda$

$\lambda_{i}$

$\lambda_{\mathrm{o}}$

$\lambda_{\text {máx }}$

$m$

M

$\mu$

n

V

$\overline{\mathbf{v}}$

$Q$

$T$

$t$

v

V der. a partir de C

$$
\mathrm{mol} \mathrm{dm}^{-3}
$$

adimensional

der. a partir de $C$ et

der. a partir de $C$ e $t$

der. a partir de $C$ e $t$

$\mathrm{cm}^{-1}$

$\mathrm{cm}^{-1}$

$\mathrm{cm}^{-1}$

$\mathrm{nm}\left(10^{-9} \mathrm{~m}\right)$

$\mathrm{mg}\left(10^{-3} \mathrm{~g}\right)$

C m

debye / $\mathrm{D}\left(3,34 \times 10^{-30} \mathrm{C} \mathrm{m}\right)$

$\mathrm{mmol}\left(10^{-3} \mathrm{~mol}\right)$

$\mathrm{s}^{-1}$ (hertz / Hz)

$\mathrm{cm}^{-1}\left(10^{2} \mathrm{~m}^{-1}\right)$

coulomb / C

kelvin / $\mathrm{K}$

s

$\mathrm{mV} \mathrm{s}^{-1}$

$\mathrm{dm}^{3}\left(10^{-3} \mathrm{~m}^{3}\right)$ ou $\mathrm{cm}^{3}\left(10^{-6} \mathrm{~m}^{3}\right)$

\section{Padronizações Adotadas}

Unidades. Todas as unidades de medida encontram-se padronizadas pelo Sistema International de pesos e medidas (SI).

Referências. A formatação das citações e das correspondentes referências bibliográficas (listadas no final da tese) segue os padrões sugeridos pela Sociedade Brasileira de Química para o Journal of the Brazilian Chemical Society. ${ }^{2}$

A lista de abreviações para periódicos foi padronizada de acordo com o Webofscience (base de dados do ISI Institute for Scientific Information; serviço disponível às instituições brasileiras através da FAPESP). ${ }^{\text {b }}$

a url: http://www.sbq.org,br/jbcs/authors.pdf (Instructions for Authors 2000, p 3).

b url: http://webofscience.fapesp.br 


\section{Constantes}

Constante fundamental ${ }^{3}$

Carga elementar

Constante de Avogadro

Constante de Boltzmann

Constante de Faraday

Constante de Planck

Constante dos gases

Permissividade do vácuo

Unidade de massa atômica $^{\text {b }}$

\author{
Simbologia
}

e

$\boldsymbol{N}_{\mathbf{A}}$

$\boldsymbol{k}_{\mathrm{B}}\left(=R / N_{\mathrm{A}}\right)$

$\boldsymbol{F}\left(=e N_{\mathrm{A}}\right)$

h

$h(=h / 2 \pi)$

$\boldsymbol{R}\left(=k_{\mathrm{B}} N_{\mathrm{A}}\right)$

$\varepsilon_{0}$

$4 \pi \varepsilon_{0}$

$\boldsymbol{u}$

\section{Unidade}

$$
1,60218 \times 10^{-19} \mathrm{C}
$$

$6,02214 \times 10^{23} \mathrm{~mol}^{-1}$

$1,38066 \times 10^{-23} \mathrm{~J} \mathrm{~K}^{-1}$

$9,64853 \times 10^{4} \mathrm{C} \mathrm{mol}^{-1}$

$6,62608 \times 10^{-34} \mathrm{~J} \mathrm{~s}$

$1,05457 \times 10^{-34} \mathrm{~J} \mathrm{~s}$

$8,3145 \mathrm{~J} \mathrm{~mol}^{-1} \mathrm{~K}^{-1}$

$8,20578 \times 10^{-2} \mathrm{dm}^{3} \mathrm{~atm} \mathrm{~K} \mathrm{~mol}^{-1}$

$8,85419 \times 10^{-12} \mathrm{~J}^{-1} \mathrm{C}^{2} \mathrm{~m}^{-1}$

$1,11265 \times 10^{-10} \mathrm{~J}^{-1} \mathrm{C}^{2} \mathrm{~m}^{-1}$

$1,66054 \times 10^{-27} \mathrm{~kg}$

\section{Conversores e Equivalências Úteis}

$1 \mathrm{eV}=96,4851 \mathrm{~kJ} \mathrm{~mol}^{-1}=23,0605 \mathrm{kcal} \mathrm{mol}^{-1}=8065,51 \mathrm{~cm}^{-1} \mathrm{c}$

$$
\begin{gathered}
R T=2,4790 \mathrm{~kJ} \mathrm{~mol}^{-1} \mathrm{~d} \\
R T / F=25,693 \mathrm{mV} \\
2,3026 \times R T / F=59,160 \mathrm{mV} d \\
T(\mathrm{~K})=T\left({ }^{\circ} \mathrm{C}\right)+273,15
\end{gathered}
$$

\footnotetext{
a V. conversores de energia abaixo.

b Os valores de massa atômica usados neste trabalho foram obtidos da Tabela de Massas Atômicas dos Flementos (1989) da Comissão de Massas Atômicas da IUPAC. ${ }^{4}$ As unidades de massa são normalizadas em relação à massa atômica do isótopo mais comum do carbono: $A_{\mathrm{r}}\left({ }^{12} \mathrm{C}\right)=12$.

c $\mathrm{J}=$ joule; $\mathrm{cal}=$ caloria; $\mathrm{eV}=$ elétron-volt $(1 \mathrm{eV}=1 \mathrm{~V}$ para um processo monoeletrônico $)$.

d $T=298,15 K$.
} 


\section{Largura de meia-banda}

Ombro

Par de ondas reversivel

Par de ondas quase-reversível

Potencial redox ou de meia-onda

Potencial de redução

Potencial de onda anódica

Potencial de onda catódica

\section{Algumas Definições}

A largura de meia-banda (que será designada pelo símbolo $\Delta \overline{\mathbf{v}}_{12}$ ) será tomada pela largura da banda no ponto equivalente à metade da absorção máxima da amostra. Isto é, $\Delta \bar{v}$ em $A=A_{\text {máx }} / 2$.

Entende-se por "ombro" (que será designado pela abreviatura sh), uma banda de absorção ou uma onda voltamétrica não-resolvidas. Isto é, em seu correspondente espectro ou voltamograma, ela aparece recoberta/sobreposta por uma similar de maior ou mesma intensidade, tornando difícil uma avaliação precisa de suas características.

A reversibilidade eletroquímica será assumida, neste trabalho, quando o VC do sistema em estudo a baixas velocidades de varredura $\left(\leq 50 \mathrm{mV} \mathrm{s}^{-1}\right)$ satisfizer as seguintes condiçōes: $\Delta E=E_{\mathrm{a}}-E_{\mathrm{c}} \approx 60 \mathrm{mV}$ e $i_{\mathrm{a}} / i_{\mathrm{c}} \approx 1$.

A quase-reversibilidade será assumida, neste trabalho, quando o $V C$ do sistema em estudo satisfizer as condiçōes $\left(V \leq 50 \mathrm{mV} \mathrm{s}^{-1}\right)$ : $80 \mathrm{mV}<\Delta E_{\mathrm{p}}<200 \mathrm{mV}$ e $i_{\mathrm{a}} l_{\mathrm{c}} \sim 1$.

Calculado pela média dos potenciais de ondas anódica e catódica (para um processo reversível): $E_{1 / 2}=1 / 2\left(E_{\mathrm{a}}+E_{\mathrm{c}}\right.$ ).

Aproximado por $E_{1 / 2}$ (para um sistema reversível).

$E_{\mathrm{a}}=$ potencial correspondente ao valor máximo de corrente (corrente de pico anódico, $i_{a}$ ) para o processo envolvendo a oxidação do sistema.

$E_{\mathrm{c}}=$ potencial correspondente ao valor mínimo de corrente (corrente de pico catódico, $i_{c}$ ) para o processo envolvendo a redução do sistema.

a Nesta definição, assurne-se que $D_{o x} \cong D_{\text {red. }}$. Para fins práticos essa aproximação é verdadeira na grande maioria dos íons complexos. ${ }^{5,6}$ 


\section{Resumo}

Neste trabalho, estudou-se a química de uma série de complexos binucleares de rutênio(III/II) e ferro(III/II) com ligantes $\mathrm{N}$-heterocíclicos. Particularmente, foram empregados os íons $\left[\mathrm{Ru}^{\mathrm{IIIII}}(\mathrm{edta})\right]^{-, 2-},\left[\mathrm{Ru}^{\mathrm{IIII}}\left(\mathrm{NH}_{3}\right)_{5}\right]^{3+, 2+}$, $\left[\mathrm{Ru}^{\mathrm{III}, \mathrm{I}} \mathrm{Cl}(\mathrm{bpy})_{2}\right]^{2+,+}$ e $\left[\mathrm{Fe}^{\mathrm{III}, \mathrm{II}}(\mathrm{CN})_{5}\right]^{2-3-}$ como unidades metálicas terminais e benzotriazol ou benzoimidazol e seus derivados aniônicos como ligantes do tipo ponte. Sistemas simétricos, $\mathrm{M}_{\mathrm{a}}-\mathrm{L}-\mathrm{M}_{\mathrm{a}}$, e assimétricos, $\mathrm{M}_{\mathrm{a}}-\mathrm{L}-\mathrm{M}_{\mathrm{b}}$, foram sintetizados e caracterizados em soluções aquosa ou orgânica por meio de técnicas convencionais de espectroscopia eletrônica e eletroquímica. Ênfase especial foi dada à investigação das propriedades de intervalência metálica associadas aos complexos de valência mista. Além disso, a aplicação de modelos teóricos como ferramenta de interpretação de processos de transferência eletrônica intramolecular fotoinduzidos (transferência de carga de intervalência), ou de interações eletrônicas do tipo metalmetal, foi largamente explorada tanto para sistemas de valência localizada como para sistemas com cargas parcialmente deslocalizadas.

Com o objetivo de compreender melhor as propriedades dos complexos binucleares, uma investigação detalhada da reatividade e da química redox das espécies mononucleares de partida também foi desenvolvida. Nesse caso, destacamse dois assuntos investigados em maior profundidade: a ocorrência de isomeria de ligação (no caso particular dos derivados de benzotriazol) e a presença de transferência de elétrons próton-acoplada em solução aquosa.

O conhecimento químico das entidades moleculares mais discretas permitiu dirigir o estudo para o planejamento de estruturas estendidas do tipo "fios moleculares", pela utilização dos mesmos espaçadores das espécies bimetálicas em complexos trinucleares do tipo $\mathrm{M}_{\mathrm{a}}-\mathrm{L}-\mathrm{M}_{\mathrm{b}}-\mathrm{L}-\mathrm{M}_{\mathrm{a}}$, com notável comunicação eletrônica entre os sítios metálicos através do ligante-ponte condutor. Avanços no estudo da influência do $\mathrm{pH}$ sobre as propriedades eletrônicas de sistemas de valência mista também revelaram a existência de um pronunciado efeito do tipo "liga/desliga" (induzido por próton) na comunicação eletrônica intermetálica destas espécies. Tal exemplo de dispositivo do tipo "chave molecular" proporciona um excelente modelo na busca por materiais com potencial emprego em nanotecnologia e/ou eletrônica molecular, cuja idéia se insere na concepção de desenvolvimento de estruturas supermoleculares, no âmbito das diversas linhas de pesquisa do laboratório onde o projeto foi desenvolvido. 


\section{Abstract}

The chemistry of a series of binuclear ruthenium(III/II) and iron(III/II) complexes with $\mathrm{N}$-heterocyclic ligands was studied. The $\left[\mathrm{Ru}^{\mathrm{III}, \mathrm{Il}}(\mathrm{edta})\right]^{-, 2-}, \quad\left[\mathrm{Ru}^{\mathrm{IIIII}}\left(\mathrm{NH}_{3}\right)_{5}\right]^{3+, 2+}$, $\left[\mathrm{Ru}^{\mathrm{IIII}} \mathrm{Cl}(\mathrm{bpy})_{2}\right]^{2+,+}$ and $\left[\mathrm{Fe}^{\mathrm{II}, \mathrm{II}}(\mathrm{CN})_{5}\right]^{2-3-3-}$ metal ions were specifically employed as the terminal moieties, and benzotriazole or benzimidazole and their anionic derivatives as the bridging ligands. Symmetric, $\mathrm{M}_{\mathrm{a}}-\mathrm{L}-\mathrm{M}_{\mathrm{a}}$, and asymmetric, $\mathrm{M}_{\mathrm{a}}-\mathrm{L}-\mathrm{M}_{\mathrm{b}}$, systems were synthesized and characterized in aqueous or organic solutions by means of conventional spectroscopy and electrochemical techniques. Special emphasis was devoted to the intervalence properties associated with the mixed-valence complexes. In addition, the application of ET theoretical models was largely stressed as useful tools to explain the photoinduced intramolecular ET processes (i.e., intervalence transfer) in valence-trapped and partially or fully delocalized systems.

In order to rationalize the properties of the binuclear complexes, a detailed investigation of the starting mononuclear complexes was carried out from the point of view of their reactivity and redox chemistry. In this case, two issues of major interest were deeply taken into account: linkage isomerism (in the particular examples involving the benzotriazole derivatives) and proton-coupled electron transfer reactions in aqueous solutions.

Knowledge acquired from the characterization of the monomer metal units made the study of larger molecules possible. In this way, extended structures like "molecular wires" were designed by using the same $\mathrm{N}$-heterocyclic spacers and metal moieties, resulting in trinuclear species of the type $\mathrm{M}_{\mathrm{a}}-\mathrm{L}-\mathrm{M}_{\mathrm{b}}-\mathrm{L}-\mathrm{M}_{\mathrm{a}}$, which displayed remarkable electronic communication between the metal units through the conductor bridge.

Advances were also reached following the $\mathrm{pH}$ effects on electronic interactions of mixed-valent species. Protonation/ deprotonation of the bridging ligand, for instance, revealed a pronounced proton-induced "on/off" molecular switching on the metal-metal coupling and electron delocalization of such species. This example of molecular devices provided an outstanding model within the search for compounds with potential usefulness in molecular electronics and/ or nanotechnology, whose conception embraces the development of supramolecular systems, an approach that has long been pursued within the research scopes in the laboratory where the current work was developed. 


\section{Introdução}

\subsection{Transferência de elétrons}

As reações envolvendo transferência de elétrons (ET) são onipresentes em sistemas biológicos, físicos e químicos (sejam inorgânicos ou orgânicos). Na natureza, a ocorrência dessas reações está intimamente relacionada aos processos de transferência de energia, a exemplo do que se dá no centro de reação fotossintética, na fosforilação oxidativa, e em muitos outros eventos com múltiplas etapas de ET acopladas, tal como ocorre na cadeia respiratória.

Em última análise, o fenômeno de ET se manifesta nos principais processos responsáveis pela manutenção da vida. A compreensão das interações desse tipo é, portanto, crucial no entendimento de mecanismos de reações fundamentais, o que explica porque esta constitui uma das áreas de pesquisa mais amplas e ativas no âmbito das ciências moleculares modernas. $^{7}$

As reações de ET podem variar desde muito simples até bastante complexas. No caso mais simples (como aquele representado na Eq. 1), ${ }^{8}$ um elétron é transferido em uma reação de troca (self-exchange) entre dois íons possuindo a mesma constituição molecular mas com diferentes estados de oxidação. Nesse caso, não existe mudança química no sistema.

$$
\begin{gathered}
{\left[\mathrm{Ru}^{\mathrm{III}}(\mathrm{bpy})_{3}\right]^{3+}+\left[\mathrm{Ru}^{\mathrm{II}}(\mathrm{bpy})_{3}\right]^{2+}} \\
\mathbb{1} \quad\left(k=10^{9} \mathrm{~mol}^{-1} \mathrm{dm}^{3} \mathrm{~s}^{-1}\right) \\
{\left[\mathrm{Ru}^{\mathrm{II}}(\mathrm{bpy})_{3}\right]^{2+}+\left[\mathrm{Ru}^{\mathrm{III}}(\mathrm{bpy})_{3}\right]^{3+}}
\end{gathered}
$$

Em contraste, a reação total da Eq. 2 é bastante complexa e envolve várias etapas de ET, bem como outras etapas de reações intermediárias. ${ }^{9}$

$$
\mathrm{FeCl}_{3}+7 \mathrm{PhLi} \rightarrow\left[\mathrm{FePh}_{4}\right]^{+}\left(\mathrm{Li}^{+}\right)_{4}+3 / 2 \mathrm{Ph}-\mathrm{Ph}+3 \mathrm{LiCl}
$$

No começo dos anos 50, Taube $^{\mathrm{a}, 10}$ propôs uma distinção essencial entre duas classes de reações de ET: as que ocorrem segundo um mecanismo de esfera externa, sem quebra ou formação intermediária de ligação química; e aquelas que se processam de acordo com um mecanismo de esfera interna, onde um ligante do tipo ponte conecta os grupos doador e aceitador em um complexo binuclear intermediário durante a transferência de elétrons.

\footnotetext{
a Henry Taube, 1915 (Stanford University, CA, USA). Laureado com o Prêmio Nobel de Química de 1983 pela sua contribuição em mecanismos de reações de ET, especialmente em complexos metálicos.
}

Exemplos clássicos de reações de ET de esfera externa são dados pelas Eqs. $1^{8}$ e 3 . $^{11}$

$$
\begin{aligned}
& {\left[\mathrm{Fe}^{\mathrm{II}}(\mathrm{CN})_{6}\right]^{4-}+} {\left[\mathrm{Ir}^{\mathrm{IV}} \mathrm{Cl}_{6}\right]^{2-} } \\
& \mathbb{N} \quad\left(k=4,1 \times 10^{5} \mathrm{~mol}^{-1} \mathrm{dm}^{3} \mathrm{~s}^{-1}\right) \\
& {\left[\mathrm{Fe}^{\mathrm{III}}(\mathrm{CN})_{6}\right]^{3-}+\left[\mathrm{Ir}^{\mathrm{III}} \mathrm{Cl}_{6}\right]^{3-} }
\end{aligned}
$$

Um exemplo bem conhecido de reação de esfera interna é aquele que se dá entre $\mathrm{Cr}^{\mathrm{II}}$ e $\mathrm{Co}^{\mathrm{III}}$. $\mathrm{O}$ íon $\mathrm{Cr}^{\mathrm{II}}$, sendo bastante lábil, troca rapidamente um ligante água pelo ligante cloreto (que atuará como ponte) do íon inerte $\mathrm{Co}^{\mathrm{III}}$ (Eq. 4). Após a etapa de ET no intermediário binuclear (Eq. 5), a labilidade é invertida. $\mathrm{O}$ íon $\mathrm{Co}^{\mathrm{II}}$ é lábil e, portanto, perde o ligante cloreto, que permanece coordenado ao íon inerte $\mathrm{Cr}^{\mathrm{III}}$ (Eq 6).

$$
\begin{gathered}
{\left[\mathrm{Cr}^{\mathrm{II}}\left(\mathrm{H}_{2} \mathrm{O}\right)_{6}\right]^{2+}+\left[\mathrm{Co}^{\mathrm{II}} \mathrm{Cl}\left(\mathrm{NH}_{3}\right)_{5}\right]^{2+}} \\
\downarrow \\
{\left[\left(\mathrm{H}_{2} \mathrm{O}\right)_{5} \mathrm{Cr}^{\mathrm{II}} \leftarrow \mathrm{Cl}-\mathrm{Co}^{\mathrm{III}}\left(\mathrm{NH}_{3}\right)_{5}\right]^{4+}} \\
\downarrow \\
{\left[\left(\mathrm{H}_{2} \mathrm{O}\right)_{5} \mathrm{Cr} r^{\mathrm{III}}-\mathrm{Cl} \rightarrow \mathrm{Co}^{\mathrm{II}}\left(\mathrm{NH}_{3}\right)_{5}\right]^{4+}} \\
\downarrow \\
{\left[\mathrm{Cr}^{\mathrm{III}} \mathrm{Cl}^{4}\left(\mathrm{H}_{2} \mathrm{O}\right)_{5}\right]^{2+}+\left[\mathrm{Co}^{\mathrm{II}}\left(\mathrm{H}_{2} \mathrm{O}\right)\left(\mathrm{NH}_{3}\right)_{5}\right]^{2+}} \\
\downarrow \\
\quad \mathrm{H}^{+}, \mathrm{H}_{2} \mathrm{O} \\
5 \mathrm{NH}_{4}^{+}+\left[\mathrm{Co}^{\mathrm{II}}\left(\mathrm{H}_{2} \mathrm{O}\right)_{6}\right]^{2+}
\end{gathered}
$$

Entretanto, os modelos mais simples para reações de ET de esfera interna são os complexos de valência mista, ${ }^{b}$ cujo exemplo pioneiro é representado pelo dímero $\mu$-pirazinabis $\{$ pentaaminrutênio $\}(5+),\left[\left(\mathrm{NH}_{3}\right)_{5} \mathrm{Ru}(\mathrm{pz}) \mathrm{Ru}\left(\mathrm{NH}_{3}\right)_{5}\right]^{5+}$, que ficou conhecido como íon de Creutz-Taube ${ }^{12,13}$ (Esq. 1).

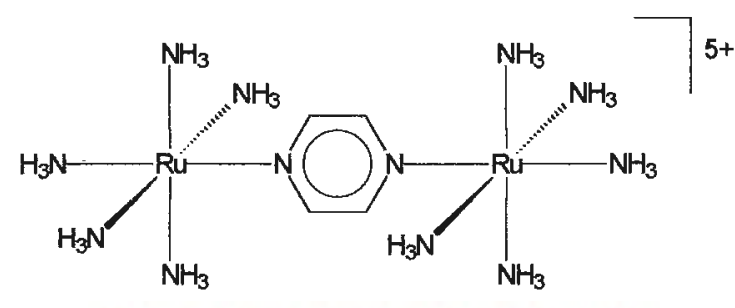

Esquema 1. O complexo de Creutz-Taube.

Em um complexo desse tipo, a assimetria redox introduz uma perturbação eletrônica no sistema molecular, através da qual a oscilação contínua de cargas é promovida. A Eq. 8 ilustra o processo para o análogo do íon de Creutz-Taube contendo 4,4'-bpy como ligante-ponte. ${ }^{14-17}$

b Tópico a ser explorado adiante na seção 1.2. 


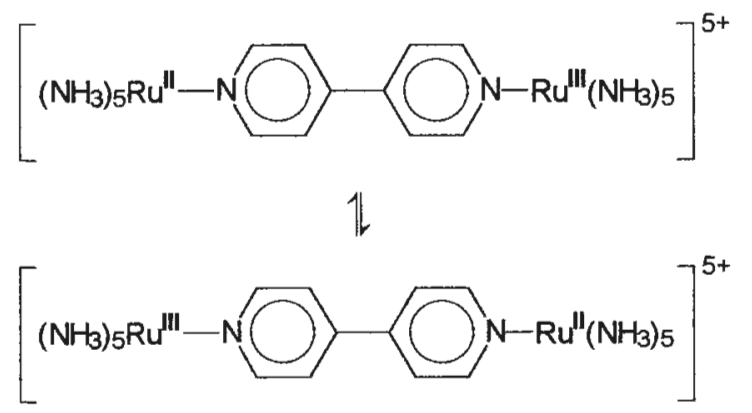

A teoria cinética de Marcus $^{\mathrm{a}, 18-21}$ para reações de ET de esfera externa e a teoria perturbacional de $\mathrm{Hush}^{22-25}$ para complexos de valência mista são ferramentas extremamente úteis na compreensão do comportamento destes sistemas. ${ }^{26}$

Um aspecto da maior importância nesse tipo de reação é a relação entre a velocidade de transferência de elétrons e a exergonicidade, $\Delta G^{0}$ (driving force). ${ }^{\text {b }}$ Quando uma reação é bastante exergônica $\left(\Delta G^{0} \ll 0\right)$, pode-se assegurar que a ET ocorre com uma alta constante de velocidade; enquanto, em uma reação endergônica $\left(\Delta G^{0} \gg 0\right)$, pode-se eliminar a possibilidade de ET. Entretanto, a situação entre esses dois extremos é quase sempre de muito interesse. Nota-se ainda que reações moderadamente endergônicas podem ocorrer se elas forem dirigidas por métodos externos, p. ex. óptica ou eletroquimicamente. Nos casos isoergônicos (onde $\Delta G^{0}=$ 0 ), tais como nas Eqs. 1 e 8, a barreira cinética $\left(\Delta G^{\ddagger}\right)$ não é zero e sua determinação experimental é bastante relevante dentro dos modelos de Marcus e Hush. ${ }^{18-25}$

Reações de ET de esfera interna são mais dificeis de se analisar do ponto de vista quântico, mas seus mecanismos moleculares complexos têm sido monitorados em muitos casos, e particularmente aprofundados em alguns estudos realizados por Taube, ${ }^{10,29-31}$ Sutin, $^{20,32-36}$ e $\operatorname{Haim}^{32,37,38}$ e colaboradores. ${ }^{39}$

Na química de organometálicos, $\mathrm{Kochi}^{40}$ tem empregado a teoria de Mulliken ${ }^{41}$ para associar as energias livres de ET térmica e fotoinduzida, com especial ênfase sobre o trabalho eletrostático requerido na aproximação e afastamento dos reagentes e produtos durante o processo de ET.

Reações de transferência de elétrons fotoinduzidas ${ }^{42-47}$ podem ser altamente endergônicas, o que permite estudar processos que seriam termodinamicamente proibidos, bem como a cinética a eles associada.

\footnotetext{
a Rudolf A. Marcus, 1923 (Califomia Institute of Technology, CA, USA); Laureado com o Prêmio Nobel de Química de 1992 pela sua contribuição à teoria de reações de ET em sistemas químicos.

b A diferença de energia livre padrão de Gibbs, $\Delta G^{\circ}$, para uma reação de ET é expressa pela equação de Rehm-Weller, onde os termos mais impontantes são relacionados ao potencial de ionização do doador $\left.\left(E_{0 x}\right)^{D}\right)$, a afinidade eletrônica do aceitador $\left(E_{\text {red }}{ }^{A}\right)$ e o fator eletrostático em função do solvente (função trabalho envolvida na aproximação das espécies reagentes). ${ }^{27}$
}
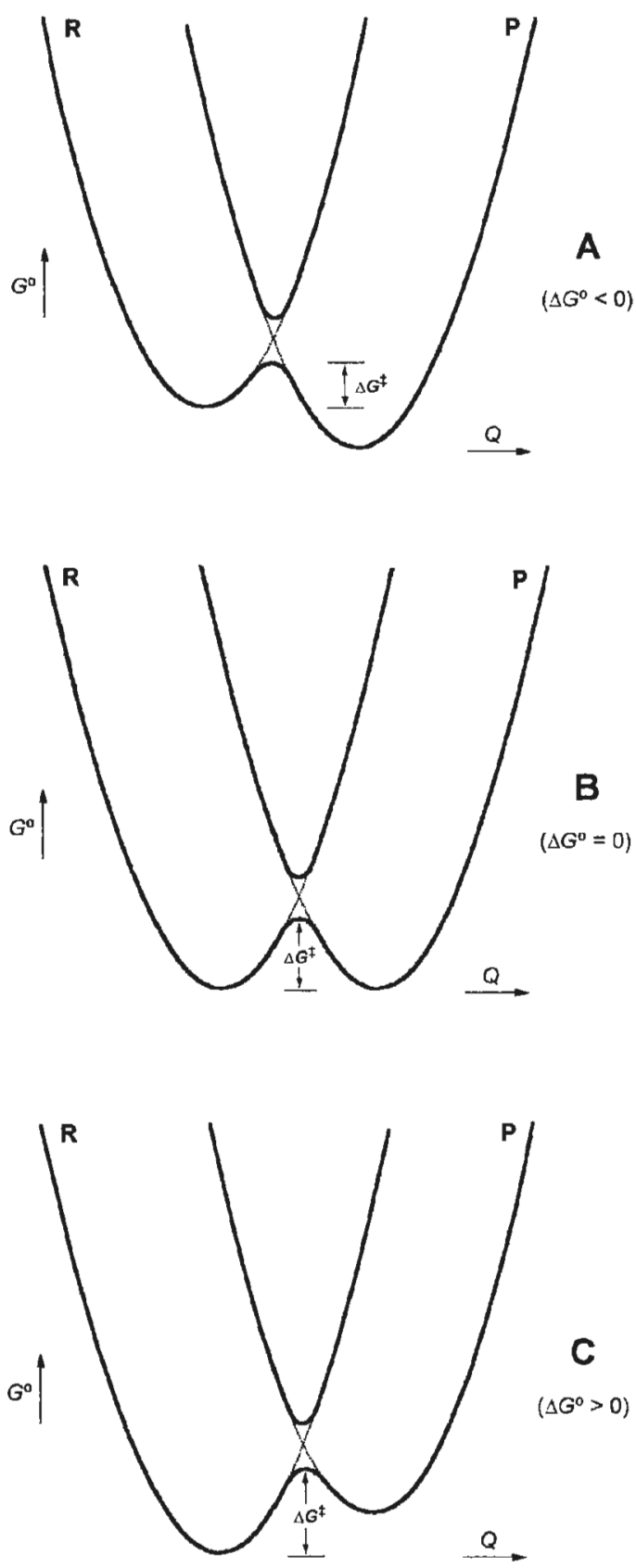

Figura 1. Diagramas ${ }^{c}$ ilustrativos de energia livre $\left(G^{\circ}\right)$ em função de coordenadas de reação $(Q)$ para três tipos de sistemas: (A) assimétrico (doador $\neq$ aceitador) e exergônico $\left(\Delta G^{\circ}<0\right)$;

(B) simétrico (doador $=$ aceitador) e isoergônico $\left(\Delta G^{\circ}=0\right)$; e (C) assimétrico (doador $\neq$ aceitador) e endergônico $\left(\Delta G^{\circ}>0\right)$. Nos diagramas, $\Delta G^{\ddagger}$ é a energia livre de ativação da reaçăo.

c Reações de ET são usual e convenientemente representadas por meio de curvas parabólicas de variação de energia potencial (sistemas discretos e/ou em fase gasosa) ou energia livre (maioria dos sistemas complexos em fase condensada) ao longo da reação em função das coordenadas nucleares dos sistemas (posições, orientações, distâncias e ângulos de ligação, etc). ${ }^{19,28}$ Essa representação bidimensional simplificada é, na verdade, o pertil da interseção entre as duas superfícies multidimensionais de energia dos estados reagente e produto na direção da reação. As duas curvas se cruzam em um ponto de não-equilibrio, no qual ocorre a ET térmica quando o elétron move-se do doador para o aceitador (isto é, ocorre a passagem do reagente ao produto). 
O estudo de transferência eletrônica biológica a longas distâncias tem sido especialmente desafiador na última década, tanto do ponto de vista teórico ${ }^{21,48,49}$ como do experimental. ${ }^{50-52}$ Tunelamento eletrônico e reconhecimento molecular são alguns dos conceitos essenciais que têm sido estabelecidos por meio de técnicas experimentais poderosas e precisas, tais como medidas de velocidade de reações de ET dependente da temperatura e engenharia de proteínas ${ }^{50-52}$ e fragmentos de DNA ${ }^{53-55}$ modificados por incorporação de complexos inorgânicos.

Atualmente, além de vários livros ${ }^{30,45,56-58}$ enfatizando aspectos inorgânicos, orgânicos, físicos e teóricos, um grande número de artigos de revisão e enciclopédias sobre vários aspectos de reações de ET encontram-se disponíveis. ${ }^{2}$

\subsubsection{Transferência de intervalência}

A transferência de intervalência (IT) é um caso particular de transferência de elétrons intramolecular que se manifesta em sistemas moleculares contendo centros redox em diferentes estados de oxidação. Por isso é que, quando um elétron é transferido de um sítio doador ( $p$. ex. menor estado de oxidação; redutor) para outro aceitador ( $p$. ex. maior estado de oxidação; oxidante), diz-se que houve uma transição com mudança "entre valências", daí o termo intervalência. Interações dessa natureza também são chamadas de transferência de carga de intervalência (IVCT) ou transferência de carga metal-metal (MMCT). Em química inorgânica, esse fenômeno tem sido estudado principalmente em complexos bi- ou polinucleares de valência mista, ${ }^{b}$ e constitui um tema que será largamente enfatizado nesta tese.
Uma transição de IT é um processo induzido por luz que, normalmente, pode ser monitorado através de uma banda de absorção de baixa energia, na região do infravermelho próximo (NIR). Essas bandas comumente apresentam uma estrutura vibracional bastante complexa, com dependência de esfera interna e do solvente.

A partir da análise desses processos (principalmente através do formalismo perturbacional clássico de MullikenHush, ${ }^{23-25,59}$ embora modelos de acoplamento vibrônico mais recentes tenham sido empregados), ${ }^{c, 60-63}$ químicos e físicos têm aprendido muito acerca da natureza dos fenômenos de ET óptica ou fotoinduzida e dos mecanismos de acoplamento eletrônico e deslocalização em sistemas do tipo doador-aceitador. Isso é particularmente verdadeiro para sistemas de interação fraca (cargas localizadas) e de acoplamento forte (cargas deslocalizadas). ${ }^{\mathrm{d}}$

Contudo, um tema que permanece tão interessante como importante neste campo, é a transição de comportamento localizado-deslocalizado em alguns tipos de sistemas. Diferentemente do que ocorre nos casos tipicamente localizados ou deslocalizados, as ferramentas teóricas disponiveis não explicam adequadamente as propriedades intrincadas e originais desse tipo de sistemas. Com o avanço dos métodos de síntese e das técnicas físico-químicas, os resultados de estudos recentes têm revelado que tais sistemas são bem mais complexos do que se imaginava. Esse aspecto da química de valência mista tem sido reconhecido como um dos mais importantes atualmente no contexto dos processos de transferência eletrônica. a V. ref. citadas ao longo desta introdução.

b V. exposição adiante nos tópicos da seção 1.2 deste mesmo capítulo. c Apesar de vários modelos com ênfase nas propriedades de esfera intema terem sido descritos, ${ }^{64,65}$ o tratamento vibrônico de Piepho, Krausz e Schatz (que é conhecido por modelo $\mathrm{PKS})^{61}$ tern recebido maior atenção. Embora esse formalismo seja quanticamente mais rigoroso, apenas os modos vibracionais intemos e simétricos são levados em conta, por meio de freqüências médias concementes às ligações metal-ligante. Isso tem limitado a sua aplicação a alguns poucos sistemas deslocalizados, já que em sistemas de perturbação moderada os modos do solvente (efeitos do meio) se tomam bastante relevantes. Nesse aspecto, o modelo clássico de Hush apresenta vantagens. Além disso, o último é mais comumente utilizado pela pouca complexidade teórica e por sua parametrização espectroscópica, tomando mais viável a tarefa de se comparar dados com séries de sistemas reportados em literatura.

d V. classificação dos tipos de interação mais adiante no item 1.2.1. 


\subsection{Sistemas de valência mista}

Em uma definição bastante abrangente, os materiais de valência mista ${ }^{66}$ referem-se àqueles compostos que contêm íons em mais de um estado de oxidação formal em uma mesma unidade molecular. Existem muitos exemplos em bioquímica (p. ex. metaloenzimas contendo múltiplos sítios de transferência de elétrons; clusters de ferro-enxofre), em química mineral (p. ex. magnetita, $\mathrm{Fe}_{3} \mathrm{O}_{4}$ ) e sólidos moleculares (p. ex. $\mathrm{Sb}^{\mathrm{II}} \mathrm{Cl}_{3} \mathrm{Sb}^{\mathrm{V}} \mathrm{Cl}_{5}$ ).

A existência de sistemas de valência mista remonta da história evolucionária da Terra e de outros planetas. Além disso, uma variedade de minerais de valência mista têm atraído atenção desde a antiguiidade. $\mathrm{O}$ caráter de valência mista é, na verdade, responsável pela coloração de vários minerais bem conhecidos. Por exemplo, o controle dos estados de oxidação do ferro em seus óxidos $\left(\mathrm{FeO}, \mathrm{Fe}_{3} \mathrm{O}_{4}\right.$, $\mathrm{Fe}_{2} \mathrm{O}_{3}$ ) foi elegantemente utilizado na pintura de vasos pelos gregos antigos para se produzir o preto e o vermelho característicos das cerâmicas áticas. ${ }^{67}$

Contudo, somente há pouco mais de três décadas é que os primeiros artigos de revisão acerca dos compostos de valência mista apareceram na literatura, ${ }^{23,68,69}$ demonstrando a primeira tentativa de se tratar os materiais de valência mista como uma classe separada de compostos, cujas propriedades podiam ser correlacionadas com as estruturas moleculares e eletrônicas de seus componentes. Desde então, o fenômeno de valência mista tem atraído o interesse de uma ampla variedade de cientistas, que se estende de químicos experimentalistas a fisicos do estado sólido, de biólogos a geólogos.

A química inorgânica, em especial, tem colaborado com grande parte do conhecimento teórico e experimental acumulado neste campo, principalmente através do estudo dos complexos polinucleares de valência mista. ${ }^{70-72} \mathrm{Os}$ compostos de coordenação tiveram, de fato, uma história antiga dentro deste assunto. Por exemplo, o azul da Prússia, $\mathrm{Fe}\left[\mathrm{Fe}(\mathrm{CN})_{6}\right]^{-}$, que é um complexo de valência mista com uma estrutura $\mathrm{Fe}(\mathrm{II})-\mathrm{Fe}$ (III) mediada por pontes de cianeto, foi um dos primeiros materiais químicos descritos na literatura há quase dois séculos. ${ }^{73}$ Mesmo assim, somente no início dos anos 70 deste século é que foram reportados os primeiros complexos planejados e preparados em laboratório, bem como estudados por meio de técnicas modernas de espectroscopia e eletroquímica. Esse é o caso do íon de Creutz-Taube ${ }^{12,13}$ (Esq. 1), e do monocátion biferroceno contendo grupos $\eta^{5}$-ciclopentadienil como ponte, $[(\mathrm{cp}) \mathrm{Fe}(\mathrm{cp}-\mathrm{cp}) \mathrm{Fe}(\mathrm{cp})]^{+}{ }^{74}$ (Esq. 2).

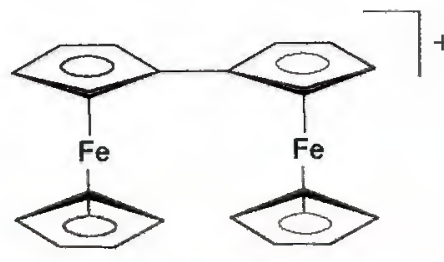

Esquema 2. 0 cation biferroceno.

Desde então, químicos inorgânicos têm demonstrado grande interesse na exploração de moléculas em que dois ou mais centros metálicos conectados por meio de um ligante-ponte (que normalmente é um orgânico heterocíclico, mas pode variar desde entidades mono ou diatômicas até ligantes polifuncionais) apresentem alguma comunicação eletrônica metal-metal do tipo doador-aceitador.

O grande sucesso dos sistemas de valência mista, em particular daqueles baseados em oligômeros de metais de transição, deve-se ao importante papel destas espécies como modelos ideais no estudo de processos de ET inter e/ou intramoleculares (v. seção 1.1). Isso porque a complexidade cinética e dinâmica e o desconhecimento da configuração nuclear/geométrica em sistemas de ET inter(bi)moleculares tornam impraticável o estudo direto de tais reações. Por outro lado, o emprego apropriado de complexos de valência mista tem sido eficaz dentro desse propósito, uma vez que a natureza química do ligante-ponte mediador pode ser convenientemente escolhida e a estrutura molecular de tais espécies é conhecida mesmo na etapa de ET. Ademais, a estrutura eletrônica dos membros que a compõem pode ser modulada por meio de perturbações químicas de esfera interna ou de esfera externa.

Essa abordagem tem sido aplicada adequadamente para espécies metal-orgânicas envolvendo principalmente alguns dos elementos da primeira e da segunda séries de transição (na maioria, complexos homo e heteronucleares contendo amina, ${ }^{70-72,75}$ carboxilato, ${ }^{70,76}$ cianeto, ${ }^{70,71,77-79}$ fosfina, ${ }^{80,81}$ e polipiridil-derivados ${ }^{70,72,82-84}$ como coligantes e uma grande variedade de ligantes-ponte envolvendo grupos carboxilato, ciano, halo, hidroxo, nitro, oxo, etc, e, principalmente heterocíclicos orgânicos nitrogenados, embora ligantes nãoinocentes oxigenados, sejam eles do tipo dioxolenos ${ }^{85-87}$ ou polifuncionais, ${ }^{88-90}$ e sulfurados ${ }^{91,92}$ tenham sido largamente empregados recentemente). Complexos dos elementos de transição do Grupo 8 (em particular, íons ferro, ${ }^{70,75,7,79,92-94}$ rutênio $^{70-72,82}$ e ósmio ${ }^{72,84,95}$ com estados de oxidação $+\mathrm{II}$ e +III - configuração eletrônica $d^{6} / d^{5}$ de spin baixo) são especialmente interessantes devido a algumas características tais como: cinética favorável, estabilidade termodinâmica, viabilidade sintética, e química redox bastante flexível ${ }^{31,96}$ (v. seção 1.7). 
Além disso, os complexos inorgânicos de valência mista apresentam propriedades originais que podem ser usadas em vários tipos de aplicações: conversão de energia, novos materiais, catálise e eletrônica molecular, entre outros. ${ }^{a}$

\subsubsection{Tipos e classificação de sistemas de VM}

Na seção 1.1 foi descrito que, para uma reação de ET ser exergônica $\left(\Delta G^{\circ}<0\right.$; termodinamicamente favorável) ou endergônica ( $\Delta G^{\circ}>0$; termodinamicamente desfavorável), o sistema deve ser assimétrico. Isto é, as espécies doadora e aceitadora de elétrons que o compõem devem ser química e/ou eletronicamente distintas. Isso porque, em ambos os casos, os estados eletrônicos dos reagentes e dos produtos devem ser diferentes para que ocorra variação de energia durante o processo de ET.

No caso específico de um complexo binuclear assimétrico de valência mista, este pode conter dois íons metálicos de elementos diferentes (sistema assimétrico heteronuclear) ou dois íons metálicos do mesmo elemento em diferentes ambientes químicos (sistema assimétrico homonuclear). Exemplos desses sistemas são dados pelas Eqs. 9 e 10, respectivamente.

$$
\begin{gathered}
{\left[\mathrm{Cl}(\mathrm{bpy})_{2} \mathrm{Os}^{\mathrm{II}}-\mathrm{L}-\mathrm{Ru}^{\mathrm{III}}(\mathrm{bpy})_{2} \mathrm{Cl}\right]^{n}} \\
{\left[\mathrm{Cl}(\mathrm{bpy})_{2} \mathrm{Os}^{\mathrm{III}}-\mathrm{L}-\mathrm{Ru}^{\mathrm{II}}(\mathrm{bpy})_{2} \mathrm{Cl}\right]^{n}} \\
{\left[\left(\mathrm{NH}_{3}\right)_{5} \mathrm{Ru}^{\mathrm{II}}-\mathrm{L}-\mathrm{Ru}{ }^{\mathrm{III}} \mathrm{Cl}(\mathrm{bpy})_{2}\right]^{n+1}} \\
\left.1\left(\mathrm{NH}_{3}\right)_{5} \mathrm{Ru}^{\mathrm{III}}-\mathrm{L}-\mathrm{Ru}^{\mathrm{II}} \mathrm{Cl}(\mathrm{bpy})_{2}\right]^{n+1}
\end{gathered}
$$

(onde $n=3$ se L for neutro)

Uma reação isoergônica, por sua vez, quase sempre envolve um sistema simétrico homonuclear; isto é, um sistema molecular contendo duas unidades terminais idênticas, a exemplo do íon de Creutz-Taube (Esq. 1) e do dímero do tipo ( $\mu$-L)bis $\{$ bis(2,2'-bipiridina)clororutênio\}(II,III), conforme representado na Eq. 11.

$$
\begin{aligned}
& {\left[\mathrm{Cl}(\mathrm{bpy})_{2} \mathrm{Ru}^{\mathrm{II}}-\mathrm{L}-\mathrm{Ru}^{\mathrm{III}}(\mathrm{bpy})_{2} \mathrm{Cl}\right]^{n+2}} \\
& {\left[\mathrm{Cl}(\mathrm{bpy})_{2} \mathrm{Ru}^{\mathrm{III}}-\mathrm{L}-\mathrm{Ru}^{\mathrm{II}}(\mathrm{bpy})_{2} \mathrm{Cl}\right]^{n+2}}
\end{aligned}
$$

Os complexos de valência mista são classificados de acordo com a intensidade da interação eletrônica entre os centros metálicos doador e aceitador. Robin e Day ${ }^{68}$ propuseram três categorias de sistemas de valência mista:

\footnotetext{
a Este tema será melhor apresentado por meio de exemplos acerca de alguns aspectos envolvendo dispositivos e sistemas supramoleculares (itens 1.3.x).
}

Classe I. A interação entre os centros redox é tão fraca que o sistema de valência mista exibe somente as propriedades individuais de cada um seus componentes redox isolados (similar à soma das unidades monômeras de partida). Essa classe é representada principalmente por sistemas contendo moléculas de ponte isolantes (p. ex. cadeias saturadas) e/ou longas distâncias entre os sítios doador e aceitador (p. ex. proteínas quimicamente modificadas pela coordenação de complexos de metais de transição em resíduos periféricos, onde $d_{\mathrm{ET}}$ é tipicamente maior que $\left.12-15 \AA\right){ }^{21,48-52}$ Nesses casos, a reação é não-adiabática $(\kappa<1)^{\mathrm{b}}$ e o mecanismo de ET se dá essencialmente por tunelamento eletrônico ${ }^{49,97-100}$ (Fig. 2A).

Classe II. Há um acoplamento eletrônico fraco, de tal forma a perturbar as características originais dos centros redox. $\mathrm{O}$ sistema de valência mista normalmente passa a apresentar novas propriedades não associadas às espécies de partida isoladamente. Essa classe corresponde à maioria das moléculas de interesse no contexto da química de valência mista. ${ }^{70-72}$ Nela, a magnitude da comunicação entre os centros doador-aceitador é grande o suficiente para tornar o sistema adiabático (com $\mathrm{k}=1$ ) mas as cargas permanecem essencialmente localizadas (Fig. 2B). ${ }^{\circ}$

Classe III. A interação eletrônica entre os centros é bastante forte e o sistema de valência média passa a exibir novas propriedades, que são totalmente diferentes daquelas de suas unidades componentes. Diferentemente dos sistemas de classe II, onde as características particulares dos monômeros isolados são apenas ligeiramente modificadas, aqui elas desaparecem por completo. Os sistemas que se incluem nessa classe são totalmente adiabáticos $(\kappa=1) \mathrm{e}$ apresentam deslocalização total de cargas (p. ex. complexos

\footnotetext{
b O fator de adiabaticidade $\mathrm{x}$ é o coeficiente de transmissão eletrônica que dá a probabilidade de um elétron passar do estado inicial do reagente para o estado final do produto no ponto de interseção de suas superficies em uma reação térmica $(Q=0,0$; onde as configurações nucleares de ambos deverm ser idênticas para que se processe a E'T). Por sua vez, essa probabilidade dependerá do grau de mistura eletrônica entre os dois estados, que é representada peĺa energia de ressonância, $J=H_{\mathrm{RP}}=H_{\mathrm{ab}}$. A constante de velocidade de ET dada pela equação de Eyring $\left(k=\kappa v_{n} \exp \left(-\Delta G^{\ddagger} / \mathrm{RT}\right)\right)$ contém um termo pré-exponencial representado pelo produto do fator de freqüência nuclear, $v_{n}$ (cujo valor médio em solução é assumido como $6 \times 10^{12} \mathrm{~s}^{-1}$ ) e da constante de adiabaticidade definida acima. Assim, Marcus tem chamado de adiabáticas $(\kappa=1)$ as reações em que o desdobramento de $2 H_{\mathrm{ab}}$ em $Q=0,0$ é grande o suficiente para não limitar a velocidade de ET. Quanto menor for $H_{a b}$, menos adiabática e, conseqüentemente, mais lenta se tomará a reação. Quando $0 \leq \kappa<1$, então a reação é não-adiabática. Newton e Sutin ${ }^{35}$ propuseram o valor de $H_{\mathrm{ab}}=0,025 \mathrm{eV}$ como critério de distinção entre ET adiabática e não-adiabática. Em uma situação limite, a estabilização por ressonância é tão grande que apenas um mínimo de energia correspondendo ao estado fundamental do sistema (deslocalizado) é observado. A teoria de Marcus só se aplica corretamente para as reações de ET adiabáticas, que é o caso mais freqüente.

c Em sistemas de classe II a teoria de Marcus-Hush se aplica (v. itens 1.2.3.x).
} 
do tipo $\mathrm{M}^{\mathrm{II} 1 / 2}-\mathrm{L}-\mathrm{M}^{\mathrm{II} 1 / 2}$ ). Como conseqüência, os estados eletrônicos simétricos defínidos pelas espécies reagente e produto deixam de existir para dar lugar a uma nova entidade onde a transferência de elétrons se manifesta, na verdade, como uma transferência de carga interna do tipo $\pi \rightarrow \pi^{*}$ (Fig. 2C). ${ }^{a}$

\section{A}

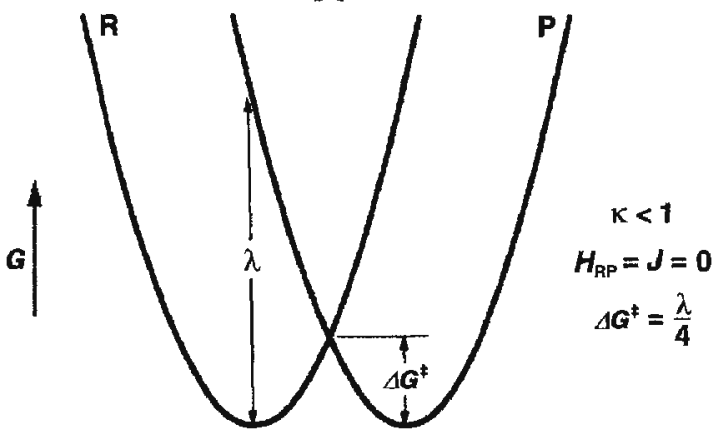

B

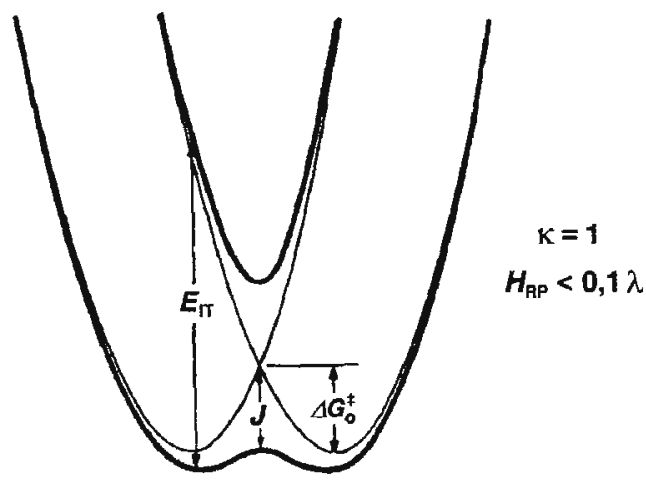

\section{C}

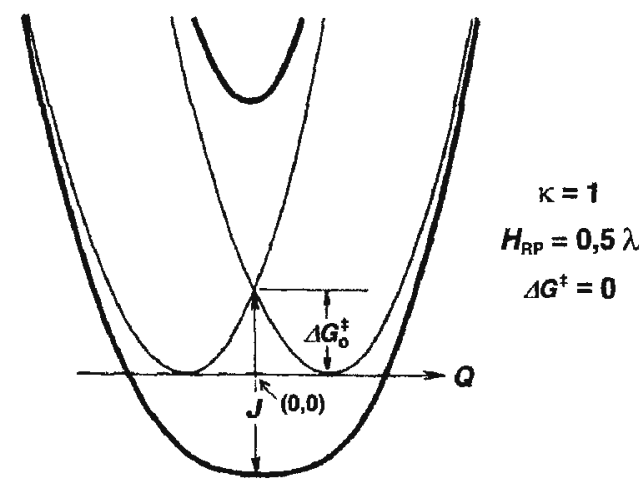

Figura 2. Curvas de energia potencial para reações de ET em sistemas de valência mista simétricos com diferentes graus de adiabaticidade: (A) classe I, (B) classe II e (C) classe III.

Nelas, $\kappa$ é o fator de adiabaticidade; $\lambda$ é a energia de reorganização; $J=H_{R P}=H_{a b}$ é a energia de ressonância; e $\Delta G_{0}^{\ddagger}$ é a energia de ativação de ordem zero, na ausência de perturbação. ${ }^{b}$ (figuras adaptadas da ref. 101)

a Em sistemas de classe III a teoria de Marcus-Hush não se aplica (v. 1.2.3.x).
Os critérios experimentais para se distinguir particularmente sistemas de classe II e III, serão explorados mais adiante dentro dos itens 1.2.3.x, conjuntamente com a análise dos fatores de esferas interna e externa que influenciam a energia da transição de IT segundo o modelo de Hush.

\subsubsection{Reação de comproporcionamento}

A manifestação mais direta da comunicação eletrônica em complexos de valência mista é a separação de potenciais redox para os centros metálicos em ambientes químicos aparentemente idênticos. ${ }^{70-72}$

Esse tipo de interação deve propagar-se através do ligante e uma ligação direta metal-metal não é necessária. Isso porque os elétrons $d$ do íon metálico estão em orbitais $d \pi$ que podem efetivamente se recobrir com aqueles do ligante aceitador- $\pi$, tornando-os deslocalizados de uma certa extensão entre ambos os centros metálicos através do ligante. Assim, a redução de um centro metálico resulta em uma mudança da densidade eletrônica que é imediatamente comunicada ao outro sítio através da ponte, tornando mais dificil uma segunda etapa de redução.

Visto que a separação redox pode ser grande em casos onde a comunicação eletrônica é forte, então a espécie de valência mista $(O, R)$ pode ser obtida em uma variedade de condições e também deverá ser estável com respeito ao seu desproporcionamento aos estados iniciais isovalentes oxidado $(\mathrm{O}, \mathrm{O})$ e reduzido $(\mathrm{R}, \mathrm{R})$. Normalmente, a espécie de valência mista é gerada eletroquimicamente por aplicação de potencial no domínio intermediário para os pares redox dos dois sítios metálicos (Fig. 3)

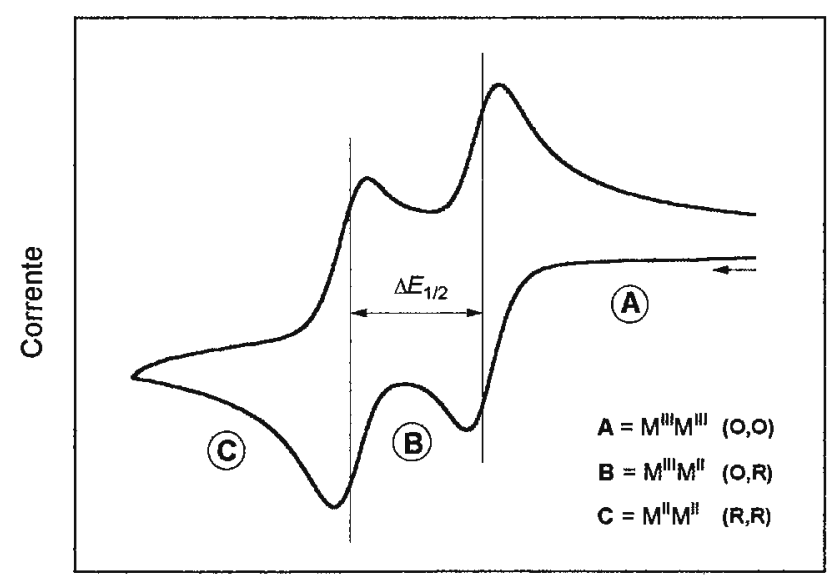

Potencial

Figura 3. Voltamograma ilustrativo de uma espécie binuclear genérica do tipo $M^{\prime \prime \prime \prime \prime}-L-M^{\prime 1 ! / 1}$ com interação eletrônica mensurável. 
Assim, a estabilidade de um complexo de valência mista hipotético, representado por $\mathbf{M}^{\mathrm{II}}-\mathbf{L}-\mathbf{M}^{\mathrm{III}}$, em relação aos seus estados isovalentes $M^{\mathrm{II}}-\mathrm{L}-\mathrm{M}^{\mathrm{II}}$ e $\mathrm{M}^{\mathrm{III}}-\mathrm{L}-\mathrm{M}^{\mathrm{III}}$ é expressa pela constante de comproporcionamento, $K_{\mathrm{c}}$ (Eq. 13), que é a constante de equilíbrio da reação: ${ }^{2}$

$$
\begin{gathered}
{\left[\mathbf{M}^{\mathrm{II}}-\mathrm{L}-\mathrm{M}^{\mathrm{II}}\right]+\left[\mathrm{M}^{\mathrm{II}}-\mathrm{L}-\mathrm{M}^{\mathrm{II}}\right] \rightleftharpoons 2\left[\mathrm{M}^{\mathrm{II}}-\mathrm{L}-\mathrm{M}^{\mathrm{III}}\right]} \\
K_{\mathrm{c}}=\frac{\left[\mathrm{M}^{\mathrm{II}} \mathbf{M}^{\mathrm{III}}\right]^{2}}{\left[\mathrm{M}^{\mathrm{II}} \mathbf{M}^{\mathrm{II}}\right]\left[\mathrm{M}^{\mathrm{III}} \mathbf{M}^{\mathrm{III}}\right]}
\end{gathered}
$$

O valor de $K_{\mathrm{c}}$ pode variar de 4 (valor estatístico mínimo), em sistemas fracamente acoplados de classe II, a $>10^{13} \mathrm{em}$ sistemas fortemente acoplados de classe III $^{70}$

Se a interação for fraca ou moderada $\left(\Delta E_{1 / 2}<100 \mathrm{mV}\right)$, tođas as três espécies $(\mathrm{O}, \mathrm{O}, \mathrm{O}, \mathrm{R}$ e R,R) são observadas em solução, e o valor de $K_{\mathrm{c}}$ deve ser obtido através de medidas espectroscópicas. ${ }^{16,17}$ Sutton e Taube têm descrito um método baseado na titulação do complexo com um agente redox, ${ }^{16}$ onde a concentração máxima da espécie de valência mista é obtida indiretamente, por meio da relação de absorbância em função do número de equivalentes da espécie titulante. ${ }^{70}$

No entanto, se a interação é forte o suficiente para promover um deslocamento total do equilíbrio da Eq. 12 no sentido favorável à reação de comproporcionamento, para fins práticos somente a espécie de valência mista poderá ser monitorada e a constante de comproporcionamento, $K_{\text {c, }}$ poderá ser estimada diretamente através dos dados eletroquímicos, ${ }^{101-103}$ já que $\Delta G^{0}=-\mathrm{R} T\left(\ln K_{\mathrm{c}}\right)=-n_{1} n_{2} F(\Delta E)$ (onde $\Delta E=\left|E_{1}-E_{2}\right|, E_{1}$ e $E_{2}$ são os potenciais associados aos pares redox representados nas Eqs. 14 e 15 , e $n_{1}$ e $n_{2}$ são os números de elétrons correspondentes a cada uma dessas etapas, respectivamente)

$$
\begin{gathered}
{[\mathrm{O}, \mathrm{O}]^{\gamma}+n_{1} \mathrm{e}^{-} \rightleftharpoons[\mathrm{R}, \mathrm{O}]^{\gamma-n_{1}} \quad\left(E_{1}\right)} \\
{[\mathrm{R}, \mathrm{O}]^{y-n_{1}}+n_{2} \mathrm{e}^{-} \rightleftharpoons[\mathrm{R}, \mathrm{R}]^{\mu-n_{1}-n_{2}} \quad\left(E_{2}\right)}
\end{gathered}
$$

Para uma reação genérica do tipo representado acima, a expressão geral de $K_{\mathrm{c}}$ é dada por: ${ }^{101,102}$

$$
K_{\mathrm{c}}=\exp \left(\frac{\left(E_{1}-E_{2}\right)\left(n_{1} n_{2}\right) F}{\mathrm{R} T}\right)
$$

\footnotetext{
a Evidentemente, se o sistema se tratar de um complexo de valência mista (ou mais rigorosamente, de valência média) de classe III, então as cargas serão deslocalizadas ( $p$. ex. $M^{171 / 2}-L-M^{11 / 3}$ ) e a reação de comproporciona-

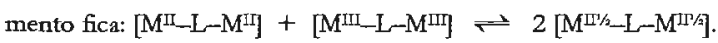

Entretanto, para uma reação simples envolvendo 1 elétron $\left(n_{1}=n_{2}=1\right)$, conforme esquematizado nas Eqs. 17 e 18 (que é o caso normalmente estudado em complexos de valência mista com metais de transição de configuração $d^{5} / d^{6}$ de baixo spin), a equação acima pode ser simplificada para resultar a Eq. 19.

$$
\begin{gathered}
{\left[\mathrm{M}^{\mathrm{III}}-\mathrm{L}-\mathrm{M}^{\mathrm{III}}\right]^{x+1}+\mathrm{e}^{-} \rightleftharpoons\left[\mathrm{M}^{\mathrm{II}}-\mathrm{L}-\mathrm{M}^{\mathrm{III}}\right]^{x} \quad\left(E_{1}\right)} \\
{\left[\mathrm{M}^{\mathrm{II}}-\mathrm{L}-\mathrm{M}^{\mathrm{III}}\right]^{x}+\mathrm{e}^{-} \rightleftharpoons\left[\mathrm{M}^{\mathrm{II}}-\mathrm{L}-\mathrm{M}^{\mathrm{II}}\right]^{x-1} \quad\left(E_{2}\right)} \\
K_{\mathrm{c}}=\exp \left(\frac{\Delta E_{1 / 2}}{25,69 \mathrm{mV}}\right) \quad(T=298 \mathrm{~K})
\end{gathered}
$$

Na equação acima, a separação $\Delta E_{1 / 2}$ deve ser dada em $\mathrm{mV}$.

A energia livre de comproporcionamento associada à constante de equilíbrio $K_{\mathrm{c}}$ é composta de uma soma de, no mínimo, quatro termos:

$$
\Delta G_{\mathrm{c}}=\Delta G_{\mathrm{en}}+\Delta G_{\mathrm{el}}+\Delta G_{\mathrm{s}}+\Delta G_{\mathrm{d}}
$$

onde $\Delta G_{\text {en }}$ é um fator entrópico que reflete a distribuição estatística da Eq. 12 (avaliado como $1 / 2 \mathrm{R} T \ln \frac{1}{1 / 4}$ ); $\Delta G_{\text {el }}$ é um fator eletrostático oriundo da repulsão dos dois centros metálicos carregados conectados pela ponte (este termo é negligenciável em sistemas de interação moderada ou forte; em sistemas de classe II fracamente acoplados com $K_{\mathrm{c}}<30$, seu valor é tipicamente $<0,15 \mathrm{kcal} \mathrm{mol}^{-1}$, o que equivale à contribuição medíocre de $\sim 6,5 \mathrm{mV}) ;{ }^{70} \Delta G_{\mathrm{s}}$ é um fator sinergístico, oriundo da estabilização por transferência de carga e efeitos aceitador-doador de esfera externa (na maioria dos sistemas de classe $I I$ simétricos, este termo é responsável pela maior parcela na estabilização da espécie de valência mista); e o quarto termo, $\Delta G_{\mathrm{d}}$ (fator de deslocalização ou ressonância), é, na verdade, o único componente da energia de estabilização com origem na deslocalização eletrônica (este é o termo dominante em sistemas de classe III).

Para sistemas fracamente acoplados, a magnitude de $\Delta G_{\mathrm{d}}$ (Eq. 21) ${ }^{70}$ pode ser estimada a partir da energia de Franck-Condon, $\lambda$, e da energia de ressonância, $H_{\mathrm{ab}}$, que pode ser extraída dos parâmetros da banda de IT ( $\mathrm{v}$. item 1.2.3.1). $\Delta G_{d}$ é comumente de $\sim 1 \%$ do valor de $H_{\mathrm{ab}}(\leq 20$ $\mathrm{mV}$ ) para a maioria dos sistemas de cargas localizadas reportados na literatura. ${ }^{70}$

$$
\Delta G_{\mathrm{d}}=\frac{H_{\mathrm{ab}}^{2}}{\lambda}
$$

Em sistemas totalmente deslocalizados, $\Delta G_{\mathrm{d}}$ é estimado por:

$$
\Delta G_{\mathrm{d}} \approx F \cdot \Delta E_{1 / 2} \approx H_{\mathrm{ab}} \approx 1 / 2 E_{\mathrm{op}}
$$


A natureza do ligante-ponte desempenha um papel bastante importante na intensidade da comunicação eletrônica, especialmente através de interações de CT combinadas do tipo $\pi$ (ligante) $\rightarrow d_{\pi}$ (metal) e do tipo $d_{\pi}$ (metal) $\rightarrow \pi^{*}$ (ligante). Ligantes de pequena dimensão molecular são mais eficientes que os maiores e, para um dado ligante-ponte, a natureza eletrônica do íon metálico e dos coligantes também pode exercer uma influência dramática sobre a magnitude do acoplamento eletrônico, cuja determinação é o assunto da próximo item.

\subsubsection{Acoplamento eletrônico e deslocalização}

O exemplo mais simples de molécula de valência mista talvez seja o cátion de hidrogênio molecular, $\mathrm{H}_{2}{ }^{+}$. Nesse caso, a interação entre as espécies se dá por meio de recobrimento orbital direto, promovendo a deslocalização da carga que, nesse exemplo em particular, será responsável pela ligação química.

Entretanto, na maioria dos complexos de valência mista inorgânicos, os centros metálicos encontram-se separados por uma espécie conectora intermediária (chamada de ponte ou ligante-ponte) a uma distância suficientemente grande para promover uma perturbação fraca ou moderada com localização de cargas. Nesse caso, o recobrimento orbital entre os centros doador e aceitador é desprezível e a interação eletrônica se propaga através do ligante-ponte, principalmente por meio de conjugação orbital do tipo $\pi$.

Se existem estados redox localizados, o elétron ímpar se comporta como uma carga em oscilação contínua através do ligante-ponte:

$$
\mathrm{M}^{\mathrm{III}}-\mathrm{L}-\mathrm{M}^{\mathrm{II}} \stackrel{k_{\mathrm{ET}}}{=} \mathrm{M}^{\mathrm{II}}--\mathrm{L}-\mathrm{M}^{\mathrm{II}}
$$

A medida direta da constante de velocidade de troca eletrônica intermetálica (Eq. 24) pode ser muito difícil. Contudo, o análogo óptico (transferência induzida por luz; Eq. 25) normalmente pode ser observado tanto em sistemas simétricos $\left(\mathrm{M}_{\mathrm{a}}=\mathrm{M}_{\mathrm{b}} ; \Delta G^{0}=0\right)$ como em assimétricos $\left(\mathrm{M}_{\mathbf{a}} \neq\right.$ $\left.\mathrm{M}_{\mathrm{b}} ; \Delta G^{0} \neq 0\right)$.

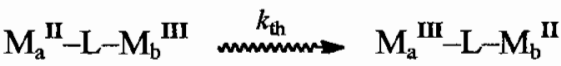

$$
\begin{aligned}
& \mathrm{M}_{\mathrm{a}}^{\mathrm{II}}-\mathrm{L}-\mathrm{M}_{\mathrm{b}}^{\mathrm{III}} \stackrel{\mathrm{h} v}{\longrightarrow} \mathrm{M}_{\mathrm{a}}^{\mathrm{III}}-\mathrm{L}-\mathrm{M}_{\mathrm{b}}{ }^{\mathrm{II}}
\end{aligned}
$$

\footnotetext{
a Estudos com ligantes saturados e/ou espiralados de várias extensões têm demonstrado que hiperconjugação- $\sigma$ também pode promover uma ressonância doador-aceitador bastante significativa, cuja magnitude não pode ser justificada exclusivamente com base em efeitos de tunelamento através da rede de ligações do tipo $\sigma .^{70,72}$
}

Em complexos de interação muito forte (classe III de acordo com a classificação de Robin e Day) ${ }^{68}$ o elétron impar do estado de valência mista está completamente deslocalizado entre os metais, e uma descrição como $\left[\Pi^{1} / 2, \amalg^{1} 1 / 2\right]$ é mais apropriada que $[\Pi, \Pi$ ] $]$ para ambos os estados de oxidação. Nesse caso, a promoção do elétron no estado fundamental para um estado de maior energia (processo radiativo) será efetivamente uma transição $\pi \rightarrow \pi^{*}$ (Eq. 26).

$$
\mathrm{M}_{\mathrm{a}}{ }^{\mathrm{II} / 2}-\mathrm{L}-\mathrm{M}_{\mathrm{b}}{ }^{\mathrm{II} 1 / 2} \stackrel{h v}{\longrightarrow}\left[\mathrm{M}_{\mathrm{a}}{ }^{\mathrm{II}}-\mathrm{L}-\mathrm{M}_{\mathrm{b}}{ }^{\mathrm{II} / 2}\right]^{*}
$$

Entretanto, em complexos onde a interação entre os metais é moderada (classe II), as valências são localizadas e uma descrição [II,III] se aplica e existe a possibilidade de um elétron ser transferido do metal de menor estado de oxidação para o outro sítio metálico de maior estado de oxidação (Eq. 25)

Esse tipo especial de transferência de carga intramolecular foi chamada de transferência de intervalência (IT) por Hush, mas é comum encontrar na literatura atribuição do mesmo fenômeno à transferência de carga metal-metal (MMCT)

\subsubsection{Modelo de Hush}

O objetivo deste tópico é fornecer uma visão geral da teoria perturbacional de $\mathrm{Hush}^{22-25}$ e introduzir as suas principais equações e relações a serem empregadas nesta tese. No caso de interesse em uma abordagem mais aprofundada do formalismo envolvido, o leitor poderá consultar o apêndice 6.1 , onde se encontra um resumo do desenvolvimento do modelo, que é baseado no formalismo de Mulliken., ${ }^{b, 41}$

Em um complexo de valência mista do tipo $\mathbf{M}^{\mathrm{II}}-\mathbf{L}-\mathbf{M}^{\mathrm{III}}$ (com cargas localizadas), a interação eletrônica entre o doador $\left(\mathrm{M}^{\mathrm{II}}\right)$ e o aceitador $\left(\mathrm{Ru}{ }^{\mathrm{III}}\right)$ de elétrons através do ligante-ponte mistura os caráteres eletrônicos e induz a transferência de elétrons. Essa comunicação também cria uma base eletrônica para indução de transferência óptica dipolo-permitida, com a magnitude da perturbação refletindo sobre a intensidade da banda de transferência de carga metal-metal. Para uma banda com formato Gaussiano em um sistema de dois níveis, a energia de ressonância $\left(H_{\mathrm{ab}}\right)$ originada pelo acoplamento eletrônico e o respectivo grau de deslocalização eletrônica $\left(\alpha^{2}\right)$ podem ser calculados a partir das Eqs. 27 e 28 , respectivamente.

b Robert S. Mulliken, 1896-1986 (University of Chicago, IL, USA). Laureado com o Prêmio Nobel de Química de 1966 pela seu trabalho fundamental sobre ligações químicas e estrutura eletrônica de moléculas pelo método dos orbitais moleculares. 


$$
\begin{gathered}
H_{\mathrm{ab}}=2,05 \times 10^{-2}\left(\frac{\varepsilon_{\text {max }} \cdot \bar{v}_{\text {máx }} \cdot \Delta \bar{v}_{1 / 2}}{d^{2}}\right)^{1 / 2} \\
\alpha^{2}=\left(\frac{H_{\mathrm{ab}}}{E_{\mathrm{op}}}\right)^{2}
\end{gathered}
$$

onde os parâmetros envolvidos são $\bar{v}_{\text {máx }}=E_{\text {op }}$, a energia da absorção máxima; $\varepsilon_{\text {măx, }}$ o coeficiente de extinção molar; $\Delta \bar{v}_{1 / 2}$, a largura da banda à metade de sua altura, obtidos diretamente a partir da banda associada à IT (v. banda de absorção ilustrativa na Fig. 4); e $d$, a distância de transferência eletrônica (que é usualmente assumida como sendo equivalente à separação metal-metal). ${ }^{\text {}}$

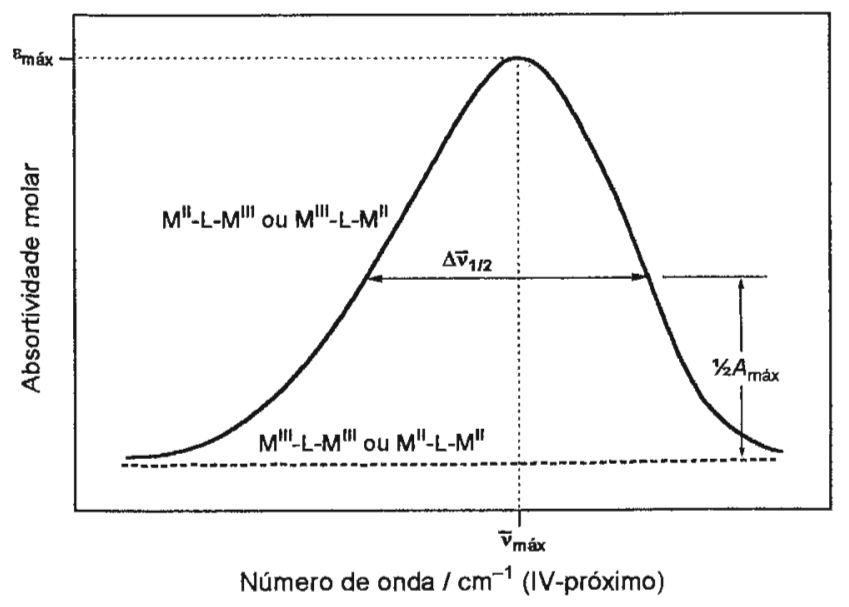

Figura 4. Espectros de absorção eletrônica na regiăo no NIR típicos de espécies isovalentes $M^{\text {III }}-L-M^{\prime \prime \prime}$ e $M^{\prime \prime}-L-M^{\prime \prime}(\cdots)$ e de valência mista $M^{\prime \prime}-L-M^{\prime \prime \prime}$ ou $M^{\prime \prime \prime}-L-M^{\prime \prime}(-)$. A banda associada à IT

ilustra alguns dos parâmetros empregados na estimativa do elemento de matriz do acoplamento eletrônico, $H_{\text {ab. }}$.

\subsubsection{Algumas relações de Marcus-Hush}

O Esq. 3 ilustra as relações energéticas em transferência de intervalência. Nessas curvas são utilizadas coordenadas generalizadas que incluem as vibrações e as oscilações acopladas do solvente, que são tratadas classicamente como um conjunto de osciladores harmônicos.

\footnotetext{
a $O$ parâmetro $d$ no denominador da Eq. 27 se refere, na verdade, à distância de ET "real” (isto é, $\Delta \vec{\mu} / e$ ), e não à separação geométrica metal-metal. Estudos recentes de espectroscopia Stark ${ }^{104}$ têm demonstrado que $d_{E T}$ é normalmente menor que a distância de separação entre os centros metálicos doador e aceitador, $d_{M-M}$. No entanto, valores de det nem sempre são acessíveis, já que a sua determinação envolve o uso técnicas nãoconvencionais e pouco disponiveis. Por isso é que a grande maioxia dos dados reportados na literatura atualmente envolvem $d_{M-M}$ e não dET. Contudo, é importante reconhecer que as magnitudes da energia de acoplamento eletrônico e da deslocalização determinadas dessa forma são intrinsecamente subestimadas.
}

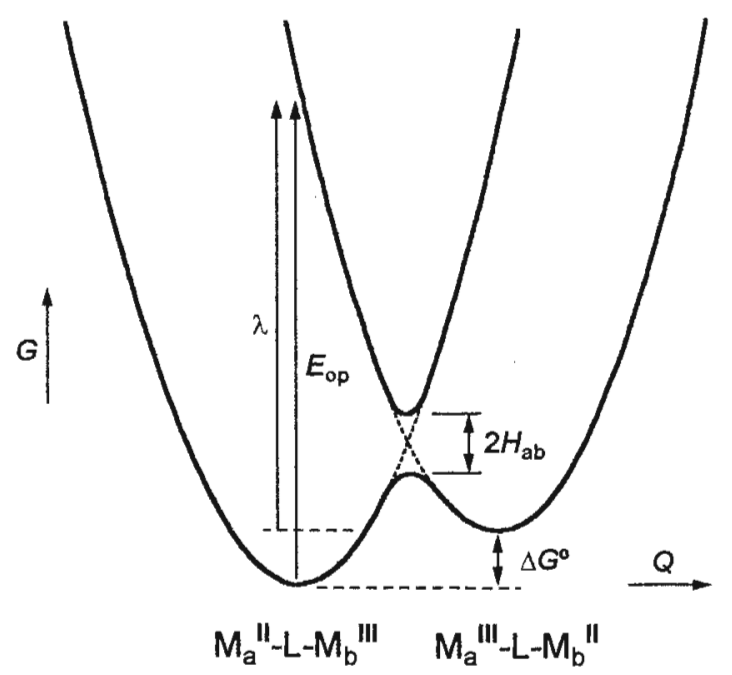

Esquema 3. Diagramas de energia vs. coordenadas nucleares para uma transferência eletrônica adiabática e assimétrica. ${ }^{b}$

Algumas relações importantes entre transferência eletrônica térmica e óptica podem ser derivadas diretamente por meio dessas curvas. ${ }^{\text {c,d }}$ A energia de ET óptica $\left(\bar{\nu}_{\text {máx }}\right.$ ou $\left.E_{\text {op }}\right)$, por exemplo, é ditada pela energia de reorganização do sistema $(\lambda){ }^{e}$ que, por sua vez, é uma função de suas componentes de esferas interna $\left(\lambda_{i}\right)$ e externa $\left(\lambda_{0}\right)$. Para os casos simétrico e assimétrico, tal relação é expressa pelas Eqs. 29 e 30, respectivamente.

$$
\begin{gathered}
\bar{v}_{\text {máx }}=\lambda=\lambda_{\mathrm{i}}+\lambda_{\mathrm{o}} \\
\bar{v}_{\text {máx }}=\Delta G^{\mathrm{o}}+\lambda=\Delta G^{\mathrm{o}}+\lambda_{\mathrm{i}}+\lambda_{\mathrm{o}}
\end{gathered}
$$

onde $\lambda_{\mathrm{i}}$ e $\lambda_{\mathrm{o}}$ são dadas pelas Eqs. 31 e 32 a seguir.

b Conforme deve ter sido notado, os diagramas de energia em função da configuração nuclear foram representados por energia livre de Gibbs, enquanto muitos outros autores utilizam curvas de energia potencial. Por isso é importante comentar que, de acordo com Marcus e Sutin, ${ }^{105}$ energias de transição óptica (tais como $E_{\Gamma \Gamma}$ ) estão relacionadas à variação de energia livre, e não de entalpia ou de energia intema.

c Uma diferença conceitual bastante importante entre ET óptica e térmica é que, no processo induzido por calor, deve haver um rearranjo estrutural que precede a etapa de ET propriamente dita. Isto é, o sistema deve atingir a configuração representada no ponto de interseção entre as curvas de energia do reagente e do produto, onde as coordenadas nucleares de ambos os estados são idênticas. Em decorrência do princípio de Franck-Condon, no processo induzido por luz a transição entre os estados ocorre verticalmente, sem rearranjo nuclear precedendo a etapa de ET. Portanto, imediatamente após a transferência do elétron, o produto se encontrará na configuração nuclear de equilibrio do reagente. Posteriormente, o sistema vibracionalmente excitado relaxa (dentro da escala de tempo vibracional) para resultar o produto em seu estado fundamental de equilibrio.

d $O$ princípio de Franck-Condon ${ }^{98-100}$ implica que, durante uma etapa elementar de ET (térmica ou fotoinduzida), as posições dos átomos (esferas interna ou extema) permanecem inalteradas. Ou seja, como as freqüências de deslocamento vibracional $\left(10^{12}-10^{13} \mathrm{~s}^{-1}\right)$, orientação dos dipolos do solvente $\left(10^{11}-10^{12} \mathrm{~s}^{-1}\right)$ e difusional $\left(10^{9}-10^{11} \mathrm{~s}^{-1}\right)$ são muito menores que a eletrônica $\left(\sim 10^{15} \mathbf{s}^{-1}\right)$, o processo de ET é praticamente instantâneo em relação às etapas de rearranjo nuclear que o precedem/sucedern. ${ }^{106}$

e Equivale à energia de Franck-Condon ${ }^{\mathrm{d}}$ em sistemas simétricos. 


$$
\begin{gathered}
\lambda_{\mathrm{i}}=\sum_{n}\left(\frac{2 f_{\mathrm{R}} f_{\mathrm{P}}}{f_{\mathrm{R}}+f_{\mathrm{P}}}\right)_{n}\left(q_{\mathrm{R}}-q_{\mathrm{P}}\right)_{n}^{2} \\
\lambda_{\mathrm{o}}=(\Delta e)^{2}\left(\frac{1}{2 r_{\mathrm{D}}}+\frac{1}{2 r_{\mathrm{A}}}-\frac{1}{r_{D A}}\right)\left(\frac{1}{\varepsilon_{\mathrm{op}}}-\frac{1}{\varepsilon_{\mathrm{s}}}\right)
\end{gathered}
$$

onde $f_{\mathrm{R}} \mathrm{e} f_{\mathrm{P}}$ são as constantes de força para o $n$-ésimo modo vibracional das ligações metal-ligante no reagente e no produto; $\left(q_{\mathrm{R}}-q_{\mathrm{P}}\right)$ é a variação de distância e ângulo de ligação que acompanha a transformação do reagente em produto; $r_{\mathrm{D}} \mathrm{e} r_{\mathrm{A}}$ são os raios iônicos dos reagentes doador $\mathrm{e}$ aceitador; $r_{\mathrm{DA}}$ é a distância de contato $r_{\mathrm{D}}+r_{\mathrm{A}}$; e $\varepsilon_{\mathrm{op}}$ e $\varepsilon_{\mathrm{s}}$ são as constantes dielétricas óptica (correspondente à polarização eletrônica do meio; $\varepsilon_{\mathrm{op}}=\eta^{2}$ ) e estática (permissividade relativa correspondente ao dipolo do solvente).

O modelo acima assume uma coordenação esférica onde cada um dos sítios (D e A) é representado pelo centro de sua esfera iônica. Além desse, um modelo elipsoidal também foi proposto por Cannon, ${ }^{107}$ onde se acredita que os elipsóides representem melhor o formato/volume molecular do sistema doador-aceitador. Ambos os modelos são fundamentados na aproximação do contínuo dielétrico; isto é, assumem uma dependência homogênea das propriedades fisico-químicas do solvente $\left(\varepsilon_{\mathrm{op}}{ }^{-1}-\varepsilon_{\mathrm{s}}{ }^{-1}\right)^{\mathrm{a}}$

Embora muitas análises de constantes de velocidade de ET tenham demonstrado uma correlação evidente com a variação de parâmetros estruturais de esfera interna (tal como distância de ligação metal-ligante), ${ }_{1}^{114} \lambda_{\mathrm{i}}$ só se torna bastante relevante quando ocorrem mudanças geométricas drásticas, como mudança de simetria molecular ou de número de coordenação com a transferência de elétrons, ou então quando a reação se dá em solventes apolares (nos quais a contribuição de $\lambda_{0}$ é aproximadamente nula). Em solventes polares, $\lambda_{0}$ é tipicamente da ordem de $1,0-1,5 \mathrm{eV}$, dominando totalmente a componente $\lambda_{\mathrm{i}}$, cujo valor típico em complexos de valência mista de configuração $d^{5} / d^{6} \mathrm{de}$ spin baixo se insere na faixa de $0,1-0,3 \mathrm{eV}$

Evidentemente, a localização/deslocalização de cargas sobre o sistema de valência mista também exerce um papel determinante na contribuição de cada um dos termos $\lambda_{\mathrm{i}} \mathrm{e} \lambda_{\mathrm{o}}$. Esse aspecto, porém, será enfatizado junto com os critérios para se distinguir sistemas de classe II ou III (item 1.2.4).

\footnotetext{
a É importante mencionar que, devido à aproximação do contínuo dielétrico, o modelo só se aplica adequadamente para sistemas relativamente hidrofóbicos na ausência de interações específicas do tipo soluto-solvente (p. ex. em complexos polipiridil-derivados) e/ou simétricos. ${ }^{70,71}$ Em complexos assimétricos contendo solvatação preferencial ( $p$. ex. amina $^{71,108,109}$ e ciano-derivados) ${ }^{1110112}$ não há correlação definida entre $E_{\mathrm{op}}$ e $\left(\varepsilon_{\mathrm{op}}{ }^{-1}-\varepsilon_{\mathrm{s}}^{-1}\right)$. Nesse caso, é tecomendável a utilização dos parâmetros DN ou AN de Gutmann. ${ }^{113}$
}

As expressões dadas nas Eqs. 29 e 30 para $\overline{\mathbf{v}}_{\text {máx }}$ estão relacionadas às correspondentes energias de ativação para um processo de ET térmica $\left(\Delta G^{\ddagger}\right)$ por

$$
\Delta G^{\ddagger}=\frac{\bar{v}_{\text {máx }}}{4}=\frac{\lambda}{4} \quad\left(\Delta G^{\circ}=0\right)
$$

$\Delta G^{*}=\frac{\left(\overline{\mathrm{v}}_{\text {máx }}\right)^{2}}{4\left(\bar{v}_{\text {max }}-\Delta G^{\circ}\right)}=\frac{\left(\lambda+\Delta G^{\circ}\right)^{2}}{4 \lambda} \quad\left(\Delta G^{\mathrm{o}} \neq 0\right)$

E a constante de velocidade da reação de ET resultante é

$$
k_{\mathrm{ET}}=v_{\mathrm{n}} \exp \left(\frac{\left(\lambda+\Delta G^{0}\right)^{2}}{4 \lambda k_{\mathrm{B}} T}\right)
$$

Nesses sistemas, a largura de meia-banda é dada por

$$
\begin{gathered}
\left(\Delta \bar{v}_{1 / 2}\right)^{2}=16\left(\bar{v}_{\text {máx }}-\Delta G^{\circ}\right) k_{\mathrm{B}} T \ln 2 \\
\Downarrow \\
\Delta \bar{v}_{1 / 2}=\left(16 \lambda k_{\mathrm{B}} T \ln 2\right)^{1 / 2}
\end{gathered}
$$

Essas relações permitem a utilização de medidas simples de espectros na determinação de barreiras de energia na ET. Mudanças de frequência nas vibrações acopladas e nas oscilações do solvente ( $\hbar \omega \cong \hbar \omega^{\prime}$ ) estão incluídas em $\Delta G^{\circ}$ como uma contribuição para a diferença entrópica entre estados (se $\left.\Delta \omega=\left|\omega-\omega^{\prime}\right|<<\omega, \omega^{\prime}\right)$. ${ }^{115}$

A aproximação clássica funciona razoavelmente bem para vibrações de baixa freqüência, tal como o estiramento metal-ligante na temperatura ambiente (ou no caso em que $\hbar \omega \sim k_{\mathrm{B}} T$ ). Entretanto, na presença de modos que são correspondentes a anéis aromáticos ou vibrações $\mathrm{CO}$ e $\mathrm{CN}$, nos quais $\hbar \omega \gg k_{\mathrm{B}} T$, deve-se incluir esta contribuição explicitamente na barreira vibracional, uma vez que, neste caso, a aproximação clássica não se aplica.

Em complexos de valência mista simétricos, as bandas de IT são tipicamente encontradas na região infravermelha próxima (de 1000 a $2000 \mathrm{~nm}$, ou de 5000 a $10000 \mathrm{~cm}^{-1}$ ). Elas podem aparecer em energias maiores para complexos assimétricos, já que $\bar{v}_{\text {máx }}$ depende de $\Delta G^{\circ}$. Além disso, essas bandas normalmente são largas e dependentes do solvente, com absortividade variando de 10 a $10^{4} \mathrm{~mol}^{-1} \mathrm{dm}^{3} \mathrm{~cm}^{-1}$, dependendo do ligante-ponte. Ligantes pequenos com níveis $\pi$ ou $\pi^{*}$ acessiveis, tais como moléculas diatômicas (p. ex. $\mathrm{O}^{2-}, \mathrm{N}_{2}, \mathrm{CN}^{-}$) e anéis heterocíclicos simples conjugados ( $\mathrm{p}$. ex. pirazina), promovem acoplamento eletrônico mais forte por mistura do caráter ligante nos orbitais $d \pi$ do metal. 


\subsubsection{Critérios de distinção entre classes II e III}

Basicamente, existem dois critérios práticos para se "tentar" distinguir entre sistemas de classes II e III: (a) análise da largura de meia-banda associada à banda de IT, e (b) investigação da dependência de $\bar{v}_{\text {máx }}$ com o solvente.

O primeiro critério (a) foi proposto por Hush e decorre diretamente das premissas do seu modelo perturbacional: se o sistema possui cargas localizadas (perturbação fraca, de primeira ordem) então a largura de meia-banda teórica pode ser estimada através da Eq. 36, que, à $T=298 \mathrm{~K}$, resulta as Eqs. 37 e 38 para sistemas simétrico e assimétrico, respectivamente.

$$
\begin{gathered}
\Delta \bar{v}_{1 / 2}=\left(2310 \cdot \bar{v}_{\text {max }}\right)^{1 / 2} \\
\Delta \bar{v}_{1 / 2}=\left[2310 \cdot\left(\bar{v}_{\text {max }}-\Delta G^{\circ}\right)\right]^{1 / 2}
\end{gathered}
$$

De acordo com essa proposição, o valor obtido dessa forma estaria no limite da transição carga localizada/deslocalizada. Assim, se o valor obtido experimentalmente for superior ou igual ao previsto pelas Eqs. 37 e 38, então o sistema é de classe II e a teoria de Hush se aplica. Se, por outro lado, $\Delta \bar{v}_{1 / 2}$ (experimental) $<\Delta \bar{v}_{1 / 2}$ (calculado), então o sistema se enquadra melhor na classe III de Robin-Day, com descrição de cargas deslocalizadas. Nesse caso, o modelo de Hush não se aplica adequadamente; todavia, ainda assim é empregado freqüentemente para fins comparativos.

O segundo critério (b) deriva do fato de que, sendo um sistema de cargas deslocalizadas (classe III), não haverá uma dependência entre energia de ET óptica $\left(\bar{v}_{\text {maxx }}\right)$ e energias de reorganização $\left(\lambda_{i}\right.$ e $\left.\lambda_{\mathrm{o}}\right)$, conforme indicado nas relações de Hush-Marcus. Nesse caso, tanto as variações de esfera interna como a reorientação de dipolo do solvente ao redor dos centros redox deixam de ser importantes na escala de tempo das transformações nucleares, uma vez que todos os modos se tornam médios/simétricos $\left(\mathrm{M}_{\mathrm{a}}-\mathrm{L}_{\mathrm{x}} \equiv \mathrm{M}_{\mathrm{b}}-\mathrm{L}_{\mathrm{x}}\right)$ e $\lambda_{\mathrm{i}}$ não é afetado. Da mesma forma, assumindo deslocalização eletrônica completa, não haverá variação líquida de carga entre $M_{a}^{I I I / 2}$ e $M_{b}^{I I 1 / 2}$, de tal forma que a reorganização do solvente se torna irrelevante/constante.

As idéias acima podem ser muito bem ilustradas através da Fig. 2C, onde os estados reagente e produto se encontram verticalmente alinhados devido à grande estabilização por ressonância (no limite onde $E_{\mathrm{op}}=2 H_{\mathrm{ab}}$ ). Isso significa que a transferência de carga não requer rearranjo nuclear.

Uma comparação prática é dada pelos dímeros análogos $\left[\left\{\left(\mathrm{NH}_{3}\right)_{5} \mathrm{Ru}\right\}_{2}(\mathrm{pz})\right]^{5+12,13}$ e $\left[\left\{\left(\mathrm{NH}_{3}\right)_{5} \mathrm{Ru}\right\}_{2}\left(4,4^{\prime}-\mathrm{bpy}\right)\right]^{5+.15-17}$ enquanto o primeiro é de classe III $\left(K_{\mathrm{c}}=4 \times 10^{6} ; H_{\mathrm{ab}}=3300\right.$ $\mathrm{cm}^{-1} ; \bar{v}_{\text {max }}=6400 \mathrm{~cm}^{-1} ; \varepsilon_{\text {max }}=5000 \mathrm{~mol}^{-1} \mathrm{dm}^{3} \mathrm{~cm}^{-1} ; \Delta \bar{v}_{1 / 2}=$ $1200 \mathrm{~cm}^{-1}$; e $\left.d=6,8 \AA\right)^{70}$ e $E_{\text {op }}$ praticamente independe do solvente, o segundo é tipicamente de classe II (parâmetros obtidos em $\mathrm{D}_{2} \mathrm{O}: K_{\mathrm{c}}=20 ; H_{\mathrm{ab}}=390 \mathrm{~cm}^{-1} ; \overline{\mathrm{v}}_{\text {máx }}=9700 \mathrm{~cm}^{-1}$; $\varepsilon_{\text {máx }}=920 \mathrm{~mol}^{-1} \mathrm{dm}^{3} \mathrm{~cm}^{-1} ; \Delta \bar{v}_{1 / 2}=5200 \mathrm{~cm}^{-1}$; e $d=11,3$ $\AA)^{70}$ e é solvatocrômico conforme o esperado pela Eq. 32 .

Embora essa distinção pareça simples e inequivocada (e realmente o é em sistemas típicos de cargas localizadas), ela pode se tornar uma tarefa bastante árdua quando se trata de sistemas com comportamento no limiar/ambíguo de classes II e III (na maioria das vezes classificado como sistemas no borderline das classes II/III), ou mesmo quando se trata de um sistema com características de classe III. ${ }^{\mathrm{a}}$

Desde que esta tese reporta sistemas que vão de cargas tipicamente localizadas a deslocalizadas, passando pelo tal comportamento intermediário de classes II/III, este é um assunto que será exaustivamente explorado.

\subsubsection{Uma breve visão da química de VM atual}

Esta seção tem o objetivo de oferecer um rápido comentário acerca de cada um dos tópicos abordados anteriormente, inseridos em um contexto prático de problemas pertinentes à química inorgânica de valência mista moderna.

Transições de intervalência têm sido bastante úteis na exploração dos efeitos estruturais e de solvente em reações de transferência de elétrons. Por exemplo, nos complexos simétricos $\left[\mathrm{Cl}(\mathrm{bpy})_{2} \mathrm{Ru}^{\mathrm{III}}(\mathrm{L}) \mathrm{Ru}^{\mathrm{II}}(\mathrm{bpy})_{2} \mathrm{Cl}\right]^{3+}\left(\mathrm{L}=\mathrm{pz}, 4,4^{\prime}\right.$ bpy, bpe), $d$ aumenta de 6,8 para $13,8 \AA$ através da série. Nela, observou-se $E_{\mathrm{op}}$ (IT) varia com $1 / \epsilon_{\mathrm{op}}-1 / \epsilon_{\mathrm{s}}$ de acordo com as Eqs. 29 a 32 em uma série de solventes orgânicos polares e aumenta com $1 / d$ em $\mathrm{CD}_{3} \mathrm{CN}^{116}\left(\bar{v}_{\text {maxx }}\right.$ aumenta de 7700 a $10800 \mathrm{~cm}^{-1}$ e $H_{\mathrm{ab}}$ diminui de $400 \mathrm{a} \sim 150 \mathrm{~cm}^{-1}$, no mesmo sentido). Ambos os efeitos são preditos pelo contínuo dielétrico resultante, cujo modelo assume duas esferas sem interpenetração. Melhor concordância foi obtida com um modelo de cavidade elipsoidal. ${ }^{117}$

A teoria do contínuo dielétrico deve funcionar bem em alguns casos, mas ela falha se existirem ligantes tais como $\mathrm{NH}_{3},{ }^{108,109,118,119}$ onde ligações/pontes de hidrogênio podem ocorrer, ou $\mathrm{CN}^{-110,111}$ onde a doação de um par eletrônico resulta em interações doador-aceitador. Esses ligantes possuem interações específicas com moléculas individuais do solvente, podendo, portanto, dar origem a uma série de

a Somente para o complexo de Creutz-Taube, por exemplo, existe mais de uma centena de artigos dedicados especificamente a esse problema. 
fenômenos. ${ }^{120}$ Por exemplo, a unidade metálica contendo o sítio oxidado $\left(\mathrm{Ru}^{\mathrm{III}}\right)$ em $\left[\left(\mathrm{NH}_{3}\right)_{5} \mathrm{Ru}^{\mathrm{III}}\left(4,4^{\prime} \text {-bpy) } \mathrm{Ru}^{\mathrm{II}}\left(\mathrm{NH}_{3}\right)_{5}\right]^{5+}\right.$ é seletivamente solvatada por dimetilsulfóxido em mistura de dimetilsulfóxido:acetonitrila. Isso maximiza a ligação de hidrogênio sobre o íon $\mathrm{Ru}^{\mathrm{III}}$, que é o mais ácido. ${ }^{121} \mathrm{Em}$ $\left[\mathrm{Cl}(\text { bpy })_{2} \mathrm{O}{ }^{\mathrm{III}}\left(4,4^{\prime} \text {-bpy }\right) \mathrm{Ru}^{\mathrm{II}}\left(\mathrm{NH}_{3}\right)_{5}\right]^{4+}$, os potenciais redox para $\mathrm{Os}^{\text {IIIII }}$ e Ru ${ }^{\text {IIIIII }}$ são muito próximos devido à diferente natureza dos ligantes presentes em cada centro. Troca do solvente por mistura de acetonitrila:propileno provoca a transferência de elétrons dirigida $\mathrm{Ru}^{\mathrm{II}} \rightarrow \mathrm{Os}^{\mathrm{III}}$, por otimização das interações do solvente com $\left\{-\mathrm{Ru}^{\text {III }}\left(\mathrm{NH}_{3}\right)_{5}\right\}^{3+}{ }^{308}$

Uma complicação que nem sempre tem sido apreciada é a existência de múltiplas transições IT no espectro de baixa energia em alguns sistemas particulares. Moléculas de baixa simetria e acoplamento spin-órbita desdobram seus orbitais $d \pi$, provocando transições sobrepostas de cada um dos orbitais cheios do íon $\mathbf{M}^{\mathrm{II}}$ para o orbital semipreenchido do ion $\mathrm{M}^{\mathrm{III}}: d \pi_{1}{ }^{2}, d \pi_{2}{ }^{2}, d \pi_{3}{ }^{2}\left(\mathrm{M}_{\mathrm{a}}{ }^{\mathrm{II}}\right) \rightarrow d \pi_{3}{ }^{1}\left(\mathrm{M}_{\mathrm{b}} \mathrm{III}\right)$. Somente a transição de menor energia $d \pi_{3}^{2}\left(\mathrm{M}_{\mathrm{a}}^{\mathrm{II}}\right) \rightarrow d \pi_{3}{ }^{\mathrm{I}}\left(\mathrm{M}_{\mathrm{b}}{ }^{\mathrm{III}}\right)$ é relevante para a transferência de elétron(s) térmica, desde que as outras possíveis transições geram estados excitados interconfiguracionais em $\mathrm{M}^{\mathrm{III}}$. Dessa forma, o processo $d \pi_{1}^{2}\left(\mathrm{M}_{\mathrm{a}}^{\mathrm{II}}\right) \rightarrow d \pi_{3}{ }^{1}\left(\mathrm{M}_{\mathrm{b}}^{\mathrm{II}}\right)$ deve resultar em $d \pi_{1}^{2} d \pi_{2}^{2} d \pi_{3}{ }^{1} \mathrm{em}$ vez de $d \pi_{1}^{1} d \pi_{2}^{2} d \pi_{3}^{2}$. ${ }^{122}$

Uma das razões do grande interesse na química dos complexos de valência mista é o possível uso de medidas espectrais para calcular $k_{\mathrm{ET}}$ através dos parâmetros da banda de intervalência. $\Delta G^{\ddagger}$ e $\lambda$ são obtidos (usando o modelo spin-bóson) do máximo da banda e da largura de meiabanda. $H_{\mathrm{ab}}$ é calculado da intensidade de banda integrada. Isso permite comparação entre constantes de velocidade de transferência de elétrons teórica e experimental, um assunto de fundamental importância que vem se destacando em várias áreas da química. ${ }^{123}$

Um tema bastante explorado e longe de estar esgotado em química de valência mista é o desenvolvimento de modelos adequados para se elucidar a transição entre o que se classifica como sistemas de comportamento localizado e deslocalizado. Conforme mencionado anteriormente, no complexo simétrico $\left[\left(\mathrm{NH}_{3}\right)_{5} \mathrm{Ru}^{\mathrm{II}}\left(4,4^{\prime} \text {-bpy }\right) \mathrm{Ru}^{\mathrm{III}}\left(\mathrm{NH}_{3}\right)_{5}\right]^{5+}$, os dois centros metálicos encontram-se fracamente acoplados eletronicamente. Diferentemente, no caso do complexo $\left[\left(\mathrm{NH}_{3}\right)_{5} \mathrm{Os}^{\mathrm{II} / 2}(\mathrm{pz}) \mathrm{Os}^{\mathrm{II} / 2}\left(\mathrm{NH}_{3}\right)_{5}\right]^{5+}$, o ligante compacto e a maior extensão radial dos orbitais $5 d$ do ósmio conferem uma forte interação intermetálica e, como conseqüência, a completa deslocalização eletrônica do sistema. ${ }^{124} \mathrm{O}$ íon $\left[\left(\mathrm{NH}_{3}\right)_{5} \mathrm{Ru}(\mathrm{pz}) \mathrm{Ru}\left(\mathrm{NH}_{3}\right)_{5}\right]^{5+}$, por sua vez, também parece possuir comportamento deslocalizado (classe III), mas é freqüentemente dado como um sistema de comportamento intermediário, na situação limite classe IV/classe III. A sua classificação tem sido um tema de muita controvérsia na literatura. $^{70,71}$

Alguns dos tópicos expostos acima e sua conexão com processos de decaimento radiativo de estados excitados e transferência de elétrons invertida constituem áreas de desafio tanto para teóricos quanto para experimentalistas. Em alguns desses exemplos a aproximação de Condon e a separação de coordenadas nucleares e eletrônicas num modelo de dois centros podem ser inadequados. ${ }^{60,65}$

Uma análise não-Condon tem sido aplicada para o íon de Creutz-Taube, mas não está esclarecido se os efeitos de simetria, escala de tempo e acoplamento spin-órbita têm sido apropriadamente introduzidos no modelo. ${ }^{60,63,65}$ Para os experimentalistas, o desafio é sintetizar novos complexos de valência mista onde as dúvidas sobre a transição de estados localizado/deslocalizado possam ser explorados de maneira sistemática.

Do ponto de vista sintético, a maioria dos estudos de ET intramolecular tem utilizado principalmente oligômeros de fragmentos contendo íons $R u(I I)$ e $R u(I I I)$, que são mais conhecidos devido a algumas de suas propriedades muito favoráveis como: facilidade de preparação, conversão redox $3+/ 2+$ totalmente reversível em potenciais acessíveis, e inércia química em ambos os estados de oxidação. As séries mais investigadas desses complexos de rutênio são aquelas constituídas de derivados polipiridi $1^{70,82} \mathrm{e}$, principalmente, de pentaaminas. ${ }^{70,71}$ Isso porque, no estado de oxidação formal (+II), o fragmento $\left[\mathrm{Ru}^{\mathrm{II}}\left(\mathrm{NH}_{3}\right)_{5}\right]^{2+}$ é um forte doador$\pi$ que interage eficientemente com ligantes aceitadores- $\pi$.

Embora as transições de intervalência (ou MMCT) consistam essencialmente num processo de transferência de elétrons intramolecular, conhecimento de seus mecanismos envolvidos em processos adiabáticos e não-adiabáticos pode ser útil no estudo de reações de ET intermolecular. Isso nos leva à principal razão de se estudar complexos binucleares de valência mista. Reações de ET a longa distância são de considerável importância em muitas áreas de química, variando desde química bioinorgânica até dispositivos eletrônicos moleculares artificiais. Em muitos casos, a transferência de elétrons entre moléculas é dependente de uma série de fatores que não podem ser conhecidos detalhadamente, tais como a separação entre os centros redox no ponto de transferência e a conformação molecular, entre outros. Entretanto, em complexos binucleares de valência mista a transferência de elétron(s) ocorre dentro da molécula, para a qual a distância entre os metais, bem como 
a estrutura eletrônica e conformação molecular do liganteponte são bem conhecidos. Sendo assim, um processo de IT em uma molécula de valência mista é um modelo natural para uma reação de transferência eletrônica intra ou intermolecular, e a informação a respeito do processo de IT é bastante relevante para outros processos de ET. Além disso, análise da interação eletrônica nesses complexos permite comparar a habilidade de determinados ligantes de atuarem como fios moleculares (dependendo da capacidade condutora destes materiais) para um potencial emprego em dispositivos eletrônicos.

Este campo de pesquisa emergiu em duas direções básicas. Primeiro, os princípios delineados acima têm sido estendidos a uma ampla variedade de unidades metálicas terminais conectadas por ligantes-ponte dos mais variados tipos. Isso proporcionou uma melhor compreensão da dependência da interação eletrônica com a natureza de diferentes ligantes e espécies metálicas. Segundo, tentativas estão sendo realizadas no sentido de se controlar essas interações a longa distância por métodos de manipulação externa, tais como mudança da conformação do ligante por rotação em torno do eixo principal de ligação ${ }^{125,126}$ ou por controle externo do potencial ${ }^{85,127}$ (em sistemas onde o ligante for eletroquimicamente ativo), por mecanismos de isomerização fotoquímica, ${ }^{128-130}$ ou ainda por ajuste da interação metal-metal por meio do $\mathrm{pH}^{131-133}$

Além disso, transições de carga de intervalência (envolvendo transferência eletrônica vetorial em complexos de valência mista) são solvatocrômicas, pois o grau de reorganização da esfera de coordenação (que inclui solvatação) requerida nos dois sítios durante a transferência de carga é dependente do solvente. Dessa forma, uma outra forma natural de se controlar interações metal-metal é feita sobre os efeitos de ambiente. ${ }^{70-72,108.134-136}$ Isso constitui alguns exemplos de protótipos de chaves ou interruptores moleculares, que é o primeiro passo na construção de dispositivos eletrônicos moleculares.

Paralelamente aos estudos de transferência eletrônica óptica, um outro assunto de fundamental importância no desenvolvimento da eletrônica molecular corresponde aos processos fotoquímicos. Processos de ET fotoquimicamente induzidos são diferentes do análogo óptico porque ocorrem em duas etapas: a absorção inicial de um fóton por um cromóforo produz um estado eletronicamente excitado, que pode ser seguida de uma transferência de elétron para outro grupo que suprime o estado excitado inicial. ${ }^{47.137}$ Visto que o cromóforo e o supressor estão diretamente ligados por um ligante-ponte, a transferência do(s) elétron(s) entre eles é dependente das propriedades da ponte exatamente da mesma maneira que os exemplos de transferência eletrônica óptica dados anteriormente.

Alternativamente, transferência de energia pode ocorrer no caso da absorção de luz por um cromóforo ser seguida pela emissão de luz de um outro, possibilitando, assim, a construção de fios moleculares fotônicos em adição aos eletrônicos. ${ }^{138}$ Exemplos interessantes de transferência de energia entre unidades metálicas conectadas por cadeias longas têm sido reportados. ${ }^{139}$ Esse tipo de comunicação a longa distância entre cromóforo e supressor está também sujeito a algum tipo de controle. $\mathrm{Na}$ verdade, em muitos casos, as propriedades luminescentes de tais complexos podem ser modificadas externa e reversivelmente de algum modo. $^{140}$ 


\subsubsection{Avanços e perspectivas}

Durante algum tempo (principalmente na década de 80 ), a importância dos compostos de valência mista esteve ligada à busca por materiais semicondutores e supercondutores. Os tão celebrados óxidos cerâmicos supercondutores em altas temperaturas são, na verdade, materiais de valência mista. Além disso, esse fenômeno foi crucial para a compreensão de muitos processos biológicos, incluindo os mecanismos de ET em metaloenzimas com múltiplos centros e da ligação de oxigênio molecular a enzimas.

Nos anos 90 , a comunidade científica tem demonstrado um interesse crescente nos compostos de valência mista e, com o surgimento de novas facilidades (métodos e técnicas de investigação modernos), este interesse deverá aumentar progressivamente no século 21 . Isso porque a presença de valência mista, em alguns tipos de sistemas, pode levar ao estabelecimento de um código binário de comutação, cujo controle desempenha um importante papel na procura de materiais eletrônicos e/ou opto-eletrônicos moleculares. $\mathrm{O}$ mesmo é válido para os dispositivos de armazenamento de energia ( $v$. itens $1.3 . \mathrm{x}$ ).
Atualmente, os campos de pesquisa de compostos de valência mista envolvem as disciplinas de química, física e biologia. A ênfase teórica envolve desde dímeros simples a oligômeros mais complicados e até sólidos estendidos. Sínteses laboriosas estão concentradas no controle fino da transição de comportamento localizado/deslocalizado. Técnicas espectroscópicas ópticas, magnéticas e de nêutrons têm sido particularmente bem-sucedidas no estudo de valência mista, as quais permitiram o mapeamento e a modulação de estados vibracionais e magnéticos de baixa energia, bem como a exploração de características especiais de novos estados excitados, pelo emprego de espectroscopia e fotoeletroquímica ultra-rápidas.

O impacto do controle sobre os processos de ET (bem como sobre os magneto-ópticos) estende-se desde as áreas tradicionais de eletrônica do estado sólido, transporte de elétrons em semicondutores e estudo de metaloenzimas com múltiplos centros redox até a mimetização de sistemas biológicos (p. ex. fotossíntese artificial), dispositivos de armazenamento de energia, sensores moleculares, e a área recente de eletrônica molecular e nanotecnologia. 


\subsection{Eletrônica molecular}

As ciências moleculares dos metais de transição têm aplicações potenciais em um novo e fascinante campo: a eletrônica molecular. ${ }^{141-144}$ Esša expectativa é baseada no fato de que os estados de oxidação dos metais de transição podem ser variados de uma grande extensão e, portanto, podem resultar processos de transferência multieletrônica.

Por meio de engenharia molecular, deve ser possível associar e sintonizar dispositivos moleculares incluindo metais de transição e organizar sua interface com o mundo macroscópico. A conjugação entre luz, transferência de elétrons, transferência de energia, e propriedades magnetoópticas proporcionará a construção de dispositivos tais como células $^{79}$ e sensores ${ }^{145-147}$ moleculares precisos e eficientes para as várias necessidades da tecnologia futura. ${ }^{148}$

$\mathrm{O}$ desafio enfrentado pela química sintética na área de eletrônica molecular é preparar moléculas com funções específicas e bem definidas (isto é, que possam atuar no nível molecular como fios, interruptores, diodos, etc); a montagem controlada de componentes selecionados em espécies supramoleculares permitirá a preparação de dispositivos de tamanho nanométrico com propriedades eletrônicas bastante sofisticadas. ${ }^{82,84,94,144,146,149-152}$

\subsubsection{Dispositivos moleculares}

Nas últimas décadas têm se observado um crescente interesse na síntese e na caracterização de entidades moleculares organizadas (supermoléculas), formadas pela interação entre moléculas menores. ${ }^{44,47,24,143,147,152-153}$ Essas idéias têm sido impulsionadas principalmente após a concepção de química supramolecular introduzida por Lehn. ${ }^{2149,156}$

Em sistemas supramoleculares podem ocorrer processos de transferência eletrônica ou de energia entre componentes, ou ainda efeitos cooperativos, os quais podem causar o desaparecimento de algumas propriedades intrínsecas dos componentes e/ou o aparecimento de novas propriedades características da supermolécula. Quando esta apresenta algumas propriedades especificas, ela pode ser interpretada como um dispositivo em nível molecular. Os dispositivos moleculares podem atuar via rearranjos eletrônicos e/ou moleculares e podern ser definidos como sistemas químicos

a Jean-Marie Lehn, 1939 (Université Louis Pasteur, Strasbourg, France; e Collège de France, Paris, France). Laureado com o Prêmio Nobel de Química de 1987 (juntamente com Donald J. Cram e Charles J. Pedersen) pelo desenvolvimento e uso de moléculas com interações estruturais específicas de alta seletividade. (organizados estruturalmente e integrados funcionalmente) construídos por meio de arquitetura supramolecular.

O planejamento desses dispositivos requer o design dos componentes moleculares para uma determinada tarefa na incorporação em uma estrutura organizada, como aqueles fornecidos pelos assemblies polimoleculares. Alguns tipos incluem os dendrímeros ${ }^{130}$ e as macromoléculas constituídas pela associação de unidades porfirínicas substituídas e/ou clusters de alta nuclearidade. ${ }^{94}$

$\mathrm{O}$ maior requisito de tais sistemas é que os componentes que guiam os mediadores das interações desempenhem suas funções em nível molecular e/ou supramolecular de forma diferente do material de partida. Além disso, é necessária uma avaliação de seu uso potencial como constituintes de dispositivos moleculares.

\subsubsection{Chaves moleculares}

Os complexos binucleares constituem exemplos protótipos de chaves moleculares, ${ }^{157,158}$ cuja elaboração consiste na etapa fundamental na direção de construção de dispositivos eletrônicos moleculares, uma vez que um circuito integrado consiste essencialmente em um grande número de chaves.

$\mathrm{O}$ controle das interações metal-metal é a base do efeito switching e pode ser feito de várias maneiras. As principais são: (i) controle conformacional e dimensional do liganteponte, ${ }^{25,72,126,159,160}$ (ii) controle eletroquímico externo dos estados redox do ligante-ponte eletroativo, ${ }^{72,85,127,161}$ (iii) controle e indução da interação por efeitos ácido-base ou de $\mathrm{pH} ;{ }^{72,131-133.162-164}$ e (iii) efeitos do meio (principalmente do solvente). $72,108,109,117,119,134,136,165$

Nos complexos binucleares de valência mista nos quais a interação é transmitida através de um sistema $\pi$ deslocalizado no ligante-ponte (o que acontece na maioria dos casos) a magnitude da interação pode ser modificada pelo controle da conformação do ligante-ponte. Isso é particularmente apropriado quando o ligante-ponte contém uma ligação do tipo bifenil, uma vez que existe uma pequena barreira de potencial para a rotação ao redor da ligação C-C central, e esta rotação afeta a extensão da deslocalização $\pi$ entre as duas extremidades do ligante de ponte. ${ }^{126.158 .160}$ Vários exemplos em que a presença de substituintes estericamente volumosos afetam a torsão do ligante-ponte têm sido reportados. ${ }^{125,126}$ Contudo, nenhum deles constitui uma verdadeira chave molecular, uma vez que eles não permitem a interconversão reversível entre as espécies. 
Uma outra maneira de se alterar a conformação é por meio de métodos eletroquímicos. Isso é válido quando o liganteponte for eletroativo, como por exemplo os catecolatos ${ }^{85} \mathrm{e}$ seus análogos nitrogenados. ${ }^{127,161}$ Nesses casos, dependendo do estado de oxidação do ligante-ponte, ele pode ou não apresentar ligações duplas conjugadas que, por sua vez, promovem maior comunicação entre os centros metálicos.

A isomerização fotoquímica ${ }^{128-130}$ é um outro mecanismo possível de switching: algumas moléculas orgânicas como os butadienos e os azobenzenos são biestáveis e sofrem uma variação conformacional com a irradiação de uma luz no comprimento de onda apropriado. ${ }^{129,130}$ Apesar de esse método ter sido usado com sucesso na mudança da afinidade de vários complexos macrocíclicos com diferentes íons metálicos, ${ }^{128}$ não há nenhum exemplo de controle de interações metal-metal a longas distâncias em complexos binucleares por esse tipo de mecanismo.

Uma outra concepção de chave molecular é baseada na indução por $\mathrm{pH}$, a qual pode ser dividida em dois tipos distintos: em um caso, o sítio básico do ligante-ponte está protonado; ; ${ }^{133,162,164}$ no outro, o sítio de reação é o ligante terminal, sensivel ao $\mathrm{pH}$, presente em um dos fragmentos metálicos. ${ }^{131,166}$ Nesses exemplos de chaves moleculares, as interações que resultam a transferência eletrônica a longas distâncias entre os sítios redox podem ser ligadas (on) ou desligadas (off), dependendo do $\mathrm{pH}$ do meio.

Pode-se também controlar as interações metal-metal através de mudanças no ambiente (esfera externa). Assim, bandas de intervalência genuinas (aquelas que envolvem transferência eletrônica vetorial em complexos de valência mista com cargas localizadas) são solvatocrômicas, uma vez que a extensão da reorganização da esfera de coordenação (a qual inclui a solvatação) requerida nos dois términos do complexo seguindo a transferência de carga é dependente do solvente.

De uma maneira simples, portanto, a extensão da interação metal-metal em um complexo binuclear de valência mista pode ser controlada pela natureza do solvente. $^{72,108,109,117,119,134,136,165,167}$ Embora muitos possam considerar que, na prática, o efeito de transferência de carga solvente $\rightarrow$ soluto não seja grande o suficiente para constituir o que se consideraria um tipo de mecanismo para switching, recentemente, Meyer e colaboradores ${ }^{109,119}$ demonstraram ser possível induzir a transferência de elétrons (inversão de estados redox entre centros metálicos assimétricos) com base exclusivamente na escolha apropriada da donicidade/ natureza do solvente.
A forma mais simples e eficiente de se controlar quimicamente a comunicação eletrônica intermetálica parece ser a de indução por próton, ou seja, mediação induzida por $\mathrm{pH}$.

\subsubsection{Fios moleculares}

Dentre os vários tipos de dispositivos e componentes que desempenham funções eletrônicas em escala molecular, os fios moleculares são de fundamental importância, pois podem operar como conectores que controlam/medeiam o fluxo eletrônico entre os diferentes elementos de um sistema eletrônico molecular.

Os fios moleculares permitem tanto a transferência eletrônica a longas distâncias quanto a interação entre componentes afastados. ${ }^{167,168}$ Podem ser consideradas três classes de processos de transferência eletrônica: transporte eletrônico, electron hopping, e condução eletrônica.

Uma função mais sofisticada é a de um interruptor, o qual é um fio molecular com uma propriedade adicional que permite a variação de seu estado de condutividade por algum tipo de mecanismo externo, como uma isomerização fotoquímica ${ }^{169}$ ou coordenação a um íon metálico. ${ }^{170}$

$O$ projeto de um fio molecular deve satisfazer pelo menos dois critérios: conter uma cadeia condutora de elétrons, e possuir um terminal eletroativo e um grupo polar para troca eletrônica reversível. ${ }^{143,154,156}$ Além disso, o acoplamento de metais ao final da cadeia policonjugada deve fornecer fios que possam combinar as propriedades eletroquímicas e as atividades fotoquímicas dos complexos metálicos com as propriedades de conjugação da cadeia, gerando sistemas capazes de atuar como transferidores eletrônicos eletroinduzidos ou fotoinduzidos em grandes distâncias. ${ }^{143,154,136}$

Condução eletrônica através de "fios moleculares" é um fenômeno bastante crítico no campo do desenvolvimento da eletrônica molecular. ${ }^{142,171}$ Existe um consenso geral que um fio em escala molecular deveria consistir de uma cadeia molecular com conjugação eletrônica estendida onde haveria promoção de um forte acoplamento entre os dois grupos (moléculas, eletrodos ou outra entidade qualquer) anexados nas extremidades da cadeia. Várias descrições teóricas da condução eletrônica através de tais fios moleculares têm surgido, ${ }^{172}$ e recentemente muitos grupos têm demonstrado condução eletrônica direta através de pequenas moléculas com alto grau de organização ${ }^{173} \mathrm{e}$ até mesmo em algumas moléculas simples usando técnicas de monitoramento proximal. ${ }^{174}$ 
Muito do atual conhecimento sobre condução eletrônica em fios moleculares é baseado nas informações acumuladas nos últimos 40 anos de trabalho sobre transferência eletrônica em moléculas do tipo doador-aceitador. Dessa forma, é conhecido que o acoplamento eletrônico através de uma cadeia ligando um doador e um aceitador eletrônico pode controlar a velocidade de transferência de elétrons entre os fragmentos terminais da molécula. ${ }^{175}$ Esse mesmo tipo de interação eletrônica mediada por ponte é reconhecida como um fator crítico no controle de transferência de elétrons a longas distâncias em muitas estruturas biológicas (p. ex. proteínas redox, ${ }^{52}$ centros de reações fotossintéticas ${ }^{176}$ e ácidos nucléicos), ${ }^{54,177}$ na condução eletrônica por meio de camadas moleculares em STM, ${ }^{178}$ emissão de elétrons em certas classes de emissores de campo, ${ }^{179}$ em transferência de elétrons em sistemas eletroquímicos, ${ }^{180}$ ou ainda na condução eletrônica através de fios moleculares.

Portanto, os oligômeros polimetálicos de valência mista também exercem um papel de fundamental importância neste campo. ${ }^{2}$ 


\subsection{Reaçóos redox próton-acopladas (PCET)}

As reações de transferência de elétrons próton-acopladas (PCET) são conhecidas por exercerem um importante papel no transporte de carga em uma variedade bastante ampla de processos eletroquímicos em solução aquosa ${ }^{19,56,181} \mathrm{e} \mathrm{em}$ reações bioquímicas, ${ }^{182,183}$ inorgânicas ${ }^{184}$ e orgânicas. ${ }^{183,184}$ Avanços recentes em química supramolecular do estado sólido estão voltados para o design de sistemas do tipo PCET com novas propriedades fotônicas e eletrônicas. ${ }^{185}$

O mecanismo redox global para esse tipo de reação é, entretanto, bastante complexo, envolvendo múltiplas etapas de transferência de elétrons e de prótons. No entanto, limitando a esfera de coordenação interna em apenas um próton ionizável é possível obter complexos que exibam reações redox de 1 elétron e 1 próton em uma ampla faixa de $\mathrm{pH}$ e região de potenciais. ${ }^{184}$

Com o objetivo de se desenvolver modelos simples para PCET, planejaram-se e prepararam-se nesta tese complexos de metais de transição (rutênio e ferro) substitucionalmente inertes e coordenativamente saturados, nos quais a oxidação do metal é acoplada à transferência de um próton em um sítio remoto do ligante ácido N-heterocíclico. ${ }^{\mathrm{a}} \mathrm{A}$ fim de se facilitar a compreensão deste tema, esta seção será dedicada à revisão de alguns conceitos correlatos.

\subsubsection{Conceitos gerais}

Quando um ligante contendo um próton ionizável se coordena a um íon metálico, observa-se um aumento de sua acidez devido à estabilização de sua base conjugada promovida pelo cátion metálico. ${ }^{184,186}$ Considerando-se que um aumento na carga do cátion normalmente promove a estabilização da base aniônica conjugada, espera-se que o ligante coordenado se torne mais ácido quando se aumenta a carga do cátion, de tal forma que a constante de equilíbrio da dissociação ácida $\left(K_{\mathrm{a}}\right)$ do complexo irá aumentar com o estado de oxidação do metal.

Dessa forma, um processo redox centrado no metal irá apresentar um par dependente do $\mathrm{pH}$ se a desprotonação/ protonação do ligante ocorrer após a oxidação/redução do complexo na faixa de $\mathrm{pH}$ estudada e se a desprotonação do ligante afetar o potencial redox associado ao íon metálico. Portanto, a observação de potenciais dependentes do $\mathrm{pH}$ é uma ferramenta útil, simples e poderosa no reconhecimento e caracterização de processos redox acoplados a prótons. ${ }^{184}$

a Este tema é de relevância no estudo do sistema do item 3.1,1.4 desta tese.
Uma vez que as reações investigadas nesta tese são do tipo expresso pela Eq. 39 e ocorrem com uma concomitante variação na quantidade de prótons, então o driving force para a reação de ET dependerá da concentração de íons hidrogênio. Dessa forma, esses processos de transferência de prótons e elétrons são considerados acoplados, conforme indicado pela presença de prótons na reação de redução

$$
\mathbf{M}^{\mathrm{I}} \mathrm{L}+\mathrm{H}^{+}+\mathrm{e}^{-} \rightleftharpoons \mathrm{M}^{\mathrm{II}} \mathrm{LH}
$$

Uma conseqüência prática disso é que o potencial redox vai depender do pH da solução. Para uma reação mais genérica, conforme representado pela Eq. 40, o potencial de meiaonda $\left(E_{12}\right)$, no qual $\left[\mathrm{ML}^{x}\right]=\left[\mathrm{ML}\left(\mathrm{H}^{\prime}\right)_{m}{ }^{x+m-n}\right]$, é previsto pela equação de Nernst como tendo uma dependência com o pH conforme a relação mostrada na Eq. $41,{ }^{6}$ onde $D_{\text {ox }}$ e $D_{\text {red }}$ são os coeficientes de difusão das espécies oxidada e reduzida, respectivamente; $m$ é o número de prótons; $n$ é o número de elétrons; $E^{0^{3}}$ é o potencial formal hipotético (assumindo-se que o processo envolvendo $n$-elétrons $/ m$-prótons ocorre em $\mathrm{pH} 0$ ); e $E_{1 / 2}$ é o potencial redox (obtido experimentalmente por meio de técnicas de voltametrias cíclica ou de pulso diferencial). ${ }^{6,187,188}$

$$
\begin{gathered}
\mathrm{ML}^{x}+m \mathrm{H}^{+}+n \mathrm{e}^{-} \rightleftharpoons \mathrm{ML}\left(\mathrm{H}^{+}\right)_{m}{ }^{x+m-n} \\
E_{1 / 2}=E^{\prime \prime}-[0,059 / n] \log \left(D_{\mathrm{o}} / D_{\mathrm{r}}\right)^{1 / 2}-0,059(m / n) \mathrm{pH}
\end{gathered}
$$

No caso particular de um par redox centrado no metal e envolvendo 1 elétron e 1 próton, como mostrado na Eq. 39, e também considerando-se que $D_{\text {ox }}$ e $D_{\text {red }}$ nesses sistemas são bastante similares e podem, assim, ser freqüentemente assumidos como sendo iguais, então a equação de Nernst (Eq. 41) pode ser reduzida a uma expressão simplificada (Eq. 42). Uma vez que os complexos mononucleares se enquadram nesses requisitos, essa relação bastante simples entre $E_{1 / 2} \mathrm{e} \mathrm{pH}$ pode ser amplamente usada.

$$
E_{1 / 2}=E^{\circ}-0,059 \cdot \mathrm{pH}
$$

A dependência do potencial redox com a concentração de prótons é convenientemente visualizada em um diagrama de potencial vs. $\mathrm{pH}$, mais comumente chamado de diagrama Pourbaix, ${ }^{181,189}$ ou diagrama de predominância de área. ${ }^{\mathrm{b}}$

Os diagramas de pH-potencial para íons de metais de transição normalmente são bastante complexos, visto que

\footnotetext{
b Rigorosamente, um diagrama Pourbaix é uma superficie tridimensional envolvendo $E, \mathrm{pH}$ e atividade. ${ }^{190} \mathrm{Um}$ diagrama bidimensional de $E$ vs. $\mathrm{pH}$ é chamado de diagrama de predominância, mas também é comumente chamado de diagrama Pourbaix. ${ }^{189}$
} 
envolvem múltiplos processos de transferência de elétrons e prótons. ${ }^{181,189} \mathrm{O}$ diagrama de $\mathrm{pH}$-potencial para um processo redox monoeletrônico envolvendo um complexo hipotético $\mathrm{M}^{\mathrm{II}} \mathrm{LH}$ contendo um único próton ionizável é mostrado na Fig. 5 (neste tratamento assumiu-se que o par centrado no metal envolve os estados de oxidação $M(I I I)$ e $M(I I)$; não obstante, este tratamento pode ser generalizado para qualquer par $\mathbf{M}^{(n+1)+} / \mathbf{M}^{n+}$ ).

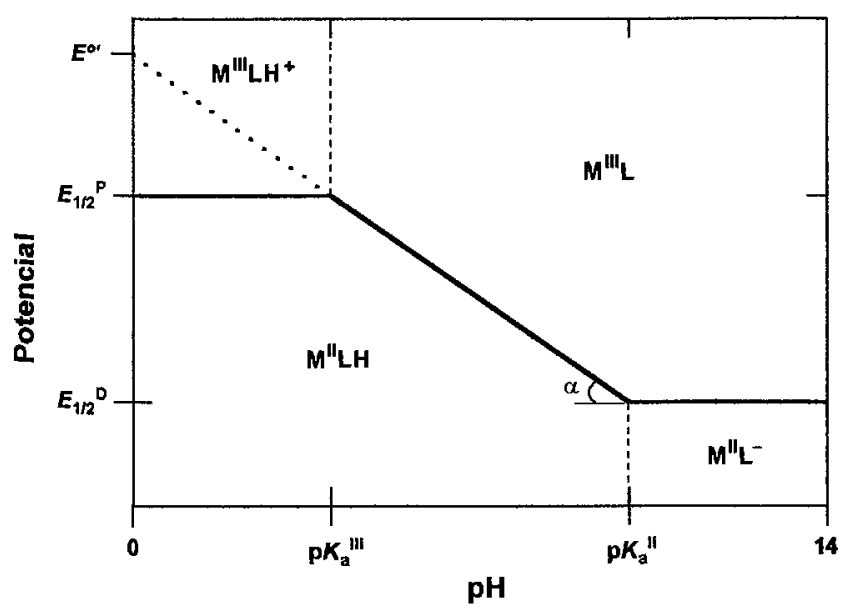

Figura 5. Diagrama de potencial vs. $\mathrm{pH}$ para um complexo do tipo $M^{\prime \prime} \mathrm{LH}$ exibindo um par redox $\mathrm{M}^{\text {III }} / \mathrm{M}^{\text {"l }}$ dependente do $\mathrm{pH}$, onde $\alpha$ é a inclinaçăo prevista de $59 \mathrm{mV} / \mathrm{pH}$; $E^{\circ}$ é o potencial formal do par $M^{\prime \prime \prime} L / M^{\prime \prime} L H(p H=0) ; E_{12}{ }^{P}$ é o potencial formal do par $M^{\prime \prime \prime} L_{H}^{+} / M^{\prime \prime} L H$; $E_{1 / 2}{ }^{D}$ é o potencial formal do par $M^{\prime \prime \prime} L / M^{\prime \prime} L^{-}$; e $p K_{a}{ }^{\prime \prime \prime}$ e $p K_{a}^{\prime \prime}$ são os valores de $p K_{a}$ das espécies $M(I I I)$ e $M(I I)$, respectivamente. (adaptado da ref. 184)

No diagrama, a linha horizontal na região ácida representa o processo redox independente do $\mathrm{pH}$, no qual ambas as espécies oxidada e reduzida estão protonadas (Eq. 43).

$$
\mathrm{M}^{\mathrm{III}} \mathrm{LH}^{+}+\mathrm{e}^{-} \rightleftharpoons \mathrm{M}^{\mathrm{II}} \mathrm{LH}
$$

A linha horizontal na região básica representa o processo redox independente do $\mathrm{pH}$, no qual ambas as espécies oxidada e reduzida estão desprotonadas (Eq. 44).

$$
\mathrm{M}^{\mathrm{II}} \mathrm{L}+\mathrm{e}^{-} \rightleftharpoons \mathrm{M}^{\mathrm{II}} \mathrm{L}^{-}
$$

A linha diagonal corresponde ao processo redox dependente do $\mathrm{pH}$ onde a redução/oxidação do centro metálico é acoplada à protonação/desprotonação do ligante (Eq. 39). De acordo com a Eq. 42, a inclinação dessa reta para um par envolvendo 1 elétron e 1 próton é de $59 \mathrm{mV} /$ unidade de $\mathrm{pH}$.

A linha vertical na região ácida representa o equilíbrio ácido/base para o complexo oxidado (Eq. 45),

$$
\mathrm{M}^{\mathrm{III}} \mathrm{LH}^{+} \rightleftharpoons \mathrm{M}^{\mathrm{III}} \mathrm{L}+\mathrm{H}^{+}
$$

para a qual a constante de dissociação ácida é dada por:

$$
K_{\mathrm{a}}^{\mathrm{III}}=\frac{\left[\mathrm{M}^{\mathrm{III}} \mathrm{L}\right]\left[\mathrm{H}^{+}\right]}{\left[\mathrm{M}^{\mathrm{III}} \mathrm{LH}^{+}\right]}
$$

A linha horizontal na região ácida corresponde ao potencial no qual $\left[\mathrm{M}^{\mathrm{III}} \mathbf{L H}^{+}\right]=\left[\mathrm{M}^{\mathrm{II}} \mathbf{L H}\right]$, e a linha diagonal, por sua vez, corresponde ao potencial no qual $\left[\mathrm{M}^{\mathrm{II}} \mathrm{L}\right]=\left[\mathrm{M}^{\mathrm{II}} \mathrm{LH}\right]$. No ponto de intersecção, $\left[\mathrm{M}^{\mathrm{III}} \mathrm{LH}^{\dagger}\right]=\left[\mathrm{M}^{\mathrm{II}} \mathrm{LH}\right]=\left[\mathrm{M}^{\mathrm{III}} \mathrm{L}\right]$ e a Eq. 46 se reduz a $K_{\mathrm{a}}^{\mathrm{III}}=\left[\mathrm{H}^{+}\right]$. Por conseqüência, $\mathrm{p} K_{\mathrm{a}}^{\mathrm{III}}=\mathrm{pH}$ na linha vertical na região ácida.

Com um argumento similar, a linha vertical na região básica representa o equilíbrio ácido/base para o complexo reduzido (Eqs. 47 e 48$)$, e $K_{\mathrm{a}}{ }^{\mathrm{II}}=\mathrm{pH}$.

$$
\begin{aligned}
\mathrm{M}^{\mathrm{II}} \mathrm{LH} & \rightleftharpoons \mathrm{M}^{\mathrm{II}} \mathrm{L}^{-}+\mathrm{H}^{+} \\
K_{\mathrm{a}}^{\mathrm{II}} & =\frac{\left[\mathrm{M}^{\mathrm{II}} \mathrm{L}^{-}\right]\left[\mathrm{H}^{+}\right]}{\left[\mathrm{M}^{\mathrm{II}} \mathbf{L H}\right]}
\end{aligned}
$$

Finalmente, é importante notar que essas correlações são consistentes com a Eq. 41, a qual prediz: (a) uma linha horizontal para uma reação redox que não envolve a transferência de prótons ( $m=0)$; (b) uma linha vertical para um equilíbrio ácido/base que não envolve reação redox $(n=0)$; e (c) uma inclinação de $59 \mathrm{mV} /$ unidade de $\mathrm{pH}$ para um processo envolvendo 1 elétron e 1 próton $(n=1 ; m=1)$.

Os conceitos acima serão bastante úteis na discussão do item 3.1.1.4 desta tese. 


\subsection{Isomeria de ligação}

A isomeria de ligação é um reflexo dos diferentes modos de coordenação que uma dada molécula pode ter, e tem sido classificada como um fenômeno associado a complexos metálicos contendo ligantes ambidentados, isto é, aqueles com pelo menos dois átomos potencialmente coordenantes.

Em uma molécula desse tipo, é importante manter a mesma denticidade e configuração geométrica, de tal forma que a coordenação dos ligantes ao ín metálico possa envolver diferentes interações com os átomos doadores, gerando os seus correspondentes isômeros. ${ }^{2}$

Esse tipo de isomeria foi reconhecido pela primeira vez por Werner ${ }^{\mathrm{b}}$ em seu trabalho clássico sobre as formas xantho e isoxantho do complexo $\left[\mathrm{Co}\left(\mathrm{NO}_{2}\right)\left(\mathrm{NH}_{3}\right)_{5}\right] \mathrm{Cl}_{2} .{ }^{191,192}$ A espécie xantho corresponde ao isômero mais estável "nitro" (modo $\mathrm{kN}$ ), enquanto a espécie isoxantho se refere ao isômero "nitrito" (forma $\kappa O$ ) ${ }^{193}$ Desde então, esse sistema tem sido extensivamente investigado em solução e no estado sólido, constituindo (mesmo atualmente) o exemplo preferido de estudo em cursos de química de coordenação. ${ }^{194,195}$

A geração de isômeros de ligação metaestáveis depende das características de labilidade/inércia intrínsecas ao complexo metálico, além das afinidades metal-ligante e dos fatores estereoquímicos. Por exemplo, os complexos metálicos que exibem configurações $d^{5}$ e $d^{6}$ de spin baixo são substitucionalmente inertes. Embora esse aspecto por si só não facilite a formação direta de isômeros de ligação metaestáveis, a maioria dos exemplos de literatura enfocam tais sistemas por razões práticas, já que uma vez formados eles podem ser facilmente monitorados usando técnicas convencionais. ${ }^{192,166,197}$

$\mathrm{Na}$ verdade, os procedimentos para se gerar isômeros de ligação raramente recaem sobre os métodos diretos, embora esta possibilidade também deva ser considerada. De fato, os métodos indiretos são mais freqüentemente empregados. Os mais comuns são: eletroquímicos, ${ }^{198-202}$ fotoquímicos ${ }^{203204} \mathrm{e}$ térmicos. ${ }^{205-207}$ Exemplos de isomeria de ligação induzida por próton ${ }^{201,202,204,206,208-210}$ e solvente $e^{208,211}$ também são conhecidos.

\footnotetext{
- Para designar um isômero, recomenda-se a utilização da letra grega " $\alpha$ " (kappa) precedendo o átomo coordenante. ${ }^{1}$

b Alfred Wemer, 1866-1919 (Zurich University, Zurich, Switzedand). Laureado corn o Prêmio Nobel de Química de 1913 em reconhecimento ao seu trabalho sobre as ligações de átomos em moléculas e pelas investigações pioneiras que inauguraram novos campos de pesquisa em química, especialmente em química inorgânica. (Wemer é reconhecido pelos químicos inorgânicos como o "criador" da química de coordenação).
}

Os ligantes ambidentados podem variar desde moléculas di- e triatômicas simples (p. ex. os íons $\mathrm{CN}^{-212} \mathrm{SCN}^{-197,213} \mathrm{e}$ $\mathrm{NO}_{2}{ }^{-195,200,214}$ até outras muito complicadas, como ligantes poli-heterocíclicos e/ou polifuncionais, ${ }^{201,210,215}$ e algumas macromoléculas de interesse biológico, tais como proteínas e polinucleotídeos. ${ }^{207,216}$

A estabilidade de compostos de coordenação isômeros é resultado de um cuidadoso balanço entre o caráter duro ou mole do centro metálico e do ligante ambidentado. Sabe-se que metais duros tendem a se complexar com os sítios duros do ligante, enquanto os metais moles preferem sítios também moles. Dessa forma, um ligante que retira elétrons incrementará o caráter duro do metal, favorecendo a sua ligação com o átomo mais duro do ligante.

Outros fatores importantes estão relacionados com os efeitos eletrônico, estérico e de solvente. Na maioria dos casos, verifica-se que solventes com alta constante dielétrica tendem a intensificar as interações controladas pelos orbitais de fronteira (covalentes) enquanto aqueles com baixa constante dielétrica favorecem interações controladas pela carga (iônicas). Além disso, os fatores cinéticos podem determinar qual isômero será formado preferencialmente, ou seja, o isômero termodinamicamente instável pode se formar e isomerizar no sentido de formação do mais estável.

$A$ isomerização desenvolve-se essencialmente através de mecanismos dissociativo ou intramolecular. $\mathrm{O}$ mecanismo dissociativo envolve a quebra da ligação original, formada antes do estabelecimento da nova espécie isômera. A isomerização intramolecular é observada na maioria dos casos e envolve apenas a quebra ou formação de ligação dentro do próprio complexo inicial (deslocamento) e por isso independe da concentração do complexo ${ }^{217}$ ou do ligante ao qual o metal está ligado. ${ }^{218}$

Um caso interessante de isomerização intramolecular é aquele em que o íon metálico troca de átomo coordenante no ligante, deslocando-se para outra posição química e estruturalmente semelhante à primeira, mas com densidade eletrônica diferente. Esse tipo de isomeria ocorre, por exemplo, na formação de complexos metálicos de transição com moléculas poliaza-heterocíclicas de nitrogênio ( $\mathrm{p}$. ex. benzotriazol, tetrazol, e seus derivados) e é conseqüência da associação de algumas características eletrônicas peculiares dos ligantes (como gradientes de densidade de carga) e do íon metálico (p. ex. capacidade doadora- $\sigma / \pi$ e aceitadora- $\pi$ ). Normalmente, esses isômeros são detectados em solução por meio de técnicas eletroquímicas e/ou espectroscópicas, pois, difícilmente é possível se isolar espécies isômeras desse tipo. 
Nesse sentido, um dos estudos pioneiros centrados no esclarecimento dos mecanismos envolvidos em isomeria de ligação em complexos foi aquele realizado por Armor e Taube, ${ }^{219}$ os quais usaram nitrogênio marcado $\left({ }^{15} \mathrm{~N}\right)$ para acompanhar a isomerização no complexo $\left[\mathrm{Ru}^{\mathrm{II}}\left(\mathrm{N}_{2}\right)\left(\mathrm{NH}_{3}\right)_{5}\right]^{2+}$, através de espectroscopia vibracional no $\mathbb{R}$. Nesse trabalho, ficou evidenciado que o processo de interconversão entre $\left[\mathrm{Ru}\left({ }^{15} \mathrm{~N} \equiv \mathrm{N}\right)\left(\mathrm{NH}_{3}\right)_{5}\right]^{2+}$ e $\left[\left({ }^{15} \mathrm{~N} \equiv \mathrm{N}\right) \mathrm{Ru}\left(\mathrm{NH}_{3}\right)_{5}\right]^{2+}$ segue um mecanismo intramolecular envolvendo um intermediário com modo de coordenação fluxional (onde a interação que caracteriza um estado $\pi$ se dá através da nuvem eletrônica deslocalizada entre os átomos $\mathrm{N}$ e ${ }^{15} \mathrm{~N}$ ).

Dois sistemas muito importantes por terem possibilitado isolar os dois isômeros neles envolvidos são os complexos pentaamincobalto(III) com 5-metil e 5-feniltetrazolato, ${ }^{217,220}$ nos quais as espécies $\kappa N I$ e $\kappa N 2$ coexistem em solução aquosa. Estudos de RMN também demonstraram a existência de equilíbrio entre os isômeros $\kappa N 1$ e $\mathrm{kN} 2$ em complexos de tetrazolato com íons $\mathrm{Pt}(\mathrm{II})^{221}$ e $\mathrm{Pd}(\mathrm{II}){ }^{222}$

\subsubsection{Alguns exemplos de isômeros de ligação}

Uma vez que o campo relacionado à isomeria de ligação é um dos mais amplos no contexto da química inorgânica clássica, além dos trabalhos iniciais já comentados acima, a introdução a seguir se limitará a uma breve revisão de alguns trabalhos com ênfase em cinética e mecanismo de isomeria de ligação, em especial aqueles desenvolvidos pelo grupo onde o presente trabalho também foi desenvolvido.

Os primeiros trabalhos nesta área realizados por Toma et al. envolvem o estudo de isômeros de ligação produzidos através de reações de substituição dissociativas, nas quais o complexo $\left[\mathrm{Fe}^{\mathrm{II}}(\mathrm{CN})_{5}(\mathrm{X})\right]^{\mathrm{n}-}$ se transforma em uma espécie intermediária coordenativamente insaturada na presença de ligantes ambidentados. Através do uso de um grande número de técnicas e condições experimentais, verificou-se que a velocidade de substituição do ligante $X$ nesses complexos apresenta um comportamento de saturação com respeito à concentração do ligante de entrada $Y^{111.223-226} \mathrm{em}$ concordância com o mecanismo descrito pelas Eqs. 49-51.

$$
\begin{aligned}
& {\left[\mathrm{Fe}(\mathrm{CN})_{5}(\mathrm{X})\right]^{3-} \rightleftharpoons\left[\mathrm{Fe}(\mathrm{CN})_{5}\right]^{3-}+\mathrm{X} \quad\left(k_{\mathrm{X}}, k_{-\mathrm{X}}\right)} \\
& {\left[\mathrm{Fe}(\mathrm{CN})_{5}\right]^{3-}+\mathrm{H}_{2} \mathrm{O} \rightleftharpoons\left[\mathrm{Fe}(\mathrm{CN})_{5}\left(\mathrm{H}_{2} \mathrm{O}\right)\right]^{3-}} \\
& {\left[\mathrm{Fe}(\mathrm{CN})_{5}\right]^{3-}+\mathrm{Y} \rightleftharpoons\left[\mathrm{Fe}(\mathrm{CN})_{5}(\mathrm{Y})\right]^{3-} \quad\left(k_{\mathrm{Y}}, k_{-\mathrm{Y}}\right)}
\end{aligned}
$$

Por causa do mecanismo dissociativo envolvido, a formação da espécie intermediária $\left[\mathrm{Fe}^{\mathrm{II}}(\mathrm{CN})_{5}\right]^{3-}$ foi convenientemente explorada na obtenção de isômeros de ligação na presença

\footnotetext{
a Em revisão bibliográfica recente, foram encontrados mais de mil artigos catalogados apenas nos últimos 50 anos. Somente aqueles sobre cianeto, nitro/nitrito, tiocianato/isotiocianato e seus derivados somam algo ao redor da metade desse total.
}

de ligantes ambidentados tais como aminoácidos ${ }^{227-229}$ e 2aminopirazina. ${ }^{230}$ Nesses casos, uma estratégia importante usada na avaliação das constantes cinéticas envolvidas no esquema de isomerização foi a introdução do ligante dimetilsulfóxido como um ligante competitivo, uma vez que ele forma um complexo bastante estável e inerte com $\left[\mathrm{Fe}^{\mathrm{II}}(\mathrm{CN})_{5}\right]^{3-}$. Esse caminho foi empregado com sucesso ${ }^{229}$ na obtenção de parâmetros cinéticos relacionados à isomeria de ligação em complexos de pentacianoferrato(II) com alguns aminoácidos; em particular, histidina, ${ }^{227}$ metionina e metioninassulfóxido. ${ }^{228,229}$

A histidina, particularmente, é um aminoácido essencial que exibe o equilíbrio tautomérico $\mathrm{N}(1)$-his $\rightleftharpoons \mathrm{N}(3)$-his

Nesse ligante, ambos os átomos de nitrogênio $\mathrm{N}(1)$ e $\mathrm{N}(3)$ do anel imidazol estão susceptíveis à coordenação, sendo que o tautômero $\mathrm{N}(3)$ deverá produzir um complexo menos estável devido a efeitos estéricos. Contudo, as medidas cinéticas mostraram que o isômero N(3) é formado preferencialmente. Apesar de ambos os isômeros $\mathrm{N}(1)$ e N(3) apresentarem espectros eletrônicos bastante similares, eles foram distinguidos cineticamente, devido a suas reatividades contrastantes na presença de dimetilsulfóxido. Todas as constantes associadas a esse sistema foram obtidas resolvendo-se uma cinética de duas etapas. A constante do equilíbrio tautomérico $\mathrm{N}(1)$-his $\rightleftharpoons \mathrm{N}(3)$-his foi calculada como $K=9$, o que explica a predominância inicial do isômero $\left[\mathrm{Fe}^{\mathrm{II}}(\mathrm{CN})_{5}(\mathrm{kN} 3\{\text { his }\})\right]^{4-}$ no sistema. Na ausência de dimetilsulfóxido, esse isômero se converte rapidamente no seu análogo mais estável $\left[\mathrm{Fe}^{\mathrm{II}}(\mathrm{CN})_{5}(\kappa N 1\{\text { his }\})\right]^{4}$.

Os estudos de Batista e Toma ${ }^{228,231}$ demonstraram também a presença de isômeros de ligação nos cianoferratocomplexos com metionina e metioninassulfóxido. Na forma 
aniônica, esses aminoácidos podem se coordenar ao íon pentacianoferrato(II) através dos sítios disponíveis $\mathrm{S}$ e $\mathrm{NH}_{2}$. A cinética realizada na presença do ligante dimetilsulfóxido permitiu diferenciar os isômeros $\mathrm{\kappa S}$ e $\mathrm{\kappa NH}_{2}$. Esse estudo revelou que, apesar de os grupos tioéter e sulfóxido se coordenarem preferencialmente a metais moles (como, por exemplo, o íon pentacianoferrato(II)), em condições dinâmicas (não equilíbrio), ambos os isômeros $\mathrm{\kappa S}$ e $\mathrm{kNH} \mathrm{H}_{2}$ são produzidos.

Métodos similares de cinética competitiva também foram empregados no estudo de isômeros envolvendo ligantes poliaza-heterocíclicos. Pode-se citar como exemplo a 2-aminopirazina, ${ }^{230}$ cuja estrutura contém três átomos potencialmente coordenantes representados pelo grupo $\mathrm{NH}_{2}$ e pelos átomos aromáticos $\mathrm{N}(1)$ e $\mathrm{N}(4)$. Experimentos de cinética rápida indicaram a formação inicial de ambos os isômeros: $\mathrm{\kappa NH}_{2}$ e $\kappa N(4)$. $\mathrm{O}$ isômero $\mathrm{\kappa NH}_{2}$ é mais lábil e menos estável, sofrendo uma conversão lenta e completa na forma análoga $\mathrm{kN}(4)$

Além de utilizar o dimetilsulfóxido como ligante de ataque em cinéticas competitivas, Toma et al. analisaram o efeito da natureza e das características eletrônicas de íons metálicos sobre as propriedades coordenantes deste ligante. ${ }^{a}$ Devido às propriedades contrastantes dos átomos $\mathrm{S}$ e $\mathrm{O}, \mathrm{o}$ dimetilsulfóxido pode formar isômeros de ligação $\mathrm{\kappa S}$ e $\kappa O$, dependendo da natureza do íon metálico de transição. Assim, o grupo sulfinil proporciona um bom sítio aceitador para espécies doadoras- $\pi$, como íons ferro(II) e rutênio(II) de spin baixo; enquanto o átomo de oxigênio é o sítio preferido por metais duros, como os cátions trivalentes $3 d$, $\mathrm{Al}^{3+}$ e lantanídeos.

Dessa forma, enquanto a maioria dos complexos de $\mathrm{Ru}^{\mathrm{II}}$ exibem uma grande afinidade por ligantes sulfurados, a preferência demonstrada pelo correspondente $\mathrm{Ru}^{\mathrm{III}}$ é quase sempre invertida, favorecendo a sua ligação com sítios $\mathrm{O}$ doadores. Os exemplos clássicos ilustrando esse efeito são baseados em sistemas do tipo $\left[\mathrm{Ru}\left(\mathrm{NH}_{3}\right)_{5}(\mathrm{~L}-\mathrm{SO})\right]^{\mathrm{n}+1},{ }^{199,234}$ onde L-SO é um sulfóxido-derivado.

No complexo $\left[\mathrm{Ru}^{\mathrm{III}}(\mathrm{edta})(\mathrm{dmso})\right]^{-235}$ em particular, o dimetilsulfóxido se coordena ao metal através do átomo de enxofre, resultando $\left[\mathrm{Ru}^{\mathrm{III}}(\mathrm{edta})(\kappa S\{\mathrm{dmso}\})\right]^{-}$. Contudo, a constante de equilíbrio dessa espécie é bastante pequena $\left(K=1,8 \mathrm{dm}^{3} \mathrm{~mol}^{-1}\right)$, devendo ser usado um grande excesso do ligante dimetilsulfóxido em relação ao íon metálico de

a No final da década de 70 , estudos de reatividade, cinética e mecanismos de transferência de elétrons envolvendo o íon pentaamin(dimetilsulfóxido)cobalto(III) ${ }^{232}$ e outras espécies substituídas de pentacianoferrato também foram largamente explorados por de Oliveira et al. 233 partida, $\left[\mathrm{Ru}^{\mathrm{III}}(\mathrm{edta})\left(\mathrm{H}_{2} \mathrm{O}\right)\right]^{-}$. Diferentemente dessa espécie oxidada, o complexo reduzido, $\left[\mathrm{Ru}^{\mathrm{II}}(\mathrm{edta})(\kappa S\{\mathrm{dmso}\})\right]^{2-}$, é extraordinariamente estável $\left(K=7,7 \times 10^{9} \mathrm{dm}^{3} \mathrm{~mol}^{-1}\right)$.

Um exemplo interessante de controle eletroquímico da isomeria de ligação em espécies contendo dimetilsulfóxido ocorre no sistema cis, cis, cis-[ $\left[\mathrm{RuCl}_{2}(\mathrm{~K} S\{\mathrm{dmso}\})_{2}(\mathrm{tbpy})_{2}\right]^{236}$ Verificou-se que o metal na forma reduzida favorece a formação do isômero $\mathrm{kS}$, enquanto na forma oxidada ambos os isômeros são observados. As constantes de velocidade $\left(k_{\mathrm{O} \rightarrow \mathrm{S}}^{\mathrm{III}}\right.$ e $\left.k_{\mathrm{S} \rightarrow \mathrm{O}}^{\mathrm{III}}\right)$ associadas à isomerização são pelo menos cinco ordens de grandeza maiores que as velocidades de substituição típicas observadas nesse tipo de complexo, sustentando um mecanismo de isomerização intramolecular.

Reações de isomerização de ligação controladas por métodos eletroquímicos também foram observadas no complexo trinuclear $\left[\mathrm{Ru}_{3} \mathrm{O}(\mathrm{ac})_{6}(\mathrm{py})_{2}(\mathrm{dmso})\right]^{+237}$ Dados espectroscópicos vibracionais e de RMN mostram que, quando os íons de rutênio apresentam estado de oxidação formal + III, o ligante dimetilsulfóxido está coordenado ao ín metálico através do átomo de oxigênio, gerando o isômero $\mathrm{Ru}^{\mathrm{III}} \mathrm{Ru}^{\mathrm{III}} \mathrm{Ru}^{\mathrm{III}}(\kappa O\{\mathrm{dmso}\})$. Diferentemente, dados de voltametria cíclica indicam que, quando o complexo é reduzido, ambos os isômeros $\kappa S$ e $\kappa O$ coexistem em equilíbrio, onde a forma predominante é o isômero $\kappa S$. As constantes de velocidade de isomerização associadas aos clusters trigonais de acetato de rutênio nas formas reduzida e oxidada são muito maiores que as velocidades usualmente observadas em reações de substituição, o que evidencia um mecanismo do tipo intramolecular.

Além das reações de isomerização eletroquimicamente controladas, Rein e Toma ${ }^{238,239}$ investigaram a influência do $\mathrm{pH}$ no complexo formado pela interação de rutênio(III)-edta com o ligante 3-hidroxipicolínico. Os autores verificaram que o complexo $\left[\mathrm{Ru}^{\mathrm{III}}(\mathrm{edta})(\kappa N, O\{\text { Hhpic }\})\right]^{2-}$ predomina em meio ácido. $\mathrm{Em} \mathrm{pH}>9$, a desprotonação do grupo fenólico promove a isomerização de ligação intramolecular,

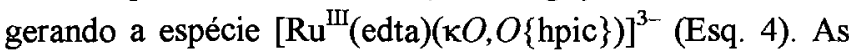
cinéticas de isomerização indicam apenas uma pequena dependência com a concentração do ligante totalmente desprotonado ( $\mathrm{hpic}^{2-}$ ), confirmando um mecanismo de rearranjo intramolecular. Deve-se destacar que ambos os isômeros podem ser eletroquimicamente reduzidos, mas são convertidos na espécie $\left[\mathrm{Ru}^{\mathrm{II}}(\mathrm{edta})(\mathrm{\kappa} N, O\{\text { Hhpic }\})\right]^{3-\cdots}$, que é altamente estabilizada por interações de transferência de carga to tipo rutênio $\rightarrow$ piridinacarboxilato. 
<smiles></smiles>

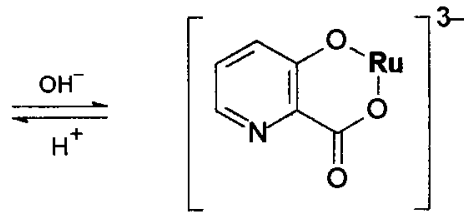<smiles>[C-]=C</smiles>

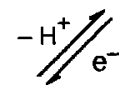<smiles></smiles>

Esquema 4. Processo de isomerização controlado por próton e elétron.

Nessa direção, Toma e Rein também reportaram ${ }^{90}$ que o rutênio-edta reage com o ácido 2-mercaptonicotínico em solução aquosa produzindo um produto vermelho $(\lambda=530$ $\mathrm{nm}$ ), cuja coordenação ocorre através do átomo de enxofre do ligante. Essa espécie sofre desprotonação com um $\mathrm{p} K_{\mathrm{a}}$ aparente igual a 3,80 , gerando um complexo azul no qual o ligante se coordena de modo bidentado (S,N). Na presença de excesso de rutênio-edta, é formada uma espécie binuclear envolvendo os modos de coordenação bidentados $(\mathrm{N}, \mathrm{S})$ e $(\mathrm{S}, \mathrm{O})$ do ligante-ponte.

Ainda no contexto da química de complexos metálicos com ligantes ácidos polifuncionais (particularmente aqueles contendo enxofre), um dos primeiros trabalhos a respeito de isomeria de ligação envolvendo rutênio-edta foi publicado por Toma et al. há mais de dez anos, ${ }^{240}$ os quais estudaram o sistema $\left[\mathrm{Ru}^{\text {Ill }} \text { (edta)(HSpy) }\right]^{\mathrm{n}-}$ do ponto de vista cinético, eletroquímico e espectroscópico. A reação entre $\mathrm{Ru}^{\mathrm{III}}$ (edta) e 2-mercaptopiridina, em meio ácido, gera um complexo vermelho $\left(\lambda_{\text {máx }}=550 \mathrm{~nm}\right)$, cuja coordenação se dá através do átomo de enxofre. Em meio básico, um outro produto de cor verde $\left(\lambda_{\text {máx }}=630 \mathrm{~nm}\right)$ foi atribuído a uma espécie coordenada bidentadamente através dos átomos de nitrogênio e enxofre. $\mathrm{O}$ valor do $\mathrm{p} K_{\mathrm{a}}$ associado ao equilíbrio entre os isômeros foi estimado em 4,35 e a conversão $\mathrm{k} S \rightarrow \mathrm{k} N$, $S$ ocorre com uma constante cinética de $0,31 \mathrm{~s}^{-1}$. Medidas de espectroscopia eletrônica e Raman ressonante deram resultados consistentes com uma interação metalligante via $\mathrm{S}$ no complexo vermelho, e ligação quelato N,S na espécie verde.

Outros trabalhos de isomeria de ligação desenvolvidos no grupo se sucederam a esses, mas serão discutidos dentro do contexto dos sistemas descritos nesta tese.

\subsubsection{Derivados de benzotriazol}

Outro caso interessante de isomeria de ligação estudado por Toma et al. são os complexos de ferro e rutênio envolvendo benzotriazol. $^{241-243} \mathrm{O}$ benzotriazol é um ligante aromático que apresenta três átomos de nitrogênio vicinais disponíveis à coordenação, particularmente na forma aniônica.

$O$ íon pentacianoferrato(II) forma dois isômeros de ligação com benzotriazol, denominados $\kappa N(3) \mathrm{e}$ $\kappa N(2)$. Essas duas espécies foram detectadas por espectroscopia RMN de ${ }^{1} \mathrm{H} \mathrm{e}{ }^{13} \mathrm{C}$, e através de métodos

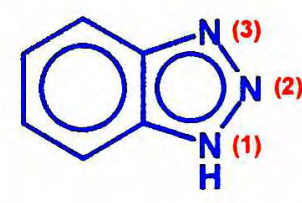
eletroquímicos, ${ }^{241}$ os quais demonstraram que os voltamogramas cíclicos são dependentes da velocidade de varredura de potenciais, sugerindo que o sistema pode ser tratado como um processo eletroquímico reversível precedido por uma reação química reversível (neste caso, a isomerização). Com base nesses resultados e usando-se as equações de Shain e Nicholson, ${ }^{244}$ as constantes cinéticas de isomerização foram determinadas. As constantes de dissociação foram obtidas através de cinética competitiva realizada na presença de dimetilsulfóxido, sendo duas ordens de magnitude menores que as de isomerização. Através desses resultados, concluiu-se que o mecanismo de isomerização operante no complexo de benzotriazol é essencialmente intramolecular.

No caso do complexo com pentaaminrutênio(II) ${ }^{242}$ $\left[\mathrm{Ru}^{\mathrm{n} 1}\left(\mathrm{NH}_{3}\right)_{5}(\mathrm{btaH})\right]^{2+}$, medidas de $\mathrm{RMN}$ e de voltametria cíclica indicaram que o isômero $\mathrm{kN}(2)$ predomina em solução. Contudo, em pH ao redor de 9 , o benzotriazol sofre desprotonação, e seu comportamento eletroquímico se torna dependente da velocidade e do sentido de varredura do potencial, revelando um processo dinâmico muito similar ao observado no análogo com pentacianoferrato(II).

Esses sistemas serão melhor explorados nesta tese mais adiante (v. item 3.1.1.2), uma vez que parte do trabalho a ser descrito aqui é complementar àquela série já estudada. 


\subsection{Os ligantes benzotriazol e benzoimidazol}

\subsubsection{Benzotriazol}

Esse composto $\mathrm{N}$-heterocíclico é bastante conhecido pelas suas inúmeras aplicações, sendo que a mais notável é a sua capacidade de agir como inibidor de corrosão, campo onde tem sido empregado com sucesso nos últimos anos. A primeira patente nesta área foi registrada há mais de meio século. ${ }^{245}$

O interesse voltado para o benzotriazol na química prática de superficies continua vigente, pois ele impede o deslustramento do cobre à temperatura ordinária ${ }^{246} \mathrm{e}$ reduz a taxa de oxidação ao ar deste elemento até aproximadamente $350{ }^{\circ} \mathrm{C}$. Além disso, ele contribui para dar proteção às superficies metálicas perante a oxidação durante o processo de empacotamento, armazenagem e transporte. ${ }^{247}$

No entanto, a sua principal aplicação continua sendo a proteção do cobre e das suas ligas quando submersas. $O$ benzotriazol também tem sido aplicado em outros campos tais como soluções limpadoras, ${ }^{248}$ detergentes, ${ }^{249}$ sistemas de refrigeração e outros fluídos. ${ }^{250}$

No final da década de 60 , o benzotriazol foi usado pela primeira vez no tratamento e conservação de artefatos de interesse arqueológico e histórico. ${ }^{251}$ Atualmente registramse muitas de suas aplicações na conservação de antigüidades e objetos corrosíveis.

A estrutura e as ligações próprias da molécula desse ligante foram pesquisadas vastamente no passado, ${ }^{252}$ o que tem sido complementado na atualidade com outros estudos espectroscópicos tais como Raman e IR, ${ }^{253}$ e UV. a Além de atribuições feitas para compostos semelhantes (como o benzoimidazol ${ }^{254} \mathrm{e}$ a ftalimida), uma atribuição vibracional mais completa, baseada em espectroscopia Raman, IR e SERS das espécies btaH, btaD e bta ${ }^{-}$, foi apresentada posteriormente. ${ }^{253}$ Mais tarde, dados de raios- $\mathrm{X}^{236} \mathrm{e}$ cálculos semi-empíricos também foram reportados. ${ }^{257}$

Estudos de espectroscopia $\mathrm{RMN}{ }^{1} \mathrm{H}$ do benzotriazol e do benzoimidazol, ${ }^{258}$ bem como espectroscopia $\mathrm{RMN}{ }^{13} \mathrm{C}$ do benzoimidazol, ${ }^{259}$ indicaram que a troca de prótons entre os átomos de nitrogênio N3 e N1 é bastante rápida, e, na escala de tempo do experimento, pode-se considerar a molécula como sendo de simetria $C_{2 \mathrm{v}}$. Porém, na espectroscopia vibracional, onde o tempo de relaxação é muito menor $\left(\sim 10^{-12} \mathrm{~s}\right)$, esse argumento não é válido, e deve-se atribuir simetria $C_{\mathrm{s}}$ tanto para o benzotriazol como para o benzoimidazol. ${ }^{257}$
O estudo da interação do ligante benzotriazol com metais de transição estende-se a uma grande variedade de elementos. ${ }^{260}$ Não obstante, a sua química de coordenação tem sido pouco explorada, o que é particularmente verdade no que se refere aos complexos de rutênio e ferro. Os primeiros trabalhos nessa direção foram realizados por Toma et al., ${ }^{241-243}$ que investigaram a reatividade e a isomeria de ligação nos complexos de benzotriazol com pentacianoferrato(II/III) ${ }^{241}$ e pentaaminrutênio(II/III), ${ }^{242}$ cujo assunto já foi abordado no tópico anterior.

\subsubsection{Imidazol $\theta$ seus derivados}

Os ligantes heterocíclicos nitrogenados desempenham um importante papel em química de coordenação. ${ }^{261,262} \mathrm{O}$ imidazol, por exemplo, é um ligante onipresente ${ }^{263}$ em sistemas químicos e, principalmente, biológicos, uma vez que ele aparece em proteínas, ácidos nucléicos, etc; seus derivados ${ }^{55,162,264-268}$ têm sido extensivamente empregados como modelos em várias áreas de química inorgânica, indo desde a bioinorgânica até dispositivos eletrônicos e algumas aplicações em ciência dos materiais

Complexos metálicos com ligantes derivados de imidazóis são de grande importância biológica devido a algumas características como atividade anti-cancerígena, ${ }^{269}$ capacidade de ligar agentes sensibilizadores ao DNA, ${ }^{270} \mathrm{e}$ também por serem empregados como modelos para se estudar ligações covalentes de metais a ácidos nucléicos (particularmente adenina e guanina) ${ }^{268,271}$ e aminoácidos, que ocorrem com mais freqüência no anel imidazólico da histidina.

Assim, parâmetros espectroscópicos obtidos para tais complexos são de grande valor na interpretação dos estudos das interações biológicas com os metais de transição, principalmente os do grupo da platina. Nesse sentido, alguns estudos pioneiros por Taube et al. ${ }^{272,273}$ da química de tetra- e pentaaminas de rutênio com imidazóis e purinas têm impulsionado este campo de pesquisa.

A coordenação do imidazol e de sua forma desprotonada foi bastante explorada em estudos com pentacianoferrato e pentaaminrutênio como espécies mononucleares. ${ }^{272-275}$ Tais sistemas do tipo $d^{6} / d^{6}$ de spin baixo são bons modelos para mimetizar a interação de centros metálicos porfirínicos com imidazóis. ${ }^{229,264,275,276}$ Além disso, os ligantes imidazólicos são capazes de agir como ponte entre sítios metálicos em metaloenzimas e intermediar interações eletrônicas e magnéticas em fragmentos metálicos. ${ }^{2 \pi}$ 
No entanto, poucos sistemas daquele tipo foram estudados para imidazolatos ${ }^{278,279} \mathrm{e}$, até onde se conhece, nenhum utiliza o ligante benzoimidazol em particular. Essa foi uma das motivações de parte do trabalho que se apresentará nesta tese.

\subsection{Complexos derivados de rutênio e ferro}

Os complexos metálicos dos íons de rutênio ${ }^{46,70,71,82,96}$ e de ferro ${ }^{38,83,223,224,280,281}$ nas configurações $d^{5} / d^{6}$ são muito convenientes no estudo de compostos de coordenação, por causa de sua química redox abundante e versátil. Além disso, eles normalmente também apresentam propriedades cinéticas favoráveis e são termodinamicamente estáveis. Por isso os complexos mono e binucleares baseados nos pares $\mathrm{Ru}^{\text {III }} / \mathrm{Ru}^{\Pi}$ e $\mathrm{Fe}^{\mathrm{III}} / \mathrm{Fe}^{\text {II }}$ desempenham um papel central em química de coordenação.

Recentemente, ${ }^{239}$ foi realizada uma revisão bibliográfica bastante extensiva e atualizada a respeito da química dos complexos derivados de rutênio(II/III)-edta.
Da mesma forma, uma descrição bastante completa acerca da química dos complexos derivados dos cianoferratos havia sido compilada anteriormente. ${ }^{282}$

Em particular, uma quantidade apreciável de artigos de revisão sobre a química e as propriedades ópticas, eletroquímicas e fotoquímicas das aminas s1,70,71,283,284 $^{\text {e }}$ polipiridinas de rutênio ${ }^{46,82,143,155,285}$ encontra-se disponível. Por isso, optou-se por não reproduzir aqui uma exaustiva descrição geral desses compostos, devido à amplitude que assume tal assunto. Em vez disso, as propriedades dos complexos de partida neste estudo serão introduzidos em caráter específico dentro dos tópicos relacionados, no desenvolvimento do texto 


\subsection{Objetivos}

Visto que os complexos polinucleares desempenham uma importante função na modelagem experimental e teórica de processos de transferência de elétrons e na elucidação dos mecanismos destas reações, a química de valência mista de oligômeros polimetálicos é devotada à compreensão da natureza das interações eletrônicas presentes nesta classe de compostos, em função das características estruturais e eletrônicas dos fragmentos orgânicos e unidades metálicas que os constituem. Inseridos nesta perspectiva, alguns aspectos de grande relevância são a natureza dos estados redox dos centros que atuam como doador e aceitador eletrônicos e a natureza química dos seus componentes individuais, tais como os ligantes terminais ou coligantes e, principalmente, o espaçador que intermedia a comunicação eletrônica doador-aceitador.

Assim, com o propósito de compreender e racionalizar alguns fatores de interesse no controle e na modulação de processos de transferência de elétrons em sistemas discretos e seus derivados supramoleculares, este trabalho visa o planejamento, preparação e investigação de uma série de complexos binucleares de valência mista $\left(\mathrm{M}_{\mathrm{a}}{ }^{\mathrm{n}}-\mathrm{L}-\mathrm{M}_{\mathrm{b}}{ }^{\mathrm{n}+1}\right)$ simétricos $\left(\mathrm{M}_{\mathrm{a}}=\mathrm{M}_{\mathrm{b}}\right)$ e assimétricos $\left(\mathrm{M}_{\mathrm{a}} \neq \mathrm{M}_{\mathrm{b}}\right)$, onde $\mathrm{M}_{x}$ são íons metálicos de transição com configurações $4 d^{6} / 3 d^{6}$ ou $4 d^{5} / 3 d^{5}$ de spin baixo, que atuarão como centros doadores (redutor) e aceitadores (oxidante) de elétrons, e L é um ligante espaçador (situado entre os sítios metálicos) que intermedia as interações metal-metal com transferência de elétrons. Como o íon $\mathrm{M}$ se tratará, na verdade, de um complexo pentacoordenado do tipo $-\mathrm{MX}_{5}$, então, somado às características intrínsecas do elemento metálico, pretende-se variar a natureza dos coligantes periféricos $\mathrm{X}$ de tal forma a gerar uma classe abrangente de propriedades ácido-base no universo das interações $\sigma$ e $\pi$.

Dentro dessa concepção, os estudos desta tese serão dirigidos especificamente para os oligômeros metálicos contendo unidades terminais de rutênio e ferro derivadas de poliaminas $\left(\left[\mathrm{Ru}^{\mathrm{IILI}}\left(\mathrm{NH}_{3}\right)_{\mathrm{n}}\right]^{3+, 2 \dagger}\right)$, poliaminocarboxilatos $\left(\left[\mathrm{Ru}^{\text {IIIII }}(\text { edta })\right]^{-2-}\right)$, polipiridinas $\left(\left[\mathrm{Ru}^{\mathrm{IIL}, \mathrm{II}} \mathrm{Cl}(\mathrm{bpy})_{2}\right]^{2+,+}\right)$, e ciano-complexos $\left(\left[\mathrm{Fe}^{\mathrm{II}, \mathrm{II}}(\mathrm{CN})_{5}\right]^{2-3-3}\right)$. Quando combinados entre si em entidades metalorgânicas, esses fragmentos permitem a geração de uma ampla classe de espécies aceitadoras e (retro)doadoras- $\pi$.

Como ligantes de ponte com habilidade condutora de caráter doador- $\sigma / \pi$ serão empregados ligantes orgânicos $\mathrm{N}$-heterocíclicos ionizáveis, particularmente o benzotriazol e o benzoimidazol. A motivação dessa escolha recai sobre a influência do próton (protonação/desprotonação) sobre as propriedades redox de seus derivados. Além disso, a grande maioria dos trabalhos neste campo se utiliza de espécies $\pi$ aceitadoras do tipo pirazina, de tal maneira que o seu papel em química de valência mista é bastante conhecido. Ao contrário, os ligantes básicos de caráter doador- $\sigma, \pi$ foram menos explorados em estudos dessa natureza, embora eles constituam uma ampla classe de modelos para reações de transferência de elétrons acopladas, tais como as reações redox dependentes do $\mathrm{pH}$. Daí que este assunto também será abordado nesta tese.

No caso particular do benzotriazol, a razão principal de seu uso inédito como ligante de ponte neste trabalho devese às suas propriedades fluxionais, cujo conhecimento vem de estudos anteriores de isomeria de ligação intramolecular em seus complexos (um assunto que também deverá ser aprofundado na presente contribuição). Assim, a partir das espécies onde a forma aniônica benzotriazolato atua como ponte, iniciativas serão encaminhadas no entendimento de sistemas doador-aceitador onde ambos os fatores eletrônico e estrutural se manifestam sinergisticamente para exercer influência sobre a modulação dos fenômenos baseados no acoplamento intermetálico (p. ex. transferência de elétrons).

Ainda do ponto de vista fenomenológico, uma ênfase especial será destinada ao problema da classificação de compostos de valência mista com base na extensão/grau de deslocalização eletrônica; bem como à determinação de parâmetros termodinânicos para reações de transferência de elétrons intramolecular em sistemas assimétricos.

Para isso, a compreensão dos modelos teóricos para processos de transferência eletrônica intramolecular induzidos por luz (transferência de intervalência) será largamente explorada como ferramenta interpretativa. Em particular, o formalismo de Hush-Mulliken deverá ser exaustivamente aplicado, e cujos limites serão averiguados por meio do planejamento adequado e conveniente de uma série de sistemas de valência mista com natureza de cargas redox variando de tipicamente localizadas a deslocalizadas.

Assim, a abordagem de investigação experimental será direcionada principalmente para os processos fotoinduzidos/ ópticos, e a caracterização dos sistemas e o monitoramento dos fenômenos de intervalência e de transferência de cargas serão realizados por meio da associação de técnicas convencionais de eletroquímica e espectroscopia, entre as quais destacam-se os métodos espectroeletroquímicos nas regiões visível e infravermelho próximo. Quando se fizerem elucidativos, métodos de análise teórica através de modelos quânticos de orbitais moleculares poderão ser empregados. 


\section{Parte Experimental}

\subsection{Sintese e preparação dos compostos}

\subsubsection{Complexos de partida}

As sínteses dos complexos $\mathrm{Ru}^{\text {IIII }}(\mathrm{Hedta})\left(\mathrm{H}_{2} \mathrm{O}\right),{ }^{286,287}$ $\left[\mathrm{Ru}^{\mathrm{III}} \mathrm{Cl}\left(\mathrm{NH}_{3}\right)_{5}\right] \mathrm{Cl}_{2}{ }^{288} \quad \mathrm{Na}_{3}\left[\mathrm{Fe}^{\mathrm{II}}(\mathrm{CN})_{5}\left(\mathrm{NH}_{3}\right)\right]^{289}$ trans$\left[\mathrm{Ru}^{\mathrm{III}} \mathrm{Cl}_{2}\left(\mathrm{NH}_{3}\right)_{4}\right] \mathrm{Cl}^{290}$ e cis- $\mathrm{Ru}^{\text {II }} \mathrm{Cl}_{2}(\mathrm{bpy})_{2}{ }^{291}$ foram baseadas em procedimentos clássicos descritos na literatura. A composição elementar dos produtos sólidos foi verificada através de microanálise de carbono, hidrogênio e nitrogênio. 0 grau de pureza dos compostos também foi avaliado por meio de métodos eletroquímicos e/ou espectroscópicos.

\subsubsection{Ligantes $\mathrm{N}$-heterocíclicos (btaH e bimH)}

Os ligantes $1 H$-benzotriazol (btaH) e benzoimidazol (bimH) empregados neste trabalho foram obtidos comercialmente da Aldrich Chem. e recristalizados a partir de soluções saturadas em mistura etanol/água. Os seus correspondentes sais de lítio, benzotriazolato [Li(bta)] e benzoimidazolato [Li(bim)] de lítio, foram preparados pela adição de quantidades equimolares do ligante ( $\mathrm{LH})$ e de hidróxido de lítio monohidratado $\left(\mathrm{LiOH} \cdot \mathrm{H}_{2} \mathrm{O}\right.$ ), após a qual a mistura foi submetida à evaporação lenta, em temperatura ambiente, até a completa cristalização do sal.

Os valores de $\mathrm{p} K_{\mathrm{a}}$ para os ligantes livres benzotriazol ${ }^{292}$ e benzoimidazol ${ }^{293}$ bem como os espectros eletrônicos na região do UV para as suas formas neutras e monoaniônicas encontram-se descritos no apêndice 6.4.2.

\subsubsection{Complexos mononucleares}

\subsubsection{Ru $u^{\prime \prime \prime}(H e d t a)(L H)$}

Os complexos derivados de $\mathrm{Ru}$ (edta) foram obtidos pela mistura de $480,4 \mathrm{mg}$ de $\left[\mathrm{Ru}(\mathrm{Hedta})\left(\mathrm{H}_{2} \mathrm{O}\right)\right] \cdot 4 \mathrm{H}_{2} \mathrm{O} \quad(1,0$ mmol) e $238,2 \mathrm{mg}$ de benzotriazol ou $236,2 \mathrm{mg}$ de benzoimidazol $(2,0 \mathrm{mmol})$ em $20 \mathrm{~cm}^{3}$ de água/etanol 3:1, sob atmosfera de argônio. Após 15 min de reação, o solvente da mistura de cor amarelo-pálida foi evaporado sob pressão reduzida, por meio de um evaporador rotatório, até restar um volume de $\sim 5 \mathrm{~cm}^{3}$, ao qual se adicionaram $15 \mathrm{~cm}^{3}$ de acetona resfriada.
O precipitado amarelo foi coletado por filtração, lavado com uma mistura acetona/etanol 2:1 para remover o excesso de ligante e mantido em vácuo por dois dias na presença de agente secante. ${ }^{a}$ Rendimento: $85-90 \%$.

Análise elementar:

Calculado para $\left[\mathrm{Ru}\left(\mathrm{C}_{10} \mathrm{H}_{13} \mathrm{~N}_{2} \mathrm{O}_{8}\right)\left(\mathrm{C}_{6} \mathrm{H}_{5} \mathrm{~N}_{3}\right)\right] \cdot 3 \mathrm{H}_{2} \mathrm{O}(\mathbf{L H}=$ btaH; $\mathrm{MM}=563,5)$ : C 34,11\%, H 4,29\%, N 12,43\%; obtido: C 34,22\%, H 4,41\%, N 12,52\%.

Calculado para $\left[\mathrm{Ru}\left(\mathrm{C}_{10} \mathrm{H}_{13} \mathrm{~N}_{2} \mathrm{O}_{8}\right)\left(\mathrm{C}_{7} \mathrm{H}_{6} \mathrm{~N}_{2}\right)\right] \cdot 3 \mathrm{H}_{2} \mathrm{O}(\mathbf{L H}=$ bimH; $\mathrm{MM}=562,5)$ : $\mathrm{C} 36,30 \%$, H 4,48\%, $\mathrm{N}$ 9,96\%; obtido: C 36,29\%, H 4,63\%, N 9,92\%.

\subsubsection{2. $\left[R u^{11,111}\left(N_{3}\right)_{5}(L H)\right]\left(P F_{6}\right)_{n}(n=2$ ou 3)}

$\left[\mathbf{R u}^{\mathrm{II}}\left(\mathrm{NH}_{3}\right)_{\mathbf{5}}(\mathbf{L H})\right]\left(\mathbf{P F}_{\mathbf{6}}\right)_{2}$. Na preparação dos derivados de pentaaminrutênio(II), $58,6 \mathrm{mg}$ do complexo de partida $\left[\mathrm{RuCl}\left(\mathrm{NH}_{3}\right)_{5}\right] \mathrm{Cl}_{2}(0,2 \mathrm{mmol})$ foram dissolvidos em $5 \mathrm{~cm}^{3}$ de água desaerada, sob argônio, contendo algumas pastilhas de zinco amalgamado. Após reagir por $30 \mathrm{~min}$, a solução amarela resultante foi anaerobicamente transferida para um recipiente contendo $238,2 \mathrm{mg}$ de benzotriazol ou $236,2 \mathrm{mg}$ de benzoimidazol $(2,0 \mathrm{mmol})$ e deixada, sob atmosfera inerte, por mais cerca de $30 \mathrm{~min}$ (no caso particular do benzoimidazol, $5 \%$ em volume de etanol foi previamente adicionado para se facilitar a dissolução do ligante). Então, $5 \mathrm{~cm}^{3}$ de uma solução concentrada de hexafluorofosfato de amônio $\left(\mathrm{NH}_{4} \mathrm{PF}_{6}\right)$ foram gotejados sobre a mistura reacional de coloração alaranjada/castanha, quando imediatamente houve formação de um precipitado amarelo. $O$ produto sólido foi filtrado, lavado com um pequeno volume de solução concentrada de hexafluorofosfato de amônio em mistura etanol/água resfriada, e seco em vácuo na presença de agente secante. Rendimento: $80-90 \%$.

Análise elementar:

Calculado para $\left[\mathrm{Ru}\left(\mathrm{NH}_{3}\right)_{5}\left(\mathrm{C}_{6} \mathrm{H}_{5} \mathrm{~N}_{3}\right)\right]\left(\mathrm{PF}_{6}\right)_{2} \cdot 2 \mathrm{H}_{2} \mathrm{O}(\mathbf{L H}=$ btaH; $\mathbf{M M}=631,3)$ : C 11,42\%, H 3,83\%, N 17,75\%; obtido: C 11,33\%, H 4,01\%, N 17,88\%.

Calculado para $\left[\mathrm{Ru}\left(\mathrm{NH}_{3}\right)_{5}\left(\mathrm{C}_{7} \mathrm{H}_{6} \mathrm{~N}_{2}\right)\right]\left(\mathrm{PF}_{6}\right)_{2} \cdot 2 \mathrm{H}_{2} \mathrm{O}(\mathbf{L H}=$ bimH; $\mathrm{MM}=630,3)$ : $\mathrm{C} 13,34 \%, \mathrm{H} 4,00 \%, \mathrm{~N} 15,56 \%$; obtido: C $13,43 \%, \mathrm{H} 4,14 \%, \mathrm{~N} 15,44 \%$.

a $V$. item 2.1.11 para informaçñes adicionais sobre os dessecantes utilizados neste trabalho. 
No caso do complexo com benzoimidazol, em particular, o sólido amarelo se torna vermelho rapidamente na presença de ar, indicando a sua conversão na espécie oxidada, Ru ${ }^{\text {III }}$. 0 mesmo também foi verificado para o benzotriazolcomplexo. Contudo, o processo é bem mais lento no último (a oxidação completa do sólido pode levar meses). Assim, por conveniência, ambos os compostos também foram isolados na forma oxidada, conforme segue.

$\left[\mathbf{R u}^{\mathrm{III}}\left(\mathbf{N H}_{3}\right)_{5}(\mathbf{L H})\right]\left(\mathbf{P F}_{6}\right)_{3}$. Os produtos da sintese anterior, $\left[\mathrm{Ru}^{\mathrm{II}}\left(\mathrm{NH}_{3}\right)_{5}(\mathrm{LH})\right]\left(\mathrm{PF}_{6}\right)_{2}$, foram redissolvidos em água $\mathrm{e}$ completamente oxidados pela passagem de um fluxo de oxigênio através da solução. $O$ sólido vermelho foi isolado por meio de evaporação lenta da solução concentrada contendo excesso de hexafluorofosfato de amônio. $\mathrm{O}$ rendimento final da sintese diminuiu para $75-80 \%$.

\section{Análise elementar:}

Calculado para $\left[\mathrm{Ru}\left(\mathrm{NH}_{3}\right)_{5}\left(\mathrm{C}_{6} \mathrm{H}_{5} \mathrm{~N}_{3}\right)\right]\left(\mathrm{PF}_{6}\right)_{3} \cdot 3 \mathrm{H}_{2} \mathrm{O}(\mathbf{L H}=$ btaH; $M M=794,3)$ : C 9,07\%, H 3,30\%, N 14,11\%; obtido: C 9,33\%, H 3,41\%, N 14,02\%.

Calculado para $\left[\mathrm{Ru}\left(\mathrm{NH}_{3}\right)_{5}\left(\mathrm{C}_{7} \mathrm{H}_{6} \mathrm{~N}_{2}\right)\right]\left(\mathrm{PF}_{6}\right)_{3} \cdot 3 \mathrm{H}_{2} \mathrm{O}(\mathbf{L H}=$ bimH; $\mathrm{MM}=793,3): \mathrm{C} 10,60 \%, \mathrm{H} 3,43 \%, \mathrm{~N} 12,36 \%$; obtido: C 10,66\%, H 3,55\%, N 12,35\%.

\subsubsection{3. $\mathrm{Na}_{\mathrm{n}}\left[\mathrm{Fe} \mathrm{F}^{\mathrm{Il}, \mathrm{III}}(\mathrm{CN})_{5}(\mathrm{LH})\right](\mathrm{n}=3$ ou 2$)$}

$\mathrm{Na}_{3}\left[\mathrm{Fe}^{\mathrm{II}}(\mathrm{CN})_{5}(\mathrm{LH})\right]$. Os cianoferrato(II)-complexos foram obtidos pela adição de $326,0 \mathrm{mg}$ do complexo de partida $\mathrm{Na}_{3}\left[\mathrm{Fe}(\mathrm{CN})_{5}\left(\mathrm{NH}_{3}\right)\right] \cdot 3 \mathrm{H}_{2} \mathrm{O}(1,0 \mathrm{mmol})$ a $20 \mathrm{~cm}^{3}$ de uma mistura desoxigenada de água/etanol 3:1 contendo $178,7 \mathrm{mg}$ de benzotriazol ou $177,2 \mathrm{mg}$ de benzoimidazol $(1,5 \mathrm{mmol})$. Após $20 \mathrm{~min}$, a mistura amarela foi levada à evaporação sob vácuo até restar um volume de $3-5 \mathrm{~cm}^{3}$. Posteriormente, $15 \mathrm{~cm}^{3}$ de acetona resfriada a $0{ }^{\circ} \mathrm{C}$ foram adicionados lentamente à solução. $\mathrm{O}$ precipitado formado foi coletado por filtração, lavado com uma mistura acetona/etanol 2:1 e, finalmente, seco em vácuo na presença de agente secante. Rendimento: $80-85 \%$.

Análise elementar:

Calculado para $\mathrm{Na}_{3}\left[\mathrm{Fe}(\mathrm{CN})_{5}\left(\mathrm{C}_{6} \mathrm{H}_{5} \mathrm{~N}_{3}\right)\right] \cdot 3 \mathrm{H}_{2} \mathrm{O}$ (LH = btaH; $\mathrm{MM}=428,1)$ : C $30,86 \%, \mathrm{H} 2,59 \%, \mathrm{~N} 26,18 \%$; obtido: C 30,93\%, H 2,66\%, N 26, $13 \%$.

Calculado para $\mathrm{Na}_{3}\left[\mathrm{Fe}(\mathrm{CN})_{5}\left(\mathrm{C}_{7} \mathrm{H}_{6} \mathrm{~N}_{2}\right)\right] \cdot 4 \mathrm{H}_{2} \mathrm{O}(\mathbf{L H}=$ $\operatorname{bimH} ; \mathrm{MM}=445,1): \mathrm{C} 32,38 \%, \mathrm{H} 3,17 \%, \mathrm{~N} 22,03 \%$; obtido: C $32,44 \%, \mathrm{H} 3,23 \%$, N 21,96\%.

$\mathrm{Na}_{2}\left[\mathrm{Fe}^{\mathrm{III}}(\mathrm{CN})_{5}(\mathrm{LH})\right]$. Os complexos de ferro(III) foram preparados através da oxidação (com peroxidissulfato de

\footnotetext{
a Observação similar foi relatada para vários complexos de pentaaminrutênio
} com derivados de imidazol. ${ }^{272}$ sódio como oxidante) do complexo $\mathrm{Na}_{3}\left[\mathrm{Fe}^{\mathrm{II}}(\mathrm{CN})_{5}(\mathrm{LH})\right]$ em solução aquosa. $O$ produto de cor alaranjada/avermelhada (benzotriazol) ou vermelha (benzoimidazol) foi isolado de maneira similar à descrita acima para o complexo reduzido. Análise elementar:

Calculado para $\mathrm{Na}_{2}\left[\mathrm{Fe}(\mathrm{CN})_{5}\left(\mathrm{C}_{6} \mathrm{H}_{5} \mathrm{~N}_{3}\right)\right] \cdot 2 \mathrm{H}_{2} \mathrm{O} \quad(\mathbf{L H}=$ btaH; $\mathrm{MM}=387,1)$ : C 34,13\%, H 2,34\%, N 28,95\%; obtido: C 34,31\%, H 2,42\%, N 28,93\%.

Calculado para $\mathrm{Na}_{2}\left[\mathrm{Fe}(\mathrm{CN})_{5}\left(\mathrm{C}_{7} \mathrm{H}_{6} \mathrm{~N}_{2}\right)\right] \cdot 2 \mathrm{H}_{2} \mathrm{O}$ (LH $=$ $\operatorname{bimH} ; \mathrm{MM}=386,1)$ : C $32,38 \%, \mathrm{H} 2,61 \%$, N 25,40\%; obtido: C 32,33\%, H 2,65\%, N 25,44\%.

\subsubsection{4. trans-[Ru" $\left.\left(\mathrm{NH}_{3}\right)_{4}(\mathrm{btaH})_{2}\right]\left(\mathrm{PF}_{6}\right)_{2}$}

O complexo mononuclear de partida para a formação do complexo trinuclear (item 2.1.6) foi preparado em solução aquosa de forma semelhante àquela realizada anteriormente para complexos análogos. ${ }^{294-296}$ Dissolveram-se $55,1 \mathrm{mg}$ de trans- $\left[\mathrm{RuCl}_{2}\left(\mathrm{NH}_{3}\right)_{4}\right] \mathrm{Cl}(0,20 \mathrm{mmol})$ em $5 \mathrm{~cm}^{3}$ de água e misturou-se à solução, sob atmosfera de argônio, algumas pastilhas de zinco amalgamado. Após 30 min de reação, a solução de coloração fortemente amarela foi transferida anaerobicamente para um balão contendo $59,6 \mathrm{mg}$ de benzotriazol $(0,50 \mathrm{mmol})$ em atmosfera inerte. A mistura assumiu rapidamente cor mais escura (alaranjada). Após 60 min, adicionaram-se à mistura reacional $5 \mathrm{~cm}^{3}$ de solução concentrada de hexafluorofosfato de amônio, após a qual ocorreu prontamente a formação de um precipitado amarelo. O sólido foi filtrado, lavado com pequeno volume de etanol e seco em vácuo na presença de agente secante.

A análise elementar do sal complexo recém-obtido forneceu resultados coerentes com os esperados para a fórmula $\left[\mathrm{Ru}\left(\mathrm{NH}_{3}\right)_{4}\left(\mathrm{C}_{6} \mathrm{H}_{5} \mathrm{~N}_{3}\right)_{2}\right]\left(\mathrm{PF}_{6}\right)_{2} \cdot \mathrm{H}_{2} \mathrm{O}(\mathrm{MM}=715,4)$ Experimental: C $20,21 \%$, H 3,49\%, N 19,53\%. Calculado: C $20,15 \%, H 3,38 \%$, N $19,58 \%$.

\subsubsection{5. cis-[Ru" $\left.\mathrm{Cl}(\text { bpy })_{2}(L H)\right] P F_{6}$}

Os compostos foram sintetizados pela adição de $260,0 \mathrm{mg}$ de $c i s-\mathrm{RuCl}_{2}(\mathrm{bpy})_{2}(0,5 \mathrm{mmol})$ e $71,5 \mathrm{mg}$ de benzotriazol ou 71,0 de benzoimidazol $(0,6 \mathrm{mmol})$ a $15 \mathrm{~cm}^{3}$ de etanol/água (2:1). A mistura foi aquecida sob refluxo por $30 \mathrm{~min}$. Após resfriamento, a solução marrom (btaH) ou vermelho escuro (bimH) foi filtrada e o solvente removido por evaporação sob vácuo em um sistema rotatório. $\mathrm{O}$ sólido foi dissolvido em $3 \mathrm{~cm}^{3}$ de água e misturado a $3 \mathrm{~cm}^{3}$ de solução $\sim 1 \mathrm{~mol}$ $\mathrm{dm}^{-3}$ de hexafluorofosfato de amônio. O precipitado foi filtrado e lavado com água fria. O produto castanho (btaH) ou vermelho (bimH) foi seco em um dessecador sob vácuo na presença de agente secante. 
Procedeu-se à purificação dos compostos por cromatografia em coluna utilizando-se alumina neutra (óxido de alumínio) como material de coluna e uma mistura acetonitrila:etanol na proporção 10:1 como eluente.

Análise elementar:

Calculado para $\left[\mathrm{Ru}\left(\mathrm{C}_{10} \mathrm{H}_{8} \mathrm{~N}_{2}\right)_{2}\left(\mathrm{C}_{6} \mathrm{H}_{5} \mathrm{~N}_{3}\right) \mathrm{Cl}_{3} \mathrm{PF}_{6} \cdot \mathrm{H}_{2} \mathrm{O}(\mathbf{L H}\right.$

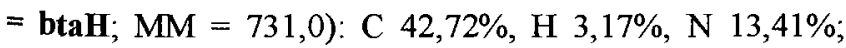
obtido: C 42,65\%; H 3,22\%; N 13,45\%.

Calculado para $\left[\mathrm{Ru}\left(\mathrm{C}_{10} \mathrm{H}_{8} \mathrm{~N}_{2}\right)_{2}\left(\mathrm{C}_{7} \mathrm{H}_{6} \mathrm{~N}_{2}\right) \mathrm{Cl}_{3} \mathrm{PF}_{6} \cdot \mathrm{H}_{2} \mathrm{O}(\mathbf{L H}\right.$

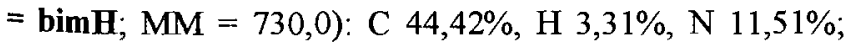
obtido: C 44,45\%, H 3,34\%, N 11,47\%.

\subsubsection{6. cis-[Ru" $\left.(b p y)_{2}(L H)_{2}\right]\left(P F_{6}\right)_{2}$}

Dissolveram-se $260,0 \mathrm{mg}$ de $\mathrm{RuCl}_{2}(\mathrm{bpy})_{2}(0,5 \mathrm{mmol})$ e $131,0 \mathrm{mg}$ de benzotriazol ou $129,9 \mathrm{mg}$ de benzoimidazol $(1,1 \mathrm{mmol}) \mathrm{em} 20 \mathrm{~cm}^{3}$ de etanol/água (1:1). A mistura foi aquecida ao refluxo sob atmosfera de argônio por $30 \mathrm{~min}$. Adicionaram-se, então, $169,9 \mathrm{mg}$ de nitrato de prata $\left(\mathrm{AgNO}_{3} ; 1,0 \mathrm{mmol}\right)$ à solução em agitação e deu-se continuidade ao aquecimento por mais $30 \mathrm{~min}$. Após resfriamento à temperatura ambiente, o sólido branco (cloreto de prata; $\mathrm{AgCl}$ ) foi removido por filtração em amianto e o filtrado foi seco em um evaporador rotatório. $\mathrm{O}$ sólido de coloração alaranjada foi dissolvido em $\sim 4 \mathrm{~cm}^{3}$ de água e, à solução final, adicionaram-se $3 \mathrm{~cm}^{3}$ de solução 1 mol dm${ }^{-3}$ de hexafluorofosfato de amônio. $O$ precipitado foi filtrado, lavado com água fria e seco em vácuo por $48 \mathrm{~h}$ em um dessecador contendo agente secante

Após purificação em coluna cromatográfica utilizandose alumina neutra como material de coluna e acetonitrila como eluente, o composto foi recristalizado em mistura de acetona/água.

Análise elementar:

Calculado para $\left[\mathrm{Ru}\left(\mathrm{C}_{10} \mathrm{H}_{8} \mathrm{~N}_{2}\right)_{2}\left(\mathrm{C}_{6} \mathrm{H}_{5} \mathrm{~N}_{3}\right)_{2}\right]\left(\mathrm{PF}_{6}\right)_{2}(\mathbf{L H}=$ btaH; $\mathrm{MM}=941,7):$ C 40,82\%, H 2,78\%, N 14,88\%; obtido: C 40,98\%; H 2,82\%; N 14,85\%.

Calculado para $\left[\mathrm{Ru}\left(\mathrm{C}_{10} \mathrm{H}_{8} \mathrm{~N}_{2}\right)_{2}\left(\mathrm{C}_{7} \mathrm{H}_{6} \mathrm{~N}_{2}\right)_{2}\right]\left(\mathrm{PF}_{6}\right)_{2}(\mathbf{L H}=$ bimH; $\mathrm{MM}=939,7)$ : C 43,46\%, H 3,00\%, N 11,93\%; obtido: C $43,54 \%$, H 3,05\%, N 11,96\%.

\subsubsection{7. cis-[Ru"(bpy) $\left.)_{2}(p y)(L H)\right]\left(P F_{6}\right)_{2}$}

A $20 \mathrm{~cm}^{3}$ de uma mistura etanol/água na proporção 3:1 (em volume) adicionaram-se $346,0 \mathrm{mg}$ do complexo $\left[\mathrm{RuCl}(\mathrm{bpy})_{2}(\mathrm{py})\right] \mathrm{PF}_{6} \cdot \mathrm{H}_{2} \mathrm{O}^{a}(0,5 \mathrm{mmol})$ e $71,5 \mathrm{mg} \mathrm{de}$

a $O$ complexo precursor $c i s-\left[\mathrm{RuCl}(\right.$ bpy) $)($ py) $] \mathrm{PF}_{6}$ foi preparado de acordo com método reportado previamente. ${ }^{2) 7,208}$ O composto castanho escuro foi purificado em coluna cromatográfica utilizando-se alumina neutra como benzotriazol ou 70,9 de benzoimidazol $(0,6 \mathrm{mmol})$. A mistura foi aquecida sob atmosfera de argônio em condições de refluxo por $30 \mathrm{~min}$. Adicionaram-se à solução reagente $85 \mathrm{mg}$ de nitrato de prata e aqueceu-se a mistura final por mais $\sim 30 \mathrm{~min}$. Após resfriamento, eliminou-se o sólido branco formado (cloreto de prata) por filtração em amianto e removeu-se o solvente por evaporação sob vácuo. $\mathrm{O}$ sólido foi dissolvido em $3 \mathrm{~cm}^{3}$ de etanol e, em seguida, juntaram-se $5 \mathrm{~cm}^{3}$ de solução concentrada $\left(1 \mathrm{~mol} \mathrm{dm}^{-3}\right)$ de hexafluorofosfato de amônio. $\mathrm{O}$ precipitado amarelo escuro foi filtrado e lavado com água fria. O produto foi seco em dessecador sob vácuo na presença de agente secante por cerca de $48 \mathrm{~h}$.

Os compostos foram purificados por cromatografia em coluna utilizando-se alumina neutra e acetonitrila/etanol. Purificação posterior foi realizada por recristalização em acetona/água.

Análise elementar:

Calculado para $\left[\mathrm{Ru}\left(\mathrm{C}_{10} \mathrm{H}_{8} \mathrm{~N}_{2}\right)_{2}\left(\mathrm{C}_{5} \mathrm{H}_{5} \mathrm{~N}\right)\left(\mathrm{C}_{6} \mathrm{H}_{5} \mathrm{~N}_{3}\right)\right]\left(\mathrm{PF}_{6}\right)_{2}$ $(\mathbf{L H}=\mathbf{b t a H} ; \mathbf{M M}=902,1): \mathbf{C} 41,24 \%, \mathrm{H} 2,90 \%, \mathrm{~N}$ 12,42\%; obtido: C 41,39\%, H 2,88\%, N $12,38 \%$.

Calculado para $\left[\mathrm{Ru}\left(\mathrm{C}_{10} \mathrm{H}_{8} \mathrm{~N}_{2}\right)_{2}\left(\mathrm{C}_{5} \mathrm{H}_{5} \mathrm{~N}\right)\left(\mathrm{C}_{7} \mathrm{H}_{6} \mathrm{~N}_{2}\right)\right]\left(\mathrm{PF}_{6}\right)_{2}$ $(\mathbf{L H}=$ bimH; $\mathrm{MM}=902,0): \mathrm{C} \mathrm{42,62 \% ,H} \mathrm{3,02 \% , \textrm {N }}$ 10,88\%; obtido: C 42,77\%, H 2,99\%, N 10,98\%.

\subsubsection{Complexos binucleares simétricos}

\subsubsection{1. $L i_{3}\left[(e d t a) R u^{\prime \prime \prime}(\mu-L) R u^{\prime \prime \prime}(e d t a)\right]$}

Os complexos binucleares de Ru(edta) foram preparados pela mistura de $960 \mathrm{mg}$ de $\left[\mathrm{Ru}(\right.$ Hedta $\left.)\left(\mathrm{H}_{2} \mathrm{O}\right)\right] \cdot 3 \mathrm{H}_{2} \mathrm{O}(2,0$ mmol) com $119 \mathrm{mg}$ de benzotriazol ou benzoimidazol $(1,0$ mmol) em $15 \mathrm{~cm}^{3}$ de uma solução água/etanol $(2: 1)$ contendo $3,0 \mathrm{mmol}$ de $\mathrm{LiOH} \cdot \mathrm{H}_{2} \mathrm{O}$. Após agitar a mistura reacional por cerca $30 \mathrm{~min}$, sob atmosfera de argônio, a solução fortemente colorida (violeta intenso) foi concentrada sob vácuo até $\sim 3 \mathrm{~cm}^{3}$ e adicionada lentamente a $15 \mathrm{~cm}^{3}$ de acetona resfriada a $0^{\circ} \mathrm{C}$. $\mathrm{O}$ composto precipitado (roxo) foi filtrado e seco em vácuo na presença de dessecante. Rendimento: $\sim 90 \%$.

Análise elementar:

Calculado para $\mathrm{Li}_{3}\left[\left\{\mathrm{Ru}\left(\mathrm{C}_{10} \mathrm{H}_{12} \mathrm{~N}_{2} \mathrm{O}_{8}\right)\right\}_{2}\left(\mathrm{C}_{6} \mathrm{H}_{4} \mathrm{~N}_{3}\right)\right] \cdot 3 \mathrm{H}_{2} \mathrm{O}$ $\left(\mathbf{L}=\mathbf{b t a}^{-} ; \mathrm{MM}=971,6\right):$ C 32,14\%, H 3,53\%, N 10,09\%; obtido: C 32,03\%, H 3,64\%, N 10,20\%.

material de coluna e acetonitrila como eluente. A análise elementar do produto final forneceu resultados coerentes com os esperados para a fórmula [RuCl( $\left.\left.\mathrm{C}_{10} \mathrm{H}_{8} \mathrm{~N}_{2}\right)_{2}\left(\mathrm{C}_{5} \mathrm{H}_{5} \mathrm{~N}\right)\right] \mathrm{PF}_{6} \cdot \mathrm{H}_{2} \mathrm{O}(\mathrm{MM}=691,0)$. Experimental C $43,53 \%$, H 3,30\%, N 10,17\%. Calculado: C 43,41\%, H 3,35\%, N 10,13\%. 
Calculado para $\mathrm{Li}_{3}\left[\left\{\mathrm{Ru}\left(\mathrm{C}_{10} \mathrm{H}_{12} \mathrm{~N}_{2} \mathrm{O}_{8}\right)\right\}_{2}\left(\mathrm{C}_{7} \mathrm{H}_{5} \mathrm{~N}_{2}\right)\right] \cdot 3 \mathrm{H}_{2} \mathrm{O}$ $\left(\mathrm{L}=\mathbf{b i m}^{-} ; \mathrm{MM}=970,6\right):$ C 33,41\%, H 3,63\%, N 8,66\%; obtido: C 33,34\%, H 3,83\%, N 8,69\%.

\subsubsection{2. [( $\left.\left.\mathrm{NH}_{3}\right)_{5} R u^{\prime \prime}(\mu-\mathrm{L}) R u^{\prime \prime}\left(\mathrm{NH}_{3}\right)_{5}\right]\left(P F_{6}\right)_{3}$}

As tentativas de obtenção dos complexos simétricos do tipo ( $\mu-\mathrm{L}$ )bis(pentaaminrutênio)(II) foram perseguidas através do método publicado por Creutz e Taube, ${ }^{13}$ que é, na verdade, o mesmo procedimento adotado na preparação da maioria dos compostos análogos descritos na literatura. Uma caracterização por meio de métodos eletroquímicos e espectroscópicos, porém, não indicou a formação do complexo binuclear. Em vez disso, apenas a mistura das espécies de partida foi verificada. As possíveis razões para isso serão comentadas na comparação geral com os outros complexos binucleares estudados com sucesso neste trabalho.

\subsubsection{3. $\mathrm{Na}_{7}\left[(\mathrm{CN})_{5} \mathrm{Fe}^{\prime \prime \prime \prime}(\mu-\mathrm{L}) \mathrm{Fe}^{\prime \prime}(\mathrm{CN})_{5}\right]$}

As tentativas de síntese das espécies binucleares simétricas ( $\mu$-L)bis(pentacianoferrato)(II) foram realizadas através do procedimento de Felix e Ludi. ${ }^{299}$ Entretanto, conforme será discutido adiante nesta tese, nenhum produto novo pôde ser evidenciado ou caracterizado por meio de técnicas eletroquímicas e espectroscópicas. Daí se concluiu que os complexos binucleares não foram formados.

\subsubsection{4. $\left.\left[C l(b p y)_{2} R u^{\prime \prime}(\mu-L) R u^{\prime \prime}(b p y)\right)_{2} C l\right] P F_{6}$}

Os compostos foram sintetizados pela adição de $520,0 \mathrm{mg}$ de $\mathrm{RuCl}_{2}$ (bpy) $)_{2}(1,0 \mathrm{mmol})$ e $53,6 \mathrm{mg}$ de benzotriazol ou $53,1 \mathrm{mg}$ de benzoimidazol $(0,45 \mathrm{mmol})$ a $15 \mathrm{~cm}^{3}$ de etanol/água (2:1). A mistura foi aquecida sob refluxo por 30 min, após os quais $0,5 \mathrm{mmol}$ de $\mathrm{LiOH}$ foi adicionado ao meio reacional. O refluxo (com borbulhamento de gás argônio) prosseguiu por mais $\sim 3 \mathrm{~h}$. Após resfriamento, a solução violeta foi filtrada e o solvente removido por evaporação sob vácuo num sistema rotatório. O sólido foi dissolvido em $3 \mathrm{~cm}^{3}$ de água e misturado a $5 \mathrm{~cm}^{3}$ de solução $1 \mathrm{~mol} \mathrm{dm}^{-3}$ de hexafluorofosfato de amônio. O precipitado foi filtrado e lavado com água fria. $O$ produto foi seco num dessecador sob vácuo na presença de dessecante.

Procedeu-se à purificação do composto por meio de cromatografía em coluna utilizando-se alumina neutra (óxido de alumínio) como material de coluna e acetonitrila (ou uma mistura acetonitrila[excesso]:álcool[etOH;meOH] em diversas proporções) como eluente.
Análise elementar:

Calculado para $\left[\left\{\mathrm{Ru}\left(\mathrm{C}_{10} \mathrm{H}_{8} \mathrm{~N}_{2}\right)_{2} \mathrm{Cl}\right\}_{2}\left(\mathrm{C}_{6} \mathrm{H}_{4} \mathrm{~N}_{3}\right)\right] \mathrm{PF}_{6} \cdot 3 \mathrm{H}_{2} \mathrm{O}$ $\left(\mathbf{L}=\mathbf{b t a}^{-} ; \mathrm{MM}=1214,9\right): \mathrm{C} 45,48 \%, \mathrm{H} \mathrm{3,48 \%}, \mathrm{N} 12,68 \%$; obtido: C 45,34\%, H 3,60\%, N 12,74\%.

Calculado para $\left[\left\{\mathrm{Ru}\left(\mathrm{C}_{10} \mathrm{H}_{8} \mathrm{~N}_{2}\right)_{2} \mathrm{Cl}\right\}_{2}\left(\mathrm{C}_{7} \mathrm{H}_{5} \mathrm{~N}_{2}\right)\right] \mathrm{PF}_{6} \cdot 2 \mathrm{H}_{2} \mathrm{O}$ $\left(\mathbf{L}=\right.$ bim $\left.^{-} ; \mathrm{MM}=1195,9\right):$ C 47,20\%, H 3,46\%, N 11,71\%; obtido: C 46,97\%, H 3,58\%, N 11,62\%.

Observação: Enquanto as sínteses dos complexos mononucleares apresentaram rendimento superior a $80 \%$, nas sínteses dos complexos binucleares, o rendimento não atingiu 50\%. Essa perda decorreu das sucessivas etapas de purificação por cromatografia ou recristalização, que foram mais exaustivas para os complexos binucleares

\subsubsection{Complexos binucleares assimétricos}

\subsubsection{1. [(edta)Ru $\left.u^{\prime \prime \prime}(\mu-L) R u^{\prime \prime \prime \prime I I ~}\left(N H_{3}\right)_{5}\right]\left(P F_{6}\right)_{n}(n=0$ ou 1)}

Os complexos binucleares assimétricos neutros foram obtidos pela adição de $96,0 \mathrm{mg}$ de $\left[\mathrm{Ru}(\mathrm{Hedta})\left(\mathrm{H}_{2} \mathrm{O}\right)\right] \cdot 4 \mathrm{H}_{2} \mathrm{O}$ $(0,20 \mathrm{mmol})$ a $5 \mathrm{~cm}^{3}$ de uma solução aquosa desoxigenada contendo $126,3(\mathrm{LH}=$ btaH $)$ ou $126,1 \mathrm{mg}(\mathrm{LH}=\mathrm{bimH}) \mathrm{de}$ $\left[\mathrm{Ru}\left(\mathrm{NH}_{3}\right)_{5}(\mathrm{LH})\right]\left(\mathrm{PF}_{6}\right)_{2} \cdot 2 \mathrm{H}_{2} \mathrm{O}(0,20 \mathrm{mmol})$. Após adicionar 1 equiv de $\mathrm{LiOH}$, sob atmosfera de argônio, a mistura inicial amarelo pálido se tornou rapidamente marrom. Depois de aguardar $\sim 30$ min de reação, $15 \mathrm{~cm}^{3}$ de acetona resfriada e desaerada foram adicionados à solução. $\mathrm{O}$ precipitado foi filtrado, lavado com mistura etanol/acetona $1: 3$, e seco em vácuo na presença de dessecante. Rendimento: $\sim 85 \%$.

Análise elementar:

Calculado para $\mathrm{Ru}\left(\mathrm{NH}_{3}\right)_{5}\left(\mathrm{C}_{6} \mathrm{~N}_{3} \mathrm{H}_{4}\right) \mathrm{Ru}\left(\mathrm{C}_{10} \mathrm{~N}_{2} \mathrm{H}_{12} \mathrm{O}_{8}\right) \cdot 4 \mathrm{H}_{2} \mathrm{O}$ $\left(\mathrm{L}=\mathbf{b t a}^{-} ; \mathrm{MM}=765,7\right): \mathrm{C} 25,10 \%, \mathrm{H} \mathrm{5,13 \%}$, N 18,29\%; obtido: C 25,17\%, H 5,05\%, N 18,33\%.

Calculado para $\mathrm{Ru}\left(\mathrm{NH}_{3}\right)_{5}\left(\mathrm{C}_{7} \mathrm{~N}_{2} \mathrm{H}_{5}\right) \mathrm{Ru}\left(\mathrm{C}_{10} \mathrm{~N}_{2} \mathrm{H}_{12} \mathrm{O}_{8}\right) \cdot 5 \mathrm{H}_{2} \mathrm{O}$ $\left(\mathbf{L}=\right.$ bim $\left.^{-} ; \mathrm{MM}=782,7\right):$ C 26,09\%, H 5,41\%, N 16,11\%; obtido: C 26,14\%, H 5,57\%, N 15,98\%.

$\left[\mathbf{R u}^{\text {III }}\left(\mathbf{N H}_{3}\right)_{\mathbf{5}}(\mathbf{L}) \mathbf{R u}^{\text {III }}\right.$ (edta) $] \mathbf{P F}_{6}$. $\quad$ O procedimento de síntese do complexo totalmente oxidado (violáceo) foi baseado naquele acima para a espécie de valência mista. Contudo, $158,9(\mathrm{LH}=$ btaH $)$ ou $158,7 \mathrm{mg}(\mathrm{LH}=$ bimH $) \mathrm{de}$ $\left[\mathrm{Ru}\left(\mathrm{NH}_{3}\right)_{5}(\mathrm{LH})\right]\left(\mathrm{PF}_{6}\right)_{3} \cdot 3 \mathrm{H}_{2} \mathrm{O} \quad(0,20 \quad \mathrm{mmol})$ foram empregados na preparação. Rendimento: 80-90\%. Análise elementar:

Calc. para $\left[\mathrm{Ru}\left(\mathrm{NH}_{3}\right)_{5}\left(\mathrm{C}_{6} \mathrm{~N}_{3} \mathrm{H}_{4}\right) \mathrm{Ru}\left(\mathrm{C}_{10} \mathrm{~N}_{2} \mathrm{H}_{12} \mathrm{O}_{8}\right)\right] \mathrm{PF}_{6} \cdot 4 \mathrm{H}_{2} \mathrm{O}$ $\left(\mathbf{L}=\mathbf{b t a}^{-} ; \mathbf{M M}=910,7\right):$ C 21,10\%, H 4,32\%, N 15,38\%; obtido: C 21,02\%, H 4,48\%, N 15,35\%.

Calc. para $\left[\mathrm{Ru}\left(\mathrm{NH}_{3}\right)_{5}\left(\mathrm{C}_{7} \mathrm{~N}_{2} \mathrm{H}_{5}\right) \mathrm{Ru}\left(\mathrm{C}_{10} \mathrm{~N}_{2} \mathrm{H}_{12} \mathrm{O}_{8}\right)\right] \mathrm{PF}_{6} \cdot 3 \mathrm{H}_{2} \mathrm{O}$ $\left(\mathbf{L}=\right.$ bim $\left.^{-} ; \mathrm{MM}=891,7\right):$ C 22,90\%, H 4,30\%, N 14,14\%; obtido: C 22,92\%, H 4,43\%, N 13,88\%. 


\subsubsection{2. $\mathrm{Na}_{5}\left[(\mathrm{edta}) \mathrm{Ru} u^{\prime \prime \prime}(\mu-L) \mathrm{Fe} \mathrm{e}^{\prime \prime}(\mathrm{CN})_{5}\right]$}

Complexos heterobinucleares de valência mista desse tipo poderiam, em princípio, ser sintetizados de maneira análoga àquela descrita por Das e Bajaj, ${ }^{300}$ onde a reação se dá entre a espécie mononuclear de rutênio, $\left[\mathrm{Ru}^{\mathrm{III}}(\mathrm{edta})(\mathrm{L})\right]^{2-}$ e o aquacomplexo de ferro, $\left[\mathrm{Fe}^{1 \mathrm{II}}(\mathrm{CN})_{5}\left(\mathrm{H}_{2} \mathrm{O}\right)\right]^{3-}$. Entretanto, no caso particular do derivado de benzotriazol, esse método não se aplica pelo fato de o complexo binuclear simétrico $\left[\left\{\mathrm{Ru}^{\text {III }}(\text { edta })\right\}(\mu-\mathrm{L})\right]^{3-}$ se formar parcialmente mesmo quando a relação molar metal:ligante se aproxima de 1:1. ${ }^{\mathrm{a}}$ Uma opção óbvia para se evitar esse problema seria a possibilidade de reação entre a espécie $\left[\mathrm{Fe}^{\mathrm{II}}(\mathrm{CN})_{5}(\mathrm{~L})\right]^{4}$ e o complexo $\left[\mathrm{Ru}^{\text {III }}(\mathrm{edta})\left(\mathrm{H}_{2} \mathrm{O}\right)\right]^{-}$. Contudo, sabe-se que esse procedimento não deveria ser levado em conta devido à forte tendência desses complexos interagirem por meio de ponte através dos grupos ciano, ${ }^{301}$ o que não resultaria o produto desejado. De fato, tentou-se utilizar esse caminho de síntese para o derivado de benzotriazolato, mas o produto final foi caracterizado como sendo equivalente à espécie $\mathrm{Na}_{5}\left[(\mathrm{bta})(\mathrm{CN})_{4} \mathrm{Fe}^{\mathrm{II}}(\mu-\mathrm{CN}) \mathrm{Ru}^{\mathrm{III}}(\right.$ edta $\left.)\right]$.

\subsubsection{3. $\mathrm{Na}_{\mathrm{n}}\left[\left(\mathrm{NH}_{3}\right)_{5} R u^{\mathrm{ll}, \mathrm{ll}}(\mu-\mathrm{bta}) \mathrm{Fe} e^{\prime \prime}(\mathrm{CN})_{5}\right](\mathrm{n}=2$ ou 1)}

0 complexo heterobinuclear em sua forma totalmente reduzida foi preparado pela adição de $65,6 \mathrm{mg}$ de $\mathrm{Na}_{3}\left[\mathrm{Fe}(\mathrm{CN})_{5}\left(\mathrm{NH}_{3}\right)\right] \cdot 3 \mathrm{H}_{2} \mathrm{O}(0,20 \mathrm{mmol})$ a $5 \mathrm{~cm}^{3}$ de uma solução aquosa neutra (saturada de argônio) contendo 126,3 $\mathrm{mg}$ de $\left[\mathrm{Ru}\left(\mathrm{NH}_{3}\right)_{5}(\mathrm{btaH})\right]\left(\mathrm{PF}_{6}\right)_{2} \cdot 2 \mathrm{H}_{2} \mathrm{O}(0,20 \mathrm{mmol})$. Após adicionar 1 equiv de base (LiOH), a mistura amarela adquiriu coloração alaranjada. Depois de $-30 \mathrm{~min}, 20 \mathrm{~cm}^{3}$ de uma mistura resfriada e desaerada de etanol/acetona 1:3 foram adicionados à mistura reacional. O precipitado amarelo escuro foi filtrado e lavado com a mesma mistura resfriada de solventes. O produto sólido foi seco em vácuo na presença de dessecante. Rendimento: $80-90 \%$.

Os resultados da análise elementar foram coerentes com a fórmula $\mathrm{Na}_{2}\left[\mathrm{Ru}\left(\mathrm{NH}_{3}\right)_{5}\left(\mathrm{C}_{6} \mathrm{~N}_{3} \mathrm{H}_{4}\right) \mathrm{Fe}(\mathrm{CN})_{5}\right] \cdot 4 \mathrm{H}_{2} \mathrm{O}(\mathrm{MM}=$ 608,3 ). Calculado: C 21,72\%, H 4,47\%, N 29,93\%; obtido: C $21,65 \%, \mathrm{H} 4,64 \%$, N $29,96 \%$.

Embora o composto fosse estável à oxidação por um período de tempo de semanas (ou mesmo meses quando armazenado em condições anaeróbicas), o complexo de valência mista também foi preparado de acordo com os procedimentos a seguir.
$\mathrm{Na}\left[\left(\mathrm{NH}_{3}\right)_{5} \mathbf{R u}^{\mathrm{III}}(\mathrm{bta}) \mathrm{Fe}^{\mathrm{II}}(\mathbf{C N})_{5}\right] \cdot \mathbf{5 H}_{2} \mathrm{O}$. O complexo de valência mista foi preparado por meio de dois métodos diferentes: (a) pela mistura de quantidades equimolares $(0,20 \mathrm{mmol})$ em solução de $\mathrm{Na}_{3}\left[\mathrm{Fe}^{\mathrm{II}}(\mathrm{CN})_{5}\left(\mathrm{NH}_{3}\right)\right] \cdot 3 \mathrm{H}_{2} \mathrm{O}$ e $\left[\mathrm{Ru}^{\text {III }}\left(\mathrm{NH}_{3}\right)_{5}(\mathrm{btaH})\right]\left(\mathrm{PF}_{6}\right)_{3} \cdot 3 \mathrm{H}_{2} \mathrm{O}$ (com posterior adição de 1 equiv de LiOH), sob atmosfera de argônio; (b) pelo tratamento de uma solução aquosa do complexo reduzido $\mathrm{Na}_{2}\left[\left(\mathrm{NH}_{3}\right)_{5} \mathrm{Ru}^{\mathrm{II}}(\mathrm{bta}) \mathrm{Fe}^{\mathrm{II}}(\mathrm{CN})_{5}\right] \cdot \mathrm{nH}_{2} \mathrm{O}$ com 1 equiv de um oxidante químico (especificamente, peroxidissulfato de sódio, $\mathrm{Na}_{2} \mathrm{~S}_{2} \mathrm{O}_{8}$ ). Em ambos os casos, o restante do procedimento para isolar o sólido castanho foi similar ao do complexo totalmente reduzido. Rendimento: (a) $85-90 \%$; (b) $\sim 75 \%$.

Os resultados da análise elementar foram coerentes com a fórmula $\mathrm{Na}\left[\mathrm{Ru}\left(\mathrm{NH}_{3}\right)_{5}\left(\mathrm{C}_{6} \mathrm{~N}_{3} \mathrm{H}_{4}\right) \mathrm{Fe}(\mathrm{CN})_{5}\right] \cdot 5 \mathrm{H}_{2} \mathrm{O}(\mathrm{MM}=$ 603,3). Calculado: C 21,90\%, H 4,84\%, N 30,18\%; obtido: C $21,99 \%, \mathrm{H} 5,02 \%$, N 30,20\%.

\subsubsection{Na[(edta)Ru $\left.u^{\prime \prime \prime}(\mu-b t a) R u^{\prime \prime}\left(N H_{3}\right)_{4}(b t a)\right]$}

Esse complexo binuclear assimétrico foi preparado e caracterizado em solução aquosa. Para as medidas eletroquímicas, a solução foi obtida pela adição de $17,9 \mathrm{mg}$ de trans- $\left[\mathrm{Ru}\left(\mathrm{NH}_{3}\right)_{4}(\mathrm{btaH})_{2}\right]\left(\mathrm{PF}_{6}\right)_{2}(0,025 \mathrm{mmol})$ em $5 \mathrm{~cm}^{3}$ de solução tampão pipes $0,05 \mathrm{~mol} \mathrm{dm}^{-3}$ (pH 7,0) previamente desaerada e contendo $12,0 \mathrm{mg}$ do complexo $\left[\mathrm{Ru}(\mathrm{Hedta})\left(\mathrm{H}_{2} \mathrm{O}\right)\right](0,025 \mathrm{mmol})$. De imediato, a mistura inicialmente amarela adquiriu coloração castanha/marrom escuro. Em seguida, o pH da solução final foi ajustado para 9,0 pela adição de hidróxido de sódio $3,0 \mathrm{~mol} \mathrm{dm}^{-3}$. A cor da solução final é intensamente vermelha.

Nas medidas espectroeletroquímicas, o complexo foi preparado de acordo com o procedimento descrito acima. No entanto, utilizaram-se $35,8 \mathrm{mg}$ do complexo de partida trans- $\left[\mathrm{Ru}\left(\mathrm{NH}_{3}\right)_{4}(\mathrm{btaH})_{2}\right]\left(\mathrm{PF}_{6}\right)_{2}(0,05 \mathrm{mmol})$ e $24,0 \mathrm{mg}$ de $\left[\mathrm{Ru}(\mathrm{Hedta})\left(\mathrm{H}_{2} \mathrm{O}\right)\right](0,05 \mathrm{mmol})$.

Para fins de comparação, o complexo binuclear também foi isolado e caracterizado na forma sólida. O procedimento é semelhante àquele realizado anteriormente ${ }^{296}$ para o derivado de pirazina, e consistiu da adição de quantidades estequiométricas dos complexos em solução aquosa em pH superior a 8,5 e posterior precipitação com acetona.

Os resultados da análise elementar foram coerentes com a fórmula: $\mathrm{Na}\left[\mathrm{Ru}\left(\mathrm{NH}_{3}\right)_{4}\left(\mathrm{C}_{6} \mathrm{H}_{4} \mathrm{~N}_{3}\right)_{2} \mathrm{Ru}\left(\mathrm{C}_{10} \mathrm{H}_{12} \mathrm{~N}_{2} \mathrm{O}_{8}\right)\right] \cdot 3 \mathrm{H}_{2} \mathrm{O}$ $(\mathrm{MM}=871,8)$. Experimental: C $30,34 \%, \mathrm{H} 4,45 \%, \mathrm{~N}$ $19,33 \%$. Esperado: C 30,31\%, H 4,39\%, N 19,28\%.

\footnotetext{
a A excepcional estabilidade deste complexo será bastante discutida nos capitulos que se seguem
} 


\subsubsection{Complexo trinuclear trans-Na $\left[\left(\mathrm{NH}_{3}\right)_{4} \mathrm{Ru}^{\mathrm{II}}\left\{(\mu-\mathrm{bta}) \mathrm{Ru}{ }^{\prime \prime \prime}(\text { edta })\right\}_{2}\right]$}

O complexo trinuclear foi preparado e caracterizado em solução. Nas medidas eletroquímicas a solução foi obtida pela adição de $17,9 \mathrm{mg}$ de $\left[\mathrm{Ru}\left(\mathrm{NH}_{3}\right)_{4}(\mathrm{btaH})_{2}\right]\left(\mathrm{PF}_{6}\right)_{2}(0,025$ mmol) a $5 \mathrm{~cm}^{3}$ de solução tampão pipes $0,05 \mathrm{~mol} \mathrm{dm}^{-3}$ (pH 7,0) previamente desaerada e contendo $24,0 \mathrm{mg}$ de $\left[\mathrm{Ru}(\mathrm{Hedta})\left(\mathrm{H}_{2} \mathrm{O}\right)\right](0,050 \mathrm{mmol})$. Imediatamente, a mistura inicialmente vermelha adquiriu coloração escura (castanho/ avermelhado escuro). Em seguida, o pH da solução final foi ajustado a 9,0 pela adição controlada de hidróxido de sódio $3,0 \mathrm{~mol} \mathrm{dm}^{-3}$. A cor da solução final é púrpura.

Nas medidas espectroeletroquímicas, o complexo foi preparado conforme método descrito acima. Entretanto, utilizaram-se $35,8 \mathrm{mg}$ de $\left[\mathrm{Ru}\left(\mathrm{NH}_{3}\right)_{4}(\mathrm{btaH})_{2}\right]\left(\mathrm{PF}_{6}\right)_{2} \quad(0,05$ $\mathrm{mmol})$ e $48,0 \mathrm{mg}$ de $\left[\mathrm{Ru}(\mathrm{Hedta})\left(\mathrm{H}_{2} \mathrm{O}\right)\right](0,10 \mathrm{mmol})$.

Para fins de comparação, o complexo trinuclear também foi isolado e caracterizado na forma sólida. $O$ procedimento é semelhante àquele realizado para a espécie binuclear, consistindo da adição de quantidades estequiométricas dos complexos em solução aquosa em $\mathrm{pH}$ superior a 9 e posterior precipitação com acetona.

Os dados da análise elementar foram coerentes com a fórmula: $\mathrm{Na}_{2}\left[\mathrm{Ru}\left(\mathrm{NH}_{3}\right)_{4}\left\{\left(\mathrm{C}_{6} \mathrm{~N}_{3} \mathrm{H}_{4}\right) \mathrm{Ru}\left(\mathrm{C}_{10} \mathrm{H}_{12} \mathrm{~N}_{2} \mathrm{O}_{8}\right)\right\}_{2}\right] \cdot 4 \mathrm{H}_{2} \mathrm{O}$ (MM 1302,0). Experimental: C 29,49\%, H 4,15\%, N $15,11 \%$; Esperado: C 29,52\%, H 4,03\%, N 15,06\%.

\subsubsection{Preparação de alguns sais}

\subsubsection{Trifluoroacetato de sódio}

0 sal $\mathrm{Na}(\mathrm{tfa})$, que foi usado como eletrólito-suporte nas medidas eletroquímicas em solução aquosa, foi preparado pela titulação ácido-base, até à neutralidade, de soluções de ácido trifluoroacético ( $\mathrm{Htfa}$ ). Utilizou-se solução de hidróxido de sódio $3,0 \mathrm{~mol} \mathrm{dm}^{-3}$, para resultar soluções de $\mathrm{Na}$ (tfa) em concentrações de 0,10 ou $0,25 \mathrm{~mol} \mathrm{dm}^{-3}$.

\subsubsection{Perclorato de tetraetilamônio}

A preparação do sal (tea) $\mathrm{ClO}_{4}$, que foi usado como eletrólito-suporte nas medidas eletroquímicas em solução orgânica, foi baseada em procedimento de literatura. ${ }^{302}$ A uma solução contendo $132,5 \mathrm{~g}$ de brometo de tetraetilamônio em $\sim 200 \mathrm{~cm}^{3}$ de água desionizada, adicionaram-se $52,5 \mathrm{~cm}^{3}$ de $\mathrm{HClO}_{4}$, lentamente. A solução foi resfriada num banho de gelo, filtrada à vácuo e o sólido obtido foi lavado com água gelada. A seguir, dissolveu-se o sal bruto no menor volume possível de água quente $(\sim 500$ $\mathrm{cm}^{3}$ ) e deixou-se em repouso por uma noite. O sólido obtido foi filtrado, lavado com água gelada e seco a $100{ }^{\circ} \mathrm{C}$ em estufa à vácuo. Obteve-se um sólido branco na forma de agulhas brancas (P.F. $=351-353{ }^{\circ} \mathrm{C}$ com decomposição). $\mathrm{O}$ rendimento da síntese foi de aproximadamente $75 \%$.

\subsubsection{Preparação de soluções dos complexos}

Nas medidas fisico-químicas, (a) as soluções dos complexos em solvente orgânico foram preparadas pela dissolução direta dos compostos sólidos, sintetizados de acordo com os procedimentos acima, em acetonitrila ou dimetilformamida; (b) as soluções aquosas dos complexos foram preparadas in situ, pela mistura direta (em água, no $\mathrm{pH}$ de interesse) das espécies reagentes, conforme descrição abaixo: ${ }^{a}$

Voltametria ciclica. Nas medidas eletroquímicas, as soluções dos complexos foram obtidas pela adição de 0,025 mmol do aquacomplexo de partida a $5,0 \mathrm{~cm}^{3}$ de uma solução tamponada ${ }^{b}$ (previamente desaerada com argônio) contendo (a) 1 equiv ou excesso do ligante $\mathrm{LH}(\geq 0,025$ $\mathrm{mmol}$ ), no caso dos complexos mononucleares; (b) 1 equiv do complexo monossubstituído do tipo $\mathrm{MX}_{5} \mathrm{LH}(0,025$ mmol), no caso dos complexos binucleares. Então, o pH das misturas foi ajustado cuidadosa e convenientemente pela adição controlada (com a utilização de seringas microvolumétricas de alta precisão) de ácido clorídrico ou hidróxido de sódio, ambos na concentração $3,0 \mathrm{~mol} \mathrm{dm}^{-3}$. Como eletrólito-suporte foi empregado trifluoroacetato de sódio $0,10 \mathrm{~mol} \mathrm{dm}^{-3}$.

Espectroeletroquímica. As medidas espectroeletroquímicas foram realizadas a partir de amostras dos complexos em soluções preparadas de acordo com o procedimento acima. A única diferença, especificamente nos casos envolvendo as espécies binucleares, é que $0,050 \mathrm{mmol}$ dos complexos foi empregado em vez de $0,025 \mathrm{mmol}$. Além disso, nas medidas espectroeletroquímicas na região do IR-próximo, $\mathrm{D}_{2} \mathrm{O}$ foi utilizado como solvente na preparação das soluções. Esse procedimento tem como objetivo evitar (ou minimizar) a absorção óptica da água naquela região do espectro. Nitrato de potássio ou trifluoroacetato de sódio $0,25 \mathrm{~mol} \mathrm{dm}^{-3}$ foram utilizados como eletrólito-suporte.

a As soluçốes recém-preparadas dos complexos oniundos tanto dos sólido previamente isolados (método A) como da mistura direta dos materiais de partida em solução (método B), apresentaram espectros eletrônicos e voltamogramas cíclicos idênticos.

b Os tampões utilizados foram: acetato ( $\mathrm{pH}^{4}, 7 ; C=0,05 \mathrm{~mol} \mathrm{dm}^{-3}$ ), pipes $\left(\mathrm{pH} 7,0 ; C=0,05 \mathrm{~mol} \mathrm{dm}^{-3}\right.$ ), ou mistura de Britton-Robinson $(\mathrm{pH} \mathrm{2-12}$; $C=0,10 \mathrm{~mol} \mathrm{dm}{ }^{-3}$; veja mais detalhes adiante) 
Medidas cinéticas. Nas medidas cinéticas, todos os complexos foram preparados in situ, pela dissolução ou da quantidade apropriada do complexo metálico de partida (isto é, $\mathrm{Ru}(\mathrm{Hedta})\left(\mathrm{H}_{2} \mathrm{O}\right), \quad\left[\mathrm{RuCl}\left(\mathrm{NH}_{3}\right)_{5}\right] \mathrm{Cl}_{2}, \quad$ ou $\mathrm{Na}_{3}\left[\mathrm{Fe}(\mathrm{CN})_{5} \mathrm{NH}_{3}\right]$ ) (nas reações de formação), ou do correspondente complexo contendo o ligante coordenado (nas reações de dissociação) em solução aquosa desoxigenada e tamponada ( $\mathrm{Hac} \mathrm{ac}^{-}$ou pipes), resultando soluções de concentrações $1-5 \times 10^{-4} \mathrm{~mol} \mathrm{dm}{ }^{-3}$. Quando necessário, os complexos foram reduzidos com amálgama de zinco, sob atmosfera inerte de argônio. As soluções dos ligantes (benzotriazol e benzoimidazol, nas reações de formação; dimetilsulfóxido, isonicotinamida, piridina, ou mercaptopiridina, nas reações de dissociação) também foram recém-preparadas para resultar concentrações na faixa de $5 \times 10^{-3}$ a $5 \times 10^{-2} \mathrm{~mol} \mathrm{dm}^{-3}$. Todas as medidas foram realizadas empregando-se soluções do metal e do ligante totalmente desaeradas.

Precauções: Todas as medidas foram realizadas com soluções sob atmosfera inerte (argônio). Esse procedimento evita, por exemplo, oxidação de complexos no estado de oxidação $\mathrm{M}^{\mathrm{II}}$ (aminrutênio(II) ou cianoferrato(II) derivados) ou, no caso de soluções de rutênio(III)-edta acima de $\mathrm{pH}$ 6,5 , processos de oxidação posteriores. ${ }^{287,303}$ Além disso, todas as transferências entre frascos/recipientes de soluções susceptíveis ao oxigênio atmosférico, foram realizadas por meio de técnicas de seringas ou tubulação de Teflon ${ }^{\text {(2) }}$ Durante todos os procedimentos envolvendo a manipulação de derivados fotossensiveis de $\left[\mathrm{Fe}(\mathrm{CN})_{5}\right]^{2-/ 3-}$, evitou-se a exposição prolongada do composto à luz, a fim de se minimizar processos fotoquímicos indesejáveis (p. ex., substituição dos ligantes cianeto).

\subsubsection{Soluções tampão}

Nas medidas físico-químicas de soluções com $\mathrm{pH}$ variável, bem como na determinação dos $\mathrm{p} K_{\mathrm{a}}$ dos complexos reportados (titulação ácido-base), utilizaram-se três tipos de tampão: (a) ácido acético/acetato (para soluções com pH restrito à faixa de $\mathrm{pH} \mathrm{4-6);} \mathrm{(b)} \mathrm{pipes} \mathrm{(soluções} \mathrm{com} \mathrm{pH}$ restrito à faixa de $\mathrm{pH}$ 6-8); (c) solução tampão de BrittonRobinson $^{304}$ modificada (onde a variação em uma ampla faixa de $\mathrm{pH}$ foi requerida; $\mathrm{pH} 2-12$ ). Este último foi preparado pela mistura dos ácidos acético $\left(0,03 \mathrm{~mol} \mathrm{dm}^{-3}\right)$, pipes $\left(0,04 \mathrm{~mol} \mathrm{dm}^{-3}\right)$ e bórico $\left(0,03 \mathrm{~mol} \mathrm{dm}^{-3}\right)$ em água. $\mathrm{O}$ $\mathrm{pH}$ das soluções foi ajustado pela adição controlada de microvolumes de ácido clorídrico ou hidróxido de sódio 3,0 $\mathrm{mol} \mathrm{dm}{ }^{-3}$.

A preparação das soluções tampão simples de acetato ( $\mathrm{pH} \mathrm{4,7)} \mathrm{e} \mathrm{pipes} \mathrm{(} \mathrm{pH} 7,0$ ) foi realizada pela titulação básica dos correspondentes ácidos até atingir o pH desejado. Nesses casos, a concentração final das soluções foi de 0,05 $\mathrm{mol} \mathrm{dm}{ }^{-3}$.

\subsubsection{Métodos de purificação}

Quando necessário, os complexos solúveis em água foram purificados por meio de recristalização a partir de solução aquosa (ou mistura alcoólica, conforme conveniência). $\mathrm{Na}$ maioria dos casos, o produto foi transferido para um frasco erlenmeyer, selado com um septo de borracha e, onde requerido, desoxigenado por saturação da atmosfera com gás argônio. Então, água fervente foi adicionada ao frasco através de seringa até se observar a dissolução total do sólido. A solução quente foi resfriada lentamente, dando agulhas cristalinas. $\mathrm{O}$ material recristalizado foi filtrado, seco em vácuo por um dia ou mais e, então, estocado sobre cloreto de cálcio em temperatura ambiente.

Todos os complexos derivados de rutênio-bipiridina foram purificados por meio de coluna cromatográfica utilizando alumina neutra como material de preenchimento e acetonitrila, e/ou diclorometano, e/ou álcoois como solventes/eluentes.

\subsubsection{Secagem dos compostos}

Conforme descrição nos tópicos acima, todos os compostos isolados no estado sólido foram secos em vácuo (ou, mais rigorosamente, em pressão reduzida) em um dessecador contendo dessecante. A escolha de tal agente e do tempo de atuação dele se deram em função do grau de umidade inicial do produto e do grau de secagem requerido para cada tipo de amostra e do estudo relacionado. Basicamente, foram três os dessecantes utilizados: cloreto de cálcio granulado $\left(\mathrm{CaCl}_{2}\right)$, a,b sílica-gel azul ( $\mathrm{SiO}_{2}$ impregnado com indicador de umidade - cloreto de cobalto), ${ }^{\text {b,c }}$ e pentóxido de fósforo anidro $\left(\mathrm{P}_{2} \mathrm{O}_{5}\right)$.

\footnotetext{
a Secagem preliminar; conteúdo de água atmosférica em equilibrio (água residual) $\left.=0,14-0,25 \mathrm{mg} \mathrm{cm}^{-3}\left(25^{\circ} \mathrm{C}\right)\right)^{\mathrm{b}}$

b Tables for the Laboraton; Merck; 1998, p 65.

c Secagem média; água residual $=0,002 \mathrm{mg} \mathrm{cm}^{-3}\left(25^{\circ} \mathrm{C}\right)$.

d Secagem fina; água residual $<0,000025 \mathrm{mg} \mathrm{cm}^{-3}\left(25^{\circ} \mathrm{C}\right)$.
} 


\subsection{Reagentes e materiais utilizados}

\begin{tabular}{|c|c|c|}
\hline Composto & Fórmula & Procedência \\
\hline Acetato de sódio & $\mathrm{CH}_{3} \mathrm{COONa}$ & Merck \\
\hline Acetona HPLC & $\mathrm{CH}_{3} \mathrm{COCH}_{3}$ & Mallinckrodt \\
\hline Acetonitrila HPLC & $\mathrm{CH}_{3} \mathrm{CN}$ & Mallinckrodt \\
\hline Ácido acético glacial & $\mathrm{CH}_{3} \mathrm{COOH}$ & Merck \\
\hline Ácido bórico & $\mathrm{H}_{3} \mathrm{BO}_{3}$ & Qeel \\
\hline Ácido clorídrico & $\mathrm{HCl}$ & Merck \\
\hline Ácido etilenodiaminotetraacético & $\mathrm{C}_{10} \mathrm{H}_{16} \mathrm{~N}_{2} \mathrm{O}_{8}$ & Carlo Erba \\
\hline Ácido perclórico & $\mathrm{HClO}_{4}$ & Merck \\
\hline Ácido 1,4-piperazinadietanossulfônico & $\mathrm{C}_{4} \mathrm{H}_{8} \mathrm{~N}_{2}\left(\mathrm{CH}_{2} \mathrm{CH}_{2} \mathrm{SO}_{3} \mathrm{H}\right)$ & SIGMA \\
\hline Ácido trifluoroacético & $\mathrm{CF}_{3} \mathrm{COOH}$ & Aldrich \\
\hline Argônio & $\mathrm{Ar}$ & White Martins \\
\hline Benzoimidazol & $\mathrm{C}_{7} \mathrm{H}_{6} \mathrm{~N}_{2}$ & Aldrich \\
\hline Benzonitrila & $\mathrm{C}_{6} \mathrm{H}_{5} \mathrm{CN}$ & Aldrich \\
\hline Benzotriazol & $\mathrm{C}_{6} \mathrm{H}_{5} \mathrm{~N}_{3}$ & Aldrich \\
\hline 2,2'-Bipiridina & $\mathrm{C}_{10} \mathrm{H}_{10} \mathrm{~N}_{2}$ & Aldrich \\
\hline Borato de sódio & $\mathrm{Na}_{3} \mathrm{BO}_{3}$ & Merck \\
\hline Brometo de potássio & $\mathrm{KBr}$ & Merck \\
\hline Brometo de tetraetilamônio & $\left(\mathrm{C}_{2} \mathrm{H}_{5}\right)_{4} \mathrm{NBr}$ & Aldrich \\
\hline Cloreto de amônio & $\mathrm{NH}_{4} \mathrm{Cl}$ & Ecibra \\
\hline Cloreto de cálcio anidro & $\mathrm{CaCl}_{2}$ & Nuclear \\
\hline Cloreto de lítio & $\mathrm{LiCl}$ & Carlo Erba \\
\hline Cloreto de mercúrio(II) & $\mathrm{HgCl}_{2}$ & Riedel-de-Haën \\
\hline Diclorometano HPLC & $\mathrm{CH}_{2} \mathrm{Cl}_{2}$ & Mallinckrodt \\
\hline N,N-Dimetilacetamida & $\left(\mathrm{CH}_{3}\right)_{2} \mathrm{NCOCH}_{3}$ & Carlo Erba \\
\hline N,N-Dimetilformamida & $\left(\mathrm{CH}_{3}\right)_{2} \mathrm{NCHO}$ & Carlo Erba \\
\hline Dimetilsulfóxido & $\left(\mathrm{CH}_{3}\right)_{2} \mathrm{SO}$ & Aldrich \\
\hline Etanol & $\mathrm{C}_{2} \mathrm{H}_{5} \mathrm{OH}$ & Merck \\
\hline Éter dietílico HPLC & $\mathrm{C}_{2} \mathrm{H}_{5} \mathrm{OC}_{2} \mathrm{H}_{5}$ & Cinética \\
\hline Formamida & $\mathrm{H}_{2} \mathrm{NCO}$ & Carlo Erba \\
\hline Hexafluorofosfato de amônio & $\mathrm{NH}_{4} \mathrm{PF}_{6}$ & Aldrich \\
\hline Hidróxido de lítio & $\mathrm{LiOH}$ & Fischer \\
\hline Hidróxido de sódio & $\mathrm{NaOH}$ & Merck \\
\hline Iodeto de sódio & $\mathrm{NaI}$ & Carlo Erba \\
\hline Isonicotinamida & $\mathrm{C}_{6} \mathrm{H}_{6} \mathrm{~N}_{2} \mathrm{O}$ & Aldrich \\
\hline Metanol & $\mathrm{CH}_{3} \mathrm{OH}$ & Merck \\
\hline 2-Mercaptopiridina & $\mathrm{C}_{5} \mathrm{H}_{5} \mathrm{NS}$ & Aldrich \\
\hline Nitrato de potássio & $\mathrm{KNO}_{3}$ & Merck \\
\hline Nitrato de prata & $\mathrm{AgNO}_{3}$ & Carlo Erba \\
\hline Nitrobenzeno & $\mathrm{C}_{6} \mathrm{H}_{5} \mathrm{NO}_{2}$ & Merck \\
\hline Nitrometano & $\mathrm{CH}_{3} \mathrm{NO}_{2}$ & Merck \\
\hline Nitroprussiato de sódio & $\mathrm{Na}_{2}\left[\mathrm{Fe}(\mathrm{CN})_{5} \mathrm{NO}\right]$ & J.T.Baker \\
\hline Óxido de alumínio neutro (alumina) & $\mathrm{Al}_{2} \mathrm{O}_{3}$ & Carlo Erba \\
\hline Óxido de deutério (água deuterada) & $\mathrm{D}_{2} \mathrm{O}$ & Aldrich \\
\hline
\end{tabular}




\begin{tabular}{lcc}
\hline Oxigênio & $\mathrm{O}_{2}$ & Air Liquid \\
Pentóxido de fósforo anidro & $\mathrm{P}_{2} \mathrm{O}_{5}$ & Aldrich \\
Perclorato de tetraetilamônió & $\left(\mathrm{CH}_{3} \mathrm{CH}_{2}\right)_{4} \mathrm{NClO}_{4}$ & Preparado conforme item 2.1.7.2 \\
Peroxidissulfato de sódio & $\mathrm{Na}_{2} \mathrm{~S}_{2} \mathrm{O}_{8}$ & SIGMA \\
Piridina HPLC & $\mathrm{C}_{5} \mathrm{H}_{5} \mathrm{~N}$ & Aldrich \\
Propilenocarbonato & $\mathrm{C}_{4} \mathrm{H}_{6} \mathrm{O}_{3}$ & Merck \\
Sílica-get & $\left(\mathrm{SiO}_{2}\right)_{\mathrm{n}}$ & Merck \\
Sulfato de cério(IV) e amônio & $\left(\mathrm{NH}_{4}\right)_{4} \mathrm{Ce}\left(\mathrm{SO}_{4}\right)_{4} \cdot 2 \mathrm{H}_{2} \mathrm{O}$ & Riedel-de-Haën \\
Tricloreto de hexaaminrutênio(III) & {$\left[\mathrm{Ru}_{(\mathrm{NH}}\right)_{6} \mathrm{Cl}_{3}$} & Johnson Matthey (recrist.) \\
Tricloreto de rutênio hidratado & $\mathrm{RuCl}_{3} \cdot \mathrm{nH}_{2} \mathrm{O}$ & Inco Europe Ltd. \\
Trifluoroacetato de sódio & $\mathrm{CF}_{3} \mathrm{COONa}_{0}$ & Preparado conforme item 2.1.7.1 \\
Zinco metálico (pastilhas) & $\mathrm{Zn}$ & Aldrich \\
\hline
\end{tabular}

Todos os reagentes e solventes obtidos comercialmente são de grau analítico e foram empregados nas sínteses sem purificação prévia.
Água desionizada foi utilizada na preparação de todas as soluções aquosas. A desionização é realizada pela passagem de água destilada através de um sistema de ultrapurificação da Nanopure ${ }^{\mathrm{TM}}$ - Barnstead.

\subsection{Apare/hagem e metodologia}

\subsubsection{Espectros eletrônicos}

Os espectros eletrônicos das soluções aquosas dos complexos estudados, na região de 190 a $1100 \mathrm{~nm}$, foram obtidos utilizando-se um espectrofotômetro de varredura rápida da Hewlett-Packard modelo 8453, acoplado a um microcomputador.

Nas medidas simples, foi empregada uma cela de quartzo convencional com caminho óptico de $1 \mathrm{~cm}$; em medidas de titulação ácido-base espectrofotométrica, usou-se uma cela especialmente projetada para este fim, que também é construída de quartzo e possui caminho óptico de $1 \mathrm{~cm}$, mas tem capacidade para um volume de $\sim 25 \mathrm{~cm}^{3}$. Foram utilizadas soluções com concentrações na faixa de $5,0 \times 10^{-4}$ a $1,0 \times 10^{-2} \mathrm{~mol} \mathrm{dm}^{-3}$.

\subsubsection{Medidas cinéticas}

O estudo cinético foi desenvolvido através de técnica de cinética rápida (stopped-flow) por meio de um equipamento da Applied Photophysics acoplado a um microcomputador. A aquisição e o processamento dos dados foram realizados pelo uso dos programas residentes fornecidos pela Applied Photophysics.
Utilizaram-se soluções dos complexos em concentrações na faixa de $1,0 \times 10^{-4}$ a $1,0 \times 10^{-3} \mathrm{~mol} \mathrm{dm}^{-3}$, e dos ligantes em concentrações pelo menos dez vezes superior em relação ao metal. As soluções foram preparadas em tampão de acetato (pH 4,7) ou pipes ( $\mathrm{pH} \mathrm{7,0)} 0,05 \mathrm{~mol} \mathrm{dm}^{-3}$, com força iônica $I=0,10 \mathrm{~mol} \mathrm{dm}^{-3}$ ajustada com trifluoroacetato de sódio. Todos os dados foram coletados a $25 \pm 1{ }^{\circ} \mathrm{C}$.

Em todas as medidas cinéticas, portanto, empregaram-se condições de reações de pseudo-primeira ordem. ${ }^{\text {a }}$

Como na maioria dos métodos stopped-flow, a evolução das reações foi seguida espectrofotometricamente pela absorção óptica monocromática em um comprimento de onda apropriado, escolhido a partir dos espectros eletrônicos dos reagentes e dos produtos.

\subsubsection{Medidas eletroquímicas}

As medidas de voltametria cíclica ou voltametria de pulso diferencial foram realizadas por meio de um potenciostato/ galvanostato modelo 283 da EG\&G Instruments - Princeton Applied Research (PAR).

a Um dos reagentes encontra-se em excesso suficientemente grande para se assumir que a sua quantidade permanece invariável durante a reação. Assim, a sua concentração pode ser aproximada como uma constante. ${ }^{305}$ 
A célula eletroquímica utilizada é constituída de um recipiente de vidro ${ }^{a}$ em cuja tampa são fixados um capilar para a entrada de argônio, o eletrodo de referência [solução aquosa: $\mathrm{Ag} / \mathrm{AgCl}$ em $\mathrm{KCl} 1,0 \mathrm{~mol} \mathrm{dm}^{-3}\left(E^{\circ}=+0,222 \mathrm{~V}\right.$ vs. $\mathrm{EPH}){ }^{6}$ solução orgânica (acetonitrila ou dimetilformamida): $\mathrm{Ag} / \mathrm{Ag}^{+} ; \mathrm{AgNO}_{3} 0,01 \mathrm{~mol} \mathrm{dm}{ }^{-3}\left(E^{\circ}=+0,503 \mathrm{~V}\right.$ vs. EPH) ${ }^{6}$ (tea) $\mathrm{ClO}_{4} \quad 0,10 \mathrm{~mol} \mathrm{dm}^{-3}$ ], o eletrodo de trabalho [solução aquosa: carbono vítreo; solução orgânica: platina], ${ }^{b}$ e eletrodo auxiliar (fio espiralado de platina).

Os voltamogramas cíclicos de soluções aquosas foram obtidos a partir de amostras em concentrações de $5,0 \times 10^{-3}$ ou $1,0 \times 10^{-2} \mathrm{~mol} \mathrm{dm}^{-3}$, em tampão ácido acético/acetato, pipes, ou mistura de Britton-Robinson 0,05 $\mathrm{mol} \mathrm{dm}^{-3}$. Como eletrólito-suporte foi utilizado $\mathrm{Na}(\mathrm{tfa}) 0,10$ ou 0,25

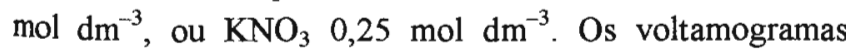
cíclicos de soluções orgânicas foram obtidos a partir de amostras em concentrações de $5,0 \times 10^{-3}$ ou $1,0 \times 10^{-2} \mathrm{~mol}$ $\mathrm{dm}^{-3}$, em acetonitrila ou dimetilformamida. Como eletrólitosuporte foi utilizado (tea) $\mathrm{ClO}_{4} 0,10$ ou $0,25 \mathrm{~mol} \mathrm{dm}^{-3}$.

Todas as soluções foram cuidadosamente desaeradas previamente aos experimentos, e o mesmo procedimento foi repetido antes de cada medida realizada, fazendo-se passar um fluxo de gás inerte (argônio) através das amostras. Assumiu-se como negligenciáveis os potenciais de junção, ${ }^{5,6,306}$ de tal forma que os valores de potenciais de redução $\left(E_{1 / 2}\right)$ obtidos não foram corrigidos. ${ }^{c}$

\subsubsection{Medidas espectroeletroquímicas}

Os espectros eletrônicos na região do UV-Vis obtidos sob aplicação de potenciais foram registrados com o auxílio de um espectrofotômetro da Hewlett-Packard modelo 8453, acoplado a um microcomputador. A aplicação de potenciais foi realizada ou através de um potenciostato modelo 173 ou com um bipotenciostato modelo 366 (ambos da PAR), usados em paralelo com o espectrofotômetro diode-array.

Utilizou-se uma cela espectrofotométrica retangular de caminho óptico interno igual a $0,025 \mathrm{~cm}$, possuindo um minigrid de ouro como eletrodo de trabalho transparente e minieletrodos de referência [solução aquosa: $\mathrm{Ag} / \mathrm{AgCl}$ em $\mathrm{KCl} 1,0 \mathrm{~mol} \mathrm{dm}^{-3}\left(E^{\circ}=+0,222 \mathrm{~V}\right.$ vs. EPH); solução

a Capacidade para até $5 \mathrm{~cm}^{3}$, embora normalmente seja utilizado um volume de amostra ao redor de $1 \mathrm{~cm}^{3}$.

b O polimento da superficie dos eletrodos de trabalho foi realizado com pasta de alumina (carbono vítreo) ou lixa fina de carbeto de silício (platina), ambos procedentes da Struers.

c Todos os dados eletroquímicos e/ou espectroeletroquímicos reportados nesta tese referem-se a valores de potenciais versus EPH (eletrodo padrão de hidrogênio). Em casos excepcionais (p. ex. comparação com dados de literatura), o ele trodo de referência será informado explicitamente. orgânica (acetonitrila ou dimetilformamida): $\mathrm{Ag} / \mathrm{Ag}^{+}$; $\mathrm{AgNO}_{3} 0,01 \mathrm{~mol} \mathrm{dm}{ }^{-3}$ ( $E^{\circ}=+0,503 \mathrm{~V}$ vs. EPH); (tea)ClO $0,10 \mathrm{~mol} \mathrm{dm}^{-3}$ ] e auxiliar (espiral de platina). A célula é localizada diretamente dentro do espectrofotômetro, e a variação da absorção é monitorada durante a eletrólise.

Em meio aquoso, as medidas foram efetuadas a partir de soluções $5,0 \times 10^{-3} \mathrm{~mol} \mathrm{dm}^{-3}$, em tampão acetato ou pipes $0,05 \mathrm{~mol} \mathrm{dm}^{-3}$. Como eletrólito-suporte usou-se $\mathrm{Na}$ (tfa) 0,10 mol dm${ }^{-3}$. Em meio orgânico, usaram-se soluções $2,0 \times 10^{-3}$ $\mathrm{mol} \mathrm{dm}{ }^{-3}$ em acetonitrila contendo (tea) $\mathrm{ClO}_{4} 0,10 \mathrm{~mol} \mathrm{dm}^{-3}$.

As medidas espectroeletroquímicas na região do NIR foram realizadas por meio de um espectrofotômetro guiado por fibra óptica modelo 260 da Guided Wave, acoplado a um bipotenciostato PAR modelo 366. Utilizou-se um arranjo de três eletrodos semelhante ao da voltametria, substituindo-se o eletrodo de carbono vítreo por um eletrodo de disco de platina polida. A sonda de fibra óptica é disposta próxima e perpendicularmente à base da célula eletroquímica, de tal forma que os espectros da fina camada de solução entre a superfície polida do eletrodo e a janela inferior da cela eletroquímica de quartzo são obtidos usando a própria superficie espelhada do eletrodo de platina como uma superficie refletora. ${ }^{d}$

\subsubsection{Espectros vibracionais}

Os espectros vibracionais na região do IR foram obtidos para amostras em pastilhas de brometo de potássio, através de um espectrofotômetro FTIR modelo 8300 da Shimadzu.

\subsubsection{Medidas de $\mathrm{pH}$}

As medidas de $\mathrm{pH}$ foram registradas com um medidor de pH digital modelo MD21 da Digimed Ltda. A calibração do aparelho foi realizada usando-se soluções tampão padrão comerciais nos seguintes $\mathrm{pH}: 4,00,7,00$ e 10,00 . Todas as medidas foram conduzidas em temperatura ambiente.

\subsubsection{Análise elementar}

Os dados de microanálise foram obtidos através da Central Analítica do Instituto de Química, Universidade de São Paulo.

d V. ref. 238 e 307 para informação complementar sobre o aparato utilizado (esquemas e descrição adicionais). 


\subsubsection{Cálculos quânticos e modelagem molecular}

Cálculos quânticos moleculares em nível semi-empírico ${ }^{308,309}$ foram realizados através do método ZINDO, a,309,310 Utilizou-se, para tanto, ou o programa ZINDO (em ambiente de trabalho Cerius $^{2}$ na versão 3.5 para IRIX; 1997) da Molecular Simulation Inc. (San Diego, CA, USA), ou o programa HyperChem ${ }^{\otimes}$ nas versões 4.5 para SGI/UNIX (1996) ou 5.1 para PC/Windows ${ }^{\$}$ (1998), fornecido pela Hypercube Inc. (Gainesville, FL, USA)

Nos cálculos de otimização geométrica envolvendo os ligantes orgânicos livres e os complexos metálicos, o método INDO/1 foi empregado, mantendo-se os seus parâmetros-padrão residentes. Cálculos de orbitais moleculares e simulação espectral, tanto para os complexos como para os ligantes livres, foram realizados pelo uso da implementação espectroscópica do método ZINDO (NDO/S), utilizando-se parametrização atômica modificada para complexos octaédricos de rutênio e ferro com configurações $4 d^{6}$ e $4 d^{5}$ de spin baixo. Os fatores universais de interação sigma e pi foram mantidos como padrão (isto é, $f_{\text {o- }}=1,267$ e $f_{\pi-\pi}=0,585$ ).
Orbitais moleculares SCF (Self-Consistent Field) foram obtidos nos níveis RHF (Restricted Hartree-Fock) e ROHF (Restricted open-shell Hartree-Fock) ${ }^{98,99,309,311}$ para as espécies de camada fechada $\left(M^{\mathrm{II}}\right)$ e camada aberta $\left(\mathbf{M}^{\mathrm{III}}\right)$ no estado fundamental, que correspondem às configurações eletrônicas normais $\left(t_{2 \mathrm{~g}}\right)^{6} \mathrm{e}\left(t_{2 \mathrm{~g}}\right)^{5}$, respectivamente.

As geometrias moleculares de partida foram otimizadas por meio de cálculos de mecânica molecular através do módulo $\mathrm{MM}+$, uma modificação do método $\mathrm{MM}^{312}$ e disponível no programa HyperChem ${ }^{\circledR}$. Nesse caso, um gradiente de $1 \times 10^{-5} \mathrm{kcal} \AA^{-1} \mathrm{~mol}^{-1}$ foi utilizado como critério de convergência em um algoritmo de gradiente conjugado. As cargas atômicas empregadas nos cálculos de modelagem molecular foram extraídas de cálculos quânticos semi-empíricos (ZINDO) single point. Os cálculos foram processados ou em uma estação de trabalho da SGI modelo Indigo $^{2}$ com processador R10000 ou em um PC Windows com microprocessador Pentium ${ }^{\circledR}$ III. 


\section{Resultados e Discussão}

Durante o período referente ao doutorado foram estudados vários tipos de sistemas, que compreendem complexos mono-, bi-, ou trinucleares estudados em soluções aquosa (espécies derivadas de etilenodiaminotetraacetatorutenato, pentaaminrutênio, ou pentacianoferrato) ou orgânica (que inclui os derivados de bis(2,2'-bipiridina)rutênio). Uma vez que a motivação de estudo para cada uma dessas séries é inerente ao conjunto de suas propriedades, optou-se nesta tese por apresentar e discutir separadamente os resultados associados a cada uma dessas classes

\begin{abstract}
Além disso, o estudo das espécies mononucleares é de fundamental importância na compreensão das espécies polimetálicas delas derivadas, de tal maneira que, neste capítulo, os sistemas serão agrupados em duas seções com respeito ao meio em que foram investigados: 3 .1. Sistemas em meio aquoso, e 3.2. Sistemas em meio orgânico. Essas seções, por sua vez, serão subdivididas em itens/subitens na seguinte ordem: complexos mononucleares (item 3.x.1.), binucleares (item 3.x.2.) e, quando houver, outros sistemas (item 3.x.3.).
\end{abstract}

\subsection{Sistemas em meio aquoso}

\subsubsection{Complexos mononucleares}

Como os sistemas mononucleares não representam o foco principal desta tese, as suas principais características, tais como reatividade, química redox, propriedades ácido-base ou peculiaridades do sistema (tal como isomerização), serão abordadas de forma breve. Alguns dos dados obtidos serão apresentados com a finalidade principal de comparação com outros membros da série e uso/referência posterior quando as espécies polinucleares derivadas forem introduzidas.

\subsubsection{Cinética e reatividade}

A reatividade dos complexos mononucleares derivados de benzotriazol com pentacianoferrato e pentaaminrutênio foi estudada previamente, ${ }^{241,242}$ enquanto os complexos de $\mathrm{Ru}$ (edta) com benzotriazol/benzotriazolato, bem como todas as espécies contendo benzoimidazol, estão sendo reportadas pela primeira vez. Dessa forma, na discussão que se segue, os dados daqueles primeiros serão apenas mencionados (e coletados em formato de tabela) para fins de comparação com todos os outros análogos envolvidos na série, enquanto todos os demais compostos posteriormente investigados serão descritos com mais detalhes.

\subsubsection{1. $\left[R u^{\prime \prime \prime I I I}(e d t a)(L H)\right]^{-2-}$}

O complexo aqua(etilenodinitrilotetraacetato)rutenato(III), $\mathrm{Ru}^{\text {III }}(\mathrm{Hedta})\left(\mathrm{H}_{2} \mathrm{O}\right)$, sofre dois processos de desprotonação, com constantes de equilíbrio ácido-base correspondendo a $\mathrm{p} K_{\mathrm{a}}^{(1)}=2,37$ e $\mathrm{p} K_{\mathrm{a}}^{(2)}=7,60:^{313}$

$$
\begin{aligned}
& {\left[\mathrm{Ru}(\text { Hedta })\left(\mathrm{H}_{2} \mathrm{O}\right)\right] \stackrel{\mathrm{K}_{\mathrm{a}}^{(1)}}{=}\left[\mathrm{Ru}(\text { edta })\left(\mathrm{H}_{2} \mathrm{O}\right)\right]^{-}+\mathrm{H}^{+}} \\
& {\left[\mathrm{Ru}(\text { edta })\left(\mathrm{H}_{2} \mathrm{O}\right)\right] \stackrel{\mathrm{K}_{\mathrm{a}}^{(2)}}{=}[\mathrm{Ru}(\text { edta })(\mathrm{OH})]^{2-}+\mathrm{H}^{+}}
\end{aligned}
$$

$\mathrm{O}$ aquacomplexo $\left[\mathrm{Ru}{ }^{\mathrm{III}}(\mathrm{edta})\left(\mathrm{H}_{2} \mathrm{O}\right)\right]$, gerado por dissolução de $\mathrm{Ru}^{\mathrm{III}}(\mathrm{Hedta})\left(\mathrm{H}_{2} \mathrm{O}\right)$ em solução aquosa ( $\mathrm{em} \mathrm{pH}>3$ ), exibe uma labilidade não-usual e elevada reatividade com muitos ligantes, cuja cinética apresenta um $\mathrm{pH}$ ótimo ao redor de $5{ }^{313}$ Essa condição coincide com a máxima formação da espécie desprotonada $\left[\mathrm{Ru}{ }^{\mathrm{III}}(\mathrm{edta})\left(\mathrm{H}_{2} \mathrm{O}\right)\right]^{]}$, que é favorecida nessa região média que fica compreendida entre os dois $\mathrm{p} K_{\mathrm{a}}$ do aquacomplexo (Eqs. 52 e 53).

$$
\begin{aligned}
& {\left[\mathrm{Ru}^{\mathrm{III}}(\mathrm{edta})\left(\mathrm{H}_{2} \mathrm{O}\right)\right]^{-}+\mathrm{LH} } \underset{k_{\mathrm{d}}^{\mathrm{III}}}{\stackrel{k_{\mathrm{fI}}^{\mathrm{II}}}{\rightleftarrows}} \\
& {\left[\mathrm{Ru}^{\mathrm{III}}(\mathrm{edta})(\mathrm{LH})\right]^{-}+\mathrm{H}_{2} \mathrm{O} }
\end{aligned}
$$

A elevada velocidade de substituição (via um mecanismo associativo) observada em reações envolvendo complexos de $\left[\mathrm{Ru}^{\mathrm{III}}(\mathrm{edta})\right]^{-}$é atribuída à formação de uma ponte de hidrogênio entre o oxigênio do grupo carboxilato livre e 0 hidrogênio da água no complexo de partida, o que provoca uma distorção geométrica e o aparecimento de uma região estericamente desimpedida. Essa hipótese tem sido proposta inicialmente por Creutz e Matsubara há uma década. ${ }^{313}$

Mais recentemente, resultados de modelagem molecular obtidos por Rein ${ }^{238,239}$ através de cálculos quânticos semiempíricos $^{239}$ e de mecânica molecular ${ }^{238}$ para as diversas conformações geométricas possíveis do aquacomplexo $\left[\mathrm{Ru}(\mathrm{edta})\left(\mathrm{H}_{2} \mathrm{O}\right)\right]^{-}$concordam com aquela proposição, como 
pode se depreender da estrutura molecular otimizada (isto é, de menor energia) ilustrada na Fig. 6.

Estudos por cristalografia de raios- $\mathrm{X}^{314}$ mostraram que o grupo carboxílico não-coordenado do ligante $\mathrm{Hedta}^{3-}$ se encontra afastado da molécula de água coordenada. No entanto, é importante perceber que a estrutura determinada se refere ao complexo $\mathrm{Ru}(\mathrm{Hedta})\left(\mathrm{H}_{2} \mathrm{O}\right)$, isto é, contendo o grupo carboxílico livre protonado $(-\mathrm{COOH})$. Ainda assim, no estado sólido cristalino também foi observada uma aproximação intermolecular entre o grupo carboxílico livre do ligante quelato $\mathrm{Hedta}^{3-}$ e um átomo de hidrogênio da

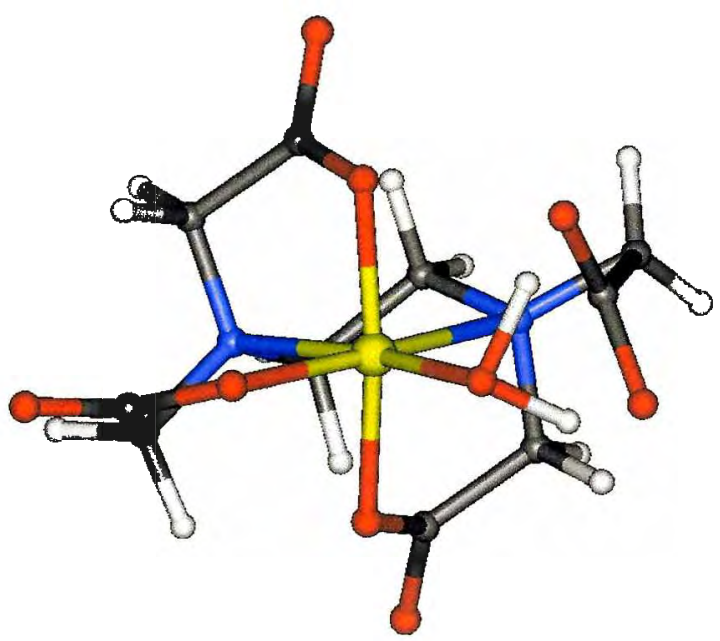

molécula de água coordenada, perfazendo uma distância típica de pontes de hidrogênio. Convém ressaltar que os cálculos realizados para a molécula do complexo protonado $\mathrm{Ru}(\mathrm{Hedta})\left(\mathrm{H}_{2} \mathrm{O}\right)$ também forneceram resultados coerentes com aqueles obtidos experimentalmente por meio de cristalografia de raios- $\mathrm{X}$, assegurando maior confiabilidade nos dados obtidos. Além disso, os valores de distâncias e ângulos de ligação determinados teoricamente são bastante próximos daqueles obtidos experimentalmente por raios-X (desvios de correlação $<5 \%$ ).

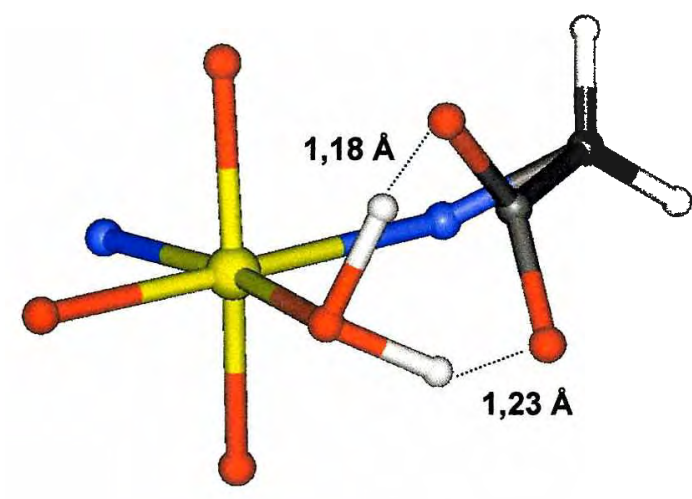

Figura 6. Estrutura molecular teórica $(M M+/ Z I N D O)$ do complexo $\left[R u^{\prime \prime \prime}(e d t a)\left(H_{2} O\right)\right]$.

No caso dos ligantes benzotriazol e benzoimidazol, a reação (em $\mathrm{pH} \mathrm{4,7} \mathrm{e} \mathrm{7,0,} \mathrm{respectivamente)} \mathrm{levou} \mathrm{à} \mathrm{formação} \mathrm{de}$ complexos bastante estáveis, exibindo bandas de absorção dependentes do $\mathrm{pH}$ ao redor de $500 \mathrm{~nm}$. A reação de formação é bastante rápida, cuja cinética seguiu uma lei de velocidade de primeira ordem por pelo menos três tempos de meia-vida. As constantes de velocidade observadas são proporcionais à concentração do ligante, na faixa de 20 a 100 vezes de excesso do ligante ( 1 a $5 \mathrm{mmol} \mathrm{dm}^{-3}$ ) em relação ao metal, resultando as seguintes constantes de velocidade específicas: $k_{\mathrm{f}}^{\mathrm{III}}=7,6( \pm 0,2) \times 10^{2} \mathrm{~mol}^{-1} \mathrm{dm}^{3} \mathrm{~s}^{-1} \mathrm{e}$ $5,0( \pm 0,1) \times 10^{2} \mathrm{~mol}^{-1} \mathrm{dm}^{3} \mathrm{~s}^{-1}$, para $\mathrm{LH}=$ btaH e bimH, respectivamente.

A dissociação dos complexos com respeito ao ligante Nheterocíclico (benzotriazol ou benzoimidazol) foi monitorada espectrofotometricamente em $600 \mathrm{~nm}$, na presença de 2mercaptopiridina como ligante de ataque. Esse ligante é conhecido por formar um complexo bastante estável $\left(K_{\mathrm{f}}=\right.$ $\left.3,1 \times 10^{6} \mathrm{~mol}^{-1} \mathrm{dm}^{3}\right)^{\mathrm{a}}$ com $\left[\mathrm{Ru}^{\mathrm{II}}(\mathrm{edta})\right]^{-240}$ exibindo bandas de transferência de carga na região do visível. Na presença

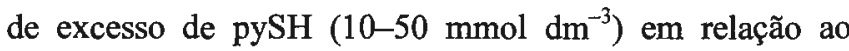
complexo $\left[\mathrm{Ru}^{\Pi \amalg}(\mathrm{edta})\left(\mathrm{H}_{2} \mathrm{O}\right)\right]^{-}\left(0,25 \mathrm{mmol} \mathrm{dm}^{-3}\right)$, a reação se procedeu por completo em poucos minutos, a $25{ }^{\circ} \mathrm{C}$, de acordo com uma cinética típica de primeira-ordem. As constantes observadas foram independentes da concentração do ligante de ataque, seguindo um comportamento de saturação, com $k_{\mathrm{d}}^{\mathrm{III}}=2,1( \pm 0,1) \times 10^{-2} \mathrm{~s}^{-1}$ e $1,38( \pm 0,05) \times 10^{-2}$ $\mathrm{s}^{-1}$, para $\mathrm{LH}=$ btaH e bimH, respectivamente. A partir das constantes de formação e dissociação, as constantes de equilíbrio foram calculadas ( $K^{\mathrm{III}}=k_{\mathrm{f}}^{\mathrm{III}} / k_{\mathrm{d}}^{\mathrm{III}}$ ) como sendo iguais a $3,6( \pm 0,1) \times 10^{4} \mathrm{~mol}^{-1} \mathrm{dm}^{3}$, para ambos os complexos $\left[\mathrm{Ru}^{\mathrm{III}}(\mathrm{edta})(\mathrm{LH})\right]^{-}(\mathrm{LH}=$ btaH e bimH $)$.

No caso do complexo reduzido, a reação de formação, partindo dos reagentes $\left[\mathrm{Ru}^{\mathrm{II}}(\mathrm{edta})\left(\mathrm{H}_{2} \mathrm{O}\right)\right]^{2-}$ e $\mathrm{LH}$, procedeuse muito rapidamente, resultando o produto de cor amarela $\left[\mathrm{Ru}^{\mathrm{II}}(\mathrm{edta})(\mathrm{LH})\right]^{2-}\left(\lambda_{\operatorname{máx}} \sim 400 \mathrm{~nm}\right)$. Entretanto, conforme 
reportado previamente na literatura, ${ }^{313}$ as medidas são prejudicadas pela presença de quantidades catalíticas da espécie lábil [ $\mathrm{Ru}^{\text {III }}($ edta $\left.)\left(\mathrm{H}_{2} \mathrm{O}\right)\right]^{-}$, levando a uma cinética de ordem zero. Por outro lado, a dissociação do ligante btaH do complexo reduzido não foi influenciada por esse tipo de interferência, de tal forma que curvas cinéticas de primeiraordem bem comportadas e reprodutiveis foram obtidas na presença do ligante de ataque (dimetilsulfóxido). ${ }^{a}$ As constantes de velocidade da dissociação se mostraram independentes da concentração do ligante de ataque $(>50$ mmol dm ${ }^{-3}$ ) e as correspondentes curvas cinéticas exibiram um comportamento típico de saturação. As constantes de dissociação calculadas foram $k_{\mathrm{d}}{ }^{\mathrm{II}}=1,52( \pm 0,05) \times 10^{-5} \mathrm{~s}^{-1} \mathrm{e}$ $4,2( \pm 0,1) \times 10^{-3} \mathrm{~s}^{-1}$, para os complexos com benzotriazol e benzoimidazol, respectivamente.

Devido às dificuldades mencionadas para se medir as constantes de formação $\left(k_{\mathrm{f}}^{\Pi}\right)$ para o complexo reduzido, um procedimento alternativo para se avaliar a constante de equilíbrio $K^{\mathrm{HI}}$ foi baseado no ciclo termodinâmico quadrado envolvendo estas quatro espécies: $\left[\mathrm{Ru}^{\mathrm{IIIII}}(\mathrm{edta})\left(\mathrm{H}_{2} \mathrm{O}\right)\right]^{-, 2-} \mathrm{e}$ $\left[\mathrm{Ru}^{\mathrm{III}, \mathrm{I}}(\mathrm{edta})(\mathrm{LH})\right]^{-2-}$.

Desde que $K^{\mathrm{III}}$ é conhecido e os potenciais redox podem ser avaliados das medidas eletroquímicas (apresentadas logo a seguir no item 3.1.1.4), o referido ciclo pode ser resolvido de acordo com procedimento descrito no apêndice 6.3.

Os valores de $K^{\mathrm{II}}$ para $\mathrm{LH}=$ btaH e bimH são $1,8 \times 10^{6}$ $\mathrm{mol}^{-1} \mathrm{dm}^{3}$ e $7,6 \times 10^{3} \mathrm{~mol}^{-1} \mathrm{dm}^{3}$, respectivamente, a partir dos quais (Eq. 55) os valores de $k_{\mathrm{f}}^{\text {II }}$ foram estimados em 32 $\mathrm{mol}^{-1} \mathrm{dm}^{3} \mathrm{~s}^{-1}$ e $27 \mathrm{~mol}^{-1} \mathrm{dm}^{3} \mathrm{~s}^{-1}$

$$
k_{\mathrm{f}}^{\mathrm{II}}=k_{\mathrm{d}}^{\mathrm{II}} \times K^{\mathrm{II}}
$$

Considerando os valores relativos de $K^{\mathrm{III}}$ e $K^{\mathrm{II}}$, pode-se perceber que o benzotriazol neutro se comporta como um ligante aceitador- $\pi$ moderado, conduzindo à estabilização preferencial do complexo reduzido, $\mathrm{Ru}^{\mathrm{I}}$. Por outro lado, o benzoimidazol parece se comportar essencialmente como um ligante típico doador- $\sigma / \pi$, levando a uma estabilização preferencial do complexo oxidado, $\mathrm{Ru}^{\mathrm{III}}$.

\subsubsection{2. $\left[R u^{11, I I I}\left(\mathrm{NH}_{3}\right)_{5}(\mathrm{LH})\right]^{2+, 3+}$}

Em solução aquosa, o complexo de partida $\left[\mathrm{RuCl}\left(\mathrm{NH}_{3}\right)_{5}\right]^{+}$, pentaaminclororutênio(II), reage prontamente para formar o aquapentaaminrutênio(II), $\left[\mathrm{Ru}\left(\mathrm{H}_{2} \mathrm{O}\right)\left(\mathrm{NH}_{3}\right)_{5}\right]^{2+}$. Este, por sua vez, é lábil e substitui a água facilmente na presença de ligantes N-heterocíclicos. ${ }^{283}$

a $\left[\operatorname{Ru}^{\mathrm{II}}(\mathrm{edta})(\mathrm{K} S\{\mathrm{dmso}\})\right]^{2-} \rightarrow K_{\mathrm{f}}=7,7 \times 10^{9} \mathrm{~mol}^{-1} \mathrm{dm}^{3} .{ }^{235}$

$$
\begin{aligned}
{\left[\mathrm{RuCl}\left(\mathrm{NH}_{3}\right)_{5}\right]^{+}+\mathrm{H}_{2} \mathrm{O} \rightleftharpoons } & {\left[\mathrm{Ru}\left(\mathrm{H}_{2} \mathrm{O}\right)\left(\mathrm{NH}_{3}\right)_{5}\right]^{2+}+\mathrm{Cl}^{-} } \\
{\left[\mathrm{Ru}\left(\mathrm{H}_{2} \mathrm{O}\right)\left(\mathrm{NH}_{3}\right)_{5}\right]^{2+}+\mathrm{LH} \underset{k_{\mathrm{d}}^{\mathrm{II}}}{\stackrel{k_{\mathrm{II}}^{\mathrm{II}}}{\rightleftarrows}} } & {\left[\mathrm{Ru}\left(\mathrm{NH}_{3}\right)_{5}(\mathrm{LH})\right]^{2+}+\mathrm{H}_{2} \mathrm{O} }
\end{aligned}
$$

A formação de $\left[\mathrm{Ru}\left(\mathrm{NH}_{3}\right)_{5}(\text { bimH })\right]^{2+}$ seguiu uma cinética de primeira-ordem por pelo menos três períodos de meia-vida. As constantes de velocidade observadas se demonstraram proporcionais à concentração do ligante, com uma constante de velocidade de segunda-ordem $\left(k_{\mathrm{f}}^{\mathrm{II}}\right)$ de $0,33 \pm 0,01 \mathrm{dm}^{3}$ $\mathrm{mol}^{-1} \mathrm{~s}^{-1}$. Esse resultado é comparável àqueles para alguns análogos de literatura, ${ }^{315}$ particularmente o complexo com benzotriazol, $\left[\mathrm{Ru}\left(\mathrm{NH}_{3}\right)_{5}(\mathrm{btaH})\right]^{2+}$, cujo valor da constante de formação, $k_{\mathrm{f}}^{\text {III }}$ é $0,32 \pm 0,01 \mathrm{dm}^{3} \mathrm{~mol}^{-1} \mathrm{~s}^{-1}$. 242

Analogamente ao benzotriazol-complexo, ${ }^{242}$ não se teve sucesso nas tentativas de se substituir o benzoimidazol por um ligante tal como piridina ou isonicotinamida na espécie $\left[\mathrm{Ru}\left(\mathrm{NH}_{3}\right)_{5}(\mathrm{bimH})\right]^{2+}$. Na verdade, as reações se procederam muito lentamente e levaram à substituição preferencial dos ligantes $\mathrm{NH}_{3} \mathrm{em}$ vez do N-heterocíclico.

\subsubsection{3. $\left[\mathrm{Fe}^{\mathrm{II}, \mathrm{II}}(\mathrm{CN})_{5}(\mathrm{LH})\right]^{3-, 2-}$}

Em solução aquosa neutra ou levemente ácida, o íon aminpentacianoferrato(II), $\left[\mathrm{Fe}(\mathrm{CN})_{5}\left(\mathrm{NH}_{3}\right)\right]^{3-}$, pode sofrer substituição da amônia para resultar o correspondente aquacomplexo, $\left[\mathrm{Fe}(\mathrm{CN})_{5}\left(\mathrm{H}_{2} \mathrm{O}\right)\right]^{3-}$, 226 que, por sua vez, reage prontamente com ligantes $\mathrm{N}$-heterocíclicos. ${ }^{224}$

$$
\begin{aligned}
{\left[\mathrm{Fe}(\mathrm{CN})_{5}\left(\mathrm{NH}_{3}\right)\right]^{3-}+\mathrm{H}_{2} \mathrm{O} \rightleftharpoons } & {\left[\mathrm{Fe}(\mathrm{CN})_{5}\left(\mathrm{H}_{2} \mathrm{O}\right)\right]^{3-}+\mathrm{NH}_{3} } \\
{\left[\mathrm{Fe}(\mathrm{CN})_{5}\left(\mathrm{H}_{2} \mathrm{O}\right)\right]^{3-}+\mathrm{LH} \underset{k_{\mathrm{d}}^{\mathrm{II}}}{\stackrel{k_{\mathrm{I}}^{\mathrm{n}}}{\rightleftarrows}} } & {\left[\mathrm{Fe}(\mathrm{CN})_{5}(\mathrm{LH})\right]^{3-}+\mathrm{H}_{2} \mathrm{O} }
\end{aligned}
$$

A cinética de formação do benzoimidazol-complexo também foi investigada por técnica de cinética rápida (stopped-flow) em condições de pseudo-primeira ordem $\left([\right.$ metal $]=0,5 \mathrm{mmol} \mathrm{dm}^{-3}$; [ligante $\left.]>10 \mathrm{mmol} \mathrm{dm}^{-3}\right)$. Uma dependência linear das constantes de velocidade observadas com respeito à concentração do ligante benzoimidazol foi encontrada, o que também é consistente com a cinética de substituição previamente descrita na literatura para o íon $\left[\mathrm{Fe}(\mathrm{CN})_{5}\left(\mathrm{H}_{2} \mathrm{O}\right)\right]^{3-}$.

A constante de velocidade específica calculada, $k_{\mathrm{f}}^{\mathrm{II}}=$ $1,7 \pm 0,1 \times 10^{2} \mathrm{~mol}^{-1} \mathrm{dm}^{3} \mathrm{~s}^{-1}$, é relativamente menor que aquela determinada para o complexo $\left[\mathrm{Fe}(\mathrm{CN})_{5}(\mathrm{btaH})\right]^{3-}$ $\left(k_{\mathrm{f}}^{\mathrm{II}}=3,3 \pm 0,1 \times 10^{2} \mathrm{~mol}^{-1} \mathrm{dm}^{3} \mathrm{~s}^{-1}\right)^{241}$ 
Tentativas de se obter a constante de dissociação $\left(k_{\mathrm{d}}^{\mathrm{II}}\right)$ do complexo $\left[\mathrm{Fe}(\mathrm{CN})_{5}(\text { bimH })\right]^{3-}$ por meio de um método de competição usando uma variedade de ligantes de entrada (dimetilsulfóxido, ${ }^{a}$ por exemplo) têm demonstrado que a cinética de substituição é praticamente independente da natureza do ligante de ataque, o que está de acordo com um mecanismo dissociativo do tipo $\mathrm{D}$ (ou D-IP). ${ }^{305}$ Como conseqüência, a constante de velocidade de dissociação, $k_{\mathrm{d}}{ }^{\mathrm{II}}$, é igual a $k_{\mathrm{f}}^{\Pi}$, a constante de formação.

\subsubsection{Isomeria de ligação}

A molécula de benzotriazol possui três átomos coordenantes de nitrogênio vicinais (v. ilustração no Esq. 5), que podem formar uma grande variedade de complexos com íons metálicos de transição, conforme exposto no item 1.6.1. Além disso, a presença de múltiplos pontos de coordenação possibilita a existência de isômeros de ligação, podendo o metal interagir através do sítio N3 (ou, equivalentemente, N1 se o ligante estiver desprotonado), ou através do átomo intermediário N2 (Esq. 5). A afinidade por um desses sítios, dependerá da natureza do íon metálico, conforme se verá adiante.

Esquema 5. Os ligantes benzotriazol (btaH) e benzotriazolato (bta').

O estudo da isomeria de ligação no benzotriazol foi iniciada no grupo há mais de uma década, para os complexos de pentacianoferrato(II)/(III) ${ }^{241}$ e pentaaminrutênio(II)/(III). ${ }^{242}$ Nesta parte do trabalho, objetivou-se estender tal estudo ao complexo com rutênio-edta, que será abordado neste item. Posteriormente, será delineada uma comparação geral dessa série, no que se refere a suas propriedades de isomeria de ligação com o benzotriazol

\subsubsection{1. $[\mathrm{Ru}(\mathrm{edta})(\mathrm{btaH})]^{, 2-}$}

Conforme pode ser observado nos voltamogramas cíclicos da Fig. 7, iniciando-se a varredura de potenciais em 0,622 $\mathrm{V}$, no sentido de potenciais mais negativos (Fig. 7A), o complexo $\left[\mathrm{Ru}^{\mathrm{III}}(\mathrm{edta})(\mathrm{btaH})\right]^{-}$é reduzido reversivelmente a $\left[\mathrm{Ru}^{\mathrm{II}}(\mathrm{edta})(\mathrm{btaH})\right]^{2-}$, com $E_{1 / 2}=0,090 \mathrm{~V}$. Ao se inverter o

a $\left[\mathrm{Fe}^{\mathrm{II}}(\mathrm{CN})_{5}(\kappa S\{\text { dmso }\})\right]^{3-} \rightarrow K_{\mathrm{f}}=3,2 \times 10^{6} \mathrm{~mol}^{-1} \mathrm{dm}^{3}$. sentido de varredura, o complexo inicial [Ru $\left.{ }^{\mathrm{III}}(\mathrm{edta})(\mathrm{btaH})\right]^{-}$ é regenerado quantitativamente à velocidade de $200 \mathrm{mV} \mathrm{s}^{-1}$. Entretanto, à medida que a velocidade de varredura é diminuída, uma segunda onda anódica se torna proeminente em $\sim 0,20 \mathrm{~V}$ (Fig. 7A).

A presença da segunda espécie se torna mais evidente nos voltamogramas obtidos pela varredura na direção inversa, começando em potenciais negativos (Fig. 7B). Esse tipo de comportamento se mostra bastante consistente com uma reação reversível envolvendo duas espécies eletroativas precedendo a etapa eletroquímica.

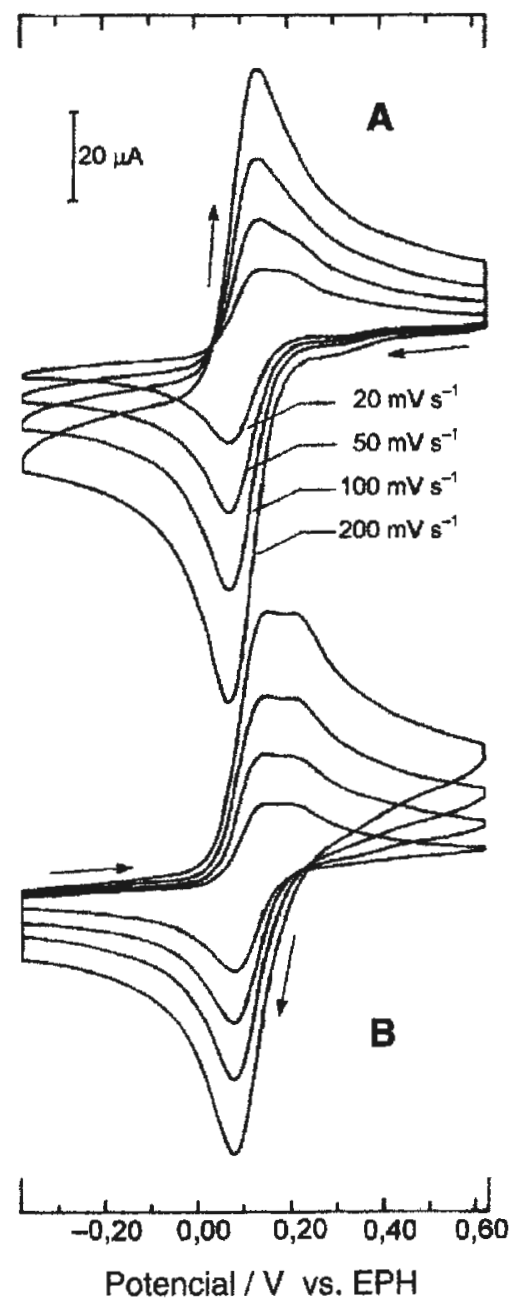

Figura 7. Voltamogramas ciclicos do complexo [Ru(edta)(btaH)] em solução aquosa. (A) Varredura inicial catódica e (B) varredura inicial anódica. ( $C=2,0 \times 10^{-3} \mathrm{~mol} \mathrm{dm}^{-3} ; l=\mathrm{Na}$ (tfa) $0,1 \mathrm{~mol} \mathrm{dm}^{-3}$; solução tampão $\mathrm{Haclac}^{-} 0,05 \mathrm{~mol} \mathrm{dm}^{-3} ; \mathrm{pH} 4.7 ; \mathrm{v}=20,50,100$ e $200 \mathrm{mV} \mathrm{s}^{-1}$ )

Um comportamento similar foi observado para o complexo $\left[\mathrm{Fe}^{\mathrm{II}}(\mathrm{CN})_{5}(\mathrm{btaH})\right]^{3-241}$ e atribuído à reação de isomeria de ligação envolvendo os sítios de coordenação N3 e N2 do benzotriazol (Esq. 6), baseado em espectroscopia $\mathrm{RMN}^{1} \mathrm{He}$ medidas espectroeletroquímicas. 


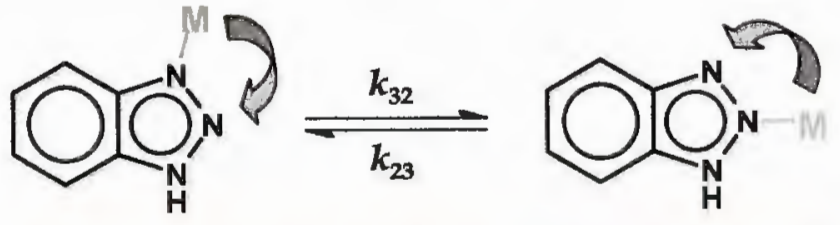

Esquema 6. Isomeria de ligaçåo em complexos de benzotriazol.

Portanto, em analogia ao ferrocianeto-complexo, a resposta eletroquímica observada na Fig. 7 pode ser descrita em termos de uma etapa de redução eletroquímica seguida de uma reação de isomerização reversível.

A reação de isomerização se mostrou bastante lenta na escala de tempo da medida dos voltamogramas cíclicos, excluindo a aplicação do tratamento teórico proposto por Shain e Nicholson ${ }^{244}$ para esse tipo de sistema. Por essa razão, as concentrações dos dois complexos isômeros $\left[\mathrm{Ru}^{\mathrm{II}}(\text { edta })(\mathrm{kN} 3\{\mathrm{btaH}\})\right]^{2-}$ e $\left[\mathrm{Ru}^{\mathrm{II}}(\text { edta })(\kappa N 2\{\mathrm{btaH}\})\right]^{2-}$ foram avaliadas pela desconvolução dos voltamogramas e relacionadas ao tempo $t_{\mathrm{c} \rightarrow \mathrm{a}}$ gasto entre os picos de redução e oxidação. A partir das curvas logarítmicas de $C$ vs. $t_{\mathrm{c} \rightarrow \mathrm{a}}$, a constante de isomerização observada foi calculada em $k_{\text {obs }}=$ $5,6 \times 10^{-3} \mathrm{~s}^{-1}$. Desde que a cinética se refere a um processo de equilíbrio, a constante de velocidade observada $\left(k_{\mathrm{obs}}\right)$ corresponde à soma das constantes $k^{\mathrm{I}}(\mathrm{N} 3 \rightarrow \mathrm{N} 2) \equiv k_{32}{ }^{\mathrm{II}} \mathrm{e}$ $k^{\Pi}(\mathrm{N} 2 \rightarrow \mathrm{N} 3) \equiv k_{23}{ }^{\Pi}$, isto é, $k_{\mathrm{obs}}=k_{32}{ }^{\mathrm{I}}+k_{23}{ }^{\mathrm{II}}$, onde 3 e 2 se referem aos isômeros $\mathrm{N} 3$ e N2, respectivamente.

As concentrações dos isômeros N3 e N2 no equilíbrio também foram avaliadas por meio da desconvolução dos voltamogramas mostrados na Fig. 7B, registrados pela varredura iniciando em $-0,378 \mathrm{~V}$, onde as espécies isômeras reduzidas já se encontram em equilíbrio. Em velocidades de varredura superiores a $200 \mathrm{mV} \mathrm{s}{ }^{-1}$; as concentrações de ambas as espécies permanecem praticamente inalteradas durante a varredura eletroquímica. Uma vez que os dois isômeros exibem coeficientes de difusão ( $D_{\mathrm{ox}}$ e $\left.D_{\mathrm{red}}\right)$ similares, a constante de equilíbrio $K^{\rrbracket}(\mathrm{N} 3 \rightarrow \mathrm{N} 2)$ pôde ser calculada a partir da relação entre as correntes dos picos anódicos, resultando $K_{32}{ }^{\mathrm{II}}=0,33$.

Por fim, considerando-se que $k_{\mathrm{obs}}=k_{32}{ }^{\mathrm{II}}+{k_{23}}^{\mathrm{II}}$ e $K_{32}{ }^{\mathrm{II}}=$ $k_{32}{ }^{\text {II }} / k_{23}{ }^{\text {II }}$, é possível se calcular $k_{32}{ }^{\text {II }}=1,4 \times 10^{-3} \mathrm{~s}^{-1}$ e $k_{23}{ }^{\text {II }}=$ $4,3 \times 10^{-3} \mathrm{~s}^{-1}$. É importante notar que $k_{32}{ }^{\text {II }}$ e $k_{23}{ }^{\text {II }}$ são duas ordens de grandeza superiores às constantes de dissociação para a espécie $\left[\mathrm{Ru}^{\mathrm{II}}(\mathrm{edta})(\mathrm{btaH})\right]^{2-}$, indicando um processo de isomerização de ligação com mecanismo tipicamente intramolecular.

A determinação das constantes de isomerização para as espécies reduzidas permitiu a estimativa da correspondente constante de equilíbrio para o complexo oxidado, $K_{32}{ }^{\mathrm{III}}$, por meio do ciclo termodinâmico associado (v. apêndice 6.3), levando a $K_{32}{ }^{\mathrm{III}}=4,6 \times 10^{-3}$.

Cálculos quânticos em nível semi-empírico para o ligante benzotriazol foram desenvolvidos neste trabalho por meio dos métodos ZINDO/1 (otimização geométrica) e ZINDO/S (MO e densidade cargas atômicas). A representação gráfica da distribuição de carga total sobre a molécula é mostrada na Fig. $8 .^{2}$

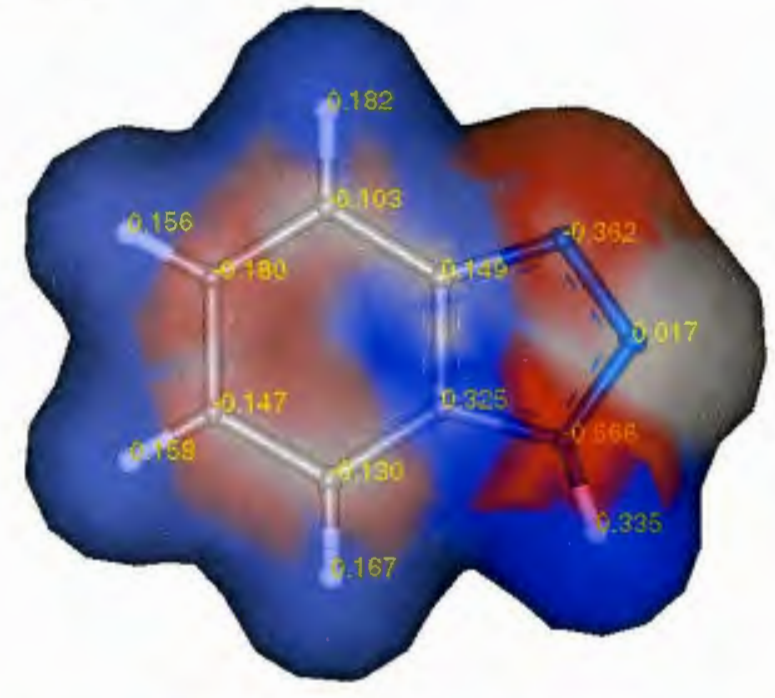

Figura 8. Distribuiçăo de cargas atómicas na molécula de benzotriazol,

De acordo com os cálculos teóricos, é evidente que o átomo N3 é mais nucleofílico que N2. Como existe uma relação direta entre nucleofilicidade e potencial de coordenação, o átomo N3 seria o sítio preferido para a interação com um ácido de Lewis, tal como os íons $\mathrm{Ru}^{\mathrm{III}}$ ou $\mathrm{Fe}^{\mathrm{III}}$. $\mathrm{O}$ átomo $\mathrm{N} 2$ por sua vez, seria o sítio de coordenação preferido por íons metálicos com uma alta capacidade de retrodoação- $\pi$, a exemplo dos íons $\mathrm{Fe}^{\mathrm{II}}$ e $\mathrm{Ru}^{\text {II }}$.

Além disso, o isômero $\left[\mathrm{M}^{\mathrm{mI}}(\mathrm{X})_{5}(\mathrm{k} N 3\{\mathrm{btaH}\})\right]^{n-}$ deveria exibir um potencial redox mais negativo em comparação com o isômero $\left[\mathrm{M}^{\mathrm{III}}(\mathrm{X})_{5}(\mathrm{kN} 2\{\mathrm{btaH}\})\right]^{n-}$, devido à sua maior afinidade pela espécie oxidada, $M^{\mathrm{III}}$. Essa expectativa é coerente com os resultados eletroquímicos reportados nesta tese.

a Esta representação é gerada a partir da análise populacional orbital de Mulliken.98,99,309,311

b Neste tipo de superficie de densidade eletrônica, as regiões com maior densidade de carga são mostradas em vermelho (regiões "quentes"; p. ex. N3 $\operatorname{com} q=-0,362$ ), enquanto nas áreas em azul há maior concentração de cargas parciais positivas (regiões "frias"). As regiões aproximadamente neutras aparecem em branco ( $p . e x . N 2 \operatorname{com} q=0,017$ ).

c Pode-se perceber que, por uma feliz coincidencia entre a numeração dos estados de oxidação do metal e da fomulação estrutural do benzotriazol, é possivel generalizar que: em complexos metálicos de configuração eletrônica $d^{5} / d^{6}$ de spin baixo, o fon no estado de oxidação formal $3+$ prefere o nitrogênio 3 do ligante e o metal 2+ prefere o sítio 2, o que oferece ưma boa regra mnemônica do tipo $\mathrm{M}(\mathrm{III}) \rightarrow \mathrm{N}(3)$ e $\mathrm{M}(\mathrm{II}) \rightarrow \mathrm{N}(2)$. 


\subsubsection{2. $\left[\mathrm{Ru}\left(\mathrm{NH}_{3}\right)_{5}(\mathrm{btaH})\right]^{2+, 3+}$ e $\left[\mathrm{Fe}(\mathrm{CN})_{5}(\mathrm{btaH})\right]^{3-, 2-}$}

Conforme mencionado, o estudo da isomeria de ligação desses complexos foi reportado anteriormente, ${ }^{241,242}$ e os dados estão coletados na Tab. 1 juntamente com os obtidos neste trabalho para o derivado de Ru(edta).

Tabela 1. Dados cinéticos e termodinâmicos relacionados à isomeria de ligaçăo dos complexos $\mathrm{X}_{5} \mathrm{M}$-btaH.

\begin{tabular}{|c|c|c|c|c|}
\hline Complexo & $k_{32} / \mathrm{s}^{-1} a$ & $k_{23} / \mathrm{s}^{-1} a$ & $K_{\mathrm{N} 3 \rightarrow \mathrm{N} 2}$ & $\boldsymbol{K}^{\mathrm{I}} / \boldsymbol{K}^{\mathrm{In} b}$ \\
\hline$\left[\mathbf{R u}^{\mathrm{III}}(\mathrm{edta})(\mathrm{btaH})\right]^{-}$ & - & - & $4,6 \times 10^{-3}$ & \multirow{2}{*}{72} \\
\hline$\left[\mathbf{R u}^{\mathrm{II}}(\mathrm{edta})(\mathrm{btaH})\right]^{2-}$ & $1,4 \times 10^{-3}$ & $4,3 \times 10^{-3}$ & 0,33 & \\
\hline$\left[\mathrm{Ru}^{\mathrm{III}}\left(\mathrm{NH}_{3}\right)_{5}(\mathrm{btaH})\right]^{3+}$ & 0,22 & 0,16 & 1,4 & \multirow{2}{*}{59} \\
\hline$\left[\mathbf{R} \mathbf{u}^{\mathbf{I I}}\left(\mathbf{N H}_{3}\right)_{\mathbf{5}}(\mathbf{b t a H})\right]^{2+}$ & $3,9 \times 10^{-2}$ & $5,0 \times 10^{-4}$ & 83 & \\
\hline$\left[\mathrm{Fe}^{\mathrm{III}}(\mathrm{CN})_{5}(\mathrm{btaH})\right]^{2-}$ & $4,0 \times 10^{-3}$ & 0,44 & $9,1 \times 10^{-3}$ & \multirow{2}{*}{46} \\
\hline$\left[\mathrm{Fe}^{\mathrm{II}}(\mathrm{CN})_{5}(\mathrm{btaH})\right]^{3-}$ & 0,65 & 1,55 & 0,42 & \\
\hline
\end{tabular}

${ }^{a}$ Determinado eletroquimicamente, por meio de voltametria cíclica;

${ }^{b} K^{\mathrm{II}}=K_{\mathrm{N} 3 \rightarrow \mathrm{N} 2}$ para a espécie reduzida $\mathrm{M}^{\mathrm{I}} \mathrm{X}_{5} \mathrm{LH}$, e $K^{\mathrm{III}}=K_{\mathrm{N} 3 \rightarrow \mathrm{N} 2}$ para a espécie oxidada $\mathrm{M}^{\mathrm{III}} \mathrm{X}_{5} \mathrm{LH}$; reflete a importância das interações do tipo $\pi$-retrodoadoras na estabilização dos íons no estado reduzido, $\mathrm{M}^{\mathrm{II}}$.

Uma análise dos dados da Tab. 1 nos permite concluir que, na ausência de retroligação- $\pi$, tanto as espécies reduzidas, $\mathbf{M}^{\mathrm{II}}$, como as oxidadas, $\mathrm{M}^{\mathrm{III}}$, deveriam se coordenar preferencialmente pelo átomo $\mathrm{N} 3$ por causa de sua nucleofilicidade muito maior, e a relação entre as constantes de isomerização $K_{32}{ }^{\mathrm{II}} / K_{32}{ }^{\mathrm{III}}$ seria próxima da unidade.
Sendo assim, os valores dessa relação determinados experimentalmente $(>40)$ podem ser entendidos como uma medida direta da importância da interação de retroligação- $\pi$ na estabilização das espécies $\mathrm{X}_{5} \mathrm{M}^{\mathrm{II}}-\mathrm{k} N 2\{\mathrm{btaH}\}$ em relação àquelas $\mathrm{X}_{5} \mathrm{M}^{\mathrm{III}}-\mathrm{kN} 2\{\mathrm{btaH}\}$, sendo coerente com resultados obtidos da análise teórica de densidade molecular de cargas.

\subsubsection{Eletroquimica e espectroeletroquímica}

\subsubsection{1. $[R u(e d t a)(L H)]^{-, 2-}$ e $[R u(e d t a)(L)]^{2-3-}$}

Os voltamogramas cíclicos do complexo $\left[\mathrm{Ru}(\text { edta })\left(\mathrm{H}_{2} \mathrm{O}\right)\right]^{-}$ são tipicamente reversíveis, com $E_{1 / 2}=-0,010 \mathrm{~V}$ (este valor concorda com o de literatura). ${ }^{313} \mathrm{Na}$ presença do ligante, a onda original é substituída por outra onda reversível com $E_{1 / 2}=0,090 \mathrm{~V}(\mathrm{btaH} ; \mathrm{pH} 4,7) \mathrm{e}-0,015 \mathrm{~V}$ (bimH; $\left.\mathrm{pH} 7,0\right)$, atribuida ao par redox $\left[\mathrm{Ru}^{\mathrm{II} / \mathrm{Il}}(\mathrm{edta})(\mathrm{LH})\right]^{-/ 2-}$.

A reação resultante de $\left[\mathrm{Ru}^{\mathrm{III}}(\mathrm{edta})\left(\mathrm{H}_{2} \mathrm{O}\right)\right]$ com o ligante benzotriazol ou benzoimidazol em solução aquosa produz um complexo amarelo pálido em meio ácido (ou neutro, no caso do bimH), que se torna vermelho em meio básico. Essa mudança é atribuída a um equilíbrio ácido-base envolvendo o ligante coordenado, o que também pode ser observado através de um deslocamento sistemático dos voltamogramas em função do $\mathrm{pH}$, indicando que o equilíbrio ácido-base é acoplado ao processo eletroquímico (este último ponto será explorado no item 3.1.1.4).

$$
\left[\mathrm{Ru}^{\mathrm{III}}(\mathrm{edta})(\mathrm{LH})\right]^{-} \stackrel{K_{\mathrm{a}}}{\rightleftharpoons}\left[\mathrm{Ru}^{\mathrm{II}}(\mathrm{edta})(\mathrm{L})\right]^{2-}+\mathrm{H}^{+}
$$

Os valores de $\mathrm{p} K_{\mathrm{a}}$ relacionados à $\mathrm{Eq}$. 60 foram obtidos por meio de titulação espectrofotométrica. ${ }^{\text {a,b }}$

A partir desse procedimento, os valores de $\mathrm{p} K_{\mathrm{a}}^{\mathrm{III}}$ das

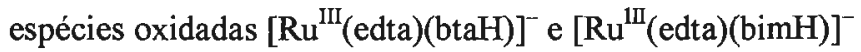
foram determinados em 6,6 e 8,8 , respectivamente, que correspondem às constantes de equilíbrio $K_{\mathrm{a}}=1,5 \times 10^{-6} \mathrm{~mol}$ $\mathrm{dm}^{-3}$ (benzotriazol) e $1,6 \times 10^{-9} \mathrm{~mol} \mathrm{dm}^{-3}$ (benzoimidazol).

\footnotetext{
a V. apêndice 6.2 para maiores detalhes do método e da derivação das equações empregadas.

b Um procedimento opcional baseia-se na titulação eletroquínica do complexo em solução aquosa. Esse método também foi utilizado e encontra-se descrito no próximo tópico desta tese (item 3.1.1.4).
} 
Devido ao equilibrio ácido-base envolvendo as espécies redox (Eq. 60), os potenciais exibidos pelos voltamogramas cíclicos também se mostraram sensíveis ao $\mathrm{pH}$. Os valores de $E_{1 / 2}$ para as espécies benzotriazolato e benzoimidazolato, se deslocam para $-0,080 \mathrm{~V}(\mathrm{pH} 10,0)$ e ao redor de $-0,20 \mathrm{~V}$ (pH 12,5), respectivamente. Esse aspecto particular desses sistemas será explorado com muito mais ênfase no item 3.1.1.4.

Conhecendo-se as constantes $K_{\mathrm{a}}^{\mathrm{III}}$ e os valores de $E_{1 / 2}$ para ambas as espécies protonada, [Ru $\left.{ }^{\mathrm{III}}(\mathrm{edta})(\mathrm{LH})\right]^{-}$, e desprotonada, $\left[\mathrm{Ru}^{\mathrm{III}}(\mathrm{edta})(\mathrm{L})\right]^{2-}$, os valores de $K_{\mathrm{a}}^{\mathrm{II}}$ para as espécies reduzidas foram calculados por meio do ciclo termodinâmico do tipo ilustrado no apêndice 6.3 .

Dessa forma, os valores de $K_{\mathrm{a}}^{\text {II }}$ para [Ru $\left.{ }^{\text {II }}(\mathrm{edta})(\mathrm{btaH})\right]^{2-}$ e $\left[\mathrm{Ru}^{\text {II }}(\text { edta)(bimH) }]^{2-}\right.$ foram estimados em $3,2 \times 10^{-10} \mathrm{~mol}$ $\mathrm{dm}^{-3}$ e $1,3 \times 10^{-12}$ mol dm${ }^{-3}$, que equivalem aos $\mathrm{p} K_{\mathrm{a}}^{\text {II }} 9,5 \mathrm{e}$ 11,9 , respectivamente.

Esses valores de $\mathrm{p} K_{\mathrm{a}}$ também foram determinados eletroquimicamente, a partir da dependência de $E_{1 / 2} \mathrm{em}$ função do $\mathrm{pH}$ (item 3.1.1.4). Pode-se antecipar que há uma correlação bastante consistente entre os resultados obtidos por ambos os métodos.

É interessante notar que os valores de $\mathrm{p} K_{\mathrm{a}}$ para os ligantes livres btaH e bimH são $8,38^{292}$ e $12,78^{293}\left(25^{\circ} \mathrm{C}\right.$; $I=$ 0,0 ), respectivamente. Portanto, essa diferença entre os valores das constantes de dissociação ácida dos complexos oxidados, $K_{\mathrm{a}}^{\text {III }}$, e aquelas dos ligantes livres benzotriazol e benzoimidazol (ao redor de $10^{3}$ vezes, favorecendo o ligante coordenado) reflete a estabilização do ligante coordenado ao metal, como uma conseqüência de seus caráteres doador$\pi$ combinado com o caráter aceitador $-\pi$ da unidade de $\mathrm{Ru}^{\mathrm{III}}$ (devido à configuração eletrônica $4 d^{6}$ de spin baixo $-t_{2 \mathrm{~g}}{ }^{5}$ ). Evidentemente, pela simples análise desses valores, pode-se inferir que a capacidade $\mathrm{N} /$ doadora- $\sigma / \pi$ do benzoimidazol é bastante superior à do benzotriazol.

Embora o íon metálico coordenante seja, por definição, um ácido de Lewis, é bem conhecido que o efeito de retrodoação- $\pi$ se torna bastante relevante em espécies do tipo $\mathrm{Ru}^{\mathrm{II}} / \mathrm{Fe}^{\mathrm{II}}$ (aquelas com configuração eletrônica $4 d^{6}$ de spin baixo $-t_{2 g}{ }^{6}$ ). Conseqüentemente, seu caráter aceitador é muito menos pronunciado em comparação ao das espécies $\mathrm{Ru}^{\mathrm{III}} / \mathrm{Fe} \mathrm{III}^{\mathrm{II}}$. Na verdade, passam a ter natureza doadora em alguns casos (a exemplo do complexo com benzotriazol; observado indiretamente pelo fato de o valor de $\mathrm{p} K_{\mathrm{a}}^{\mathrm{II}}$ ser mais elevado que aquele do ligante livre); em outros, onde o ligante já possui um caráter básico bastante pronunciado (bimH), $\mathrm{p} K_{\mathrm{a}}^{\text {II }}$ é bem superior ao $\mathrm{p} K_{\mathrm{a}}^{\text {III }}$ mas ainda é inferior ao do ligante livre.
Medidas espectroeletroquímicas para o complexo derivado de benzotriazol mostraram que, em $\mathrm{pH} \mathrm{4,7,} \mathrm{a} \mathrm{espécie}$ protonada [Ru $\left.{ }^{\text {II }}(\mathrm{edta})(\mathrm{btaH})\right]^{2-}$ exibe uma banda de absorção intensa do tipo transferência de carga metal-ligante (MLCT) em $400 \mathrm{~nm}\left(\varepsilon=6500 \mathrm{~mol}^{-1} \mathrm{dm}^{3} \mathrm{~cm}^{-1}\right)$, atribuída à transição $\left(\mathrm{Ru}^{\mathrm{II}}\right) d_{\pi} \rightarrow p_{\pi}^{*}(\mathrm{btaH})$. As medidas espectroeletroquímicas se comportam com um padrão tipicamente Nernstiono, com um potencial redox de $0,090 \mathrm{~V}$ (em pH 4,7). O complexo oxidado exibe somente uma banda de absorção fraca ao redor de $350 \mathrm{~nm}$, atribuída a transições internas na unidade [Ru ${ }^{\text {III }}$ (edta) $]^{-}$. Quando desprotonado $(\mathrm{pH}>7,0)$, o complexo $\left[\mathrm{Ru}^{\mathrm{III}} \text { (edta)(bta) }\right]^{2-}$ apresenta uma banda característica de transferência de carga ligante-metal (LMCT) em $510 \mathrm{~nm}$ $\left(\varepsilon=1540 \mathrm{~mol}^{-1} \mathrm{dm}^{3} \mathrm{~cm}^{-1}\right)$, que origina de uma transição do tipo (bta $) p_{\pi} \rightarrow d_{\pi}\left(\mathrm{Ru}^{\text {II }}\right)$. A correspondente espécie reduzida, $\left[\mathrm{Ru}^{\text {II }} \text { (edta)(bta) }\right]^{3-}$, apresenta uma banda MLCT em $395 \mathrm{~nm}$ $\left(\varepsilon=6000 \mathrm{~mol}^{-1} \mathrm{dm}^{3} \mathrm{~cm}^{-1}\right.$ ).

O estudo espectroeletroquímico para os complexos com benzoimidazol mostrou que a espécie $\left[\mathrm{Ru}^{\mathrm{III}}\right.$ (edta)(bimH)] apresenta uma banda LMCT em $360 \mathrm{~nm}\left(\varepsilon=1280 \mathrm{~mol}^{-1}\right.$ $\left.\mathrm{dm}^{3} \mathrm{~cm}^{-1}\right)$, atribuída à transição (bimH) $p_{\pi} \rightarrow d_{\pi}\left(\mathrm{Ru}^{\mathrm{III}}\right)$; e que a espécie reduzida protonada, $\left[\mathrm{Ru}^{\mathrm{II}}(\mathrm{edta})(\mathrm{bimH})\right]^{2-}$, possui uma banda MLCT em $330 \mathrm{~nm}\left(\varepsilon=3280 \mathrm{~mol}^{-1} \mathrm{dm}^{3} \mathrm{~cm}^{-1}\right)$, que foi associada à transição $\left(\mathrm{Ru}^{\mathrm{II}}\right) d_{\pi} \rightarrow p_{\pi}{ }^{*}$ (bimH).

Os espectros do ín complexo oxidado desprotonado, $\left[\mathrm{Ru}^{\text {III }} \text { (edta)(bim) }\right]^{2-}$, mostraram uma banda LMCT de baixa intensidade em $520 \mathrm{~nm}\left(\varepsilon=350 \mathrm{~mol}^{-1} \mathrm{dm}^{3} \mathrm{~cm}^{-1}\right)$, devido à transição eletrônica $\left(\mathrm{bim}^{-}\right) p_{\pi} \rightarrow d_{\pi}\left(\mathrm{Ru}^{\mathrm{III}}\right)$, e uma banda MLCT intensa em $325 \mathrm{~nm}\left(\varepsilon=3060 \mathrm{~mol}^{-1} \mathrm{dm}^{3} \mathrm{~cm}^{-1}\right)$ para a espécie reduzida, referente à transição $(\mathrm{Ru}) d_{\pi} \rightarrow p_{\pi}{ }^{*}\left(\mathrm{bim}^{-}\right)$.

Algumas das observações, tais como o deslocamento batocrômico da banda LMCT durante a desprotonação do complexo e a ocorrência das respectivas bandas MLCT em regiões de maior energia (com $\lambda$ de absorção máxima muito próximo para ambas as espécies protonada e desprotonada), corroboram mais uma vez o poder $N /$ doador- $\sigma / \pi$ do ligante bimH, bem como a importância da retroligação- $\pi$ no caso dos complexos reduzidos.

Mais adiante, as propriedades individuais de cada uma dessas espécies serão muito importantes no planejamento dos complexos binucleares e na descrição das propriedades envolvendo interação eletrônica metal-metal, no caso das espécies de valência mista. 


\subsubsection{2. $\left[\mathrm{Ru}\left(\mathrm{NH}_{3}\right)_{5}(\mathrm{bimH})\right]^{2+, 3+}$ e $\left[\mathrm{Ru}\left(\mathrm{NH}_{3}\right)_{5}(\mathrm{bim})\right]^{+, 2+}$}

As propriedades eletrônicas e eletroquímicas do complexo $\left[\mathrm{Ru}\left(\mathrm{NH}_{3}\right)_{5}(\mathrm{btaH})\right]^{\mathrm{n+}}$, que já foram relatadas previamente, ${ }^{242}$ serão comparadas com as do benzoimidazol-derivado mais adiante, no item 3.1.1.4.

A reação entre $\left[\mathrm{Ru}^{\mathrm{II}}\left(\mathrm{NH}_{3}\right)_{5}\left(\mathrm{H}_{2} \mathrm{O}\right)\right]^{2+}$ e benzoimidazol produz, em solução aquosa neutra, um complexo amarelo, cujo potencial de redução é $0,115 \mathrm{~V}(\mathrm{em} \mathrm{pH} \mathrm{7,0)}$. Quando o produto substituído é oxidado a $\left[\mathrm{Ru}^{\mathrm{III}}\left(\mathrm{NH}_{3}\right)_{5}(\mathrm{bimH})\right]^{3+}$, ele assume coloração vermelha. Entretanto, em meio levemente ácido (pH 5,5), a solução apresenta mudança de cor para amarelo/alaranjado, e seu espectro eletrônico apresenta uma banda de absorção (LMCT) em $445 \mathrm{~nm}\left(\varepsilon=1050 \mathrm{~mol}^{-1} \mathrm{dm}^{3}\right.$ $\mathrm{cm}^{-1}$ ), envolvendo uma transição (bimH) $p_{\pi} \rightarrow d_{\pi}\left(\mathrm{Ru}^{\mathrm{III}}\right) . \mathrm{O}$ espectro da espécie reduzida mostra uma banda MLCT em $360 \mathrm{~nm}\left(\varepsilon=1300 \mathrm{~mol}^{-1} \mathrm{dm}^{3} \mathrm{~cm}^{-1}\right)$, atribuída à transição eletrônica ( $\left(\mathrm{Ru}^{\mathrm{II}}\right) d_{\pi} \rightarrow p_{\pi}^{*}$ (bimH).

Em $\mathrm{pH}$ mais elevados, a coloração da solução muda de laranja/vermelho claro (em meio neutro) para vermelho escuro/violeta (em pH superior a 8). Essa mudança ocorre devido à desprotonação do ligante coordenado, cujo equilibrio ácido-base pode ser representado na Eq. 61:

$$
\left[\mathrm{Ru}\left(\mathrm{NH}_{3}\right)_{5}(\mathrm{bimH})\right]^{3+} \stackrel{K_{\mathrm{a}}}{\rightleftharpoons}\left[\mathrm{Ru}\left(\mathrm{NH}_{3}\right)_{5}(\mathrm{bim})\right]^{2+}+\mathrm{H}^{+}
$$

$\mathrm{O} \mathrm{p} K_{\mathrm{a}}$ do processo foi obtido por meio de titulação espectrofotométrica (v. apêndice 6.2), resultando um valor de 7,7 , que corresponde a uma constante de equilíbrio de $5,4 \times 10^{-8} \mathrm{~mol} \mathrm{dm}^{-3}$. Novamente, é importante notar que o $\mathrm{p} K_{\mathrm{a}}$ do ligante livre é $12,78\left(25^{\circ} \mathrm{C} ; I=0.0\right){ }^{293}$ Assim, essa diferença de $\mathrm{p} K_{\mathrm{a}}$ entre $o$ complexo e o ligante nãocoordenado (superior a $10^{5}$ vezes), indica a estabilização do ligante desprotonado ligado ao metal, que é devido à interação entre um doador- $\pi$ forte (bim ${ }^{-}>$bimH) e um ácido de Lewis ( $\mathrm{Ru}^{\mathrm{III}}$-aceitador- $\pi$ ).

O potencial redox do complexo, cujos voltamogramas cíclicos apresentam um único par de ondas reversíveis, também se mostrou sensível ao $\mathrm{pH}$. $\mathrm{O}$ valor de $E_{1 / 2}$ varia, por exemplo, de $0,125 \mathrm{~V}$ em pH 5,5 (benzoimidazolcomplexo) a $\sim-0,12 \mathrm{~V}$ em pH 12,0 (benzoimidazolatocomplexo). Esse aspecto particular desses sistemas será explorado com muito mais ênfase no item 3.1.1.4.

Partindo dos processos redox envolvidos nas medidas eletroquímicas de ambas as espécies, desprotonada e protonada, foi possivel calcular a constante de equilíbrio ácido-base para a espécie reduzida $\left(K_{\mathrm{a}}^{\mathrm{II}}=2,5 \times 10^{-12} \mathrm{~mol}\right.$ $\left.\mathrm{dm}^{-3} ; \mathrm{p} K_{\mathrm{a}}=11,6\right)$ através do ciclo termodinâmico associado (seção 6.3).
Medidas espectroeletroquímicas do complexo desprotonado (em $\mathrm{pH} 12$; baseado nos potenciais obtidos através de voltametria cíclica) mostraram que, enquanto a espécie oxidada $\left[\mathrm{Ru}\left(\mathrm{NH}_{3}\right)_{5}(\mathrm{bim})\right]^{2+}$ apresenta uma banda típica LMCT em $500 \mathrm{~nm}\left(\varepsilon=1170 \mathrm{~mol}^{-1} \mathrm{dm}^{-3} \mathrm{~cm}^{-1}\right)$, atribuída à transição $\left(\mathrm{bim}^{-}\right) p_{\pi} \rightarrow d_{\pi}\left(\mathrm{Ru}^{\mathrm{III}}\right)$, no estado reduzido, a banda MLCT se dá ao redor de $350 \mathrm{~nm}\left(\varepsilon \sim 1000 \mathrm{~mol}^{-1} \mathrm{dm}^{-3} \mathrm{~cm}^{-1}\right)$ e caracteriza uma transição do tipo ( $\left(\mathrm{Ru}^{\mathrm{II}}\right) d_{\pi} \rightarrow p_{\pi}{ }^{*}(\mathrm{bim})$.

Dos resultados acima, as informações para o complexo pentaamin(L)rutênio(II/III) $\left(\mathrm{L}=\right.$ bimH, bim $\left.{ }^{-}\right)$podem ser sumarizadas como segue: quando o bimH-complexo sofre desprotonação, seu potencial redox diminui em $250 \mathrm{mV}$ e sua banda LMCT se desloca batocromicamente mais de 50 $\mathrm{nm}$; por outro lado, tanto a energia como a intensidade da banda MLCT praticamente não se alteram com o processo; a constante de dissociação ácida do complexo oxidado é aproximadamente $10^{4}$ vezes maior que aquela associada ao seu análogo reduzido.

\subsubsection{3. $\left[\mathrm{Fe}(\mathrm{CN})_{5}(\mathrm{bimH})\right]^{3-, 2-}$ e $\left[\mathrm{Fe}(\mathrm{CN})_{5}(\mathrm{bim})\right]^{4,3-}$}

As propriedades eletrônicas e eletroquímicas do complexo $\left[\mathrm{Fe}^{\mathrm{III}, \mathrm{II}}(\mathrm{CN})_{5}(\mathrm{btaH})\right]^{\mathrm{n}-}$ já foram reportadas previamente, ${ }^{241} \mathrm{e}$ serão comparadas com as do benzoimidazol-derivado mais adiante, no item 3.1.1.4.

A reação de substituição de aquapentacianoferrato(II) com benzoimidazol em solução aquosa, em $\mathrm{pH}$ ao redor de 6 , resulta um composto amarelo, que se torna vermelho em meios neutro ou levemente básico e, em pH superior a 9 , azul-esverdeado. Tal mudança ocorre devido ao equilíbrio ácido-base envolvendo o ligante bimH coordenado, para o qual o $\mathrm{p} K_{\mathrm{a}}$ foi obtido por titulação espectrofotométrica (apêndice 6.2) em 12,3, correspondendo a uma constante de equilíbrio $K_{\mathrm{a}}^{\mathrm{III}}=5,0 \times 10^{-13} \mathrm{~mol} \mathrm{dm}^{-3}$.

Os voltamogramas cíclicos de ambos os complexos $\left[\mathrm{Fe}^{\mathrm{II}}(\mathrm{CN})_{5}(\mathrm{bimH})\right]^{3-}, \mathrm{em} \mathrm{pH} \mathrm{6,5,} \mathrm{e}\left[\mathrm{Fe}^{\mathrm{II}}(\mathrm{CN})_{5}(\mathrm{bim})\right]^{4-}$, em $\mathrm{pH} 12,0$, apresentam um par simples de ondas reversíveis com $E_{1 / 2}$ em $0,305 \mathrm{~V}$ e $\sim 0,16 \mathrm{~V}$, respectivamente. A partir desses valores e de $\mathrm{p} K_{\mathrm{a}}^{\mathrm{II}}$, o valor de $K_{\mathrm{a}}^{\mathrm{III}}$ foi estimado pelo correspondente ciclo termodinâmico, e equivale a $1,3 \times 10^{-10}$ $\mathrm{mol} \mathrm{dm}{ }^{-3}, \operatorname{com~} K_{\mathrm{a}}^{\mathrm{III}}=9,9$.

Uma comparação entre os potenciais do complexo com benzoimidazol com aqueles para os derivados de piridina $\mathrm{e}$ pirazina, ${ }^{223,224,316} \mathrm{faz}$ evidente o caráter eletrônico doador do ligante imidazólico. 
Por meio de medidas espectroeletroquímicas em $\mathrm{pH}$ 6,5, foi mostrado que a espécie reduzida, $\mathrm{Fe}^{\mathrm{II}}$, possui uma banda MLCT em $322 \mathrm{~nm}\left(\varepsilon=1650 \mathrm{~mol}^{-1} \mathrm{dm}^{3} \mathrm{~cm}^{-1}\right)$, atribuída à transição ( $\left.\mathrm{Fe}^{\mathrm{II}}\right) d_{\pi} \rightarrow p_{\pi}{ }^{*}($ bimH). A espécie oxidada recíproca exibe uma banda LMCT típica em $505 \mathrm{~nm}\left(\varepsilon=1800 \mathrm{~mol}^{-1}\right.$ $\left.\mathrm{dm}^{3} \mathrm{~cm}^{-1}\right)$, que foi atribuída à transição $(\operatorname{bimH}) p_{\pi} \rightarrow d_{\pi}\left(\mathrm{Fe}^{\mathrm{III}}\right)$.

A espectroeletroquímica do complexo desprotonado foi realizada em $\mathrm{pH} 11,0$. O espectro da espécie reduzida apresenta uma banda típica MLCT em $320 \mathrm{~nm}(\varepsilon=1500$ $\mathrm{mol}^{-1} \mathrm{dm}^{3} \mathrm{~cm}^{-1}$ ), devido ao processo $\left(\mathrm{Fe}^{\mathrm{II}}\right) d_{\pi} \rightarrow p_{\pi}{ }^{*}\left(\mathrm{bim}^{-}\right)$; enquanto no estado oxidado ela apresenta uma banda LMCT em $610 \mathrm{~nm}\left(\varepsilon=1900 \mathrm{~mol}^{-1} \mathrm{dm}^{3} \mathrm{~cm}^{-1}\right)$, relacionada à transição eletrônica ( $\left.\mathrm{bim}^{-}\right) p_{\pi^{-} \rightarrow d_{\pi}}\left(\mathrm{Fe}^{\mathrm{II}}\right)$.

\subsection{Comparação dos espectros eletrônicos}

Tabela 2. Comparação dos espectros de absorção UV-Vis para a série de complexos mononucleares em solução aquosa.

\begin{tabular}{|c|c|c|}
\hline Complexo. & $\begin{array}{c}\text { LMCT } \\
\mathrm{nm}\left(\mathrm{mol}^{-1} \mathrm{dm}^{3} \mathrm{~cm}^{-1}\right)\end{array}$ & $\begin{array}{c}\text { MLCT } \\
\mathrm{nm}\left(\mathrm{mol}^{-1} \mathrm{dm}^{3} \mathrm{~cm}^{-1}\right)\end{array}$ \\
\hline$[R u(\text { edta })(b t a H)]^{-}$ & $350(\mathrm{sh})^{a}$ & $400(6500)$ \\
\hline$\left[\operatorname{Ru}(\text { edta)}(\mathbf{b t a})]^{\mathbf{m}}\right.$ & $510(1540)$ & $395(6000)$ \\
\hline$\left[\operatorname{Ru}(\text { edta)}(\mathrm{bimH})]^{\mathrm{m}}\right.$ & $360(1280)$ & $330(3280)$ \\
\hline$[\operatorname{Ru}(\operatorname{edta})(\operatorname{bim})]^{\mathrm{n}-}$ & $520(350)$ & $325(3060)$ \\
\hline$\left[\mathbf{R u}\left(\mathrm{NH}_{3}\right)_{5}(\mathrm{btaH})\right]^{\mathbf{n}+}$ & $327_{2}^{b} 448^{c}(660 ; 360)$ & $410(11310)$ \\
\hline$\left[\mathbf{R u}\left(\mathbf{N H}_{3}\right)_{s}(\mathrm{bta})\right]^{\mathrm{nt}}$ & $325 ;^{b} 467^{c}(3650 ; 2060)$ & $389(7760)$ \\
\hline$\left[\mathbf{R u}\left(\mathrm{NH}_{3}\right)_{5}(\mathrm{bimH})\right]^{\mathrm{ut}}$ & $445(1050)$ & $360(1300)$ \\
\hline$\left[\mathbf{R u}\left(\mathbf{N H}_{3}\right)_{5}(\mathrm{bim})\right]^{\mathbf{n}^{+}}$ & $500(1170)$ & $350(1000 ; \mathrm{sh})$ \\
\hline$\left[\mathrm{Fe}(\mathrm{CN})_{5}(\mathrm{btaH})\right]^{\mathrm{n}-}$ & $\begin{array}{c}365(1170)^{d} \\
396^{b} 487^{c}(875 ; 1020)\end{array}$ & $388(4440)$ \\
\hline$\left[\mathrm{Fe}(\mathrm{CN})_{\mathbf{s}}(\mathrm{bta})\right]^{\mathbb{R}}$ & $\begin{array}{c}365(990)^{d} \\
392^{b} 582^{c}(840 ; 2180)\end{array}$ & $350(2100)$ \\
\hline$\left[\mathrm{Fe}(\mathrm{CN})_{5}(\mathrm{bimH})\right]^{\mathbb{N}-}$ & $505(1800)$ & $322(1650)$ \\
\hline$\left[\mathrm{Fe}(\mathrm{CN})_{\mathbf{S}}(\mathrm{bim})\right]^{\mathrm{n}-}$ & $610(1900)$ & $320(1500)$ \\
\hline
\end{tabular}

O conjunto de resultados obtidos para todos os complexos mononucleares estudados em solução aquosa foi coletado na Tab. 2 para fins comparativos.

A partir das energias envolvidas nas transições de transferência de carga (metal $\rightarrow$ ligante e ligante $\rightarrow$ metal) entre os níveis redox do metal (HOMO/SOMO $-d \pi$ ) e de fronteira $\left(\pi\right.$ e $\left.\pi^{*}\right)$ do ligante, pode-se inferir os caráteres eletrônicos doador típico e aceitador- $\pi$ fraco dos ligantes benzoimidazol e benzotriazol e doador- $\sigma, \pi$ dos ligantes benzoimidazolato (caráter mais intenso) e benzotriazolato, diferentemente dos derivados de piridina e pirazina, onde o forte caráter aceitador- $\pi$ é bastante marcante.

Essas características dos complexos/ligantes podem ser mais facilmente deduzidas a partir do diagrama de energia do Esq. 7, que exibe tanto as energias absolutas aproximadas dos níveis redox mais externos do metal $\left(E_{\text {HOMO }-~} \pi^{3}\right)$ como as energias relativas experimentais dos níveis eletrônicos $\pi$ e $\pi^{*}$ do ligante (calculadas a partir das $E_{\mathrm{CT}}$ )., ${ }^{\mathrm{a} b} \mathrm{Nele}$, pode-se perceber que (i) o potencial de ionização varia de acordo com o esperado para a série espectroquímica, considerando a natureza do metal (p. ex. $3 d$ [ferro] ou $4 d$ [rutênio]) e aceitadora/doadora dos coligantes. Assim, $E_{\mathrm{d} n}$ para os níveis centrados no metal segue a ordem: $\{\mathrm{Ru}($ edta $)\}>\left\{\mathrm{Ru}\left(\mathrm{NH}_{3}\right)_{5}\right\}$ $>\left\{\mathrm{Fe}(\mathrm{CN})_{5}\right\}$; (ii) a segunda e talvez mais importante informação obtida desta análise refere-se aos gradientes $\Delta_{1} \mathrm{e}$ $\Delta_{2}$ (associados às diferenças de energia eletrônica $\pi_{\mathrm{L}}^{-} \leftrightarrow d \pi_{\mathrm{M}}$ e $d \pi_{\mathrm{M}} \leftrightarrow \pi_{\mathrm{L}^{*}}^{*}$, respectivamente): enquanto o primeiro é maior para a espécie benzotriazolato $\left(\Delta_{1}\left(\right.\right.$ bta $\left.^{-}\right)>\Delta_{1}\left(\right.$ bim $\left.\left.^{-}\right)\right)$ em toda a série, o segundo aparece sempre maior para o derivado benzoimidazolato $\left(\Delta_{2}\left(\mathrm{bim}^{-}\right)>\Delta_{2}\left(\mathrm{bta}^{-}\right)\right)$. Além disso, $\Delta_{2}>\Delta_{1}$ em todos os casos (independentemente do ligante).

Somados ao fato de o ligante benzotriazolato promover uma maior estabilização dos níveis $\pi$ do ín metálico para toda a série, o conjunto de observações acima indica mais uma vez que: (a) na forma desprotonada, ambos os ligantes agem como bons doadores- $\sigma / \pi$; (b) o caráter doador é mais pronunciado no benzoimidazolato; (c) na série investigada, o grau de covalência metal-ligante parece seguir a ordem: $\left\{(\mathrm{CN})_{5} \mathrm{Fe}-\mathrm{L}\right\}>\{($ edta $) \mathrm{Ru}-\mathrm{L}\}>\left\{\left(\mathrm{NH}_{3}\right)_{5} \mathrm{Ru}-\mathrm{L}\right\}$.

Essas características são muito importantes como ponto de partida no design de sistemas supramoleculares e no controle de interações eletrônicas intermetálicas através de moléculas $\mathrm{N}$-heterocíclicas baseadas em ligantes de ponte mistos, conforme se observará nas seções posteriores.

\footnotetext{
a Os diagramas foram construídos apenas para os ligantes monoaniônicos desprotonados por pura conveniência, já que eles serão empregados como ligantes de ponte no estudo dos complexos binucleares. Contudo, baseados nos resultados da Tab. 2, pode-se afirmar que as conclusões obtidas nesse caso podem ser estendidas sem restriçôes às espécies contendo os ligantes neutros.

b Nos diagramas do Esq. 7, os valores de energia dos orbitais redox do metal (escala da esquerda) referem-se aos potenciais de ionização determinados experimentalmente; os valores de energia relativa dos niveis $\pi$ e $\pi^{*}$ dos ligantes básicos (escala da direita) foram estimados indiretamente através das energias das transições de CT, onde $E_{\pi}$ e $E_{\pi^{*}}$ foram aproximados por $I_{M}-E_{L M C T} \in \Pi_{M}+E_{M L C T}$, respectivamente.
} 


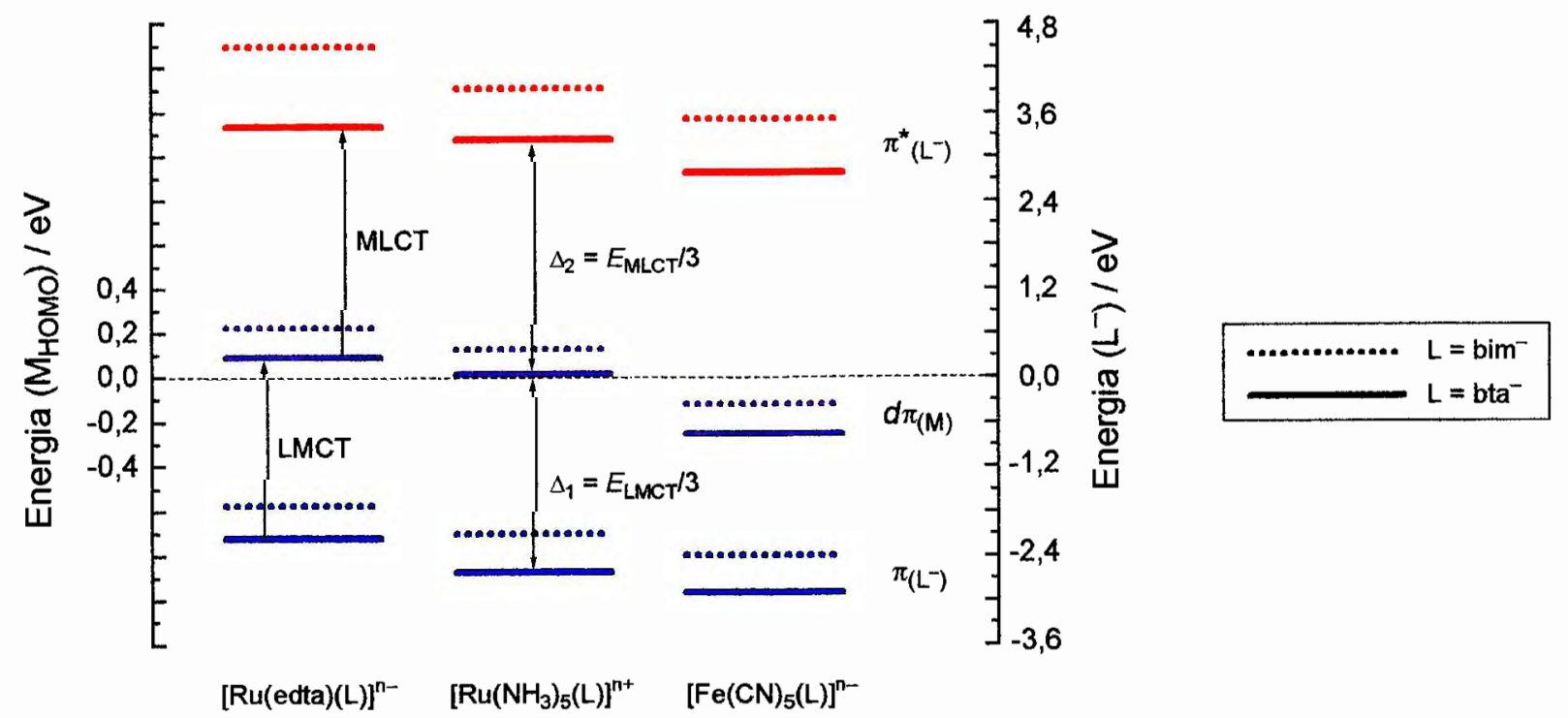

Esquema 7. Diagramas de energia para os niveis redox dos complexos mononucleares desprotonados.

\subsubsection{Reaçס̃es PCET}

Como a reatividade, a caracterização e as propriedades espectrais e eletroquímicas dos complexos mononucleares do tipo $\mathrm{M}^{x}$ - $\mathrm{LH}$ (onde $\mathrm{M}=\mathrm{Ru}\left(\right.$ edta), $\mathrm{Ru}\left(\mathrm{NH}_{3}\right)_{5}$ ou $\mathrm{Fe}(\mathrm{CN})_{5}$; $\mathrm{LH}=$ btaH ou bimH; e $\boldsymbol{x}=\mathrm{II}$ ou III) já foram discutidas nos itens anteriores, somente as suas propriedades relacionadas às reações do tipo PCET (v. seção 1.4) serão abordadas neste tópico.

Antes de se avançar na discussão dos resultados, alguns comentários prévios importantes acerca do comportamento eletroquímico de todos os sistemas se faz necessário:

(i) os voltamogramas dos derivados de benzoimidazol apresentam, conforme esperado, um único par de ondas, que são reversíveis em toda a faixa de $\mathrm{pH}$ investigada (3-13);

(ii) os voltamogramas das espécies com benzotriazol, por sua vez, apresentam uma onda anódica adicional de menor intensidade e positivamente deslocada de cerca de $100 \mathrm{mV}$. Conforme tem sido discutido em 3.1.1.2, esse processo é atribuído à isomerização parcial dos complexos formulados como [M-N3-btaH] (espécies kN3) para aqueles formulados como [M-N2-btaH] (isômeros $\mathrm{kN} 2$ ) (Esq. 6);

(iii) desde que esse processo químico (isomeria) segue uma etapa eletroquímica (redução) e a espécie [M-N2-btaH] praticamente não existe na forma oxidada (Tab. 1), então, nesta parte do trabalho, somente os potenciais redox associados às ondas reversíveis (referentes aos pares $\mathrm{M}^{\mathrm{II} / \mathrm{II}}$ - $\mathrm{KN} 3\{\mathrm{btaH}\}$ ) serão considerados para os propósitos envolvendo as reações redox dependentes de próton. Isso possibilita também a comparação dos resultados com o análogo benzoimidazol, onde não existe um modo de coordenação equivalente àquele em $\mathrm{M}-\mathrm{kN} 2\{\mathrm{btaH}\}$;

(iv) em todos os exemplos estudados, as reações de eletrodo resultantes dos pares redox $\mathrm{M}^{\mathrm{III}} / \mathrm{M}^{\mathrm{II}}$ envolvem 1 elétron e são essencialmente eletroquimicamente reversíveis. A reversibilidade pode ser observada através da diferença entre os potenciais dos picos anódico e catódico obtidos através dos experimentos de voltametria cíclica $\left(\Delta E_{\mathrm{p}}=\right.$ 60-70 mV). ${ }^{5,6,306}$ Além disso, os valores de corrente dos pares de redução apresentam uma dependência raizquadrática em função das velocidades de varredura correspondentes, o que caracteriza um comportamento típico de um processo controlado por difusão. ${ }^{5,6,306}$ Nesse tipo de reação, o número de elétrons envolvidos no processo $(n)$ pode ser estimado a partir da separação teórica entre os picos, que é de $59 \mathrm{mV} / n^{188}$ 


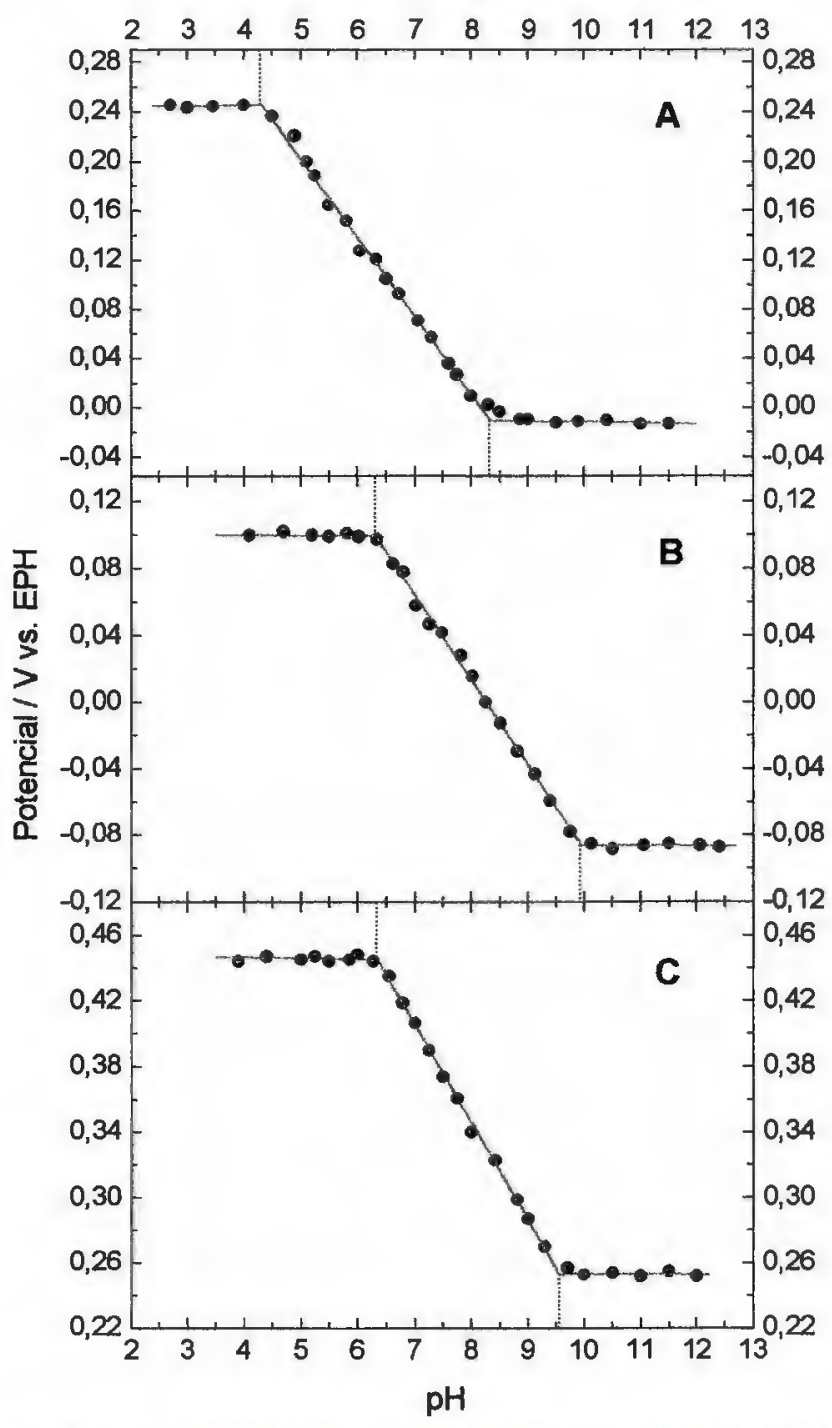

Figura 9. Diagramas de pH-potencial para: $(\mathbf{A})\left[\mathrm{Ru}\left(\mathrm{NH}_{3}\right)_{5}(\mathrm{btaH})\right]^{2+}$, (B) $[\mathrm{Ru}(\mathrm{edta})(\mathrm{btaH})], \mathrm{e}(\mathrm{C})\left[\mathrm{Fe}(\mathrm{CN})_{5}(\mathrm{btaH})\right]^{3-}$.

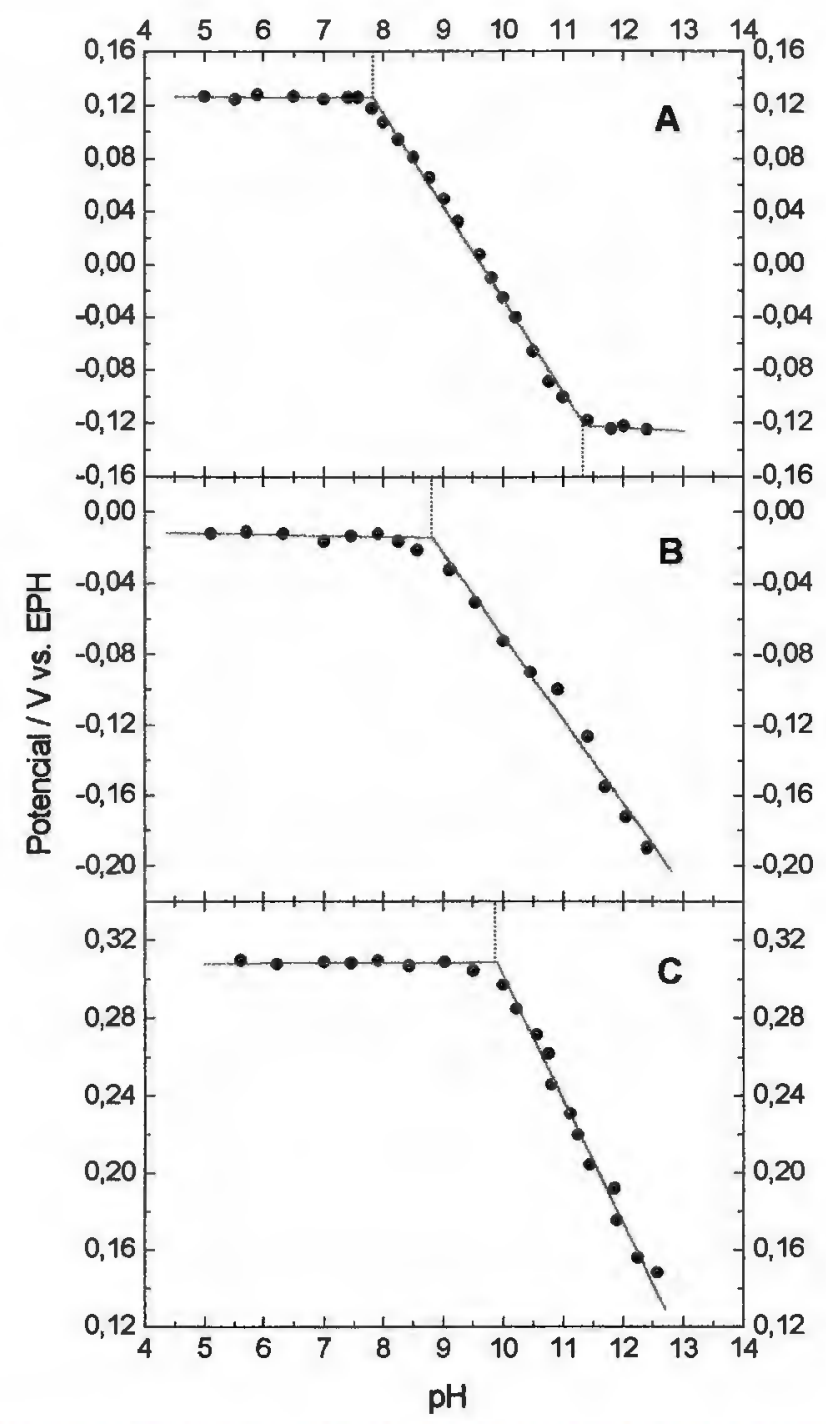

Figura 10. Diagramas de pH-potencial para: $(\mathbf{A})\left[\mathrm{Ru}\left(\mathrm{NH}_{3}\right)_{5}(\mathrm{bimH})\right]^{2+}$, (B) $[\mathrm{Ru}(\mathrm{edta})(\mathrm{bimH})]^{-}, \mathrm{e}(\mathrm{C})\left[\mathrm{Fe}(\mathrm{CN})_{5}(\text { bimH })\right]^{3-}$.

Tabela 3. Parâmetros PCET para a série de complexos mononucleares de rutênio e ferro estudada.

\begin{tabular}{|c|c|c|c|c|c|c|c|c|}
\hline Complexo & $\mathbf{p} \boldsymbol{K}_{\text {III }}^{\text {III }}$ & $\rho K_{\mathbf{a}}^{\text {II }}$ & $\Delta \mathrm{pK}$ & $\begin{array}{l}E_{1 / 2}{ }^{P} \\
(V)^{b}\end{array}$ & $\begin{array}{l}E_{12}^{D} \\
(V)^{b}\end{array}$ & $\begin{array}{l}\Delta E_{1 / 2}{ }^{e} \\
(\mathrm{mV})\end{array}$ & $\begin{array}{c}E^{\circ} \\
\text { (V) }\end{array}$ & $(\mathrm{m} V / p H)$ \\
\hline$\left[\mathbf{R u}(\text { edta) }(\mathbf{b t a} \mathbf{H})]^{\mathrm{n}}\right.$ & 6,31 & 9,94 & 3,63 & 0,100 & $-0,086$ & 186 & 0,422 & $-54,7$ \\
\hline$[\mathbf{R u}(\text { edta })(\text { bimH) })]^{\mathrm{t}-}$ & 8,82 & $>12^{e}$ & $>3,8$ & $-0,011$ & $<-0,20$ & $>180$ & 0,403 & $-52,5$ \\
\hline$\left[\mathbf{R u}\left(\mathbf{N H}_{3}\right)_{5}(\mathbf{b t a H})\right]^{\mathrm{nt}}$ & 4,32 & 8,33 & 4,01 & 0,245 & $-0,012$ & 257 & 0,522 & $-63,9$ \\
\hline$\left[\mathrm{Ru}\left(\mathrm{NH}_{3}\right)_{5}(\mathrm{bimH})\right]^{\mathrm{nt}}$ & 7,82 & 11,36 & 3,54 & 0,127 & $-0,125$ & 252 & 0,674 & $-69,0$ \\
\hline $\left.\left.\mathrm{Fu}_{(\mathrm{CN}}\right)_{5}(\mathrm{btaA})\right]^{\mathrm{n}-}$ & 6,34 & 9,55 & 3,21 & 0,447 & 0,253 & 194 & 0,823 & $-59,7$ \\
\hline$\left[\mathrm{Fe}(\mathrm{CN})_{5}(\mathrm{bimH})\right]^{\mathrm{n}-}$ & 9,88 & $>12^{f}$ & $>2,6$ & 0,308 & $<0,14$ & $>170$ & 0,939 & $-63,8$ \\
\hline
\end{tabular}

${ }^{a} \mathrm{p} K_{\mathrm{a}}^{\text {II }}-\mathrm{p} K_{\mathrm{a}}^{\text {III }},{ }^{b} \mathrm{~V}$ vs. EPH; ${ }^{c} E_{1 / 2}{ }^{\mathrm{p}}-E_{1 / 2}{ }^{\mathrm{D}} ;{ }^{d}$ Potencial redox próton-acoplado em $\mathrm{pH} 0 ;$

- Obtido espectrofotometricamente em 11,9; $f$ Obtido espectrofotometricamente em 12,3. 


\subsection{Comparação geral}

Todos os complexos do tipo $\left[\mathrm{M}^{\mathrm{II} / \mathrm{I}}-\mathrm{LH}\right]^{n}$ (e suas bases associadas $\left.\left[\mathrm{M}^{\mathrm{II} / \mathrm{I}}-\mathrm{L}^{-}\right]^{n}\right)$ aqui descritos, foram caracterizados espectroscopicamente em solução aquosa, conforme dados apresentados em 3.1.1.3 e resumidos na Tab. 2 .

A partir das Tabs. 2 e 3, pode-se inferir que os derivados triazolato e imidazolato comportam-se essencialmente como doadores- $\sigma / \pi$, levando a uma estabilização preferencial dos complexos $\mathrm{M}^{\mathrm{III}}-\mathrm{LH}^{+}$ou $\mathrm{M}^{\mathrm{III}}-\mathrm{L}$ (ao contrário dos derivados de piridina e pirazina, onde normalmente prevalece o caráter aceitador- $\pi$ ). ${ }^{262}$ Isso justifica o fato de os potenciais de redução desses complexos serem relativamente menores (mais negativos) que outros complexos similares envolvendo ligantes N-heterocíclicos.

Em alguns dos complexos envolvendo o benzoimidazol (particularmente no caso do $\mathrm{Ru}\left(\right.$ edta) e $\mathrm{Fe}(\mathrm{CN})_{5}$ ), seus $\mathrm{p} K_{\mathrm{a}}$ para as espécies reduzidas (denominados aqui como $\mathrm{p} K_{\mathrm{a}}^{\mathrm{Il}}$ ) são tão elevados que eles não podem ser determinados eletroquimicamente, ${ }^{b}$ uma vez que acima de $\mathrm{pH} 12$ a resposta da voltametria cíclica é muito prejudicada e a estabilidade dos complexos é afetada. Apesar de os $\mathrm{p} K_{\mathrm{a}}{ }^{\mathrm{II}}$ desses exemplos não terem sido determinados precisamente, seus limites superiores ( $\mathrm{pH}$ máximo; acima dos quais os potenciais não puderam ser medidos com sucesso) são indicados na Tab. 3.

A análise dos resultados espectroscópicos relacionados com as transições LMCT e MLCT desses complexos (Tab. 2) sugere que o benzoimidazol e sua base conjugada, benzoimidazolato, são ambos doadores eletrônicos mais fortes que seus análogos benzotriazol e benzotriazolato. Assim, o primeiro derivado possui um caráter mais básico que o último, que pode ser claramente observado através da série de parâmetros ácido/base e eletroquímico envolvidos em suas reações de ET próton-acopladas (Tab. 3).

Uma vez que a acidez do ligante aumenta quando este se encontra coordenado a um metal contendo orbitais $d \pi$ parcialmente vazios (como no caso dos íons $d \pi^{5}$ ), a capacidade doadora- $\pi$ dos ligantes pode ser avaliada pela análise da diminuição dos valores do $\mathrm{p} K_{\mathrm{a}}$ quando ele se coordena a complexos oxidados do tipo $\mathrm{M}^{\mathrm{Ill}} \mathrm{X}_{5}-\mathrm{LH}$ ou $\mathrm{M}^{\mathrm{III}} \mathrm{X}_{5}-\mathrm{L}^{-}$(esta variação é chamada de efeito $\pi$ ). Nesse sentido, enquanto $\circ \Delta \mathrm{p} K_{\mathrm{a}}{ }^{\text {"c }}$ do ligante benzoimidazol não-

\footnotetext{
a Embora o ligante benzotriazol neutro, em particular, possa apresentar comportamento intermediário doador/aceitador- $\pi$, como se depreenderá do conjunto de resultados apresentados nesta tese.

b $\mathrm{Na}$ verdade, estes valores foram determinados por meio de titulação espectrofotométrica, cujos valores obtidos são coerentes com a observação eletroquímica.

c $\Delta \mathrm{p} K_{\mathrm{a}}^{\prime}=\mathrm{p}_{\mathrm{a}}(\mathrm{LH})-\mathrm{p} K_{\mathrm{a}}(\mathrm{M}-\mathrm{LH})$.
}

coordenado (cujo $\mathrm{p} K_{\mathfrak{a}}$ é $\left.12,78 \pm 0,04\right)^{293}$ para os complexos $\left[\mathrm{Ru}^{\mathrm{III}}\left(\mathrm{NH}_{3}\right)_{5}(\mathrm{LH})\right]^{3+},\left[\mathrm{Ru}^{\mathrm{III}}(\mathrm{edta})(\mathrm{LH})\right]^{-}$e $\left[\mathrm{Fe}^{\mathrm{III}}(\mathrm{CN})_{5}(\mathrm{LH})\right]^{2-}$ é 4,$96 ; 3,96 ; 2,90$, respectivamente, a variação na série análoga para o benzotriazol (cujo $\mathrm{p} K_{\mathrm{a}}$ na forma livre é $8,38 \pm 0,03)^{292}$ é bem menor: $\Delta \mathrm{p} K_{\mathrm{a}}{ }^{\prime}=4,06 ; 2,07 ; 2,04$.

A maior estabilização relativa das espécies envolvendo benzoimidazol coordenado em relação àquelas contendo benzotriazol reflete o maior caráter doador- $\pi$ deste ligante; isto é, a coordenação promove um maior aumento na sua acidez que na acidez do benzotriazol, apesar de o último ser um ácido melhor quando analisado em termos de valor absoluto de $\mathrm{p} K_{\mathrm{a}}$, tanto dos ligantes livres quanto em seus correspondentes complexos.

A variação de $\Delta E_{1 / 2}\left(E_{1 / 2}{ }^{\mathrm{P}}-E_{1 / 2}{ }^{\mathrm{D}}\right)$ segue a mesma tendência de $\Delta \mathrm{p} K_{\mathrm{a}}$, indicando que a acidez do ligante coordenado aumenta com a polarizabilidade e com a eletronegatividade do metal, com ambos os fatores levando a um aumento na covalência da ligação $\mathrm{M}-\mathrm{L}$.

A fim de entender a importância dos fatores envolvidos nas unidades $\mathrm{MX}_{5}$, nesta comparação, deve-se destacar a natureza química de seus coligantes. Dessa forma, pode-se correlacionar os maiores gradientes $\left(\Delta \mathrm{p} K_{\mathrm{a}}\right.$ e $\left.\Delta E_{1 / 2}\right)$ apresentados pelos derivados de $\left\{\mathrm{Ru}\left(\mathrm{NH}_{3}\right)_{5}\right\}$ com a menor capacidade doadora- $\sigma$ do $\mathrm{NH}_{3}$ quando comparada com a dos outros coligantes (edta ou $\mathrm{CN}^{-}$).

A Tab. 3 também mostra a maior estabilização do íon metálico oxidado quando se encontra coordenado ao ligante desprotonado, o qual é mais básico (doador). De fato, em todos os casos $E_{1 / 2}{ }^{\mathrm{D}}$ encontra-se deslocado em $\sim 200 \mathrm{mV}$ para potenciais menores que $E_{1 / 2}{ }^{\mathbf{P}}$. Além disso, as espécies reduzidas, $\mathrm{M}^{\mathrm{II}}-\mathrm{LH}$, têm valores de $\mathrm{p} K_{\mathrm{a}}$ cerca de 3,5 unidades de $\mathrm{pH}$ maiores que as oxidadas, $\mathrm{M}^{\mathrm{III}}-\mathrm{LH}^{+}$. Isso poderia ser esperado devido ao íon $\mathrm{M}^{\mathrm{II}}-d \pi^{6}$ ser capaz de promover uma grande estabilização do complexo através de retrodoação- $\pi$ em direção do ligante protonado (mais ácido/aceitador- $\pi$ ). Por outro lado, o íon oxidado, $\mathrm{M}^{\mathrm{III}}-d \pi^{5}$ (ácido de Lewis), será estabilizado melhor através de interações doadoras $\sigma, \pi$ do ligante desprotonado aniônico. Essas correlações também se refletem nas energias das transições LMCT e MLCT (Tab. 2).

Finalmente, uma prova muito importante de que esses pares redox envolvendo 1 elétron são dependentes de apenas 1 próton, isto é, $\mathrm{M}^{\mathrm{III}}-\mathrm{L}+\mathrm{e}^{-} \rightarrow \mathrm{M}^{\mathrm{II}}-\mathrm{LH}$, provém do valor da inclinação de seus diagramas $\mathrm{pH}$-potencial (v. item 1.4.1). Nesse caso, todos eles estão bem próximos do valor esperado de $-59 \mathrm{mV} / \mathrm{pH}$ (Tab. 3), sendo consistente com a equação de Nernst simplificada (Eq. 42) para um processo eletroquímico envolvendo 1 elétron e 1 próton. 


\subsection{Comentários finais}

Os complexos aqui estudados constituem modelos simples e eficientes no estudo e exploração de reações redox prótonacopladas. Apesar de que qualquer reação redox com troca rápida de próton pode, em princípio, ocasionar um processo redox dependente do $\mathrm{pH}$, os sistemas aqui descritos satisfazem um número de fatores adicionais e critérios relacionados a este fenômeno. ${ }^{184}$ Suas características mais relevantes são:

(i) os pares redox envolvendo 1 elétron e 1 próton são observados dentro da faixa de trabalho do solvente, enquanto muitos exemplos da literatura envolvem complexos que apresentam múltiplos processos eletrônicos ou que envolvem etapas sucessivas de protonação/desprotonação, gerando espécies que não podem ser estudadas dentro das condições de trabalho (faixas de potencial e $\mathrm{pH}$ );

(ii) faixas amplas de $\mathrm{pH}$ e potencial onde ocorre a PCET; nos casos estudados, $\Delta \mathrm{p} K_{\mathrm{a}}\left(\mathrm{p} K_{\mathrm{a}}^{\mathrm{II}}-\mathrm{p} K_{\mathrm{a}}^{\mathrm{III}}\right)$ é tipicamente maior que 3 unidades de $\mathrm{pH}$ (alcançando o valor de 4 unidades de $\mathrm{pH}$ em alguns casos), e $\Delta E_{1 / 2}\left(E_{1 / 2}{ }^{\mathrm{P}}-E_{1 / 2}{ }^{\mathrm{D}}\right)$ fica ao redor de $200 \mathrm{mV}$ ou mais; tais parâmetros não só definem completamente a região de comportamento dependente do $\mathrm{pH}$ como também descrevem o ciclo termodinâmico relacionado;

(iii) estável e inerte à substituição em ambos os estados de oxidação, tornando o par quimicamente reversível; além disso, a esfera de coordenação em todos os exemplos é saturada, evitando dependências de $\mathrm{pH}$ secundárias devido à entrada de ligantes aqua; (iv) cinética rápida de transferência eletrônica heterogênea entre a superficie do eletrodo e a interface do reagente químico, tornando o par eletroquimicamente reversível, conforme indicado pela pequena separação entre os picos anódico e catódico $\left(\Delta E_{\mathrm{p}} \sim 60 \mathrm{mV}\right.$ em todos os exemplos) e iguais relações de correntes de pico nos voltamogramas cíclicos;

(v) altamente solúveis em água em toda a faixa de $\mathrm{pH}$, em ambos os estados de oxidação; enquanto a maioria dos exemplos da literatura envolve sistemas que são pouco solúveis ou insolúveis em água, tornando necessário o uso de mistura de solventes do tipo água $x$ : $y$ orgânico (onde geralmente $x<<$ ).

Assim, o melhor modelo nessa série de sistemas seria o representado pelo complexo $\left[\mathrm{Ru}\left(\mathrm{NH}_{3}\right)_{5}(\mathrm{btaH})\right]^{2+}$, apesar de todos os outros complexos com benzotriazol apresentarem uma região de PCET larga e acessível. Os derivados de imidazol apresentam uma pequena desvantagem em relação aos análogos envolvendo triazol devido à alta basicidade intrínseca ao ligante, que usualmente resulta nos altos valores de $\mathrm{p} K_{\mathrm{a}}$ de seus complexos.

Como observação final, a comparação das propriedades de PCET em complexos da mesma família (isto é, aqueles contendo o mesmo ligante substituinte; p. ex. M-btaH ou M-bimH) pode ser entendida puramente em termos da natureza eletrônica da unidade metálica de partida $(\mathrm{M})$ e efeitos de ligação $\pi$.

A consideração de efeitos indutivos sigma (through bond) e de campo (through space) não é relevante, uma vez que eles são proporcionais a $Z / r$; isto é, a carga do íon e seu raio iônico, o qual é muito similar em todos os complexos de rutênio e ferro estudados. Além disso, a distância do centro do íon ao próton ionizável é praticamente idêntica em toda a série. 


\subsubsection{Complexos binucleares}

\subsubsection{1. [(edta)Ru( $\mu-L) R u(e d t a)]^{n-}(n=3,4,5)$}

\subsection{Eletroquímica e espectroeletroquímica}

Conforme descrito no item 3.1.1.2, na presença de excesso de benzotriazol, o complexo rutênio(III)-edta forma uma espécie monossubstituída coordenada pelo átomo N3 (Esq. 5). A preferência por esse sítio está de acordo com os cálculos teóricos efetuados para o ligante, que indicam um caráter nucleofilico sobre o átomo N3 mas um caráter neutro para o átomo N2. Na forma reduzida, o complexo isomeriza em uma grande extensão para a forma $\mathrm{N} 2$, com $K_{\mathrm{N} 3 \rightarrow \mathrm{N} 2}=0,33$, como uma conseqüência das propriedades retrodoadoras- $\pi$ do íon rutênio(III). $\mathbf{O}$ complexo monômero de rutênio-edta com benzotriazol também sofre equilíbrio ácido-base em solução aquosa, com $\mathrm{p} K_{\mathrm{a}}=6,6$ e 9,5 (para as espécies oxidada e reduzida, respectivamente).

Nesta parte do trabalho, observou-se que mesmo quando o ligante benzotriazol se encontra em ligeiro excesso sobre o metal, a espécie binuclear é formada em grande extensão, em $\mathrm{pH}$ 6-7. Isso pode ser prontamente detectado por voltametria cíclica, pela presença de dois pares de ondas reversíveis com $E_{1 / 2}=0,020 \mathrm{e}-0,180 \mathrm{~V}$, somados às ondas características da espécie mononuclear em $-0,040 \mathrm{~V}$. Essas duas ondas passam a predominar à medida que a relação molar benzotriazol : rutênio se aproxima de 1:2, conforme mostrado na Fig. 11A, exibindo intensidades idênticas, e uma resposta linear com respeito à raiz quadrática da velocidade de varredura. ${ }^{a}$

O comportamento observado é coerente com a formação de um complexo binuclear, onde os dois pares de ondas se referem aos pares redox $\mathbf{R u}^{\text {III }}$ (bta) $\mathbf{R u} u^{\mathrm{II}} / \mathbf{R} \mathbf{u}^{\mathrm{II}}$ (bta) $\mathbf{R u}^{\text {II }}$ (aqui referido como $E_{1}$ ) e $\mathbf{R u}^{\text {II }}$ (bta)Ru II $_{R} / \mathrm{Ru}^{\text {II }}$ (bta)Ru II $^{\text {II }}\left(E_{2}\right)$ (Eqs. 62 e 63), cuja separação redox é dada por $\Delta E_{1 / 2}=200 \mathrm{mV}$.

$$
\begin{aligned}
& R u^{\text {III }}(\mathrm{bta}) \mathrm{R} \mathrm{u}^{\text {III }}+\mathrm{e}^{-} \stackrel{E_{1}}{=} \mathrm{Ru} \mathrm{u}^{\text {III }}(\mathrm{bta}) \mathrm{Ru} \mathrm{u}^{\text {III }} \\
& \mathrm{Ru}^{\mathrm{IIII}}(\mathrm{bta}) \mathrm{Ru}^{\mathrm{II}}+\mathrm{e}^{-} \stackrel{E_{2}}{=} \mathrm{Ru}^{\text {III }}(\mathrm{bta}) \mathrm{Ru}^{\mathrm{II}}
\end{aligned}
$$

\footnotetext{
a De acordo com Nicholson e Shain, ${ }^{244}$ para um processo reversível a equação de Randles-Sevick, ${ }^{5,6,306}$ fica j$_{0}=2,69 \times 10^{5} \cdot n^{3 / 2} \cdot A \cdot D_{i}^{1 / 2} \cdot C_{1} \cdot \tau^{1 / 2}$, onde í é a corrente de pico catódico ou anódico; $n$ é o númexo de elétrons envolvidos no processo; $A$ é a área do eletrodo $\left(\mathrm{cm}^{2}\right) ; D_{1}$ é a constante difusional da espécie reduzida ou oxidada no seio da solução $\left(\mathrm{cm}^{2} \mathrm{~s}^{-1}\right) ; C_{\mathrm{i}}$ é a concentração da espécie reduzida ou oxidada $\left(\mathrm{mol} \mathrm{cm}^{-3}\right)$; e ý a velocidade de varredura de potenciais $\left(\mathrm{V} \mathrm{s}^{-1}\right)$. Assim, (a) $i_{\mathrm{p}} \propto C_{i j}$ (b) $i_{\mathrm{p}} \propto v^{1 / 2}$.
}

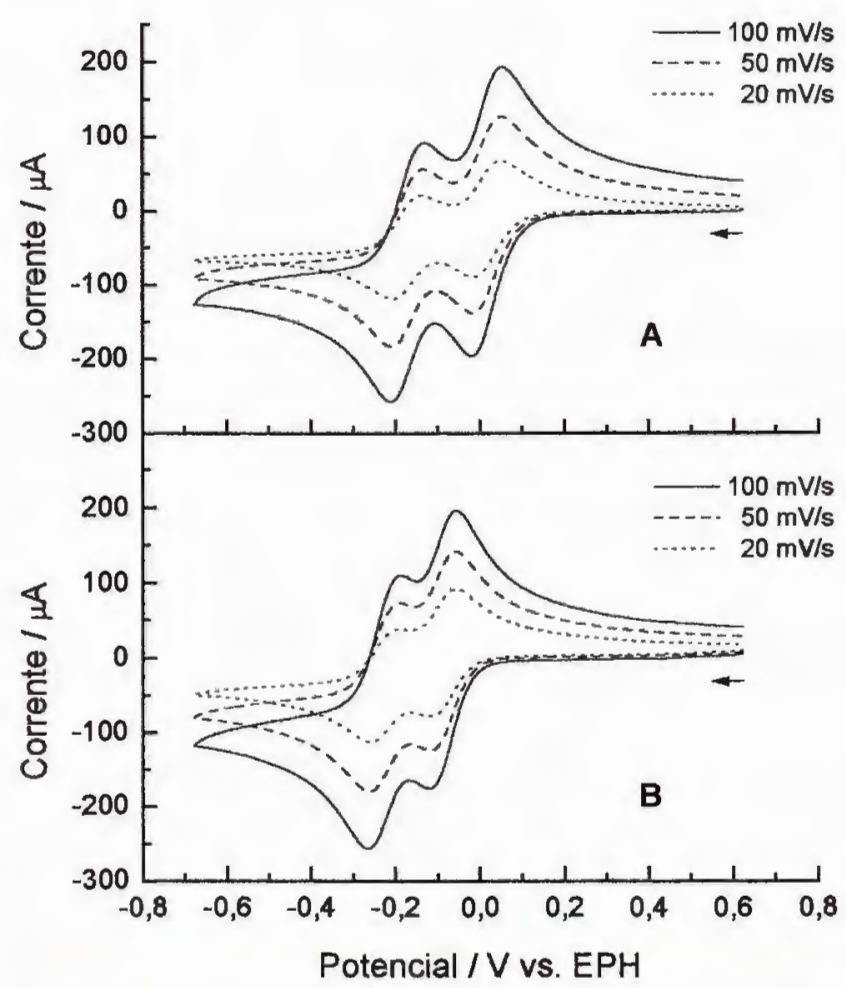

Figura 11. Voltamogramas clclicos de soluçōes aquosas dos complexos (A) $\left[\{\text { Ru(edta) }\}_{2} \text { (bta) }\right]^{3-}$ e (B) $\left[\{\text { Ru(edta) }\}_{2} \text { (bim) }\right]^{3-}$ em pH 7,0 e 10,0, respectivamente. $\left(C=5,0 \times 10^{-3} \mathrm{~mol} \mathrm{dm}^{-3} ; I=0,1 \mathrm{~mol} \mathrm{dm}^{-3}\right)$

A constante de equilíbrio, $K_{\mathrm{c}}$, para a reação de comproporcionamento (Eq. 64) pode ser calculada a partir da separação de potenciais $\Delta E_{1 / 2}$ através da Eq. 19.

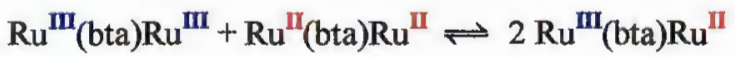

O valor calculado é $K_{\mathrm{c}}=2,4 \times 10^{3}$, que reflete a substancial estabilização da espécie de valência mista em relação a suas espécies isovalente correlatas.

Analogamente ao ligante benzotriazol, observou-se que o benzoimidazol também forma um complexo mononuclear estável com Ru(edta), exibindo $E_{1 / 2}=-0,015 \mathrm{~V}(\mathrm{pH} 7,0)$ ou $-0,100 \mathrm{~V}$ para a espécie desprotonada em $\mathrm{pH} 10,0 . \mathrm{O} \mathrm{p} K_{\mathrm{a}}$ do ligante benzoimidazol coordenado no complexo oxidado $\left(\mathrm{Ru}^{\mathrm{II}}\right)$ foi determinado como sendo 8,8 , tanto por método espectrofotométrico como por medidas eletroquímicas em função do $\mathrm{pH}$. A formação da espécie binuclear pode ser detectada somente em $\mathrm{pH}$ superior a 9, quando a relação benzoimidazol : rutênio é 1:2, conforme mostrado na Fig. 11B. Nesse caso, duas ondas reversíveis correspondentes aos pares redox formais $\mathrm{Ru}^{\text {III }}(\mathrm{bim}) \mathrm{Ru}^{\text {II }} / \mathrm{Ru}^{\text {III }}(\mathrm{bim}) \mathrm{Ru}^{\text {III }}\left(E_{1}\right) \mathrm{e}$ $\mathrm{Ru}^{\mathrm{II}}(\mathrm{bim}) \mathbf{R} \mathbf{u}^{\mathrm{II}} / \mathbf{R} \mathbf{u}^{\mathrm{II}}(\mathrm{bim}) \mathbf{R} \mathbf{u}^{\text {II }}\left(E_{2}\right)$ são observadas em $-0,090$ e $-0,230 \mathrm{~V}$, respectivamente, com $\Delta E_{1 / 2}=140 \mathrm{mV}$. 
A constante de comproporcionamento para o sistema benzoimidazolato foi estimada em $K_{\mathrm{c}}=2,3 \times 10^{2}$, indicando uma significante estabilização do complexo de valência mista, mas dez vezes menor que aquela determinada para 0 sistema benzotriazolato.

O comportamento espectroeletroquímico desses dois sistemas binucleares pode ser acompanhado nas Figs. $12 \mathrm{e}$ $14(\mathrm{~L}=$ bta $)$ e nas Figs. 13 e $15\left(\mathrm{~L}=\mathrm{bim}^{-}\right)$.

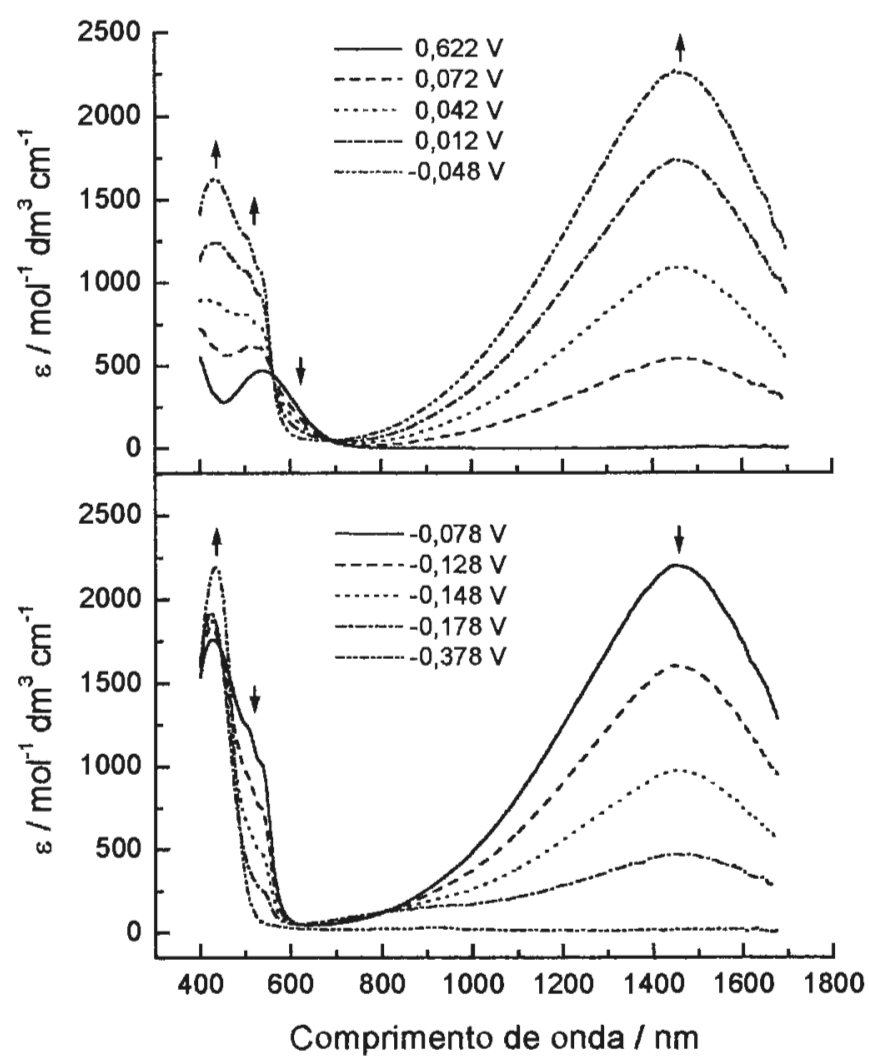

Figura 12. Espectros eletrônicos do complexo $\left[\{R u(e d t a)\}_{2}(b t a)\right]^{n-}$ sob aplicação de potencial em solução de $\mathrm{D}_{2} \mathrm{O}$.

$\left(C=1,0 \times 10^{-2} \mathrm{~mol} \mathrm{dm}^{-3} ; I=0,25 \mathrm{~mol} \mathrm{dm}^{-3} ; \mathrm{pD}=6,5\right)$

O complexo binuclear oxidado $\mathrm{Ru}^{\text {III }}(\mathrm{bta}) \mathrm{Ru} \mathrm{u}^{\mathrm{III}}$ apresenta uma banda de absorção em $540 \mathrm{~nm}\left(\varepsilon=480 \mathrm{~mol}^{-1} \mathrm{dm}^{3} \mathrm{~cm}^{-1}\right)$, atribuída à transição de transferência de carga ligante-metal $\pi\left(\mathrm{bta}^{-}\right) \rightarrow d_{\pi}\left(\mathrm{Ru^{ \textrm {III } }}\right)$, enquanto a espécie totalmente reduzida é caracterizada por uma banda intensa em $430 \mathrm{~nm}(\varepsilon=2200$ $\mathrm{mol}^{-1} \mathrm{dm}^{3} \mathrm{~cm}^{-1}$ ) associada à transição de transferência de carga metal-ligante $d_{\pi}\left(\mathrm{Ru}^{\mathrm{I}}\right) \rightarrow \pi^{*}\left(\mathrm{bta}^{-}\right)$.

$\mathrm{Na}$ região de $0,010 \mathrm{~V}$ a $-0,200 \mathrm{~V}$, que corresponde à faixa de potenciais sob os quais a espécie de valência mista, $\mathrm{Ru}^{\mathrm{III}}$ (bta)Ru ${ }^{\mathrm{II}}$, pode ser gerada por eletrólise, os espectros eletrônicos são dominados por uma intensa banda de absorção na região do infravermelho próximo $\left(\lambda_{\text {máx }}=1450\right.$ $\mathrm{nm}$ ). Essa banda apresenta seu máximo de intensidade ao redor de $-0,080 \mathrm{~V}$ (cujo valor se situa no ponto médio entre os dois pares redox ( $E_{1}$ e $\left.E_{2}\right)$, e pode ser atribuída a uma transferência de intervalência (IT) ou transferência de carga metal-metal (MMCT) de acordo com o processo da Eq. 65.

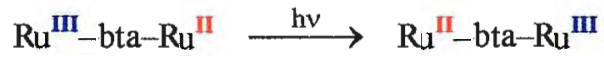

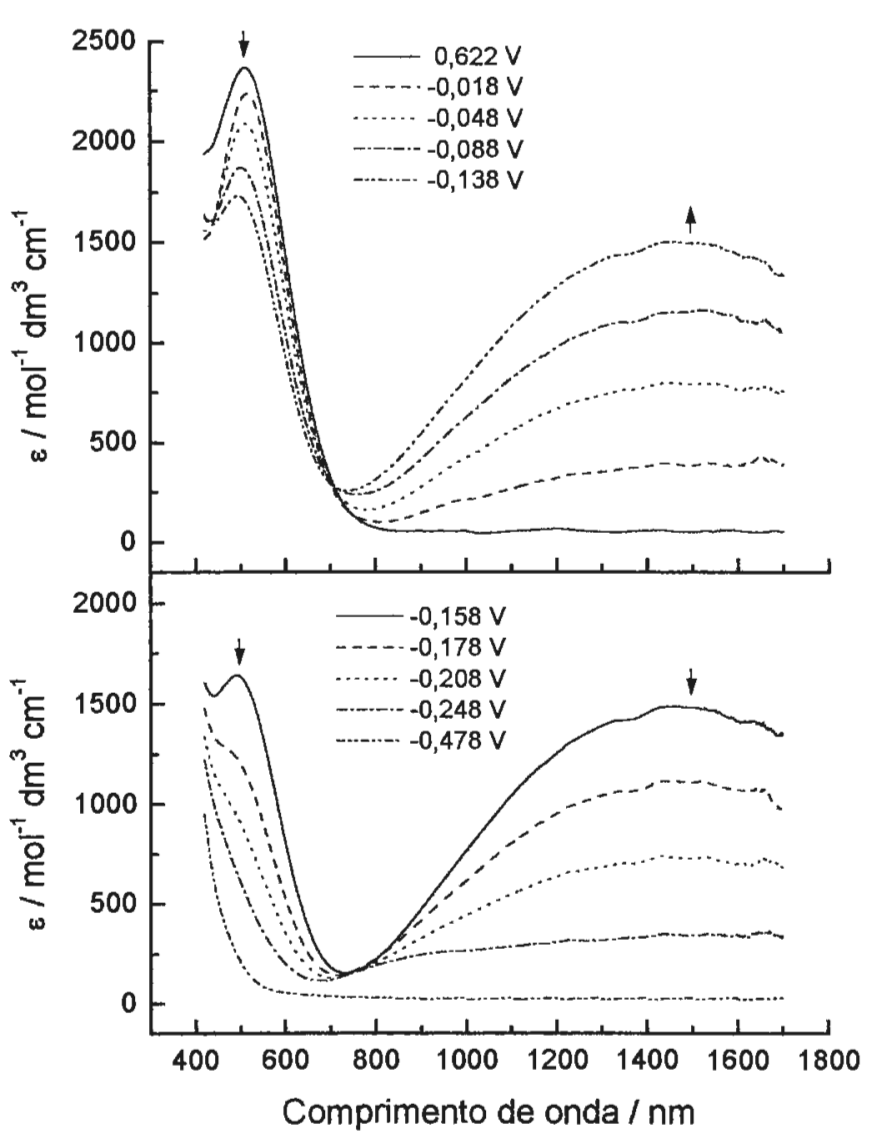

Figura 13. Espectros eletrônicos do complexo [\{Ru(edta) $\}_{2}($ bim $\left.)\right]^{\text {n- }}$ sob aplicação de potencial em solução de $\mathrm{D}_{2} \mathrm{O}$.

$\left(C=1,0 \times 10^{-2} \mathrm{~mol} \mathrm{dm}^{-3} ; /=0,25 \mathrm{~mol} \mathrm{dm}^{-3} ; \mathrm{pD}=9,5\right)$

As variações espectrais na região do visível (Fig. 14) seguem um comportamento reversível em função do potencial aplicado. A ocorrência de três bandas em 430, 500 e $530 \mathrm{~nm}$ parece refletir uma substancial perturbação com mistura dos níveis eletrônicos na espécie de valência mista.

O espectro da espécie de valência mista nas regiões do Vis-NIR pode ser observado melhor na Fig. 16A. É interessante notar que a banda de intervalência é bastante estreita $\left(\Delta \bar{v}_{1 / 2}=2850 \mathrm{~cm}^{-1}\right)$ e intensa $\left(\varepsilon_{\text {máx }}=2200 \mathrm{~mol}^{-1} \mathrm{dm}^{3}\right.$ $\mathrm{cm}^{-1}$ ). Além disso, no estado de valência mista as bandas de absorção na região do visível afastam-se do perfil esperado considerando as duas bandas de transferência de carga em 500 (MLCT) e $530 \mathrm{~nm}$ (LMCT) associadas aos fragmentos terminais $\left\{(\right.$ edta $\left.) \mathrm{Ru}^{\mathrm{II}}(\mathrm{bta})-\right\}$ e $\left\{-\right.$ (bta)Ru ${ }^{\mathrm{III}}($ edta $\left.)\right\}(3.1 .1 .3)$. 


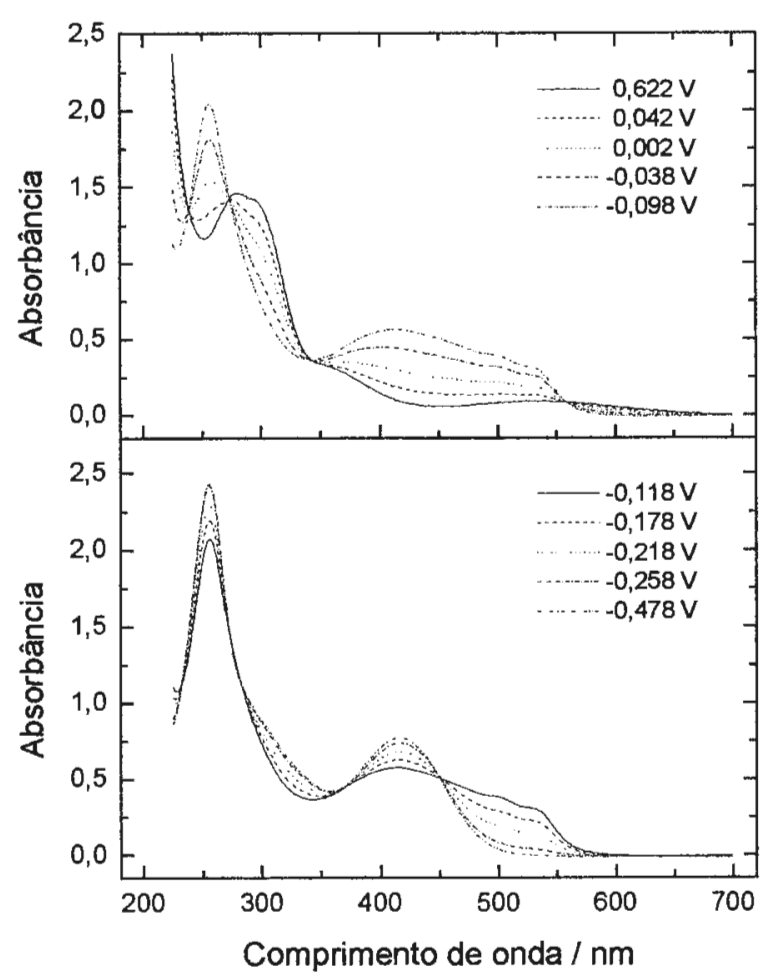

Figura 14. Espectros eletrônicos do complexo $\left[\{R u(\text { edta })\}_{2}(\mu-b \text { ta) }]^{n-}\right.$ $(n=3,4,5)$ em solução aquosa.

$\left(C=1,0 \times 10^{-2} \mathrm{~mol} \mathrm{dm}^{-3} ; I=0,25 \mathrm{~mol} \mathrm{dm}^{-3} ; \mathrm{pH} 7,0\right)$

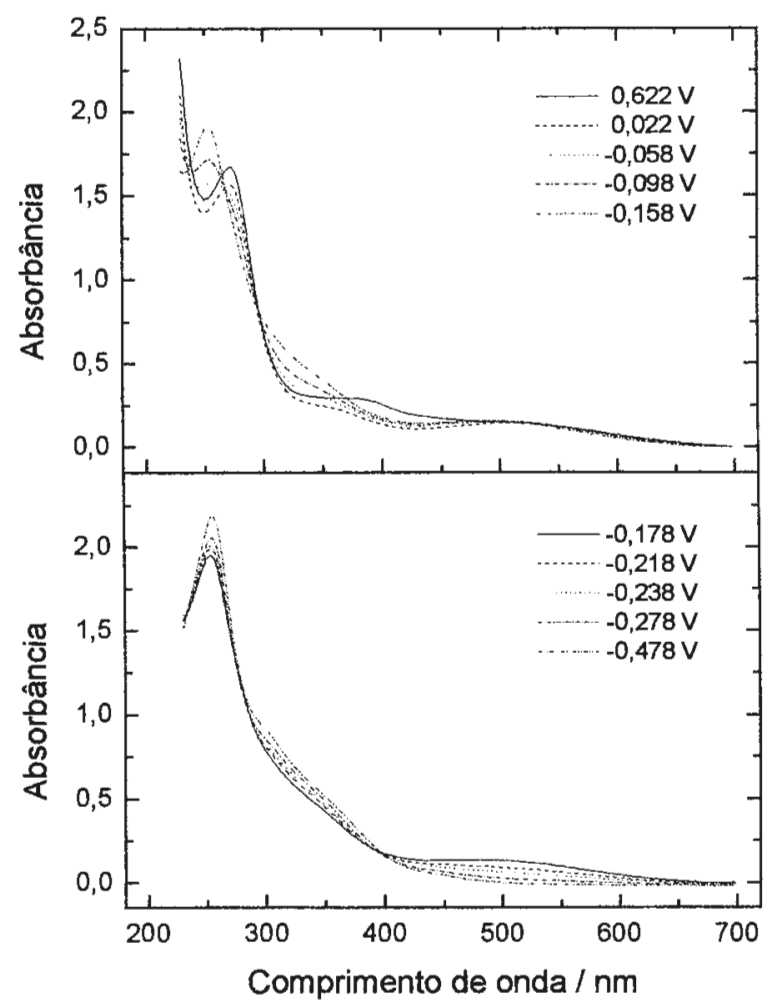

Figura 15. Espectros eletrônicos do complexo $\left[\{R u(e d t a)\}_{2}(\mu \text {-bim) }]^{n-}\right.$ $(n=3,4,5)$ em solução aquosa.

$\left(C=1,0 \times 10^{-2} \mathrm{~mol} \mathrm{dm}^{-3} ; I=0,25 \mathrm{~mol} \mathrm{dm}^{-3} ; \mathrm{pH} 10,0\right)$

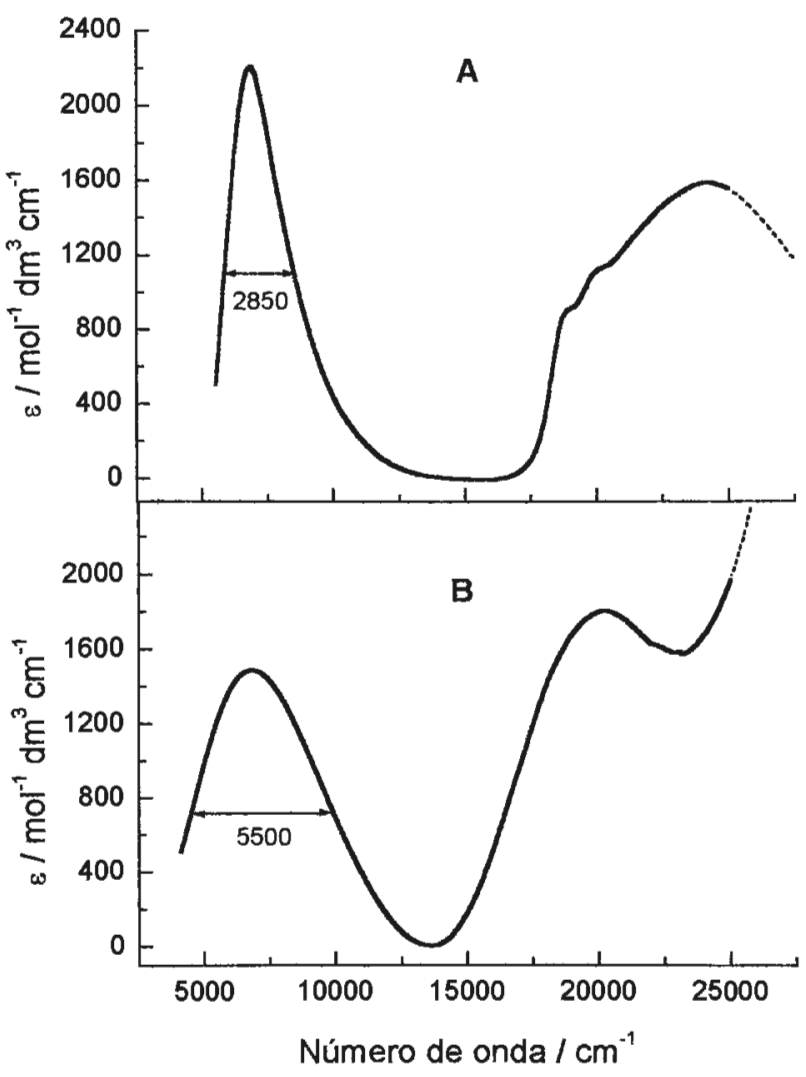

Figura 16. Espectros eletrônicos dos complexos de valência mista (A) $\left[\left\{R u(\text { edta) }\}_{2}(\text { bta })\right]^{4}\left(p D\right.\right.$ 6,5) e (B) $\left[\left\{R u(\text { edta) }\}_{2}(\text { bim })\right]^{4}\right.$ (pD 9,5) em solução aquosa $\left(D_{2} \mathrm{O}\right)$. Os complexos foram gerados in situ pela aplicação de $-0,080$ e $-0,150 \mathrm{~V}$, respectivamente. $\left(C=1,0 \times 10^{-2} \mathrm{~mol} \mathrm{dm}^{-3} ; I=0,25 \mathrm{~mol} \mathrm{dm}^{-3}\right)$

No caso do complexo binuclear contendo benzoimidazolato como ligante-ponte, a espécie oxidada $\mathrm{Ru}^{\text {III }}(\mathrm{bim}) \mathrm{Ru}{ }^{\mathrm{III}}$ exibe uma banda característica em $510 \mathrm{~nm}\left(\varepsilon=2350 \mathrm{~mol}^{-1} \mathrm{dm}^{3}\right.$ $\mathrm{cm}^{-1}$ ) atribuída à transição LMCT $\pi\left(\mathrm{bim}^{-}\right) \rightarrow d_{\pi}\left(\mathrm{Ru}^{\mathrm{III}}\right)$ (Figs. 13 e 15). Essa banda também foi observada no complexo mononuclear desprotonado, $\left[\mathrm{Ru}^{\mathrm{II}}(\mathrm{edta})(\mathrm{bim})\right]^{2-}, \mathrm{em} 510 \mathrm{~nm}$ $\left(\varepsilon=3500 \mathrm{~mol}^{-1} \mathrm{dm}^{3} \mathrm{~cm}^{-1}\right)$ (Tab. 2). A espécie isovalente reduzida, $\mathrm{Ru}^{\mathrm{II}}(\mathrm{bim}) \mathrm{Ru}{ }^{\mathrm{II}}$, não apresenta bandas de absorção intensas na região do visível; mas, assim como no complexo mononuclear, um ombro pode ser observado em $350 \mathrm{~nm}$, que corresponde à transição MLCT $d_{\pi}\left(\mathrm{Ru}^{\mathrm{II}}\right) \rightarrow \pi^{*}(\mathrm{bim})$.

A espécie de valência mista, $\mathrm{Ru}^{\mathrm{III}}(\mathrm{bim}) \mathrm{Ru}^{\mathrm{II}}$, por sua vez, apresenta uma banda de intervalência larga e relativamente intensa em $1500 \mathrm{~nm}\left(\varepsilon_{\max }=1500 \mathrm{~mol}^{-1} \mathrm{dm}^{3} \mathrm{~cm}^{-1}\right)$, a qual alcança seu máximo de intensidade na região média entre os dois potenciais redox $E_{1} \mathrm{e} E_{2}$, conforme mostrado nas Figs. 13 e 16B. Na região do visível, o espectro apresenta essencialmente a transferência de carga $\pi\left(\mathrm{bim}^{-}\right) \rightarrow d_{\pi}\left(\mathrm{Ru}^{\mathrm{III}}\right)$ em $510 \mathrm{~nm}$ para o centro oxidado, a qual decai quando o potencial aplicado diminui. Isso é seguido pelo surgimento da banda MLCT para o centro reduzido, $d_{\pi}\left(\mathrm{Ru}^{\mathrm{II}}\right) \rightarrow \pi^{*}(\mathrm{bim})$, na região do UV $(350 \mathrm{~nm})$. 
Diferentemente do sistema envolvendo benzotriazolato, no complexo $\left[(\text { edta }) \mathrm{Ru}{ }^{\mathrm{III}}(\mu \text {-bim }) \mathrm{Ru}^{\mathrm{Il}}(\text { edta })\right]^{4-}$ o espectro de absorção na região UV-Vis pode ser descrito em termos da contribuição dos dois grupos terminais, \{(edta)Ru $\mathrm{Ru}^{\mathrm{III}}$ (bim)- $\}$ e $\left\{\right.$-(bim) $\mathrm{Ru}^{\Pi}$ (edta) $\}$, sem evidências de uma nova banda ou forte perturbação eletrônica nos níveis de energia dos centros de rutênio oxidado e reduzido.

\subsection{Estrutura molecular}

A estrutura molecular teórica para o complexo binuclear $\left[(\right.$ edta $) \mathrm{Ru}^{\mathrm{III}}\left(\mu \text {-bim) Ru }{ }^{\mathrm{II}}(\text { edta })\right]^{3-}$ encontra-se ilustrada na Fig. 17 e foi baseada em cálculos de otimização geométrica em nível de mecânica molecular (método $\mathrm{MM}+$ ). Nela, os dois íons metálicos e o ligante-ponte estão localizados no mesmo plano, exibindo uma distância metal-metal igual a $5,9 \AA$.
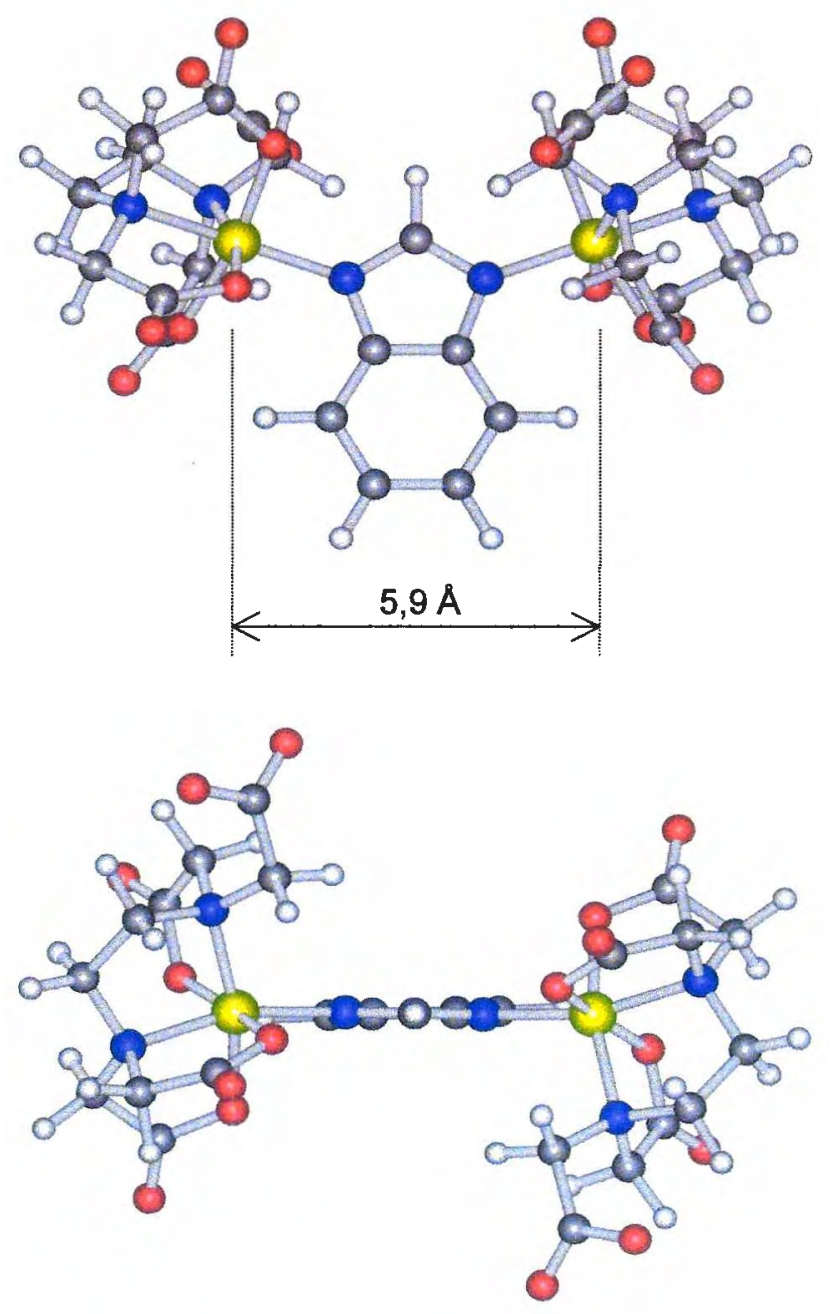

Figura 17. Estrutura molecular teórica do complexo binuclear $\left[\{R u(e d t a)\}_{2}(\mu \text {-bim })\right]^{3-}$, calculada por otimização de geometria em nivel de mecânica molecular segundo o método $\mathrm{MM}+\left(\right.$ simetria $\mathrm{C}_{2}$ ).
No caso do benzotriazolato-complexo, $\mathrm{Ru}^{\mathrm{III}}(\mathrm{bta}) \mathrm{Ru}^{\mathrm{III}}$, a simulação da geometria depende da proposição dos modos de ligação para os íons de rutênio. Assumindo-se uma coordenação simétrica $\mathrm{N} 1, \mathrm{~N} 3$, a geometria final resultante é bastante próxima àquela calculada para o análogo com benzoimidazolato, com uma distância metal-metal igual a $5,7 \AA$. No entanto, para a espécie de valência mista, $\mathrm{Ru}^{\mathrm{III}}$ (bta)Ru $\mathrm{u}^{\mathrm{II}}$, o envolvimento do átomo N2 não pode ser negligenciado, por causa das contribuições esperadas de interações de retrodoação do centro $\mathrm{Ru}(\mathrm{II})$. Teoricamente, a coordenação através dos átomos vicinais $\mathrm{N} 1$ e N2 deveria levar a uma grande distorção da geometria planar, devido ao impedimento estérico, mas uma coordenação intermediária parece ser bastante plausivel, considerando as propriedades fluxionais previamente observadas nesse sistema (item 3.1.1.2). Portanto, pode-se esperar algum deslocamento da configuração regular $\mathrm{N} 1, \mathrm{~N} 3$ proposta aqui para o complexo com benzoimidazolato (Esq. 8A), para uma configuração intermediária (Esq. 8B) onde a participação do sítio N2 torna-se relevante. Nesse caso, a distância metal-metal poderia ser diminuída para até $4,4 \AA$, sem uma distorção apreciável da geometria planar. Essa distância seria um valor limite para propósitos de comparação e modelagem. Infelizmente, cálculos eletrônicos específicos não puderam ser implementados nos métodos de mecânica molecular disponíveis, excluindo a avaliação da estabilidade relativa do complexo em sua configuração limite.

(A)

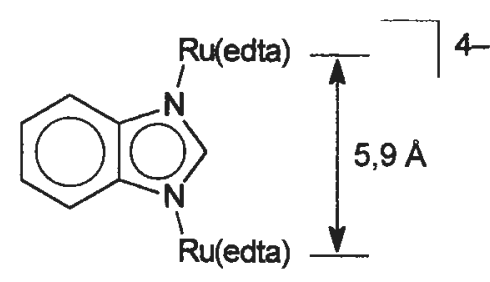

(B)

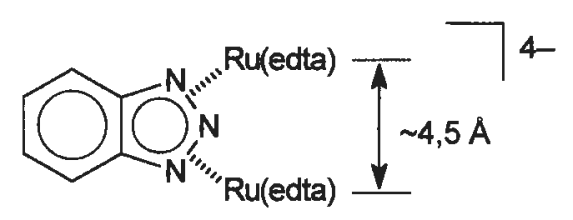

Esquema 8. Coordenação fluxional no ligante benzotriazolato (B).

\subsection{Propriedades de intervalência}

A largura de meia-banda para uma banda de intervalência de um sistema simétrico pode ser expressa em termos do formalismo de Hush de acordo com a Eq. 37. 
Essa estimativa corresponde ao valor limite para um complexo de valência mista de classe II.$^{68,70-72}$ Os valores experimentais abaixo desse valor determinado teoricamente são típicos de sistemas exibindo substancial acoplamento eletrônico entre os centros metálicos, a exemplo daqueles para complexos de valência deslocalizada (v. item 1.2.4).

No caso do complexo $\mathrm{Ru}^{\mathrm{III}}$ (bim)Ru $\mathrm{u}^{\mathrm{II}}, \Delta \bar{v}_{1 / 2}$ (teórico) é $3900 \mathrm{~cm}^{-1}$, e o valor experimental de $5500 \mathrm{~cm}^{-1}$ confirma a sua descrição em termos de um sistema de valência mista de classe II. Para esse tipo de sistema, a energia de acoplamento eletrônico $\left(H_{\mathrm{ab}}\right)$ e o fator de deslocalização $\left(\alpha^{2}\right)$ podem ser expressos pelas propriedades da banda de intervalência de acordo com as Eqs. 27 e 28 (item 1.2.3.1).

Os valores calculados para o complexo $\mathrm{Ru}^{\mathrm{III}}(\mathrm{bim}) \mathrm{Ru}^{\mathrm{II}}$, $H_{\mathrm{ab}}=820 \mathrm{~cm}^{-1}$ e $\alpha^{2}=0,015$, indicam que a interação eletrônica é significante, mas consistente com o sistema de carga localizadas.

Em contraste, é interessante que para o complexo $\mathrm{Ru}^{\mathrm{III}}$ btaRu , o valor experimental da largura de meia-banda $\left(\Delta \bar{v}_{1 / 2}=2850 \mathrm{~cm}^{-1}\right)^{\mathrm{a}}$ é bem inferior ao valor calculado, que corresponde a $4000 \mathrm{~cm}^{-1}$. De acordo com o formalismo teórico, o sistema não pode ser descrito apropriadamente em termos de um modelo de valência mista localizado (classe II). A forte interação eletrônica observada é típica de um sistema de classe III. Isso também se reflete no elevado coeficiente de extinção molar para o complexo, bem como em sua constante de comproporcionamento, que são superiores, por exemplo, àqueles relatados para o complexo binuclear análogo de rutênio(edta)-pirazina. ${ }^{318}$

Apesar das considerações acima, uma tentativa de cálculo baseada nas Eqs. 27 e 28 (para sistemas de classe II), levaram aos valores $H_{\mathrm{ab}}=1000 \mathrm{~cm}^{-1}$ e $\alpha^{2}=0,022$ para o benzotriazolato-complexo de valência mista, assumindo uma distância intermetálica de $4,4 \AA$. Embora seja conhecido que essas equações não são válidas para o sistema de classe III, elas podem oferecer uma estimativa no limite inferior dos parâmetros de intervalência. Na verdade, os resultados são bastante atípicos para esse tipo de complexo, aproximando-se daqueles previamente reportados para complexos de classe III.

\footnotetext{
a Como pode ser observado nos espectros NIR, a leitura do equipamento é limitada à faixa de trabalho de 400 a $1700 \mathrm{~nm}$. Embora essa região não seja suficientemente ampla para incluir a banda IT na extremidade de menor energia, a maior parte envolvendo a absorção máxima pode ser claramente defizida. Além disso, pode-se verificar que o perfil da banda é aproximadamente simétrico e pode ser ajustado assumindo um formato de Gaussiana simétrica. Dessa forma, o cálculo de $\Delta \vec{\nabla}_{1 / 2}$ (exp) para a banda completa foi tomado pela projeção de sua metade de maior energia e então, medindo-se $\Delta \bar{v}_{1 / 2}$ diretamente do espectro total em unidades de energia $\left(\mathrm{cm}^{-1}\right), \mathrm{em} A=A_{\max } / 2$.
}

De acordo com cálculos ZINDO, a aproximação dos centros metálicos a uma distância de 4,4 A permite uma interação expressiva com o sítio N2, levando a um forte acoplamento eletrônico por meio do ligante-ponte. Orbitais moleculares de fronteira ocupados para o benzotriazolato-complexo, gerados por cálculos ZINDO, revelam um recobrimento $\sigma \mathrm{e}$ $\pi$ significativo entre os orbitais Ru $d$ (de ambos os tipos, $t_{2 \mathrm{~g}}$ ou $e_{\mathrm{g}}$ ) e o orbital $p$ (do tipo $s p^{2}$ contendo um par eletrônico/ condutor - lone pair) do átomo N2 do ligante-ponte (além da combinação esperada com os sítios N1 e N2). Uma representação simplificada da interação intermetálica, de acordo com o modelo proposto, é ilustrada no Esq. 9.

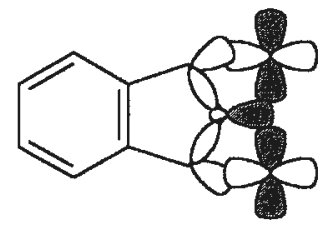

Esquema 9. Interação metal-metal por conjugaçăo $d \pi_{M 1}-p_{\text {N2-L }}-d \pi_{M 2}$.

Em adição a esse modelo, deve-se considerar também a possibilidade da interação metal-metal através do ligante benzotriazolato ser maior que aquela através da ponte de benzoimidazolato devido ao fato de a energia dos orbitais $\pi$ relevantes do ligante-ponte terem sua energia diminuída pela presença do átomo eletronegativo adicional de nitrogênio. Entretanto, de acordo com os cálculos quânticos para os dois sistemas, a diferença de energia entre os orbitais $\pi^{*}$ de menor energia para os ligantes-ponte é de apenas $0,280 \mathrm{eV}\left(2260 \mathrm{~cm}^{-1}\right)$, e difícilmente pode explicar esses resultados.

Uma comparação mais ilustrativa é fornecida pelo sistema similar contendo a pirazina como ligante-ponte, que exibe um valor muito menor de energia para o nível LUMO $(\Delta E=4,142 \mathrm{eV})$. Apesar disso, a diferença não é refletida em suas propriedades da transferência de intervalência $\left(H_{\mathrm{ab}}\right.$, $\alpha, \Delta \bar{v}_{1 / 2}$ e $K_{c}$ ), cujos valores são bem modestos e típicos de complexos de valência mista de classe II. $^{318}$

Como conclusão preliminar, pode-se inferir que o estudo comparativo das propriedades ópticas e eletroquímicas dos complexos binucleares de valência mista do tipo [(edta)Ru$\mu-\mathrm{L}-\mathrm{Ru}(\mathrm{edta})]^{4}\left(\mathrm{~L}=\mathrm{bta}^{-}\right.$e bim$\left.{ }^{-}\right)$revelam comportamento contrastante, evidenciando a ocorrência de um acoplamento eletrônico mais intenso para o primeiro, promovido pelo ligante-ponte fluxional. Os cálculos teóricos indicam que a capacidade do ligante intensificar o acoplamento metalmetal é um fator bastante importante, além da interação convencional por meio da propagação da conjugação $\pi$ em exemplos clássicos. 


\subsection{Efeitos do solvente}

Apesar de a exploração dos efeitos solvatocrômicos sobre as propriedades de valência mista desses complexos ter sido bastante dificultada devido à baixa solubilidade deles em solventes orgânicos, ${ }^{\mathrm{a}, \mathrm{b}}$ medidas de espectros eletrônicos sob aplicação de potencial na região do NIR para soluções superdiluídas da espécie $\left[\{\mathrm{Ru}(\text { edta })\}_{2}(\mu \text {-bta })\right]^{4}$, em alguns poucos solventes (dmf, dmso e meOH) nos quais se observou absorção mensurável, confirmaram a natureza deslocalizada em grande extensão das cargas dos sítios metálicos sobre o complexo. Isto é, nenhuma obediência ou correlação de $\widetilde{v}_{\text {max }}$ com os parâmetros físico-químicos $\left(\eta^{-2}-\varepsilon_{s}^{-1}\right)$ do solvente (Eq. 32) pôde ser detectada (Tab. 4).

Tabela 4. Energia óptica da IT para a espécie $\left[\{R u(e d t a)\}_{2}(\mu-b t a)\right]^{4-}$ em alguns solventes.

\begin{tabular}{ccccc}
\hline Solvente & $\begin{array}{c}\overline{\mathbf{v}}_{\text {mix }} \\
\left(\mathbf{c m}^{-1}\right)\end{array}$ & $\begin{array}{c}\Delta \overline{\mathbf{v}}_{\mathbf{1}} \\
\left(\mathbf{c m}^{-1}\right)\end{array}$ & $\boldsymbol{\varepsilon}_{\mathbf{o p}}{ }^{-1}-\boldsymbol{\varepsilon}_{\mathbf{s}}^{-1}$ & DN \\
\hline $\mathrm{D}_{2} \mathrm{O}$ & 6900 & 2850 & 0,546 & 18,0 \\
meOD & 7000 & 3200 & 0,534 & 19,0 \\
dmf & 6700 & 2800 & 0,473 & 26,6 \\
dmso & 6700 & 2700 & 0,435 & 29,9 \\
\hline
\end{tabular}

Além de não apresentar solvatocromismo de acordo com o modelo do contínuo dielétrico, pode-se observar na Tab. 4 que a variação total de $\bar{v}_{\text {rnáx }}$ na série não passa de $300 \mathrm{~cm}^{-1}$, enquanto em complexos de cargas localizadas (classe II) este gradiente pode ser superior a $2000 \mathrm{~cm}^{-1}$. No complexo $\left[\left\{\left(\mathrm{NH}_{3}\right)_{5} \mathrm{Ru}\right\}_{2}\left(\mu-4,4^{\prime}-\text { bpy }\right)\right]^{5+}$, por exemplo, $E_{\mathrm{op}}$ varia de $9550 \mathrm{~cm}^{-1} \mathrm{em} \mathrm{H}_{2} \mathrm{O} / \mathrm{D}_{2} \mathrm{O}$ a $8100 \mathrm{~cm}^{-1}$ em dmso. ${ }^{15,70}$

Alternativamente, construíram-se curvas de $\vec{v}_{\text {máx }}$ e $\Delta \bar{v}_{\text {máx }}$ em função do número de doador do solvente, $\mathrm{DN}^{113,325}$ mas nenhuma correlação foi igualmente observada.

Portanto, esse critério para avaliar o grau de localização de cargas em uma espécie de valência mista corrobora as atribuições desse complexo como um sistema de classe III ou, pelo menos, intermediário de classes II/III com elevado grau de deslocalização. ${ }^{\text {c }}$

\footnotetext{
a No caso específico do benzoimidazolato-complexo, a solubilidade é ainda mais prejudicada. Além disso, o complexo parece ser mais instável e se desproporciona na maioria dos solventes testados.

b Acetona $(17,0)$, bn $(11,9)$, dmso $(29,9)$, dma $(27,8)$, dmf $(26,6)$, fm $(24,0)$, meCN $(14,1), \mathrm{meOH}(19,0), \mathrm{nb}(4,4), \mathrm{nm}(2,7)$ e pc $(15,1)$. (Os valores entre parênteses referem-se ao parâmetro $\mathrm{DN}=$ número de doador).

c Como comparação, vale mencionar que no complexo de valência mista de rutênio-polipiridina com benzotriazolato (v. item 3.2.3) a dependência do solvente é coerente com os dados espectroscópicos (que o caracterizam como um sistema localizado) e é consistente com a Eq. 32 para classe II.
}

Um comentário final sobre a discussão e as conclusões extraídas desta contribuição se faz necessário: a decisão de onde delinear o limite entre as classes de valência mista II $e$ III é uma tarefa muito dificil. $O$ íon de Creutz-Taube ${ }^{12,13}$ tem sofrido uma caracterização fisica extremamente rigorosa por praticamente todos os métodos conhecidos. ${ }^{70,71} \mathrm{O}$ mesmo grau de examinação deveria ser aplicado para os complexos estudados aqui (simétricos ou assimétricos) ${ }^{d}$ para justificar totalmente a atribuição deles em termos de classe III e/ou no limiar das classes II/IIII.

\subsubsection{2. $\left[\left(N_{3}\right)_{5} R u(\mu-L) R u(e d t a)\right]^{n}(n=+1,0,-1)$}

\subsection{Complexo $\left[\left(\mathrm{NH}_{3}\right)_{5} \mathrm{Ru}(\mu-\mathrm{bta}) \mathrm{Ru}(\mathrm{edta})\right]^{n}$}

A mistura de $\left[\mathrm{Ru}\left(\mathrm{NH}_{3}\right)_{5}(\mathrm{btaH})\right]^{2+}$ e $\left[\mathrm{Ru}(\text { edta })\left(\mathrm{H}_{2} \mathrm{O}\right)\right]^{-}(1: 1)$ em solução aquosa $(\mathrm{pH}>5,5)$ resulta uma espécie marrom idêntica à isolada na forma sólida. Os voltamogramas cíclicos exibem duas ondas reversíveis (Fig. 18A), de intensidades idênticas, apresentando resposta linear com respeito à raiz quadrática das velocidades de varredura Similarmente, os correspondentes voltamogramas de pulso diferencial (Fig. 18B) apresentam dois picos bem definidos em potenciais redox $E_{1}=0,175 \mathrm{~V} \mathrm{e} E_{2}=-0,110 \mathrm{~V}$.

Por comparação com os potenciais de redução do par redox $\mathrm{Ru}^{\mathrm{III}} / \mathrm{Ru}^{\mathrm{II}}$ nos complexos de partida e nas espécies mononucleares (item 3.1.1.4; Tab. 3), a formação do novo complexo binuclear assimétrico $\left(\mathrm{NH}_{3}\right)_{5} \mathrm{Ru}^{\mathrm{II}}$ (bta) $\mathrm{Ru}{ }^{\mathrm{III}}$ (edta) foi evidenciado eletroquimicamente. Outra indicação importante de sua existência é a presença de uma forte banda de absorção eletrônica na região do infravermelho próximo. Medidas espectroeletroquímicas nas regiões do visível e do infravermelho próximo confirmaram que a nova banda em $1475 \mathrm{~nm}$ ocorre somente quando o sistema é submetido a potenciais entre 0,2 e $-0,1 \mathrm{~V}$ (Fig. 19), cuja intensidade de absorção máxima $\left(\varepsilon=2300 \mathrm{~mol}^{-1} \mathrm{dm}^{3} \mathrm{~cm}^{-1}\right)$ é atingida quando o potencial aplicado se aproxima de 0,05 $\mathrm{V}$, o ponto médio entre os dois pares de ondas reversíveis observadas nos voltamogramas cíclicos (Fig. 18). Sob potenciais acima ou abaixo dessa região, a absortividade diminui gradualmente até o desaparecimento completo da banda nos extremos positivo $(\sim 0,4 \mathrm{~V})$ e negativo $(\sim-0,5 \mathrm{~V})$ da faixa de potenciais (Fig. 19).

d O comentário vale para o complexo assimétrico (edta) $R u\left(\mu\right.$-bta) $R u\left(N_{3}\right)_{5}$ a ser apresentado no próximo item (3.1.2.2). 


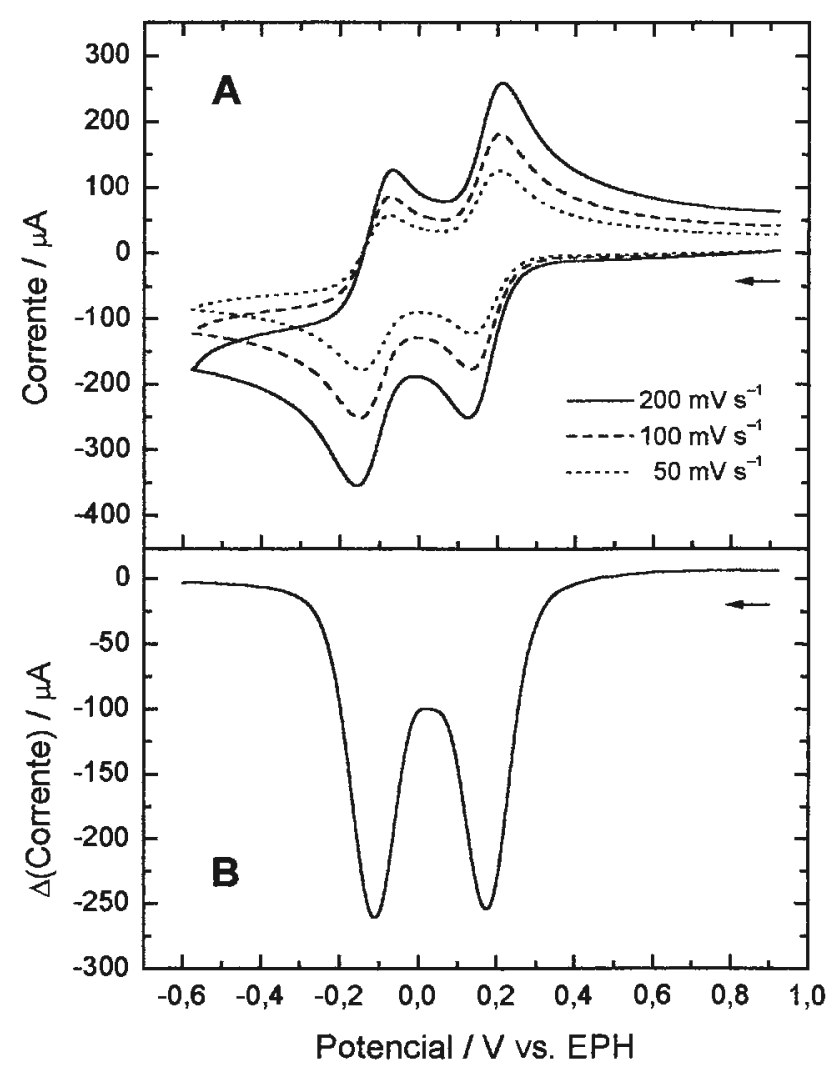

Figura 18. Voltamogramas ciclicos (A) e voltamograma de pulso diferencial (B) do complexo $\left(\mathrm{NH}_{3}\right)_{5} \mathrm{Ru}(\mathrm{bta}) \mathrm{Ru}(\mathrm{edta})$ em solução aquosa ( $C=5,0 \times 10^{-3} \mathrm{~mol} \mathrm{dm}^{-3} ; l=\mathrm{Na}$ (tfa) $0,25 \mathrm{~mol} \mathrm{dm}^{-3} ; \mathrm{pH} 6,0$ ).

(condições de trabalho da DPV: altura do pulso $=0,025 \mathrm{~V}$; largura do pulso $=0,050 \mathrm{~s} ; v=100 \mathrm{mV} \mathrm{s}^{-1}$ )

Portanto, baseado nos valores de $E_{1 / 2}$ das unidades metálicas individuais (v. item 3.1.1.4; Tab. 3), os dois pares redox podem ser atribuídos como segue:

$$
\begin{aligned}
& {\left[\left(\mathrm{NH}_{3}\right)_{5} \mathrm{Ru}{ }^{\mathrm{III}}-\mathrm{bta}-\mathrm{Ru}^{\mathrm{III}}(\text { edta })\right]^{+}} \\
& 11 \quad E_{1}=0,175 \mathrm{~V} \\
& \left(\mathrm{NH}_{3}\right)_{5} \mathrm{Ru}^{\mathrm{II}} \text { bta-Ru}{ }^{\mathrm{III}}(\text { edta }) \\
& 11 \quad E_{2}=-0,110 \mathrm{~V} \\
& {\left[\left(\mathrm{NH}_{3}\right)_{5} \mathrm{Ru}^{\Pi}{ }^{\Pi-} \text { bta-Ru}{ }^{\Pi}(\text { edta })\right]^{-}}
\end{aligned}
$$

O primeiro processo de redução centrado sobre o fragmento terminal pentaaminrutênio(III) é esperado ser menor que o potencial para o correspondente par na espécie mononuclear de origem $\left[\mathrm{Ru}^{\mathrm{III} / \mathrm{I}}\left(\mathrm{NH}_{3}\right)_{5}(\mathrm{btaH})\right]^{3+/ 2+}(0,230 \mathrm{~V})$. De fato, isso realmente ocorre $\left(E_{1}=0,175 \mathrm{~V}\right)$ e é consistente com a capacidade do íon etilenodinitrilotetraacetatorutenato(III) em retirar elétrons ser menor que a de um próton em um complexo do tipo "dímero" genérico $\left[\mathrm{Ru}\left(\mathrm{NH}_{3}\right)_{5}-\mathrm{L}_{\mathrm{b}}-\mathrm{M}\right]^{\mathrm{n}}$ (onde, neste caso, $\mathrm{M}=\mathrm{H}^{+}$ou $\mathrm{Ru}($ edta)). $\mathrm{Na}$ análise do potencial bem mais negativo da segunda etapa de redução centrada na unidade de $\mathrm{Ru}^{\mathrm{III}}$ (edta), as considerações acerca dos efeitos de comunicação eletrônica na espécie de valência mista são, por sua vez, mais relevantes. Além disso, no estado $\mathrm{Ru}{ }^{\text {III }}-\mathrm{L}_{\mathrm{b}}-\mathrm{Ru}^{\mathrm{II}}$, o íon $\mathrm{Ru}{ }^{\mathrm{III}}$ age como centro ácido, desempenhando uma função estabilizante do grupo $\mathrm{Ru}^{\mathrm{II}}\left(\mathrm{NH}_{3}\right)_{5} \mathrm{~L}_{\mathrm{b}}$, pela remoção parcial da densidade de carga negativa do ligante-ponte, que origina devido à retroligação do ín $\mathrm{Ru}^{\mathrm{II}}\left(\mathrm{NH}_{3}\right)_{5}$, $\left(\mathrm{Ru}^{\mathrm{II}}\right) d \pi \rightarrow \pi^{*}\left(\mathrm{~L}_{\mathrm{b}}\right)$. Isso justifica porque o potencial para a reação $\mathrm{Ru}^{\mathrm{II}} \mathrm{Ru}{ }^{\mathrm{III}}+\mathrm{e}^{-} \rightarrow \mathrm{Ru}^{\mathrm{II}} \mathrm{Ru} \mathrm{u}^{\mathrm{II}}$ é diminuída por $200 \mathrm{mV}$ quando comparada ao par redox $\left[\mathrm{Ru}^{\mathrm{III} / \mathrm{II}} \text { (edta)(btaH) }\right]^{-12-}$ (Tab. 3), embora a carga seja mais positiva sobre o dímero.

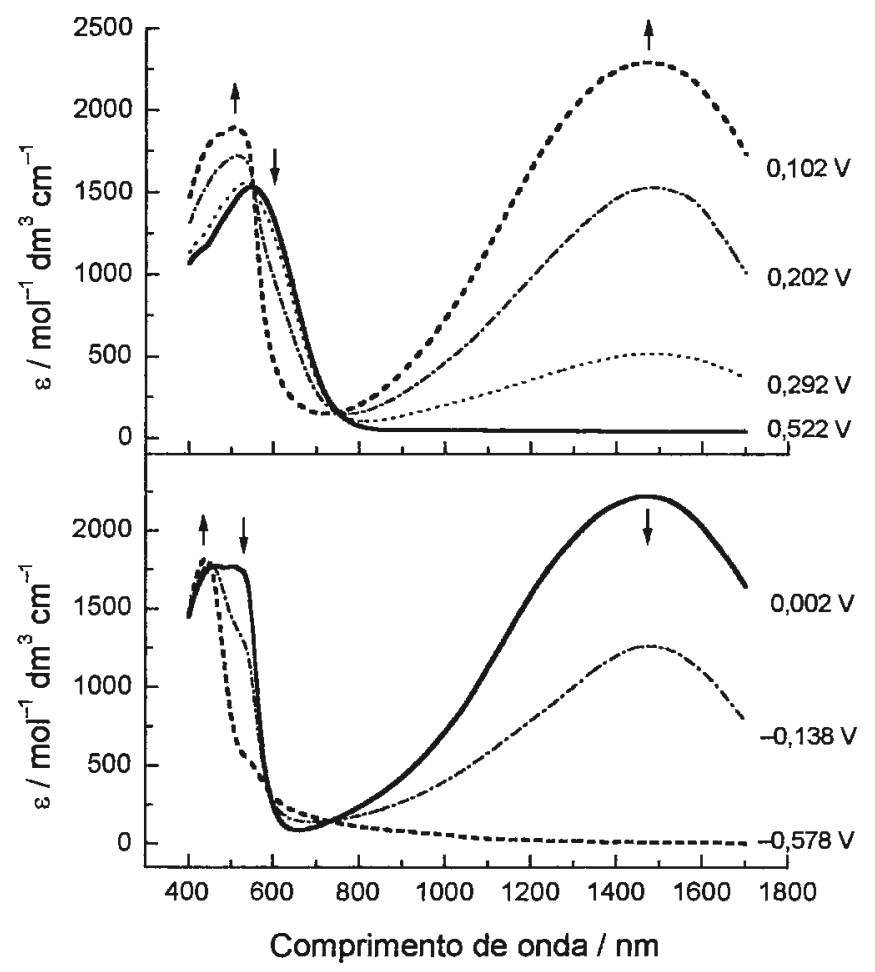

Figura 19. Espectros eletrônicos sob aplicação de potencial do complexo binuclear $\left(\mathrm{NH}_{3}\right)_{5} \mathrm{Ru}\left(\right.$ bta) Ru(edta) em $\mathrm{D}_{2} \mathrm{O}$. $\left(I=\mathrm{KNO}_{3} 0,25 \mathrm{~mol} \mathrm{dm}{ }^{-3} ; \mathrm{pD} \mathrm{5,5}\right)$

A banda em $1475 \mathrm{~nm}$ origina-se de uma transferência de intervalência, ou transferência de carga metal-metal, do sítio doador $\left\{\left(\mathrm{NH}_{3}\right)_{5} \mathrm{Ru}^{\mathrm{II}}-\right\}$ para o sítio aceitador $\left\{-\mathrm{Ru}^{\mathrm{III}}(\right.$ edta $\left.)\right\}$, conforme representado na Eq. 68 , na qual $d \pi_{3}$ é o nível de energia $d \pi$ de maior energia entre os três orbitais $\mathrm{Ru}\left(t_{2 \mathrm{~g}}\right)$ quase degenerados. 


$$
\begin{aligned}
& \left(\mathrm{NH}_{3}\right)_{5} \mathrm{Ru}^{\mathrm{II}}\left(d \pi_{3}{ }^{2}\right)-\mathrm{bta}-\left(d \pi_{3}{ }^{1}\right) \mathrm{Ru}{ }^{\mathrm{III}}(\mathrm{edta}) \\
& \downarrow_{\mathrm{h} v} \\
& \left(\mathrm{NH}_{3}\right)_{5} \mathrm{Ru} \\
& \mathrm{II}_{\left(d \pi_{3}{ }^{1}\right)-\mathrm{bta}-\left(d \pi_{3}{ }^{2}\right) \mathrm{Ru}}{ }^{\mathrm{II}}(\text { edta })
\end{aligned}
$$

Após a etapa de transferência eletrônica óptica, um processo térmico inverso deve ocorrer (veja representação no diagrama do Esq. 10), desde que o sistema é assimétrico e existe um driving force, $\Delta G^{\circ}$ ou $\Delta E_{0}$, favorecendo o isômero eletrônico $\left(\mathrm{NH}_{3}\right)_{5} \mathrm{Ru}^{\text {II }}$ (bta) Ru ${ }^{\text {III }}$ (edta):
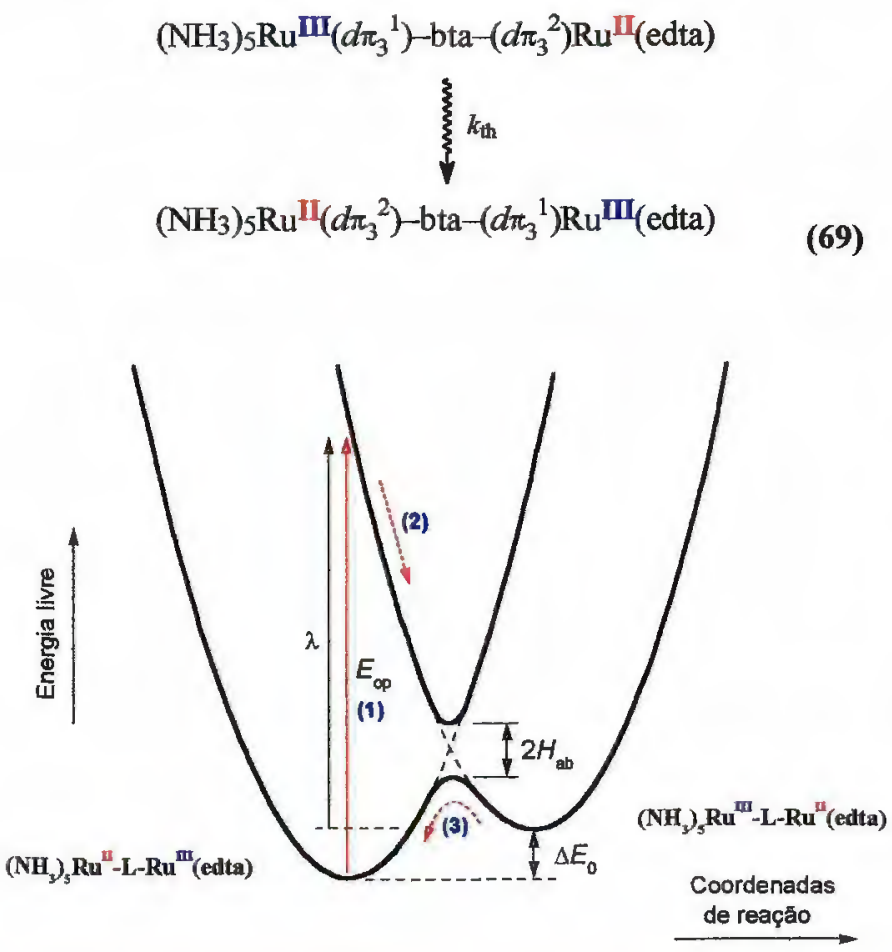

Esquema 10. Diagrama de energia qualitativo para a reaçăo de ET no complexo de valencia mista neutro $\left(\mathrm{NH}_{3}\right)_{5} R \mathrm{R}-\mu-L-R u(e d t a)$.

Conforme descrito no capítulo introdutório (seção 1.1), os diagramas de energia potencial ou de energia livre têm sido usados nos modelos de Marcus e Hush como uma poderosa ferramenta na descrição de reações de ET induzidas por calor ou por luz. O Esq. 10 ilustra um diagrama desse tipo para o complexo assimétrico genérico representado como $\left(\mathrm{NH}_{3}\right)_{5} \mathrm{Ru}^{\mathrm{II}}-\mathrm{L}-\mathrm{Ru} \mathrm{u}^{\mathrm{II}}$ (edta) (onde $\mathrm{L}$ deve ser um ligante-ponte monoaniônico; p. ex. benzotriazolato ou benzoimidazolato). Portanto, a energia de transição IT $\left(E_{\mathrm{op}}\right)$ para esses sistemas será igual a soma de $\lambda$, a energia reorganizacional (isto é, a energia de Franck-Condon), e $\Delta E_{0}$, a diferença de energia interna entre o complexo neutro equilibrado termicamente $\left(\mathrm{NH}_{3}\right)_{5} \mathrm{Ru}^{\mathrm{II}}-\mathrm{L}-\mathrm{Ru}^{\mathrm{III}}$ (edta) e seu isômero redox de maior energia $\left(\mathrm{NH}_{3}\right)_{5} \mathrm{Ru}{ }^{\mathrm{II}}-\mathrm{L}-\mathrm{Ru}{ }^{\mathrm{II}}(\mathrm{edta})$, que é o produto da transferência de elétrons óptica após ter sofrido relaxação vibracional e rotacional. O significado de $H_{\text {ab }}$, a energia de ressonância entre os estados reagente e produto no ponto de intersecção das curvas, foi exaustivamente explorado nas seções 1.2 e 6.1, e sua magnitude para os sistemas com $\mathrm{L}=$ $\mathrm{bta}^{-}$e bim${ }^{-}$será estimada mais adiante no item 3.1.2.2.4.

A estabilidade termodinâmica do complexo de valência mista, relativa às espécies isovalentes, pode ser estimada a partir da constante de comproporcionamento associada com o equilíbrio da reação:

$$
\begin{gathered}
{\left[\left(\mathrm{NH}_{3}\right)_{5} \mathrm{Ru}^{\mathrm{III}}-\mathrm{bta}-\mathrm{Ru}^{\mathrm{III}}(\mathrm{edta})\right]^{+}+\left[\left(\mathrm{NH}_{3}\right)_{5} \mathrm{Ru}^{\mathrm{III}}-\mathrm{bta}-\mathrm{Ru}^{\mathrm{II}}(\mathrm{edta})\right]^{-}} \\
{ }_{2\left(\mathrm{NH}_{3}\right)_{5} \mathrm{Ru}^{\mathrm{II}}-\text { bta- }-\mathrm{Ru}^{\mathrm{III}}(\mathrm{edta})}
\end{gathered}
$$

Considerando-se que $\Delta E_{1 / 2}=\left|E_{2}-E_{1}\right|=285 \mathrm{mV}$, então $K_{\mathrm{c}}$ foi estimado baseado na Eq. 19, que forneceu o valor de $6,55 \times 10^{4}$, correspondendo a $\Delta G_{c}=-6,57 \mathrm{kcal} \mathrm{mol}^{-1}(2300$ $\mathrm{cm}^{-1}$ ).

Apesar da alta magnitude de $K_{\mathrm{c}}$, que é típica de sistemas com acoplamento eletrônico forte, é importante lembrar que - sistema não é simétrico e existe um $\Delta E$ intrínseco associado à diferença de potencial de redução nas unidades monômeras de partida $\left(E_{1 / 2}\right.$ para $\left[\mathrm{Ru}\left(\mathrm{NH}_{3}\right)_{5}(\mathrm{bta})\right]^{2+} \mathrm{e}$ $[R \text { u(edta)(bta) }]^{2-}$ são 0,075 e $-0,040 \mathrm{~V}$, respectivamente; de tal forma que $\Delta E_{\text {(mono) }}=115 \mathrm{mV}$ ). Portanto, a magnitude de $\Delta G_{\mathrm{c}}$ não deve ser totalmente relacionada à estabilização do complexo por deslocalização eletrônica no estado de valência mista. ${ }^{16,17,319} \mathrm{Na}$ verdade, esse $\Delta G_{\mathrm{c}}$ obtido é resultante principalmente da substancial assimetria redox, e não da contribuição puramente por deslocalização.

Para uma aproximação na comparação com resultados dos sistemas de valência mista simétricos, $\Delta E_{\text {(mono) }}$ deve ser subtraído de $\Delta E_{12}$ (isto é, $285-115 \mathrm{mV}$ ), resultando uma estabilização efetiva de $170 \mathrm{mV}$. Essa estabilização resultante (chamada aqui de $\Delta G_{\mathrm{c}}{ }^{\prime}$ ) contribuiria com 1370 $\mathrm{cm}^{-1}$ para a energia de comproporcionamento (Tab. 5).

Ainda assim, é importante reconhecer que essa energia é uma soma de, no mínimo, ${ }^{319}$ quatro termos: ${ }^{17,70} \Delta G_{\text {en }}+\Delta G_{\text {el }}$ $+\Delta G_{\mathrm{s}}+\Delta G_{\mathrm{d}}$, onde $\Delta G_{\text {en }}$ é um fator entrópico que reflete a distribuição estatística da Eq. 70 (avaliado como $1 / 2 R T \ln 1 / 4$ ); $\Delta G_{\text {el }}$ é um fator eletrostático oriundo da repulsão dos dois centros metálicos carregados conectados pela ponte; $\Delta G_{\mathrm{s}}$ é um fator sinergístico, oriundo da estabilização por transferência de carga e efeitos aceitador-doador de esfera externa; e o quarto termo, $\Delta G_{\mathrm{d}}$ (fator de deslocalização ou 
ressonância), é na verdade o único componente da energia de estabilização com origem na deslocalização eletrônica. Para sistemas fracamente acoplados, a sua magnitude pode ser estimada por $\Delta G_{\mathrm{d}}=H_{\mathrm{ab}}{ }^{2} / \lambda$ (item 1.2.3), a partir da energia de Franck-Condon, $\lambda$, e da energia de ressonância, $H_{\text {ab, }}$ que pode ser extraída dos parâmetros da banda de IT.
No sistema assimétrico de benzotriazolato, o valor de $\Delta G_{\mathrm{d}}$ assim calculado é superior a $128 \mathrm{~cm}^{-1}$. Considerado que $\Delta G_{\mathrm{d}}$ é geralmente $\sim 1 \%(<20 \mathrm{mV})$ de $H_{\mathrm{ab}}$ na maioria dos casos reportados de classe II, $^{70} \circ$ valor obtido $(>15 \%)$ reflete uma deslocalização bastante significativa nesse complexo.

Tabela 5. Parâmetros termodinâmicos para os complexos binucleares simétricos [(edta)Ru- $\left.L_{b}-R u(e d t a)\right]^{n-}$ e assimétricos $\left[\left(\mathrm{NH}_{3}\right)_{5} \mathrm{Ru}-\mathrm{L}_{\mathrm{b}}-\mathrm{Ru}(\mathrm{edta})\right]^{\mathrm{n}-}\left(\mathrm{L}_{\mathrm{b}}=\mathrm{bta}^{-}\right.$ou bim $)$.

\begin{tabular}{|c|c|c|c|c|c|c|c|c|}
\hline Complexo ${ }^{a}$ & $\begin{array}{c}E_{12}(\mathbf{1}) \\
\text { (V) }\end{array}$ & $\begin{array}{c}E_{12}(2) \\
(V)\end{array}$ & $\begin{array}{l}\Delta E_{12} \\
(\mathrm{mV})\end{array}$ & $\boldsymbol{K}_{\mathrm{c}}$ & $\begin{array}{c}\Delta G_{\mathrm{c}} \\
\left(\mathrm{cm}^{-1}\right)\end{array}$ & $\begin{array}{c}\Delta E_{(\mathrm{mom})} \\
(\mathrm{mV})\end{array}$ & $\begin{array}{c}\Delta G_{\mathrm{c}}^{\prime} \\
\left(\mathrm{cm}^{-1}\right)\end{array}$ & $\begin{array}{c}\Delta G_{\mathrm{d}} \\
\left(\mathrm{cm}^{-1}\right)\end{array}$ \\
\hline $\mathbf{1}$ & 0,020 & $-0,180$ & 200 & $2,4 \times 10^{3}$ & 1610 & - & - & $\leq 3450^{b}$ \\
\hline 2 & 0,175 & $-0,110$ & 285 & $6,6 \times 10^{4}$ & 2300 & 115 & 1370 & $>128$ \\
\hline 3 & $-0,090$ & $-0,230$ & 140 & $2,3 \times 10^{2}$ & 1130 & - & - & 103 \\
\hline 4 & 0,035 & $-0,175$ & 210 & $3,6 \times 10^{3}$ & 1695 & $\sim 100$ & 885 & 117 \\
\hline
\end{tabular}

${ }^{a}$ Onde: $\quad 1=[(\text { edta }) \mathrm{Ru}-\mathrm{bta}-\mathrm{Ru}(\text { edta })]^{4-} ; \quad 2=\left(\mathrm{NH}_{3}\right)_{5} \mathrm{Ru}-\mathrm{bta}-\mathrm{Ru}(\mathrm{edta})$;

$3=[(\text { edta }) \mathrm{Ru}-\mathrm{bim}-\mathrm{Ru}(\text { edta })]^{4-} ; \mathbf{4}=\left(\mathrm{NH}_{3}\right)_{5} \mathrm{Ru}$-bim-Ru(edta);

${ }^{b}$ Para sistemas de classe III, $\Delta G_{\mathrm{d}}$ deve ser expresso pelo seu limite máximo onde $\Delta G_{\mathrm{d}}=1 / 2 E_{\mathrm{op}}$.

Medidas espectroeletroquímicas na região do Vis também foram realizadas e as mudanças espectrais mostradas na Fig. 20 podem ser sumarizadas como segue: em potenciais aplicados com formação da espécie completamente oxidada, uma banda é observada em $520 \mathrm{~nm}\left(\varepsilon=1550 \mathrm{~mol}^{-1} \mathrm{dm}^{3}\right.$ $\mathrm{cm}^{-1}$ ), atribuída a transições LMCT sobrepostas, isto é $\left(\mathrm{bta}^{-}\right) p_{\pi} \rightarrow d_{\pi}\left\{\mathrm{Ru}^{\mathrm{III}}\left(\mathrm{NH}_{3}\right)_{5}\right\}$ e $\left(\mathrm{bta}^{-}\right) p_{\pi} \rightarrow d_{\pi}\left\{\mathrm{Ru}^{\mathrm{III}}\right.$ (edta) $\}$, por analogia às transições LMCT nas correspondentes espécies mononucleares (Tab. 2). Por outro lado, em potenciais aplicados correspondendo à formação da espécie isovalente reduzida, uma forte banda de absorção é observada em 410 $\mathrm{nm}\left(\varepsilon=6650 \mathrm{~mol}^{-1} \mathrm{dm}^{3} \mathrm{~cm}^{-1}\right)$, associada às transiçð̃es MLCT recobertas envolvendo ambas as unidades metálicas, $\left\{(\right.$ edta $\left.) \mathrm{Ru}^{\mathrm{II}}\right\} d_{\pi} \rightarrow p_{\pi}{ }^{*}\left(\mathrm{bta}^{-}\right)$e $\left\{\left(\mathrm{NH}_{3}\right)_{5} \mathrm{Ru}^{\mathrm{II}}\right\} d_{\pi} \rightarrow p_{\pi}{ }^{*}\left(\mathrm{bta}^{-}\right)$.

Em potenciais intermediários, correspondendo à geração do estado de valência mista, duas bandas de transferência de carga podem ser vistas: uma em $410 \mathrm{~nm}$ e outra em $520 \mathrm{~nm}$, que é na verdade constituída de dois ombros estreitos e bem definidos em 500 e $530 \mathrm{~nm}$. Uma vez que a separação deles equivale a uma energia de $1130 \mathrm{~cm}^{-1}$, então eles foram atribuídos como sendo duas transições componentes de uma separação vibrônica da transferência de carga ligante-metal. Dessa forma, em uma primeira aproximação, essas duas bandas poderiam ser atribuídas às transições MLCT e LMCT nos cromóforos assimétricos, por exemplo $\left\{\left(\mathrm{NH}_{3}\right)_{5} \mathrm{Ru}^{\mathrm{II}}(\mathrm{bta})\right\} \quad$ e $\left\{(\mathrm{bta}) \mathrm{Ru}^{\mathrm{III}}(\right.$ edta $\left.)\right\}$, respectivamente Particularmente complicado (e inconsistente com fatores simplesmente eletrostáticos) é o fato de que ambas as transições LMCT e MLCT para a espécie neutra de valência mista ocorrem aproximadamente na mesma energia que seus semelhantes dirutênio(III) (cátion; +1) e dirutênio(II) (ânion; -1). Apesar da coincidência de energia, uma mudança dramática nos perfis de absorção tem sido observada para as bandas de transferência de carga no complexo de valência mista, quando comparado com as espécies isovalentes (Fig. 20). Comportamento similar foi previamente encontrado no complexo binuclear simétrico $\left[\{\mathrm{Ru}(\text { edta })\}_{2}(\mathrm{bta})\right]^{4}$, indicando uma perturbação forte nos níveis eletrônicos dos dois cromóforos, no estado de intervalência.

De acordo com estudos de literatura, ${ }^{320}$ as características espectroscópicas na região do UV-Vis para os complexos binucleares ligados por ponte são de interesse na análise das propriedades de valência mista, uma vez que elas devem refletir o efeito das interações entre os íons metálicos. Se a interação eletrônica entre os centros metálicos doador e 
aceitador for fraca, as transições devem ser essencialmente localizadas em um dos dois íons metálicos do dímero. Entretanto, no presente exemplo, o espectro do complexo binuclear não é simplesmente a soma daqueles dos íons mononucleares. Isso origina da perturbação dos níveis metálicos, e é melhor visualizado na comparação com o complexo benzoimidazolato no item seguinte.

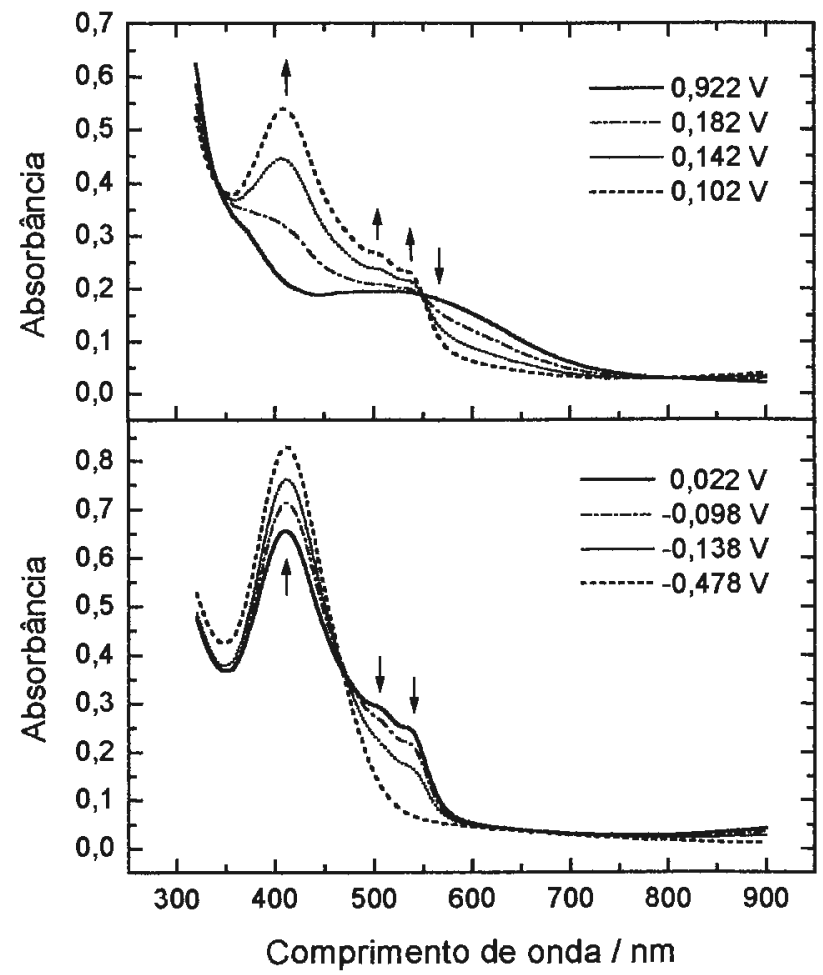

Figura 20. Espectros eletrônicos dos complexos binucleares $\left[\left(\mathrm{NH}_{3}\right)_{5} \mathrm{Ru}(\mathrm{bta}) \mathrm{Ru}(\mathrm{edta})\right]^{n}(n=+1,0,-1)$ em pH 6,0. $\left(C=5,0 \times 10^{-3} \mathrm{~mol} \mathrm{dm} ; /=0,025 \mathrm{~cm} ; I=\mathrm{Na}\right.$ (tfa) $0,25 \mathrm{~mol} \mathrm{dm}^{-3}$ )

\subsection{Complexo $\left[\left(\mathrm{NH}_{3}\right)_{5} \mathrm{Ru}(\mu \text {-bim) Ru(edta) }]^{n}\right.$}

A mistura de $\left[\mathrm{Ru}\left(\mathrm{NH}_{3}\right)_{5}(\text { bimH })\right]^{3+}$ e $\left[\mathrm{Ru}(\text { edta })\left(\mathrm{H}_{2} \mathrm{O}\right)\right]^{-}$em solução aquosa ( $\mathrm{pH}$ maior que 7,0 ) produz um composto vermelho. Similarmente à espécie benzotriazolato, a presença do novo complexo binuclear assimétrico $\left[\left(\mathrm{NH}_{3}\right)_{5} \mathrm{Ru}^{\mathrm{III}}(\mathrm{bim}) \mathrm{Ru}^{\mathrm{III}} \text { (edta) }\right]^{+}$foi detectada por voltametria cíclica, pelo surgimento de dois pares de ondas reversiveis em $E_{1}=0,035 \mathrm{~V}$ e $E_{2}=-0,175 \mathrm{~V}$ (Fig. 21A), em comparação com as ondas características das espécies mononucleares em $-0,100$ e $\sim-0,20 \mathrm{~V}$, respectivamente (Tab. 3). Da mesma forma, os voltamogramas de pulso diferencial (Fig. 21B) apresentam dois picos bem definidos representando aqueles potenciais redox. As duas ondas predominam a medida que a relação $\left[\mathrm{Ru}\left(\mathrm{NH}_{3}\right)_{5}(\mathrm{bimH})\right]^{3+}$ : $\left[\mathrm{Ru}(\right.$ edta $\left.)\left(\mathrm{H}_{2} \mathrm{O}\right)\right]$ se aproxima de $1: 1$, conforme mostrado na Fig. 21A. Esse tipo de comportamento eletroquímico é coerente com a formação de um complexo binuclear, onde o par de ondas corresponde aos dois pares redox formais

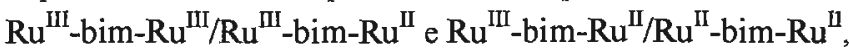
separados por $\Delta E_{1 / 2}=210 \mathrm{mV}$.

$$
\begin{aligned}
& {\left[\left(\mathrm{NH}_{3}\right)_{5} \mathrm{Ru}^{\mathrm{III}} \text {-bim-Ru}{ }^{\mathrm{III}_{(}}(\text {edta })\right]^{+}} \\
& 11 \quad E_{1}=0,035 \mathrm{~V} \\
& \left(\mathrm{NH}_{3}\right)_{5} \mathrm{Ru}^{\mathrm{II}} \text {-bim-Ru }{ }^{\text {III }} \text { (edta) } \\
& 1 \quad E_{2}=-0,175 \mathrm{~V} \\
& \text { [(NH} \left.)_{3} \mathrm{Ru}^{\mathrm{II}}-\text { bim-Ru}{ }^{\text {III }}(\text { edta })\right]^{-}
\end{aligned}
$$

A constante de comproporcionamento para o sistema com benzoimidazolato foi calculada pela Eq. 19 em $3,55 \times 10^{3}$ $\left(\Delta G_{\mathrm{c}}=-4,84 \mathrm{kcal} \mathrm{mol}^{-1}\right.$ ou $\left.1695 \mathrm{~cm}^{-1}\right)$. Pela subtração de $\Delta E_{\text {(mono) }} \sim 100 \mathrm{mV}$ do valor observado de $\Delta E_{1 / 2}$, a influência adicional dos efeitos eletrônicos sobre a espécie de valência mista pode ser estimado em $110 \mathrm{mV}$ (da qual a contribuição efetiva à $\Delta G_{\mathrm{c}}$ é $\Delta G_{\mathrm{c}}{ }^{\prime}=885 \mathrm{~cm}^{-1}$ ); isto é, muito menor que aquela para o caso do benzotriazolato (Tab. 5).

Outra forte indicação da presença da espécie binuclear vem de uma intensa banda de absorção eletrônica na região do NIR para o complexo de valência mista, cujo comportamento espectroeletroquímico pode ser visto na Fig. 22. Começando pelo complexo completamente oxidado $\left[\left(\mathrm{NH}_{3}\right)_{5} \mathrm{Ru}^{\text {III }}(\mathrm{bim}) \mathrm{Ru}^{\text {III }}(\mathrm{edta})\right]^{+}(\sim 0,7 \mathrm{~V})$ e gradualmente diminuindo o potencial aplicado, uma banda bastante intensa e larga origina em $1430 \mathrm{~nm}$ para potenciais abaixo de $0,1 \mathrm{~V}$ (Fig. 22), devido à formação da espécie de valência mista $\left(\mathrm{NH}_{3}\right)_{5} \mathrm{Ru}^{\mathrm{II}}$ (bim) Ru ${ }^{\mathrm{MI}}$ (edta). $\mathrm{A}$ intensidade de absorção máxima $\left(\varepsilon=1500 \mathrm{~mol}^{-1} \mathrm{dm}^{3} \mathrm{~cm}^{-1}\right)$ é atingida quando o potencial aplicado aproxima-se de $-0,07 \mathrm{~V}$, que é o ponto médio entre os dois pares de ondas reversíveis mostrados na Fig. 21. Aplicando-se potenciais mais negativos, a intensidade da banda se torna gradualmente menor conforme a espécie completamente reduzida $\left[\left(\mathrm{NH}_{3}\right)_{5} \mathrm{Ru}^{\mathrm{II}}(\mathrm{bim}) \mathrm{Ru}^{\mathrm{II}}(\mathrm{edta})\right]^{-}$é gerada, até seu completo desaparecimento no extremo negativo $(\sim-0,4 \mathrm{~V})$ da faixa de trabalho (Fig. 22). Assim, a banda no NIR pode ser atribuída a uma transição de IT, conforme ilustrado abaixo

$$
\begin{aligned}
& \left(\mathrm{NH}_{3}\right)_{5} \mathrm{Ru}^{\mathrm{II}}\left(d \pi_{3}{ }^{2}\right)-\text { bim- }\left(d \pi_{3}{ }^{1}\right) \mathrm{Ru}^{\mathrm{III}}(\mathrm{edta}) \\
& \left(\mathrm{NH}_{3}\right)_{5} \mathrm{Ru}^{\mathrm{III}}\left(d \pi_{3}{ }^{1}\right) \text {-bim- }\left(d_{\pi_{3}}{ }^{2}\right) \mathrm{Ru}^{\mathrm{II}}(\mathrm{edta})
\end{aligned}
$$




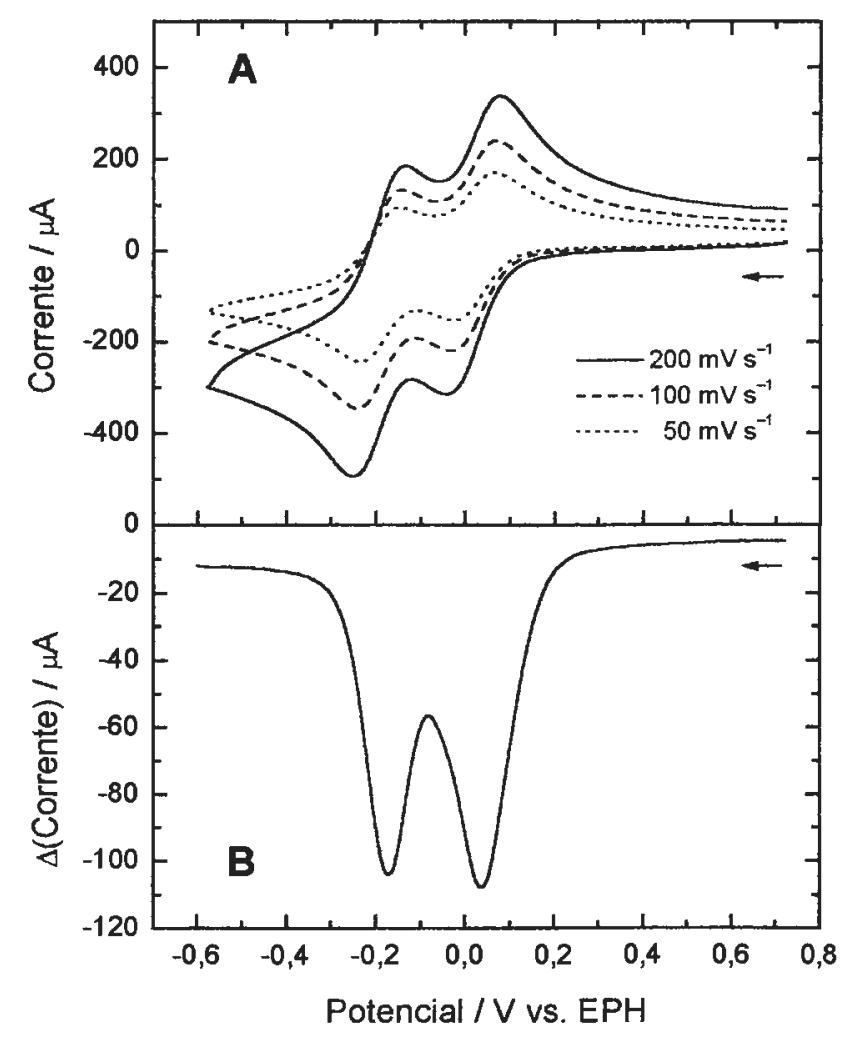

Figura 21. Voltamogramas ciclicos (A) e voltamograma de pulso diferencial (B) do complexo [ $\left(\mathrm{NH}_{3}\right)_{5} \mathrm{Ru}(\text { bim) Ru(edta) }]^{+}$em soluçăo aquosa $\left(C=5,0 \times 10^{-3} \mathrm{~mol} \mathrm{dm}^{-3} ; I=\mathrm{Na}\right.$ (tfa) $0,25 \mathrm{~mol} \mathrm{dm}^{-3} ; \mathrm{pH} \mathrm{9,0)}$. (condições de trabalho da DPV: altura do pulso $=0,025 \mathrm{~V}$; largura do pulso $=0,050 \mathrm{~s} ; v=100 \mathrm{mV} \mathrm{s}^{-1}$ )

A contribuição do fator de deslocalização eletrônica $\left(\Delta G_{\mathrm{d}}\right)$ para a energia de comproporcionamento foi calculada (a partir dos parâmetros de acoplamento eletrônico; v. próximo item) em $117 \mathrm{~cm}^{-1}$ (Tab. 5).

Somadas à banda IT na região NIR, mudanças espectrais na região do Vis também têm sido monitoradas, como podem ser observadas na Fig. 23 e resumidas como segue: se o potencial aplicado corresponde à espécie isovalente oxidada, então uma banda em $570 \mathrm{~nm}\left(\varepsilon=1680 \mathrm{~mol}^{-1} \mathrm{dm}^{3}\right.$ $\left.\mathrm{cm}^{-1}\right)$ e um ombro próximo de $475 \mathrm{~nm}\left(\varepsilon<1000 \mathrm{~mol}^{-1} \mathrm{dm}^{3}\right.$ $\mathrm{cm}^{-1}$ ) são observados; a banda é atribuída às transições LMCT associadas com os cromóforos $\left\{\mathrm{Ru}^{\mathrm{III}}\right.$ (edta)(bim) $\}$ e $\left\{\mathrm{Ru}^{\mathrm{II}}\left(\mathrm{NH}_{3}\right)_{5}(\right.$ bim $\left.)\right\}$, respectivamente, em analogia com as espécies mononucleares (Tab. 2). Em contraste, para as espécies completamente reduzidas, não foram observadas bandas de absorção na região do visivel; as bandas de absorção correspondentes às transições MLCT ocorrem na região do UV, ao redor de $330 \mathrm{~nm}$.

No caso da espécie de valência mista, as bandas LMCT em $475 \mathrm{~nm}$ praticamente desaparecem, enquanto uma banda de absorção se torna evidente ao redor de $300 \mathrm{~nm}$, correspondendo à transição do tipo MLCT da unidade
$\left\{\mathrm{Ru}^{\mathrm{II}}\left(\mathrm{NH}_{3}\right)_{5}(\right.$ bim $\left.)\right\}$. Portanto, o comportamento das bandas eletrônicas na região do visível para o complexo de valência mista $\left(\mathrm{NH}_{3}\right)_{5} \mathrm{Ru}^{\mathrm{II}}$ (bim)Ru ${ }^{\mathrm{III}}$ (edta) pode ser explicado pela soma das contribuições dos dois fragmentos metálicos de partida, em contraste com o análogo benzotriazolato. Essa descrição é característica de um sistema fracamente acoplado. $^{70,320}$

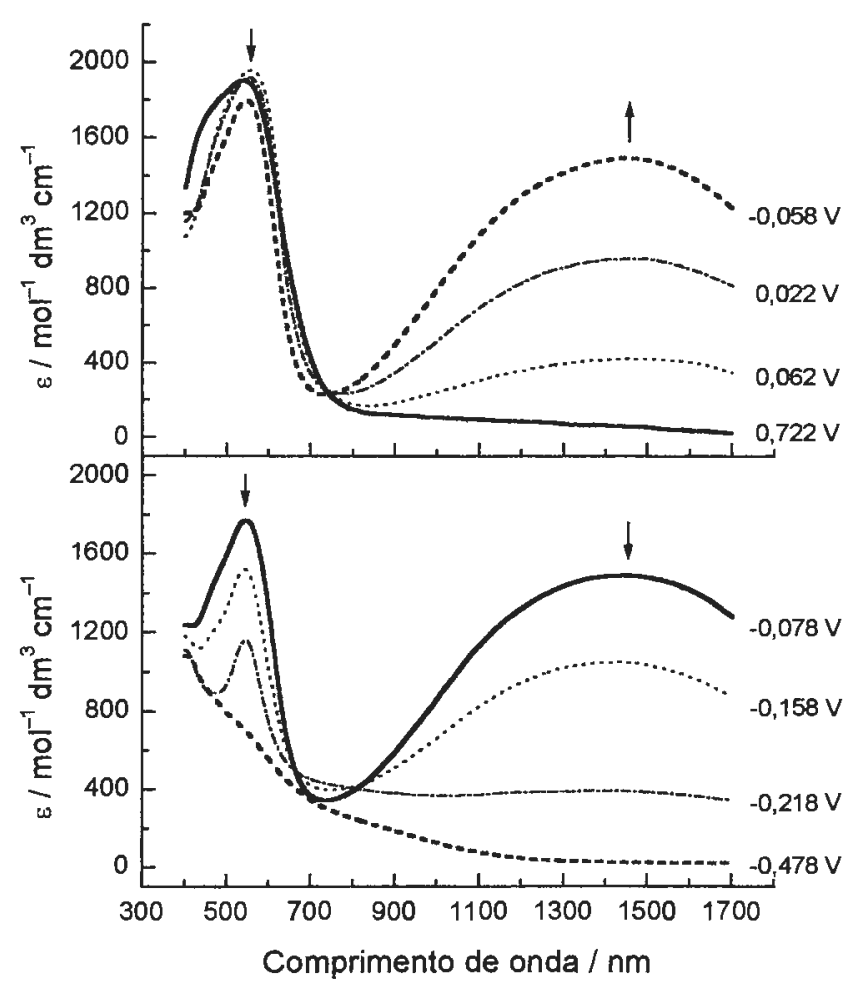

Figura 22. Espectros eletrônicos sob aplicação de potencial do complexo $\left[\left(\mathrm{NH}_{3}\right)_{5} \mathrm{Ru}(\mathrm{bim}) \mathrm{Ru}(\text { edta })\right]^{+}$em $\mathrm{D}_{2} \mathrm{O}$. $\left(I=\mathrm{KNO}_{3} 0,25 \mathrm{~mol} \mathrm{dm}^{-3} ; \mathrm{pD} 8,8\right)$

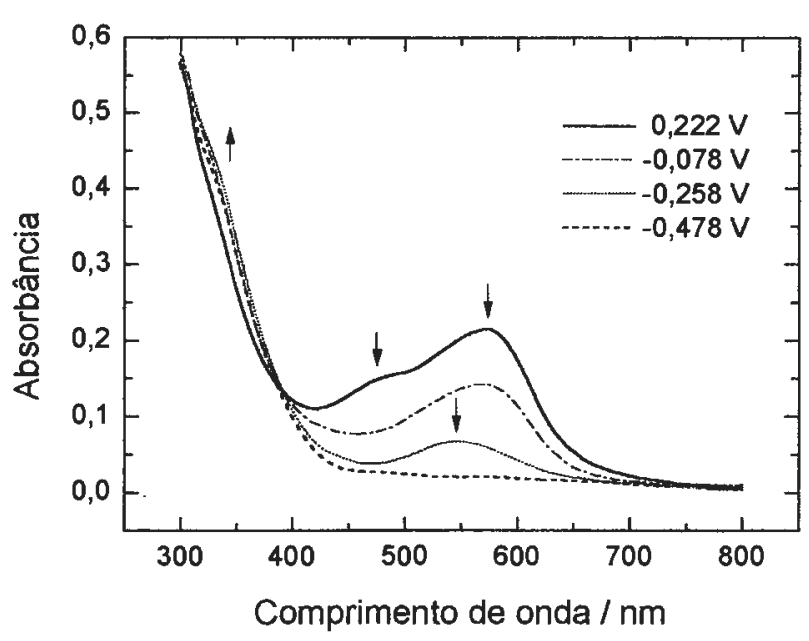

Figura 23. Espectros eletrônicos do complexo binuclear $\left[\left(\mathrm{NH}_{3}\right)_{5} \mathrm{Ru}(\mathrm{bim}) \mathrm{Ru}(\text { edta })\right]^{+}$sob aplicação de potenciais em pH 9,0. ( $C=5,0 \times 10^{-3} \mathrm{~mol} \mathrm{dm}^{-3} ; I=0,025 \mathrm{~cm} ; /=\mathrm{Na}$ (tfa) $0,25 \mathrm{~mol} \mathrm{dm}^{-3}$ ) 
Resumindo, no sistema benzoimidazolato, todos os dados eletroquímicos e espectroscópicos são consistentes com um modelo de complexo binuclear em que as interações entre os íons de rutênio são relativamente fracas. Ademais, onde perturbações significativas ocorrem (o que é revelado pela pequena diferença entre os espectros dos monômeros e do dímero em todos os estados redox), elas parecem originar dos efeitos de coordenação de uma unidade de rutênio adicional na extremidade remota, podendo ser interpretado separadamente pela influência do caráter ácido ou das interações retrodoadoras- $\pi$ no caso das unidades $\mathrm{Ru}^{\mathrm{III}}$ e $\mathrm{Ru}{ }^{\mathrm{II}}$, respectivamente.

\subsection{Estrutura molecular}

A estrutura molecular simulada do complexo binuclear neutro $\left(\mathrm{NH}_{3}\right)_{5} \mathrm{Ru}^{\mathrm{II}}\left(\right.$ bim) $\mathrm{Ru}^{\mathrm{III}}$ (edta), baseada em cálculos de otimização geométrica em nível de mecânica molecular (método $\mathrm{MM}+$ ), mostra que os dois íons metálicos e o ligante-ponte estão localizados no mesmo plano, exibindo uma distância metal-metal de 5,79 $\AA$.
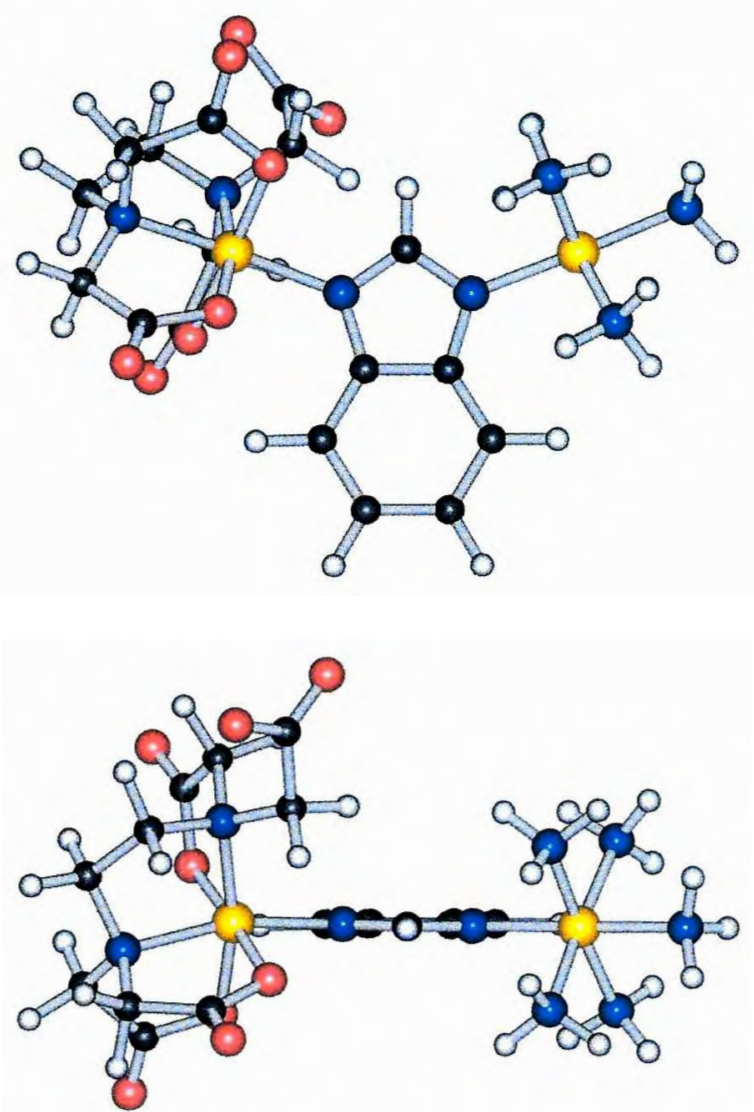

Figura 24. Estrutura molecular teórica do complexo binuclear $\left(\mathrm{NH}_{3}\right)_{5} \mathrm{Ru}^{\prime \prime}$ (bim)Ru (edta), calculada por otimização de geometria em nivel de mecânica molecular segundo o método $\mathrm{MM}+$.
No caso do complexo $\left[\left(\mathrm{NH}_{3}\right)_{5} \mathrm{Ru}^{\mathrm{III}}(\text { bta }) \mathrm{Ru}^{\mathrm{III}} \text { (edta) }\right]^{+}$, a simulação estrutural depende da proposição dos modos de ligação para os íons de rutênio. Assumindo-se uma coordenação simétrica com os íons de rutênio ligados aos átomos $\mathrm{N} 1$ e N3, a geometria final é muito similar à do análogo benzoimidazolato, com uma distância metal-metal de 5,68 $\AA$. Entretanto, para a espécie de valência mista, $\left(\mathrm{NH}_{3}\right)_{5} \mathrm{Ru}^{\text {II }}$ (bta)Ru $\mathrm{Ru}^{\mathrm{III}}$ (edta), algum envolvimento do átomo $\mathrm{N} 2$ mais ácido/aceitador- $\pi$ não pode ser ignorado devido à contribuição esperada das interações retrodoadoras- $\pi$ do centro de $\mathrm{Ru}^{\mathrm{II}}$. Teoricamente, em uma situação extrema a coordenação via átomos vicinais $\mathrm{N} 1$ e N2 levaria a uma grande distorção da geometria planar, devido ao elevado impedimento estérico resultante. Todavia, uma configuração intermediária parece ser bastante plausivel, considerando-se as propriedades fluxionais previamente observadas nesse sistema. Assim, pode-se esperar algum deslocamento da configuração regular $\mathrm{N} 1, \mathrm{~N} 3$, proposta aqui para o benzoimidazolato-derivado, para uma outra configuração intermediária onde a participação do sítio N2 é relevante (v. representação no Esq. 11).<smiles></smiles>

$\left(\mathrm{NH}_{3}\right)_{5} \mathrm{Ru}(\mathbf{b i m}) \mathrm{Ru}($ edta $)$

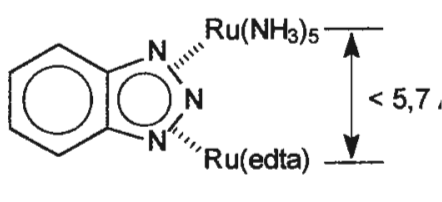

$\left(\mathrm{NH}_{3}\right)_{5} \mathrm{Ru}($ bta $) \mathrm{Ru}($ edta $)$
Esquema 11. Modelo de aproximação fluxional no benzotriazolato.

De acordo com observações teóricas anteriores para o complexo de valência mista simétrico de rutênio-edta, uma aproximação intermetálica de até $4,5 \AA$ seria plausível, conduzindo a uma grande intensificação do acoplamento eletrônico, conforme observado experimentalmente. Nesse caso específico do complexo assimétrico, cálculos híbridos (usando-se métodos em diferentes níveis; particularmente, MM+/ZINDO) forneceram alguma indicação de que a distância metal-metal pode ser diminuída até cerca de 5,0 , sem distorção apreciável da geometria planar. Essa distância seria um valor limite para os propósitos de modelagem e comparação. 


\subsection{Propriedades de intervalência}

Os espectros dos complexos de valência mista são melhor observados na Fig. 25. É interessante notar que a banda IT no bta-complexo é mais estreita $\left(\Delta \bar{v}_{1 / 2}=3700 \mathrm{~cm}^{-1}\right)$ e intensa $\left(\varepsilon=2300 \mathrm{~mol}^{-1} \mathrm{dm}^{3} \mathrm{~cm}^{-1}\right.$ ) que a observada no bimcomplexo $\left(\Delta \bar{v}_{1 / 2}=5500 \mathrm{~cm}^{-1} ; \varepsilon=1500 \mathrm{~mol}^{-1} \mathrm{dm}^{3} \mathrm{~cm}^{-1}\right)$. Essas diferenças não são refletidas diretamente na força do oscilador $\left(f_{\text {osc }}=0,039\right.$ e 0,038$)$ e no momento de dipolo da transição $(M=0,732$ e 0,710 para os complexos com benzotriazolato e benzoimidazolato), devido à compensação largura versus intensidade em ambos os sistemas. ${ }^{a}$

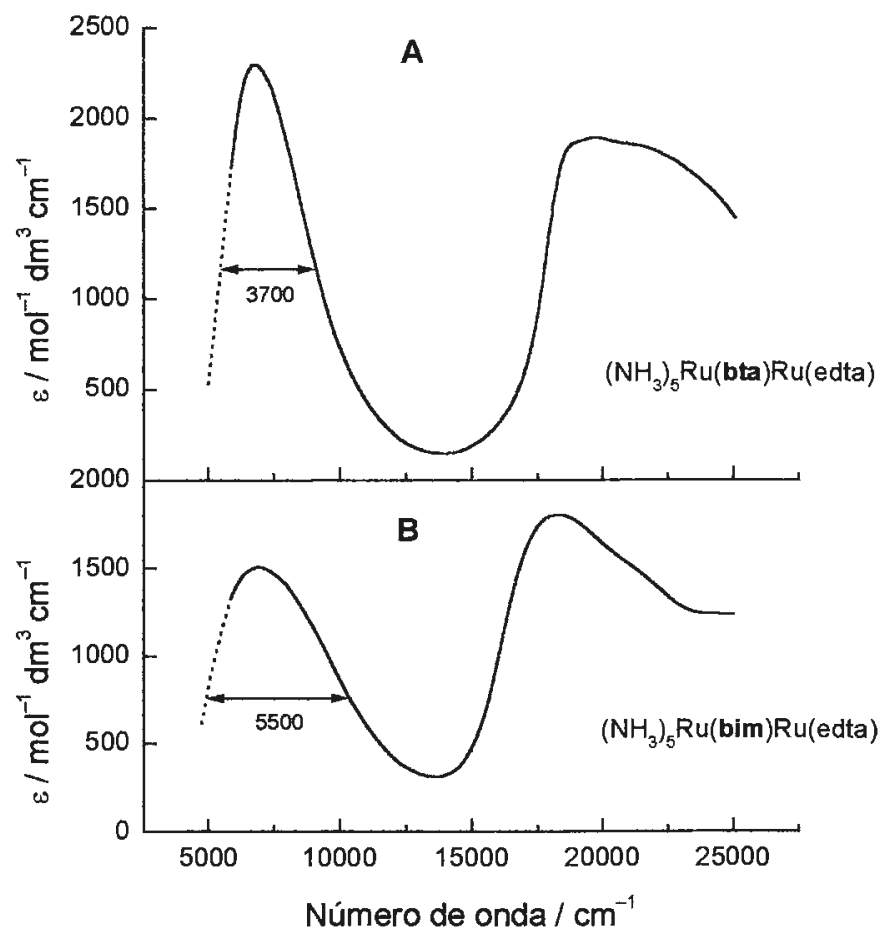

Figura 25. Espectros eletrônicos dos complexos de valência mista (A) $\left(\mathrm{NH}_{3}\right)_{5} \mathrm{Ru}(\mathrm{bta}) \mathrm{Ru}\left(\right.$ edta) e (B) $\left(\mathrm{NH}_{3}\right)_{5} \mathrm{Ru}(\mathrm{bim}) \mathrm{Ru}$ (edta) em $\mathrm{D}_{2} \mathrm{O}$. Os complexos foram gerados in situ pela aplicacão de $0,100 \mathrm{~V}$ e $-0,060 \mathrm{~V}$, respectivamente. $\left(l=\mathrm{KNO}_{3} 0,25 \mathrm{~mol} \mathrm{dm}^{-3} ; \mathrm{pD} 5,5(\mathrm{~A})\right.$ e 8,8 (B))

Conforme discussão anterior, três classes de sistemas de VM podem ser distinguidas dependendo da magnitude da interação entre os sítios doador e aceitador (item 1.2.1). Usando o formalismo de Mulliken, Hush demonstrou que o elemento de matriz do acoplamento eletrônico e a extensão da deslocalização eletrônica na espécie de valência mista podem ser estimados dos parâmetros da banda de IT (item 1.2.3.1), onde se assume um sistema de classe II, onde a interação eletrônica é fraca ou moderadamente forte para ser tratada como uma perturbação discreta.

a As equações para o cálculo de $f_{\text {osc }}$ e $M$ encontram-se dadas no apêndice 6.1.
Então, um critério para avaliar ou classificar o grau de acoplamento eletrônico é dado pelo próprio modelo de Hush (item 1.2.4), através do cálculo da largura de meia-banda espectral $\Delta \bar{v}_{1 / 2}$ para a banda relacionada à transferência de intervalência, que, em um sistema assimétrico, é expressa pela Eq. 38. Assim, o valor calculado por essa equação corresponde ao valor limite mínimo para um complexo de valência mista de classe II. Os valores experimentais abaixo desse $\Delta \bar{v}_{1 / 2}$ estimado, são típicos de sistemas com acoplamento eletrônico substancial entre os centros metálicos, como é o caso de complexos com valência deslocalizada (classe III).

Os valores teórico e experimental de $\Delta \bar{v}_{1 / 2}$ para o complexo $\left(\mathrm{NH}_{3}\right)_{5} \mathrm{Ru}$ (bta)Ru(edta) são 3600 e $3700 \mathrm{~cm}^{-1}$, respectivamente. De acordo com o resultado acima, esse sistema não pode ser inequivocadamente descrito em termos de um modelo de valência mista tipicamente localizado (classe II), somente pelo critério de $\Delta \bar{v}_{1 / 2}$ (observe-se que os valores de $\Delta \bar{v}_{1 / 2}$ calculados para sistemas de classe II típicos $^{70}$ são geralmente $30-40 \%$ superiores/superestimados que os esperados pela equação de Hush (Eq. 27)). Talvez esse sistema pudesse ser melhor descrito como um caso de fronteira classe II/III, ou ainda do tipo fortemente acoplado dentro do limite superior da classe II do esquema de Robin e Day. Tal fato também é refletido no alto valor do coeficiente de extinção molar do complexo, bem como na elevada contribuição eletrônica para a energia de comproporcionamento e na forte perturbação dos níveis eletrônicos dos dois cromóforos terminais.

Ao contrário, os valores teórico e experimental de $\Delta \bar{v}_{1 / 2}$ para o complexo $\left(\mathrm{NH}_{3}\right)_{5} \mathrm{Ru}$ (bim)Ru(edta) são 3600 e 5500 $\mathrm{cm}^{-1}$, respectivamente. Portanto, baseado no valor estimado, que é muito menor que o observado, esse sistema pode ser diretamente enquadrado na classe II de Robin-Day

Ainda que a aplicação das Eqs. 27 e 28 para o cálculo da energia de acoplamento eletrônico e grau de deslocalização seja apropriada somente para sistemas fracamente perturbados que se incluem na classe II, uma estimativa aproximada (no limite inferior) dos parâmetros da IT pode ser determinada para o benzotriazolato-derivado, somente para propósitos de comparação com outros análogos (v. abaixo). Na verdade, métodos mais sofisticados para análise de sistemas com acoplamento forte têm sido descritos, ${ }^{\mathrm{b}}$ mas o tratamento clássico de Hush é mais direto, simples, intuitivo, e permite comparações.

\footnotetext{
b Onde se destacam aqueles propostos por Piepho, Krausz e Schatz (PKS) ${ }^{6}$ e por Reimers e Hush. ${ }^{321}$
} 
A energia de absorção óptica $\bar{v}_{\text {máx }}=E_{\mathrm{op}}$, sua absortividade molar $\varepsilon_{\text {máx }}$ e a correspondente largura de meia-banda $\Delta \bar{v}_{1 / 2}$ para a banda de IT das duas espécies de valência mista, $\left(\mathrm{NH}_{3}\right)_{5} \mathrm{Ru}^{\mathrm{II}}$ (bta) Ru ${ }^{\mathrm{III}}$ (edta) e $\left(\mathrm{NH}_{3}\right)_{5} \mathrm{Ru}^{\mathrm{II}}$ (bim) Ru ${ }^{\mathrm{III}}$ (edta), são dadas na Tab. 6. A distância de transferência de elétrons, $d$, que é freqüentemente assumida como sendo a separação intermetálica ( $\mathrm{v}$. item 1.2.3.1), foi extraída dos cálculos teóricos de otimização geométrica. No caso específico do benzotriazolato-complexo, uma faixa de possíveis valores foi considerada, devido à possibilidade de uma coordenação fluxional envolvendo os três átomos de nitrogênio.
Desde que as considerações acima foram introduzidas, os parâmetros $H_{\mathrm{ab}}$ e $\alpha^{2}$ para a energia de acoplamento eletrônico e o grau de deslocalização de elétrons no estado fundamental foram calculados como $>865 \mathrm{~cm}^{-1}$ e $>0,016$; e $850 \mathrm{~cm}^{-1}$ e 0,015 para $\left(\mathrm{NH}_{3}\right)_{5} \mathrm{Ru}^{\mathrm{II}}$ (bta) $\mathrm{Ru}^{\mathrm{III}}$ (edta) e $\left(\mathrm{NH}_{3}\right)_{5} \mathrm{Ru}^{\mathrm{II}}$ (bim) $\mathrm{Ru}^{11 \mathrm{I}}$ (edta), respectivamente (Tab. 6).

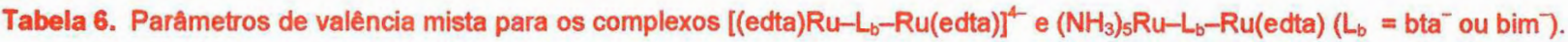

\begin{tabular}{|c|c|c|c|c|c|c|c|c|c|c|}
\hline Complexo $^{a}$ & $\begin{array}{c}\Delta E_{0} \\
\left(\mathrm{~cm}^{-1}\right)\end{array}$ & $\begin{array}{c}\bar{v}_{\max }\left(E_{\mathrm{op}}\right) \\
\left(\mathrm{cm}^{-1}\right)\end{array}$ & $\begin{array}{c}\lambda \\
\left(\mathrm{cm}^{-1}\right)\end{array}$ & $\begin{array}{c}\varepsilon_{\max } \\
\left(\mathrm{mol}^{-1} \mathrm{dm}^{3} \mathrm{~cm}^{-1}\right)\end{array}$ & $\begin{array}{c}\Delta \bar{v}_{1 / 2}(\exp ) \\
\quad\left(\mathrm{cm}^{-1}\right)\end{array}$ & $\begin{array}{c}\Delta \bar{v}_{1 / 2} \text { (calc) } \\
\left(\mathrm{cm}^{-1}\right)\end{array}$ & (A) & $\begin{array}{c}\boldsymbol{H}_{\mathbf{a b}} \\
\left(\mathrm{cm}^{-1}\right)\end{array}$ & $\alpha^{2}$ & Classe \\
\hline 1 & - & 6900 & $6900^{b}$ & 2200 & 2850 & 4000 & $<<5,7$ & $\leq 3450$ & $\sim 0,25$ & III \\
\hline 2 & 1250 & 6780 & $\sim 5530$ & 2300 & 3700 & 3600 & $<5,7$ & $>865^{k}$ & $>0,016^{c}$ & $\Pi / \Pi \mathrm{I}^{d}$ \\
\hline 3 & - & 6670 & $6670^{b}$ & 1500 & 5500 & 3900 & 5,8 & 830 & 0,015 & II \\
\hline 4 & 1370 & 6990 & $\sim 5620$ & 1500 & 5500 & 3600 & 5,8 & 850 & 0,015 & II \\
\hline
\end{tabular}

${ }^{a}$ Onde: $1=[(\text { edta }) \mathrm{Ru}-\text { bta-Ru(edta) }]^{4}, 2=\left(\mathrm{NH}_{3}\right)_{5} \mathrm{Ru}-$ bta-Ru(edta); $3=[(\text { edta }) \mathrm{Ru}-\text { bim-Ru(edta) }]^{4}, 4=\left(\mathrm{NH}_{3}\right)_{5} \mathrm{Ru}-$ bim-Ru(edta);

${ }^{b}$ Sistema simétrico: $\lambda=E_{\mathrm{op}}$;

${ }^{c}$ Valores subestimados devido à distância superestimada no limite de coordenação N1,N3;

${ }^{d} \mathrm{O}$ sistema se comporta como caso típico de fronteira classe II/III.

Ainda que esses valores para a espécie benzotriazolato estejam subestimados, sua magnitude é superior àquele calculado para a espécie benzoimidazolato e reflete a extensão da interação intermetálica. $\mathrm{Na}$ verdade, os resultados a respeito da energia de ressonância, $H_{\mathrm{ab}}$, são extraordinários para esse tipo de complexo, superando sistemas similares de classe II e igualando-se a alguns previamente reportados para sistemas de valência mista pertencentes a classe III.

Uma comparação bastante ilustrativa é dada pelos complexos análogos com $\mathrm{L}_{b}=\mathrm{pz},\left[\mathrm{Ru}\left(\mathrm{NH}_{3}\right)_{5}(\mathrm{pz}) \mathrm{Ru}(\text { edta })\right]^{+}$ e $[(\text { edta }) \operatorname{Ru}(\mathrm{pz}) \mathrm{Ru}(\mathrm{edta})]^{3--},{ }^{30,318}$ cujas propriedades de IT são bastante modestas e tipicamente de sistemas de valência mista fracamente acoplados (espécie assimétrica: $\Delta E_{1 / 2}=$ $140 \mathrm{mV}, K_{\mathrm{c}}=240, \bar{v}_{\text {máx }}=9800 \mathrm{~cm}^{-1}(1020 \mathrm{~nm}), \varepsilon_{\text {máx }}=300$ $\mathrm{mol}^{-1} \mathrm{dm}^{3} \mathrm{~cm}^{-1}, H_{\mathrm{ab}}=280 \mathrm{~cm}^{-1}$; espécie simétrica: $\Delta E_{1 / 2}=$ $140 \mathrm{mV}, K_{\mathrm{c}}=240, \bar{v}_{\text {máx }}=10300 \mathrm{~cm}^{-1}(970 \mathrm{~nm}), \varepsilon_{\text {máx }}=240$ $\left.\mathrm{mol}^{-1} \mathrm{dm}^{3} \mathrm{~cm}^{-1}, H_{\mathrm{ab}}=320 \mathrm{~cm}^{-1}\right)$., 70,318

a Valores calculados a partir dos dados reportados nas ref. 70 e 318 .
É interessante também ressaltar que o complexo de pirazina apresenta distância doador-aceitador equivalente a $6,8 \AA i^{70}$ isto é, dentro de um erro de $1-2 \%$, somente $1,0 \AA$ mais extensa que a distância metal-metal para os sistemas benzotriazolato (assumindo o modo de coordenação N1,N3) ou benzoimidazolato.

Mesmo diante das observações acima, os valores absolutos de $\alpha^{2}$ para ambos os complexos revelam uma significativa mas pequena deslocalização eletrônica entre os íons de rutênio, cujas cargas parecem ser localizadas. Além disso, a fração aproximada da carga transferida $(F)$ durante a absorção óptica de intervalência pode ser determinada pelo uso da descrição de Hush-Mulliken para um sistema de valência localizada, de acordo com a seguinte fórmula: $F=1-2\left(H_{\mathrm{ab}} / E_{\mathrm{op}}\right)^{2} \cdot{ }^{34}$ Nesses casos, $F=0,967$ (bta) e 0,970 (bim) representam sua natureza localizada.

Os valores de $\Delta E_{\text {(mono) }}$ discutidos previamente $(115 \mathrm{mV}$ ou $970 \mathrm{~cm}^{-1}$, e $100 \mathrm{mV}$ ou $810 \mathrm{~cm}^{-1}$; para os derivados mononucleares de benzotriazolato e benzoimidazolato, 
respectivamente) podem ser assumidos como sendo uma aproximação razoável de $\Delta E_{0}$, ${ }^{a}$ que é, por sua vez, uma aproximação de $\Delta G^{\mathrm{o}},{ }^{35,36,70,71,322,323}$ o driving force da reação de ET termodinamicamente favorável (Esq. 10 e Eq. 69). Além disso, de acordo com o formalismo de HushMulliken, o processo de ET intramolecular induzido por luz em um sistema assimétrico ocorre com $E_{\text {op }}=\bar{v}_{\text {máx }}=\Delta E_{0}+\lambda$ (Eq. 30), onde $\lambda$ é a energia reorganizacional e $\Delta E_{0}$ é a barreira termodinâmica interna. Conseqüentemente, dentro da limitação dessa abordagem, ambos os parâmetros podem ser avaliados das relações: $\Delta E_{0} \approx \Delta E_{\text {(mono) }}$ e $\lambda=E_{\text {op }}-\Delta E_{0}$ (Tab. 6). Os valores dados para a energia de FranckCondon, $\lambda$, são consistentes com a largura de meia-banda, $\Delta \bar{v}_{1 / 2}$, das bandas de IT de $\left(\mathrm{NH}_{3}\right)_{5} \mathrm{Ru}(\mathrm{bta}) \mathrm{Ru}($ edta) e $\left(\mathrm{NH}_{3}\right)_{5} \mathrm{Ru}(\mathrm{bim}) \mathrm{Ru}($ edta).

Cálculos quânticos em nível semi-empírico ZINDO para diversas estruturas moleculares com variação da distância intermetálica, mostraram que a aproximação dos centros metálicos para 5,0 ̊ permite uma interação significativa dos átomos metálicos com o sítio $\mathrm{N} 2$, levando a um forte acoplamento eletrônico via ligante-ponte. ${ }^{\mathrm{b}}$ Analogamente à análise de MO realizada anteriormente para o complexo simétrico [(edta)Ru( $\mu$-bta)Ru(edta) $]^{4-}$, os cálculos teóricos revelaram a existência de considerável interação $\sigma \mathrm{e} \pi$ entre os íons de rutênio e o átomo N2 intermediário (somada à combinação esperada pelos sítios de coordenação extremos N1 e N3), representando a natureza da interação metalmetal no ligante-ponte benzotriazolato (Esq. 9).

Se o valor hipotético de $5,0 \AA^{c}$ para a distância da IT for assumido, os parâmetros $H_{\mathrm{ab}}$ e $\alpha^{2}$ para a espécie benzotriazolato de valência mista se tornam $985 \mathrm{~cm}^{-1} \mathrm{e}$ 0,021 , refletindo a intensificação da interação eletrônica

\footnotetext{
a $\Delta E_{0}$ tem sido usualmente obtido dos potenciais de redução de compostos modelo ou diretamente de $\Delta E_{1 / 2}$, a diferença direta entre os potenciais de redução (III,III) e (III,II) do próprio dímero. Entretanto, este último método é prejudicado pelo fato de que efeitos sinexgísticos, estabilização de Ru(II) por Ru(III), deslocalização eletrônica, etc., não podem ser determinados apropriadamente. Dessa forma, embora o método adotado nesta tese não resulte um valor exato de $\Delta E_{0}$, parece que ele é mais realista que os demais de literatura para o tipo de sistema investigado.

b Vale destacar que, tanto nesse sistema assimétrico como no simétrico com $\mathrm{Ru}(\mathrm{edta})$ (v. item 3.1.21), a otimização da interação eletrônica metal-metal "nunca" envolve recobrimento orbital direto do tipo metálico (d-d). Essa estabilização "extra" devido à fluxionalidade do ligante "sempre" envolve a participação do átomo de nitrogênio central em uma conjugação do tipo $(\mathrm{M}) d-p(\mathrm{~N} 2) p-d(\mathrm{M})$, em adição à interação esperada segundo um modo rígido $(\mathrm{M}) d-\pi(\mathrm{N} 1) \mathrm{bta}(\mathrm{N} 3) \pi-d(\mathrm{M})$. A coordenação resultante pode ser assumida como sendo intermediária $\mathrm{M}-\eta^{2}-(\mathrm{N} 1, \mathrm{~N} 2) \mathrm{bta}(\mathrm{N} 2, \mathrm{~N} 3)-\eta^{2}-\mathrm{M}$. Contudo, no complexo mononuclear desprotonado, a isomeria fluxional sobre o ligante aniônico não deve ser entendida como uma coordenação $M-\eta^{3}-(N 1, N 2, N 3)$, mas $\operatorname{sim} M-\eta^{2}-(N 1, N 2) \Leftrightarrow(N 2, N 3)-\eta^{2}-M$.

c $O$ que é um valor plausível de acordo com os cálculos single-point para as estruturas geométricas "tentativas" consideradas.
}

metal-metal num modo dinâmico de coordenação fluxional, ainda que tais valores ainda se encontrem subestimados. ${ }^{\mathrm{d}}$

\subsection{Efeitos do solvente}

Com o objetivo de explorar os limites da teoria de Hush, realizou-se ainda um conjunto de medidas eletroquímicas e espectroeletroquímicas para o complexo de valência mista neutro $\left(\mathrm{NH}_{3}\right)_{5} \mathrm{Ru}^{\text {II }}$ (bta) $\mathrm{Ru}^{\text {III }}$ (edta) em solventes orgânicos. Infelizmente, esse tipo de medida foi limitada pela baixa solubilidade desse tipo de complexo em todos os solventes testados. $^{\text {e }}$

Ainda assim, por meio de dissolução do complexo em um microvolume de $\mathrm{D}_{2} \mathrm{O}$, seguido de mistura com $1 \mathrm{~cm}^{3}$ do solvente orgânico, uma solução diluída $\left(\sim 10^{-5} \mathrm{~mol} \mathrm{dm}^{-3}\right)$ pôde ser preparada para propósitos exploratórios. Esse procedimento foi exeqüível somente para os solventes dimetilformamida e dimetilsulfóxido. No caso do análogo benzoimidazolato, todas as tentativas de se solubilizar uma quantidade detectável (por eletroquímica e espectroscopia eletrônica) do complexo falharam, presumivelmente por causa de sua maior susceptibilidade à decomposição em soluções não aquosas.

A idéia de usar efeito de solvente foi enfatizada com grande interesse neste trabalho, por causa da presença das duas unidades terminais de rutênio não-equivalentes nos complexos binucleares assimétricos. Isso porque a unidade pentaaminrutênio(II)/(III) é bastante sensível a efeitos de solvente específicos, ${ }^{81,89,109,118-120,324}$ via interações doadoraceitador, conforme expresso pelas numerosas correlações com o parâmetro número de doador (DN). ${ }^{113,325}$ Dessa forma, pelo uso de solventes de elevado $\mathrm{DN}$, tais como dimetilformamida ou dimetilsulfóxido, o potencial redox (bem como as energias eletrônicas) do fragmento metálico pentaaminrutênio(II)/(III) aproximar-se-ia daquele para o etilenodinitrilotetraacetatorutenato(II)/(III). A aproximação dos níveis eletrônicos conduziria a uma forte deslocalização eletrônica no complexo de valência mista, intensificando o comportamento de classe III para o complexo neutro $\left(\mathrm{NH}_{3}\right)_{5} \mathrm{Ru}^{\mathrm{II}}(\mathrm{bta}) \mathrm{Ru}^{\mathrm{III}}$ (edta).

\footnotetext{
d Estes valores resultantes de $H_{\mathrm{ab}}$ encontram-se subestimados por duas razões: (i) por não levarem em conta a distância "real" de ET; ${ }^{104}$ e (ii) pelo fato do modelo de Hush não se aplicar adequadamente em sistemas com exibição de propriedades associadas à classe III de Robin-Day (seção 1.2).

e Acetona, acetonitrila, dime tilacetamida, dimetilformamida, dimetilsulfóxido, etanol, formamida, metanol, nitrobenzeno e propilenocarbonato.
} 


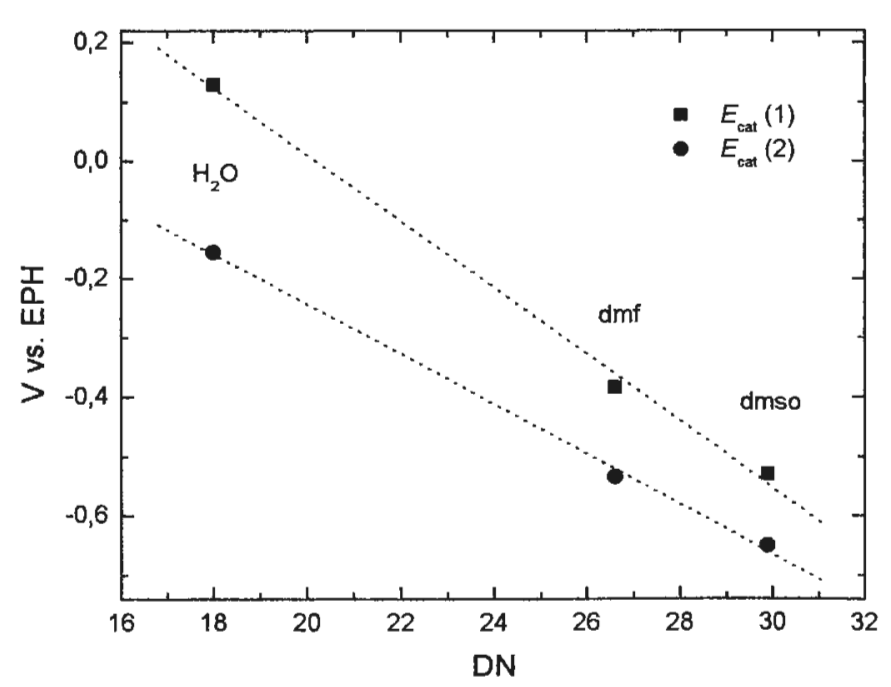

Figura 26. Potenciais catódicos de $\left(\mathrm{NH}_{3}\right)_{5} \mathrm{Ru}(\mathrm{bta}) \mathrm{Ru}(\mathrm{edta})^{+}$em funçăo do número de doador (DN) do solvente $\left(\mathrm{H}_{2} \mathrm{O} / \mathrm{D}_{2} \mathrm{O}=18,0\right.$; $\mathrm{dmf}=26,6 ; \mathrm{dmso}=29,8$; valores de DN extraídos da ref. 325 ).

Como se pode observar na Fig. 26 e Tab. 7, existe uma correlação linear entre os potenciais redox das espécies $\left[\left(\mathrm{NH}_{3}\right)_{5} \mathrm{Ru}(\mathrm{bta}) \mathrm{Ru}(\mathrm{edta})\right]^{\mathrm{n}}$ e o parâmetro DN do solvente. Além disso, a sensibilidade do fragmento $\left\{\mathrm{Ru}^{\mathrm{II}}\left(\mathrm{NH}_{3}\right)_{5}\right\}$ é maior que aquela da unidade $\left\{\mathrm{Ru}^{\mathrm{III}}(\mathrm{edta})\right\}$, de tal forma a existir um decréscimo sistemático em $\Delta E_{1 / 2}\left(E_{(1)}-E_{(2)}\right)$ à medida que DN aumenta. De fato, a inclinação negativa da curva de potencial catódico $v s$. DN é maior para $E_{(1)}(56,4$ $\mathrm{mV} / \mathrm{DN})$ que $E_{(2)}(42,1 \mathrm{mV} / \mathrm{DN})$. Isto é, o potencial de redução decresce mais rapidamente em função de DN para o par $\left(\mathrm{NH}_{3}\right)_{5} \mathrm{Ru}^{\mathrm{IIII}}-\mathrm{L}_{\mathrm{b}}$ que para $\mathrm{L}_{\mathrm{b}}-\mathrm{Ru}^{\mathrm{IIII} / \mathrm{I}}$ (edta). ${ }^{\mathrm{a}}$

Tabela 7. Parâmetros eletroquímicos para o complexo assimétrico $\left(\mathrm{NH}_{3}\right)_{5} \mathrm{Ru}(\mathrm{bta}) \mathrm{Ru}(\mathrm{edta})$ em diferentes solventes.

\begin{tabular}{ccccc}
\hline Solvente & DN & $E_{\mathbf{c}}(\mathbf{1})$ & $E_{\mathbf{c}}(\mathbf{2})$ & $\Delta E_{\mathbf{c}}(\mathbf{m V})$ \\
\hline $\mathrm{H}_{2} \mathrm{O}$ & 18,0 & 0,130 & $-0,155$ & 285 \\
$\mathrm{dmf}^{a}$ & 26,6 & $-0,385$ & $-0,535$ & 150 \\
$\mathrm{dmso}^{\boldsymbol{a}}$ & 29,9 & $-0,530$ & $-0,650$ & 120 \\
\hline
\end{tabular}

${ }^{a}$ Mistura $\mathrm{H}_{2} \mathrm{O}$ /solvente na proporção aproximada 1:50.

\footnotetext{
a De fato, por extrapolação das curvas a valores de DN mais elevados, tem sido demonstrado que um ponto de interseção é previsto em $\mathrm{DN}=37,8$; acima deste ponto, uma inversão dos processos de rectução seria esperada, sendo que o primeiro deles seria centrado sobre a unidade de Ru(edta). Contudo, tentativas de se dissolver o complexo em solventes com DN extremamente alto não foram bern sucedidas e essa tendência não pode ser experimentalmente testada nesse limite extremo.
}

As observações realizadas são coerentes com a estabilização preferencial, em solventes com elevado $\mathrm{DN}$, do centro $\mathrm{Ru}$ III relativamente ao estado $\mathrm{Ru}^{\mathrm{II}}$. Como demonstrado por esses resultados, esse efeito é mais pronunciado no fragmento $\left\{\mathrm{Ru}\left(\mathrm{NH}_{3}\right)_{5}\right\}$, porque a interação através de ligações de hidrogênio de esfera externa solvente-aminrutênio ${ }^{81,89,109,118-}$ 120,324 é, aparentemente, mais eficiente que aquela por meio de transferência de carga doador-aceitador solventecarboxilatorutênio.

Em termos de diagramas de energia para a reação de ET (Esq. 10), aumentando a donicidade do solvente, diminuise, em princípio, a extensão da assimetria redox, $\Delta E_{0}$ (um deslocamento vertical relativo das parábolas, aproximando as superficies do reagente e do produto no estado de equilíbrio), e portanto aumenta o grau de acoplamento eletrônico, $H_{\mathrm{ab}}$.

As medidas ópticas realizadas na região do NIR para o complexo de valência mista em dimetilformamida e dimetilsulfóxido revelaram um pequeno deslocamento batocrômico de $1475 \mathrm{~nm}$ (em solução de $\mathrm{D}_{2} \mathrm{O}$ ) para 1400 $\mathrm{nm}$, enquanto o parâmetro $\Delta \bar{v}_{1 / 2}$ diminuiu de 3700 para cerca de $3000 \mathrm{~cm}^{-1}$, aproximando-se do valor de $2850 \mathrm{~cm}^{-1}$ previamente obtido para o sistema simétrico, de classe III, $[(\text { edta }) \operatorname{Ru}(\mu-b t a) R u(\text { edta })]^{4}$.

De acordo com a representação qualitativa do Esq. 10, esperar-se-ia um decréscimo em $E_{\text {op }}$ com o aumento da donicidade do solvente. Entretanto, a contribuição de esfera externa da energia de Franck-Condon $\left(\lambda_{0}\right)$ deve aumentar com $\mathrm{DN}$, porque interações de ponte de hidrogênio fortes aumentam efetivamente a extensão da reorganização. ${ }^{70}$

Como conclusão, os efeitos de solvente corroboram uma descrição no limite das classes II/III para o complexo de valência mista assimétrico $\left(\mathrm{NH}_{3}\right)_{5} \mathrm{Ru}^{\mathrm{II}}(\mathrm{bta}) \mathrm{Ru}{ }^{\mathrm{II}}$ (edta). 


\subsubsection{3. $\left[\left(\mathrm{NH}_{3}\right)_{5} R u(\mu-b t a) F e(C N)_{5}\right]^{n-}(n=0,1,2)$}

Em uma solução aquosa levemente ácida, o íon complexo aminpentacianoferrato(I), $\left[\mathrm{Fe}(\mathrm{CN})_{5}\left(\mathrm{NH}_{3}\right)\right]^{3-}$, pode substituir facilmente o ligante amônia para formar o correspondente aquacomplexo, $\left[\mathrm{Fe}(\mathrm{CN})_{5}\left(\mathrm{H}_{2} \mathrm{O}\right)\right]^{3-226}$ que por sua vez reage prontamente na presença de ligantes $\mathrm{N}$-heterocíclicos. ${ }^{224} \mathrm{~A}$ reação de $\left[\mathrm{Ru}^{\mathrm{II}}\left(\mathrm{NH}_{3}\right)_{5}(\text { bta })\right]^{+}$e $\left[\mathrm{Fe}^{\mathrm{II}}(\mathrm{CN})_{5}\left(\mathrm{NH}_{3}\right)\right]^{3--}$ (relação equimolar) em solução aquosa em $\mathrm{pH}$ ao redor de 9,0 produziu, sob atmosfera inerte, um complexo de coloração alaranjada, parecida com aquela isolada na forma sólida (a reação das espécies oxidada, $\left[\mathrm{Ru}^{\mathrm{III}}\left(\mathrm{NH}_{3}\right)_{5}(\mathrm{bta})\right]^{2+}$, e reduzida, $\left[\mathrm{Fe}^{\mathrm{II}}(\mathrm{CN})_{5}\left(\mathrm{NH}_{3}\right)\right]^{3-}$, também foi acompanhada em $\mathrm{pH} 6,0$, gerando um produto marrom). No $\mathrm{pH}$ de trabalho, ocorre desprotonação do benzotriazol mono-coordenado, possibilitando sua ligação à unidade de cianoferrato(II) (do íon $\left.\left[\mathrm{Fe}(\mathrm{CN})_{5}\left(\mathrm{H}_{2} \mathrm{O}\right)\right]^{3-}\right)$.

\subsection{Propriedades redox e termodinâmicas}

Os voltamogramas cíclicos e de pulso diferencial dessa nova espécie exibem dois processos de redução bem definidos nos potenciais $E_{1}=0,390 \mathrm{~V}$ e $E_{2}=-0,090 \mathrm{~V}$ (Fig. 27), fornecendo a primeira evidência de formação do novo complexo binuclear assimétrico, $\left[\left(\mathrm{NH}_{3}\right)_{5} \mathrm{Ru}(\mathrm{bta}) \mathrm{Fe}(\mathrm{CN})_{5}\right]^{2-}$.

Outra indicação importante da presença dessa espécie é a existência de uma forte absorção na região do NIR após a adição de 1 equiv de um oxidante químico (peroxidissulfato de sódio), o que é consistente com a geração da espécie de valência mista $\left[\left(\mathrm{NH}_{3}\right)_{5} \mathrm{Ru}^{\mathrm{III}}(\mathrm{bta}) \mathrm{Fe}^{\mathrm{II}}(\mathrm{CN})_{5}\right]$, cuja formulação dos estados de oxidação $\mathrm{Ru}$ (III) e Fe(II) foi baseada inicialmente nas comparações entre os potenciais de redução observados, $E_{1}$ e $E_{2}$, com o pares $\mathrm{Fe}^{\mathrm{III} /} / \mathrm{Fe}^{\mathrm{II}}$ e $\mathrm{Ru}^{\mathrm{III}} / \mathrm{Ru}^{\mathrm{II}}$, respectivamente, nos complexos mononucleares de partida (Tab. 3).

Esse tipo de atribuição refere-se a uma importante característica de complexos assimétricos do tipo Fe-L-Ru e correlatos, desde que seus estados de oxidação podem ser formulados como $\mathrm{Fe}^{\mathrm{II}}-\mathrm{Ru}^{\mathrm{III}}$ (como realmente é o caso da maioria dos exemplos de literatura, ${ }^{279,326-331} \mathrm{Fe}^{\text {III }}-\mathrm{Ru}^{\text {II }}{ }^{332}$ ou até mesmo uma mistura de ambos os isômeros eletrônicos. ${ }^{332}$

A fim de se confirmar essa atribuição preliminar dos estados de oxidação formal simplesmente pela análise dos potenciais redox, medidas de espectros vibracionais no $\mathbb{R}$ (Tab. 8) e espectroeletroquímicas na região do UV-Vis (Fig. 28) também foram realizadas e levaram a conclusões semelhantes.

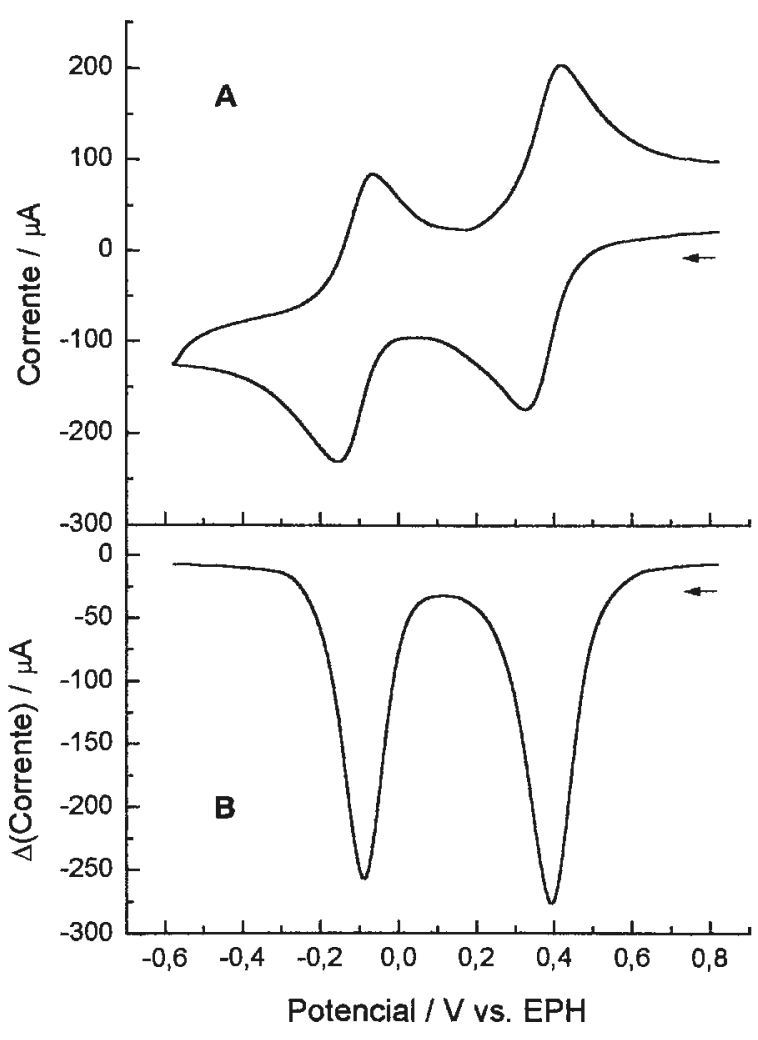

Figura 27. Voltamogramas cíclicos (A) e voltamograma de pulso diferencial (B) do complexo [( $\left.\left.\mathrm{NH}_{3}\right)_{5} \mathrm{Ru}(\mathrm{bta}) \mathrm{Fe}(\mathrm{CN})_{5}\right]^{\top}$ em solução aquosa $\left(C=5,0 \times 10^{-3} \mathrm{~mol} \mathrm{dm}^{-3} ; l=\mathrm{Na}\right.$ (tfa) $0,25 \mathrm{~mol} \mathrm{dm}^{-3} ; \mathrm{pH} \mathrm{6,5)}$. (condiçoses de trabalho da DPV: altura do pulso $=0,025 \mathrm{~V}$; largura do pulso $=0,005 \mathrm{~s} ; \mathrm{v}=100 \mathrm{mV} \mathrm{s}^{-1}$ )

Tabela 8. Dados de infravermelho para os complexos $\left.\mathrm{Na}_{n}\left[\left(\mathrm{NH}_{3}\right)_{5} \mathrm{Ru}^{11,111}(\mathrm{bta}) \mathrm{Fe}^{11, \text { ll1 }}(\mathrm{CN})_{5}\right](n=2,1,0)\right)^{a, b}$

\begin{tabular}{|c|c|c|c|}
\hline Complexo & $\begin{array}{l}\mathrm{YoN} \\
\left(\mathrm{cm}^{-1}\right)\end{array}$ & $\begin{array}{c}\delta_{\mathrm{NH}_{3}(\mathrm{sm})} \\
\left(\mathrm{cm}^{-1}\right)\end{array}$ & $\begin{array}{c}\mathbf{p}_{\mathrm{NH}_{3}} \\
\left(\mathrm{~cm}^{-1}\right)\end{array}$ \\
\hline $\mathrm{Na}_{2}\left[\left(\mathrm{NH}_{3}\right)_{5} \mathrm{Ru}(\mathrm{bta}) \mathrm{Fe}(\mathrm{CN})_{5}\right]$ & $2055(\mathrm{~s})$ & $1263(\mathrm{~s})$ & $754(\mathrm{~m})$ \\
\hline $\mathrm{Na}\left[\left(\mathrm{NH}_{3}\right)_{5} \mathrm{Ru}(\mathrm{bta}) \mathrm{Fe}(\mathrm{CN})_{5}\right]$ & $2054(\mathrm{~s})$ & $1308(\mathrm{~s})$ & $795(\mathrm{~m})$ \\
\hline$\left(\mathrm{NH}_{3}\right)_{5} \mathrm{Ru}(\mathrm{bta}) \mathrm{Fe}(\mathrm{CN})_{5}$ & $\begin{array}{l}2117(\mathrm{~s}) \\
2161(\mathrm{~m})\end{array}$ & $1315(s)$ & $804(\mathrm{~m})$ \\
\hline
\end{tabular}

${ }^{a}$ Espectros obtidos em pastilhas de $\mathrm{KBr},{ }^{b}$ Intensidade: $\mathrm{s}=$ forte, $\mathrm{m}=$ média,

Conforme reportado anteriormente para a espécie análoga $\left[\left(\mathrm{NH}_{3}\right)_{5} \mathrm{Ru}(\mathrm{pz}) \mathrm{Fe}(\mathrm{CN})_{5}\right]^{\mathrm{n}-326}$ comparação entre os espectros IR do complexo binuclear em seus três estados de oxidação possíveis (espécies isovalentes reduzida $[\mathrm{II}, \mathrm{I}]$ e oxidada [III,III], e de valência mista [II,III]) mostrou que eles são aproximadamente iguais, exceto pelas bandas de absorção dos grupos $\mathrm{CN}^{-}$e $\mathrm{NH}_{3}$. Atualmente é conhecido que as freqüências associadas com os modos vibracionais desses grupos dependem da natureza e da carga dos íons metálicos aos quais eles estão coordenados. ${ }^{333}$ 
Os modos vibracionais de deformação simétrica $\left(\delta_{\text {sim }}\right)$ e rocking $(\rho)$ do ligante amônia coordenado ocorrem em freqüências que normalmente aumentam com o estado de oxidação e a eletronegatividade do íon central no complexo. ${ }^{334}$ Para hexaaminrutênio nos estados de oxidação +II e +III, elas aparecem em 1220 e $769 \mathrm{~cm}^{-1335}$ e 1316 1362 e $788 \mathrm{~cm}^{-1}, 336$ respectivamente. Portanto, para o complexo $\left[\left(\mathrm{NH}_{3}\right)_{5} \mathrm{Ru}(\mu-\mathrm{bta}) \mathrm{Fe}(\mathrm{CN})_{5}\right]^{\mathrm{n}--}$, os deslocamentos observados de $1263 \mathrm{~cm}^{-1}\left(\delta_{\mathrm{NH}_{3}(\mathrm{sim})}\right)$ e $754 \mathrm{~cm}^{-1}\left(\rho_{\mathrm{NH}_{3}}\right)$ no complexo totalmente reduzido [II,II] para $1308 \mathrm{~cm}^{-1}$ e 795 $\mathrm{cm}^{-1}$ no complexo de valência mista [II,III] são indicativos da oxidação do centro Ru(II). Essa hipótese é corroborada pelo fato de que praticamente nenhuma mudança foi observada nessas bandas do complexo de valência mista para a espécie totalmente oxidada [III,III] (Tab. 8).

Por sua vez, a freqüência de estiramento do cianeto ( $v_{\mathrm{CN}}$ ) é observada em $2055 \mathrm{~cm}^{-1}$ para ambas as espécies mono ou bi-reduzidas [II,III] e [II,II], e é característica do complexo cianoferrato(II). ${ }^{333,337}$ No caso dos complexos de ferro(III), ela é normalmente encontrada na região de 2100$2150 \mathrm{~cm}^{-1}$, que realmente concorda com as absorções para esse modo na espécie totalmente oxidada [III,III] (Tab. 8).

Esses resultados, portanto, referem-se a um sistema de valência confinada em que o centro aceitador oxidado está localizado principalmente sobre a unidade aminrutênio.

Os espectros eletrônicos na região UV-Vis do complexo isovalente oxidado, $\mathrm{Ru}^{\mathrm{II}}$-bta-Fe ${ }^{\mathrm{II}}$ (gerado em potenciais superiores a $0,4 \mathrm{~V}$ ), apresentam duas bandas de absorção em $495 \mathrm{~nm}\left(3700 \mathrm{~mol}^{-1} \mathrm{dm}^{3} \mathrm{~cm}^{-1}\right)$ e $590 \mathrm{~nm}\left(\mathrm{sh} ; 2800 \mathrm{~mol}^{-1}\right.$ $\mathrm{dm}^{3} \mathrm{~cm}^{-1}$ ) (Fig. 28). Essas bandas foram atribuídas às transições LMCT envolvendo os centros de rutênio e ferro, isto é $\left\{\mathrm{bta}^{-}\right\} \pi \rightarrow d_{\pi}\left\{\mathrm{Ru}^{\mathrm{III}}\left(\mathrm{NH}_{3}\right)_{5}\right\}$ e $\left\{\mathrm{bta}^{-}\right\} \pi \rightarrow d_{\pi}\left\{\mathrm{Fe}^{\mathrm{III}}(\mathrm{CN})_{5}\right\}$. As bandas análogas para os complexos mononucleares ocorrem em $467 \mathrm{~nm}\left(2060 \mathrm{~mol}^{-1} \mathrm{dm}^{3} \mathrm{~cm}^{-1}\right)$ e $582 \mathrm{~nm}(2180$ $\mathrm{mol}^{-1} \mathrm{dm}^{3} \mathrm{~cm}^{-1}$ ), respectivamente (Tab. 2). O fato de a transição LMCT para Fe(III) aparecer em energias menores em relação aquela centrada sobre $\mathrm{Ru}$ (III) é coerente com o poder oxidante mais forte do ferro. Um ombro também é observado ao redor de $360 \mathrm{~nm}$ e pode ser tentativamente atribuído à transição $\left(\mathrm{CN}^{-}\right) \rightarrow d_{\pi}\left(\mathrm{Fe}^{\mathrm{III}}\right)$. ${ }^{279,317,338}$

Quando a espécie de valência mista $\mathrm{Ru}^{\mathrm{III}}$-bta-Fe ${ }^{\mathrm{II}}$ é eletroliticamente produzida pela aplicação de potenciais na região entre os dois potenciais redox ( $E_{1}$ e $E_{2}$; Fig. 27), duas bandas podem ser vistas no espectro: uma ao redor de 500 $\mathrm{nm}$, que se refere à já mencionada transição envolvendo a unidade $\left\{\mathrm{Ru}^{\text {III }}\left(\mathrm{NH}_{3}\right)_{5}\right\}$; e uma nova que aparece em $390 \mathrm{~nm}$ $\left(4300 \mathrm{~mol}^{-1} \mathrm{dm}^{3} \mathrm{~cm}^{-1}\right)$, correspondendo à transição MLCT na unidade terminal do ferro, $\left\{\mathrm{Fe}^{\mathrm{II}}(\mathrm{CN})_{5}\right\} d_{\pi} \rightarrow \pi^{*}\left\{\mathrm{bta}^{-}\right\}$. No complexo mononuclear de cianoferrato, a banda análoga foi observada em $350 \mathrm{~nm}\left(2100 \mathrm{~mol}^{-1} \mathrm{dm}^{3} \mathrm{~cm}^{-1}\right)$ e $388 \mathrm{~nm}$ (4440 $\mathrm{mol}^{-1} \mathrm{dm}^{3} \mathrm{~cm}^{-1}$ ), para as espécies desprotonada $\mathrm{e}$ protonada, respectivamente (Tab. 2), revelando o efeito $\pi$ aceitador da unidade de rutênio(III) sobre o centro $\pi$-doador de ferro(II) no complexo binuclear de valência mista. $\mathrm{Na}$ verdade, esta comparação sugere que o íon hidrogênio, $\mathrm{H}^{+}$, e o fragmento $\left\{\mathrm{Ru}^{\mathrm{III}}\left(\mathrm{NH}_{3}\right)_{5}\right\}^{3+}$ exercem efeitos eletrônicos similares quando ligados ao ligante benzotriazolato no complexo $\left[\mathrm{Fe}^{\mathrm{II}}(\mathrm{CN})_{5}(\mathrm{bta})\right]^{4-}$, uma vez que a energia MLCT na espécie de valência mista $\mathrm{Ru}^{\mathrm{III}}-\mathrm{Fe}^{\mathrm{II}}$ e o potencial de redução para o par $\mathrm{Ru}^{\mathrm{III}}-\mathrm{Fe}^{\mathrm{IIIII}}$ são ambos praticamente iguais àqueles observados no monômero protonado $\left[\mathrm{Fe}(\mathrm{CN})_{5}(\mathrm{btaH})\right]^{3-}$ (Tab. 3).

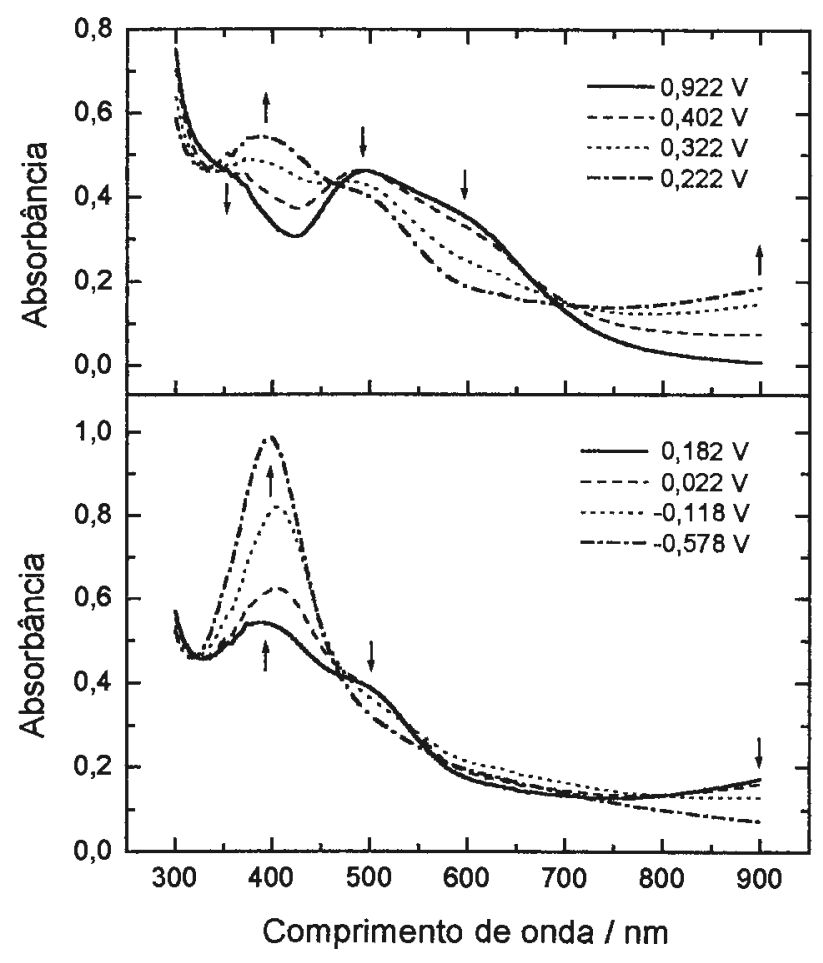

Figura 28. Espectros eletrônicos do complexo binuclear $\left[\left(\mathrm{NH}_{3}\right)_{5} \mathrm{Ru}(\mathrm{bta}) \mathrm{Fe}(\mathrm{CN})_{5}\right]^{n}$ em pH 6,5 sob a aplicação de potenciais. (C $=5,0 \times 10^{-3} \mathrm{~mol} \mathrm{dm}^{-3} ; l=0,025 \mathrm{~cm} ; l=\mathrm{Na}$ (tfa) $0,25 \mathrm{~mol} \mathrm{dm}^{-3}$ )

Sob potenciais inferiores a $0 \mathrm{~V}$, para os quais a espécie completamente reduzida $\mathrm{Ru}^{\mathrm{II}}$-bta-Fe ${ }^{\mathrm{II}}$ é produzida, os espectros (Fig. 28) mostram apenas uma banda intensa $\left(7800 \mathrm{~mol}^{-1} \mathrm{dm}^{3} \mathrm{~cm}^{-1}\right)$ e larga que surge ao redor de 400 nm. Esse "envelope" foi considerado consistir de ambas as transições do tipo MLCT, $\mathrm{Ru}^{\mathrm{II}} \rightarrow \mathrm{bta}^{-}$e $\mathrm{Fe}^{\mathrm{II}} \rightarrow \mathrm{bta}^{-}$, cujas correspondentes bandas nas espécies mononucleares se dão em 389 e $350 \mathrm{~nm}$, respectivamente (Tab. 2).

a Nas medidas espectroeletroquímicas tanto na região do UV-Vis como no NIR, todas as espécies foram praticamente $100 \%$ regeneradas. 
Baseando-se no exposto acima, a formulação alternativa para o isômero eletrônico de distribuição $\mathrm{Ru}^{\mathrm{II}}-\mathrm{Fe} \mathrm{e}^{\mathrm{III}}$ pode ser desconsiderada, e o complexo pode ser caracterizado como possuindo a configuração $\left[\left(\mathrm{NH}_{3}\right)_{5} \mathrm{Ru}^{\mathrm{II}}(\mathrm{bta}) \mathrm{Fe}^{\mathrm{II}}(\mathrm{CN})_{5}\right]^{-}$.

Com o propósito de investigar os processos relacionados à transferência de intervalência para a espécie de valência mista, estudos espectroeletroquímicos na região do Vis-NIR foram desenvolvidos (Fig. 29), confirmando a ocorrência de uma banda intensa $\left(\varepsilon=3900 \mathrm{~mol}^{-1} \mathrm{dm}^{3} \mathrm{~cm}^{-1}\right)$ e larga $\left(\Delta \overline{\mathbf{v}}_{1 / 2}\right.$ $=6500 \mathrm{~cm}^{-1}$ ) $\mathrm{em} 1210 \mathrm{~nm}$ (ou $8265 \mathrm{~cm}^{-1}$ ) somente quando o sistema é submetido a potenciais entre 0,4 e $-0,1 \mathrm{~V}$ (Fig. 27), atingindo seu máximo de absorção quando o potencial aplicado se aproxima de $0,15 \mathrm{~V}$ (Fig. 29), que é o ponto intermédio entre os dois pares de ondas reversíveis $\left(E_{1}\right.$ e $\left.E_{2}\right)$ observados nos voltamogramas cíclicos (Fig. 27). Sob potenciais acima ou abaixo desse ponto, a absortividade decresce gradualmente até o completo desaparecimento da banda nos extremos positivo $(>0,5 \mathrm{~V})$ e negativo $(<-0,2 \mathrm{~V})$ da faixa, onde as espécies isovalentes oxidada e reduzida são geradas.

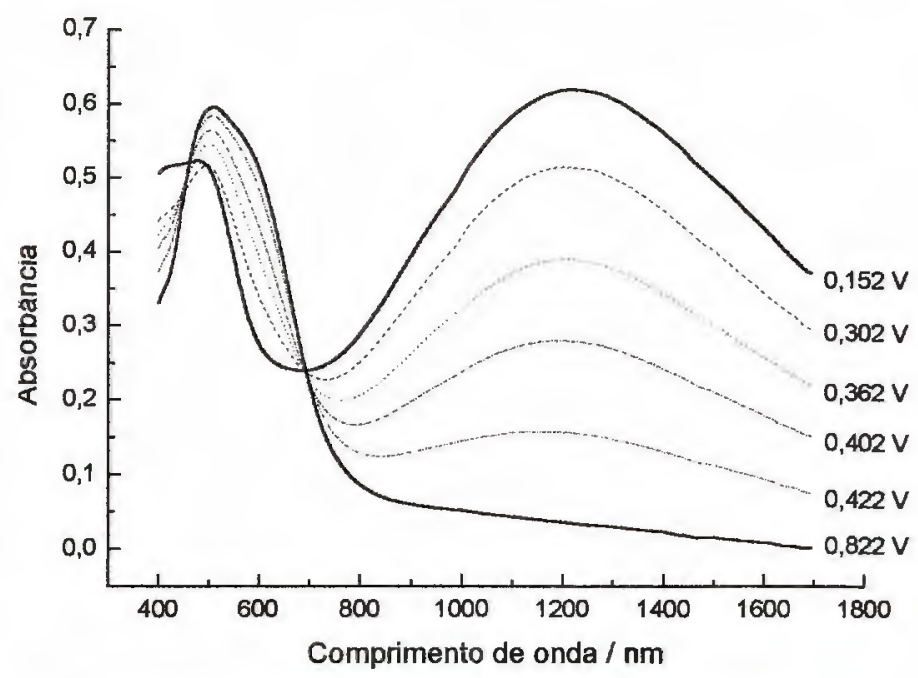

Figura 29. Espectros eletrónicos sob aplicaçăo de potencial para o complexo binuclear $\left[\left(\mathrm{NH}_{3}\right)_{5} \mathrm{Ru}(\mathrm{bta}) \mathrm{Fe}(\mathrm{CN})_{3}\right]^{\mathrm{n}-}$ em $\mathrm{D}_{2} \mathrm{O}(\mathrm{pD} 6,0)$. $\left(C=1,0 \times 10^{-2} \mathrm{~mol} \mathrm{dm}^{-3} ; /=0,016 \mathrm{~cm} ; /=\mathrm{KNO}_{3} 0,25 \mathrm{~mol} \mathrm{dm}^{-3}\right)$

O comportamento descrito revela claramente a presença de um sítio oxidado (aceitador) e outro reduzido (doador) na faixa de $E_{1}$ a $E_{2}$, cuja banda de baixa energia observada é consistente com uma transferência de carga metal-metal (MM'CT), que por sua vez é característica de complexos de

\footnotetext{
a A banda de absorção no NIR foi desconvoluída das bandas CT na região do visível assumindo-se que a transição IT é dada por uma única banda Gaussiono simétrica (espectro em unidades de energia, $\mathrm{cm}^{-1}$ ) e nenhuma mudança no perfil das bandas no Vis. Tais métodos de desconvolução têm sido bastante discutidos em detalhes na literatura. ${ }^{136}$
}

valência mista. Assim, de acordo com o exposto acima, os dois pares redox obtidos pelos dados eletroquímicos podem ser atribuídos como segue nas Eqs. 74 e 75.

$$
\begin{aligned}
& \left(\mathrm{NH}_{3}\right)_{5} \mathrm{Ru}^{\mathrm{II}}-\mathrm{bta}-\mathrm{Fe}^{\mathrm{III}}(\mathrm{CN})_{5} \stackrel{E_{1}=0,390 \mathrm{~V}}{=}\left[\left(\mathrm{NH}_{3}\right)_{5} \mathrm{Ru}^{\mathrm{II}}-\mathrm{bta}-\mathrm{Fe}^{\mathrm{II}}(\mathrm{CN})_{5}\right] \\
& {\left[\left(\mathrm{NH}_{3}\right)_{5} \mathrm{Ru}^{\mathrm{II}}-\mathrm{bta}-\mathrm{Fe}^{\mathrm{II}}(\mathrm{CNN})_{5}\right]^{-} \stackrel{E_{2}=-0,090 \mathrm{~V}}{\rightleftharpoons}\left[\left(\mathrm{NH}_{3}\right)_{5} \mathrm{Ru}^{\mathrm{II}}-\mathrm{bta}-\mathrm{Fe}^{\mathrm{II}}(\mathrm{CN})_{5}\right]^{\prime}}
\end{aligned}
$$

Além disso, a banda em $1210 \mathrm{~nm}$ é oriunda de uma transição de intervalência da unidade doadora $\left\{(\mathrm{CN})_{5} \mathrm{Fe}^{\mathrm{II}}-\right\}$ à aceitadora $\left\{-\mathrm{Ru}^{\mathrm{III}}\left(\mathrm{NH}_{3}\right)_{5}\right\}$, que pode ser ilustrada pelo processo da Eq. 76 .

$$
\begin{gathered}
{\left[\left(\mathrm{NH}_{3}\right)_{5} \mathrm{Ru}^{\mathrm{III}}\left(d \pi_{3}{ }^{1}\right)-\mathrm{bta}-\left(d \pi_{3}{ }^{2}\right) \mathrm{Fe}^{\mathrm{III}}(\mathrm{CN})_{5} \Gamma\right.} \\
\downarrow_{\mathrm{hv}} \\
{\left[\left(\mathrm{NH}_{3}\right)_{5} \mathrm{Ru}^{\Pi 1}\left(d \pi_{3}{ }^{2}\right) \text {-bta- }\left(d \pi_{3}{ }^{1}\right) \mathrm{Fe}^{\mathrm{III}}(\mathrm{CN})_{5}\right]^{-}}
\end{gathered}
$$

onde $d \pi_{3}$ é o nível de energia $d \pi$ de maior energia entre os três orbitais metálicos do tipo $t_{2 \mathrm{~g}}$ quase degenerados.

Em uma etapa subseqüente ao processo de transferência eletrônica óptica, um processo térmico inverso (Eq. 77) deve ocorrer (veja representação no diagrama do Esq. 12), uma vez que o sistema é assimétrico e, no estado de equilíbrio, existe um driving force, $\Delta G^{\circ}$ ou $\Delta E_{0}$, favorecendo o isômero eletrônico mais estável $\left[\left(\mathrm{NH}_{3}\right)_{5} \mathrm{Ru}^{\mathrm{II}}(\mathrm{bta}) \mathrm{Fe}^{\mathrm{II}}(\mathrm{CN})_{5}\right]^{-}$.
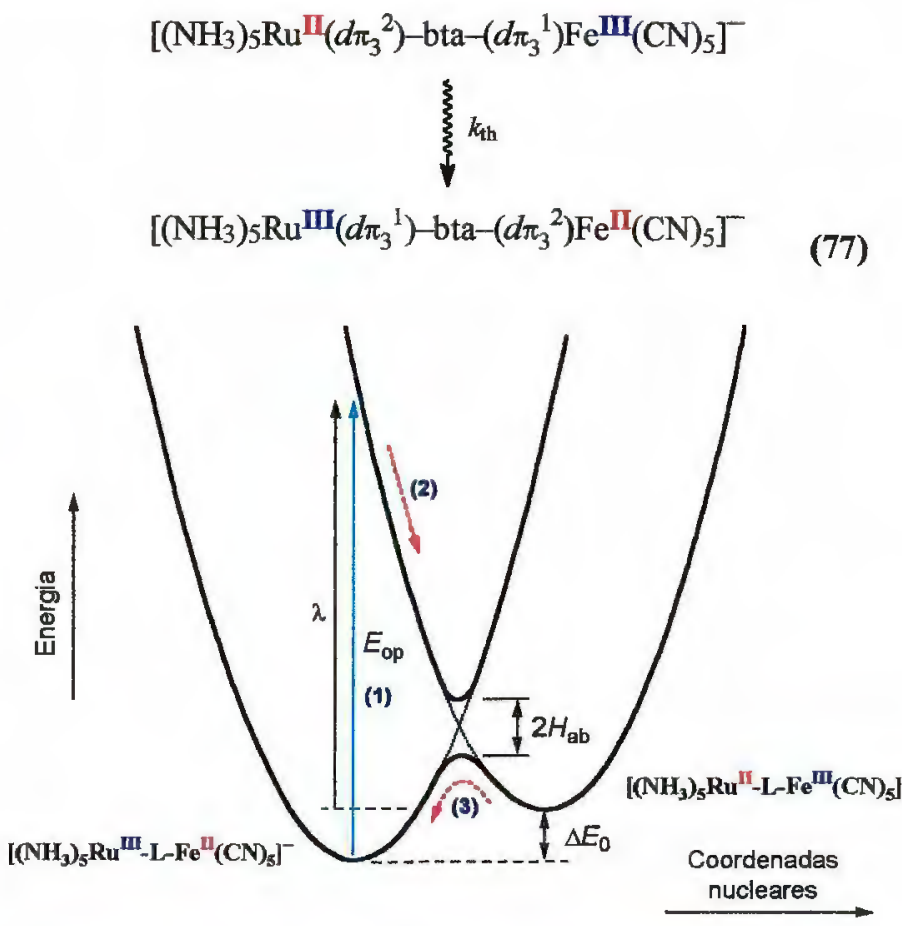

Esquema 12. Diagrama de energia qualitativo para a reaçăo de ET envolvendo o complexo heterobinuclear $\left[\left(\mathrm{NH}_{3}\right)_{5} \mathrm{Ru}(\mathrm{bta}) \mathrm{Fe}(\mathrm{CN})_{5} \Gamma\right.$. 
A partir das relações $\Delta G_{\mathrm{c}}=-\mathrm{R} T \ln \left(K_{\mathrm{c}}\right)=-n \mathrm{~F}\left(\Delta E_{1 / 2}\right)$ e da separação de potenciais $\Delta E_{1 / 2}=480 \mathrm{mV}$ para o sistema $\left[\left(\mathrm{NH}_{3}\right)_{5} \mathrm{Ru}(\mu \text {-bta }) \mathrm{Fe}(\mathrm{CN})_{5}\right]^{\mathrm{n}}$, a estabilidade termodinâmica do complexo de valência mista foi estimada pelo cálculo da constante de comproporcionamento, $K_{\mathrm{c}}=1,30 \times 10^{8}$, cuja energia associada é $\Delta G_{\mathrm{c}}=-11,1 \mathrm{kcal} \mathrm{mol}^{-1}\left(3870 \mathrm{~cm}^{-1}\right)$.

$$
\begin{gathered}
\left(\mathrm{NH}_{3}\right)_{5} \mathrm{Ru}^{\mathrm{III}}-\mathrm{bta}-\mathrm{Fe}^{\mathrm{III}}(\mathrm{CN})_{5}+\left[\left(\mathrm{NH}_{3}\right)_{5} \mathrm{Ru} \mathrm{u}^{\mathrm{II}}-\mathrm{bta}-\mathrm{Fe}^{\mathrm{II}}(\mathrm{CN})_{5}\right]^{2-} \\
\|_{K_{\mathrm{c}}} \\
2\left[\left(\mathrm{NH}_{3}\right)_{5} \mathrm{Ru}^{\mathrm{III}}-\mathrm{bta}-\mathrm{Fe}^{\mathrm{II}}(\mathrm{CN})_{5}\right]^{-}
\end{gathered}
$$

Mais uma vez, vale lembrar que, apesar da alta magnitude de $K_{c}$, o sistema não é simétrico e existe um $\Delta E$ intrínseco associado à diferença de potencial de redução nas unidades monômeras de partida $\left(E_{1 / 2}\right.$ para $\left[\mathrm{Ru}\left(\mathrm{NH}_{3}\right)_{5}(\mathrm{bta})\right]^{2+}$ e $\left[\mathrm{Fe}(\mathrm{CN})_{5}(\mathrm{bta})\right]^{3--}$ são 0,025 e $0,215 \mathrm{~V}$, respectivamente; de tal forma que $\Delta E_{\text {(mono) }}=190 \mathrm{mV}$ ). Portanto, a grandeza de $\Delta G_{\mathrm{c}}$ não deve ser totalmente relacionada à estabilização do complexo por deslocalização eletrônica no estado de valência mista.

Seguindo o mesmo procedimento adotado para o sistema assimétrico de rutênio, $\left(\mathrm{NH}_{3}\right)_{5} \mathrm{Ru}$-bta-Ru(edta), o valor de $\Delta E_{0}$ foi aproximado por $\Delta E_{\text {(mono), }}$, que, nesse caso, seria próximo de $0,19 \mathrm{eV}$ (ou $\sim 1530 \mathrm{~cm}^{-1}$ ) e refere-se a uma aproximação de $\Delta G^{\circ}$, o driving force da reação de ET termicamente favorável; isto é, a energia liberada na reação de ET inversa $\mathrm{Ru}^{\text {II }}$-bta-Fe ${ }^{\mathrm{III}} \rightarrow \mathrm{Ru}^{\text {III }}$-bta-Fe ${ }^{\text {II }}$. Igualmente, como o princípio de Franck-Condon impõe que a reação de ET intramolecular óptica ocorre com $E_{\text {op }}=\bar{v}_{\text {máx }}=\lambda+\Delta E_{0}$, então a energia de reorganização, $\lambda$, foi estimada em 6735 $\mathrm{cm}^{-1}$

Embora alguns esforços tenham sido realizados com o intuito de se determinar a contribuição isolada da energia de deslocalização em sistemas assimétricos, ${ }^{109,120,319}$ ainda não se conhece hoje nenhum tratamento teórico incluindo a normalização de $\Delta E_{1 / 2}\left(E_{2}-E_{1}\right.$ na espécie binuclear) em

\footnotetext{
a Todos os dímeros aqui investigados possuem $\Delta E_{1 / 2}$ suficientemente grande, de tal forma que correções espectroscópicas para os parâmetros de comproporcionamento por meio dos coeficientes de extinção molar foram ignorados.

b $\triangle E_{0}$ tem sido usualmente obtido dos potenciais de redução de compostos modelo ou diretamente de $\Delta E_{1 / 2}$, a diferença direta entre os potenciais de redução (III,III) e (III,II) do próprio dímero. Entretanto, este último método é prejudicado pelo fato de que efeitos sinergísticos, estabilização de Ru(II) por Ru(III), deslocalização eletrônica, etc., não podem ser determinados apropriadamente. Dessa forma, embora o método adotado nesta tese não resulte um valor exato de $\Delta E_{0}$, parece que ele é mais realista que os demais de literatura para o tipo de sistema investigado.
}

função da diferença intrínseca de potencial das unidades de partida distintas, ou seja, $\delta(\Delta E)$. Como uma aproximação, entretanto, na comparação com os resultados dos sistemas de valência mista simétricos, $\Delta E_{\text {(mono) }}$ deve ser subtraído de $\Delta E_{1 / 2}$ (i.e., 480 - $190 \mathrm{mV}$ ), resultando uma estabilização efetiva de $290 \mathrm{mV}$ (dos monômeros para o dímero). Essa estabilização resultante (chamada aqui de $\Delta G_{\mathrm{c}}{ }^{\text {') }}$ ) contribuiria com $2340 \mathrm{~cm}^{-1}$ para a energia de comproporcionamento. Ainda assim, é importante ter em mente que essa energia é uma soma de quatro termos $\Delta G_{\text {en }}+\Delta G_{\text {el }}+\Delta G_{\mathrm{s}}+\Delta G_{\mathrm{d}}$, onde $\Delta G_{\mathrm{d}}$ se refere à contribuição por ressonância no estado de valência mista. $\mathbf{O}$ significado individual de cada um desses fatores já foi enfocado antes (itens 1.2 .2 e 3.1.2.2).

Para o íon $\left[\left(\mathrm{NH}_{3}\right)_{5} \mathrm{Ru}^{\mathrm{III}}(\mathrm{bta}) \mathrm{Fe}^{\mathrm{II}}(\mathrm{CN})_{5}\right]^{-}$, o valor de $\Delta G_{\mathrm{d}}$ foi calculado em $417 \mathrm{~cm}^{-1}$, o que representa $\sim 25 \%$ de $H_{\mathrm{ab}}$, a energia de acoplamento eletrônico. Considerado que essa relação geralmente fica ao redor de $1 \%$ na maioria dos casos reportados de classe $\mathrm{II},{ }^{70,71}$ tal valor reflete uma significante deslocalização nesse complexo, ainda que ele represente apenas $50 \mathrm{mV}$ dos $340 \mathrm{mV}$ correspondentes a $\Delta G_{\mathrm{c}}$ ', o que é esperado, uma vez que o sistema é caracterizado melhor por estados de valência tipicamente localizados, $\mathrm{Ru}^{\mathrm{III}}-\mathrm{Fe}^{\mathrm{II}}$.

Portanto, diferentemente dos complexos simétrico (item 3.1.2.1) e assimétrico (item 3.1.2.2) de rutênio introduzidos anteriormente, essa espécie heterobinuclear é um sistema típico de classe II de Robin-Day onde a maior parte da estabilização no estado de valência mista se origina do efeito sinergístico devido à propagação das interações de transferência de carga vetorial $\left(\mathrm{Fe}^{\mathrm{II}}\right) d_{\pi} \rightarrow \pi_{\mathrm{L}}{ }^{*} \rightarrow d_{\pi}\left(\mathrm{Ru}^{\mathrm{III}}\right)$.

\subsection{Estrutura molecular}

Similarmente ao procedimento descrito previamente para os complexos de rutênio-edta, a estrutura molecular do íon $\left[\left(\mathrm{NH}_{3}\right)_{5} \mathrm{Ru}(\mathrm{bta}) \mathrm{Fe}(\mathrm{CN})_{5}\right]^{-}$foi simulada por meio de cálculos de otimização geométrica em nível de mecânica molecular (Fig. 30). Nela, os dois centros metálicos e o ligante-ponte estão localizados no mesmo plano, exibindo uma distância metal-metal de $5,6 \AA$. 

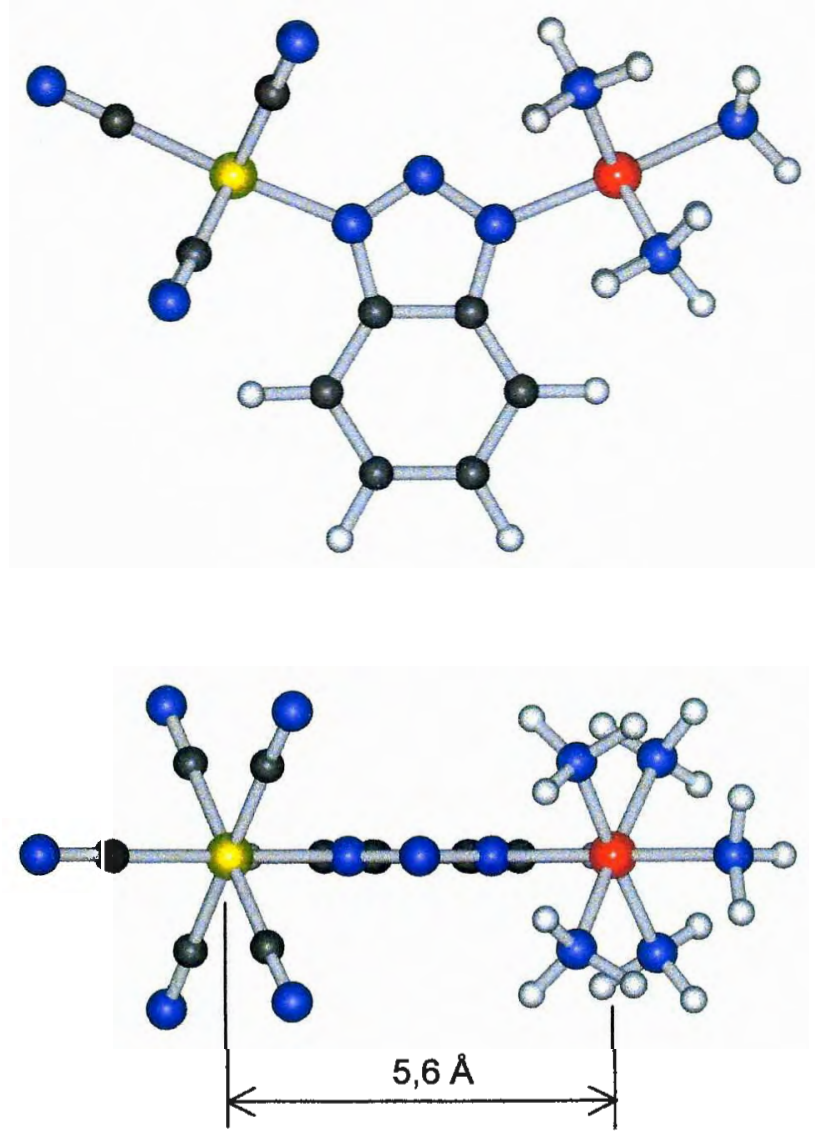

Figura 30. Estrutura molecular do complexo binuclear assimétrico $\left[\left(\mathrm{NH}_{3}\right)_{5} \mathrm{Ru}(\mathrm{bta}) \mathrm{Fe}(\mathrm{CN})_{5}\right]^{-}$, calculada por otimização de geometria em nivel de mecânica molecular (MM+).

Nos exemplos anteriores envolvendo $\left[\{\operatorname{Ru}(\text { edta })\}_{2}(\mu-\mathrm{L})\right]^{4-} \mathrm{e}$ $\left(\mathrm{NH}_{3}\right)_{5} \mathrm{Ru}(\mu-\mathrm{L}) \mathrm{Ru}(\mathrm{edta})\left(\mathrm{L}=\mathrm{bta}^{-}\right.$ou bim $\left.{ }^{-}\right)$, foi proposto que as diferenças contrastantes em suas propriedades IT podiam ser parcialmente explicadas pelo modo de coordenação fluxional do ligante-ponte benzotriazolato. Tal proposição deve-se principalmente a uma qualidade especial da unidade terminal $\{\mathrm{Ru}($ edta $)\}$, devido à existência de uma vacância em sua estrutura, ${ }^{a}$ conforme demonstrado por cálculos teóricos. ${ }^{238,239}$ Somada às propriedades de coordenação do benzotriazol, essas características poderiam promover uma situação ótima para a interação metal-metal através do ligante-ponte (v. itens 3.1.2.1.3 e 3.1.2.2.4 e Esq. 13).
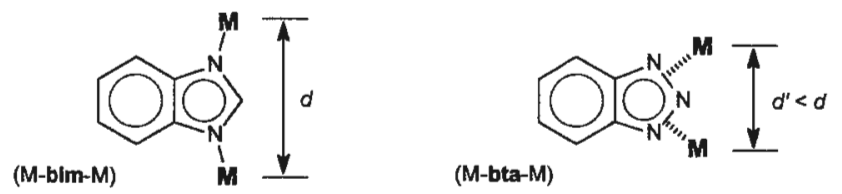

Esquema 13. Modos de coordenação "rígido" $\kappa N 1, \kappa N 3 e$ fluxional $\eta^{2}-N 1, N 2 ; \eta^{2}-N 2, N 3$ nos ligantes-ponte bim $^{-}$e bta'.

\footnotetext{
a Região estericamente desimpedida na estrutura do rutênio-edta, conforme
} jâ havia sido observado por Creutz e Matsubara. ${ }^{313}$
Neste presente sistema, por outro lado, esse tipo de comportamento não é esperado devido à sua estrutura estericamente mais impedida associada às unidades mais volumosas dos ligantes pentacoordenados cianeto e amina. $O$ derivado assimétrico de benzotriazolato terá, assim, uma separação geométrica metal-metal muito próxima daquela observada para o análogo benzoimidazolato, onde não se observa nenhum mecanismo fluxional operante.

Assim, pode-se considerar que a distância rutênio-ferro é apenas ligeiramente menor que aquela calculada para uma coordenação "rígida" $\left[\left(\mathrm{NH}_{3}\right)_{5} \mathrm{Ru}-\mathrm{N} 1\right.$ (bta) $\left.\mathrm{N} 3-\mathrm{Fe}(\mathrm{CN})_{5}\right]$ ", que é $5,6 \AA$. Esse valor será usado como uma aproximação da distância de ET na avaliação do acoplamento eletrônico.

\subsection{Propriedades de valência mista}

É interessante notar que a banda de IT para esse complexo de valência mista é muito mais larga e intensa que as observadas anteriormente para as espécies homonucleares de rutênio. Tais características estão refletidas na força de oscilador $\left(f_{\text {osc }}=0,117\right)$ e no momento de transição ${ }^{\mathrm{b}}(M=$ $1,14)$ associados a esse complexo heterobinuclear.

$\mathrm{O}$ valor teórico de $\Delta \vec{v}_{1 / 2}$ para a banda de intervalência do complexo $\left[\left(\mathrm{NH}_{3}\right)_{5} \mathrm{Ru}^{\mathrm{II}}(\mathrm{bta}) \mathrm{Fe}^{\mathrm{II}}(\mathrm{CN})_{5}\right]^{-}$é $4060 \mathrm{~cm}^{-1}$. Como uma consequêencia do valor estimado ser muito menor que o observado $\left(6500 \mathrm{~cm}^{-1}\right)$, a natureza localizada das cargas nesse sistema de valência mista foi confirmada, podendo ser apropriadamente descrito pela classe II nas categorias de Robin e Day. ${ }^{\mathrm{c}}$

Dentre os exemplos já discutidos, esse é, portanto, o único benzotriazolato-derivado que satisfaz rigorosamente as condições do modelo de Hush para a aplicação adequada das Eqs. 27 e 28 para providenciar a magnitude da interação eletrônica entre os centros metálicos.

A energia de absorção óptica $E_{\mathrm{op}}$, sua absortividade molar $\varepsilon_{\text {máx }}$, e a correspondente largura de meia-banda $\Delta \bar{v}_{1 / 2}$ para a banda IT da espécie $\left[\left(\mathrm{NH}_{3}\right)_{5} \mathrm{Ru}^{\mathrm{III}}(\mathrm{bta}) \mathrm{Fe}^{\mathrm{II}}(\mathrm{CN})_{5}\right]^{-}$são 8265 $\mathrm{cm}^{-1}, 3900 \mathrm{~mol}^{-1} \mathrm{dm}^{3} \mathrm{~cm}^{-1}$, e $6500 \mathrm{~cm}^{-1}$, respectivamente. A distância intermetálica $d(5,6 \AA)$ foi baseada nos cálculos de mecânica molecular. Assim, os parâmetros $H_{\mathrm{ab}}$ e $\alpha^{2}$ para a energia de acoplamento eletrônico e o grau de deslocalização eletrônica no estado fundamental foram calculados em $1675 \mathrm{~cm}^{-1}$ e 0,041 , respectivamente.

b V. seção 6.1

c V. critérios de classificação no item 1.2.4. 


\subsection{Comentários finais}

Mesmo que essa nova espécie benzotriazolato contenha um ligante-ponte "não-linear", surpreendentemente, a sua magnitude de $H_{\mathrm{ab}}$ é bastante superior à do análogo com pirazina ${ }^{326,327}$ e reflete a comunicação metal-metal eficiente através do ligante-ponte benzotriazolato, que aparentemente é melhor condutor. Como nesse caso a mobilidade fluxional no benzotriazol não deve ocorrer em uma extensão significante, essa diferença inesperada nas propriedades de intervalência entre os sistemas $\mathrm{Fe}^{\mathrm{II}}$-pz-Ru ${ }^{\mathrm{III}}$ e Fe $\mathrm{F}^{\mathrm{II}}$-bta-Ru ${ }^{\text {III }}$ é melhor interpretada em termos do caráter eletrônico $\pi$ do ligante-ponte, que, por sua vez, dita o tipo de mecanismo da interação. $^{51,339}$

Dessa forma, enquanto o benzotriazol age tanto como um doador ou como um aceitador- $\pi$ fracos (relativamente rico em elétrons), a pirazina se comporta como um ligante fortemente aceitador- $\pi$ (pobre em elétrons), de tal forma que a transferência de elétrons deve ocorrer segundo um mecanismo do tipo hole-transfer na espécie benzotriazolato e do tipo electron-transfer no complexo tendo a pirazina como ponte.

$\mathrm{Na}$ verdade, como nas espécies de valência mista o próprio fragmento cianoferrato(II) também se comporta como uma unidade parcialmente doadora- $\pi$ (uma vez que ele se estabiliza através de interações de retrodoação- $\pi$ ) e o pentaaminrutênio(III) como um grupo aceitador- $\pi$ (ácido de Lewis $-t_{2 g}{ }^{5}$ ), então os niveis $\pi$ de fronteira (HOMO) do benzotriazolato se aproximam em energia dos orbitais $d \pi$ metálicos e podem, portanto, distribuir/comunicar melhor a carga extra do ferro ao rutênio. Apenas para uma melhor visualização das energias relativas dos níveis eletrônicos externos desses ligantes, a Fig. 31 esquematiza o diagrama comparativo de energias HOMO (níveis ocupados $\pi$ mais externos) dos ligantes "universais" pirazina e piridina, com os dos ligantes de estudo benzotriazol/benzotriazolato e benzoimidazol/benzoimidazolato. Através do diagrama, pode-se constatar que a ordem de donicidade/basicidade nas formas neutras obedece ao padrão esperado (devido às propriedades já conhecidas desses ligantes), onde o caráter aceitador- $\pi$ diminui na ordem (aceitador) $\mathrm{pz}>\mathrm{py}>\mathrm{btaH}>$ bimH (doador). No entanto, a informação mais importante para o atual estudo que se extrai desta comparação deve-se à enorme diferença em energia (e, portanto de caráter eletrônico) entre os ligantes potencialmente empregáveis como ponte, que são a pirazina e os ânions benzotriazolato e benzoimidazolato.
Dessa maneira, confirmando todos os resultados obtidos experimentalmente para os complexos mononucleares, o caráter $\pi$ do ligante benzotriazol é intermediário entre um aceitador típico (pirazina) e um doador típico (imidazol). Contudo, nas formas desprotonadas ambos os ligantes benzotriazolato e benzoimidazolato são muito mais básicos que o ligante de comparação geral, pirazina (embora o ligante imidazolato continue, conforme esperado, sendo relativamente mais doador que o triazolato derivado). Em outras palavras, em complexos metálicos de transição do tipo $d^{5} / d^{6}$ de spin baixo com níveis redox centrados no metal relativamente altos, ${ }^{\text {a }}$ os niveis $\pi$ ligantes dos ligantes bta $^{-}$e bim ${ }^{-}$estão muito mais acessíveis para interagir com os níveis $d \pi$ metálicos que os da pirazina, cuja interação pode, eventualmente, ser mais efetiva através de seus níveis $\pi^{*}$ de baixa energia.

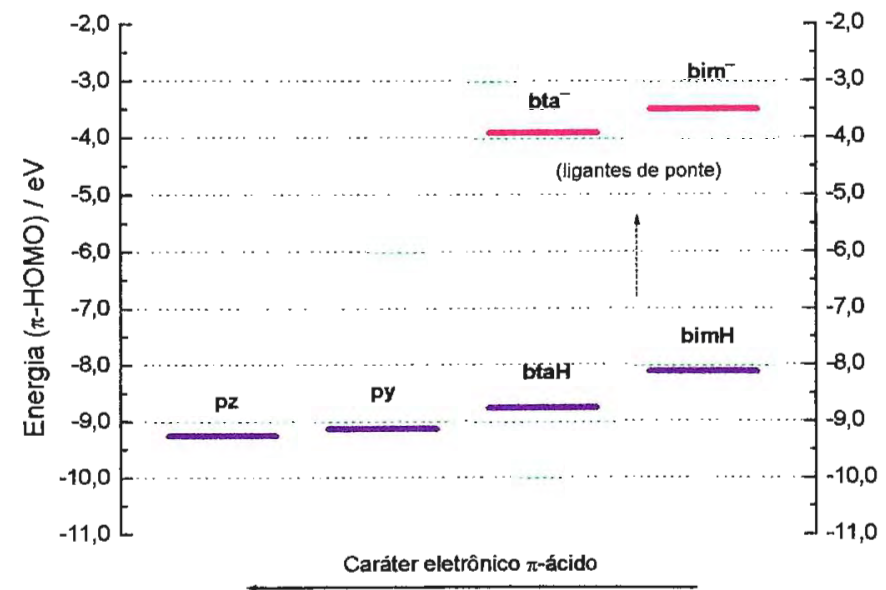

Figura 31. Diagramas de energia para os niveis $\pi$ (HOMO) de uma série de ligantes $\mathrm{N}$-heterociclicos ácidos e básicos.

Da discussão acima, conclui-se que, em interações de ET com acoplamento eletrônico do tipo metal-metal mediadas por ponte, o papel do ligante intermediário é fundamental não só no que concerne à natureza condutor/isolante mas, principalmente, na determinação do mecanismo envolvido no processamento da comunicação eletrônica. Assim, a partir dos exemplos dados nesta tese (em comparação com outros de literatura), pode-se concluir que, enquanto nos sistemas com ligantes do tipo pirazina o mecanismo de electron transfer prevalece, nos sistemas análogos com benzotriazolato ou benzoimidazolato predomina o de holetransfer. ${ }^{151}$ Esses conceitos encontram-se qualitativamente esquematizados a seguir.

\footnotetext{
a Isso ocorre na maioria dos complexos contendo ligantes poliaminas e carboxilatos, mas não é verdade no caso particular dos complexos contendo coligantes polipiridinicos.
} 


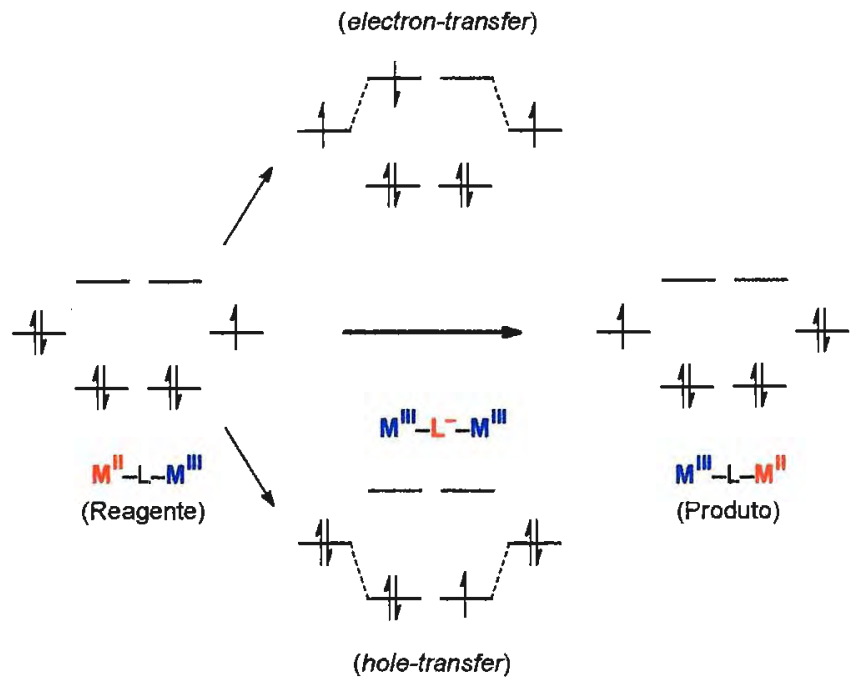

Esquema 14. Diagrama de MO ilustrativo para os mecanismos de superexchange: electron transfer e hole transfer.

Por extrapolação do raciocínio acima e, baseando-se em um mecanismo de superexchange por hole-transfer, poder-se-ia parecer óbvio que, quanto mais forte o caráter doador $-\sigma, \pi$ de um ligante, mais eficiente e intenso deveria ser a interação eletrônica metal-metal. Curiosamente, a espécie imidazolato do mesmo tipo aqui estudado, $\left[\left(\mathrm{NH}_{3}\right)_{5} \mathrm{Ru}^{\mathrm{III}}-\mathrm{im}-\right.$ $\left.\mathrm{Fe}^{\mathrm{II}}(\mathrm{CN})_{5}\right]^{-279}$ apresentou apenas cerca da metade da energia de ressonância envolvida no sistema benzotriazolato aqui relatado (vale mencionar que os ligante imidazolato e benzotriazolato promovem praticamente a mesma distância de ET metal-metal). Se o mesmo mecanismo de interação está operando em ambos os sistemas, alguma característica extra faz do benzotriazol um ligante com propriedades de condução eletrônica especiais.

\subsection{Comparação geral de uma série}

Com base na consideração acima, pode-se concluir que os resultados para a espécie $\left[\left(\mathrm{NH}_{3}\right)_{5} \mathrm{Ru}^{\mathrm{III}}(\mathrm{bta}) \mathrm{Fe}^{\mathrm{II}}(\mathrm{CN})_{5}\right]$ são extraordinários para este tipo de complexo de valência mista, praticamente igualando-se a sistemas de classe III reportados em literatura, ${ }^{70,71}$ ainda que as suas cargas eletrônicas sejam de natureza localizada. Uma comparação mais ilustrativa é dada pelos complexos binucleares análogos da série $\left[\left(\mathrm{NH}_{3}\right)_{5} \mathrm{Ru}(\mathrm{L}) \mathrm{Fe}(\mathrm{CN})_{5}\right]^{\mathrm{n}}$ que têm emergido nos últimos anos (onde $\mathrm{L}=$ pirazina, ${ }^{326,327} 4,4^{\prime}$-bipiridina, ${ }^{327}$ cianeto, ${ }^{328}$ 1,2-bis(4-piridil)etano, ${ }^{329}$ piridinacarboxamido, ${ }^{330}$ imidazolato, ${ }^{279}$ 3-cianopiridina e 4-cianopiridina, ${ }^{332}$ e 4,4'dipiridilamina), ${ }^{331}$ para os quais as propriedades de valência mista e de comproporcionamento (Tab. 9) são bem mais modestas que aquelas observadas nesta contribuição.

Na realidade, esses exemplos de literatura possuem $H_{\mathrm{ab}}$ de no máximo $750 \mathrm{~cm}^{-1}$, 279 enquanto para o benzotriazolderivado tal valor é maior que $1600 \mathrm{~cm}^{-1}$. Deve-se ainda levar em consideração a não-linearidade do ligante-ponte empregado neste trabalho, enquanto muitos dos exemplos de literatura compreendem ligantes lineares e $\mu$-simétricos de dimensões estruturais similares. ${ }^{70,71}$ Isso torna a interação atípica observada neste estudo ainda mais excepcional. 
Tabela 9. Propriedades de valência mista para os complexos $\left[\left(\mathrm{NH}_{3}\right)_{5} \mathrm{R} \mathrm{u}^{\prime \prime \prime}-\mathrm{L}_{b}-\mathrm{Fe} e^{\prime \prime}(\mathrm{CN})_{5}\right]^{\mathrm{n}}$ (os ligantes $\mathrm{L}_{b}$ são dados na tabela como $1=$ pirazina; $2=4,4^{\prime}$-bipiridina, $3=$ cianeto, $4=1,2$-bis(4-piridil)etano, $5=$ piridinacarboxamida, $6=$ imidazolato, $7=4$-cianopiridina,

$8=3$-cianopiridina, $9=4,4^{\prime}$-dipiridilamina, e 10 = benzotriazolato).

\begin{tabular}{|c|c|c|c|c|c|c|c|c|c|c|}
\hline 4 & $\begin{array}{l}E_{2}(1)^{a} \\
(N)\end{array}$ & $\begin{array}{c}E_{w}(2) \\
(\mathrm{N})\end{array}$ & $\begin{array}{l}\Delta F_{12} \\
N\end{array}$ & $\boldsymbol{K}_{\mathrm{e}}$ & $\begin{array}{l}\lambda_{\text {max }} \\
\text { (nm) }\end{array}$ & $\begin{array}{c}\mathrm{s}_{\mathrm{mar}} \\
\left(\mathrm{mol}^{-1} \mathrm{dm}^{3} \mathrm{em}\right)\end{array}$ & $\begin{array}{l}\Delta v_{1}(\exp ) \\
(\mathrm{cn})\end{array}$ & $\begin{array}{c}\mathrm{Av}_{\mathrm{r}}(\mathrm{call}) \\
\left(\mathrm{cm}^{-1}\right)\end{array}$ & $\begin{array}{c}\mathrm{H}_{\mathrm{b}} \\
(\mathrm{cm})\end{array}$ & $\begin{array}{r}\alpha^{2} \\
\left(\times 10^{3}\right)\end{array}$ \\
\hline $1^{10}$ & 0,72 & 0,49 & 0,23 & $7,7 \times 10^{3}$ & 1650 & 1550 & 4300 & 3700 & 600 & 9,8 \\
\hline 2 & 0,64 & 0,31 & 0,33 & $3,8 \times 10^{5}$ & - & - & - & - & - & - \\
\hline 3 & - & - & - & - & 1020 & 3000 & - & 4900 & 1500 & 22 \\
\hline 4 & 0,44 & 0,29 & 0,15 & $3,4 \times 10^{2}$ & - & - & - & - & - & - \\
\hline 5 & - & - & - & - & 645 & 570 & 5100 & 5100 & 480 & 9,5 \\
\hline 6 & 0,30 & $-0,20$ & 0,50 & $2,8 \times 10^{8}$ & 979 & 962 & 5000 & 4100 & 756 & 5,4 \\
\hline 4 & $0,66^{b}$ & $0,50^{a}$ & 0,16 & $5,0 \times 10^{2}$ & 938 & 850 & 3900 & 4900 & 410 & 1,5 \\
\hline 8 & $0,60^{b}$ & $0,53^{a}$ & $\sim 0,07$ & $\sim 15$ & - & - & - & - & - & - \\
\hline 9 & 0,44 & 0,17 & 0,27 & $3,9 \times 10^{4}$ & 725 & 600 & 5400 & 5400 & 500 & 1,3 \\
\hline 10 & 0,390 & $-0,090$ & 0,480 & $1,30 \times 10^{8}$ & 1210 & 3900 & 6500 & 4370 & 1675 & 41 \\
\hline
\end{tabular}

${ }^{a}$ Referem-se ao par Fe ${ }^{\text {III }} / \mathrm{Fe}^{\mathrm{II}}$; ${ }^{b}$ Referem-se ao par $\mathrm{Ru}{ }^{\mathrm{III}} / \mathrm{Ru}^{\mathrm{II}}$; $\quad$ ' Potencial versus $\mathrm{EPH}$.

Um aspecto favorável tanto para o acoplamento metal-metal relativamente forte bem como para a alta estabilidade dos isômeros eletrônicos (ou redox) formulados como $\mathrm{Ru}^{\mathrm{III}}-\mathrm{Fe}^{\mathrm{II}}$, é a existência da transferência de carga (ligante-ponte doador) $\pi \rightarrow d_{n}$ (ín $\mathrm{Ru}$ III aceitador), que é reforçado pela capacidade retrodoadora- $\pi$ da unidade $\left[\mathrm{Fe}^{\Pi 1}(\mathrm{CN})_{5}\right]^{3-}$. Esta última afirmação é apoiada pelo fato de que o potencial redox no centro de rutênio é mais negativo no complexo binuclear $(-0,090 \mathrm{~V})$ que no mononuclear protonado $\left[\mathrm{Ru}^{\mathrm{IIIII}}\left(\mathrm{NH}_{3}\right)_{5}(\mathrm{btaH})\right]^{3+/ 2+}(0,210 \mathrm{~V})$, ou até mesmo no monômero desprotonado $\left[\mathrm{Ru}^{\mathrm{II/I}}\left(\mathrm{NH}_{3}\right)_{5}(\mathrm{bta})\right]^{2+/+}(0,025 \mathrm{~V})$. Partindo desse mesmo raciocínio, essa conjugação- $\pi$ unidirecional poderia, eventualmente, provocar a baixa estabilidade de algumas espécies isovalentes $\mathrm{Ru}^{\mathrm{I}}-\mathrm{Fe}^{\mathrm{II}}$ com ligantes fortemente doadores- $\pi,{ }^{279}$ nos quais o efeito doador- $\pi$ ocorre sobre ambos os centros rutênio(II) e ferro(II), mas em direção oposta. Por outro lado, no estado completamente oxidado, $\mathrm{Ru}^{\mathrm{III}}-\mathrm{Fe} \mathrm{F}^{\mathrm{III}}$, as unidades aceitadoras $\mathrm{M}^{\mathrm{II}} \mathrm{X}_{5}$ competem pelo fraco potencial doador- $\pi$ do ligante benzotriazol.
Embora o benzotriazol neutro não seja tipicamente um forte ligante doador- $\sigma / \pi$, como é o caso do imidazol ${ }^{279}$ e seus derivados, muitos fatos aqui observados corroboram a hipótese de a forma monoaniônica benzotriazolato agir primariamente como bom doador em vez de aceitador $-\pi$. $O$ par $\mathrm{Fe}^{\mathrm{II}} / \mathrm{Fe}^{\mathrm{II}}$ nos complexos benzotriazolato, por exemplo, possuem potenciais menores que $\left[\mathrm{Fe}^{\Pi / \pi}(\mathrm{CN})_{5}\left(\mathrm{H}_{2} \mathrm{O}\right)\right]^{2-13-}$, o que indica a fraca capacidade $\pi$-aceitadora desse ligante.

A interação (superexchange) operante na condução de cargas através da ponte nesse exemplo deveria ser melhor representada por um mecanismo do tipo hole-transfer em detrimento daquele por electron-transfer. Este último tipo de interação é bem estabelecido em derivados de pirazina ou piridina com orbitais $\pi^{*}$ de baixa energia, e, conforme demonstrado no presente estudo, este não é o caso do benzotriazolato. Pelo contrário, o primeiro é favorecido pela semelhança de energia entre os níveis $d_{\pi}$ do metal e $\pi$ populados do ligante. 


\subsubsection{Outros sistemas}

\subsubsection{Complexo binuclear $\left[\{(\text { edta }) R u\}_{2}(\mu-b t a)\right\}^{4}$ : "molecular switching"}

Nesta parte do trabalho, a capacidade do complexo binuclear de valência mista $\left[(\text { edta }) \mathrm{Ru}\left(\mu-\mathrm{L}_{\mathrm{b}}\right) \mathrm{Ru}(\text { edta })\right]^{n-}\left(\mathrm{L}_{\mathrm{b}}=\mathrm{btaH}\right.$, $n=3 ; \mathrm{L}_{\mathrm{b}}=$ bta $^{-}, n=4$ ) atuar como um dispositivo molecular induzido por próton (do tipo molecular switching) será enfatizada. Essa investigação foi realizada por meio da monitoração de suas propriedades redox e de intervalência (em solução aquosa) em função do $\mathrm{pH}$ do meio, através de métodos eletroquímicos e espectroeletroquímicos.

\subsection{Propriedades eletroquímicas}

Os voltamogramas cíclicos de $\left[(\text { edta }) \mathrm{Ru}\left(\mu-\mathrm{L}_{\mathrm{b}}\right) \mathrm{Ru}(\text { edta })\right]^{\mathrm{n}-}$ em solução aquosa a vários $\mathrm{pH}^{\mathrm{a}}$ (Fig. 32) apresentam dois pares de ondas reversíveis de mesma intensidade entre si a qualquer velocidade de vartedura, com comportamento individual de $E_{1 / 2}^{(1)}$ e $E_{1 / 2}^{(2)}$ tipicamente Nernstiano monoeletrônico (ambos com $\Delta E_{\mathrm{p}}=65 \pm 5 \mathrm{mV}$ e $i_{\mathrm{a}} / i_{\mathrm{c}}=1$ ).

Conforme enfatizado na Introdução desta tese (v. item 1.2.2), a manifestação mais direta da presença de uma interação eletrônica pronunciada entre dois centros metálicos (doador e aceitador) acoplados por meio de uma ponte é a separação dos potenciais associados aos pares redox centrados em ambos os sítios metálicos. ${ }^{70-72}$ Isso porque, se houver comunicação intermetálica, a carga extra resultante do processo de redução/oxidação em uma das unidades terminais será imediatamente transmitida à outra unidade, cuja perturbação introduzirá uma modificação em seu potencial redox.

No caso do sistema simétrico [(edta)Ru( $\left.\mathrm{L}_{\mathrm{b}}\right) \mathrm{Ru}($ edta $\left.)\right]^{\mathrm{n}-}$, os centros doador e aceitador seriam os íons $\mathrm{Ru}^{\mathrm{II}}$ e $\mathrm{Ru}^{\mathrm{III}}$, respectivamente, e os dois processos reversíveis observados em seus voltamogramas cíclicos (Fig. 32) foram atribuídos aos dois pares redox $\mathrm{Ru}^{\mathrm{III}} \mathrm{Ru}{ }^{\mathrm{III}} / \mathrm{Ru}^{\mathrm{III}} \mathrm{Ru}{ }^{\mathrm{II}}\left[E_{1 / 2}{ }^{(1)}\right]$ e $\mathrm{Ru}^{\mathrm{III}} \mathrm{Ru}{ }^{\mathrm{II}} / \mathrm{Ru}{ }^{\mathrm{II}} \mathrm{Ru}^{\mathrm{II}}\left[E_{1 / 2}{ }^{(2)}\right]$ (Eqs. 79 e 80), em analogia direta com o sistema envolvendo apenas o ligante-ponte desprotonado benzotriazolato (v. item 3.1.2.1.1).

$$
\begin{aligned}
\mathrm{Ru}^{\mathrm{III}}-\mathrm{L}_{\mathrm{b}}-\mathrm{Ru}^{\mathrm{III}}+\mathrm{e}^{-} \rightleftharpoons \mathrm{Ru}^{\mathrm{II}}-\mathrm{L}_{\mathrm{b}}-\mathrm{Ru}^{\mathrm{II}} & {\left[E_{1 / 2}{ }^{(1)}\right] } \\
\mathrm{Ru}^{\mathrm{III}}-\mathrm{L}_{\mathrm{b}}-\mathrm{Ru}^{\mathrm{II}}+\mathrm{e}^{-} \rightleftharpoons \mathrm{Ru}{ }^{\mathrm{II}}-\mathrm{L}_{\mathrm{b}}-\mathrm{Ru}^{\mathrm{II}} & {\left[E_{1 / 2}{ }^{(2)}\right] }
\end{aligned}
$$

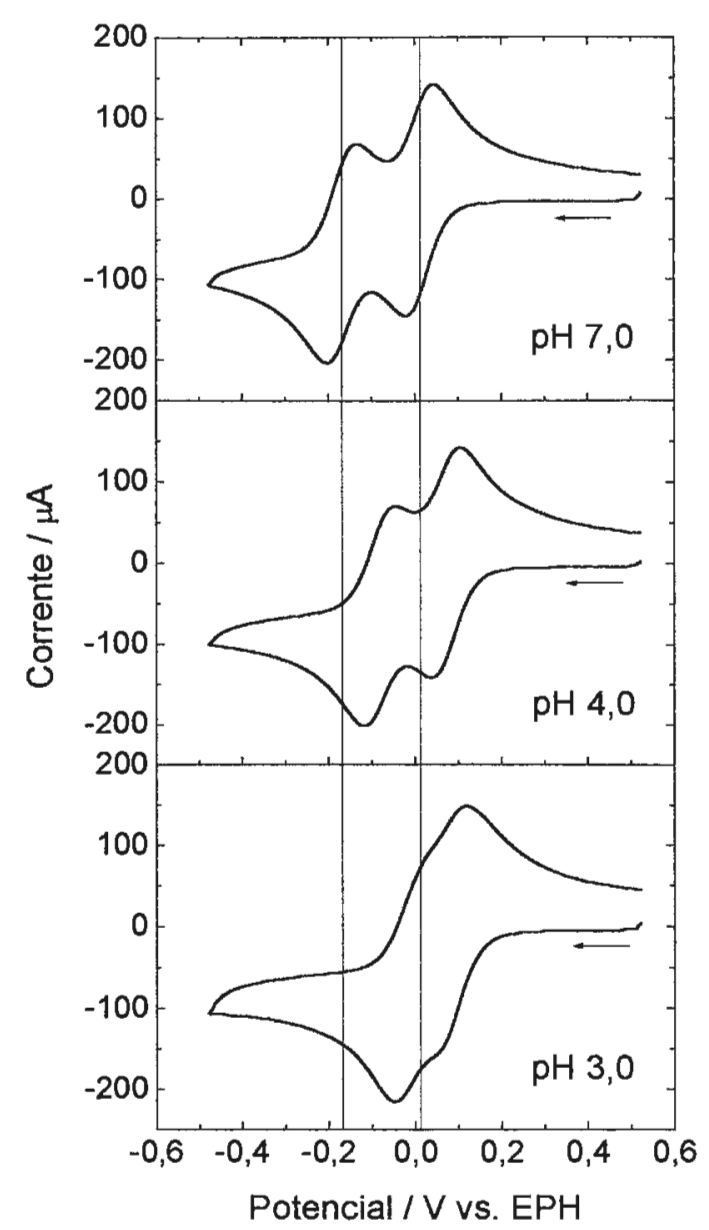

Figura 32. Voltamogramas cíclicos dos complexos simétricos [(edta)Ru( $\left.\mu-L_{\mathrm{p}}\right) R u($ edta $\left.)\right]^{n-}$ em solução aquosa a vários $\mathrm{pH}$. $\left(C=5,0 \times 10^{-3} \mathrm{~mol} \mathrm{dm}^{-3} ; I=0,1 \mathrm{~mol} \mathrm{dm}^{-3} ; v=100 \mathrm{mV} \mathrm{s}^{-1}\right)$

A diferença mais evidente nos $\mathrm{VC}$ quando se diminui o $\mathrm{pH}$ da solução é o estreitamento progressivo da diferença entre os potenciais correspondentes aos dois processos de redução. Assim, $\Delta E_{1 / 2}\left(E_{1 / 2}^{(1)}-E_{1 / 2}{ }^{(2)}\right)$ varia de $195 \mathrm{mV}$ em pH 8,0 a $\sim 75 \mathrm{mV}$ em pH 2,5 (Tab. 10), através do qual e, baseando-se no exposto acima, pode-se inferir apenas dos dados eletroquímicos que a comunicação eletrônica metalmetal diminui no mesmo sentido que o $\mathrm{pH}$.

É interessante destacar ainda que, acima de $\mathrm{pH} \mathrm{8,0} \mathrm{e}$ abaixo de $\mathrm{pH} 2,5$, praticamente não se observam mais alterações nos VC, de modo que o sítio envolvido no processo ácido-base deve encontrar-se em suas formas totalmente desprotonada e protonada, respectivamente.

\footnotetext{
a Embora as medidas eletroquímicas e espectroscópicas tenham sido realizadas em vários $\mathrm{pH}$, é importante salientar que a reação de formação inicial do complexo binuclear ocorreu sempre em meio básico. Essa informação é bastante pertinente para as implicações que se seguirão.
} 
Tabela 10. Parâmetros eletroquímicos para o complexo binuclear [(edta)Ru(bta/btaH)Ru(edta) $]^{n-}$ em soluçito aquosa a varios pH.

\begin{tabular}{cccc}
\hline pH & $E_{1 / 2^{(1)}}(\mathrm{V})$ & $E_{1 / 2}^{(2)}(\mathbf{V})$ & $\Delta E_{1 / 2}(\mathbf{m V})$ \\
\hline 8,0 & 0,015 & $-0,180$ & 195 \\
7,0 & 0,017 & $-0,175$ & 192 \\
6,0 & 0,020 & $-0,155$ & 175 \\
50 & 0,037 & $-0,121$ & 158 \\
4,0 & 0,072 & $-0,082$ & 154 \\
35 & 0,079 & $-0,052$ & 131 \\
3,0 & $0,088^{\circ}$ & $-0,012^{2}$ & 100 \\
2,5 & $-0,120^{a}$ & $-0,045^{\circ}$ & $\sim 75$ \\
\hline
\end{tabular}

a As duas ondas encontram-se recobertas; os potenciais redox foram obtidos por meio de titulação espectrofotométrica ou eletroquímica (v. ref. 16,102).

As curvas da Fig. 33 ilustram também a variação individual de cada um dos potenciais redox, $E_{1 / 2}{ }^{(1)}$ e $E_{1 / 2}{ }^{(2)}$, bem como da separação $\Delta E_{1 / 2}$ entre eles, em função do $\mathrm{pH}$. Nelas, pode-se verificar que o deslocamento de potencial com a variação de $\mathrm{pH}$ é maior sobre $E_{1 / 2}{ }^{(2)}$ que em $E_{1 / 2}{ }^{(1)}$. Apenas para ilustrar esse efeito, quando se passa de $\mathrm{pH} 8,0$ para $\mathrm{pH}$ $2,5, \Delta E_{1 / 2}{ }^{(2)}$ é de $\sim 225 \mathrm{mV}$ enquanto $\Delta E_{1 / 2}{ }^{(1)}$ fica ao redor de $100 \mathrm{mV}$.

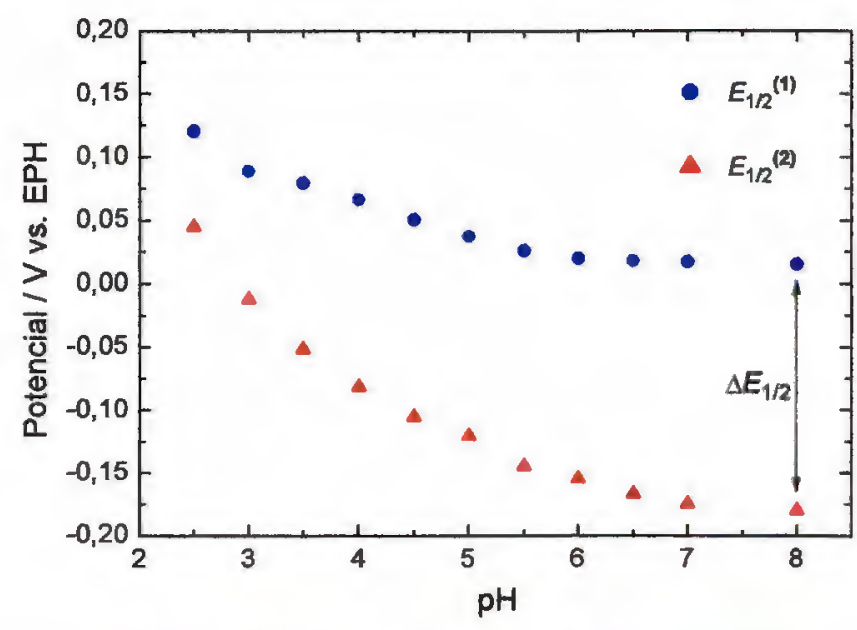

Figura 33. Variaçăo dos potenciais redox dos complexces [(edta)Ru(bta/btaH)Ru(edta) $]^{n-2}$ em funçato do pH.

A observação acima é explicada pelo fato de que a primeira etapa de redução, que se dá sobre a espécie isovalente oxidada, $R u^{I I I} R u^{\text {III }}$, será influenciada basicamente pelas propriedades ácido-base (interações LMCT) do complexo, que afetarão a energia dos níveis redox do metal. A segunda etapa de redução, por sua vez, se dá sobre o complexo de valência mista $\mathbb{R u}{ }^{\text {III }} \mathrm{Ru}$ ", no qual a perturbação oriunda da deslocalização eletrônica se torna muito mais importante. Assim, além da protonação/desprotonação do complexo, a interação eletrônica que opera nessa espécie será, evidentemente, mais discreta quando o ligante-ponte estiver protonado, já que a sua densidade de carga será menor e, conseqüentemente, a comunicação intermetálica por meio de deslocalização de elétrons será menos intensa.

\subsection{Propriedades espectroeletroquímicas}

No item 3.1.2.1, o complexo [(edta)Ru(bta)Ru(edta) ${ }^{n-}$ foi caracterizado espectroscopicamente em todos os seus estados de oxidação possíveis $(n=3,4,5)$ por meio de medidas espectroeletroquímicas tanto na região do UV-Vis como na região do NIR.

Uma vez que, nesta etapa, o interesse é voltado apenas para as propriedades de ET do sistema, então será dada uma ênfase especial para a banda de transferência de carga metal-metal na região do infravermelho próximo, cujos espectros foram obtidos por aplicação de potencial correspondente à geração eletroquímica in situ da espécie de valência mista, $\mathrm{Ru}^{\mathrm{III}} \mathrm{Ru}{ }^{\mathrm{II}}$. Como critério para a escolha do potencial a ser empregado, foi utilizado aquele que promove a maior quantidade da espécie absorvente, deduzido pelo monitoramento do máximo de absorção da banda que, em todos os casos, foi obtido quando o potencial aplicado culminava com o valor médio de $E_{1 / 2}^{(1)}$ e $E_{1 / 2}{ }^{(2)}$.

Assim, conforme tem sido caracterizado anteriormente (v. item 3.1.2.1.1), a presença de uma banda intensa na região do NIR para a espécie de valência mista foi atribuída à transferência de intervalência:

$$
\begin{aligned}
& {\left[\left(\text { edta) } R u^{\text {III }}-\mathrm{L}_{b}-\mathrm{Ru}^{\text {II }}(\text { edta })\right]^{n-} \stackrel{\text { hv }}{\longrightarrow}\right.}
\end{aligned}
$$

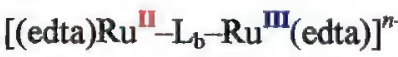

A partir da banda associada a essa transição, é possível estimar a grandeza da interação eletrônica e também da deslocalização de cargas metal-metal por meio das equações de Hush (Eqs. 27 e 28).

De acordo com esse modelo, ${ }^{23,24}$ um critério simples para se avaliar a natureza da deslocalização de um sistema simétrico é dado pelo cálculo da largura de meia-banda de $\Gamma$, através da Eq. 37.

Quanto mais larga for a banda de IT em relação ao valor estimado, menor será interação e mais localizado será o sistema (classe II). Assim, de uma maneira qualitativa, por meio de simples análise dos espectros eletrônicos para um dado sistema, pode-se inferir que, quanto mais intensa e 
estreita for a banda de IT, maior será o acoplamento eletrônico e a deslocalização de elétrons neste sistema, podendo ser típicos de classe III no caso extremo onde o valor de $\Delta \bar{v}_{1 / 2}$ teórico for maior que o mesmo obtido experimentalmente.

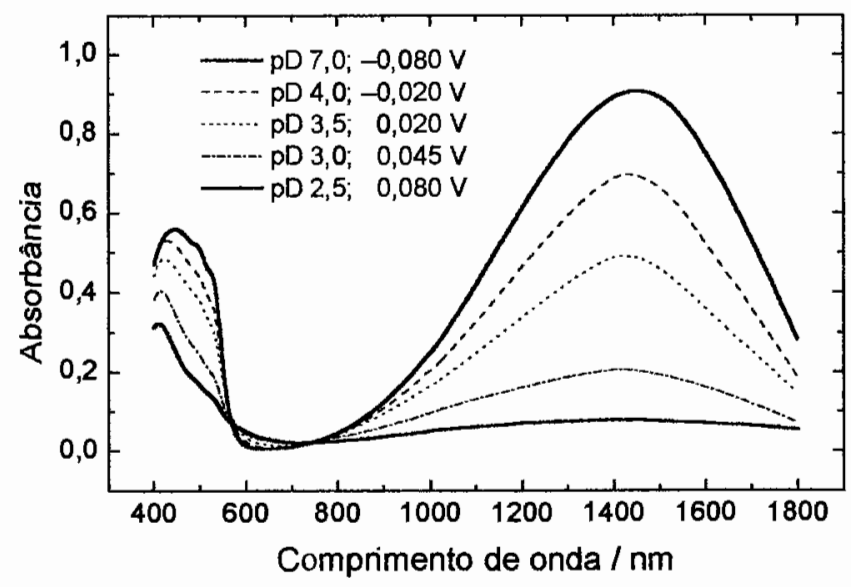

Figura 34. Espectros eletrônicos dos complexos de valência mista $\left[(\text { edta }) R u\left(\mu-L_{b}\right) R u(\text { edta })\right]^{n-}$ (onde $L_{b}=$ bta ou btaH) em $D_{2} O$. $\left(C=5,0 \times 10^{-3} \mathrm{~mol} \mathrm{dm}^{-3} ; l=0,1 \mathrm{~mol} \mathrm{dm}^{-3}\right)$

Conforme pode ser observado na Fig. 34, à medida que o $\mathrm{pD}$ é diminuído, a absortividade da espécie de valência mista, [(edta)Ru(bta)Ru(edta) $]^{4-}$, em solução de $\mathrm{D}_{2} \mathrm{O}$, diminui na mesma razão em que aumenta a largura da banda de intervalência (Tab. 11). De acordo com o exposto acima, isso está mostrando claramente, uma vez mais, que a comunicação eletrônica intermetálica no complexo está diminuindo com o $\mathrm{pD}$, atingindo o seu ponto mínimo em $\mathrm{pD}$ ao redor de 2,5 (Fig. 34).

Baseado na variação espectral da banda de IT, o $\mathrm{p} K_{\mathrm{a}}$ associado ao equilíbrio de dissociação ácido-base (v. seção 6.2) da espécie de valência mista $\left(\mathrm{p} K_{\mathfrak{a}}^{\mathrm{VM}}\right)$ foi obtido em 3,3 (Eq. 82).

$$
\begin{gathered}
{[(\text { edta }) \operatorname{Ru}(\mu-\{2 H-\text { btaH }\}) \operatorname{Ru}(\text { edta })]^{3-}} \\
\| \quad\left[K_{\mathrm{a}}^{\mathrm{VM}}=10^{-3,3}\right] \\
{[(\text { edta }) \operatorname{Ru}(\mu-\text { bta }) \operatorname{Ru}(\text { edta })]^{4-}+\mathrm{H}^{+}}
\end{gathered}
$$

Os valores calculados da largura de meia-banda, $\Delta \bar{v}_{1 / 2}$, em função do $\mathrm{pD}$ também foram coletados na Tab. 11 para fins de comparação com os experimentais e categorização do sistema no esquema de Robin-Day ${ }^{68}$ (v. item 1.2.1). Assim, observa-se que, enquanto em meio neutro ou levemente ácido, o sistema é de classe III; a partir de $\mathrm{pD} 3,0$ ou inferior, o complexo passa a se comportar como sendo tipicamente de classe II com cargas localizadas e interação apenas medíocre. Ao redor de $\mathrm{pD} 3,3$, o sistema exibe ainda um comportamento limítrofe de classes II/III (borderline).

Tabela 11. Parâmetros espectroscópicos da banda de IT dos

\begin{tabular}{|c|c|c|c|c|c|}
\hline pD & $\begin{array}{c}\lambda \\
(\mathrm{nm})\end{array}$ & $\left(\mathrm{mol}^{-1} \mathrm{dm}^{3} \mathrm{~cm}^{-1}\right)$ & $\begin{array}{c}\Delta \nabla_{/ / 2}(\exp ) \\
\left(\mathrm{cm}^{-1}\right)\end{array}$ & $\begin{array}{c}\Delta \bar{v}_{3 / 2}(\text { calc }) \\
\left(\mathrm{cm}^{-1}\right)\end{array}$ & Classe \\
\hline 7,0 & 1450 & 2200 & 2900 & 3990 & III \\
\hline 3,7 & 1435 & 1610 & 3100 & 4010 & III \\
\hline 3,3 & 1425 & 1140 & 3400 & 4030 & II/III \\
\hline 3,0 & 1415 & 480 & 4125 & 4040 & II \\
\hline 2,5 & 1410 & 185 & 5600 & 4050 & II \\
\hline
\end{tabular}
complexos de valência mista [(edta)Ru( $\left.\left.\mu-L_{b}\right) R u(e d t a)\right]^{n}$ (onde $L_{b}=b^{-}{ }^{-}$ou btaH).

Baseando-se no formalismo de Mulliken-Hush, ${ }^{23-25,70,71}$ as magnitudes da energia de ressonância e da deslocalização de elétrons, $H_{\mathrm{ab}}$ e $\alpha^{2}$, podem ser determinadas através dos parâmetros da banda de IT, de acordo com as Eqs. 27 e 28 .

Embora essas expressões sejam aplicáveis apenas para sistemas com perturbação fraca (de classe II), os valores das energias de acoplamento eletrônico, $H_{\mathrm{ab}}$, e de deslocalização, $\Delta G_{\text {d }}$ (Eq. 21), ${ }^{70}$ foram estimados para o complexo em diversos pD (mesmo naqueles onde ele não se comporta como um sistema de classe II) e compilados na Tab. 12.

Para fins de comparação, assumiu-se nos cálculos um valor fixo de 5,7 $\AA$ para a distância intermetálica, $d$ (este valor foi determinado por meio de cálculos de mecânica molecular para uma estrutura com coordenação "rígida" do tipo $\mathrm{N} 1, \mathrm{~N} 3$, análoga à observada para a espécie benzoimidazolato; item 3.1.2.1.2).

\begin{tabular}{|c|c|c|}
\hline $\mathbf{p D}$ & $\begin{array}{l}\max \left(E_{0}\right. \\
\left(\mathrm{cm}^{-1}\right)\end{array}$ & $\begin{array}{c}\boldsymbol{H}_{\mathrm{ab}} \\
\left(\mathrm{cm}^{-1}\right)\end{array}$ \\
\hline 7,0 & 6900 & $\gg 755$ \\
\hline$\therefore \quad 3,7$ & 6970 & $>670$ \\
\hline$\therefore \quad 3,3$ & 7020 & $\sim 590$ \\
\hline $\mathbf{3 , 0}$ & 7070 & 425 \\
\hline$\quad 2,5$ & 7090 & 305 \\
\hline
\end{tabular}

Tabela 12. Energia de acoplamento eletrônico para os complexos de valência mista [(edta)Ru(bta/btaH)Ru(edta) $]^{4-,-3}$ em vários $\mathrm{pH}$. 


\subsection{Reatividade, estrutura e propriedades gerais}

$0 \mathrm{p} K_{\mathrm{a}}$ do ligante benzotriazol livre neutro é 8,38 e refere-se ao sítio de protonação $\mathrm{N} 1{ }^{292} \mathrm{O}$ átomo de nitrogênio N3 também se protona em $\mathrm{pH}$ bastante baixo para formar a espécie btaH ${ }_{2}{ }^{+}$, cujo $\mathrm{p} K_{\mathrm{a}}$ é $1,177^{292} \mathrm{O}$ átomo $\mathrm{N} 2$, por outro lado, é muito menos nucleofilico e deveria, portanto, possuir $\mathrm{p} K_{\mathrm{a}}$ muito menor que N1 ou N3. Para o ligante livre, contudo, nenhum relato de sua determinação foi encontrado na literatura. Isso deve explicar-se pela elevada acidez da espécie btaH ${ }_{3}^{2+}$, onde os três átomos de nitrogênio estariam protonados e $\mathrm{N} 2$ seria o mais ácido deles $\left(\operatorname{com} \mathrm{p} K_{\mathrm{a}}<0\right)$.

Quando o ligante neutro está coordenado ao $\mathrm{Ru}^{\mathrm{III}}$ (edta) através do átomo $\mathrm{N} 3$ (isômero $\mathrm{kN} 3$ ), o seu $\mathrm{p} K_{\mathrm{a}}$ diminui cerca de 3 unidades ( $\mathrm{v}$. itens 3.1.1.3 e 3.1.1.4), devido ao caráter aceitador $-\pi$ do complexo oxidado. Por isso é que a reação de formação do complexo binuclear $\mathrm{Ru}^{\mathrm{III}}$-bta-Ru $\mathrm{Ru}^{\mathrm{III}} \mathrm{se}$ processa em meio neutro ou levemente ácido, caso contrário o sítio potencialmente coordenante com outro íon $\mathrm{Ru}^{\mathrm{III}}$ (isto é, Nl) ainda estaria protonado, dificultando ou até mesmo impossibilitando a ligação

A reação por meio do átomo menos nucleofilico N2 só é observada através de isomeria de ligação no complexo mononuclear reduzido (item 3.1.1.2), que é melhor estabilizado por meio de interações com o ligante do tipo $\pi$ retrodoadoras. Nesse caso, a constante ácida $K_{\mathrm{a}}$ do ligante coordenado diminui em uma ordem de grandeza. Por isso é que ficou caracterizado anteriormente que, devido às propriedades fluxionais do ligante benzotriazolato, a distância intermetálica pode ser otimizada para promover uma coordenação simétrica do tipo N1,N3 "aproximada", mas não do tipo $\mathrm{N} 1, \mathrm{~N} 2$, o que seria um modo de ligação totalmente impedido estericamente, conforme demonstrado por meio de cálculos de modelagem molecular. A existência de uma molécula binuclear com modo de coordenação do tipo N3,N2 e protonada em N1 seria, portanto, muito improvável.

$\mathrm{O}$ exposto acima suporta fortemente o fato de que a reação de substituição entre as espécies $\left[R u(\text { edta })\left(\mathrm{H}_{2} \mathrm{O}\right)\right]^{-}$e [Ru(edta)(btaH)] não foi observada pela mistura destes complexos diretamente em $\mathrm{pH}$ inferior a 4,0, sendo que os resultados eletroquímicos e espectroscópicos são coerentes apenas com a presença da "mistura" e não de uma nova espécie binuclear. Isso corrobora a idéia de que, para haver o efeito observado de $\mathrm{pH}$, primeiro o complexo binuclear deve ser formado em meio neutro ou levemente ácido e, então, esta espécie formada pode ser protonada em N2 de maneira totalmente reversível na faixa de $\mathrm{pH} 8$ a 2 , o que reforça o modelo de switching induzido por protonação/ desprotonação do benzotriazolato na posição intermediária $\mathrm{N} 2$, entre os dois centros metálicos ligados em N1,N3.

Além das questões previamente já enfatizadas, no que diz respeito à modulação da transferência eletrônica metalmetal, pode-se especular a possibilidade das variações nas propriedades de valência mista em função do $\mathrm{pH}$ terem sido provocadas pela eventual dissociação do complexo binuclear quando o $\mathrm{pH}$ da solução se torna menor que o $\mathrm{p} K_{\mathrm{a}}$ da espécie mononuclear. Ou seja, em $\mathrm{pH}$ inferior a 6 , poderse-ia considerar a competição entre $o$ íon hidrogênio e a unidade de rutênio-edta pela segunda coordenação sobre o átomo de nitrogênio adicional $(\mathrm{N} 1$; se assumir-se que N3 é o primeiro sítio de ligação no complexo mononuclear). Contudo, um número de comentários abaixo relacionados conta a favor de um modelo molecular em que a protonação/desprotonação da espécie binuclear realmente se dá no átomo de nitrogênio intermediário (N2) do liganteponte benzotriazolato, com manutenção das interações metal-ligante do complexo binuclear através das posições N1 e N3:

(i) os dois pares de ondas reversíveis atribuídos aos processos $\mathrm{Ru}^{\mathrm{III}} \mathrm{Ru}^{\mathrm{III}} / \mathrm{Ru}^{\mathrm{II}} \mathrm{Ru}^{\mathrm{II}}\left(E_{1 / 2}{ }^{(1)}\right)$ e $\mathrm{Ru}^{\mathrm{II}} \mathrm{Ru}^{\mathrm{II}} / \mathrm{Ru}^{\mathrm{II}} \mathrm{Ru}{ }^{\mathrm{II}}$ $\left(E_{1 / 2}{ }^{(2)}\right)$ apenas se deslocam com a variação do $\mathrm{pH}$ (v. Fig. 32 e Tab. 10), o que é consistente com um deslocamento do equilíbrio ácido-base, uma vez que uma reação de dissociação ou substituição deveria envolver o aparecimento de novos pares de ondas em potenciais redox característicos dos produtos gerados. Como possíveis produtos de uma eventual dissociação do complexo [(edta)Ru(N1-bta-N3)Ru(edta) $]^{4-}$ devido à protonação de $\mathrm{Nl}$, seriam geradas as espécies de partida $\left[\mathrm{Ru}^{\text {II }}(\mathrm{edta})(\mathrm{btaH})\right]^{2-}$ e $\left[\mathrm{Ru}^{\mathrm{III}}(\mathrm{edta})\left(\mathrm{H}_{2} \mathrm{O}\right)\right]^{-}$. No entanto, em $\mathrm{pH} 3,0$, por exemplo, os potenciais de redução individuais para 0 complexo mononuclear e $o$ aquacomplexo foram determinados neste trabalho como sendo $0,150 \mathrm{e} 0,072 \mathrm{~V}$; enquanto no mesmo $\mathrm{pH}, E_{1 / 2}{ }^{(1)} \mathrm{e}$ $E_{1 / 2}{ }^{(2)}$ para o complexo binuclear são $0,088 \mathrm{e}-0,012 \mathrm{~V}$, respectivamente;

(ii) os voltamogramas cíclicos apresentam, em todos os $\mathrm{pH}$, uma proporção idêntica e constante entre as suas intensidades de corrente dos picos anódico e catódico tanto quando comparadas para um mesmo par de ondas $\left(i_{\mathrm{a}}{ }^{(1)} / i_{\mathrm{c}}{ }^{(1)}=1\right)$ como em relação aos pares de ondas distintos $\left(i_{\mathrm{a}}{ }^{(1)} / i_{\mathrm{a}}^{(2)}=1\right)$ (Fig. 32). Mesmo em $\mathrm{pH}$ abaixo de 3 , quando as ondas dos VC se sobrepõem devido à proximidade dos pares redox $\left(E_{1 / 2}{ }^{(1)}\right.$ e $\left.E_{1 / 2}{ }^{(2)}\right)$ e ocorre a intensificação de corrente devido à soma parcial das 
etapas eletroquímicas quase simultâneas, pode-se notar uma relação unitária bem definida entre os processos anódicos e catódicos;

(iii) a diminuição da absortividade da banda IT na região do NIR e as mudanças na energia de transição $\left(\bar{v}_{\text {máx }}\right)$ e na largura de meia-banda $\left(\Delta \bar{v}_{1 / 2}\right)$ ocorrem com dependência do pH (Fig. 34 e Tab. 11). Como esses parâmetros dizem respeito ao grau de acoplamento eletrônico na molécula, isso significa que o complexo está sofrendo uma modificação em sua natureza química (nesse caso, através do ligante-ponte). De fato, o sistema passa de classe III (desprotonado) à classe II (protonado) na classificação de Robin-Day durante o processo de protonação, passando ainda por uma situação intermediária (próximo de pH 3,3, cujo valor coincide com $\mathrm{p} K_{\mathrm{a}}{ }^{\mathrm{VM}}$ ) onde o sistema exibe características limítrofes de classes II/III (Tab. 12);

(iv) ainda acerca da espectroeletroquímica, deve-se enfatizar que a formação da espécie de valência mista foi efetuada eletroliticamente em potenciais de geração que variaram com $\mathrm{pD}$ de acordo os dados eletroquímicos para o correspondente $\mathrm{pD}$. Como a média $1 / 2\left(E_{1 / 2}{ }^{(1)}+\right.$ $\left.E_{1 / 2}^{(2)}\right)$ foi freqüentemente empregada como um critério na aplicação dos potenciais, a coerência observada entre os resultados eletroquímicos e espectrais é plausível somente no caso de um equilíbrio ácido-base;

(v) finalmente, a presença de dois pontos isosbésticos (em 570 e $750 \mathrm{~nm}$ ) nos espectros das regiões Vis-NIR sob vários $\mathrm{pD}$ (Fig. 34) corrobora as observações anteriores.

\subsection{Comentários finais}

Sendo assim, esse sistema certamente oferece um exemplo simples e interessante de molecular switching, uma vez que o complexo de valência mista envolvido é bastante solúvel e estável em água (enquanto a maioria dos exemplos de literatura $^{72,133,162,164,184}$ não o são); a dependência de suas propriedades eletrônicas com o próton é observada em uma larga faixa de $\mathrm{pH}$; e, além de tudo, a modulação do acoplamento eletrônico pode ser sintonizada por pelo menos duas vezes em magnitude (Tab. 12). Na verdade, se for considerada a natureza deslocalizada (classe III) da espécie desprotonada ( $\mathrm{pH}>6$ ), o grau de acoplamento eletrônico poderia ser estimado melhor como $\bar{v}_{\text {max }} / 2$ e não usando a Eq. 27, conforme mencionado na Tab. 12. Levando-se isso em consideração, $H_{\mathrm{ab}}$ é aumentado de aproximadamente 10 vezes com a desprotonação do ligante-ponte.
Um outro aspecto bastante importante desse sistema se refere ao posicionamento do átomo de nitrogênio ionizável. A maioria dos molecular switches contém derivados de imidazolil, pirazil, ou piridil como anéis espaçadores, a, 133,162164 onde a protonação/desprotonação ocorre em um sítio posicionado lateralmente no grupo ligante (isto é, não se situa diretamente no "caminho" do processo de ET de menor percurso), ou mesmo em ligantes terminais ou coligantes; ${ }^{72}$ enquanto no presente exemplo, o átomo de nitrogênio protonável (N2) está situado exatamente na posição intermediária entre os dois sítios doador/aceitador, cuja função pode ser imaginada como um espaçador monoatômico "entre" N1 e N3. Portanto, esse sistema pode ser descrito como um dispositivo molecular com uma função de chaveamento eletrônico, onde o íon hidrogênio (que é, provavelmente, o sinal químico mais simples conhecido) age como uma "chave" que abre ( $O N$; quando ausente) ou fecha ( $O F F$; quando presente) a passagem eletrônica (onde o electron gate seria representado pelo sítio N2-bta) para a comunicação através do ligante condutor benzotriazolato. Essas idéias encontram-se resumidas no Esq. 15.

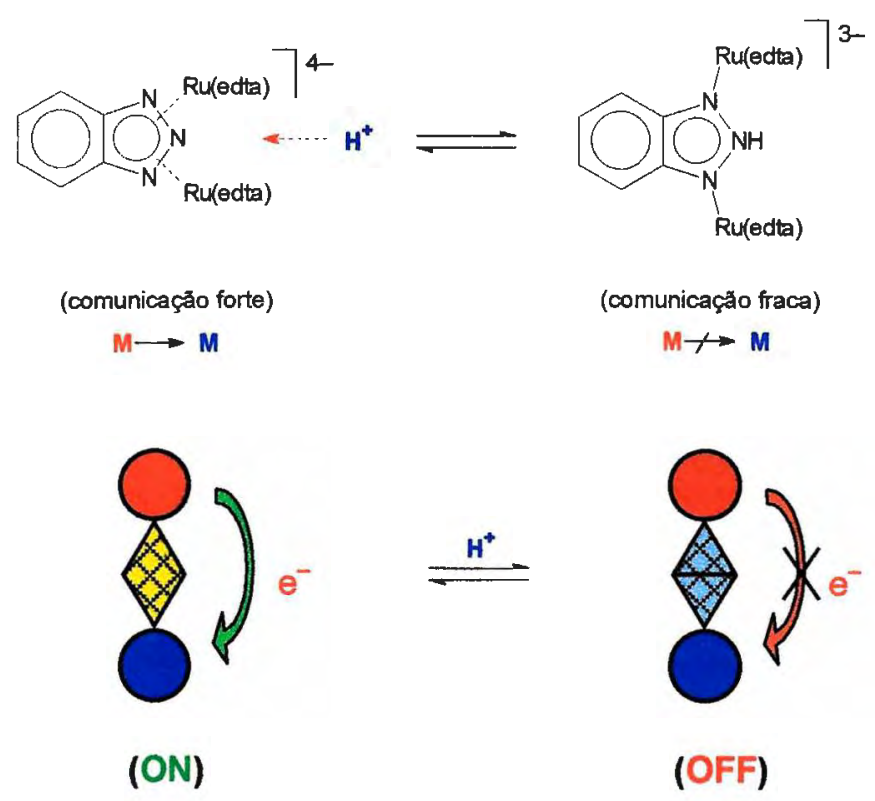

Esquema 15. Ilustração idealizada do efeito "reversivel" de molecular switching próton-induzido no complexo binuclear de valência mista $\left[\{(\text { edta }) \mathrm{Ru}\}_{2}(\mathrm{bta} / \mathrm{btaH})\right]^{4,3-}$.

\footnotetext{
a Principalmente 2-(2-piridil)imidazol ou -benzoimidazol derivados.
} 
Além de ilustrar um interessante exemplo de modulação de interação eletrônica e deslocalização intermetálica, o modelo acima reforça ainda a proposição do mecanismo de coordenação fluxional presente na molécula, praticamente eliminando a hipótese de qualquer outro modo de ligação para o complexo no estado de valência mista. 


\subsubsection{Complexo trinuclear $\mathrm{Na}_{2}\left[\left(\mathrm{NH}_{3}\right)_{4} \mathrm{Ru}\{(\text { bta }) R u(e d t a)\}_{2}\right]$ : "molecular wires"}

\subsection{Precursores mononucleares: trans-[Ru $\left.{ }^{\text {III,II }}\left(\mathrm{NH}_{3}\right)_{4}(\mathrm{~L} 1)(\mathrm{L} 2)\right]^{n}$} (L1 = btaH/bta $;$ ' L2 = btaH/bta-; $n=3,2,1,0$ )

Analogamente ao pentaaminclororutênio, ${ }^{283}$ o complexo de partida trans- $\mathrm{Ru}^{\text {II }} \mathrm{Cl}_{2}\left(\mathrm{NH}_{3}\right)_{4}$ reage rapidamente em água para formar o aquacomplexo trans- $\left[\mathrm{Ru}^{\mathrm{II}}\left(\mathrm{H}_{2} \mathrm{O}\right)_{2}\left(\mathrm{NH}_{3}\right)_{4}\right]^{2+}$, que é lábil e substitui facilmente a água na presença de ligantes $\mathrm{N}$-heterocíclicos $(\mathrm{LH}){ }^{\mathrm{a}}$

$$
\left[\mathrm{Ru}\left(\mathrm{H}_{2} \mathrm{O}\right)_{2}\left(\mathrm{NH}_{3}\right)_{4}\right]^{2+}+\mathrm{LH} \rightleftharpoons\left[\mathrm{Ru}\left(\mathrm{H}_{2} \mathrm{O}\right)\left(\mathrm{NH}_{3}\right)_{4}(\mathrm{LH})\right]^{2+}
$$$$
\left[\mathrm{Ru}\left(\mathrm{H}_{2} \mathrm{O}\right)\left(\mathrm{NH}_{3}\right)_{4}(\mathrm{LH})\right]^{2+}+\mathrm{LH} \rightleftharpoons\left[\mathrm{Ru}\left(\mathrm{NH}_{3}\right)_{4}(\mathrm{LH})_{2}\right]^{2+}
$$

No caso particular da reação com o ligante benzotriazol, as duas etapas de formação do complexo dissubstituído ocorrem com $k_{1}$ e $k_{2}$ iguais a $1,9 \pm 0,2 \times 10^{2}$ e $0,28 \pm 0,03 \times 10^{2}$ $\mathrm{mol}^{-1} \mathrm{dm}^{3} \mathrm{~s}^{-1}$, respectivamente $\left(T=25^{\circ} \mathrm{C} ; I=0,1 \mathrm{~mol} \mathrm{dm}^{-3}\right.$; $\mathrm{pH} 4,5){ }^{243} \mathrm{E}$ interessante notar que a segunda etapa de substituição é muito mais lenta que a primeira. Essa é uma manifestação do chamado efeito trans. ${ }^{340} \mathrm{O}$ mecanismo dessas reações é essencialmente dissociativo, próximo do limite $S_{\mathrm{N}} 1$.

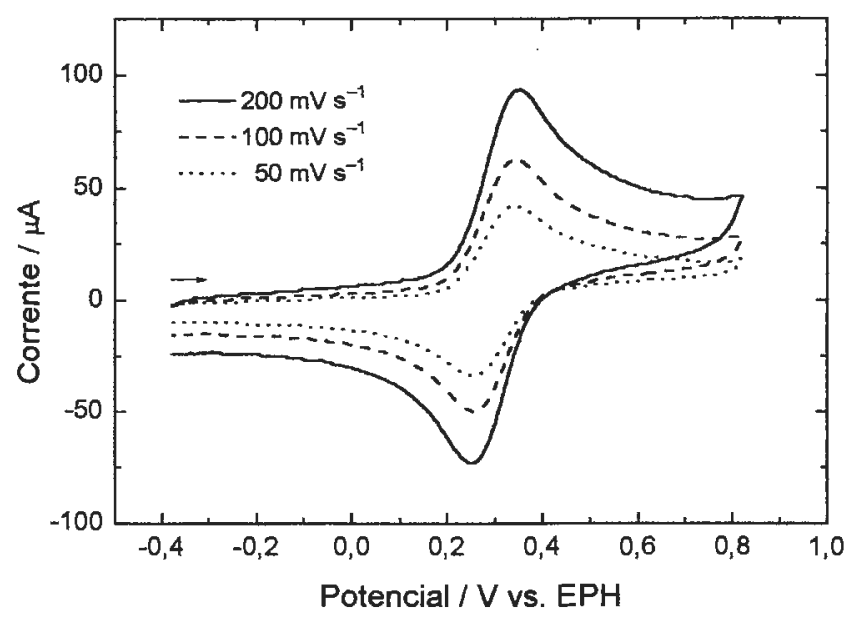

Figura 35. Voltamogramas ciclicos do complexo trans$\left[\mathrm{Ru}\left(\mathrm{NH}_{3}\right)_{4}(\mathrm{btaH})_{2}\right]^{2+}$ em soluçăo aquosa. (C $=3,0 \times 10^{-3} \mathrm{~mol} \mathrm{dm}^{-3} ; I=\mathrm{Na}$ (tfa) $0,10 \mathrm{~mol} \mathrm{dm}^{-3} ; \mathrm{pH} 4,7$ )
A reação resultante da mistura de trans- $\left[\mathrm{Ru}\left(\mathrm{H}_{2} \mathrm{O}\right)_{2}\left(\mathrm{NH}_{3}\right)_{4}\right]^{2+}$ e benzotriazol em excesso (na proporção molar 1:5) produz, em solução aquosa desaerada e levemente ácida, um composto de cor amarela, cujo potencial redox foi determinado em $0,300 \mathrm{~V}$ por voltametria cíclica (Fig. 35), Quando é oxidado nessas condições, o complexo possui coloração vermelha e apresenta uma banda LMCT em 510 $\mathrm{nm}\left(\varepsilon=2100 \mathrm{~mol}^{-1} \mathrm{dm}^{3} \mathrm{~cm}^{-1}\right)$ envolvendo as transições $\operatorname{btaH}\left(p_{\pi}\right) \rightarrow \mathrm{Ru}^{\text {III }}\left(d_{\pi}\right)$. A espécie reduzida apresenta uma banda do tipo MLCT em $425 \mathrm{~nm}$ (com $\varepsilon=9000 \mathrm{~mol}^{-1} \mathrm{dm}^{3}$ $\left.\mathrm{cm}^{-1}\right)$, atribuída às transições $\mathrm{Ru}^{\mathrm{II}}\left(d_{\pi}\right) \rightarrow \operatorname{btaH}\left(p_{\pi}{ }^{*}\right)$ (Fig. 36).

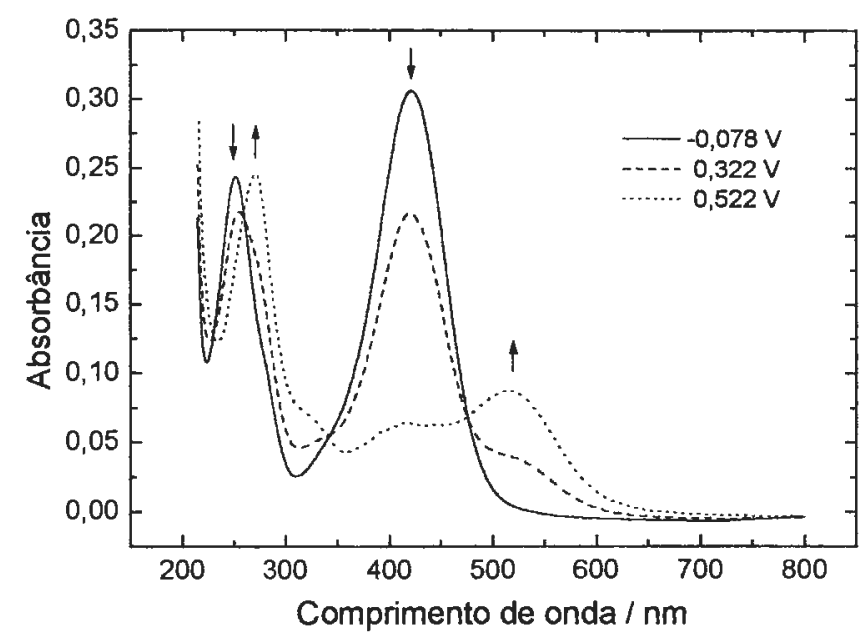

Figura 36. Espectros eletrônicos do complexo trans$\left[\mathrm{Ru}\left(\mathrm{NH}_{3}\right)_{4}(\mathrm{btaH})_{2}\right]^{2+}$ obtidos sob aplicaçăo de potencial $(\mathrm{pH} \mathrm{4,7)}$. $\left(C=3,0 \times 10^{-3} \mathrm{~mol} \mathrm{dm}^{-3} ; I=0,025 \mathrm{~cm} ; I=\mathrm{Na}(\mathrm{tfa}) 0,10 \mathrm{~mol} \mathrm{dm}^{-3}\right)$

Quando o pH de uma solução de $\left[\mathrm{Ru}\left(\mathrm{NH}_{3}\right)_{4}(\mathrm{btaH})_{2}\right]^{2+}$ é elevado a $8,5-9,0$, a sua coloração passa de amarela para laranja/castanha. Tal mudança foi atribuída à desprotonação do ligante coordenado, cujos equilíbrios ácido-base estão representados nas equações abaixo.

$$
\begin{aligned}
& \text { trans-[Ru } \left.{ }^{\text {II }}\left(\mathrm{NH}_{3}\right)_{4}(\mathrm{btaH})_{2}\right]^{2+} \\
& 1 \quad\left(K_{\mathrm{al}}\right) \\
& \text { trans-[Ru } \left.{ }^{\mathrm{II}}\left(\mathrm{NH}_{3}\right)_{4}(\mathrm{btaH})(\mathrm{bta})\right]^{+} \\
& 1 \quad\left(K_{\mathrm{a} 2}\right) \\
& \text { trans- } \mathrm{Ru}^{\mathrm{I}}\left(\mathrm{NH}_{3}\right)_{4}(\mathrm{bta})_{2}
\end{aligned}
$$

\footnotetext{
a Visto que os ligantes aqui utilizados são ácidos monoionizáveis, a notação LH empregada nas seções anteriores continuará sendo convenientemente empregadas neste trabalho (na literatura é comum encontrar estes ligantes representados simplesmente por $L$ ).
} 
Os valores de $\mathrm{p} K_{\mathrm{a} 1}$ e $\mathrm{p} K_{\mathrm{a} 2}$ foram determinados através de métodos espectrofotométricos como sendo 6,0 e 8,6 , que correspondem a constantes de equilíbrio ácido-base iguais a $1,0 \times 10^{-6} \mathrm{~mol} \mathrm{dm}^{-3}$ e $2,5 \times 10^{-9} \mathrm{~mol} \mathrm{dm}^{-3}$, respectivamente. ${ }^{\mathrm{a}}$

É importante lembrar que o $\mathrm{p} K_{\mathrm{a}}$ do ligante livre ${ }^{\mathrm{b}}$ é $8,38 .{ }^{292}$ Portanto, enquanto a primeira desprotonação ocorre com relativa estabilização do ligante coordenado em relação ao livre, a segunda constante de dissociação ácida reflete nenhuma estabilização extra do outro ligante coordenado ao rutênio. Essa é uma das conseqüências do efeito trans, ${ }^{340}$ que permitirá uma comunicação eletrônica mais efetiva entre a densidade de carga sobre os ligantes através do íon metálico central. Daí a desestabilização sutil do segundo processo de desprotonação relativa ao ligante livre, devido ao aumento significativo de carga eletrônica sobre a molécula, oriunda do primeiro ligante desprotonado. Além disso, é preciso lembrar que o íon rutênio se encontra no estado reduzido $\mathrm{Ru}^{2+}$ ( $4 d^{6}$ de baixo spin $-t_{2 \mathrm{~g}}{ }^{6}$ ), o que acentua a retrodoação- $\pi$ e reduz o caráter ácido/aceitador de elétrons do metal.

Os voltamogramas cíclicos do complexo, que apresentam um único par de ondas reversíveis (Fig. 35), também se demonstraram sensíveis ao $\mathrm{pH}$, cujo potencial redox varia de $0,300 \mathrm{~V}$ em pH 4,7 (para o complexo totalmente protonado trans-[Ru( $\left.\left.\left(\mathrm{NH}_{3}\right)_{4}(\mathrm{btaH})_{2}\right]^{2+}\right)$ a $\sim 0,06 \mathrm{~V}$ em $\mathrm{pH}>$ 9,0 (para o complexo totalmente desprotonado trans-Ru(NH$\left.)_{4}(\mathrm{bta})_{2}\right)$.

Através de medidas espectroeletroquímicas do complexo totalmente desprotonado (realizadas em $\mathrm{pH} 9,0$ e baseadas nos resultados eletroquímicos por voltametria cíclica), observou-se que, enquanto a espécie reduzida trans$\mathrm{Ru}\left(\mathrm{NH}_{3}\right)_{4}(\mathrm{bta})_{2}$ possui uma banda MLCT em $410 \mathrm{~nm}$ $\left(\varepsilon=7000 \mathrm{~mol}^{-1} \mathrm{dm}^{3} \mathrm{~cm}^{-1}\right)$ atribuída às transições $d_{\pi}\left(\mathrm{Ru}^{\mathrm{I}}\right) \rightarrow \pi^{*}\left(\mathrm{bta}^{-}\right)$, no estado oxidado a banda de LMCT ocorre em $515 \mathrm{~nm}\left(\varepsilon=2200 \mathrm{~mol}^{-1} \mathrm{dm}^{3} \mathrm{~cm}^{-1}\right)$ e caracteriza as transições $\pi\left(\mathrm{bta}^{-}\right) \rightarrow d_{\pi}\left(\mathrm{Ru}^{\text {III }}\right)$ (Fig. 37).

Podemos sumarizar as informações obtidas para o complexo mononuclear de partida da seguinte forma: $(i)$ quando é desprotonado, seu potencial de redução diminui em $260 \mathrm{mV}$; (ii) por outro lado, essa variação considerável de $E_{1 / 2}$ não se reflete nem no deslocamento batocrômico, que é inferior a $10 \mathrm{~nm}$, nem na intensidade da banda LMCT; (iii) da mesma forma, a energia da banda do tipo MLCT praticamente não se altera naquele mesmo processo; (iv) em

a Os cálculos de $K_{\mathrm{a} 1}$ e $K_{\mathrm{a} 2}$ foram realizados por um procedimento de análise gráfica, aplicável a equilíbrios sucessivos. ${ }^{341}$

b Por $\mathrm{p} K_{\mathrm{a}}$ do ligante livre considera-se a dissociação ácida da molécula neutra $\mathrm{LH} \rightleftharpoons \mathrm{L}^{-}+\mathrm{H}^{+}$. Para a espécie $\mathrm{H}_{2} \mathrm{~L}^{+}$, o $\mathrm{p} K_{\mathrm{a}}$ é $1,17\left(25^{\circ} \mathrm{C}, I=0\right){ }^{292}$ analogia à série de aminas de rutênio monossubstituídas, nos complexos dissubstituídos a constante de dissociação ácida é maior para a espécie oxidada que para a reduzida; contudo, ela não pode ser estimada por via direta devido à etapa de desprotonação intermediária de LH no complexo dissubstituído (Eq. 85).

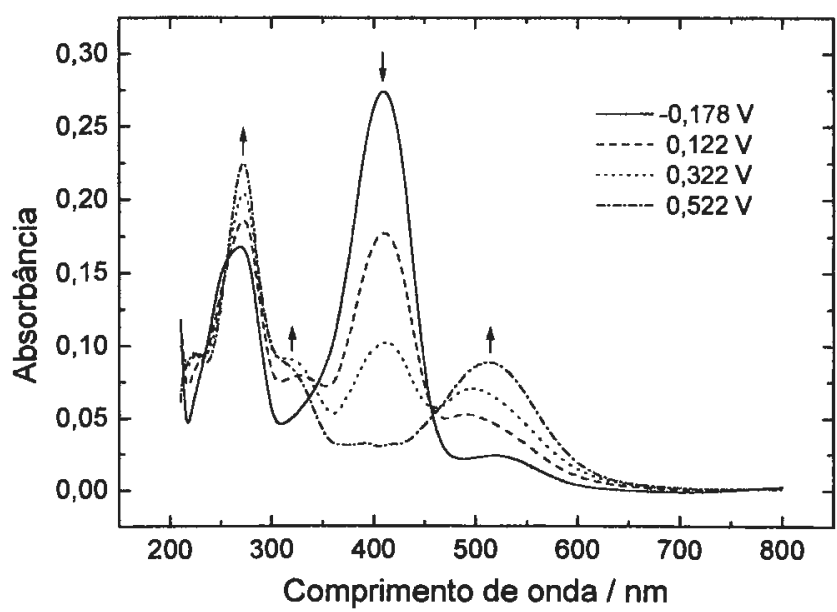

Figura 37. Espectros eletrônicos do complexo $\mathrm{Ru}\left(\mathrm{NH}_{3}\right)_{4}(\mathrm{bta})_{2}$, obtidos sob aplicaçăo de potencial $(\mathrm{pH} 9,0)$. $\left(C=3,0 \times 10^{-3} \mathrm{~mol} \mathrm{dm}^{-3} ; l=0,025 \mathrm{~cm} ; I=\mathrm{Na}\right.$ (tfa) $\left.0,10 \mathrm{~mol} \mathrm{dm}^{-3}\right)$
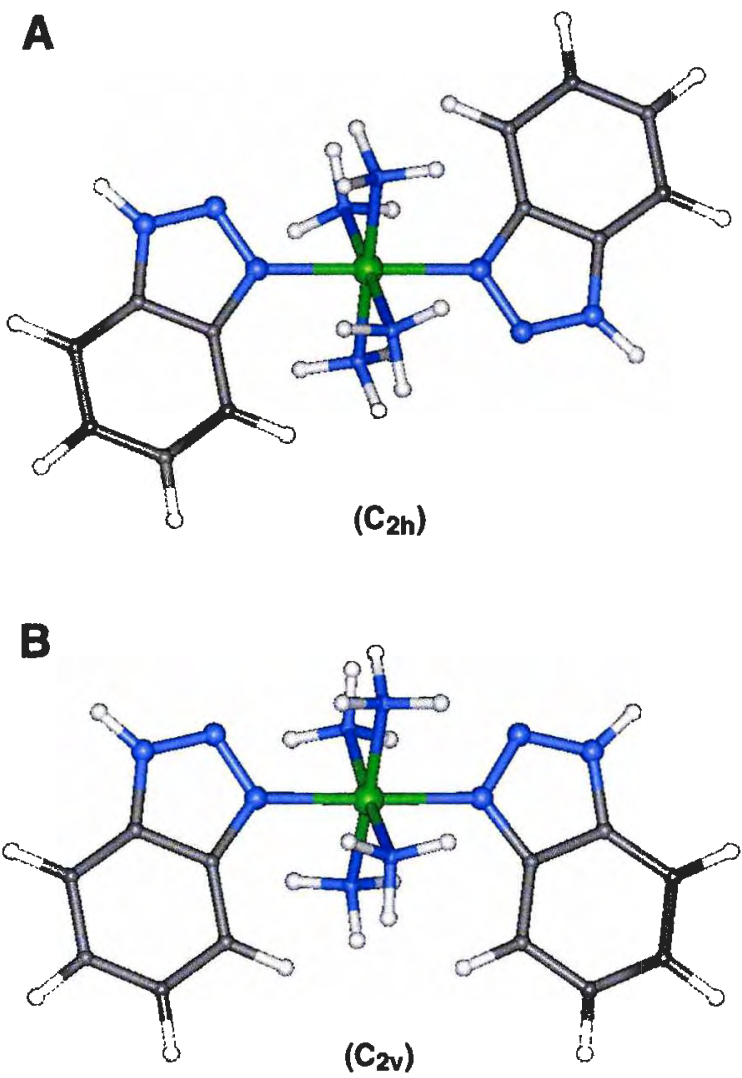

Figura 38. Isômeros estruturais do complexo mononuclear trans$\left[\mathrm{Ru}\left(\mathrm{NH}_{3}\right)_{4}(\mathrm{btaH})_{2}\right]^{2+}$. (MM+/ZINDO; v. item 2.3.8 para detalhes). 
Assim, o conjunto de resultados acima para o complexo mononuclear indica um caráter eletrônico intermediário doador/aceitador- $\pi$ para o benzotriazol neutro e doador- $\sigma / \pi$ na forma desprotonada (básica), conforme já havia sido observado pela sua utilização como espaçador/ligante-ponte em complexos binucleares derivados de carboxilatos de rutênio (item 3.1.2.1), de aminas de rutênio (item 3.1.2.2), $\mathrm{e}$ de cianoferratos (item 3.1.2.3)

$\mathrm{Na}$ Fig. 38 são mostradas as duas estruturas moleculares esperadas para o complexo mononuclear dissubstituído. Os resultados teóricos indicaram que a molécula com simetria $\mathrm{C}_{2 \mathrm{~h}}$ é $2,8 \times 10^{3} \mathrm{kcal} \mathrm{mol}^{-1}$ mais estável que aquela de simetria $\mathrm{C}_{2 v}$. Por essa razão, considerar-se-á neste trabalho apenas a estrutura da Fig. 38A.

\subsection{Precursor binuclear: trans-[(L)Ru( $\left.\mathrm{NH}_{3}\right)_{4}(\mu \text {-bta)Ru(edta) }]^{n-}$ $(\mathrm{L}=\mathrm{btaH} / \mathrm{bta} ; n=0,1,2)$}

A mistura de $\left[(\mathrm{btaH}) \mathrm{Ru}^{\mathrm{II}}\left(\mathrm{NH}_{3}\right)_{4}(\mathrm{bta})\right]^{+}$e $\left[\mathrm{Ru}^{\mathrm{III}}(\mathrm{edta})\left(\mathrm{H}_{2} \mathrm{O}\right)\right]^{-}$ na proporção molar $1: 0,75^{\mathrm{a}}$ em solução aquosa produz, em $\mathrm{pH}$ próximo a 7,0 , um composto de coloração marrom bastante intensa. A mistura é produzida pela adição lenta de uma solução de $\left[\mathrm{Ru}^{\text {III }}(\mathrm{edta})\left(\mathrm{H}_{2} \mathrm{O}\right)\right]^{-}$sobre outra contendo trans- $\left[\mathrm{Ru}^{\mathrm{II}}\left(\mathrm{NH}_{3}\right)_{4}(\mathrm{LH})(\mathrm{L})\right]^{+}$, na mesma concentração molar. Posteriormente, o pH final da solução tamponada é ajustado a 9,0 pela adição controlada de base.

Os voltamogramas cíclicos da mistura em meio básico apresentam três pares de ondas reversíveis (Fig. 39), sendo que aquelas nas extremidades (I e III) com potenciais redox em $0,153 \mathrm{e}-0,208 \mathrm{~V}$, possuem mesma intensidade de pico. ${ }^{\mathrm{c}}$ O par de ondas intermediárias (II), por sua vez, apresenta intensidade apenas ao redor de $30 \%$ das anteriores e possui $E_{1 / 2}=0,054 \mathrm{~V}$

Comparando-se os potenciais redox do complexos de partida trans-Ru( $\left(\mathrm{NH}_{3}\right)_{4}(\mathrm{~L})_{2}$ e $\left[\mathrm{Ru}(\text { edta })\left(\mathrm{H}_{2} \mathrm{O}\right)\right]^{-}$no mesmo $\mathrm{pH}(\sim 0,06 \mathrm{~V}$ e $-0,010 \mathrm{~V}$, respectivamente) com aqueles obtidos para a mistura, evidenciou-se eletroquimicamente a formação da espécie binuclear assimétrica de formulação [(bta) $\left(\mathrm{NH}_{3}\right)_{4} \mathrm{Ru}$ (bta)Ru(edta) ] ${ }^{-}$, cujos potenciais redox para os processos $\mathrm{Ru}^{\text {III }} \mathrm{Ru}^{\mathrm{III}} \rightarrow \mathrm{Ru}^{\mathrm{III}} \mathrm{Ru}^{\mathrm{II}}\left(E_{1}\right)$ e $\mathrm{Ru}^{\mathrm{III}} \mathrm{Ru}^{\mathrm{II}} \rightarrow \mathrm{Ru}^{\mathrm{II}} \mathrm{Ru}^{\mathrm{II}}$ $\left(E_{2}\right)$ correspondem aos $E_{1 / 2}$ iguais a $0,153 \mathrm{~V}$ e $-0,208 \mathrm{~V}$,

a $O$ emprego de um ligeiro excesso do complexo de aminrutênio tem a função de evitar a formação da espécie trinuclear.

b Aproximando-se a relação molar dos dois complexos para 1:1, o par de ondas II tende a desaparecer, intensificando os pares I e III.

c Embora as ondas I e II estejam parcialmente sobrepostas, cálculos foram realizados e as ondas anódica e catódica de cada uma simuladas pela subtração da corrente residual do outro par redox. respectivamente, dos pares de ondas reversíveis I e III dos voltamogramas cíclicos da Fig. 39. O par de ondas também reversíveis intermediário (II) está vinculado à presença do complexo de partida trans- $\mathrm{Ru}\left(\mathrm{NH}_{3}\right)_{4} \mathrm{~L}_{2}$ (em ligeiro excesso) e tende a desaparecer na mesma medida em que a proporção estequiométrica de $\left[\mathrm{Ru}(\text { edta })\left(\mathrm{H}_{2} \mathrm{O}\right)\right]^{-}$é aumentada. Contudo, nessas condições existe o risco de se iniciar a formação da espécie trinuclear, devido à alta estabilidade observada em complexos deste tipo. ${ }^{296}$

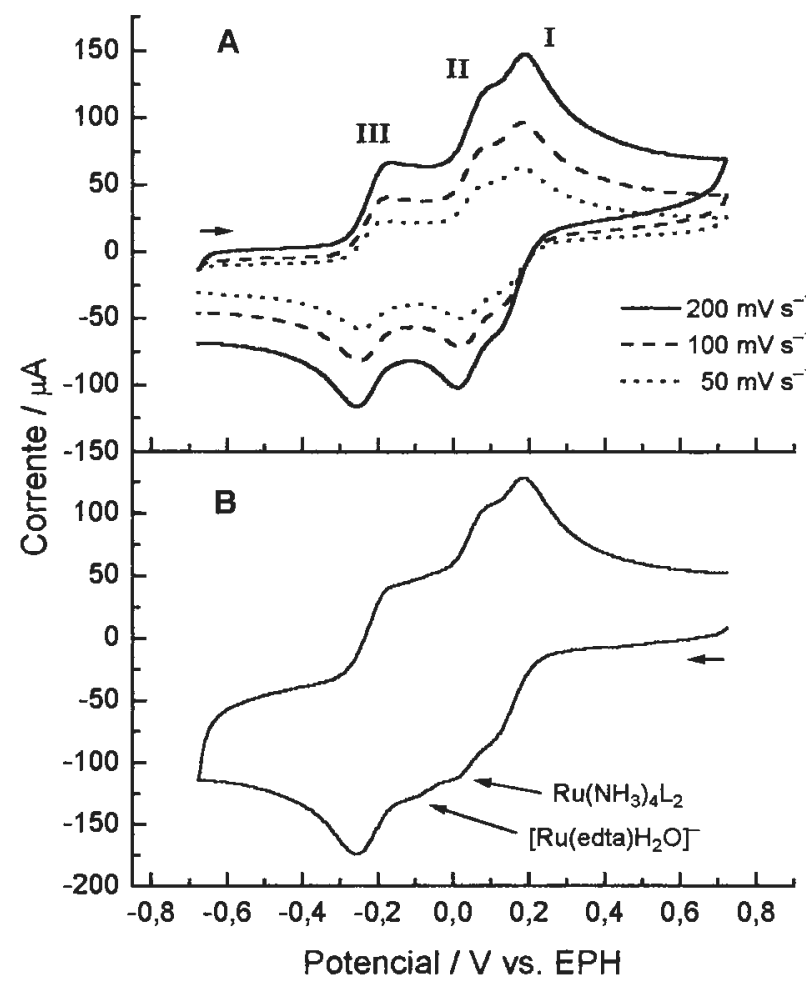

Figura 39. Voltamogramas ciclicos da mistura [(bta) $\left.\left(\mathrm{NH}_{3}\right)_{4} \mathrm{Ru}(\mathrm{bta})\right]^{+}$: [Ru(edta) $\left(\mathrm{H}_{2} \mathrm{O}\right) \Gamma$ em soluçăo aquosa nas proporçőes: (A) 1:0,75; (B) 1:0,90.

$\left(C=1,0 \times 10^{-2} \mathrm{~mol} \mathrm{dm}^{-3} ; \mathrm{pH} 9,0 ; l=\mathrm{KNO}_{3} 0,25 \mathrm{~mol} \mathrm{dm}^{-3}\right)$

Outra forte indicação da existência do complexo de interesse foi a presença de uma intensa banda de absorção na região do NIR. Dados os estados redox dos metais de partida $\left(\mathrm{Ru}^{\mathrm{II}}, \mathbf{R u}{ }^{\mathrm{III}}\right)$, essa observação é coerente com a formação de uma espécie de valência mista. Dessa forma, com intuito de se comprovar as evidências anteriores mediante análise dos espectros eletrônicos para os possiveis estados redox da molécula, realizaram-se medidas espectroeletroquímicas nas regiões Vis e NIR.

Partindo-se do complexo totalmente oxidado $(\sim 0,5 \mathrm{~V}) \mathrm{e}$ diminuindo-se o potencial aplicado gradualmente, observase a partir de $0,25 \mathrm{~V}$ o desenvolvimento de uma banda larga e intensa com máximo de absorção em $1510 \mathrm{~nm}(\varepsilon=1620$ $\mathrm{mol}^{-1} \mathrm{dm}^{3} \mathrm{~cm}^{-1}$ ) (Fig. 40). 


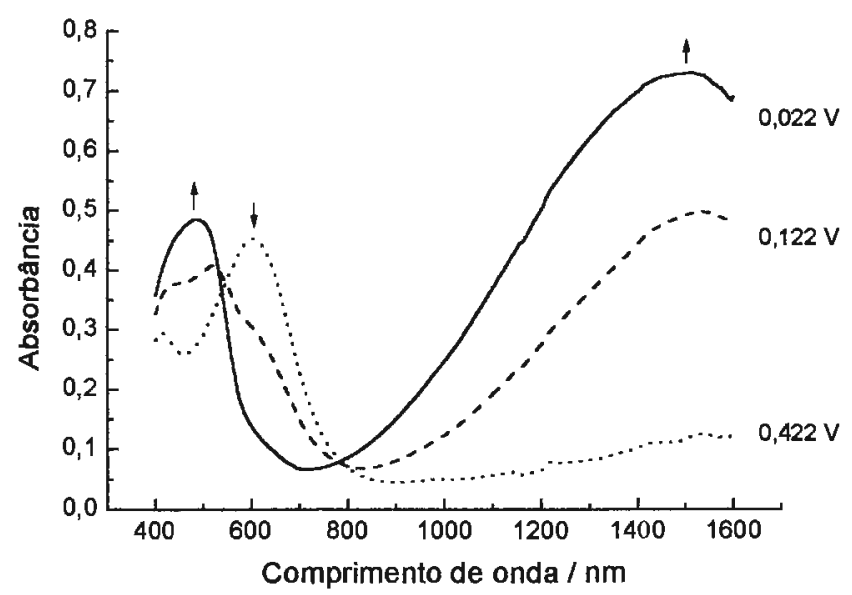

Figura 40. Espectros eletrônicos do complexo binuclear [(bta) $\left(\mathrm{NH}_{3}\right)_{4} \mathrm{Ru}(\mathrm{bta}) \mathrm{Ru}($ edta $\left.)\right]$ sob aplicaçăo de potencial em solução de $\mathrm{D}_{2} \mathrm{O}(\mathrm{pD} 9,0)$.

$\left(C=1,0 \times 10^{-2} \mathrm{~mol} \mathrm{dm}^{-3} ; /=0,045 \mathrm{~cm} ; /=\mathrm{KNO}_{3} 0,25 \mathrm{~mol} \mathrm{dm}^{-3}\right.$ )

À medida que o complexo é reduzido a intensidade da banda aumenta, culminando com um máximo quando o potencial aplicado se encontra ao redor de $0,0 \mathrm{~V}$. Considerando-se os valores dos potenciais redox obtidos dos voltamogramas cíclicos (Fig. 39), pode-se observar que a intensidade máxima da banda é atingida quando o potencial aplicado corresponde à região média entre os dois pares redox do sistema. Aplicando-se potenciais mais negativos, então a intensidade de absorção volta a diminuir progressivamente até o desaparecimento total da banda, quando é gerado o complexo totalmente reduzido (v. espectros na região do UV-Vis mais adiante).

$\mathrm{O}$ comportamento acima descrito indica que a variação na intensidade da banda no NIR com a aplicação de potencial é dependente da presença de um sítio oxidado e outro reduzido; sendo, portanto, coerente com uma transição de carga de intervalência (IVCT) e intrínseco à presença de um complexo binuclear de valência mista.

Dessa maneira, os dois pares de ondas observados nos voltamogramas cíclicos (Fig. 39) podem ser atribuídos aos seguintes processos redox:

$$
\begin{aligned}
& \text { (bta) }\left(\mathrm{NH}_{3}\right)_{4} \mathrm{Ru}^{\mathrm{III}}-\mathrm{bta}-\mathrm{Ru}{ }^{\mathrm{III}}(\text { edta }) \\
& E_{1}=0,150 \mathrm{~V} \\
& {\left[(\mathrm{bta})\left(\mathrm{NH}_{3}\right)_{4} \mathrm{Ru}^{\mathrm{II}}-\mathrm{bta}-\mathrm{Ru}^{\mathrm{III}}(\mathrm{edta})\right]^{-}} \\
& E_{2}=-0,210 \mathrm{~V}
\end{aligned}
$$

É interessante notar que o potencial de redução da espécie de partida mononuclear $\mathrm{Ru}\left(\mathrm{NH}_{3}\right)_{4}(\mathrm{bta})_{2}$ (II) aumenta em $\sim 100 \mathrm{mV}$ após a ligação com o Ru(edta) para formar o complexo binuclear (I), como pode ser observado pelos pares de ondas nos próprios voltamogramas da espécie binuclear (já que os VC são obtidos na presença de pequeno excesso de $\left.\mathrm{Ru}\left(\mathrm{NH}_{3}\right)_{4}(\mathrm{~L})_{2}\right)$.

Semelhantemente, mas em sentido oposto, o potencial redox da unidade $[R u(e d t a)(b t a)]^{2-}$ decresce da mesma magnitude $\left(E_{1 / 2}{ }^{\text {(mono) }}=-0,100 \mathrm{~V}\right)$ quando presente na molécula bimetálica. Isso é explicado pela redistribuição de densidade eletrônica sobre a molécula na associação de uma unidade fortemente $\pi$-retrodoadora $\left(\mathrm{Ru}^{\mathrm{II}}\left(\mathrm{NH}_{3}\right)_{4}\right)$ com outra $\pi$-aceitadora (Ru ${ }^{\text {III }}$ (edta)). Logo, a carga líquida sobre esses sítios será diminuída e aumentada, respectivamente, como poderá ser visto adiante na comparação dos espectros eletrônicos envolvendo transferência de carga (metal-ligante e ligante-metal) de ambos os fragmentos.

De acordo com o exposto, a espécie de valência mista [(bta) $\left(\mathrm{NH}_{3}\right)_{4} \mathrm{Ru}$ (bta) $\mathrm{Ru}$ (edta) $]^{-}$pode ser sintetizada tanto diretamente, pela reação de troca entre $\mathrm{Ru}^{\mathrm{II}}\left(\mathrm{NH}_{3}\right)_{4}(\mathrm{bta})_{2} \mathrm{e}$ $\left[\mathrm{Ru}^{\mathrm{III}}(\text { edta }) \mathrm{H}_{2} \mathrm{O}\right]^{-}$, como gerada eletroquimicamente, quando o potencial aplicado ao sistema está compreendido entre $E_{1}$ e $E_{2}$; e a banda observada em $1510 \mathrm{~nm}$ tem origem numa transferência de carga de intervalência, que pode ser representada da seguinte maneira:

$$
\begin{aligned}
& \text { (bta) }\left(\mathrm{NH}_{3}\right)_{4} \mathrm{Ru}^{\mathrm{II}}\left(d_{\pi_{3}}{ }^{2}\right)-\left(d_{\pi_{3}}{ }^{1}\right) \mathrm{Ru}^{\mathrm{III}}(\text { edta }) \stackrel{\mathrm{h} v}{\longrightarrow} \\
& \text { (bta) }\left(\mathrm{NH}_{3}\right)_{4} \mathrm{Ru}^{\mathrm{III}}\left(d_{\pi_{3}}{ }^{1}\right)-\left(d_{\pi_{3}}{ }^{2}\right) \mathrm{Ru}^{\text {II }} \text { (edta) }
\end{aligned}
$$

Posteriormente à transição induzida por luz (transferência óptica), deve ocorrer uma transferência de elétron térmica no sentido oposto, uma vez que o sistema é assimétrico e no equilíbrio existe um driving force, $\Delta G^{0}$, favorecendo a formação do isômero eletrônico termodinamicamente estável [(bta) $\left(\mathrm{NH}_{3}\right)_{4} \mathrm{Ru}^{\mathrm{II}}$-bta-Ru ${ }^{\mathrm{III}}($ edta $\left.)\right]^{-a}$.

$$
\begin{aligned}
& \text { (bta) }\left(\mathrm{NH}_{3}\right)_{4} \mathrm{Ru}{ }^{\mathrm{III}}\left(d \pi_{3}{ }^{1}\right)-\mathrm{bta}-\left(d \pi_{3}{ }^{2}\right) \mathrm{Ru}{ }^{\mathrm{II}}(\mathrm{edta}) \\
& \text { (bta) }\left(\mathrm{NH}_{3}\right)_{4} \mathrm{Ru}^{\mathrm{II}}\left(d \pi_{3}{ }^{2}\right)-\mathrm{bta}-\left(d \pi_{3}{ }^{1}\right) \mathrm{Ru}^{\mathrm{III}}(\mathrm{edta})
\end{aligned}
$$

\footnotetext{
a As curvas de potencial para os estados $\mathrm{R}$ e $\mathrm{P}$ na reação de ET exergônica

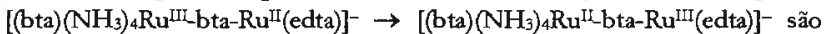
similares àquelas para o análogo assimétrico com pentaaminrutênio (v. Esq. 10 ; item 3.1.2.2). Nesse caso, o valor de $\Delta G^{\circ}$ é $\approx \Delta E(0,36 \mathrm{eV})$ e, embora $k_{\text {th }}$ não possa ser obtido diretamente (dependência de $\delta T$ ), a reação pode ser considerada adiabática e deve ocorrer facilmente (v. cálculo de $H_{\mathrm{ab}}$ adiante).
} 
A estabilidade do complexo de valência mista em relação às espécies isovalentes pode ser estimada pela constante de comproporcionamento, associada ao equilíbrio da reação:

$$
\begin{aligned}
& \text { bta-Ru III }-b t a-R u^{\text {III }}+b t a-R u^{\text {II }}-b t a-R u^{\text {II }} \\
& 1 \\
& 2 \text { bta-Ru }{ }^{\text {II }}-\text { bta-Ru }{ }^{\text {III }}
\end{aligned}
$$

Nesse caso, para uma separação redox $\Delta E_{1 / 2}=360 \mathrm{mV}$ o valor de $K_{\mathfrak{c}}$ foi estimado pela Eq. $19 \mathrm{em} 1,22 \times 10^{6}$, que corresponde a uma energia livre de comproporcionamento, $\Delta G_{\mathrm{c}}, \mathrm{de}-8,3 \mathrm{kcal} \mathrm{mol}^{-1}$.

O critério de Hush para avaliação do tipo de sistema com base na largura de meia-banda também foi levado em consideração para a espécie [(bta) $\left(\mathrm{NH}_{3}\right)_{4} \mathrm{Ru}$ (bta)Ru(edta)] onde os valores de $\Delta \bar{v}_{1 / 2}$ calculado e experimental são 3900 e $5500 \mathrm{~cm}^{-1}$, respectivamente. Como consequiência do valor estimado teoricamente ser inferior ao observado, o sistema deve ser melhor descrito pela classe II de Robin e Day. Assim, pode-se utilizar as Eqs. 27 e 28 para calcular o acoplamento eletrônico e a deslocalização eletrônica do complexo a partir dos parâmetros da banda de IVCT.

Nesse caso, os valores do coeficiente de extinção molar $\varepsilon_{\text {máx }}$ número de onda no máximo de absorção $\vec{v}_{\text {máx }}$ e largura de meia-banda $\Delta \overline{\mathbf{v}}_{1 / 2}$ da banda associada à IVCT (Fig. 40) são $1,62 \times 10^{3} \mathrm{~mol}^{-1} \mathrm{dm}^{3} \mathrm{~cm}^{-1}, 6,62 \times 10^{3}$ e $5,50 \times 10^{3} \mathrm{~cm}^{-1}$, respectivamente. $\mathrm{O}$ valor da distância intermetálica $d(5,70$ $\pm 0,02 \AA$ ) foi obtido da geometria molecular otimizada em nível de mecânica molecular $\mathrm{MM}+$ utilizando distribuição de cargas atômicas previamente geradas por meio de cálculos semi-empíricos ZINDO (Fig. 41).

Feitas as considerações anteriores, os valores de $\alpha^{2}$ e $H_{\mathrm{ab}}$ foram calculados em 0,017 e $870 \mathrm{~cm}^{-1}$, respectivamente, cuja magnitude reflete uma interação eletrônica metal-metal relativamente forte para sistemas de cargas localizadas.

Além da banda característica IVCT na região do NIR, a variação espectral na região do visível durante as medidas espectroeletroquímicas pode ser observada na Fig. 42 e resumida da seguinte maneira: quando o potencial aplicado corresponde à região redox da espécie completamente oxidada, observa-se a presença de uma banda de absorção em $610 \mathrm{~nm}\left(\varepsilon=1150 \mathrm{~mol}^{-1} \mathrm{dm}^{3} \mathrm{~cm}^{-1}\right)$ e de uma outra em $\sim 380 \mathrm{~nm}$ de menor intensidade $\left(\varepsilon=1000 \mathrm{~mol}^{-1} \mathrm{dm}^{3} \mathrm{~cm}^{-1}\right)$. Essas bandas são atribuídas a processos de transferência de carga do tipo ligante-metal envolvendo as transições $\left[\mathrm{bta}^{-}\right] p_{\pi} \rightarrow d_{\pi}\left[\mathrm{Ru}^{\mathrm{III}}\left(\mathrm{NH}_{3}\right)_{4}\right] \quad$ e $\quad\left[\mathrm{bta}^{-}\right] p_{\pi} \rightarrow d_{\pi}\left[\mathrm{Ru}^{\mathrm{III}}(\mathrm{edta})\right]$, respectivamente. Essa atribuição foi feita com base nos potenciais redox e nos espectros eletrônicos das espécies mononucleares. No entanto, é interessante notar que há um deslocamento batocrômico de $\sim 100 \mathrm{~nm}$ para o fragmento - $\left[\mathrm{Ru}^{\mathrm{III}}\left(\mathrm{NH}_{3}\right)_{4}\right.$ (bta) $]$ e hipsocrômico de $\sim 130 \mathrm{~nm}$ para o fragmento $-\left[(\right.$ bta $) \mathrm{Ru}^{\text {III }}($ edta $\left.)\right]$, em relação às suas espécies mononucleares correspondentes $(\lambda=515 \mathrm{~nm}$ e $510 \mathrm{~nm})$. Coerente com os deslocamentos de potenciais redox mostrados para essas unidades, tal comportamento indica mais uma vez o efeito de redistribuição de cargas pela coordenação do grupo $\mathrm{Ru}\left(\right.$ edta) ao complexo $\mathrm{Ru}\left(\mathrm{NH}_{3}\right)_{4}\left(\mathrm{~L}_{2}\right)$, que possuem diferentes naturezas eletrônicas. Conclui-se ainda dos resultados anteriores que a transição envolvendo o ligante benzotriazolato periférico deve prevalecer na LMCT [bta $] p_{\pi} \rightarrow d_{\pi}\left[\mathrm{Ru}^{\mathrm{III}}\left(\mathrm{NH}_{3}\right)_{4}\right]$, contribuindo para um aumento de carga localizada sobre o ligante benzotriazolato em ponte, que, por sua vez, estará envolvido na outra transição LMCT, especificamente $\left[\mathrm{bta}^{-}\right] p_{\pi} \rightarrow d_{\pi}\left[\mathrm{Ru}^{\mathrm{III}}\right.$ (edta) $]$.
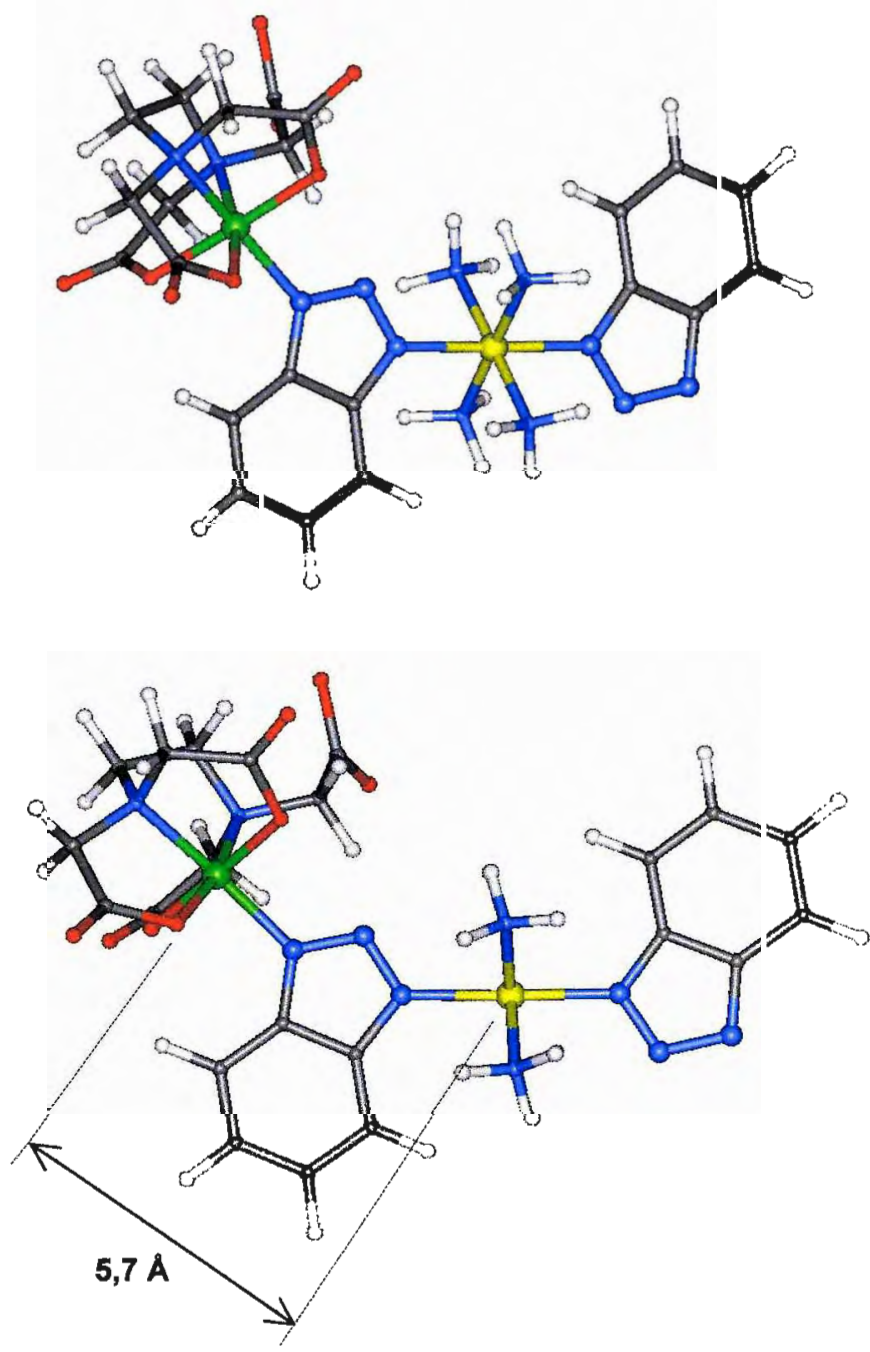

Figura 41. Estrutura molecular do complexo binuclear

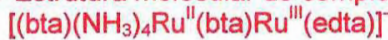




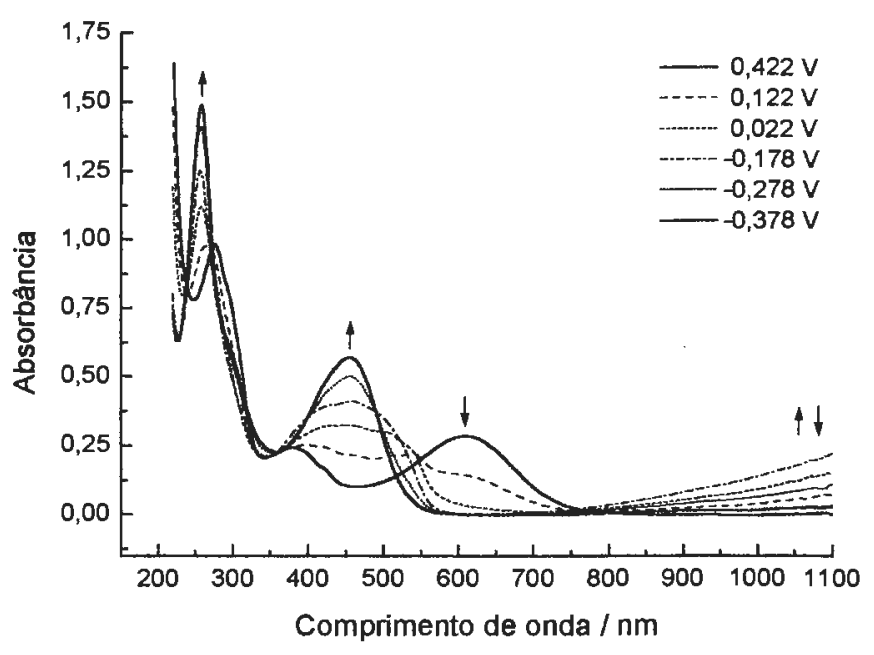

Figura 42. Espectros eletrônicos do complexo binuclear [(bta) $\left(\mathrm{NH}_{3}\right)_{4} \mathrm{Ru}(\mathrm{bta}) \mathrm{Ru}($ edta $\left.)\right]$ a vários potenciais em soluçăo aquosa $(\mathrm{pH} \mathrm{9,0)}$

$\left(C=1,0 \times 10^{-2} \mathrm{~mol} \mathrm{dm}^{-3} ; I=\mathrm{KNO}_{3} 0,25 \mathrm{~mol} \mathrm{dm}^{-3} ; I=0,025 \mathrm{~cm}\right)$

Quando o potencial aplicado é inferior ao $E_{1 / 2}$ do par redox $\mathrm{Ru}^{\mathrm{III}} / \mathbf{R u}{ }^{\mathrm{II}} \rightarrow \mathrm{Ru}^{\mathrm{II}} \mathrm{Ru}^{\mathrm{II}}$, uma única banda de maior intensidade é definida em $455 \mathrm{~nm}\left(\varepsilon=2300 \mathrm{~mol}^{-1} \mathrm{dm}^{3} \mathrm{~cm}^{-1}\right)$ e surge na medida em que aquela em $610 \mathrm{~nm}$ desaparece. Essa banda caracteriza a transição $\left[\mathrm{Ru}^{\mathrm{II}}\left(\mathrm{NH}_{3}\right)_{4}\right] d_{\pi} \rightarrow p_{\pi}[$ bta $]$ e desloca-se batocromicamente em $\sim 50 \mathrm{~nm}$ com respeito ao mesmo processo no complexo mononuclear (Fig. 37). A transição correspondente ao processo $[\mathrm{Ru}$ (II (edta) $] d_{\pi} \rightarrow p_{\pi}[$ bta $]$ deve ocorrer abaixo de $350 \mathrm{~nm}$, cuja banda aparece recoberta por aquelas do tipo $\pi \rightarrow \pi^{*}$ interna do ligante na região do UV. Entretanto, os espectros obtidos sob aplicação de potencial na região média dos dois pares redox $\mathrm{Ru}^{\mathrm{III}} / \mathrm{Ru}^{\mathrm{III}} \rightarrow \mathrm{Ru}^{\mathrm{III}} \mathrm{Ru}^{\text {III }}$ e $\mathrm{Ru}^{\mathrm{II}} / \mathrm{Ru}^{\mathrm{II}} \rightarrow \mathrm{Ru}^{\mathrm{II}} \mathrm{Ru}^{\mathrm{II}}$, apresentam várias bandas com sobreposição na faixa de 350 a $550 \mathrm{~nm}$. Uma delas se refere ao deslocamento da banda LMCT referente à transição $[$ bta $] p_{\pi} \rightarrow d_{\pi}\left[\mathrm{Ru}{ }^{\text {III }}\right.$ (edta) $]$ para $540 \mathrm{~nm}\left(\varepsilon \sim 800 \mathrm{~mol}^{-1} \mathrm{dm}^{3}\right.$ $\mathrm{cm}^{-1}$ ) em virtude da redução do sítio central de $\mathrm{Ru}\left(\mathrm{II}\left(\mathrm{NH}_{3}\right)_{4}\right.$, que vai provocar um aumento de energia no nível $\pi$-HOMO do ligante-ponte por retrodoação- $\pi$. Como conseqüência direta, a energia da transição [bta ${ }^{\top} p_{\pi} \rightarrow d_{\pi}\left[\mathrm{Ru}^{\text {III }}\right.$ (edta)] é diminuída em relação à mesma da espécie isovalente oxidada. Inclusive, a banda do tipo MLCT da transição $\left[\mathrm{Ru}^{\mathrm{II}}\left(\mathrm{NH}_{3}\right)_{4}\right] d_{\pi} \rightarrow p_{\pi}[\mathrm{bta}]$ definida em $455 \mathrm{~nm}$ para potenciais abaixo de $-0,2 \mathrm{~V}$, também aparece deslocada para o vermelho (ao redor de $500 \mathrm{~nm}$ ) na região de potenciais da espécie de valência mista. Esse comportamento no UV-Vis é típico de sistemas de valência mista com acoplamento eletrônico/deslocalização relativamente intensa e reflete a forte perturbação nos níveis eletrônicos de fronteira da espécie de valência mista [(bta) $\left(\mathrm{NH}_{3}\right)_{4} \mathrm{Ru}^{\text {II }}$ (bta) Ru ${ }^{\text {III }}$ (edta) $]^{-}$.

\subsection{Complexo trans-[( $\left.\left(\mathrm{NH}_{3}\right)_{4} \mathrm{Ru}\{(\text { bta }) \mathrm{Ru}(\text { edta })\}_{2}\right]^{n-}$ $(n=1,2,4)$}

A reação de trans- $\mathrm{Ru}\left(\mathrm{NH}_{3}\right)_{4}(\mathrm{bta})_{2}$ e $\left[\mathrm{Ru}(\text { edta })\left(\mathrm{H}_{2} \mathrm{O}\right)\right]^{-}$na proporção molar 1:3 em solução aquosa produz, em $\mathrm{pH}$ ao redor de 9,5 e sob atmosfera inerte, um composto de cor púrpura. A adição de excesso de Ru(edta) em relação ao complexo de partida é necessária para assegurar a formação completa da espécie trinuclear. ${ }^{296}$

O voltamograma cíclico (Fig. 43) da mistura apresenta três pares (I, II, e III) de ondas reversíveis com potenciais em $0,145,-0,050$ e $-0,220 \mathrm{~V}$, respectivamente.

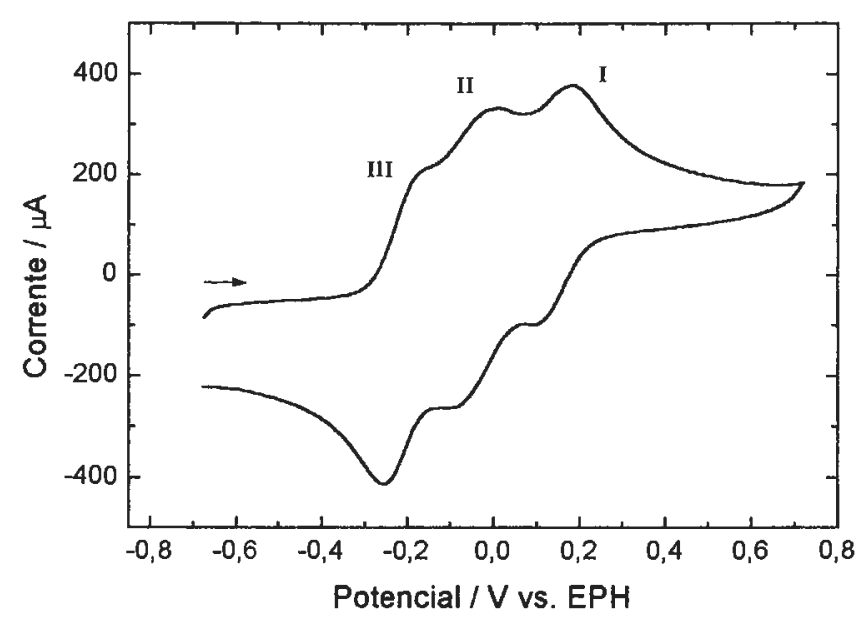

Figura 43. Voltamograma cíclico do complexo trans$\left[\left(\mathrm{NH}_{3}\right)_{4} \mathrm{Ru}\{(\text { bta }) \mathrm{Ru}(\text { edta })\}_{2}\right]^{2-}$ em solução aquosa ( $\left.\mathrm{pH} 9,5\right)$. $\left(C=2,0 \times 10^{-2} \mathrm{~mol} \mathrm{dm}^{-3} ; I=\mathrm{KNO}_{3} 0,25 \mathrm{~mol} \mathrm{dm}^{-3} ; v=200 \mathrm{mV} \mathrm{s}^{-1}\right)$

Em analogia aos valores de $E_{1 / 2}$ para os complexos mono e bimetálicos, tais potenciais caracterizam os seguintes processos redox:

(I)

$$
\begin{gathered}
{\left[\left(\mathrm{NH}_{3}\right)_{4} \mathrm{Ru}^{\mathrm{III}}\left\{(\mathrm{bta}) \mathrm{Ru}^{\mathrm{III}}(\mathrm{edta})\right\}_{2}\right]} \\
\mathbb{1} \mathrm{e}^{-} \\
{\left[\left(\mathrm{NH}_{3}\right)_{4} \mathrm{Ru}^{\mathrm{II}}\left\{(\mathrm{bta}) \mathrm{Ru}^{\mathrm{III}}(\text { edta })\right\}_{2}\right]^{2-}} \\
{\left[\mathrm{Ru}^{\mathrm{III}}(\mathrm{edta})\left(\mathrm{H}_{2} \mathrm{O}\right)\right]^{-}} \\
\mathbb{\mathrm { e } ^ { - }} \\
{\left[\mathrm{Ru}^{\mathrm{II}}(\mathrm{edta})\left(\mathrm{H}_{2} \mathrm{O}\right)\right]^{2-}}
\end{gathered}
$$

(III)

$$
\begin{aligned}
& {\left[\left(\mathrm{NH}_{3}\right)_{4} \mathrm{Ru}^{\mathrm{II}}\left\{(\mathrm{bta}) \mathrm{Ru}{ }^{\mathrm{III}}(\mathrm{edta})\right\}_{2}\right]^{2-}} \\
& 12 \mathbf{e}^{-} \quad(-0,220 \mathrm{~V}) \\
& {\left[\left(\mathrm{NH}_{3}\right)_{4} \mathrm{Ru}^{\text {II }}\left\{(\text { bta }) \mathrm{Ru}^{\text {II }}(\mathrm{edta})\right\}_{2}\right]^{4-}}
\end{aligned}
$$

Como pode ser observado no voltamograma acima, a redução dos dois sítios terminais idênticos de Ru(edta) ocorre no mesmo potencial. Se houver alguma separação, 
esta deve ser muito pequena e não pode ser observada diretamente nem estimada. Por isso é que as ondas do par reversível III possuem o dobro de intensidade de corrente $i_{\mathrm{p}}$ em relação ao par I, a partir do que se concluiu não haver nenhuma perturbação redox envolvendo esses dois centros simétricos em relação ao trans- $\mathrm{Ru}\left(\mathrm{NH}_{3}\right)_{4}$ e considerou-se um único processo de redução com participação de 2 elétrons. Estudo anterior já havia reportado comportamento parecido para o análogo com pirazina. ${ }^{296}$

Os resultados de espectroeletroquímica na região do NIR também não variam significativamente se comparados àqueles da espécie binuclear, conforme demostram os espectros eletrônicos da Fig. 44.

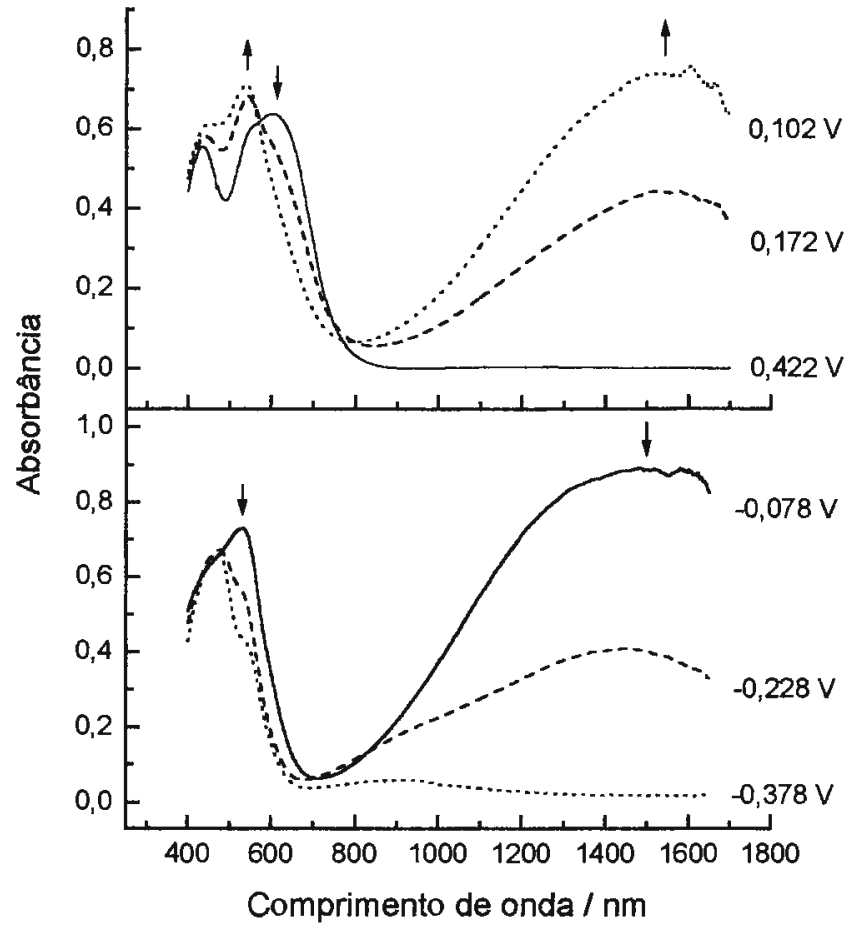

Figura 44. Espectros eletrônicos do complexo trinuclear $\left[\left(\mathrm{NH}_{3}\right)_{4} \mathrm{Ru}\{(\text { bta }) R u(e d t a)\}_{2}\right]^{2-}$ a vários potenciais em solução de $D_{2} O(p D 9,5)$

$\left(C=2,0 \times 10^{-2} \mathrm{~mol} \mathrm{dm}^{-3} ; I=0,024 \mathrm{~cm} ; I=\mathrm{KCl} 0,25 \mathrm{~mol} \mathrm{dm}^{-3}\right)$

Partindo-se do complexo totalmente oxidado $(\sim 0,5 \mathrm{~V})$ e diminuindo-se o potencial aplicado gradualmente, observase a partir de 0,25 $\mathrm{V}$ o desenvolvimento de uma banda larga e intensa em $1530 \mathrm{~nm}$ (Fig. 44), cujo máximo de absorção é atingido quando o potencial se encontra ao redor de $0,0 \mathrm{~V}$ $\left(\varepsilon=1850 \mathrm{~mol}^{-1} \mathrm{dm}^{3} \mathrm{~cm}^{-1}\right)$, que corresponde a região média entre os pares redox $\mathrm{Ru}^{\text {III }}-\mathrm{Ru}^{\text {III }} \mathrm{Ru}{ }^{\text {III }} \rightarrow \mathrm{Ru}{ }^{\text {II }}-\mathrm{Ru}{ }^{\text {III }} \mathrm{Ru}{ }^{\text {III }}$

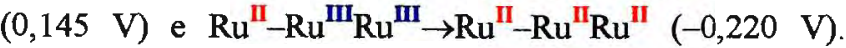
Aplicando-se potenciais mais negativos, a intensidade de absorção volta a decair progressivamente com a geração da espécie totalmente reduzida $\left[\left(\mathrm{NH}_{3}\right)_{4} \mathrm{Ru}\{(\mathrm{bta}) \mathrm{Ru}(\text { edta })\}_{2}\right]^{4}$.
O comportamento acima descrito indica que a variação na intensidade da banda no NIR com a aplicação de potencial é dependente da presença de um sítio reduzido e outros dois oxidados; sendo, portanto, coerente com uma transferência de carga metal $\rightarrow$ metal (MMCT) atribuída à presença do complexo trinuclear de valência mista

Conforme mencionado antes, é interessante ressaltar que, apesar da presença de um fragmento extra de rutênioedta, os resultados eletroquímicos e espectroeletroquímicos são praticamente idênticos aos do complexo binuclear. As únicas diferenças observadas foram: (i) aumento de $10 \mathrm{mV}$ no $\Delta E_{1 / 2}$ dos pares de ondas I e III; (ii) deslocamento para o infravermelho de $20 \mathrm{~nm}$ na banda de intervalência; (iii) abaixo de $0,05 \mathrm{~V}$, ocorre um alargamento atípico na banda de intervalência do complexo trinuclear de valência mista (Fig. 44). Esta última observação não está claramente compreendida e pode estar relacionada à presença de dois processos de transferência de carga metal-metal envolvendo diferentes níveis orbitais $d_{\pi}$ do metal central $\mathrm{Ru}{ }^{\mathrm{II}}$ para os dois sítios $\mathrm{Ru}^{\mathrm{III}}$ periféricos. Uma outra possibilidade seria uma perturbação de cargas localizadas devido à assimetria de configuração eletrônica quando se inicia a redução dos sítios periféricos; (iv) a diferença mais nítida entre os dois sistemas se refere à intensidade da banda de intervalência, que, no complexo trinuclear, é superior à do binuclear.

Nesse exemplo de sistema trinuclear de valência mista, 0 valor da constante de comproporcionamento $K_{\mathrm{c}}$ para o sistema será de $1,48 \times 10^{6}$, que corresponde a uma energia, $\Delta G_{\mathrm{c}}=0,365 \mathrm{eV}=-8,4 \mathrm{kcal} \mathrm{mol}^{-1}$. Evidentemente, essa medida refere-se a cada um dos centros metálicos de $\mathrm{Ru}\left(\right.$ edta) em relação ao de $\mathrm{Ru}\left(\mathrm{NH}_{3}\right)_{4}$, já que não há separação redox nem estabilização por comunicação eletrônica entre os dois sítios periféricos idênticos. Mais uma vez, é importante lembrar que existe um $\Delta E$ intrínseco aos diferentes potenciais redox das unidades de partida. Portanto, o valor de $\Delta G_{\mathrm{c}}$ corresponde apenas parcialmente à estabilização do complexo por deslocalização eletrônica no estado de valência mista.

Para o complexo $\left[\left(\mathrm{NH}_{3}\right)_{4} \mathrm{Ru}\{(\text { bta }) \mathrm{Ru}(\text { edta })\}_{2}\right]^{2-}$, os valores calculado e experimental de $\Delta \bar{v}_{1 / 2}$ são 3880 e 5600 $\mathrm{cm}^{-1}$, respectivamente. Assim, pelo critério de Hush para sistemas de perturbação fraca (v, item 1.2.4), o sistema deve ser melhor descrito pela classe II de Robin e Day e as Eqs 27 e 28 para $H_{\mathrm{ab}}$ e $\alpha^{2}$ se aplicam adequadamente.

Os parâmetros $\varepsilon_{\text {maxx }}, \bar{v}_{\text {máx }}$ e $\Delta \bar{v}_{1 / 2}$ associados à banda de IVCT (Fig. 44) são $1,85 \times 10^{3} \mathrm{~mol}^{-1} \mathrm{dm}^{3} \mathrm{~cm}^{-1}, 6,54 \times 10^{3} \mathrm{e}$ $5,60 \times 10^{3} \mathrm{~cm}^{-1}$, respectivamente. $\mathrm{O}$ valor da distância intermetálica $d$ entre o íon metálico central e os íons 
periféricos é a mesma do complexo binuclear $(5,70 \pm 0,02 \AA)$ e foi obtida por meio de modelagem molecular (Fig. 45).

Dessa maneira, os valores da energia de acoplamento eletrônico $\left(H_{\mathrm{ab}}\right)$ e do coeficiente de deslocalização $\left(\alpha^{2}\right)$ foram determinados em $940 \mathrm{~cm}^{-1}$ e 0,020 , respectivamente. Esse resultado é muito interessante porque mostra que a magnitude da deslocalização eletrônica é ligeiramente superior ao valor obtido para o complexo binuclear.
Além disso, como uma consequiência da intensificação da absortividade molar da espécie trimetálica o cálculo da energia de acoplamento eletrônico resultou um valor bastante elevado; típico de complexos com deslocalização de elétrons significativa e comparável àqueles determinados para os complexos assimétricos análogos de $\mathrm{Ru}($ edta) com $\mathrm{Ru}\left(\mathrm{NH}_{3}\right)_{5}$ tendo o benzotriazolato como ligante de ponte.

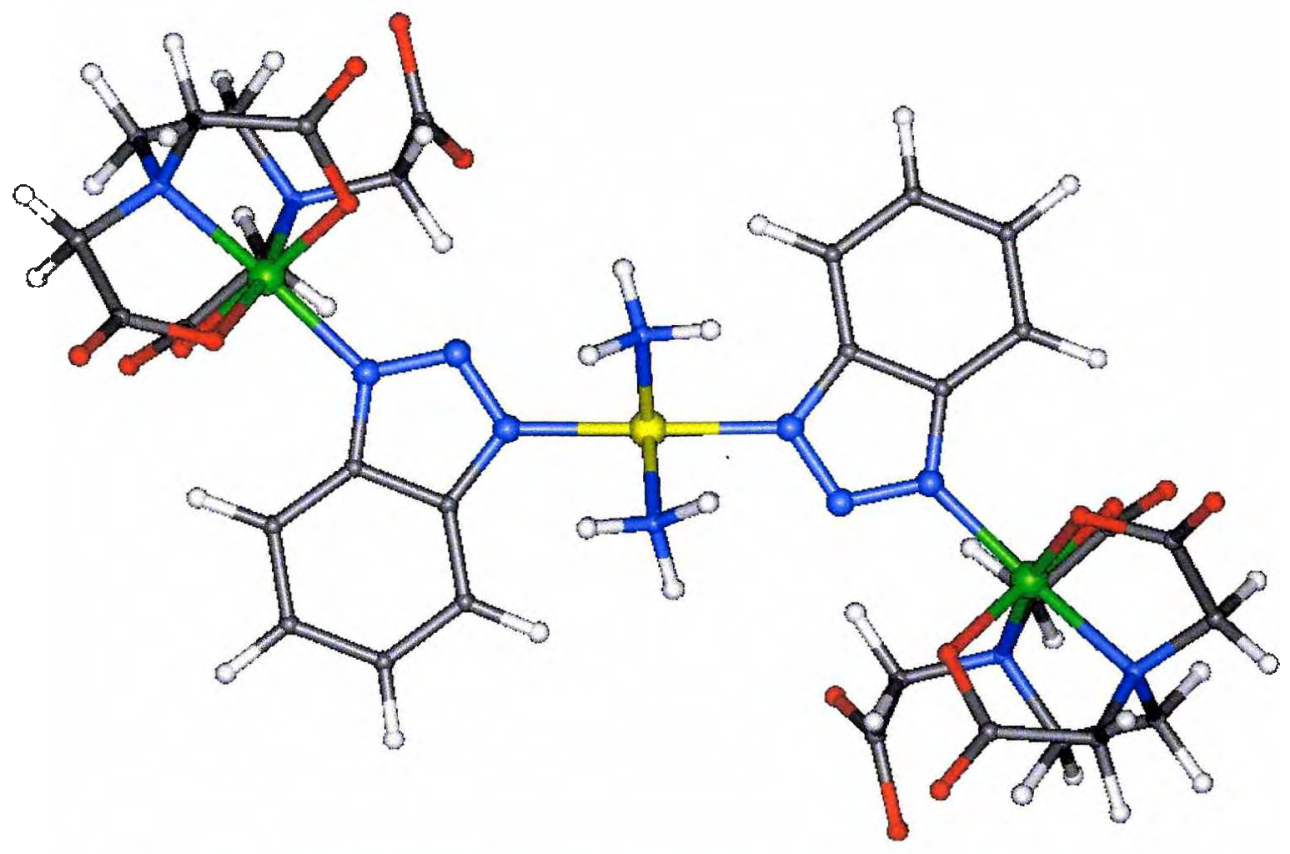

Figura 45. Estrutura molecular do complexo trinuclear $\left[\left(\mathrm{NH}_{3}\right)_{4} \mathrm{Ru}^{\prime \prime}\left\{(\mathrm{bta}) \mathrm{Ru} \mathrm{u}^{\prime \prime \prime}(\text { edta })\right\}_{2}\right]^{2-}$.

Além da banda de IVCT característica na região do NIR, a variação espectral na região do visível durante as medidas espectroeletroquímicas é bastante similar à da espécie binuclear e pode ser observada na Fig. 46. A interpretação desses resultados é a mesma daquela efetuada para o complexo binuclear (v. item anterior). Assim, os dados e atribuições das principais bandas de transferências de carga (LMCT e MLCT) para ambas as espécies estão resumidos na Tab. 13, com o intuito de se facilitar a comparação entre eles.

Todos os deslocamentos de $\lambda$ das bandas de absorção dos tipos LMCT e MLCT do complexo trinuclear em relação ao binuclear podem ser coerentemente explicados pelo efeito indutivo ácido-base de cargas eletrônicas pela coordenação do segundo fragmento de rutênio-edta.

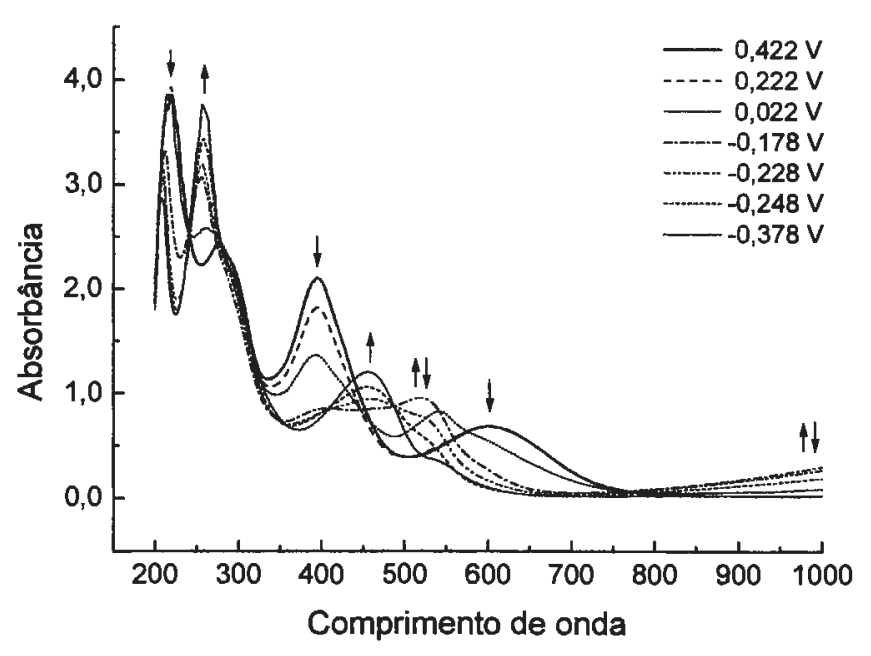

Figura 46. Espectros eletrônicos do complexo trinuclear $\left[\left(\mathrm{NH}_{3}\right)_{4} \mathrm{Ru}\{(\text { bta }) \mathrm{Ru}(\text { edta })\}_{2}\right]^{2-}$ a vários potenciais em solução aquosa (pH 9,5).

$\left(C=2,0 \times 10^{-2} \mathrm{~mol} \mathrm{dm}^{-3} ; I=\mathrm{KNO}_{3} 0,25 \mathrm{~mol} \mathrm{dm}^{-3} ; I=0,025 \mathrm{~cm}\right)$ 
Tabela 13. Espectros eletrônicos dos complexos binuclear e trinuclear em seus vários estados redox.

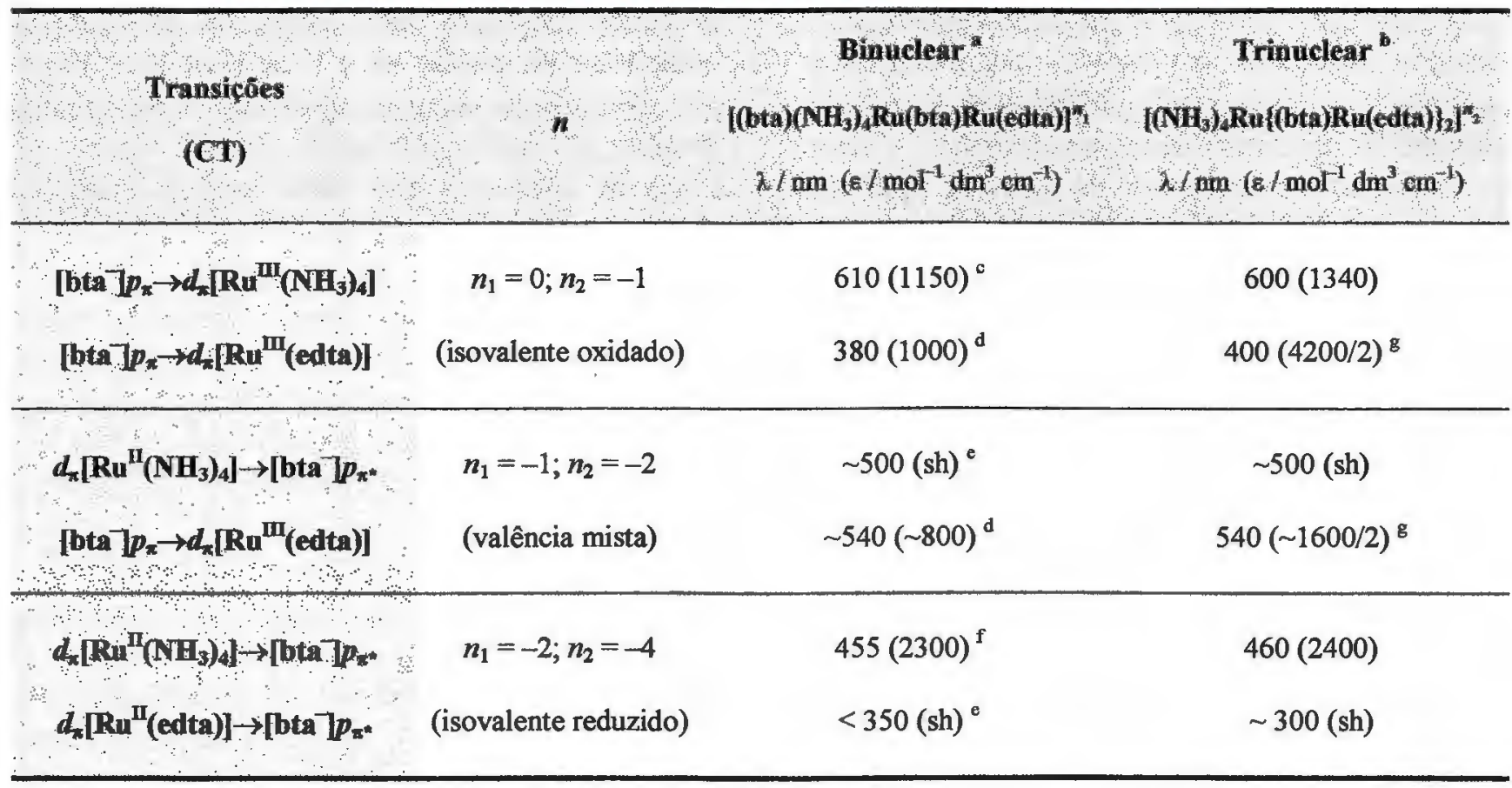

a Os dois ligantes benzotriazolato não são equivalentes no complexo binuclear do tipo $\left[\left(\mathrm{L}_{\mathrm{p}}\right)\left(\mathrm{NH}_{3}\right)_{4} \mathrm{Ru}\left(\mathrm{L}_{\mathrm{b}}\right) \mathrm{Ru}(\text { edta })\right]^{n}$; isto é, um deles funciona como ligante periférico $\left(\mathrm{L}_{\mathrm{p}}\right.$ - coordenado apenas por uma unidade metálica $\left.\left\{\mathrm{Ru}\left(\mathrm{NH}_{3}\right)_{4}\right\}\right)$ e o outro atua como ligante-ponte $\left(\mathrm{L}_{\mathrm{b}}-\right.$ conecta as unidades metảlicas $\left\{\mathrm{Ru}\left(\mathrm{NH}_{3}\right)_{4}\right\}$ e $\{\mathrm{Ru}($ edta $\left.)\}\right)$;

${ }^{b}$ Os dois ligantes benzotriazolato são equivalentes no complexo trinuclear do tipo [(edta)Ru( $\left(\mathrm{I}_{b}\right)\left(\mathrm{NH}_{3}\right)_{4} \operatorname{Ru}\left(\mathrm{L}_{\mathrm{b}}\right) \mathrm{Ru}($ edta $\left.)\right]^{n_{2} ;}$ isto é, os dois atuam como ligante do tipo ponte $\left(\mathrm{L}_{b}\right.$ - conecta as unidades metálicas $\left\{\mathrm{Ru}\left(\mathrm{NH}_{3}\right)_{4}\right\}$ e $\left.\{\mathrm{Ru}(\mathrm{edta})\}\right)$;

${ }^{c} \mathrm{~L}_{\mathrm{p}} \rightarrow \mathrm{Ru}{ }^{\mathrm{II}}$; ${ }^{\mathrm{d}} \mathrm{L}_{\mathbf{b}} \rightarrow \mathrm{Ru} \mathbf{}^{\text {III; }}{ }^{\mathrm{e}} \mathrm{Ru}{ }^{\text {II }} \rightarrow \mathrm{L}_{\mathbf{b}} ;{ }^{\mathrm{f}} \mathrm{Ru}^{\mathrm{II}} \rightarrow \mathrm{L}_{\mathrm{p}}$;

${ }^{g}$ Deve-se levar em consideração que os valores de absortividade molar das bandas de transferência de carga envolvendo o Ru(edta) no complexo trinuclear resultam da contribuição de duas transições que se somam, em decorrência da presença de duas unidades metálicas periféricas idênticas que não se interagem diretamente.

Finalmente, observa-se que as propriedades eletrônicas e termodinâmicas associadas ao acoplamento eletrônico e à deslocalização para os complexos de valência mista binuclear, [(bta) $\left(\mathrm{NH}_{3}\right)_{4} \mathrm{Ru}^{\mathrm{II}}$ (bta) $\mathrm{Ru}^{\mathrm{III}}($ edta $\left.)\right]^{\text {, e trinuclear, }}$ $\left[\left(\mathrm{NH}_{3}\right)_{4} \mathrm{Ru}^{\mathrm{II}}\left\{(\mathrm{bta}) \mathrm{Ru}{ }^{\mathrm{III}}(\mathrm{edta})\right\}_{2}\right]^{2-}$, se assemelham àquelas obtidas para a toda a série estudada em solução aquosa. $\mathrm{Na}$ verdade, à exceção dos casos onde a natureza deslocalizada da carga não permite uma estimativa precisa das energias de ressonância e de deslocalização, todos os demais exibem parâmetros compatíveis com sistemas com perturbação no limite de interação moderada/forte de classe II. Para aquelas espécies, a magnitude do acoplamento eletrônico parece ter maior dependência da natureza eletrônica do ligante que da natureza da unidade metálica.

Dos últimos sistemas estudados e reportados nesta tese, pode-se dizer ainda que, se a estimativa de $H_{\mathrm{ab}}$ e $\alpha^{2}$ puder ser utilizada de maneira aproximada na previsão do tipo ou característica eletrônica (condutor/isolante) do sistema polimetálico estendido (a exemplo dos fios moleculares), então, para um mesmo ligante espaçador empregado, a deslocalização de cargas e, conseqüentemente, a condução/ comunicação de elétrons aumenta com a nuclearidade do oligômero. 


\subsection{Comentários finais}

Complexos polimetálicos com centros redox-ativos são particularmente interessantes como grupos mediadores em dispositivos moleculares ${ }^{152}$ e em catálise de transferência multieletrônica. ${ }^{94} \mathrm{Um}$ composto típico apresentando uma forte resposta eletrocatalítica na redução de oxigênio molecular tem sido obtido pela associação de quatro complexos $\left[\mathrm{Ru}^{\mathrm{II}} \text { (edta) }\right]^{-}$à espécie meso-tetrapiridilporfirina de ferro(II). ${ }^{342}$ A ligação do complexo [Ru(edta) $]^{-}$a espécies multiponte consiste em uma maneira bastante simples de se obter sistemas polimetálicos. Entretanto, em alguns casos a ausência de excesso do complexo de rutênio pode resultar uma intrincada miscelânea de reações em equilibrio, como tem sido mostrado em trabalho prévio do grupo. $^{296}$

Neste trabalho, a investigação de espécies mono-, bi-, e trinucleares de $\mathrm{Ru}\left(\mathrm{NH}_{3}\right)_{4} \mathrm{~L}_{2}$ com $\mathrm{Ru}($ edta) permite concluir que os derivados multimetálicos contendo o benzotriazol como ponte proporcionam interações eletrônicas típicas de mediadores condutores.
Uma idéia que surge naturalmente deste trabalho é o planejamento/confecção de supermoléculas do tipo fios moleculares, pela extensão do número de unidades de construção trans-Ru( $\left.\mathrm{NH}_{3}\right)_{4}$ associadas (v. representação abaixo). Posteriormente, unidades terminais de $\mathrm{Ru}$ (edta) ou $\mathrm{Ru}\left(\mathrm{NH}_{3}\right)_{5}$ poderiam ser empregadas no "fechamento" dos pontos de ligação nas extremidades da molécula.

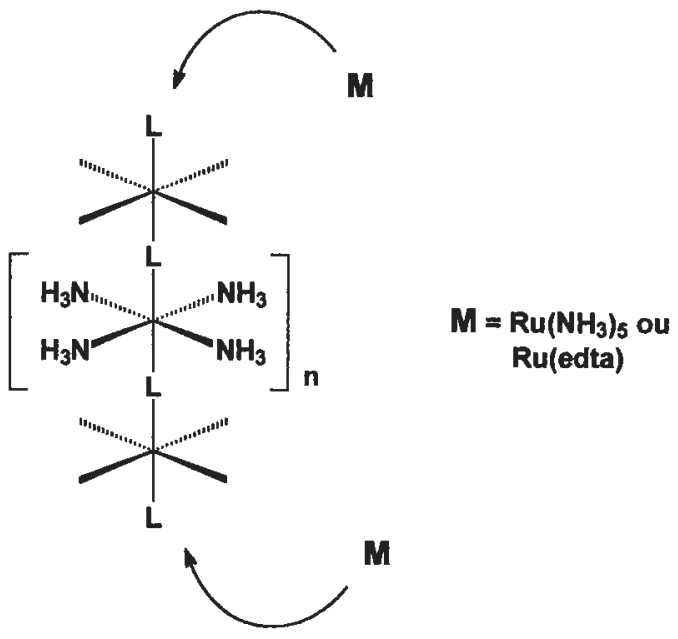

Um detalhe notável e bastante interessante no planejamento de supermoléculas do tipo estendida com base nesses fragmentos metálicos é que, a utilização do benzotriazol como ligante-ponte ou intermediário gera fios moleculares condutores simétricos mas não-lineares. No caso dos amincomplexos dissubstituídos em trans, formar-se-iam estruturas angulares do tipo representado na Fig. 47.
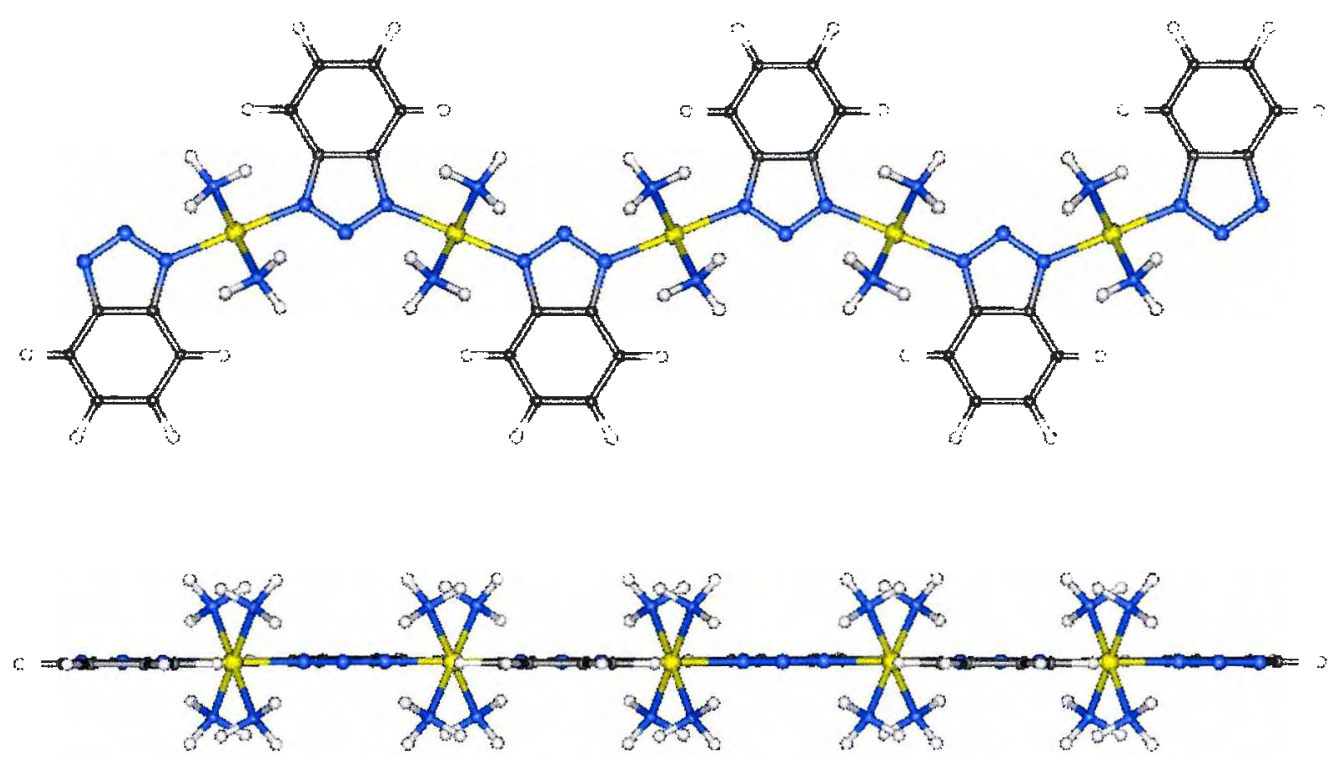

Figura 47. Idealização de novos tipos de fios moleculares baseados em unidades metálicas conectadas por pontes de benzotriazolato (MM+). 
Ignorando o esqueleto molecular e representando apenas as ligações envolvidas no "transporte de carga" ou "caminho eletrônico" entre as unidades metálicas, tais estruturas poderiam ser esquematizadas como idealizado abaixo.

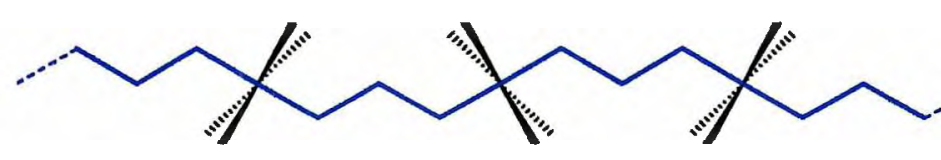

Por outro lado, os complexos dissubstituídos em cis formam estruturas moleculares que tendem a se fechar/organizar circularmente. Todavia, se esses últimos forem utilizados em associação com aqueles trans, estruturas supramoleculares curvilíneas (como aquela esquematizada abaixo) podem ser planejadas.

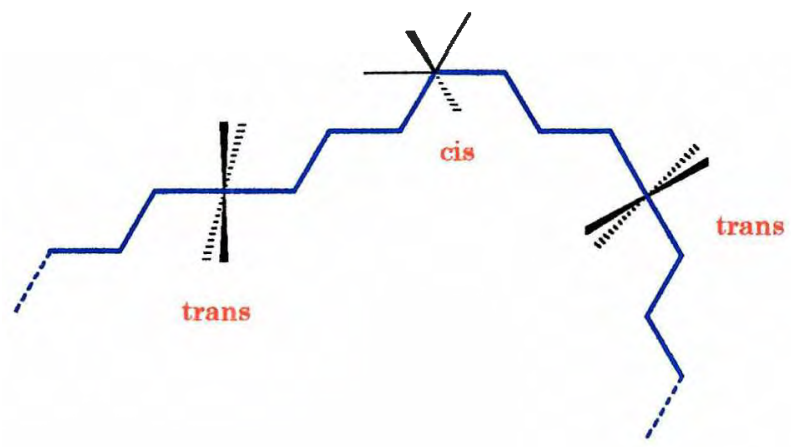

Em relação aos complexos tri ou polinucleares derivados de cis/trans tetraaminas de rutênio, acrescenta-se ainda que outras unidades metálicas não utilizadas no trabalho desta tese podem ser empregadas em projetos em andamento no grupo. Dentre elas, destacam-se as pentaaminas de rutênio e os cianoferratos. Assim, seguindo a mesma idéia até então aplicada para os análogos binucleares assimétricos e simétricos, complexos do tipo esquematizado abaixo podem ser produzidos.<smiles></smiles>

M, M = Ru(edta), $\mathrm{Ru}\left(\mathrm{NH}_{3}\right)_{5}$ $\mathrm{Ru}(\mathrm{bpy})_{2} \mathrm{Cl}$ ou $\mathrm{Fe}(\mathrm{CN})_{5}$ 


\subsection{Sistemas em meio orgânico}

\subsubsection{Síntese e purificação dos compostos}

Os complexos monossubstituídos cis-[Ru $\left.{ }^{\mathrm{II}} \mathrm{Cl}(\mathrm{bpy})_{2}(\mathrm{LH})\right]^{+}$ foram preparados pela reação do ligante LH (btaH ou bimH) com $\left[\mathrm{Ru}^{\mathrm{II}} \mathrm{Cl}(\mathrm{bpy})_{2}\left(\mathrm{H}_{2} \mathrm{O}\right)\right]^{+}$. Isso porque a espécie de partida cis- $\mathrm{RuCl}_{2}(\mathrm{bpy})_{2}{ }^{343-345}$ é lábil e, em soluções aquecidas, troca rapidamente um cloreto para formar o monoaquocomplexo. ${ }^{346}$ Esse intermediário é de grande valor sintético e consiste em um dos pontos favoráveis à vasta química dos complexos derivados de rutêniopolipiridina. ${ }^{347}$

$$
\begin{aligned}
& \text { cis-RuCl }{ }_{2}(\text { bpy })_{2} \frac{\text { EtoH } / \mathrm{H}_{2} \mathrm{O}}{\Delta} \rightarrow\left[\mathrm{RuCl}(\mathrm{bpy})_{2}\left(\mathrm{H}_{2} \mathrm{O}\right)\right]^{+}+\mathrm{Cl}^{-} \\
& {\left[\mathrm{RuCl}(\mathrm{bpy})_{2}\left(\mathrm{H}_{2} \mathrm{O}\right)\right]^{+}+\mathrm{LH} \rightarrow\left[\mathrm{RuCl}(\mathrm{bpy})_{2}(\mathrm{LH})\right]^{+}+\mathrm{H}_{2} \mathrm{O}}
\end{aligned}
$$

O procedimento envolvido na dissubstituição do material de partida $c i s-\mathrm{RuCl}_{2}(\mathrm{bpy})_{2}$ por dois ligantes $\mathrm{N}$-heterocíclicos foi análogo àquele para a monossubstituição. Nesse caso, porém, 2 equivalentes de nitrato de prata foram adicionados ao meio reacional para favorecer a retirada do segundo cloreto, que é inerte (ou pouco lábil) à substituição direta por tais ligantes monodentados.

$$
\begin{gathered}
c i s-\mathrm{RuCl}_{2}(\mathrm{bpy})_{2}+2 \mathrm{AgNO}_{3} \frac{\mathrm{ErOH} / \mathrm{H}_{2} \mathrm{O}}{\Delta} \\
c i s-\left[\mathrm{Ru}(\mathrm{bpy})_{2}\left(\mathrm{H}_{2} \mathrm{O}\right)_{2}\right]^{+}+2 \mathrm{AgCl}
\end{gathered}
$$

$$
c i s-\left[\operatorname{Ru}(\mathrm{bpy})_{2}\left(\mathrm{H}_{2} \mathrm{O}\right)_{2}\right]^{2+}+\underset{c i s-\left[\mathrm{Ru}(\mathrm{bpy})_{2}(\mathrm{LH})_{2}\right]^{2+}+\mathrm{H}_{2} \mathrm{O}}{2 \mathrm{LH}}
$$

Tentativas de síntese pela dissubstituição direta do cis$\mathrm{RuCl}_{2}(\mathrm{bpy})_{2}$ pelos ligantes de interesse também foram realizadas, mas o tempo de reação deve ser muito maior (mesmo em condições de aquecimento mais rigorosas) e o rendimento é bem menor.

$$
c i s-\mathrm{RuCl}_{2}(\mathrm{bpy})_{2}+2 \mathrm{LH} \stackrel{\mathrm{ErH} / \mathrm{H}_{2} \mathrm{O}}{\Delta} \underset{c i s-\left[\mathrm{Ru}(\mathrm{bpy})_{2}(\mathrm{LH})_{2}\right]^{+}+2 \mathrm{Cl}^{-}}{ }
$$

Essa rota pode ser usada mais eficientemente para sistemas com ligante substituinte quelato, onde a coordenação do segundo sítio é favorecida/assistida pelo primeiro.
Todos os complexos foram isolados por adição de $\mathrm{NH}_{4} \mathrm{PF}_{6}$, que induz a precipitação. $\mathrm{O}$ produto sólido foi purificado por meio de coluna cromatográfica (v. item 2.1.10) e por reprecipitação de soluções em acetona pela adição de água (ou éter, em alguns poucos casos). A cor do produto final varia de vermelho escuro à laranja, dependendo do número de ligantes LH adicionados (os complexos dissubstituídos são mais claros). Os rendimentos das reações são todos superiores a $80 \%$.

No caso específico dos complexos binucleares do tipo $\left[\left\{\mathrm{Ru}^{\mathrm{II}} \mathrm{Cl}(\mathrm{bpy})_{2}\right\}_{2}(\mathrm{~L})\right]^{+}$, a síntese foi realizada a partir da reação do ligante com dois equivalentes do complexo de partida $c i s-\mathrm{RuCl}_{2}(\mathrm{bpy})_{2}$. A equação geral para a reação é:

$2 c i s-\mathrm{RuCl}_{2}(\mathrm{bpy})_{2}+\mathrm{LH} \underset{\mathrm{EtOH} / \mathrm{H}_{2} \mathrm{O} / \mathrm{OH}^{-}}{\Delta}$

$$
\left[\mathrm{Cl}(\mathrm{bpy})_{2} \mathrm{Ru}(\mu-\mathrm{L}) \mathrm{Ru}(\mathrm{bpy})_{2} \mathrm{Cl}\right]^{+}+2 \mathrm{Cl}^{-}
$$

$\mathrm{Na}$ verdade, os ligantes estudados são ácidos do tipo $\mathrm{LH}$ (onde $\mathrm{o}$ átomo $\mathrm{H}$ ocupa uma das posições de coordenação), havendo, portanto, a necessidade de se desprotonar o ligante do complexo mononuclear para que ocorra a reação de formação da espécie binuclear. Assim, chamando os ligantes neutros de LH e os ligantes-ponte de $\mathrm{L}^{-}$, a seqüência de etapas envolvidas nas reações é dada abaixo:

$$
\text { cis- } \mathrm{RuCl}_{2}(\mathrm{bpy})_{2} \underset{\mathrm{EtOH} / \mathrm{H}_{2} \mathrm{O}}{\Delta}\left[\mathrm{RuCl}(\mathrm{bpy})_{2}\left(\mathrm{H}_{2} \mathrm{O}\right)\right]^{+}+\mathrm{Cl}^{-}
$$

$$
\begin{aligned}
& {\left[\mathrm{RuCl}(\mathrm{bpy})_{2}\left(\mathrm{H}_{2} \mathrm{O}\right)\right]^{+}+\mathrm{LH} \rightarrow\left[\mathrm{RuCl}(\mathrm{bpy})_{2}(\mathrm{LH})\right]^{+}+\mathrm{H}_{2} \mathrm{O}} \\
& {\left[\mathrm{RuCl}(\mathrm{bpy})_{2}(\mathrm{LH})\right]^{+} \frac{\mathrm{LiOH}_{2} \mathrm{H}_{2} \mathrm{O}}{\Delta} \rightarrow \mathrm{RuCl}(\mathrm{bpy})_{2}(\mathrm{~L})}
\end{aligned}
$$

$$
\begin{array}{r}
\mathrm{RuCl}(\mathrm{bpy})_{2}(\mathrm{~L})+c i s-\mathrm{RuCl}_{2}(\mathrm{bpy})_{2} \underset{\Delta}{\longrightarrow} \\
{\left[\mathrm{Cl}(\mathrm{bpy})_{2} \mathrm{Ru}(\mu-\mathrm{L}) \mathrm{Ru}(\mathrm{bpy})_{2} \mathrm{Cl}^{+}+\mathrm{Cl}^{-}\right.}
\end{array}
$$

Os complexos binucleares também foram isolados por precipitação com $\mathrm{NH}_{4} \mathrm{PF}_{6}$. $\mathrm{O}$ produto sólido foi purificado por meio de coluna cromatográfica e por reprecipitação. Nesse caso, entretanto, a purificação foi mais dificil que naqueles para os complexos mononucleares. Por alguma razão, eluição com solvente puro (acetonitrila) ou mistura de pequenas quantidades de álcoois, provocou o surgimento de "rastros" dos compostos ao longo da coluna, tornando 
significativa a perda do material. Por outro lado, utilização de proporções elevadas de solventes de alta polaridade não favoreceu a separação dos produtos indesejáveis. Tentativa de se usar coluna de sílica gel apresentou maior associação dos compostos com o material de suporte. Pelas razões citadas, o rendimento final desses complexos foi de $\sim 50 \%$. Os produtos têm cor violeta.

\subsubsection{Complexos mononucleares}

Devido ao grande volume de dados eletroquímicos e espectroeletroquímicos coletados para a série de compostos estudada $^{a}$ e para não tornar a apresentação dos resultados muito exaustiva, os voltamogramas cíclicos e espectros eletrônicos de todos os complexos mononucleares derivados de rutênio-bipiridina, juntamente com uma breve descrição dos resultados que os acompanham, foram depositados para consulta em um "banco de dados" no apêndice 6.4.3.

Assim, neste item, será dada maior ênfase à comparação e racionalização desses resultados em seu conjunto.

\subsubsection{Comparação geral}

\subsection{Eletroquímica}

Na aproximação dos orbitais moleculares localizados, os processos eletroquímicos de oxidação e redução em complexos mononucleares são interpretados como sendo centrados no metal ou no ligante. ${ }^{46,350} \mathrm{O}$ orbital molecular ocupado de maior energia (HOMO) é comumente centrado no metal, enquanto o orbital molecular não-ocupado de menor energia (LUMO) pode ser centrado no ligante ou no metal, dependendo da natureza do campo ligante. Quando o campo do ligante for suficientemente fraco, então a redução do complexo será centrada no metal. Freqüentemente, esse processo é baseado no ligante (quando este é eletroativo).

Em muitos casos, os processos redox levam à decomposição do complexo; em outros, ambas as espécies redox são estáveis. Essa estabilidade redox é essencial no planejamento de complexos polinucleares voltados para a construção de dispositivos moleculares.
Tabela 14. Potenciais redox para uma série de complexos.

\begin{tabular}{|c|c|c|c|}
\hline Conplexo & $\begin{array}{l}\text { Metal (Ru) } \\
\text { E }_{\text {in }}(\mathrm{V})\end{array}$ & $\begin{array}{c}\text { Ligante (boy) } \\
E_{\mathrm{c}}(\mathrm{V})\end{array}$ & $\begin{array}{l}\text { Ligante (boy) } \\
E_{\alpha 2}(\mathrm{v})\end{array}$ \\
\hline 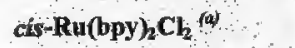 & 0,53 & $-1,30$ & $(-1,62)$ \\
\hline$\left[\mathrm{Ru}(\mathrm{bpy})\right.$ (btaH)Cl] ${ }^{+}$ & 0,$91 ; 1,08$ & $-1,28$ & $-1,40$ \\
\hline 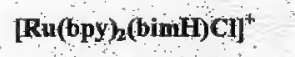 & 0,77 & $-1,45$ & - \\
\hline$\left[\mathrm{Rui}(\mathrm{bpy})_{2}(\mathrm{btaH})_{2}\right]^{2+}$ & 1,32 & $-1,37$ & $-1,48$ \\
\hline$\left[R u(b p y)_{2}(b i m a)_{h}\right]^{2+}$ & 1,16 & $-1,36$ & - \\
\hline$\left[\mathbf{R u}(\mathbf{b p y})_{2}(\mathrm{py}) \mathrm{Cu}^{+}\right.$ & 0,97 & $-1,25$ & $(-1,47)$ \\
\hline$\left[\mathrm{Ru}(\mathrm{bpy})_{2}(\mathrm{py})(\mathrm{btaH})\right]^{2+}$ & 1,39 & $-1,31$ & - \\
\hline$\left[\mathrm{Ru}(\mathrm{bpy})_{2}(\mathrm{py})(\mathrm{bimF})\right]^{2+}$ & 1,45 & $-1,19$ & $-1,41$ \\
\hline$\left[\left\{\mathbf{R u}(\mathrm{bpy})_{2} \mathrm{CR}_{3}(\mathrm{bta})\right]^{+}\right.$ & 0,$99 ; 1,34$ & $-1,28$ & $-1,52$ \\
\hline$\left[\left\{\mathbf{R u}(\mathrm{bpy})_{2} \mathrm{Cl}\right\}_{2}(\mathrm{bim})\right]^{+}$ & 0,$95 ; 1,21$ & $-1,30$ & $-1,46$ \\
\hline
\end{tabular}

${ }^{a}$ Os valores de literatura (ref. 297,348) são: $E_{\mathrm{V} / 2}\left(\mathrm{Ru}^{\mathrm{III}} / \mathrm{Ru}^{\mathrm{I}}\right)=0,32 \mathrm{~V}$; $E_{\mathrm{o}, 1}=-1,61 ; \mathrm{e} E_{\mathrm{c}, 2}=-1,86 \mathrm{~V}$ (vs. SCE). ${ }^{c}$

${ }^{b}$ Os valores de literatura (Tef. 297,298$)$ são: $E_{\mathrm{t} / 2}\left(\mathrm{Ru}^{\mathrm{III}} / \mathrm{Ru}^{\mathrm{II}}\right)=0,79 \mathrm{~V}$; $E_{\mathrm{c}, 1}=-1,51 ;$ e $E_{\mathrm{c}, 2}=-1,71 \mathrm{~V}$ (vs. SCE). ${ }^{c}$

${ }^{c} E(\mathrm{SCE}, \mathrm{V})=E(\mathrm{EPH}, \mathrm{V})-0,2412 \mathrm{~V}$; a $25^{\circ} \mathrm{C}$ (ref. 6,349).

${ }^{d}$ Valores em parênteses foram extraídos da literatura.

Os complexos de polipiridinas, particularmente aqueles do tipo $\left[\mathrm{Ru}^{\mathrm{II}} \mathrm{Cl}(\mathrm{bpy})_{2}(\mathrm{LH})\right]^{+}$, são exemplos de compostos eletroquimicamente bem-comportados. Neles, a oxidação é centrada no metal e leva à formação de espécies $R u^{\text {III }}$ estáveis, de configuração $d \pi\left(t_{2 \mathrm{~g}}\right)^{5}$ de spin baixo, que são inertes em relação à substituição dos ligantes.

$$
\left[\mathrm{Ru}^{\mathrm{II}}(\mathrm{bpy})_{2}(\mathrm{~L} 1)(\mathrm{L} 2)\right]^{\mathrm{n}} \rightleftharpoons\left[\mathrm{Ru}^{\mathrm{III}}(\mathrm{bpy})_{2}(\mathrm{~L} 1)(\mathrm{L} 2)\right]^{\mathrm{n}-1}+\mathrm{e}^{-}
$$

Somente o primeiro processo de oxidação do metal pode ser observado na faixa de trabalho da maioria dos solventes convencionais (acetonitrila e dimetilformamida). Contudo, em condições menos usuais, ${ }^{351}$ outros processos de oxidação envolvendo o ligante são observados.

Por outro lado, a redução dos complexos $\mathrm{Ru}(\mathrm{II})-$ polipiridina ocorre nos níveis $\pi^{*}$ dos ligantes polipiridina (bipiridina no caso específico deste trabalho). A forma reduzida mantém a configuração $d \pi\left(t_{2 \mathrm{~g}}\right)^{6}$ de spin baixo e o processo é quase-reversível.

$\left[\mathrm{Ru}^{\mathrm{II}}(\mathrm{bpy})_{2}(\mathrm{~L} 1)(\mathrm{L} 2)\right]^{\mathrm{n}}+\mathrm{e}^{-} \rightleftharpoons\left[\mathrm{Ru}^{\mathrm{II}}(\mathrm{bpy})\left(\mathrm{bpy} \cdot{ }^{-}\right)(\mathrm{L} 1)(\mathrm{L} 2)\right]^{\mathrm{I}-1}$

\footnotetext{
a Compleros do tipo: cis- $\left[\mathrm{RuCl}(\mathrm{bpy})_{2}(\mathrm{LH})\right]^{*}$; is- $\left[\mathrm{Ru}(\mathrm{bPy})_{2}(\mathrm{LH})_{2}\right]^{\text {; }}$ e as $\left.\left[\mathrm{Ru}(\mathrm{bpy})_{2}(\mathrm{py}) \mathrm{LH}\right)\right]^{\mathrm{y}}$; onde $\mathrm{LH}=\mathrm{btaH}$ ou bimH; $x=0,1$, ou 2 e $y=1,2$, ou 3 .
} 
Além do mais, o elétron adicionado é localizado sobre um único ligante. Várias etapas de redução podem ser observadas, $^{352}$ dependendo da faixa de potenciais de trabalho para um determinado solvente e da natureza dos ligantes L1,L2 presentes na esfera de coordenação.

Se o teorema de Koopman for válido para o complexo inicial e para sua forma reduzida por um elétron, os orbitais $\pi^{*}{ }_{L}$ e $\sigma^{*}{ }_{M}$ envolvidos no processo de redução (orbitais redox) serão os mesmos orbitais envolvidos nas transições do tipo MLCT e interna $d-d$ do metal, respectivamente (orbitais espectroscópicos). ${ }^{353}$

\subsection{Processos redox centrados no metal}

$\mathrm{Na}$ série dos complexos monocátions, o processo de oxidação ocorre de 0,77 a $0,99 \mathrm{~V}$ (V vs. EPH). Nos dicátions, esse processo ocorre de 1,16 a $1,45 \mathrm{~V}$ (a primeira oxidação dos complexos binucleares poderia ser incluída na série de monocátions). Por outro lado, o primeiro processo de redução ocorre de $-1,45 \mathrm{a}-1,25 \mathrm{~V}$ nos monocátions e de $-1,37$ a $-1,19 \mathrm{~V}$ nos complexos dicátions. De uma forma geral, esse aumento tanto nos potenciais de oxidação como nos potenciais de redução quando se passa das espécies monocatiônicas para aquelas dicatiônicas, resulta de dois fatores: o aumento de carga positiva sobre os complexos e o deslocamento de um ligante $\sigma$-doador (o íon cloreto, $\mathrm{Cl}^{-}$) por outro ligante $\pi$-aceitador (py) ou $\pi$-doador (btaH ou bimH), mas com caráter doador muito mais atenuado (na verdade, os ligantes empregados - btaH e bimH - são mais doadores que $N$-heterocíclicos $\pi$-aceitadores típicos, mas não podem ser confundidos com aqueles $\pi$-doadores genuínos, a exemplo dos ligantes aniônicos).

Os potenciais de redução para o par $\mathrm{Ru}^{\mathrm{III}} / \mathrm{Ru}^{\mathrm{II}}$ são sensíveis a ambas as propriedades dos ligantes: caráteres $\sigma$ doador ou $\pi$-aceitador. Propriedades doadoras dos ligantes levam a uma estabilização extra do íon $\mathrm{Ru}(\mathrm{III})$ em relação ao íon $\mathrm{Ru}(\mathrm{II})$, enquanto as propriedades aceitadoras são importantes na estabilização da espécie Ru(II). A basicidade dos ligantes em relação ao próton é uma medida da extensão de sua donicidade- $\sigma$. A ordem de acidez dos ligantes estudados é btaH ${ }^{+}>\mathrm{pyH}^{+}>\mathrm{bimH}_{2}^{+}\left(\mathrm{p} K_{\mathrm{a}}=1,6 ; 5,3 ; \mathrm{e}\right.$ 8,6). Assim, se não houvesse nenhuma interação do tipo $\pi$-retrodoadora nesses complexos, esperar-se-ia a seguinte ordem de $E_{1 / 2}$ para o processo de oxidação do metal: $\left[\mathrm{Ru}^{\mathrm{II} / \mathrm{I}} \mathrm{Cl}(\mathrm{bpy})_{2}(\mathrm{bimH})\right]^{+/ 2+}<\quad\left[\mathrm{Ru}^{\mathrm{I} / \mathrm{III}} \mathrm{Cl}(\text { bpy })_{2}(\mathrm{py})\right]^{+/ 2+}<<$ $\left[\mathrm{Ru}^{\mathrm{II} / \mathrm{II}} \mathrm{Cl}(\mathrm{bpy})_{2}(\mathrm{btaH})\right]^{+/ 2+}$. Entretanto, a ordem empírica é $\left[\mathrm{Ru}^{\mathrm{II} / \mathrm{III}} \mathrm{Cl}(\mathrm{bpy})_{2}(\mathrm{bimH})\right]^{+/ 2+} \ll\left[\mathrm{Ru}^{\mathrm{I} / \mathrm{III}} \mathrm{Cl}(\text { bpy })_{2}(\mathrm{btaH})\right]^{+/ 2+}<$
$\left[\mathrm{Ru}^{\mathrm{II} / \mathrm{III}} \mathrm{Cl}(\mathrm{bpy})_{2}(\mathrm{py})\right]^{+/ 2+}$ (caso seja considerado o isômero $\mathrm{Ru}-\mathrm{N} 3$ para o complexo $\left.\left[\mathrm{RuCl}(\mathrm{bpy})_{2}(\mathrm{btaH})\right]^{\dagger}\right)$; ou, $\left[\mathrm{Ru}^{\mathrm{IVIIII}} \mathrm{Cl}(\mathrm{bpy})_{2}(\mathrm{bimH})\right]^{+/ 2+} \ll\left[\mathrm{Ru}^{\mathrm{II} / \mathrm{III}} \mathrm{Cl}(\mathrm{bpy})_{2}(\mathrm{py})\right]^{+/ 2+}<$ $\left[\mathrm{Ru}^{\mathrm{IVIII}} \mathrm{Cl}(\mathrm{bpy})_{2}(\mathrm{btaH})\right]^{+/ 2+}$ (se for considerado o isômero $\mathrm{Ru}-\mathrm{N} 2$ para $\left.\left[\mathrm{RuCl}(\mathrm{bpy})_{2}(\mathrm{btaH})\right]^{+}\right)$.

Essa observação confirma a ordem btaH $\geq$ py $\gg \operatorname{bimH}^{a}$ na capacidade de aceitar elétrons- $\pi$, e reflete a importância da interação de retrodoação- $\pi$ (que parece ser mais efetiva na piridina) na estabilização da espécie $\mathrm{Ru}(\mathrm{II})$. É interessante notar que os valores de energia das transições MLCT $\left(\mathrm{Ru} \rightarrow\right.$ bpy) nesses complexos seguem a ordem: $E_{\mathrm{CT}}$ $(\mathrm{Ru}-\mathrm{btaH})>E_{\mathrm{CT}}(\mathrm{Ru}-\mathrm{py})>E_{\mathrm{CT}}(\mathrm{Ru}-\mathrm{bimH})$. Uma vez que essa ordem indica o efeito indutivo do ligante secundário LH exercido sobre o metal (que por sua vez, transfere a carga para um ligante bpy), então ela é coerente com aquela observada acima para os potenciais de oxidação do metal (v. resultados tabelados no próximo item).

\subsection{Processos redox centrados no ligante}

Complexos metálicos contendo ligantes polipiridil, tais como 2,2'-bipiridina (bpy) e seus derivados, apresentam propriedades eletroquímicas distintas, que derivam de ambos os processos: centrados no metal ou no ligante. $\mathrm{Na}$ maioria dos casos, os complexos mostram pelo menos uma redução (de um elétron) reversível eletroquimicamente para cada um dos ligantes polipiridil presentes na esfera de coordenação. Normalmente, esses processos redox ocorrem em potenciais inferiores a $-1,0 \mathrm{~V}$, embora o potencial exato dependa de alguns fatores como o poder $\sigma$-doador ou $\pi$ aceitador do ligante e da carga total desses complexos. ${ }^{291}$

Um importante aspecto da reatividade dos complexos reduzidos é a capacidade deles agirem como fonte de múltiplos elétrons, que pode ter importantes aplicações em reduções químicas. $\mathrm{O}$ emprego de complexos de $\mathrm{Ru}(\mathrm{II}) \mathrm{e}$ Os(II) em esquemas de conversão de energia fotoquímica envolvendo mecanismos redutivos no estado excitado de processos do tipo MLCT também foi explorado. ${ }^{354}$

Através de trabalhos pioneiros realizados na década de $70,^{355}$ ficou bem estabelecido que as duas primeiras reduções de complexos do tipo $\left[\mathrm{M}(\mathrm{bpy})_{3}\right]^{2+}(\mathrm{M}=\mathrm{Fe}(\mathrm{II})$, $\mathrm{Ru}(\mathrm{II})$, Os(II)) são localizadas no ligante.

\footnotetext{
Este resultado não invalida as conclusões da parte 3.1a. da tese sobre o caráter "doador" do benzotriazolato (que é aniônico e doador por natureza). Além disso, essa é mais uma prova de que nesses complexos de polipiridina $\left(\mathrm{Ru}^{\mathrm{I}}\right.$ ) a coordenação se dá preferencialmente pelo $\mathrm{N} 2$ (um aceitador- $\pi$ ), enquanto naquelas espécies estudadas em solução aquosa $\left(\mathrm{Ru}^{\mathrm{II}}\right.$ ), ela se dá pelo $\mathrm{N} 3$ (um doador- $\left.\sigma / \pi\right)$.
} 
Posteriormente, ficou demonstrado que, em complexos do tipo cis- e trans- $\left[\mathrm{Ru}^{\mathrm{II}}(\mathrm{bpy})_{2}(\mathrm{~L})_{2}\right]^{2+}$ as duas primeiras etapas de redução também se dão sobre as bpy. ${ }^{356}$

Em 1985, Meyer et al ${ }^{297}$ reportaram evidências para a ocorrência de substituição de ligantes aniônicos induzida pela redução dos ligantes polipiridina (particularmente, bpy). A reação envolve a troca de ânions como o cloreto por uma molécula do solvente, $\mathrm{S}$, conforme pode ser ilustrado na equação abaixo.

$$
\left[\mathrm{RuCl}\left(\mathrm{bpy} \cdot{ }^{-}\right)_{2}(\mathrm{LH})\right]^{-}+\mathrm{S} \rightleftharpoons\left[\mathrm{Ru}\left(\mathrm{bpy} \cdot{ }^{-}\right)_{2}(\mathrm{LH})(\mathrm{S})\right]^{-}+\mathrm{Cl}^{-}
$$

O interesse em processos desse tipo está relacionado à ativação e à redução catalítica de pequenas moléculas em solução.

Evidentemente, a eficácia da reação de substituição acima depende do potencial que é atingido no limite negativo, do tempo de aplicação do potencial (velocidade de varredura) e do número de ciclos na determinação do voltamograma (se for o caso). Essa é uma das razões pelas quais os voltamogramas cíclicos apresentados nesta parte da tese foram obtidos em varreduras monocíclicas à velocidade de $200 \mathrm{mV} \mathrm{s}^{-1}$; ou seja, para evitar aquela reação.

No caso particular do complexo $\left[\mathrm{Ru}^{\mathrm{II}} \mathrm{Cl}(\mathrm{bpy})_{2}(\mathrm{py})\right]^{+}$, a reação de substituição do ligante cloreto pelo solvente acetonitrila, induzida pela redução dos ligantes bipiridina, pode ser esquematizada conforme segue.

$$
\begin{aligned}
& {\left[\mathrm{Ru}^{\mathrm{II}} \mathrm{Cl}(\mathrm{bpy})_{2}(\mathrm{py})\right]^{+}+\mathrm{e}^{-} \stackrel{-1,27 \mathrm{~V}}{\rightleftarrows}\left[\mathrm{Ru}^{\mathrm{ul}} \mathrm{Cl}\left(\mathrm{bpy}{ }^{-}\right)(\mathrm{bpy})(\mathrm{py})\right]^{0}} \\
& {\left[\mathrm{Ru}^{\mathrm{I}} \mathrm{Cl}\left(\mathrm{bpy} \cdot{ }^{-}\right)(\mathrm{bpy})(\mathrm{py})\right]^{0}+\mathrm{e}^{-} \stackrel{-1,47 \mathrm{~V}}{\rightleftharpoons}\left[\mathrm{Ru}^{\mathrm{n}} \mathrm{Cl}\left(\mathrm{bpy}{ }^{-}\right)_{2}(\mathrm{py})\right]^{-}} \\
& {\left[\mathrm{Ru}^{\mathrm{Il}} \mathrm{Cl}\left(\mathrm{bpy} \cdot{ }^{-}\right)_{2}(\mathrm{py})\right]^{-}+\mathrm{CH}_{3} \mathrm{CN} \rightleftarrows\left[\mathrm{Ru}^{\mathrm{II}}\left(\mathrm{bpy} \mathrm{y}^{-}\right)_{2}(\mathrm{py})\left(\mathrm{CH}_{3} \mathrm{CN}\right)\right]^{0}+\mathrm{Cl}^{-}} \\
& {\left[\mathrm{Ru}^{\mathrm{II}}\left(\mathrm{bpy}{ }^{-}\right)_{2}(\mathrm{py})\left(\mathrm{CH}_{3} \mathrm{CN}\right)\right]^{0} \underset{-1,34 \mathrm{~V}}{\rightleftarrows}\left[\mathrm{Ru}^{\mathrm{II}}\left(\mathrm{bpy} \mathrm{-}^{-}\right)(\mathrm{bpy})(\mathrm{py})\left(\mathrm{CH}_{3} \mathrm{CN}\right)\right]^{+}+\mathrm{e}^{-}} \\
& {\left[\mathrm{Ru}^{\mathrm{II}}\left(\mathrm{bpy} \mathbf{-}^{-}\right)(\mathrm{bpy})(\mathrm{py})\left(\mathrm{CH}_{3} \mathrm{CN}\right)\right]^{+} \underset{-1,13 \mathrm{~V}}{\stackrel{\longrightarrow}{\rightleftarrows}}\left[\mathrm{Ru}^{\mathrm{II}}(\mathrm{bpy})_{2}(\mathrm{py})\left(\mathrm{CH}_{3} \mathrm{CN}\right)\right]^{2+}+\mathrm{e}^{-}}
\end{aligned}
$$

$(108,109,110,111,112)$

Da Tab. 14, observa-se ainda que, para um dado complexo do tipo $\left[\mathrm{RuCl}(\mathrm{bpy})_{2}(\mathrm{LH})\right]^{+}$, ou do tipo $\left[\mathrm{Ru}(\mathrm{bpy})_{2}(\mathrm{LH})\left(\mathrm{L}^{\prime}\right)\right]^{2+}$, variação do ligante LH na série provoca deslocamentos no $E_{1 / 2}$ do metal de até $0,7 \mathrm{~V}$, enquanto o deslocamento nos potenciais catódicos do ligante bpy não supera os $150 \mathrm{mV}$. Isso reforça mais uma vez a natureza bpy-localizada dos processos de redução na região de potenciais negativos. Além do exposto acima, uma maneira alternativa de entender o efeito da substituição de LH sobre os potenciais redox é analisando a retrodoação- $\pi$ : se ela for intensificada com LH então, ao mesmo tempo, será diminuída na bpy que, conseqüentemente, terá a energia de seus níveis $\pi^{*}$ (aceitadores) diminuída

\subsection{Espectroeletroquímica}

Os complexos mononucleares estudados são dos seguintes tipos: monocátion, cis-[RuCl(bpy $\left.)_{2}(\mathrm{LH})\right]^{+}$, e dicátion, cis$\left[\mathrm{Ru}(\mathrm{bpy})_{2}(\mathrm{LH})_{2}\right]^{2+}$, onde $\mathrm{LH}=$ btaH ou bimH (o material de partida cis- $\mathrm{RuCl}_{2}(\mathrm{bpy})_{2}$ e o complexo intermediário cis$\left[\mathrm{RuCl}(\mathrm{bpy})_{2}(\mathrm{py})\right]^{+}$, que é do tipo cis-[RuCl(bpy $\left.)_{2}(\mathrm{LH})\right]^{+}$, também serão usados para fins comparativos).

Todos eles apresentam duas intensas bandas na região ultravioleta (UV) do espectro, na faixa de 240 a $310 \mathrm{~nm}$ (Tab. 15). Na maioria dos casos, apenas a primeira banda (de menor energia) aparece bem definida, sendo a segunda encoberta pelas demais transições de maior energia. Tais bandas também foram observadas nos espectros eletrônicos de absorção ${ }^{357}$ da bipiridina livre e foram atribuídas ${ }^{358,359}$ a transições intraligante $\pi \rightarrow \pi_{1}{ }^{*} \mathrm{e} \pi \rightarrow \pi_{2}{ }^{*}$ (bpy). Os valores de absortividade molar dessas bandas variam de $2 \times 10^{4}$ a $5 \times 10^{4}$ $\mathrm{mol}^{-1} \mathrm{dm}^{3} \mathrm{~cm}^{-1}$

Para os complexos nos estados reduzidos (aqueles com $\mathrm{Ru}^{\text {II }}$ ), a região do espectro que compreende a absorção de luz visivel (Vis) apresenta duas bandas, ao redor de $350 \mathrm{e}$ $500 \mathrm{~nm}$ (para as espécies $\mathrm{Ru}^{\mathrm{II}}$-bpy) e ao redor de 380 e 550 $\mathrm{nm}$ (para as espécies $\mathrm{Ru}^{\mathrm{II}}{ }^{-}$-bpy-${ }^{-}$) (Tab. 15). Essas bandas foram atribuídas a transições envolvendo processos de transferência de carga do tipo metal $\rightarrow$ ligante (MLCT), do nível $d \pi$ do $\mathrm{Ru}(\mathrm{II})$ para os níveis $\pi^{*}$ da bipiridina.

Conforme se pode inferir das características dos espectros obtidos, os ligantes LH não mostram evidências de participação em processos de transferência de carga metal $\rightarrow$ ligante, embora eles afetem substancialmente as transições envolvendo a bipiridina. É dificil afirmar se as transições $\mathrm{Ru}$ II $\rightarrow$ LH estão ausentes ou se fazem presentes mas encontram-se mascaradas pelas bandas de transferência de carga $\mathrm{Ru}^{\mathrm{II}} \rightarrow$ bpy.

\subsection{Transferência de carga metal-ligante}

Nos complexos $\left[\mathrm{Ru}(\mathrm{bpy})_{2}(\mathrm{LH})_{2}\right]^{2+}$ e $\left[\mathrm{RuCl}(\mathrm{bpy})_{2}\left(\mathrm{~L}^{\prime}\right)\right]^{+}(\mathrm{LH}$ = btaH ou bimH e L' = py ou LH), as bandas MLCT de menor energia (ao redor de $500 \mathrm{~nm}$ ) possuem intensidades (ع) superiores a $5 \times 10^{3} \mathrm{~mol}^{-1} \mathrm{dm}^{3} \mathrm{~cm}^{-1}$ e são atribuídas a transições típicas $\left(\mathrm{Ru}^{\mathrm{II}}\right) d \pi \rightarrow \pi_{1}{ }^{*}$ (bpy). ${ }^{344,345,358,360}$ De acordo com esses estudos espectroscópicos pioneiros de complexos similares, o aspecto assimétrico dessas bandas é atribuído à estrutura vibracional dos estados eletrônicos. 
A segunda banda MLCT (a de maior energia) ocorre ao redor de $350 \mathrm{~nm}$ para todos aqueles complexos e possui valor médio de absortividade molar próximo de $1 \times 10^{4} \mathrm{~mol}^{-1}$ $\mathrm{dm}^{3} \mathrm{~cm}^{-1}$. A natureza dessa banda foi atribuída inicialmente por Powell et al. ${ }^{345}$ e parece ser, até hoje, a mais aceita. Assim, o processo é devido à transição $\left(\mathrm{Ru}^{\mathrm{II}}\right) d \pi \rightarrow \pi_{2}{ }^{*}$ (bpy). Uma relação empírica que reforça essa atribuição é que, na maioria dos complexos bis(bipiridil)-rutênio(II) do tipo aqui estudado, $\left[\mathrm{Ru}(\mathrm{bpy})_{2}(\mathrm{~L} 1)(\mathrm{L} 2)\right]^{\mathrm{n}}$, a diferença média de energia das transições $d \pi \rightarrow \pi_{1}{ }^{*}$ e $d \pi \rightarrow \pi_{2}{ }^{*}$ (que é de $\sim 8000$ $\mathrm{cm}^{-1}$ ) é similar à diferença de energia das transições $\pi \rightarrow \pi_{1}{ }^{*}$ e $\pi \rightarrow \pi_{2}{ }^{*}$ na bpy livre. ${ }^{357}$
Observa-se dos valores de energia no máximo de absorção para as bandas MLCT das espécies mononucleares (Tab. 16) que o deslocamento hipsocrômico, quando se passa da espécie cis- $\mathrm{RuCl}_{2}(\mathrm{bpy})_{2}$ para a $\left[\mathrm{Ru}(\mathrm{bpy})_{2}(\mathrm{btaH})_{2}\right]^{2+}$, ocorre sistemática e simultaneamente nas bandas de transferência de carga MLCT(1) e (2). Isto é, ela se dá no mesmo sentido, conforme se pode visualizar no gráfico de $E_{\mathrm{MLCT}(2)}$ vs. $E_{\mathrm{MLCT}(1)}$ da Fig. 48, que apresenta uma correlação linear e crescente, na mesma ordem apresentada para a série da Tab. 16. 
Tabela 15. Dados espectroscópicos para uma série de complexos do tipo cis-[Ru(bpy)2(L1)(L2)] $]^{n}$.

\begin{tabular}{|c|c|c|c|}
\hline Complexo & $\begin{array}{c}\text { MLCT } \\
\lambda / \mathrm{mm}\left(\mathrm{C} / \mathrm{M}^{-1} \mathrm{~cm}^{-1}\right)\end{array}$ & $\begin{array}{c}\text { LMCT } \\
\lambda / \mathrm{mm}^{-1}\left(\mathrm{M}^{-1} \mathrm{~cm}^{-1}\right)\end{array}$ & $\begin{array}{l}\text { Interna } \mathrm{L}\left(\mathrm{r} \rightarrow \pi^{*}\right) \\
\lambda / \mathrm{nm}\left(\mathrm{c} / \mathrm{N}^{-1} \mathrm{~cm}^{-1}\right)\end{array}$ \\
\hline$c i s-\mathrm{RuCl}_{2}(\mathrm{bpy})_{2}$ & $375(3150) ; 550(3100)$ & - & $293\left(1,5 \times 10^{4}\right)$ \\
\hline$c i s-\left[\mathrm{RuC}_{2}(\mathrm{bpy})_{2}\right]^{\dagger}$ & $375(1880)$ & $440(900)$ & $305(8400)$ \\
\hline $\operatorname{cis}\left[\mathbf{R u C}_{2}(\mathbf{b p y})_{2}\right]$ & $380(3560) ; 555$ (3140) & - & $292\left(1,7 \times 10^{4}\right)$ \\
\hline$\left[\text { RuCl(bpy) }_{\mathbf{2}}(\mathrm{btaH})\right]^{+}$ & $347(8540) ; 465(5700)$ & - & $242 ; 290\left(2,0 ; 4,0 \times 10^{4}\right)$ \\
\hline$\left[R u C l(b p y)_{2}(b t a H)\right]^{2+}$ & - & $423(3500)$ & $248 ; 288\left(2,1 ; 2,4 \times 10^{4}\right)$ \\
\hline RuCl(bpy) (btaH) & 367 (7840); 540 (5720) & - & $294\left(3,6 \times 10^{4}\right)$ \\
\hline$\left[\mathbb{R u C l}(\mathbf{b p y})_{2}(\mathbf{b i m} \mathbf{H})\right]^{+}$ & 353 (7620); 512 (7250) & - & $240 ; 294\left(2,6 ; 4,4 \times 10^{4}\right)$ \\
\hline$\left[\mathbb{R u C l}(\text { bpy })_{2}(\text { bim H })\right]^{2+}$ & - & $414 ; 495$ (ombros) & $248 ; 297\left(2,5 ; 2,4 \times 10^{4}\right)$ \\
\hline $\mathrm{RuCl}(\mathrm{bpy})_{2}(\mathrm{bimH})$ & 372 (8480); 555 (7200) & - & $294\left(4,1 \times 10^{4}\right)$ \\
\hline$\left[\mathrm{Ru}(\mathrm{bpy})_{2}(\mathrm{btaH})_{2}\right]^{2+}$ & $340\left(1,1 \times 10^{4}\right) ; 434(7460)$ & - & $240 ; 287\left(2,4 ; 4,4 \times 10^{4}\right)$ \\
\hline$\left[\mathrm{Ru}(\mathrm{bpy})_{2}(\mathrm{btaH})_{2}\right]^{3+}$ & - & $408(1540) ; 650(1350)$ & $252 ; 304\left(2,3 \times 10^{4}\right)$ \\
\hline$\left[\mathbb{R u}(\mathbf{b p y})_{2}(\mathbf{b t a H})_{2}\right]^{+}$ & $348(11920) ; 523(6660)$ & - & $294\left(4,1 \times 10^{4}\right)$ \\
\hline$\left[\mathbf{R u}(\mathbf{b p y})_{2}(\operatorname{bimH})_{2}\right]^{2+}$ & $337(6280) ; 455 / 484(6120)$ & - & $290\left(3,7 \times 10^{4}\right)$ \\
\hline$\left[\mathbb{R u}(\mathbf{b p y})_{2}(\text { bimH })_{2}\right]^{3+}$ & - & $600(2240)$ & $251 ; 310\left(2,7 ; 2,1 \times 10^{4}\right)$ \\
\hline$\left[\mathbb{R} u(\mathbf{b p y})_{2}(\mathbf{b i m} \mathbf{H})_{2}\right]^{+}$ & 368 (6880); 567 (6000) & - & $295\left(3,3 \times 10^{4}\right)$ \\
\hline$\left[\mathbf{R u C l}(\mathbf{b p y})_{2}(\mathbf{p y})\right]^{+}$ & $353(3680) ; 498(5940)$ & - & $243 ; 292\left(1,6 ; 3,5 \times 10^{4}\right)$ \\
\hline$\left.[\text { RuCl(bpy) })_{2}(\mathbf{p y})\right]^{2+}$ & - & $424(1860)$ & $250 ; 308\left(2,0 ; 1,9 \times 10^{4}\right)$ \\
\hline $\mathbf{R u C l}(\mathbf{b p y})_{2}(\mathbf{p y})$ & $363(12400) ; 525(5840)$ & - & $293\left(2,6 \times 10^{4}\right)$ \\
\hline$\left[\mathbf{R u}(\mathbf{b p y})_{2}(\mathbf{p y})(\mathbf{b t a H})\right]^{2+}$ & $334(10600) ; 440(7600)$ & - & $243 ; 287\left(2,2 ; 4,4 \times 10^{4}\right)$ \\
\hline$\left[\mathrm{Ru}(\mathrm{bpy})_{2}(\mathrm{py})(\mathrm{btaH})\right]^{3+}$ & - & $410(1460) ; 655(620)$ & $249 ; 307\left(2,7 ; 2,5 \times 10^{4}\right)$ \\
\hline$\left.\left[\text { Ru}_{(\mathbf{b p y}}\right)_{2}(\mathbf{p y})(\mathbf{b t a H})\right]^{-}$ & $357\left(2,1 \times 10^{4}\right) ; 500 / 529(8800)$ & - & $294\left(3,0 \times 10^{4}\right)$ \\
\hline$\left[\mathbf{R u}(\text { bpy })_{2}(\mathbf{p y})(\mathbf{b i m} H)\right]^{2+}$ & 333 (9800); 438 (7840) & - & $243 ; 285\left(2,0 ; 4,6 \times 10^{4}\right)$ \\
\hline$\left[\mathbf{R u}(\text { bpy })_{2}(\right.$ py) $)(\text { bim H) }]^{3+}$ & - & $438(6600)$ & $285\left(4,0 \times 10^{4}\right)$ \\
\hline$\left[\mathrm{Ru}(\mathrm{bpy})_{2}(\mathrm{py})(\mathrm{bimH})\right]^{]}$ & $360\left(1,8 \times 10^{4}\right) ; 497 / 532(7800)$ & - & $246 ; 294\left(2,3 ; 2,9 \times 10^{4}\right)$ \\
\hline$\left.\left[\{\operatorname{RuCl(bpy})_{2}\right\}_{2}(\mathbf{b t a})\right]^{+}$ & $344(8920) ; 464(5900)$ & - & $288\left(4,5 \times 10^{4}\right)$ \\
\hline [RuCl(bpy $\left.)_{2}\right\}_{2}($ bta $\left.)\right]^{2+}$ & $425(5160)$ & $586(3180)$ & $243 ; 287\left(2,4 ; 3,9 \times 10^{4}\right)$ \\
\hline$\left[\{\text { RuCl(bpy) }\}_{2}(\mathrm{bta})\right]^{3+}$ & - & $456(3380) ; 634(2000)$ & $246 ; 300\left(1,3 ; 2,8 \times 10^{4}\right)$ \\
\hline RuCl(bpy $\left.)_{2}\right\}_{2}$ bta & $353\left(2,7 \times 10^{4}\right) ; 528(11400)$ & - & $240,294\left(2,9 ; 3,1 \times 10^{4}\right)$ \\
\hline$\left[\left\{\mathbf{R u C l}(\mathbf{b p y})_{2_{2}}\right\}_{2}(\mathbf{b i m})\right]^{+}$ & $344(9000) ; 464 / 505(7280)$ & - & $287\left(5,2 \times 10^{4}\right)$ \\
\hline$\left[\left\{R_{u C l}(\mathbf{b p y})_{\}_{2}}\right\}_{2} \text { (bim) }\right]^{2+}$ & 390 (ombro); 450 (4700) & $665(2160)$ & $287\left(4,2 \times 10^{4}\right)$ \\
\hline$\left[\left\{R u C(b p y)_{2}\right\}_{2}(\mathrm{bim})\right]^{3+}$ & 367 (ombro) & $720(4800)$ & $247 ; 302\left(3,4 ; 3,1 \times 10^{4}\right)$ \\
\hline \{Rucl(bpy) \} $\}_{2}$ bim & $350\left(1,8 \times 10^{4}\right) ; 504 / 532(8800)$ & $610(5880)$ & $294\left(3,3 \times 10^{4}\right)$ \\
\hline
\end{tabular}


Tabela 16. Valores de energia MLCT para uma série de complexos mononucleares do tipo cis-[Ru(bpy)2(L1)(L2)] ${ }^{n}$.

\begin{tabular}{|c|c|c|}
\hline Complexo & $\begin{array}{c}\text { MLCT (1) } \\
E / \mathrm{cm}^{-1}\left(\varepsilon / \mathrm{M}^{-1} \mathrm{~cm}^{-1}\right)\end{array}$ & $\begin{array}{c}\text { MLCT (2) } \\
E / \mathrm{cm}^{-1}\left(\varepsilon / M^{-1} \mathrm{~cm}^{-1}\right)\end{array}$ \\
\hline$c i s-\mathrm{RuCl}_{\mathbf{2}}(\mathrm{bpy})_{\mathbf{2}}$ & $18180(3100)$ & $26670(3150)$ \\
\hline$\left[\mathbf{R u C l}(\mathbf{b p y})_{\mathbf{2}}(\mathrm{bimH})\right]^{+}$ & $19530(7250)$ & $28330(7620)$ \\
\hline$\left[\mathbf{R u C l}(\mathbf{b p y})_{\mathbf{2}}(\mathbf{p y})\right]^{+}$ & $20080(5940)$ & $28340(3680)$ \\
\hline$\left[\mathrm{RuCl}(\mathrm{bpy})_{\mathbf{2}}(\mathrm{btaH})\right]^{+}$ & $21510(5700)$ & $28820(8540)$ \\
\hline$\left[\operatorname{Ru}(\text { bpy })_{2}(\operatorname{bimH})_{2}\right]^{2+}$ & $21980(6120)$ & $29670(6280)$ \\
\hline$\left[\mathbf{R u}(\mathrm{bpy})_{2}(\mathrm{py})(\mathrm{btaH})\right]^{2+}$ & $22730(7600)$ & $29940\left(1,1 \times 10^{4}\right)$ \\
\hline$\left[\mathbf{R u}(\mathbf{b p y})_{2}(\mathrm{py})(\mathrm{bimH})\right]^{2+}$ & $22830(7840)$ & $30030(9800)$ \\
\hline$\left[\mathbf{R u}(\mathbf{b p y})_{2}(\mathbf{b t a H})_{2}\right]^{2+}$ & $23040(7460)$ & $29410\left(1,1 \times 10^{4}\right)$ \\
\hline
\end{tabular}

Nota-se ainda que, quanto maior for o potencial $\sigma / \pi$-doador das espécies secundárias L1 e L2 coordenadas ao metal $\mathrm{Ru}(\mathrm{II})$, mais deslocadas para a região de menor energia estarão as bandas MLCT. Apesar de esses ligantes não estarem envolvidos nas transições MLCT, como já foi descrito acima, o resultado aqui observado é coerente com a seguinte visualização: (i) se o ligante tiver caráter doador pronunciado, então ele induzirá um aumento de densidade de carga sobre o metal que, por sua vez, provocará um acréscimo de energia nos níveis $d \pi$ do Ru(II). Assim, uma transição HOMO(metal) $\rightarrow$ LUMO(ligante primário - bpy) seria facilitada; (ii) ao contrário, se o caráter $\pi$-aceitador do ligante substituinte prevalecer, uma deficiência na densidade de carga localizada sobre o metal induzirá um decréscimo na energia dos níveis $d \pi$ do $\mathrm{Ru}(\mathrm{II})$, tomando a transferência de carga HOMO(Ru- $d \pi) \rightarrow$ LUMOs(bpy$\left.\pi_{1}{ }^{*}, \pi_{2}{ }^{*}\right)$ mais dificil (energeticamente).

Portanto, a ordem de energia MLCT é conseqüência da natureza combinada daqueles ligantes L1 e L2, que produzem o chamado "efeito de sonda/sensor" sobre as propriedades eletrônicas da estrutura primária (ou bloco molecular) bis(bipiridina)rutênio(II), Ru ${ }^{\text {II }}(\mathrm{bpy})_{2}{ }^{2+}$.

$\mathrm{O}$ único aspecto da análise anterior que provoca uma certa estranheza é a posição dos complexos dicátions $\left[\mathrm{Ru}(\mathrm{bpy})_{2}(\mathrm{py})(\mathrm{btaH})\right]^{2+}$ e $\left[\mathrm{Ru}(\mathrm{bpy})_{2}(\mathrm{py})(\mathrm{bimH})\right]^{2+}$ dentro da ordem relativa de suas energias MLCT. De acordo com os dados obtidos para as séries cis-[RuCl(bpy $\left.)_{2}\left(\mathrm{~L}^{\prime}\right)\right]^{+}$e cis$\left[\mathrm{Ru}(\mathrm{bpy})_{2}(\mathrm{LH})_{2}\right]^{2+}\left(\mathrm{LH}=\right.$ btaH ou bimH; $\mathrm{L}^{\prime}=\mathrm{LH}$ ou py), o esperado seria a ordem inversa, ou seja, $E_{\mathrm{MLCT}}$ (Ru-py,btaH) $>E_{\mathrm{MLCT}}(\mathrm{Ru}$-py,bimH). No demais, o conjunto de resultados apresentados é coerente com a seguinte ordem relativa de donicidade:

(doador- $\sigma / \pi) \mathrm{Cl}>>$ bimH $>$ py $\geq$ N2-btaH (aceitador- $\pi$ )

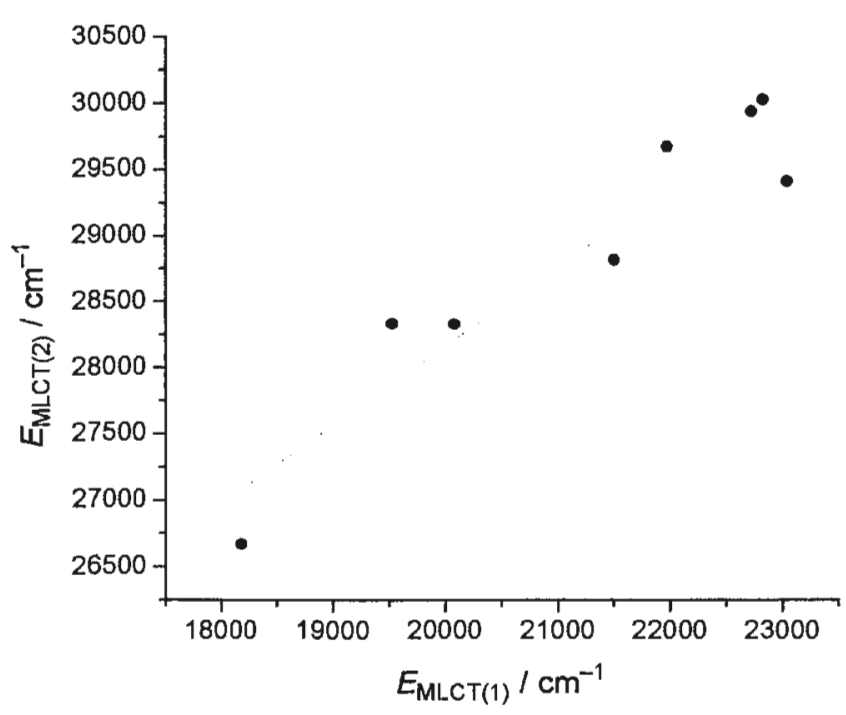

Figura 48. Curva de $E_{\mathrm{MLct}(2)}$ vs. $E_{\mathrm{MLCT}(1)}$ para os complexos mononucleares do tipo [Ru'(bpy $\left.)_{2}(\mathrm{~L} 1)(\mathrm{L} 2)\right]^{n+}$. 
Se fosse considerado o isômero de coordenação N3 do btaH, a ordem esperada seria:

\section{$($ doador $-\sigma / \pi) \mathrm{Cl} \gg$ bimH $>\mathrm{N} 3-\mathrm{btaH}>$ py $($ aceitador $-\pi)$}

A potencialidade de $\mathrm{LH}$ em promover interações de retrodoação- $\pi$ vai no sentido oposto.

\subsection{Transferência de carga ligante-metal}

Diferentemente dos processos MLCT para os complexos no estado reduzido $\mathrm{Ru}(\mathrm{II})$, as transições de transferência de carga ligante $\rightarrow$ metal nas suas correspondentes espécies oxidadas, Ru(III), demostraram-se muito complexas e pouco correlacionáveis entre si (Tab. 17).

Tabela 17. Valores de energia LMCT de alguns complexos.

\begin{tabular}{|c|c|}
\hline Complexo & $\begin{array}{c}\text { LMCT } \\
E / \mathrm{cm}^{-1}\left(\mathrm{E} / \mathrm{M}^{-1} \mathrm{~cm}^{-1}\right)\end{array}$ \\
\hline cis- $\left\{\mathrm{RuCl}_{2}(\mathbf{b p y})_{2}\right]^{+}$ & $22730(900)$ \\
\hline$\left[\mathrm{RuCl}(\mathrm{bpy})_{2}(\mathrm{btaH})\right]^{2+}$ & $23640(3500)$ \\
\hline$\left[\mathrm{RuCl}(\mathrm{bpy})_{2}(\mathrm{bimH})\right]^{2+}$ & $24150 ; \mathbf{2 0 2 0 0}$ (ombros) \\
\hline$\left[\mathrm{Ru}(\mathrm{bpy})_{2}(\mathrm{btaH})_{2}\right]^{3+}$ & $24510(1540) ; 15380(1350)$ \\
\hline$\left[\mathrm{Ru}(\mathrm{bpy})_{2}(\mathrm{bimH})_{2}\right]^{3+}$ & $16670(2240)$ \\
\hline$\left[\mathrm{RuCl}(\mathrm{bpy})_{2}(\mathbf{p y})\right]^{\mathbf{2}^{+}}$ & $23580(1860)$ \\
\hline$\left[R u(b p y)_{2}(p y)(b t a H)\right]^{3+}$ & $24390(1460) ; 15270(620)$ \\
\hline$\left[\mathbf{R u}(\mathbf{b p y})_{2}(\mathrm{py})(\mathrm{bimH})\right]^{3+}$ & $22830(6600)$ \\
\hline
\end{tabular}

${ }^{a}$ Os valores de $E_{\text {LMCT }}$ para as possiveis transições envolvendo os ligantes substituintes L estão ern negrito.

O que pode se deduzir imediatamente desses valores de $E_{\mathrm{LMCT}}$ é que nem todas as transições envolvem níveis eletrônicos de mesma natureza. Assim, em praticamente

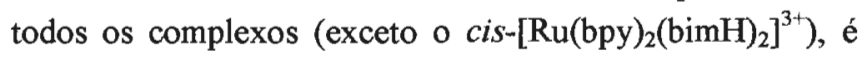
observada uma banda no Vis com energia ao redor de 2,3$2,4 \times 10^{4} \mathrm{~cm}^{-1}$. A concluir pelo espectro do cis- $\mathrm{RuCl}_{2}(\mathrm{bpy})_{2}$, essas bandas são atribuíveis a transições LMCT envolvendo o ligante bipiridina, (bpy) $\pi \rightarrow d \pi\left(\mathrm{Ru}^{\mathrm{III}}\right)$.

Alguns complexos, entretanto, exibem uma segunda banda de absorção, cujo valor de energia é inferior àquele do primeiro conjunto de transições (bpy $\rightarrow R^{\text {III }}$ ) e varia de $1,5 \times 10^{4} \mathrm{~cm}^{-1}$ nos complexos cis- $\left[\mathrm{Ru}(\mathrm{bpy})_{2}(\mathrm{btaH})_{2}\right]^{3+}$ e cis$\left[\operatorname{Ru}(\mathrm{bpy})_{2}(\mathrm{py})(\mathrm{btaH})\right]^{3+}$ a $2,0 \times 10^{4} \mathrm{~cm}^{-1}$ no complexo cis$\left[\mathrm{RuCl}(\mathrm{bpy})_{2}(\mathrm{bimH})\right]^{2+}$. Essas últimas parecem ser transições envolvendo processos LMCT do ligante $\mathrm{L}$ substituinte para o metal, $\mathrm{L}(\pi) \rightarrow d \pi\left(\mathrm{Ru}^{\mathrm{III}}\right)$ (nesse caso, $\mathrm{L}=$ btaH ou bimH).

Evidentemente, essas atribuições requerem um grau de exploração em maior profundidade. Contudo, no exemplo específico do complexo cis- $\left[\mathrm{Ru}(\mathrm{bpy})_{2}(\mathrm{bimH})_{2}\right]^{3+}$, uma única banda é observada na região Vis do espectro e pode ser atribuída à transição bimH $(\pi) \rightarrow d \pi\left(\mathrm{Ru}^{\mathrm{III}}\right)$. Além disso, agora fica mais evidente a natureza eletrônica $\pi$-doadora desse ligante, que possui os seus níveis $\pi$ com energias elevadas o suficiente para promover a interação LMCT no Vis e estabilizar o $\mathrm{Ru}^{\mathrm{III}}$.

\subsection{Correlação das propriedades eletrônicas e redox}

Para finalizar esta seção da tese, apresenta-se abaixo uma curva de $E_{\mathrm{MLCT}}$ versus $E_{1 / 2}$ do par redox Ru $\mathrm{Ru}^{\mathrm{II}} / \mathrm{Ru}$ " para todos os complexos mononucleares estudados em solução orgânica (aqueles derivados de bipiridinas de rutênio).

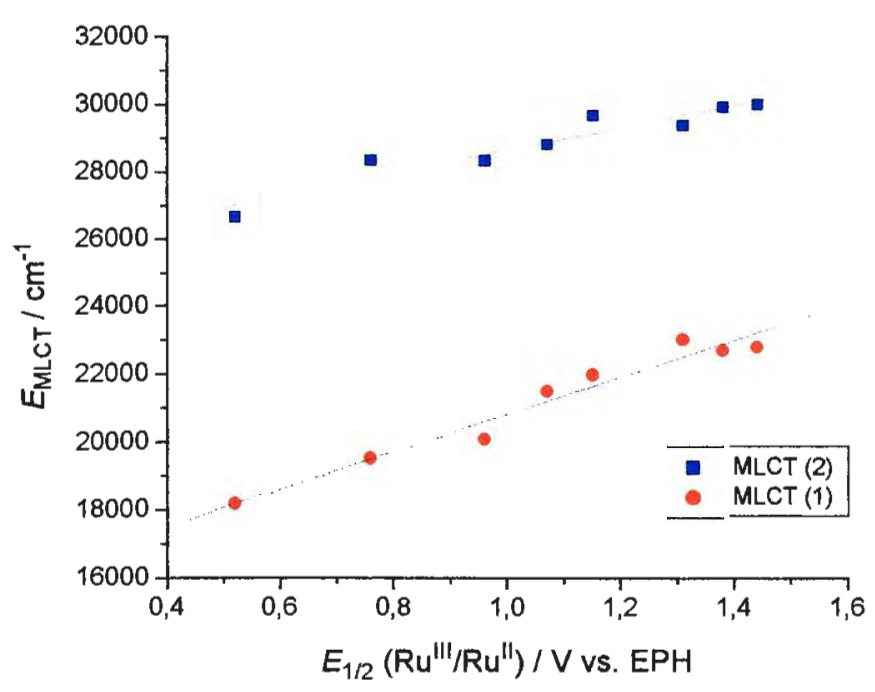

Figura 49. Curva de $E_{\mathrm{MLCT}}$ vs. $E_{1 / 2}\left(\mathrm{Ru}^{\mathrm{II}} / \mathrm{Ru} \mathrm{u}^{\prime \prime}\right)$ para os complexos mononucleares do tipo $\left[R u^{\prime \prime}(b p y)_{2}(L 1)(L 2)\right]^{n+}$.

O gráfico da Fig. 49 mostra dois conjuntos de pontos [MLCT(1) e (2)] cujas tendências podem ser claramente correlacionáveis com funções lineares aproximadamente paralelas. Entre outras, uma interpretação direta dessas curvas é a evidente dependência do potencial redox sobre as energias dos níveis de fronteira (HOMO), nos quais se dá a ionização/oxidação em ambos os processos, redox e/ou de transferência de carga. Além disso, a maior dependência/ sensibilidade de $E_{\mathrm{MLCT}(1)} \operatorname{com} E_{1 / 2}$ já era esperada, uma vez que MLCT(1) envolve os níveis $\pi^{*}$ mais acessíveis $\left(\pi_{1}{ }^{*}\right)$ do 
ligante, cuja interação com os orbitais $d \pi$ do íon metálico é mais efetiva (mais covalente). As interações $\mathrm{MLCT}(2)$, por outro lado, envolvem os níveis $\pi_{2}{ }^{*}$ que estão mais afastados energeticamente, e o grau de mistura metal-ligante é menor. Uma outra informação que pode ser extraída indiretamente diz respeito à natureza essencialmente metálica do nível orbital ocupado de maior energia. Como os niveis LUMO são, por sua vez, centrados na bipiridina, ambos os parâmetros $E_{\mathrm{MLCT}}$ e $E_{1 / 2}$ (par $\mathrm{Ru}^{\mathrm{III}} / \mathrm{Ru}{ }^{\mathrm{II}}$ ) dependerão quase exclusivamente da natureza da interação entre os ligantes substituintes L1 e L2 e o íon rutênio e de seus caráteres eletrônicos, que funcionam como "reguladores" dos níveis de energia $d \pi$ do metal sem afetar de maneira significativa os níveis não-preenchidos $\pi^{*}$ da bpy (LUMO). Finalmente, pode-se inferir que a correlação análoga de LMCT (bpy $\rightarrow \mathrm{Ru}{ }^{\mathrm{III}}$ ) com o potencial redox do íon metálico central daria como resultado uma tendência linear decrescente de energia de transição em função de $E_{1 / 2}$. 


\subsubsection{Complexos binucleares}

\subsubsection{1. $\left[\mathrm{Cl}(\mathrm{bpy})_{2} \mathrm{Ru}(\mu-\mathrm{L}) \mathrm{Ru}(\mathrm{bpy})_{2} \mathrm{Cl}\right]^{\mathrm{n}}(\mathrm{n}=1,2,3)$}

A discussão acerca dos métodos de síntese e de purificação desses complexos binucleares foi realizada previamente em conjunto com as espécies mononucleares da mesma série (v. item 3.2.1).

\subsection{Complexo $\left[\left\{c i s-R u C l(b p y)_{2}\right\}_{2}(\mu-b t a)\right]^{n+}$}

O voltamograma cíclico do complexo $\left[\left\{\mathrm{RuCl}(\mathrm{bpy})_{2}\right\}_{2}(\mathrm{bta})\right]^{+}$ apresenta $(i)$ dois pares de ondas reversíveis com potenciais em 1,340 V e 0,990 V (Fig. 50), associados aos processos redox centrados nos metais (ou seja, $R u^{\text {III }} \mathrm{Ru}^{\mathrm{III}} \rightarrow \mathrm{R} \mathrm{u}^{\mathrm{III}} \mathrm{Ru}{ }^{\mathrm{II}}$ e $\mathrm{Ru}^{\mathrm{II}} \mathrm{Ru}{ }^{\mathrm{II}} \rightarrow \mathrm{Ru}{ }^{\mathrm{II}} \mathrm{Ru}{ }^{\mathrm{II}}$, respectivamente); e (ii) duas ondas na região característica da redução da bpy $\left(E_{\mathrm{c}, 1}=-1,280 \mathrm{~V}\right.$ e $E_{\mathrm{c}, 2} \sim-1,52 \mathrm{~V}$ ), possuindo o dobro de intensidade em relação àquelas envolvendo os íons rutênio.

É interessante notar que o $E_{1 / 2}$ para o isômero $\mathrm{Ru}-\kappa N 3$ do complexo mononuclear, que, em princípio, corresponde às duas unidades metálicas terminais que formam o binuclear, ${ }^{\text {a }}$ tem valor próximo $(0,910 \mathrm{~V})$ ao potencial $E_{2}$ $(0,990 \mathrm{~V})$ do $\left[\left\{\mathrm{RuCl}(\mathrm{bpy})_{2}\right\}_{2}\right.$ (bta $\left.)\right]^{+}$, enquanto $E_{1}$ tem um valor bem mais positivo $(1,340 \mathrm{~V})$. Assim, o efeito da coordenação de um segundo grupo $\left\{\right.$ cis- $\left[\mathrm{Ru}^{\mathrm{II}} \mathrm{Cl}(\mathrm{bpy})_{2}\right]^{+}$\} na posição $\mathrm{N} 1$ do ligante benzotriazolato na espécie mononuclear é parecido com o do próton (ligeiramente mais básico) para o complexo protonado. Uma segunda etapa de oxidação (partindo-se da espécie redox de origem $\mathrm{Ru}^{\mathrm{II}} \mathrm{Ru}{ }^{\mathrm{II}}$ ) provoca o deslocamento do potencial para a região mais positiva, em conseqüência da carga positiva adicional, gerando uma diferença de potenciais redox $\Delta E_{1 / 2}=350 \mathrm{mV}$.

$O$ espectro eletrônico da espécie binuclear de valência mista, $\left[\left\{\mathrm{RuCl}(\mathrm{bpy})_{2}\right\}_{2}(\mathrm{bta})\right]^{2+}$, na região do infravermelho próximo (Fig. 51) foi obtido in situ pela aplicação de 1,170 $\mathrm{V}$, cujo potencial corresponde à região intermediária de $E_{1} \mathrm{e}$ $E_{2}$ (Fig. 50). Uma banda intensa (1350 mol dm$\left.{ }^{-3} \mathrm{~cm}^{-1}\right) \mathrm{e}$ larga $\left(\Delta \bar{v}_{1 / 2}=5440 \mathrm{~cm}^{-1}\right)$ é observada em $1460 \mathrm{~nm}$. Essa absorção está relacionada à transição de $\mathrm{IT}$, que é típica de complexos de valência mista.

A estabilidade do complexo de valência mista em relação às espécies isovalentes pode ser estimada pela constante de equilíbrio $K_{\mathrm{c}}$, que está associada à reação de comproporcionamento.

a Embora a existência da isomeria de ligação intramolecular seja, por si só, uma evidência de uma possivel coordenação fluxional.

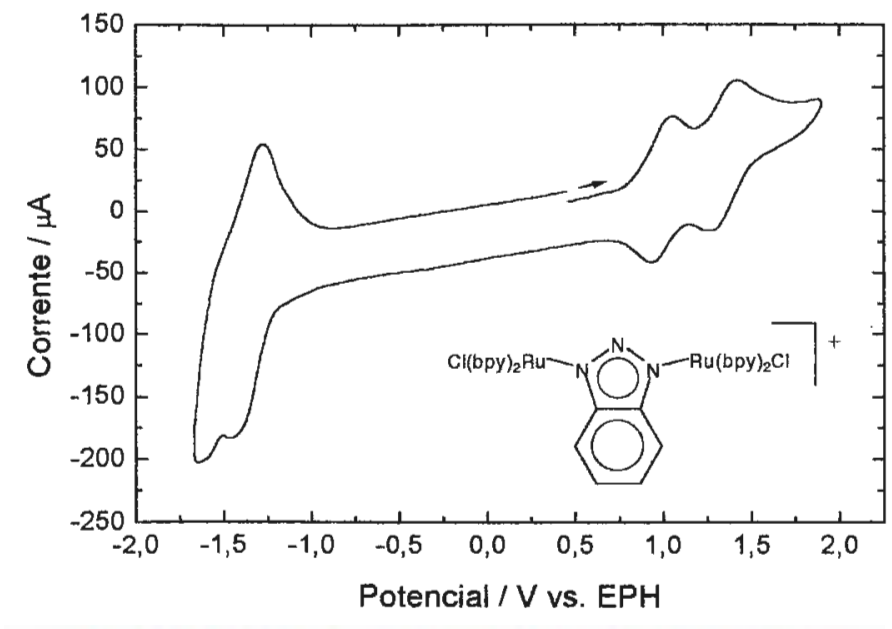

Figura 50. Voltamograma cíclico do complexo binuclear [\{RuCl(bpy $\left.)_{2}\right\}_{2}(\mu-$ bta $\left.)\right]^{+}$em solução de acetonitrila. $\left(C=2,0 \times 10^{-3} \mathrm{~mol} \mathrm{dm}^{-3} ; l=(\right.$ tea $\left.) \mathrm{ClO}_{4} 0,10 \mathrm{~mol} \mathrm{dm}^{-3} ; v=200 \mathrm{mV} \mathrm{s}^{-1}\right)$

Nesse caso, o valor de $K_{\mathrm{c}}$ (calculado através da Eq. 19) é equivalente a $8,3 \times 10^{5}$, que corresponde a uma energia livre de comproporcionamento, $\Delta G_{\mathrm{c}}$, de $-8,1 \mathrm{kcal} \mathrm{mol}^{-1}$.

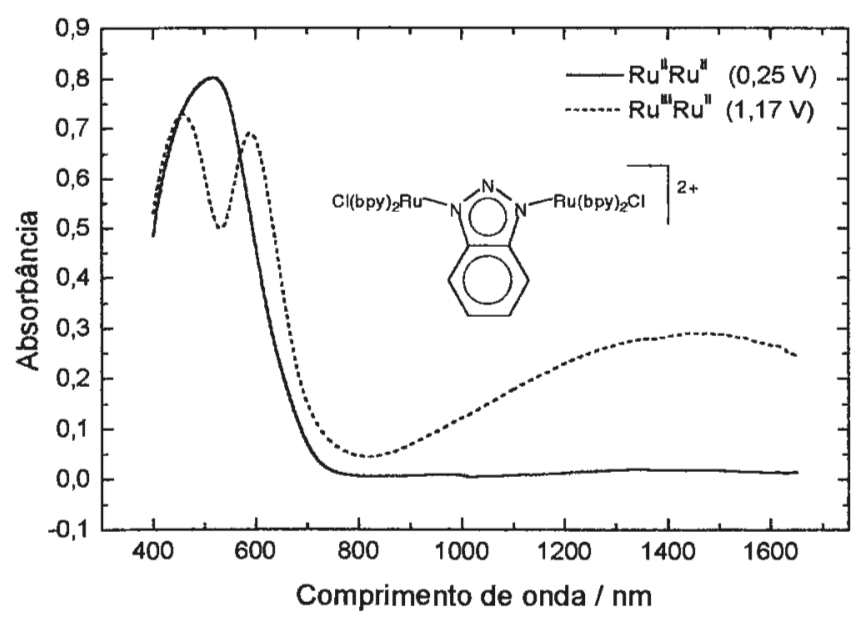

Figura 51. Espectros eletrônicos das espécies [\{RuCl(bpy $\left.\left.)_{2}\right\}_{2}(\mathrm{bta})\right]^{+}$ e [\{RuCl(bpy $\left.\left.)_{2}\right\}_{2}(\mathrm{bta})\right]^{2+}$ em acetonitrila.

$\left(C=5,0 \times 10^{-3} \mathrm{~mol} \mathrm{dm}^{-3} ; I=(\right.$ tea $\left.) \mathrm{ClO}_{4} 0,10 \mathrm{~mol} \mathrm{dm}^{-3} ; I=0,043 \mathrm{~cm}\right)$

Para o complexo $\left[\mathrm{Cl}(\mathrm{bpy})_{2} \mathrm{Ru}-\mathrm{bta}-\mathrm{Ru}(\mathrm{bpy})_{2} \mathrm{Cl}\right]^{2+}$, os valores de $\Delta \bar{v}_{1 / 2}$ calculado (Eq. 37) e experimental são 3980 e 5440 $\mathrm{cm}^{-1}$, respectivamente. Como uma conseqüência de o valor

b Conforme pode ser observado nos espectros da Fig. 51, a leitura do equipamento utilizado é limitada à faixa de 400 a $1700 \mathrm{~nm}$. Embora nessa região não seja possível negistrat a cauda da banda IVCT na região de baixa energia, a parte que envolve o máximo de absorção pode ser nitidamente definida. Igualmente, verificou-se que seu perfil aproximadamente simétrico pode ser ajustado de acondo com uma função gaussiana. Feitas essas considerações, o cálculo de $\Delta \bar{v}_{1 / 2}$ foi efetuado para a banda completada pela projeção de sua metade de maior energia, o que equivalente a $2 \times 1 / 2 \Delta \vec{v}_{1 / 2}$ (onde $1 / 2 \Delta \bar{v}_{1 / 2}=2720 \mathrm{~cm}^{-1}$ é a largura de uma metade de banda). 
estimado teoricamente ser inferior ao observado, o sistema deve ser melhor descrito pela classe II de Robin e Day, e as Eqs. 27 e 28 se aplicam para o cálculo de $H_{\mathrm{ab}}$ e $\alpha^{2}$.

Dessa forma, para a espécie $\left[\left\{\mathrm{RuCl}(\mathrm{bpy})_{2}\right\}_{2}(\mathrm{bta})\right]^{2+}$, os

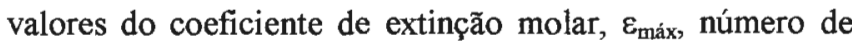
onda no máximo de absorção, $\overline{\mathrm{v}}_{\text {máx }}$ e largura de meia-banda daquela associada à intervalência, $\Delta \bar{\nu}_{1 / 2}$, são $1,35 \times 10^{3} \mathrm{~mol}^{-1}$ $\mathrm{dm}^{3} \mathrm{~cm}^{-1}, 6,85 \times 10^{3} \mathrm{~cm}^{-1}$ e $5,44 \times 10^{3} \mathrm{~cm}^{-1}$, respectivamente. $\mathrm{O}$ valor da distância intermetálica $d(5,90 \pm 0,02 \AA)$ foi obtido da geometria molecular otimizada em nível de mecânica molecular MM+ utilizando distribuição de cargas atômicas previamente geradas por meio de cálculos semiempíricos ZINDO.

Feitas as considerações anteriores, os valores de $\alpha^{2}$ e $H_{\mathrm{ab}}$ foram determinados em 0,013 e $780 \mathrm{~cm}^{-1}$, respectivamente. Esse resultado reflete uma interação moderadamente forte entre os centros metálicos, cujas cargas eletrônicas são localizadas.

Além da banda característica IVCT na região do NIR, a variação espectral na região do visível durante as medidas espectroeletroquímicas pode ser observada na Fig. 52, cuja interpretação foi realizada na comparação geral do item 3.2.2.1, conjuntamente com as espécies mononucleares.

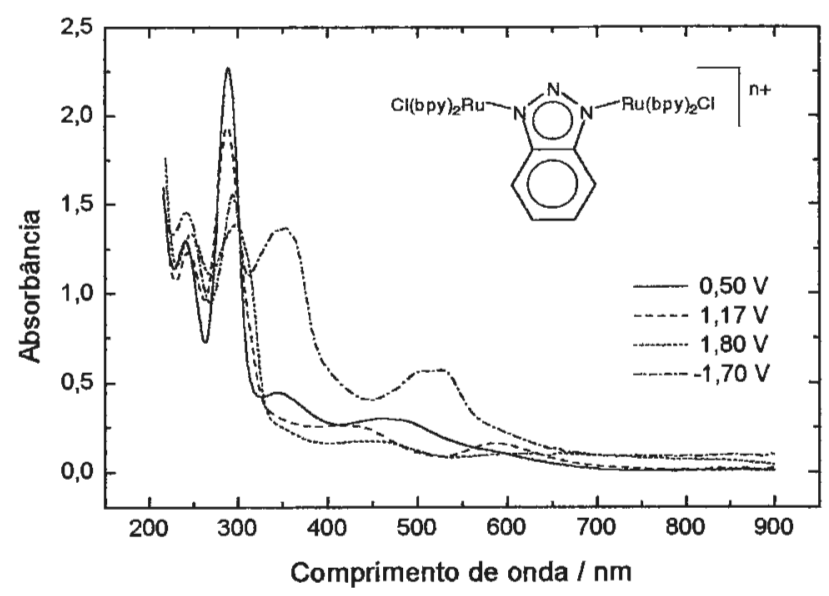

Figura 52. Espectros eletrônicos do complexo binuclear $\left.\left.\{\text { RuCl(bpy) }\}_{2}\right\}_{2}(\mathrm{bta})\right\}^{2+}$ em acetonitrila.

$\left(C=2,0 \times 10^{-3} \mathrm{~mol} \mathrm{dm}^{-3} ; I=(\right.$ tea $\left.) \mathrm{ClO}_{4} 0,10 \mathrm{~mol} \mathrm{dm}^{-3} ; I=0,025 \mathrm{~cm}\right)$

\subsection{Complexo $\left[\left\{c i s-R u C l(b p y)_{2}\right\}_{2}(\mu-\text { bim })\right]^{n+}$}

Analogamente ao $\left[\left\{\mathrm{RuCl}(\mathrm{bpy})_{2}\right\}_{2}(\mathrm{bta})\right]^{+}$, o voltamograma do complexo binuclear $\left[\left\{\mathrm{RuCl}(\mathrm{bpy})_{2}\right\}_{2}(\mathrm{bim})\right]^{+}$também apresenta dois pares de ondas reversíveis. Nesse caso, com potenciais redox em 1,210 e 0,950 V (Fig. 53), atribuídos aos processos centrados nos metais, $\mathrm{Ru}^{\mathrm{III}} \mathrm{Ru}{ }^{\mathrm{III}} \rightarrow \mathrm{Ru} \mathrm{u}^{\mathrm{II}} \mathrm{Ru}{ }^{\Pi} \mathrm{e}$ $\mathrm{Ru}^{\mathrm{III}} \mathrm{Ru}{ }^{\mathrm{II}} \rightarrow \mathrm{Ru}{ }^{\mathrm{II}} \mathrm{Ru}{ }^{\mathrm{III}}$; e duas ondas (típicas da bpy) com $E_{\mathrm{c}, 1}$ em $-1,300 \mathrm{~V}$ e $E_{\mathrm{c}, 2}$ em $\sim-1,46 \mathrm{~V}$. Essas ondas na região negativa apresentam o dobro de intensidade de corrente de pico em relação àquelas na região positiva (coerente com um processo envolvendo 2 elétrons).

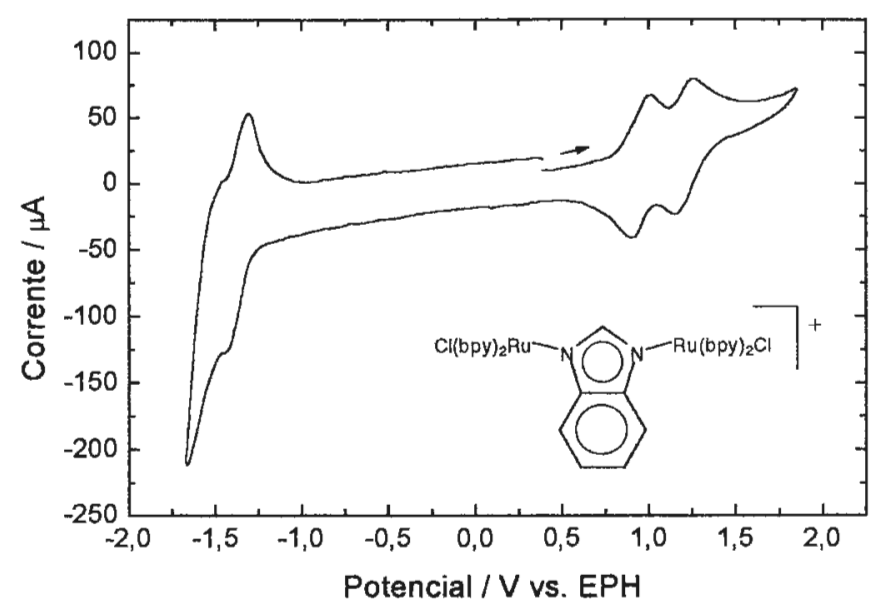

Figura 53. Voltamograma ciclico do complexo binuclear [\{RuCl(bpy) $\}_{2}$ (bim) $]^{+}$em acetonitrila.

$\left(C=2,0 \times 10^{-3} \mathrm{~mol} \mathrm{dm}^{-3} ; I=(\right.$ tea $\left.) \mathrm{ClO}_{4} 0,10 \mathrm{~mol} \mathrm{dm}^{-3} ; v=200 \mathrm{mV} \mathrm{s}^{-1}\right)$

O potencial redox para o complexo mononuclear cis$\left[\mathrm{RuCl}(\text { bpy })_{2}(\text { bimH })\right]^{+}$é igual a $0,770 \mathrm{~V}$ e difere do menor potencial $E_{2}$ do $\left[\left\{\mathrm{RuCl}(\mathrm{bpy})_{2}\right\}_{2}(\mathrm{bim})\right]^{+}(0,950 \mathrm{~V})$ em quase $180 \mathrm{mV}$, indicando uma diferença em comportamento quando comparado ao sistema com benzotriazol. Observase ainda que a separação redox dos pares $R u^{I I I} R u^{\mathrm{II}} / R u^{1 \mathrm{II}} R u^{\mathrm{II}}$ e $\mathrm{Ru}^{\mathrm{II}} \mathrm{Ru}{ }^{\mathrm{II}} / \mathrm{Ru}{ }^{\mathrm{I}} \mathrm{Ru}{ }^{\mathrm{II}}$ é de $260 \mathrm{mV}$ para esse complexo, enquanto no sistema com benzotriazol o $\Delta E$ é de $350 \mathrm{mV}$.

A variação espectral na região do visível durante as medidas espectroeletroquímicas pode ser observada na Fig. 54 e foi discutida no item 3.2.2.1, conjuntamente com as espécies mononucleares.

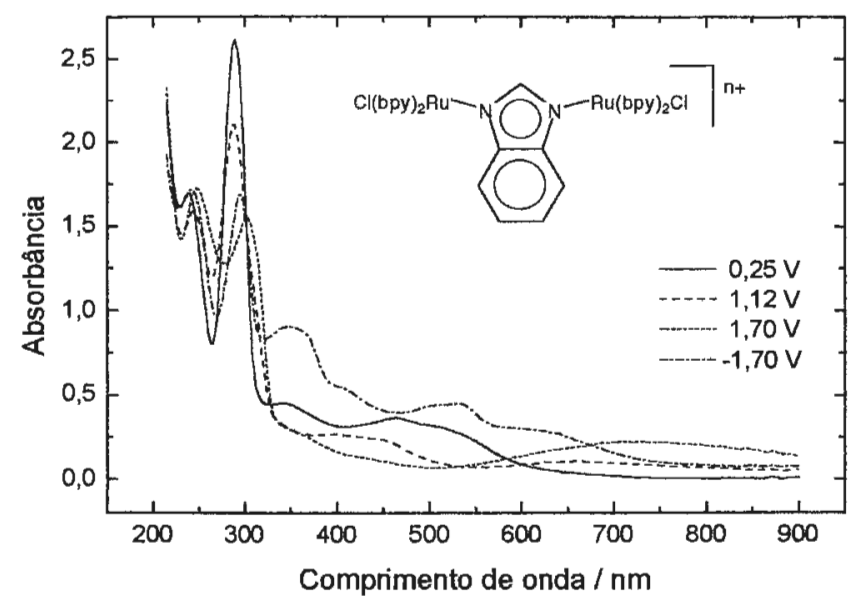

Figura 54. Espectros eletrônicos do complexo binuclear $\left[\left\{\mathrm{RuCl}(\mathrm{bpy})_{2}\right\}_{2}(\mathrm{bim})\right]^{2+}$ em acetonitrila.

$\left(C=2,0 \times 10^{-3} \mathrm{~mol} \mathrm{dm}^{-3} ; l=(\right.$ tea $\left.) \mathrm{ClO}_{4} 0,10 \mathrm{~mol} \mathrm{dm}^{-3} ; l=0,025 \mathrm{~cm}\right)$ 
Utilizando o mesmo procedimento descrito acima para o complexo de benzotriazolato, o espectro eletrônico da espécie binuclear de valência mista com benzoimidazolato, $\left[\left\{\mathrm{RuCl}(\mathrm{bpy})_{2}\right\}_{2}(\mathrm{bim})\right]^{2+}$, na região do infravermelho próximo (Fig. 55) foi obtido in situ pela aplicação de potencial que, neste caso, foi de $1,120 \mathrm{~V}$, que corresponde à região intermediária de $E_{1}$ e $E_{2}$ (Fig. 53). Observou-se uma banda intensa em $\lambda=1330 \mathrm{~nm}\left(\varepsilon=1570 \mathrm{~mol}^{-1} \mathrm{dm}^{3} \mathrm{~cm}^{-1}\right) \mathrm{e}$ larga $\left(\Delta \bar{v}_{1 / 2}=6000 \mathrm{~cm}^{-1}\right)$, típica de complexos de valência mista onde ocorre transferência de carga metal-metal, de acordo com o processo:

$$
\mathrm{Ru}^{\text {II }}-\mathrm{L}-\mathrm{Ru}^{\mathrm{III}} \stackrel{\mathrm{hv}}{\longrightarrow} \mathrm{Ru}{ }^{\text {III }-\mathrm{L}-\mathrm{Ru}}
$$

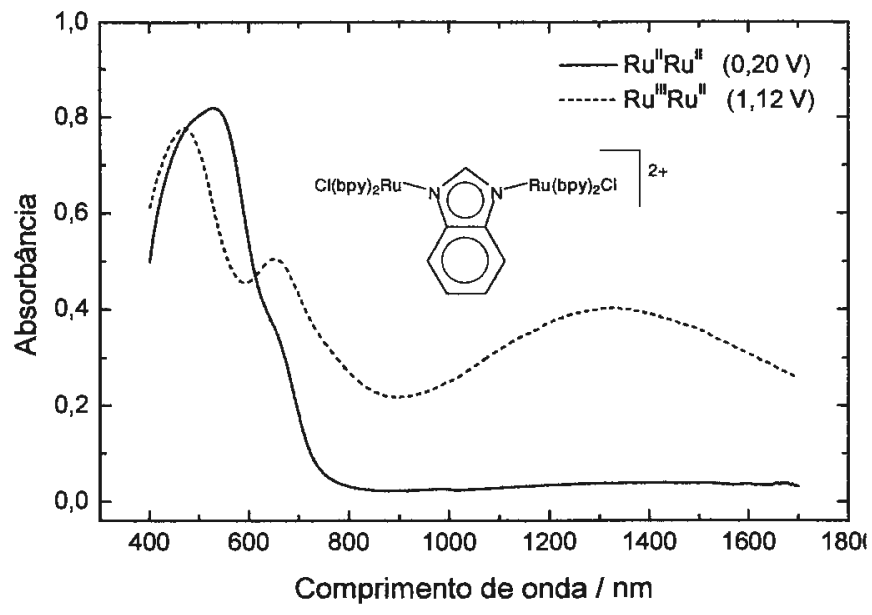

Figura 55. Espectros eletrônicos dos complexos $\left[\left\{\mathrm{RuCl}(\mathrm{bpy})_{2}\right\}_{2}(\mathrm{bim})\right]^{+}$e $\left[\left\{\mathrm{RuCl}(\mathrm{bpy})_{2}\right\}_{2}(\mathrm{bim})\right]^{2+} \mathrm{em}$ acetonitrila. $\left(C=2,0 \times 10^{-3} \mathrm{~mol} \mathrm{dm}^{-3} ; I=(\right.$ tea $) \mathrm{ClO}_{4} 0,10 \mathrm{~mol} \mathrm{dm}^{-3} ; I=0,025 \mathrm{~cm}$ )

A estabilidade do complexo de valência mista em relação às espécies isovalentes, estimada por $K_{c}$, a constante de comproporcionamento (para uma diferença de potenciais redox $\Delta E=260 \mathrm{mV}$ ), é de $2,5 \times 10^{4}$, que corresponde a uma energia livre, $\Delta G_{c}$, de $-6,0 \mathrm{kcal} \mathrm{mol}^{-1}$. Esse valor obtido é resultante de uma estabilização extra para o complexo pela comunicação eletrônica intermetálica.

Pelo uso do critério de Hush para avaliar a intensidade da interação eletrônica, cálculo da largura de meia-banda, $\Delta \bar{v}_{1 / 2}$, resulta $4170 \mathrm{~cm}^{-1}$, enquanto o valor experimental é bastante superior e foi determinado em $6000 \mathrm{~cm}^{-1}$.

Portanto, o complexo binuclear de valência mista $\left[\left\{\mathrm{RuCl}(\mathrm{bpy})_{2}\right\}_{2}(\mathrm{bim})\right]^{+}$é característico da classe II, e a teoria de Hush se aplica no cálculo da deslocalização eletrônica e do acoplamento eletrônico (Eqs. 27 e 28). Considerando uma distância intermetálica de 5,92 $\AA$ (Fig. 56), determinada por cálculos de mecânica molecular e semi-empíricos usando os métodos $\mathrm{MM}+$ e ZINDO, os valores de $\alpha^{2}$ e $H_{\mathrm{ab}}$ são 0,015 e $922 \mathrm{~cm}^{-1}$, respectivamente. Esses valores são compatíveis com um sistema de carga localizada $(1,5 \%$ do elétron ímpar é compartilhado por ambos os sítios), porém, com forte perturbação eletrônica, conforme revela a magnitude da energia de ressonância.

Os resultados acima demonstram que o acoplamento eletrônico no sistema envolvendo o benzoimidazolato como ligante-ponte é maior que no sistema análogo contendo o benzotriazolato como mediador da interação.

$\mathrm{Na}$ verdade, esse fator diferencial atribui a este trabalho um dos sucessos obtidos e também representa a motivação de estudo dos sistemas rutênio-polipiridina, que permitiram, dessa forma, provar que na ausência de efeitos estruturais dinâmicos (particularmente, a coordenação fluxional, que não se manifesta nestes sistemas devido ao elevado grau de repulsão eletrostática na direção de aproximação metalmetal e de suas estruturas moleculares altamente impedidas estericamente), a magnitude da interação eletrônica aumenta com a donicidade- $\pi$ do ligante se o mecanismo de ET for do tipo "hole-transfer", em concordância com o proposto para os sistemas da série estudada nesta tese (v. conclusões no item 3.1.2.3.4).
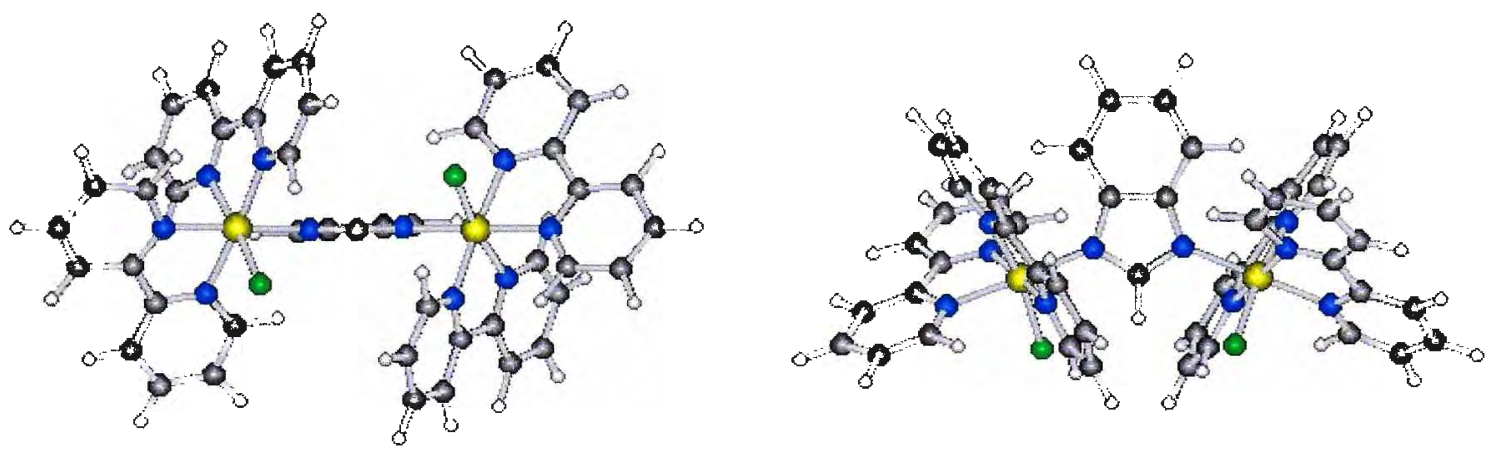

Figura 56. Estrutura molecular teórica do complexo binuclear $\left[\left\{\mathrm{RuCl}(\mathrm{bpy})_{2}\right\}_{2}(\text { bim })\right]^{*}(\mathrm{MM}+/ \mathrm{ZINDO})$ 


\subsection{Comentários finais}

Muita atenção tem sido dedicada aos compostos de rutênio contendo o ligante $2,2^{\prime}$-bipiridina devido à sua potencial aplicação como catalisadores na clivagem fotoquímica da água. ${ }^{96,322,361,362} \mathrm{Em}$ particular, a influência dos ligantes substituintes, $\mathrm{L}$ (ou $\mathrm{LH}$ ), nas propriedades dos complexos derivados do tipo cis- $\left[\mathbb{R u}(\text { bpy })_{2}(\mathrm{~L})_{2}\right]^{2+}$ tem sido examinada sistematicamente. $46,82,322,334,361,363$

Em muitos desses estudos, $\mathrm{L}$ é um ligante do tipo $\mathrm{N}$ heterocíclico com forte caráter aceitador- $\pi$. Entretanto, em menor quantidade têm sido estudados aqueles ligantes com fraco caráter aceitador- $\pi$. Alguns desses exemplos incluem o imidazol, ${ }^{267,364, a \mathrm{a}}$ o 1,2,4-triazol ${ }^{364,365}$ e seus derivados com piridil, ${ }^{366}$ o pirazol, ${ }^{367}$ e o imidazol/bis-imidazol. ${ }^{368}$ Quando comparados com a bipiridina, esses ligantes são fortes doadores- $\sigma / \pi$. Em geral, ligantes com valores altos de $\mathrm{p} K_{\mathrm{a}}$ (ácido) são fortes doadores- $\sigma / \pi$ e fracos aceitadores- $\pi{ }^{369} \mathrm{O}$ $\mathrm{p} K_{\mathrm{a}}$ (básico) da bipiridina é de $4,4,{ }^{370}$ enquanto naqueles ligantes derivados de imidazóis, por exemplo, este valor ocorre geralmente ao redor de $10 .^{278}$

Para a série de complexos mononucleares reportada no presente trabalho, observou-se que os ligantes protonados btaH e bimH são aceitador- $\pi$ e doador- $\sigma / \pi$, respectivamente. Já os seus correspondentes desprotonados aniônicos são tipicamente doadores- $\pi$. A natureza do btaH é mais difícil de ser analisada, porque a interação poderá se manifestar de diferentes maneiras, dependendo se a coordenação ocorrer por N3 (rico em elétrons - doador) ou por N2 (pobre em elétrons - aceitador). Mas, essa versatilidade da natureza eletrônica do ligante é muito apreciada no controle da interação intermetálica em sistemas polinucleares.

Por sua vez, complexos bi- e polinucleares de rutêniopolipiridina também têm sido amplamente explorados nos últimos anos, em conexão com o planejamento de dispositivos e sistemas supramoleculares com aplicação na conversão de energia solar e no processamento de informações. Compreensão dos processos de transferência de elétrons e/ou de energia nesses complexos é de crucial importância para a confecção de dispọsitivos eletrônicos ou fotônicos. ${ }^{47,58,86,137,371}$

Nos sistemas supramoleculares de maior interesse, essas interações eletrônicas se propagam através do ligante-ponte, que tem a função de mediador na comunicação doadoraceitador na espécie polinuclear. Portanto, a escolha ou o design desses ligantes consiste numa etapa chave na tarefa de se planejar aquelas moléculas. ${ }^{43,372}$

Vários fragmentos $\mathrm{N}$-heterocíclicos tais como piridina, pirazina e pirimidina têm sido usados na concepção desses ligantes. ${ }^{262373}$ Esses derivados possuem niveis orbitais $\pi^{*}$ de energia relativamente baixa, por isso agem como bons aceitadores- $\pi$. Em contraste, os ligantes com fragmentos imidazólicos são melhores doadores- $\sigma / \pi$, cujas propriedades têm sido exploradas por Haga et al. em uma variedade de trabalhos. ${ }^{133,162,266,374}$ A estratégia envolvida nesses estudos é a associação adequada de várias unidades intermediárias para produzir uma molécula contendo múltiplos pontos de coordenação, onde as propriedades doador- $\pi \rightarrow$ aceitador $-\pi$ do ligante-ponte possam ser controladas pela combinação apropriada desses fragmentos. Uma das vantagens no emprego de fragmentos derivados de triazol $1^{204,370,375,376}$ ou imidazol ${ }^{133,162,266,374}$ é a possibilidade de se regular a energia dos orbitais $\pi$ (e, conseqüentemente, a interação eletrônica) pela protonação/desprotonação de LH, o ligante-ponte. Esse é o chamado efeito switching induzido por próton, ou pelo $\mathrm{pH}^{133,162,204,266,370,374,377}$ Tais ligantes também são modelos bastante apropriados no estudo de transferência eletrônica próton-acoplada (PCET). ${ }^{\mathrm{b}, 183,184}$

Uma diferença interessante as duas classes de ligantes acima é que os ligantes com caráter aceitador- $\pi$ podem mediar a comunicação metal-metal por um mecanismo de superexchange baseado nos níveis $\pi^{*}$ de baixa energia (electron-transfer), enquanto os ligantes ricos em elétrons utilizam os seus níveis ocupados $\pi$ de alta energia (holetransfer). ${ }^{103,151,376,378}$

Muitos desses conceitos foram amplamente investigados nesta tese.

\footnotetext{
2 Entre outros sistemas, a ref. 364 também reporta o estudo do complexo $\left[\mathrm{Ru} \text { (bpy) }{ }_{2}(1,2,4 \text {-triazoI })_{2}\right]^{2+}$, cujos isốmeros de ligação foram observados. Diferentemente, o complexo análogo $\left[\mathrm{Ru}(\mathrm{bpy})_{2}(1,2,3-\mathrm{btaH})_{2}\right]^{2+}$, estudado nesta tese, não apresentou qualquer evidência de isomerização por meio de investigação eletroquírnica. Esse fato leva a acreditar que os fatores estéricos são relevantes na consideração de isomeria de ligação em sistemas desse tipo, onde os ligantes isomerizáveis se encontram em posiçôes

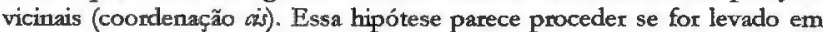
conta que a estrutura molecular do ligante benzotriazol é mais volumosa que a do 1,2,4-triazol, tomando o rearranjo intramolecular dificultado devido à presença dos coligantes 2,2 '-bipiridina nas vizinhanças.
}

b Ambos os conceitos foram explorados nesta tese. 


\section{Considerações Finais}

Como avaliação final, pode-se afirmar que os objetivos gerais do projeto vinculado ao desenvolvimento desta tese (v. seção 1.8) foram cumpridos satisfatoriamente. $O$ estudo se iniciou basicamente com a investigação das propriedades redox e espectroscópicas dos complexos binucleares de valência mista, com especial ênfase na compreensão da natureza eletrônica dos ligantes-ponte e/ou espaçadores empregados. Em virtude desse enfoque, e associado a um número bastante significativo de combinações simétricas e assimétricas de entidades metálicas de diferentes caráteres, o trabalho resultou em uma base de parametrização bastante importante para a compreensão das interações do tipo intermetálicas em complexos polimetálicos e subunidades de estruturas supramoleculares. Essa é uma abordagem que vem sendo adotada no âmbito do grupo e pode servir como ponto de partida no planejamento de supermoléculas com propriedades específicas de interesse. Daí a extensão natural do presente trabalho ao estágio que se encontra atualmente, e que envolve a utilização das unidades e fragmentos aqui empregados na concepção de dispositivos moleculares.
Dentro desta perspectiva, protótipos de chaves ou fios moleculares condutores seriam aqueles apresentados na seção 3.3. e seus (sub)itens. Uma outra alternativa bastante interessante dentro dos propósitos do grupo, é a construção de superestruturas do tipo assemblies pela incorporação de complexos metálicos periféricos em moléculas do tipo clusters. Essa conexão seria uma tarefa das pontes derivadas dos ligantes aqui estudados, cuja função seria proporcionar e/ou modular a comunicação eletrônica entre os centros metálicos envolvidos em processos como transferência de elétrons ou de energia.

A descrição acima representa idéias comuns nas linhas de pesquisa do laboratório e o aproveitamento particular dos sistemas que contribuíram para este trabalho devem ser adotados em trabalhos desenvolvidos em projetos paralelos e poderá ter continuidade com o enfoque mencionado.

As considerações e conclusões especificas para cada um dos assuntos enfatizados nesta tese foram realizadas no final de cada uma das seções correspondentes.

As conclusões gerais acerca desta contribuição encontramse dispostas no próximo capitulo (5. Conclusões). 


\section{Conclusões}

A finalidade deste capítulo é relacionar algumas conclusões mais gerais obtidas diretamente por análise dos resultados obtidos e discutidos nesta tese. Outras implicações indiretas que possam ser extraídas destes estudos (p. ex. sua extensão em outras áreas ou aplicabilidade em dispositivos voltados para eletrônica molecular) encontram-se bem delineadas no capítulo 3, em suas respectivas seções. ${ }^{a}$

- o ligante benzotriazol(ato) é peculiar no que concerne às suas propriedades de coordenação com íons metálicos de transição com configurações $d^{5}$ ( $\pi$-ácido) e $d^{6}$ ( $\pi$-retrodoador) de spin baixo: quando o íon se encontra no estado de oxidação + III, o sítio de coordenação preferencial é o nitrogênio da extremidade ( $\mathrm{N} 1$ ou N3), mas quando o íon se encontra em seu estado + II, o átomo de nitrogênio N2 (intermediário) se torna importante na estabilização do complexo por meio de interações do tipo retroligação- $\pi$;

- a existência de sítios potencialmente coordenantes com diferentes naturezas eletrônicas possibilita a presença de isomeria de ligação nas espécies derivadas do ligante benzotriazol, onde a interconversão entre os modos de coordenação através dos átomos de nitrogênio vicinais se dá por um mecanismo fluxional, isto é, um rearranjo ou deslocamento intramolecular sem dissociação/quebra de ligação. Essa proposição é fundada no fato de que a constante cinética de isomeria é duas ordens de grandeza superior à velocidade de dissociação para o respectivo complexo;

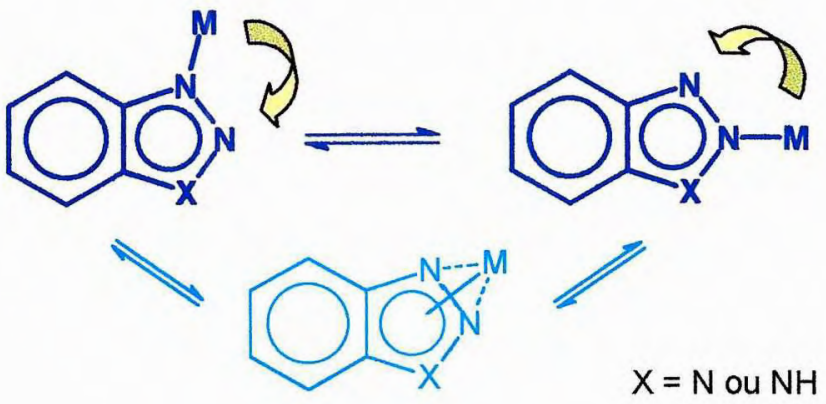

- as propriedades fluxionais do benzotriazolato o tornam um ligante-ponte com características especiais, podendo promover uma otimização da comunicação metal-metal em complexos de valência mista por meio de um modo de coordenação "bidentado/intermediário" $\mathrm{N} 1-\mathrm{M}_{\mathrm{a}}-\mathrm{N} 2 \mathrm{e}$ $\mathrm{N} 2-\mathrm{M}_{\mathrm{b}}-\mathrm{N} 3$, conforme esquematizado a seguir:

a Os parâmetros compilados no Apêndice 6.4.4 podem ser de grande auxilio na visualização das conclusões e inferências acerca dos sistemas polimetálicos.

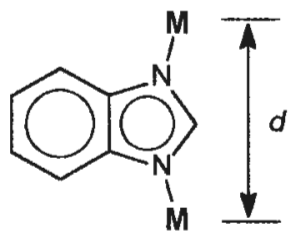

(M-bim-M)

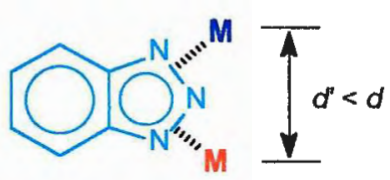

(M-bta-M)
- o mesmo efeito não é observado nas espécies binucleares contendo o benzoimidazolato como ligante-ponte, onde a coordenação fluxional não se faz presente. Isso se reflete na magnitude da energia de acoplamento eletrônico intermetálico, que é maior nos derivados de benzotriazolato que nos análogos benzoimidazolato (naqueles casos onde as unidades metálicas terminais permitem aproximação mútua sem implicar um aumento significativo da energia de repulsão estérica; v. comparação no Apêndice 6.4.4);

- a conclusão acima se baseia particularmente nos exemplos envolvendo os complexos de rutênio-edta, o que também o torna um fragmento metálico terminal bastante peculiar do ponto de vista estrutural e de fundamental importância para os propósitos deste estudo. Convém ressaltar que os fatores estruturais e eletrônicos são normalmente tratados independentemente na investigação de parâmetros de ET em sistemas onde tais efeitos de coordenação dinâmicos não operam. Na série estudada, independentemente da natureza eletrônica do grupo terminal $\mathbf{M}_{x}$, a intensidade da comunicação eletrônica e a extensão da deslocalização de elétrons poderiam ser moduladas/variadas na ordem: (edta)Ru-bta-Ru(edta) $>$ (edta)Ru-bta- $\mathrm{M}_{x}>\mathrm{M}_{\mathrm{a}}-\mathrm{bta}-\mathrm{M}_{\mathrm{b}}$ (simétricos, $a=b$, ou assimétricos, $a \neq b)\left(M_{x} \neq R u(\right.$ edta));

- a série de complexos binucleares de valência mista aqui reportados abrange desde sistemas com características típicas de cargas deslocalizadas (exemplo particular do complexo simétrico de rutênio-edta com benzotriazolato; classe III) ou parcialmente localizadas (caso do complexo assimétrico de aminrutênio/rutênio-edta; comportamento intermediário no limiar das classes $\Pi / \mathrm{III}$ ) a sistemas com cargas totalmente localizadas (p. ex. espécies simétricas derivadas de rutênio-polipiridina e complexo assimétrico heterobinuclear de cianoferrato/aminrutênio; classe II); ${ }^{\mathrm{a}}$

- as magnitudes absolutas da energia de ressonância, $H_{\mathrm{ab}}$, $\mathrm{e}$ do fator de deslocalização, $\alpha^{2}$, não permitiram por si classificar apropriadamente os complexos de valência mista, já que suas estimativas se originam de um modelo perturbacional para sistemas de interação fraca. Nessa tarefa, os critérios de Hush (tal como análise da largura 
de meia-banda, $\Delta \bar{v}_{1 / 2}$ ), o estudo dos efeitos do solvente sobre as propriedades de intervalência (especialmente $o$ solvatocromismo da banda IT) e a análise espectral na região do visível (investigação das transições envolvendo processos LMCT e MLCT) foram de crucial importância;

- o mecanismo de transferência de elétrons que prevalece nos sistemas de valência mista estudados é do tipo holetransfer:

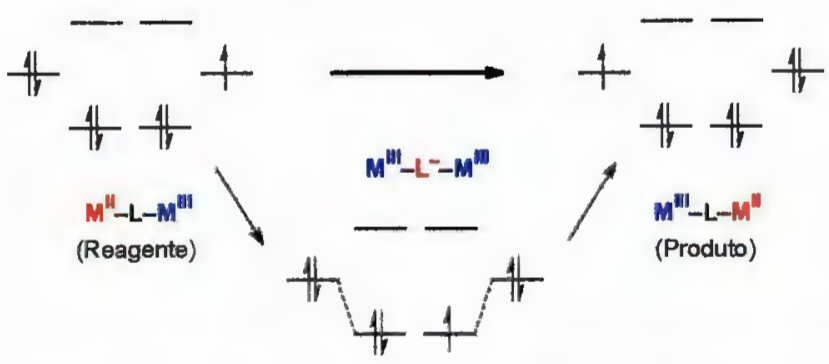

- a conclusão anterior foi baseada em dados eletroquímicos e espectroeletroquímicos dos complexos mononucleares que constituem as espécies binucleares de valência mista, cuja investigação (somada à análise de MO dos ligantes de ponte por meio de cálculos quânticos semi-empíricos), por sua vez, permitiu construir o seguinte diagrama:

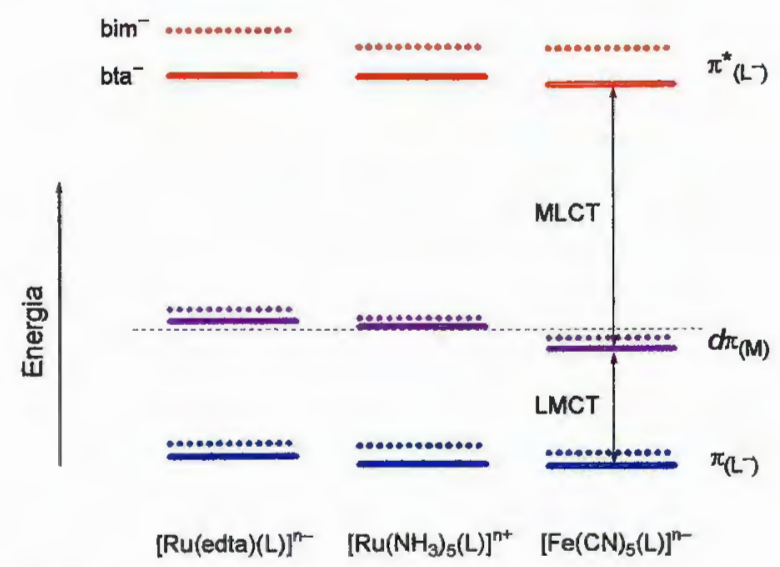

- do diagrama de energia semiquantitativo acima, pode-se inferir acerca do caráter eletrônico predominantemente doador $(\sigma, \pi$-básico) dos ligantes benzotriazolato e benzoimidazolato, conforme se pode deduzir de suas energias de transferência de carga LMCT e MLCT. Dessa forma, todos os resultados indicam que, em interações do tipo metal-metal com transferência de elétrons (IT) mediada por esses ligantes (M-L-M), os niveis eletrônicos $\pi$ dos ligantes de ponte são muito mais acessíveis do que os correspondentes (de mesma simetria) não ocupados $\left(\pi^{*}\right)$, confirmando a proposição acima de um mecanismo de superexchange por hole-transfer e não electron transfer (tal como ocorre nos ligantes-ponte $\pi$-ácidos/aceitadores);
- de acordo com o mecanismo proposto, quanto maior for a basicidade do ligante-ponte, maior a interação metalmetal deve ser. Entretanto, o que se observa nas espécies simétricas e assimétricas contendo rutênio-edta, é que o derivado de benzotriazol promove maior acoplamento, corroborando a idéia de um modelo de ligação fluxional onde a estabilização/interação extra vem da aproximação geométrica entre os centros metálicos, com recobrimento orbital $d_{\mathrm{M}}-p_{\mathrm{N} 2 \mathrm{bta}}-d_{\mathrm{M}}$ envolvendo o sítio intermediário N2. Uma evidência extra para o mecanismo proposto se origina dos sistemas de valência mista simétricos do tipo $\left[\left\{\operatorname{RuCl}(\text { bpy })_{2}\right\}_{2}(\mu-\mathrm{L})\right]^{2+}$, onde a fluxionalidade do liganteponte não é relevante devido ao grau de impedimento estérico e repulsão eletrostática na direção da interação metal-metal. Neles, a espécie benzoimidazolato promove maior acoplamento que a análoga benzotriazolato, que é o esperado na ausência de efeitos estruturais dinâmicos;

- à exceção dos complexos de classe III ou II/III onde a energia de ressonância associada à deslocalização deve predominar, a elevada estabilização termodinâmica dos complexos de valência mista em relação às espécies isovalentes pode ser racionalizada principalmente em termos da contribuição sinergística oriunda de interações de transferência de carga (nos exemplos estudados, os fatores eletrostático e entrópico são irrelevantes). Assim, enquanto nas espécies binucleares isovalentes as CT se propagam em direções opostas (isto é, oxidada: $\mathrm{LMCT}+$ LMCT; reduzida: MLCT + MLCT), na espécie de valência

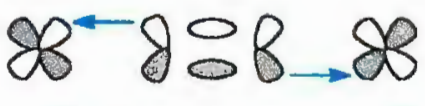
$M^{\text {III }} \quad$ L $\quad M^{\text {III }}$

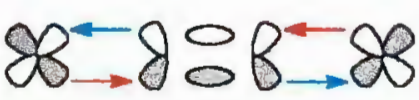
mista elas se somam M $^{11} \quad$ L L $\quad \mathbf{M}^{\text {II }}$ (MLCT + LMCT) para conduzir a um fenômeno cuja interação (sinergismo) resultante é direcional/vetorial:

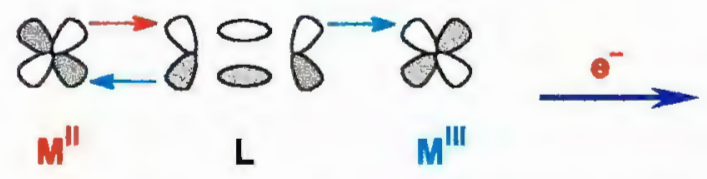

- a conclusão anterior não só justifica a estabilidade de sistemas de valência mista como também pode explicar a ausência de reatividade em alguns casos onde ambas as unidades metálicas terminais possuem o mesmo caráter eletrônico ácido/básico- $\pi$ do ligante-ponte (p. ex., nos complexos simétricos $\left[(\mathrm{CN})_{5} \mathrm{Fe}^{\mathrm{II}}\left(\mathrm{bta}^{-} / \mathrm{bim}^{-}\right) \mathrm{Fe}^{\mathrm{II}}(\mathrm{CN})_{5}\right]^{7}$ ou $\left[\left(\mathrm{NH}_{3}\right)_{5} \mathrm{Ru}^{\mathrm{II}}\left(\mathrm{bta}^{-} / \mathrm{bim}^{-}\right) \mathrm{Ru}^{\mathrm{II}}\left(\mathrm{NH}_{3}\right)_{5}\right]^{3+}$ tanto os centros metálicos extremos como $\mathrm{L}_{\mathrm{b}}$ seriam fortemente (retro)/ doadores- $\pi$, tornando improvável a sua observação). 


\section{Apêndices}

\subsection{A base do formalismo de Hush}

O modelo de Hush ${ }^{23,24}$ para acoplamento eletrônico metalmetal baseado em parametrização espectroscópica teve a sua origem no tratamento perturbacional de Murrell ${ }^{379}$ e foi derivado da teoria das interações doador-aceitador de Mulliken. $^{41}$

De acordo com esse formalismo, o campo de potencial do ion aceitador não-reduzido é tratado como um termo de perturbação no Hamiltoniano que opera sobre a função de onda de ordem zero (não perturbada), $\varphi_{\mathrm{D}}$, que descreve o sistema quando o elétron ímpar a ser transferido se encontra completamente localizado sobre o sítio doador. $\mathrm{O}$ estado de ordem zero com o elétron totalmente localizado sobre o íon aceitador é denominado $\varphi_{\mathrm{A}}$

As funções de onda resultantes (perturbadas) para ambos os estados fundamental (Eq. 114) e excitado (Eq. 115) são escritas como

$$
\begin{aligned}
& \varphi_{\mathrm{D}}{ }^{\prime}=\varphi_{\mathrm{D}}+\alpha \varphi_{\mathrm{A}} \\
& \varphi_{\mathrm{A}}{ }^{\prime}=\varphi_{\mathrm{A}}+\lambda \varphi_{\mathrm{D}}
\end{aligned}
$$

Murrell derivou as expressões perturbacionais para $\alpha$ e $\lambda$ para resultar as Eqs. 116 e 117, respectivamente.

$$
\begin{gathered}
\alpha=\frac{H_{\mathrm{AD}}-S_{\mathrm{AD}} H_{\mathrm{DD}}}{E_{\mathrm{D}}-E_{\mathrm{A}}} \\
\lambda=\frac{H_{\mathrm{AD}}-S_{\mathrm{AD}} H_{\mathrm{AA}}}{E_{\mathrm{A}}-E_{\mathrm{D}}}
\end{gathered}
$$

onde

$$
H_{\mathrm{AD}}=\left\langle\varphi_{\mathrm{A}}|H| \varphi_{\mathrm{D}}\right\rangle
$$

e

$$
S_{\mathrm{AD}}=\left\langle\varphi_{\mathrm{A}} \mid \varphi_{\mathrm{D}}\right\rangle
$$

Assumindo-se que $|\lambda| \gg|\alpha|$, então o momento de transição (na aproximação do dipolo elétrico) entre $\varphi_{D}{ }^{\prime}$ e $\varphi_{A}$ ' será dado pelas Eqs. 120 e 121 .

$$
\begin{gathered}
M_{\mathrm{D}^{\prime} \mathrm{A}^{\prime}}=\left\langle\varphi_{\mathrm{D}}^{\prime}|\vec{\mu}| \varphi_{\mathrm{A}}^{\prime}\right\rangle \\
M_{\mathrm{D}^{\prime} \mathrm{A}^{\prime}}=\alpha\left(M_{\mathrm{AA}}=M_{\mathrm{DD}}\right)+\left(M_{\mathrm{DA}}-S_{\mathrm{AD}} M_{\mathrm{DD}}\right)
\end{gathered}
$$

Hush destacou que no limite onde $S_{\mathrm{AD}} \sim 0$, isto é, quando a integral de recobrimento entre $\varphi_{A}$ e $\varphi_{D}$ for negligenciável, a Eq. 121 se reduz à seguinte fórmula simplificada:

$$
M_{\mathrm{D}^{\prime} \mathrm{A}^{\prime}} \cong e_{0} \alpha r
$$

onde $e_{0}$ é carga do elétron e $r$ (igual a $d$ na notação utilizada nesta tese) é a distância entre os sítios doador e aceitador.

A magnitude da força do oscilador, $f_{\text {osc }}$, por sua vez, pode ser estimada experimentalmente dos dados espectroscópicos pela Eq. $123^{23,36,380,381}$ e teoricamente pela Eq. $124,{ }^{23,98,380}$

$$
\begin{gathered}
f_{\mathrm{osc}}=4,32 \times 10^{-9} \int \varepsilon \mathrm{d} \nu \cong 4,32 \times 10^{-9} \cdot \varepsilon_{\text {máx }} \cdot \Delta \overline{\mathbf{v}}_{1 / 2} \\
f_{\mathrm{osc}}=1,09 \times 10^{-5}\left(M_{\mathrm{DA}} / e_{0}\right)^{2} \bar{v}
\end{gathered}
$$

onde: na Eq. 123 a absortividade molar $(\varepsilon)$ e a largura de meia-banda $\left(\Delta \bar{\nu}_{1 / 2}\right)$ são dados em $\mathrm{mol}^{-1} \mathrm{dm}^{3} \mathrm{~cm}^{-1}$ (ou $\mathrm{cm}^{2}$ $10^{3} / \mathrm{mol}$ ) e $\mathrm{cm}^{-1}$, respectivamente; ${ }^{2}$ e na Eq. 124 as unidades de $M_{\mathrm{DA}}$ são elétron ångström ( $e \AA \AA$ ).

Dessa forma, o momento de transição é dado por:

$$
\left|M_{\mathrm{DA}}\right|=0,02\left(\frac{\varepsilon \cdot \Delta \overline{\mathrm{v}}_{1 / 2}}{\bar{v}}\right)^{1 / 2}
$$

e segue que

$$
\alpha^{2}=4,24 \times 10^{-4}\left(\frac{\varepsilon_{\text {máx }} \cdot \Delta \bar{v}_{1 / 2}}{\bar{v} \cdot d^{2}}\right)
$$

onde a distância $d=r_{\mathrm{DA}}$ é dada em $\AA$, e $\overline{\mathrm{v}}$ é a energia de transição $\left(E_{\text {op }}\right)$ em cm$~^{-1}$, que comumente é obtida de $\bar{v}_{\text {máx. }}{ }^{\text {b }}$

A partir das Eqs. 116 e 117 no limite $S=0$, conclui-se que a energia de ressonância resultante da interação eletrônica (por transferência de carga) em um sistema fracamente acoplado é dada pela expressão final (Eq. 128) da Eq. 127, que é exatamente a fórmula de Hush introduzida na seção 1.2 .

$$
\begin{gathered}
H_{\mathrm{AD}}=\alpha\left(E_{\mathrm{A}}-E_{\mathrm{D}}\right) \cong \alpha \cdot \overline{\mathrm{v}}_{\text {máx }} \\
H_{\mathrm{AD}}=\frac{2,05 \times 10^{-2}}{d} \cdot \sqrt{\varepsilon_{\text {max }} \cdot \bar{v}_{\text {máx }} \cdot \Delta \bar{v}_{1 / 2}}
\end{gathered}
$$

Nesta tese, utilizou-se o símbolo $H_{\mathrm{ab}}{ }^{\mathrm{c}}$ para se referir à energia de acoplamento eletrônico. Essa é a notação mais comum entre os químicos inorgânicos, apesar de não ser dificil de se encontrar outras formas como $H_{\mathrm{DA}}$ ou $J$.

\footnotetext{
A expressão aproximada final de $f$ assume que o cálculo será efetuado para uma banda simétrica com um perfil tipicamente Gaussiano.

b Isso é rigorosamente verdadeiro somente para bandas com formato Gaussiano. $^{25}$

c Não é incomum se encontrar textos com referência a $H_{\mathrm{ab}}$ ou $H_{\mathrm{DA}}$ como sendo um "Hamiltoniano" do sistema, o que é urm grave equívoco. Enquanto o Hamiltoniano $(H)$ é um operador maternático, a energia de ressonância $\left(H_{a b}\right)$ é um autovalor, dado pelo elemento de matriz $H_{a b}=$ $\left\langle\psi_{\mathrm{a}}|H| \psi_{\mathrm{b}}\right\rangle$
} 


\subsection{Determinação espectrofotométrica de $p K_{a}$}

Para um equilíbrio ácido-base do tipo representado na Eq. 129 , a relação entre as concentrações das espécies para cada valor de $\mathrm{pH}$ varia de acordo com a expressão de HendersonHasselbach (Eq. 130), ${ }^{382}$ onde $[\mathrm{X}]=$ concentração da espécie desprotonada e $[\mathrm{HX}]=$ concentração da espécie protonada.

$$
\begin{gathered}
\mathrm{HX} \rightleftharpoons \mathrm{H}^{+}+\mathrm{X}^{-} \\
\mathrm{pH}=\mathrm{p} K_{\mathrm{a}}+\log \frac{\left[\mathrm{X}^{-}\right]}{[\mathrm{HX}]}
\end{gathered}
$$

De acordo com a lei de Beer-Lambert, ${ }^{382,383}$ a concentração da espécie absorvente é proporcional à sua absorbância segundo a relação $A=\varepsilon \cdot b \cdot C$, onde $\varepsilon$ é a absortividade molar, $b$ é o caminho óptico da amostra, e $C$ é a concentração da espécie. Portanto, pode-se reescrever a equação acima em termos de absorbância, que após rearranjo resulta a expressão final a seguir:

$$
\mathrm{pH}=\mathrm{p} K_{\mathrm{a}}+z \cdot \log \left(\frac{A-A_{\text {mín }}}{A_{\text {máx }}-A}\right)
$$

onde:

$A_{\text {min }}=$ menor absorbância da amostra;

$A_{\text {máx }}=$ maior absorbância da amostra;

$A=$ absorbância total da mistura para um dado $\mathrm{pH}$;

$z=+1$ se $A\left(\mathrm{X}^{-}\right)>A(\mathrm{HX}) \therefore A_{\text {min }}=A(\mathrm{HX})$ e $A_{\text {máx }}=A(\mathrm{X})$;

$z=-1$ se $A(\mathrm{X})<A(\mathrm{HX}) \therefore A_{\min }=A(\mathrm{X})$ e $A_{\max }=A(\mathrm{HX})$.

A derivação completa da Eq. 131 segue abaixo.

\section{Definições: ${ }^{a}$}

$C_{\mathrm{t}}=$ concentração total da amostra;

$C_{1}=$ concentração da espécie de menor absortividade;

$\varepsilon_{1}=$ absortividade molar da espécie menos absorvente;

$A_{\min }=$ absorbância da amostra onde $C_{\mathrm{t}}=C_{1}$;

$C_{2}=$ concentração da espécie de maior absorção;

$\varepsilon_{2}=$ absortividade molar da espécie mais absorvente;

$A_{\text {max }}=$ absorbância da amostra onde $C_{\mathrm{t}}=C_{2}$.

Da Lei de Lambert-Beer,

$$
A_{\text {min }}=\varepsilon_{1} \cdot C_{\mathrm{t}} \text { e } A_{\text {máx }}=\varepsilon_{2} \cdot C_{\mathrm{t}}
$$

A absorbância total da mistura (isto é, espécies protonada e desprotonada) é dada por

\footnotetext{
a Evidentemente, os parâmetros envolvidos neste tratamento referem-se a uma absorção monocromática; isto é, monitorados $\mathrm{em}$ um $\lambda$ fixo.
}

$$
A=\varepsilon_{1} \cdot C_{1}+\varepsilon_{2} \cdot C_{2}
$$

Considerando que $C_{\mathrm{t}}=C_{1}+C_{2}$, então

$$
A=\varepsilon_{1} \cdot C_{1}+\varepsilon_{2} \cdot C_{\mathrm{t}}-\varepsilon_{2} \cdot C_{1}
$$

Substituição de $\varepsilon_{2} \cdot C_{\mathrm{t}}$ por $A_{\text {máx }}$ resulta

$$
A-A_{\text {máx }}=\left(\varepsilon_{1}-\varepsilon_{2}\right) \cdot C_{1}
$$

Trocando $\varepsilon_{1}$ e $\varepsilon_{2}$ na função de $A_{\min }$ e $A_{\text {máx }}$ respectivamente, tem-se que

$$
A-A_{\text {máx }}=\left(A_{\text {min }}+A_{\text {máx }}\right) \cdot C_{1} / C_{\mathrm{t}}
$$

onde

$$
C_{\mathrm{I}} / C_{\mathrm{t}}=\left(A-A_{\text {máx }}\right) /\left(A_{\text {mín }}+A_{\text {máx }}\right)
$$

Levando em conta que $C_{1} / C_{\mathrm{t}}+C_{2} / C_{\mathrm{t}}=1$, então

$$
C_{1} / C_{2}=\left(A-A_{\text {máx }}\right) /\left(A_{\text {min }}-A\right)
$$

ou, equivalentemente

$$
C_{2} / C_{1}=\left(A-A_{\text {min }}\right) /\left(A_{\text {máx }}-A\right)
$$

Substituindo os resultados acima na equação de HendersonHasselbach (Eq. 130), ${ }^{\text {b }}$ obtém-se finalmente a Eq. 140.

$$
\mathrm{pH}=\mathrm{p} K_{\mathrm{a}}+\log \left(\frac{A-A_{\text {min }}}{A_{\text {max }}-A}\right)
$$

onde $A_{\min }$ e $A_{\max }$ foram denominados desta maneira porque, em todos os casos estudados nesta tese, a absorbância em meio básico (correspondente à espécie desprotonada) foi maior que aquela em meio ácido (espécie protonada). Daí decorre que, no termo logarítmico, o numerador $A-A_{\min } \propto$ [X] , e o denominador $A_{\text {máx }}-A \propto[\mathrm{HX}]$. Nos casos em que essa suposição não é obedecida (ou seja, se $\varepsilon_{\mathrm{HX}}>\varepsilon_{\mathrm{X}^{-}}$), então o coeficiente angular deve ser corrigido pelo termo unitário negativo. Por isso é que a Eq. 140 foi condicionada ao fator de correção $z$ que aparece na Eq. 131

Assim, monitorando a absorbância de uma amostra em um comprimento de onda específico de uma amostra em função do $\mathrm{pH}$ da solução, é possivel obter o valor de $\mathrm{p} K_{\mathrm{a}}$ a partir do coeficiente linear da curva construída tomando-se a relação pH vs. $\log \left[\left(A-A_{\min }\right) /\left(A_{\operatorname{máx}}-A\right)\right]$ (Eq. 131).

A Fig. 57 ilustra, por exemplo, a variação espectral que acompanha a titulação ácido-base de um dos complexos aqui estudados, mais especificamente o $\left[\mathrm{Ru}^{\mathrm{III}}(\text { edta })(\mathrm{bimH})\right]^{-}$ (neste caso, a absorbância foi acompanhada em $\lambda=500 \mathrm{~nm}$ e $\left.\mathrm{p} K_{\mathrm{a}}=8,8\right)$

b A Eq. 130 equivale a $\mathrm{pH}=\mathrm{pK}_{\mathrm{a}}+\log \left(\mathrm{C}_{2} / \mathrm{C}_{1}\right)$ na notação aqui empregada. 


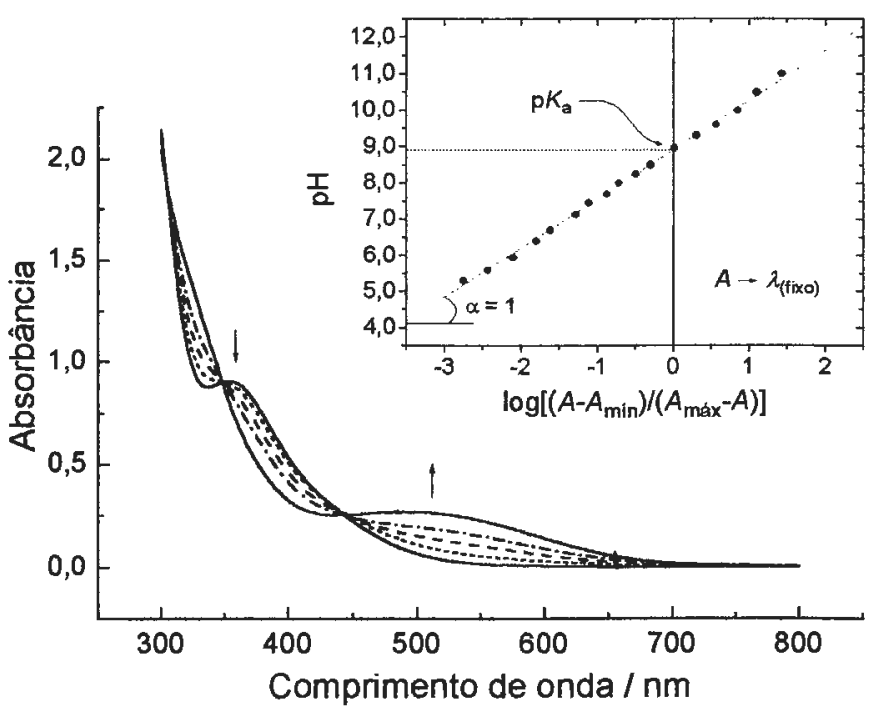

Figura 57. Espectros eletrônicos dos complexos mononucleares $\left.\left[\mathrm{Ru}^{\mathrm{III}}(\mathrm{edta})(\mathrm{bimH})\right] / \mathrm{Ru}^{\prime \prime \prime}(\mathrm{edta})(\mathrm{bim})\right]^{2-}$ em vários $\mathrm{pH}$; determinação do $\mathrm{p} K_{\mathrm{a}}$ por titulaçăo espectrofotométrica. $\left[C=1,0 \times 10^{-3} \mathrm{~mol} \mathrm{dm}^{-3} ; l=1,0 \mathrm{~cm}\right.$; soluçăo tampão de BrittonRobinson ( $\mathrm{pH} 2-12$; v. item 2.1.9 para detalhes].

\subsection{Ciclo termodinâmico: avaliação de $\boldsymbol{K}_{\mathrm{eq}}$}

O diagrama do Esq. 16 ilustra um ciclo termodinâmico genérico envolvendo quatro espécies interconversíveis em equilíbrio. Esse exemplo particular de ciclo "quadrado" foi convenientemente escolhido por representar a maioria dos processos redox acoplados a uma reação paralela (p. ex. substituição ou protonação) envolvidos neste trabalho. Nele, quatro parâmetros descrevem completamente o sistema: os potenciais de redução $E^{(\mathrm{A})}$ e $E^{(\mathrm{B})}$, que se referem aos pares redox centrados no metal de cada uma das espécies hipotéticas $\mathrm{M}^{\mathrm{III} / \mathrm{l}} \mathrm{X}_{5} \mathrm{~L}_{\mathrm{A}}$ e $\mathrm{M}^{\mathrm{III} / \mathrm{I}} \mathrm{X}_{5} \mathrm{~L}_{\mathrm{B}}$, e as constantes de equilíbrio entre estas espécies nos estados oxidado $\left(K^{\mathrm{HII}}\right)$ e reduzido $\left(K^{\mathrm{II}}\right)$.

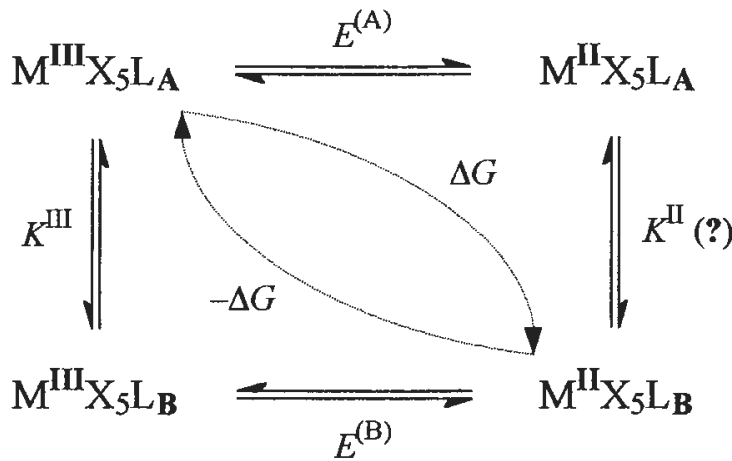

Esquema 16. Ciclo termodinâmico "quadrado" para espécies genéricas semelhantes aos complexos estudados nesta tese.
De acordo com o princípio da conservação de energia, desde que o sistema esteja em equilíbrio qualquer caminho que leva à conversão de uma espécie (p. ex. $M^{\mathrm{IIl}} \mathrm{X}_{5} \mathrm{~L}_{\mathrm{A}}$ ) em outra (p. ex. $\mathrm{M}^{\mathrm{II}} \mathrm{X}_{5} \mathrm{~L}_{\mathrm{B}}$ ) deve envolver a mesma quantidade de trabalho e energia. Assim, neste exemplo, a variação de energia livre $\Delta G$ na transformação de $\mathrm{M}^{\mathrm{III}} \mathrm{X}_{5} \mathrm{~L}_{\mathrm{A}}$ em $\mathrm{M}^{\mathrm{II}} \mathrm{X}_{5} \mathrm{~L}_{\mathrm{B}}$ pelo caminho 1 (através da espécie intermediária $M^{\mathrm{II}} \mathrm{X}_{5} \mathrm{~L}_{\mathrm{A}}$ ) é dada pela Eq. 141, onde $\Delta G_{1}{ }^{\prime}$ e $\Delta G_{1}$ " (Eqs. 142a,b) são as relações termodinâmicas para cada uma das etapas.

$$
\begin{gathered}
\Delta G_{1}=\Delta G_{1}{ }^{\prime}+\Delta G_{1}{ }^{\prime \prime} \\
\Delta G_{1}{ }^{\prime}=-n \mathrm{~F} E^{(\mathrm{A})} \text { e } \Delta G_{1}{ }^{\prime}=-\mathrm{R} T \ln K^{\mathrm{II}}
\end{gathered}
$$

(onde $n=1$ para o caso particular representado no Esq. 16)

Pelo mesmo raciocínio, a variação de energia $\Delta G_{2}$ para o percurso 2 é dada pelas Eqs. 143 e 144:

$$
\begin{gathered}
\Delta G_{2}=\Delta G_{2}{ }^{\prime}+\Delta G_{2}{ }^{\prime \prime} \\
\Delta G_{2}{ }^{\prime}=-\mathrm{R} T \ln K^{\mathrm{III}} \text { e } \Delta G_{2}{ }^{\prime \prime}=-n \mathrm{~F} E^{(\mathrm{B})}
\end{gathered}
$$

Respeitando a conservação de energia total, então $\Delta G_{1}=$ $\Delta G_{2}$. De outra forma, $\Delta G_{\mathrm{I}}-\Delta G_{2}=0$, o que significa que a energia necessária para se retornar à mesma inicial é nula Assim, a relação entre $\Delta G_{\mathrm{I}}$ e $\Delta G_{2}$ em termos dos parâmetros dados no diagrama é expressa por:

$$
\begin{gathered}
-n \mathrm{~F} E^{(\mathrm{A})}+\left(-\mathrm{R} T \ln K^{\mathrm{Il}}\right)=-\mathrm{R} T \ln K^{\mathrm{III}}+\left(-n \mathrm{~F} E^{(\mathrm{B})}\right) \\
n \mathrm{~F}\left(E^{(\mathrm{B})}-E^{(\mathrm{A})}\right)+\mathrm{R} T \ln \left(K^{\mathrm{III}} / K^{\mathrm{HI}}\right)=0
\end{gathered}
$$

Visto que a igualdade acima deve ser verdadeira em qualquer situação, então podemos afirmar que, conhecendo três dos parâmetros do ciclo termodinâmico (p. ex. $E^{(\mathrm{A})}, E^{(\mathrm{B})}$ e $K^{\mathrm{III}}$ ), o quarto deles (p. ex. $K^{\mathrm{II}}$; representado pela incógnita no Esq. 16) pode ser facilmente calculado através da Eq 146.

Neste exemplo específico, um rearranjo simples das Eqs. 145 e 146 resulta a expressão de $K^{\text {Il }}$ (Eq. 147), que pode ser utilizada para qualquer sistema do tipo aqui considerado desde que as analogias apropriadas sejam corretamente aplicadas

$$
K^{\mathrm{II}}=K^{\mathrm{III}} \cdot \exp \left[-\frac{n F}{\mathrm{R} T}\left(E^{(\mathrm{A})}-E^{(\mathrm{B})}\right)\right]
$$

Para $n=1$ e $T=298 \mathrm{~K}$, a expressão resultante é:

$$
K^{\mathrm{II}}=K^{\mathrm{III}} \cdot \exp \left[38,92 \cdot\left(E^{(\mathrm{B})}-E^{(\mathrm{A})}\right)\right]
$$




\subsection{Material suplementar}

6.4.1. Parâmetros ácido-base, redox e termodinâmicos para complexos de ferro e rutênio de partida em química de solução aquosa

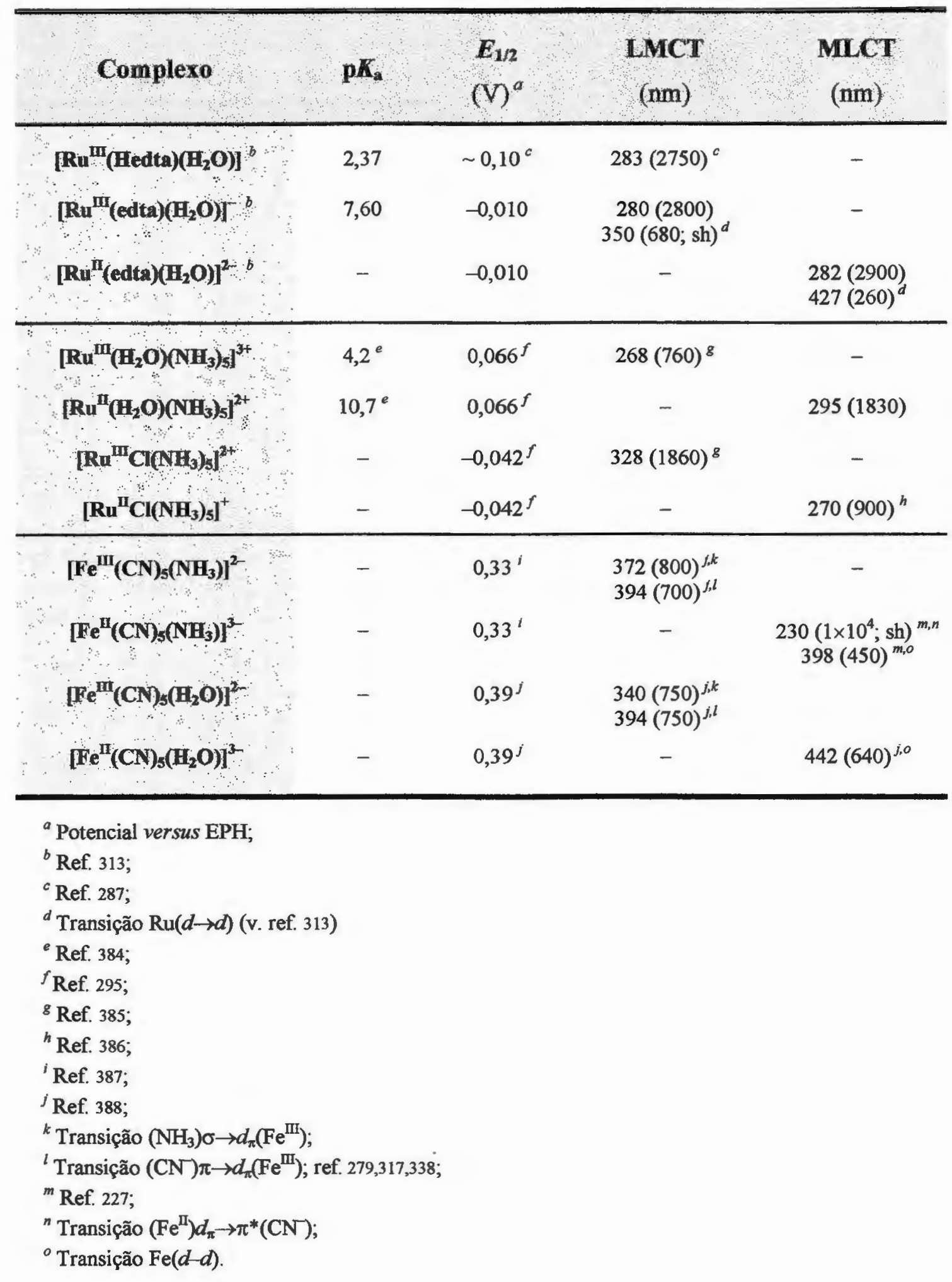




\subsubsection{Constantes de dissociação ácida e espectros eletrônicos dos ligantes de partida}

Os espectros eletrônicos na região do UV para os ligantes neutros (LH) e de seus ânions ( $\mathrm{L}^{-}$), em misturas aquosas (etanol/água 1:10), resultaram bandas de absorção conforme coletado na Tab. 18

Tabela 18. Transições $\pi \rightarrow \pi^{*}$ dos ligantes de partida.

\begin{tabular}{ccc}
\hline Ligante & $\lambda / \mathbf{n m}$ & $\varepsilon / \mathbf{m o l}^{\mathbf{1}} \mathbf{d m}^{\mathbf{3}} \mathbf{c m}^{-1}$ \\
\hline btaH & 257 & 4560 \\
bta & 274 & $3800 ; \mathrm{sh}$ \\
& 273 & 6990 \\
\hline & 243 & 3160 \\
bimH & 270 & 3300 \\
& 277 & 3330 \\
bim & 252 & $3500 ; \mathrm{sh}$ \\
& 276 & 4490 \\
& 280 & $3750 ; \mathrm{sh}$ \\
\hline
\end{tabular}

Os valores de $\mathrm{p} K_{\mathrm{a}}$ para os ligantes livres benzotriazol e benzoimidazol foram extraídos da literatura (ref. 292 e 293 , respectivamente) e estão relacionados aos correspondentes equilíbrios ácido-base das equações abaixo:

$$
\begin{array}{rlr}
\mathrm{btaH}_{2}^{+} & \rightarrow \text { btaH }+\mathrm{H}^{+} & {\left[\mathrm{p} K_{\mathrm{a}}=1,17 \pm 0,03\right]} \\
\mathrm{btaH} & \rightarrow \mathrm{bta}^{-}+\mathrm{H}^{+} & {\left[\mathrm{p} K_{\mathrm{a}}=8,38 \pm 0,03\right]} \\
\mathrm{bimH}_{2}^{+} & \rightarrow \text { bimH }+\mathrm{H}^{+} & {\left[\mathrm{p} K_{\mathrm{a}}=5,54 \pm 0,04\right]} \\
\mathrm{bimH} & \rightarrow \mathrm{bim}^{-}+\mathrm{H}^{+} & {\left[\mathrm{p} K_{\mathrm{a}}=12,78 \pm 0,04\right]}
\end{array}
$$

\subsubsection{Dados eletroquímicos e espectrais para alguns complexos de rutênio-polipiridina de partida ou substituídos em meio orgânico}

$\mathrm{O}$ conjunto de dados apresentados a seguir refere-se aos sistemas discutidos nos itens 3.2.2.x.

\subsubsection{Complexos de partida}

\subsubsection{1. cis- $-\mathrm{RuCl}_{2}(\mathrm{bpy})_{2}$}

Uma vez que serão feitas várias referências e comparações dos espectros eletrônicos e também dos potenciais redox dos complexos preparados/substituídos com os do material de partida, cis-bis(2,2'-bipiridina)diclororutênio(II), seguem abaixo o seu voltamograma cíclico e os seus espectros de absorção. ${ }^{2}$

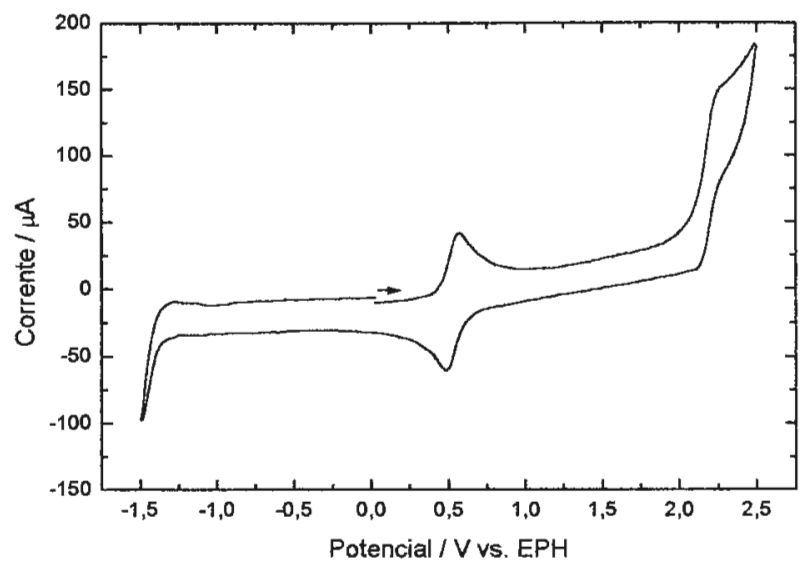

Figura 58. Voltamograma cíclico do cis-RuCl$(b p y)_{2}$ em MeCN $\left(C=2,0 \times 10^{-3} \mathrm{~mol} \mathrm{dm}^{-3} ; I=(\right.$ tea $\left.) \mathrm{ClO}_{4} 0,10 \mathrm{~mol} \mathrm{dm}^{-3}\right)$

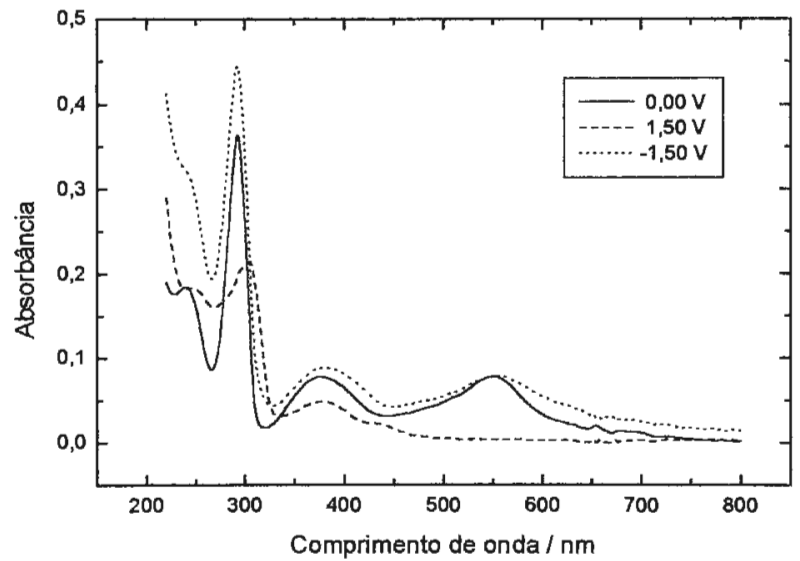

Figura 59. Espectros eletrônicos do cis-RuCl $\mathrm{Cl}_{2}(\mathrm{bpy})_{2}$ em MeCN ( $C=1,0 \times 10^{-3} \mathrm{~mol} \mathrm{dm}^{-3} ; l=($ tea $) \mathrm{ClO}_{4} 0,10 \mathrm{~mol} \mathrm{dm}^{-3} ; l=0,025 \mathrm{~cm}$ )

\subsubsection{2. cis-[RuCl(bpy $\left.)_{2}(\mathrm{py})\right]^{+}$}

Apesar de o cis-[RuCl(bpy $\left.)_{2}(\mathrm{py})\right]^{+}$também ser conhecido de estudos anteriormente reportados, ${ }^{297,298}$ o propósito de se preparar e caracterizar este complexo está associado à sua utilização como material intermediário na preparação de outros complexos do tipo cis-[Ru(bpy) $\left.)_{2}(\mathrm{py})(\mathrm{LH})\right]^{2+}$, onde LH pode ser benzotriazol ou benzoimidazol. A motivação para essa escolha, em paralelo com os sistemas do tipo $\left[\mathrm{RuCl}(\mathrm{bpy})_{2}(\mathrm{LH})\right]^{+}$, deve-se ao fato de os primeiros serem

a Evidentemente, estudos deste complexo têm sido previamente descritos na literatura. ${ }^{297,348}$ Contudo, além de oferecer uma base comparativa, a apresentação desses dados permite a verificação do grau de pureza do material de partida na síntese de todos os demais da série de compostos introduzidos neste item. 
mais interessantes do ponto de vista fotoquímico, tornandoos potencialmente empregáveis em outras linhas do grupo.

Os potenciais para as ondas voltamétricas reversíveis do metal e catódica do ligante bipiridina são $E_{1 / 2}=0,97$ e $E_{\mathrm{c}, 1}=$ $-1,25 \mathrm{~V}$, respectivamente. Essa atribuição está de acordo com os dados disponíveis na literatura, ${ }^{297}$ e reflete o caráter $\pi$-aceitador mais pronunciado na bipiridina do que piridina, que não é eletroquimicamente ativa na faixa de potenciais utilizada. Dessa maneira, é certo que o segundo potencial de redução da bpy $\left(E_{\mathrm{c}, 2}\right)$ ocorra abaixo de $-1,5 \mathrm{~V}$. Esse deslocamento é conseqüência da primeira etapa de redução localizada na bpy(1) e, também, pela diminuição do caráter $\pi$-aceitador da bpy(2) devido à presença (em posição trans) da piridina, que deve induzir um decréscimo no valor de $E_{\mathrm{c}, 2}$.

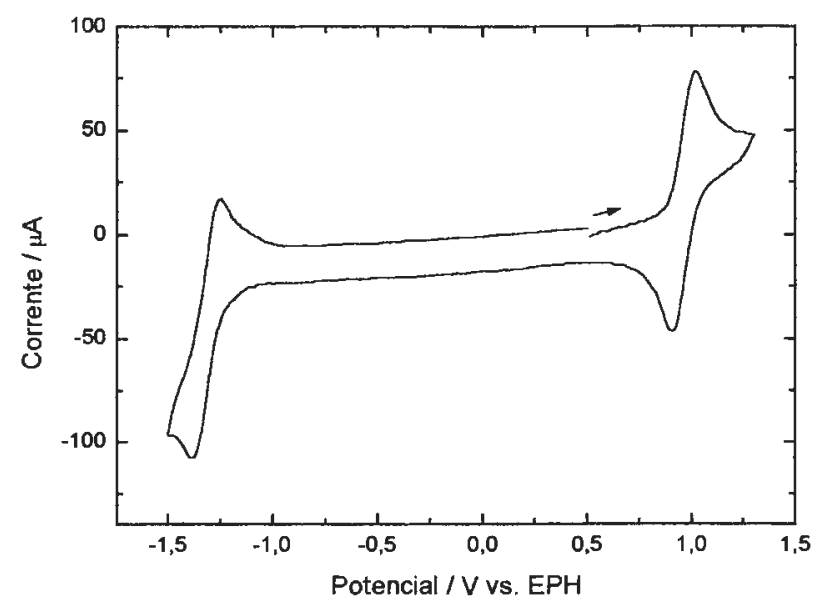

Figura 60. Voltamograma ciclico do $\left[\mathrm{RuCl}(\mathrm{bpy})_{2}(\mathrm{py})\right]^{+} \mathrm{em} \mathrm{MeCN}$. $\left(C=2,0 \times 10^{-3} \mathrm{~mol} \mathrm{dm}^{-3} ; l=(\right.$ tea $\left.) \mathrm{ClO}_{4} 0,10 \mathrm{~mol} \mathrm{dm}^{-3} ; v=200 \mathrm{mV} / \mathrm{s}\right)$

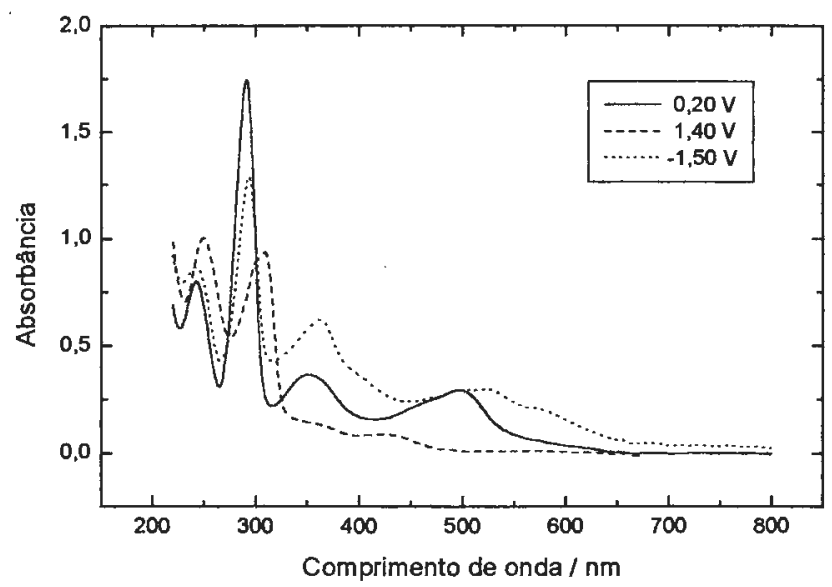

Figura 61. Espectros eletrônicos do $\left[\mathrm{RuCl}(\mathrm{bpy})_{2}(\mathrm{py})\right]^{*}$ em MeCN. ( $C=2,0 \times 10^{-3} \mathrm{~mol} \mathrm{dm}^{-3} ; I=($ tea $\left.) \mathrm{ClO}_{4} 0,10 \mathrm{~mol} \mathrm{dm}^{-3} ; /=0,025 \mathrm{~cm}\right)$

\subsubsection{Complexos cis-[RuCl(bpy $\left.)_{2}(L H)\right]^{n+}(n=0,1,2)$}

\subsubsection{1. $\mathrm{LH}=\mathrm{btaH}$}

$\mathrm{O}$ voltamograma cíclico do complexo $\left[\mathrm{Ru}^{\mathrm{Il}} \mathrm{Cl}(\mathrm{bpy})_{2}(\mathrm{btaH})\right]^{+}$ em acetonitrila apresenta dois pares de ondas na região positiva, sendo que a onda anódica com potencial mais positivo $(1,120 \mathrm{~V})$ e a catódica com potencial mais negativo $(0,870 \mathrm{~V})$ predominam em intensidade (Fig. 62).

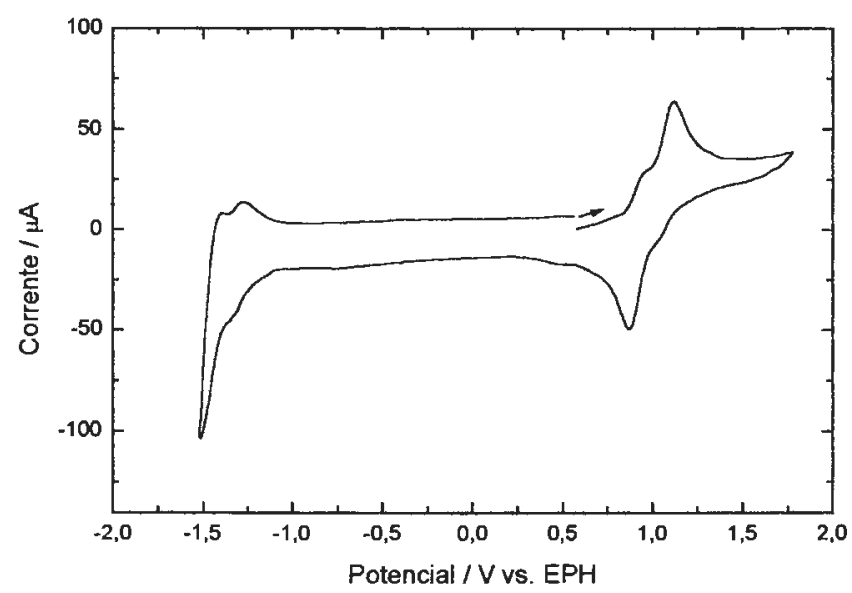

Figura 62. Voltamograma cíclico do $\left[\mathrm{RuCl}(\mathrm{bpy})_{2}(\mathrm{btaH})\right]^{+}$em $\mathrm{MeCN}$. $\left(C=2,0 \times 10^{-3} \mathrm{~mol} \mathrm{dm}^{-3} ; I=(\right.$ tea $\left.) \mathrm{ClO}_{4} 0,10 \mathrm{~mol} \mathrm{dm}^{-3} ; v=200 \mathrm{mV} \mathrm{s}^{-1}\right)$

Observou-se ainda que a relação entre as correntes de pico dessas ondas é dependente da velocidade de varredura de potencial, conforme se pode notar abaixo, na Fig. 63.

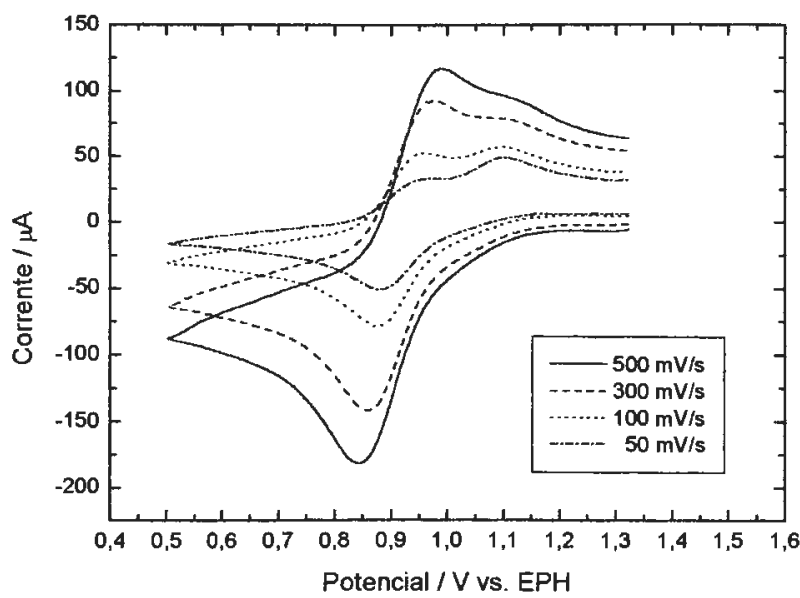

Figura 63. Voltamogramas ciclicos do $\left[\mathrm{RuCl}(\mathrm{bpy})_{2}(\mathrm{btaH})\right]^{+}$em $\mathrm{MeCN}$ a várias velocidades de varredura de potencial. 
A dependência da intensidade das ondas com a velocidade de varredura de potenciais fica mais evidenciada quando os voltamogramas são registrados a partir da espécie oxidada, no sentido de potenciais mais negativos (Fig. 63). As ondas com menor intensidade de corrente ocorrem em potenciais bastante próximos de $0,95 \mathrm{~V}$ e $1,04 \mathrm{~V}$ (ombros anódico e catódico, respectivamente).

O comportamento acima é característico de uma etapa eletroquímica acoplada a um processo químico, que nesse sistema em particular, evidencia a isomeria de ligação $\mathrm{Ru}$ $\mathrm{N} 2 \rightarrow \mathrm{Ru}-\mathrm{N} 3$, observada anteriormente para os complexos de benzotriazol com pentaaminrutênio ${ }^{242}$ e pentacianoferrato ${ }^{241}$ e rutênio-edta (v. item 3.1.1.2).

De acordo com o exposto em seções anteriores, cálculos teóricos em nível semi-empírico demonstraram que o sítio N2 é menos nucleofilico e favorece interações do tipo $\pi$ retrodoadoras, preferindo, portanto, coordenar-se aos íons $\mathrm{Ru}^{\mathrm{II}}$. Por sua vez, a posição N3 interage mais efetivamente com íons metálicos $\pi$-aceitadores e deve favorecer a coordenação com o íon $\mathrm{Ru}^{\mathrm{III}}$. Feitas essas considerações, e tomando $0,910 \mathrm{~V}$ e $1,080 \mathrm{~V}\left(E_{1 / 2}\right)$ como sendo $E_{\mathrm{N} 3}$ e $E_{\mathrm{N} 2}$, presume-se que o processo possa ser representado como no diagrama abaixo.

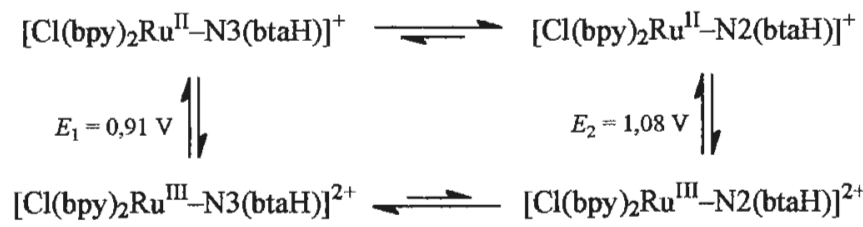

Esquema 17. Isomeria de ligação no $\left[\mathrm{RuCl}(\mathrm{bpy})_{2}(\mathrm{btaH})\right]^{*}$.

A proposição acima é apoiada por outros dois fatos: (i) nas medidas eletroquímicas, partindo-se da espécie reduzida em direção de potenciais mais positivos, praticamente uma única onda é observada (aquela em 1,120 V), e esta não é afetada pela velocidade de varredura dos potenciais. Igualmente, quando se parte da espécie oxidada, apenas a onda em $0,870 \mathrm{~V}$ é observada na região catódica e também não é influenciada pela velocidade de varredura de potenciais (Fig. 63). Isso porque nos dois casos o sistema já se encontra em equilíbrio para aquele estado de oxidação inicial, prevalecendo os isômeros de maior estabilidade (isto é, $R u^{\text {II }}-\mathrm{N} 2$ e $R u^{\text {III }}-\mathrm{N} 3$ ). Assim, apenas a sua espécie redox recíproca (que é formada durante o processo dinâmico de varredura de potenciais) terá a intensidade de pico afetada pela velocidade $\mathrm{d} E / \mathrm{d} t$. (ii) $\mathrm{Se} \mathrm{N} 3$ possui maior densidade de carga que N2 (Fig. 8), então é totalmente coerente a relação $E_{\mathrm{N} 2}\left(\mathrm{Ru}^{\mathrm{III}}-\mathrm{N} 2 \rightarrow \mathrm{Ru}^{\mathrm{II}}-\mathrm{N} 2\right)>E_{\mathrm{N} 3}\left(\mathrm{Ru}^{\mathrm{III}}-\mathrm{N} 3 \rightarrow \mathrm{Ru}^{\mathrm{II}}-\mathrm{N} 3\right)$.
Além dos processos envolvendo o metal, as ondas típicas dos pares redox centrados nos ligantes bipiridina aparecem na região de $-1,2 \mathrm{~V} \mathrm{a}-1,5 \mathrm{~V}$, característica desta espécie. ${ }^{297}$ Nesse caso, os valores de $E_{\mathrm{c}, 1}$ e $E_{\mathrm{c}, 2}$ são $-1,280$ e $-1,400 \mathrm{~V}$, respectivamente. ${ }^{a}$ Esses potenciais catódicos correspondem às etapas (monoeletrônicas) consecutivas de redução dos dois ligantes bpy. ${ }^{297}$

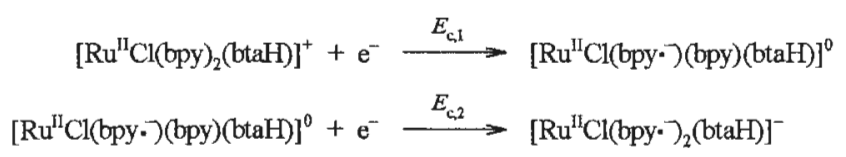

$(153,154)$

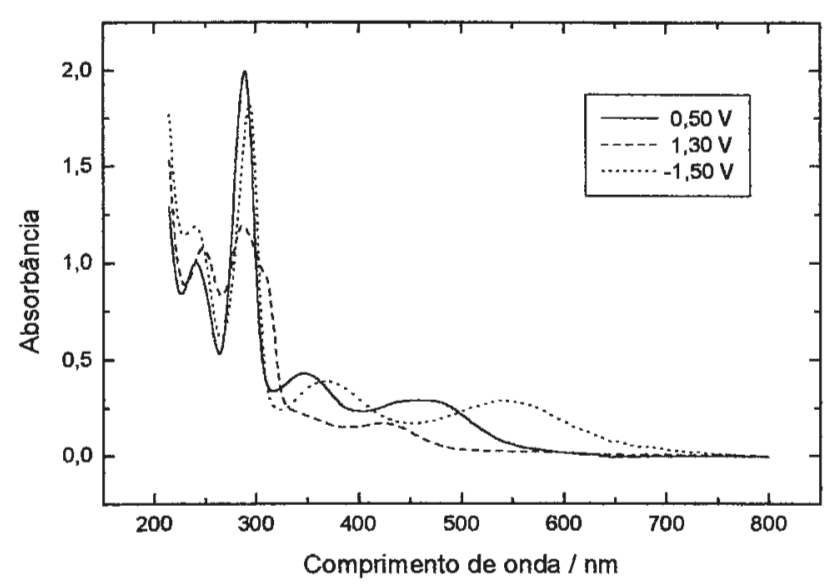

Figura 64. Espectros eletrônicos do [RuCl(bpy $\left.)_{2}(\mathrm{btaH})\right]^{+}$em MeCN. $\left(C=2,0 \times 10^{-3} \mathrm{~mol} \mathrm{dm}^{-3} ; I=(\right.$ tea $\left.) \mathrm{ClO}_{4} 0,10 \mathrm{~mol} \mathrm{dm}^{-3} ; I=0,025 \mathrm{~cm}\right)$

\subsubsection{2. $\mathrm{LH}=\mathrm{bimH}$}

O voltamograma do complexo $\left[\mathrm{Ru}^{\mathrm{II}} \mathrm{Cl}(\mathrm{bpy})_{2}(\mathrm{bimH})\right]^{+}$em solução de acetonitrila apresenta uma onda reversível com $E_{1 / 2}{ }^{\mathrm{b}}$ em $0,770 \mathrm{~V}$, atribuída ao par $\mathrm{Ru}^{\mathrm{III}} / \mathrm{Ru}^{\mathrm{I}}$ e outra onda com potencial catódico $E_{\mathrm{c}}=-1,450 \mathrm{~V}$, característica do processo redox centrado no ligante, bpy/bpy- ${ }^{-}$(Fig. 65).

\footnotetext{
a Salvo algumas exceções, as ondas voltamétricas (reversíveis) envolvendo os ligantes bpy ${ }^{297}$ não pudexam ser totaimente registradas. Isso decorre da faixa de trabalho do solvente utilizado, que é limitada à região de -2 a $2 \mathrm{~V}$ vs. $\mathrm{Ag} / \mathrm{Ag}^{+} . \mathrm{Em}$ alguns casos, foi possivel estender essa faixa no extremo negativo, atingindo valores ao redor de $-2,2 \mathrm{~V}$. Assim, devido a essas dificuldades e, para facilitat a comparação entre esses potenciais para os diversos complexos abordados, apenas o valor de pico catódico $-E_{c}-$ será considerado.

b $\bigcirc E_{1 / 2}$ foi tomado como a média dos potenciais de pico anódico e catódico, $E_{1 / 2}=\left(E_{3}+E_{c}\right) / 2$. Em média a separação $E_{a}-E_{c}$ ficou na faixa de $60-80 \mathrm{mV}$.
} 
De acordo com o previsto, o potencial redox do par $\mathrm{Ru}^{\text {III }} / \mathrm{Ru}^{\mathrm{II}}$ é menor para o complexo de benzoimidazol que para o análogo de benzotriazol, cujos potenciais são $E_{1}=$ $0,910 \mathrm{~V}$ e $E_{2}=1,080 \mathrm{~V}$ para os isômeros Ru-N3 e Ru-N2, respectivamente. Considerando que a coordenação do bimH se encontra na posição equivalente ao N3 do btaH, então o mais correto seria considerar apenas o potencial $E_{1}$ para fins de comparação. Ainda assim, os $140 \mathrm{mV}$ que os diferem implica num substancial acréscimo da natureza $\pi$-doadora do benzoimidazol, que estabilizará a espécie $\mathrm{Ru}^{\mathrm{III}}$ melhor que o benzotriazol.

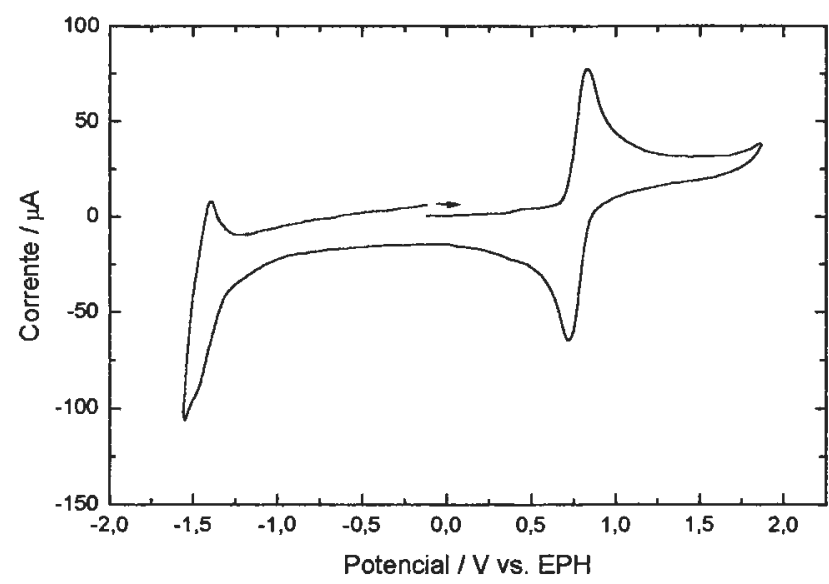

Figura 65. Voltamograma cíclico do $\left[\mathrm{RuCl}(\mathrm{bpy})_{2}(\mathrm{bimH})\right]^{+}$em MeCN. ( $C=2,0 \times 10^{-3} \mathrm{~mol} \mathrm{dm}^{-3} ; I=$ (tea) $\mathrm{ClO}_{4} 0,10 \mathrm{~mol} \mathrm{dm}^{-3} ; v=200 \mathrm{mV} / \mathrm{s}$ )

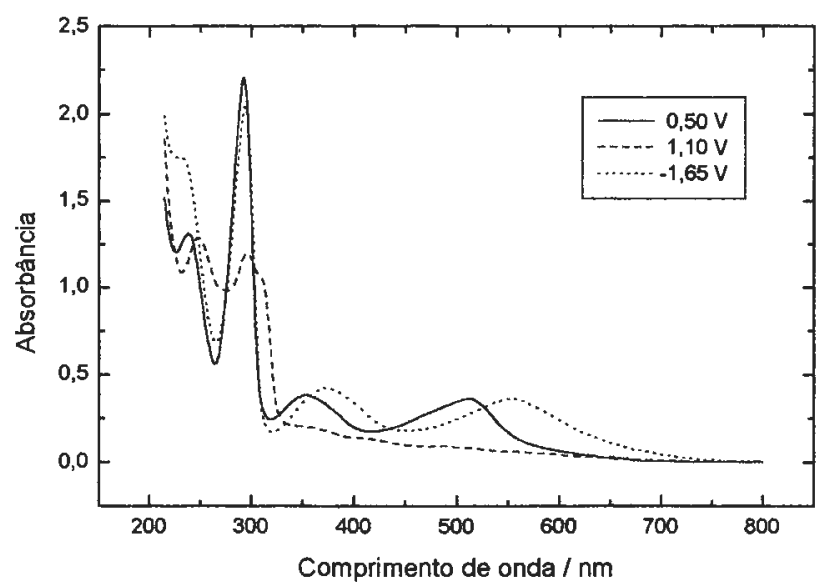

Figura 66. Espectros eletrônicos do $\left[\mathrm{RuCl}(\mathrm{bpy})_{2}(\mathrm{bimH})\right]^{+} \mathrm{em} \mathrm{MeCN}$. $\left(C=2,0 \times 10^{-3} \mathrm{~mol} \mathrm{dm}^{-3} ; l=(\right.$ tea $\left.) \mathrm{ClO}_{4} 0,10 \mathrm{~mol} \mathrm{dm}^{-3} ; l=0,025 \mathrm{~cm}\right)$

\subsubsection{Complexos cis- $\left[R u(b p y)_{2}(L H)_{2}\right]^{n+}(n=1,2,3)$}

\subsubsection{1. $\mathrm{LH}=\mathrm{btaH}$}

Diferentemente do complexo monossubstituído com btaH, $\left[\mathrm{Ru}^{\mathrm{II}} \mathrm{Cl}(\mathrm{bpy})_{2}(\mathrm{btaH})\right]^{+}$, o dissubstituído $\left[\mathrm{Ru}^{\mathrm{II}}(\mathrm{bpy})_{2}(\mathrm{btaH})_{2}\right]^{2+}$ não demonstra evidências de isomerização e apresenta apenas um par de ondas reversíveis em 1,320 V envolvendo a oxirredução do metal, $\mathrm{Ru}^{\mathrm{III}} \rightarrow \mathrm{Ru}^{\mathrm{II}}$ (Fig. 67). Os pares que envolvem a redução dos ligantes bipiridina, bpy $\rightarrow$ bpy $^{-}$, ocorrem com potenciais catódicos em $E_{\mathrm{c}, 1}=-1,370 \mathrm{~V}$ e $E_{\mathrm{c}, 2}$ $=-1,480 \mathrm{~V}$. Os processos centrados no metal e no ligante apresentam seus potenciais deslocados para a região mais positiva e mais negativa, respectivamente, em relação ao seu similar monossubstituído. Essa tendência é coerente com o esperado na inclusão de sucessivos ligantes do tipo $\mathrm{N}$-heterocíclicos (pela substituição ou troca de íons cloreto) ao complexo de partida $c i s-\mathrm{RuCl}_{2}(\mathrm{bpy})_{2}$.

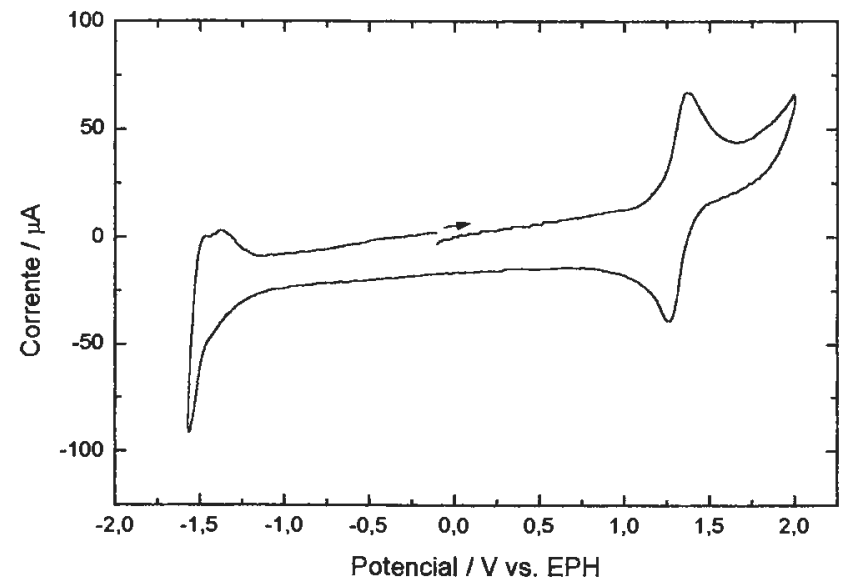

Figura 67. Voltamograma cíclico do $\left[\mathrm{Ru}(\mathrm{bpy})_{2}(\mathrm{btaH})_{2}\right]^{2+} \mathrm{em} \mathrm{MeCN}$ $\left(C=2,0 \times 10^{-3} \mathrm{~mol} \mathrm{dm}^{-3} ; I=\right.$ (tea) $\left.\mathrm{ClO}_{4} 0,10 \mathrm{~mol} \mathrm{dm}^{-3} ; v=200 \mathrm{mV} / \mathrm{s}\right)$

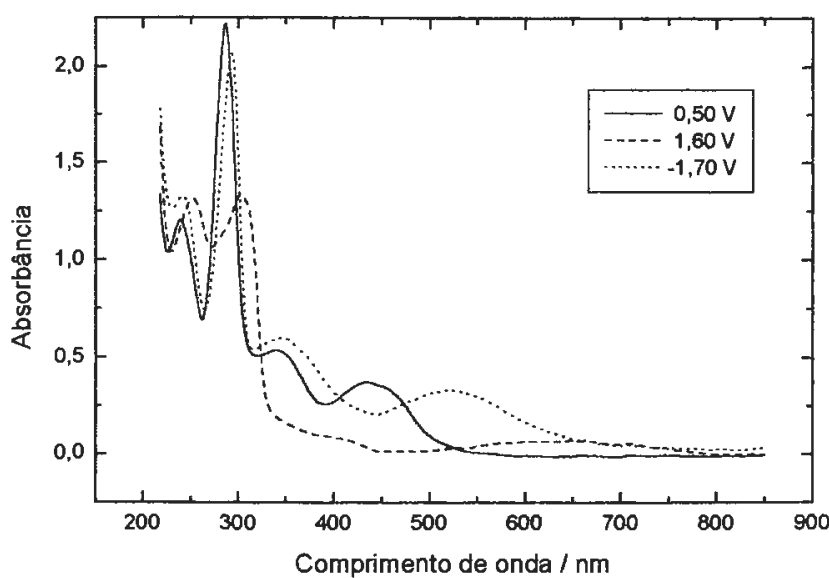

Figura 68. Espectros eletrônicos do $\left[\mathrm{Ru}(\mathrm{bpy})_{2}(\mathrm{btaH})_{2}\right]^{2+}$ em MeCN. (C $=2,0 \times 10^{-3} \mathrm{~mol} \mathrm{dm}^{-3} ; I=$ (tea) $\mathrm{ClO}_{4} 0,10 \mathrm{~mol} \mathrm{dm}^{-3} ; I=0,025 \mathrm{~cm}$ ) 


\subsubsection{2. $\mathrm{LH}=\mathrm{bimH}$}

O voltamograma cíclico da espécie dissubstituída de bimH, $\left[\mathrm{Ru}^{\mathrm{II}}(\mathrm{bpy})_{2}(\mathrm{bimH})_{2}\right]^{2+}$, em acetonitrila, apresenta um par de ondas reversíveis com $E_{1 / 2}=1,160 \mathrm{~V}$ (Fig. 69). Seguindo a tendência dos complexos descritos acima, houve tanto um aumento do potencial redox para o par $\mathrm{Ru}^{\mathrm{III}} \rightarrow \mathrm{Ru}^{\mathrm{II}} \mathrm{em}$ relação à espécie monossubstituída, $\left[\mathrm{Ru}^{\mathrm{II}} \mathrm{Cl}(\mathrm{bpy})_{2}(\mathrm{bimH})\right]^{+}$ $(0,770 \mathrm{~V})$, como sua diminuição em valor em relação ao similar com benzotriazol $\left[\mathrm{Ru}^{\mathrm{II}}(\mathrm{bpy})_{2}(\mathrm{btaH})_{2}\right]^{2+}(1,320 \mathrm{~V})$. As razões são as mesmas discutidas anteriormente.

A onda catódica de redução da bpy(1) se dá em $-1,360$ V. Esse valor é $\sim 100 \mathrm{mV}$ maior que $E_{\mathrm{c}, 1}$ para a espécie monossubstituída e reflete um decréscimo da densidade de carga localizada sobre os ligantes bipiridina.

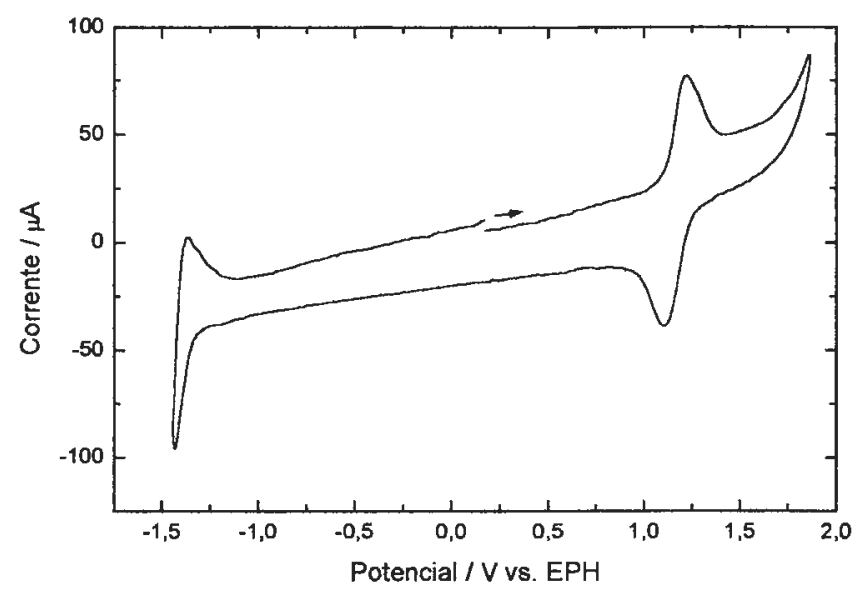

Figura 69. Voltamograma ciclico do $\left[\mathrm{Ru}(\mathrm{bpy})_{2}(\mathrm{bimH})_{2}\right]^{2+}$ em MeCN. ( $C=2,0 \times 10^{-3} \mathrm{~mol} \mathrm{dm}^{-3} ; I=($ tea $) \mathrm{ClO}_{4} 0,10 \mathrm{~mol} \mathrm{dm}^{-3} ; v=200 \mathrm{mV} / \mathrm{s}$ )

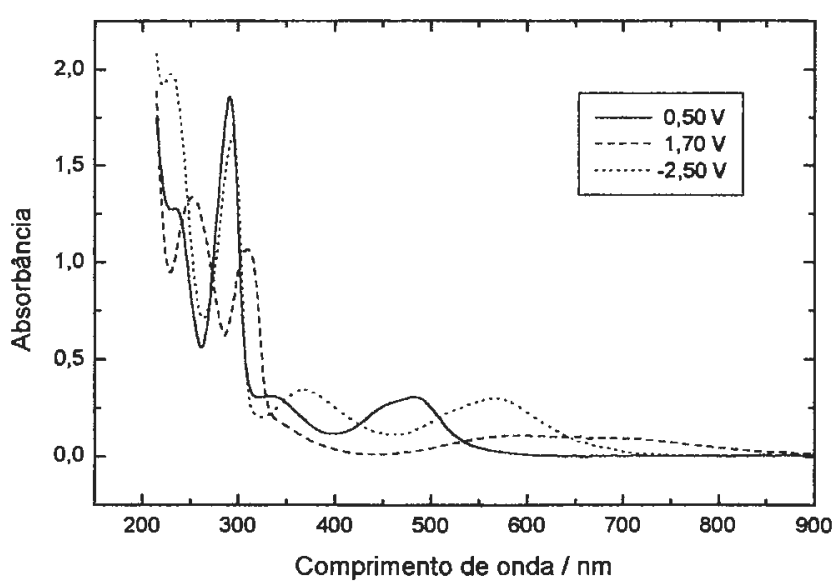

Figura 70. Espectros eletrônicos do $\left[\mathrm{Ru}(\mathrm{bpy})_{2}(\mathrm{bimH})_{2}\right]^{2+} \mathrm{em} \mathrm{MeCN}$. $\left(C=2,0 \times 10^{-3} \mathrm{~mol} \mathrm{dm}^{-3} ; I=(\right.$ tea $\left.) \mathrm{ClO}_{4} 0,10 \mathrm{~mol} \mathrm{dm}^{-3} ; /=0,025 \mathrm{~cm}\right)$
6.4.3.4. Complexos cis-[Ru(bpy $\left.)_{2}(p y)(L H)\right]^{n+}(n=1,2,3)$

\subsubsection{1. $\mathrm{LH}=\mathrm{btaH}$}

Dois pares de ondas reversíveis podem ser observados no voltamograma cíclico do complexo $\left[\mathrm{Ru}(\mathrm{bpy})_{2}(\mathrm{py})(\mathrm{btaH})\right]^{2+}$ (Fig. 71). Um ocorre em 1,39 V, cujo potencial corresponde ao processo redox do metal, e o outro, em $-1,35 \mathrm{~V}\left(E_{\mathrm{c}, 1}=\right.$ $-1,31 \mathrm{~V})$, que deve estar associado à oxirredução da bpy. A onda voltamétrica do ligante bpy(2) não pode ser verificada porque, nesse caso em particular, $E_{\mathrm{c}, 2}$ ocorre abaixo do limite inferior da região de trabalho em acetonitrila.

Destaca-se nesse sistema o aumento no valor de $E_{1 / 2} \mathrm{em}$ relação ao complexo de partida $\left[\mathrm{RuCl}(\mathrm{bpy})_{2}(\mathrm{py})\right]^{+}(0,97 \mathrm{~V})$, que é de $0,42 \mathrm{~V}$. Conforme explicado anteriormente, essa variação é esperada nas substituições de íons cloreto por ligantes $\pi$-aceitadores, e diminui na medida que o caráter eletrônico doador se acentua.

Ao contrário do que poderia ser esperado, nenhuma evidência eletroquímica de isomeria de ligação (observada antes para o complexo $\left[\mathrm{RuCl}(\mathrm{bpy})_{2}(\mathrm{btaH})\right]^{+}$) foi registrada para a espécie $\left[R u(b p y)_{2}(\mathrm{py})(\mathrm{btaH})\right]^{2+}$. Visto que o mesmo ocorreu para o complexo dissubstituído $\left[\mathrm{Ru}(\mathrm{bpy})_{2}(\mathrm{btaH})_{2}\right]^{2+}$, acredita-se que a presença de um segundo ligante do tipo Nheterocíclico na posição cis ao ligante benzotriazol inibe a ocorrência de isomeria.

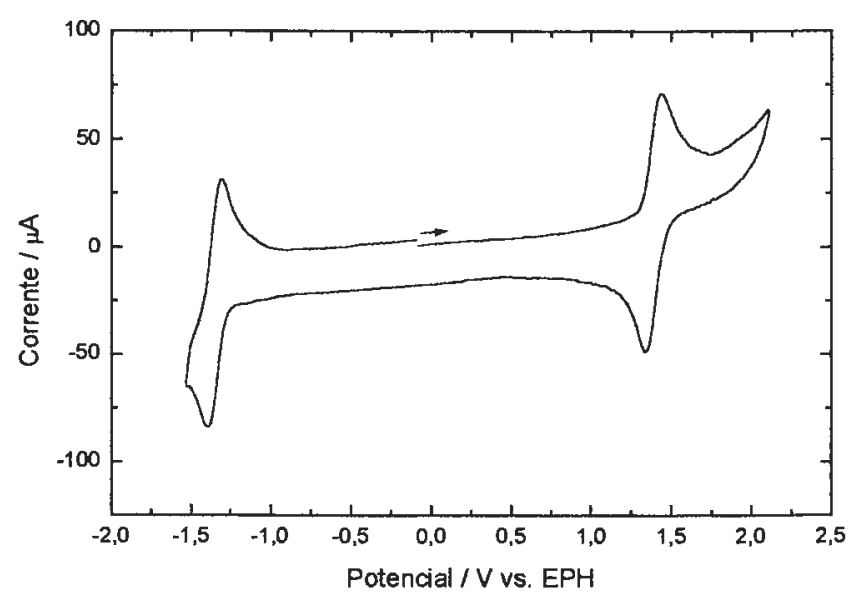

Figura 71. Voltamograma ciclico do $\left[\mathrm{Ru}(\mathrm{bpy})_{2}(\mathrm{py})(\mathrm{btaH})\right]^{2+}$ em MeCN. ( $C=2,0 \times 10^{-3} \mathrm{~mol} \mathrm{dm}^{-3} ; I=($ tea $) \mathrm{ClO}_{4} 0,10 \mathrm{~mol} \mathrm{dm}^{-3} ; v=200 \mathrm{mV} / \mathrm{s}$ ) 


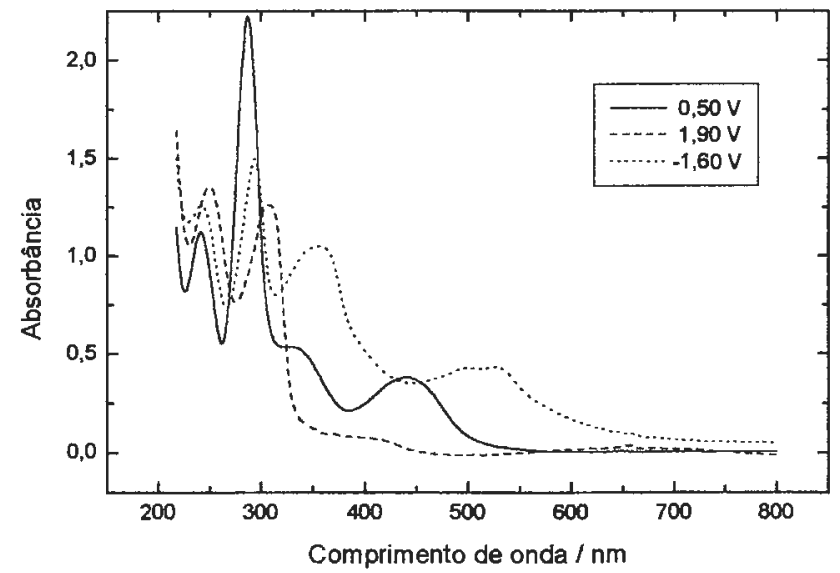

Figura 72. Espectros eletrônicos do $\left[R u(b p y)_{2}(\mathrm{py})(\mathrm{btaH})\right]^{2+}$ em MeCN. (C $=2,0 \times 10^{-3} \mathrm{~mol} \mathrm{dm}^{-3} ; I=($ tea $\left.) \mathrm{ClO}_{4} 0,10 \mathrm{~mol} \mathrm{dm}^{-3} ; I=0,025 \mathrm{~cm}\right)$

\subsubsection{2. $\mathrm{LH}=\mathrm{bimH}$}

A partir do voltamograma cíclico do complexo com bimH, cis-[Ru(bpy $\left.)_{2}(\mathrm{py})(\mathrm{bimH})\right]^{2+}$, em solução de acetonitrila, os potenciais para as ondas reversíveis do metal e catódicas dos ligantes foram determinados em $E_{1 / 2}=1,45 \mathrm{~V}, E_{\mathrm{c}, 1}=-1,19$ $\mathrm{V}$ e $E_{\mathrm{c}, 2}=-1,41 \mathrm{~V}$, respectivamente. Embora as ondas dos ligantes também sejam reversíveis e tenham sido registradas integralmente nesse caso específico $\left(\operatorname{com} E_{1 / 2}(1)=-1,23 \mathrm{~V}\right.$ e $E_{1 / 2}(2)=-1,45 \mathrm{~V}$ ), manteve-se aqui a apresentação desses potenciais em termos de $E_{\mathrm{c}}$ para facilitar a comparação dos dados posteriormente.

Comparação dos potenciais redox para os complexos $\left[\mathrm{Ru}(\mathrm{bpy})_{2}(\mathrm{py})(\mathrm{bimH})\right]^{2+}$ e $c i s-\left[\mathrm{Ru}(\mathrm{bpy})_{2}(\mathrm{bimH})_{2}\right]^{2+}(1,45 \mathrm{e}$ $1,16 \mathrm{~V}$, respectivamente) revela, indiretamente, a diferença de natureza eletrônica entre os ligantes piridil-derivados (que são essencialmente $\pi$-aceitadores) e aqueles imidazolilderivados (cujos caráteres $\sigma / \pi$-doadores prevalece). Esse é um aspecto favorável na escolha dessa série para estudo e tem sido explorado no design de complexos polinucleares.

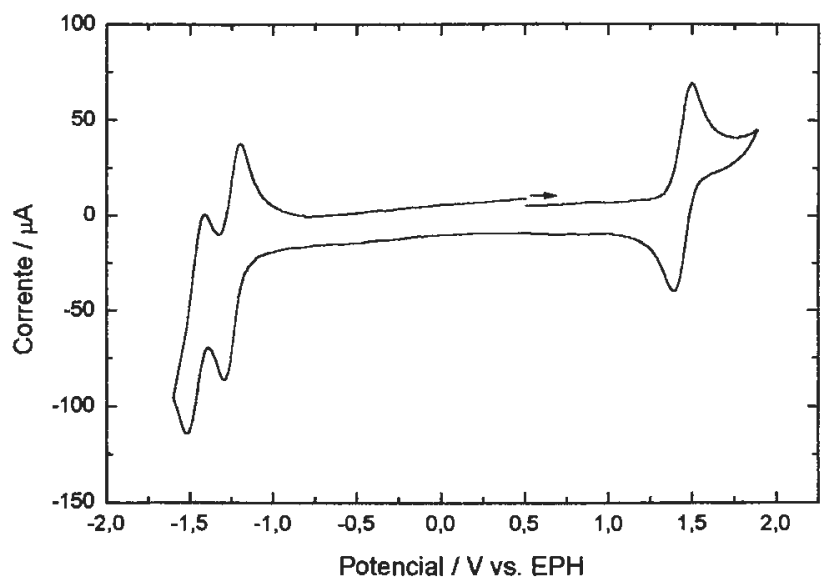

Figura 73. Voltamograma cíclico do $\left[\mathrm{Ru}(\mathrm{bpy})_{2}(\mathrm{py})(\mathrm{bimH})\right]^{2+}$ em MeCN $\left(C=2,0 \times 10^{-3} \mathrm{~mol} \mathrm{dm}^{-3} ; I=(\right.$ tea $\left.) \mathrm{ClO}_{4} 0,10 \mathrm{~mol} \mathrm{dm}^{-3} ; v=200 \mathrm{mV} / \mathrm{s}\right)$

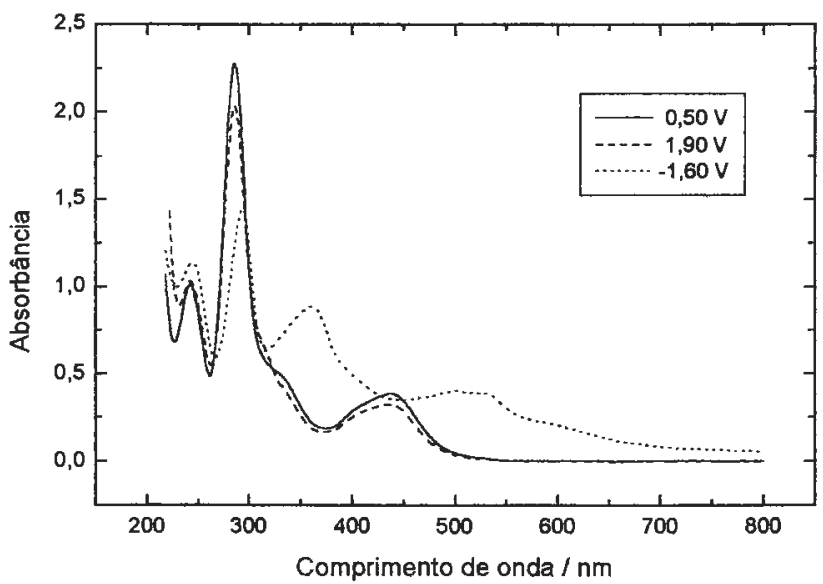

Figura 74. Espectros eletrônicos do $\left[R u(b p y)_{2}(p y)(b i m H)\right]^{2+}$ em $M e C N$. $\left(C=2,0 \times 10^{-3} \mathrm{~mol} \mathrm{dm}^{-3} ; I=(\right.$ tea $\left.) \mathrm{ClO}_{4} 0,10 \mathrm{~mol} \mathrm{dm}^{-3} ; I=0,025 \mathrm{~cm}\right)$ 


\subsection{Cálculo das constantes de velocidade de transferência de elétrons para uma série de sistemas de valência mista}

Conforme tem sido enfatizado na Introdução desta tese, um dos motivos principais do grande interesse na química dos complexos de valência mista, é o possível uso de medidas espectrais para se acessar as constantes de velocidade de transferência eletrônica, $k_{\mathrm{ET}}$ (v. seção 1.2).

Uma vez que os parâmetros $\lambda$ (energia reorganizacional) e $\Delta E_{0}$ (diferença de energia interna entre o reagente e o produto no estado fundamental) são conhecidos, então $\Delta G^{*}$, (barreira de ativação térmica na ausência de acoplamento eletrônico/perturbação nula) pode ser calculado através das Eqs. 33 e 34. Posteriormente, a energia de ativação para o processo de ET térmico $\left(\Delta G^{*}\right.$ ou $\left.\Delta G^{\ddagger}\right)$ pode ser obtida pela subtração da energia de ressonância ou de acoplamento eletrônico $\left(H_{\mathrm{ab}}\right)$ oriunda da interação intermetálica no estado de valência mista que, por sua vez, pode ser determinada a partir dos parâmetros espectrais de intervalência (Eq. 27).

Por fim, a constante de velocidade da transferência de elétrons térmica, $k_{\mathrm{ET}}$, é calculada de acordo com a expressão clássica do modelo cinético de ET segundo Marcus (Eq. 35; sistemas adiabáticos $-\kappa=1$; isso porque, nesses sistemas, $\left.4,6 \times 10^{-3} \cdot H_{\mathrm{ab}}{ }^{2} \cdot\left(\bar{v}_{\text {max }}\right)^{-1 / 2}>1\right){ }^{70}$ Nela, a freqüência nuclear, $v_{\mathrm{n}}$ é tomada pelos valores médios $6 \times 10^{12} \mathrm{~s}^{-1}$ (meio aquoso) e $8 \times 10^{12} \mathrm{~s}^{-1}$ (meio orgânico; $\mathrm{CH}_{3} \mathrm{CN}$ ), que são decorrentes das freqüências médias do solvente $\left(v_{\text {out }} \sim 10^{12} \mathrm{~s}^{-1}\right)$ e de esfera interna $\left(v_{\text {in }} \sim 400 \mathrm{~cm}^{-1}\right.$ para o modo vibracional $v_{\mathrm{M}-L}$, o que equivale a $\sim 10^{13} \mathrm{~s}^{-1}$ ) observadas experimentalmente.

Os valores de $k_{\mathrm{ET}}$ obtidos dessa forma estão mostrados na Tab. 20, juntamente com seus parâmetros relacionados.

Tabela 20. Constantes de velocidade de transferência de elétrons de toda a série estudada de sistemas polinucleares de valência mista simétricos e assimétricos de rutênio e ferro contendo benzotriazolato e benzoimidazolato como ligantes de ponte.

\begin{tabular}{|c|c|c|c|c|c|c|}
\hline Complexo & $\begin{array}{c}\lambda \\
\left(\mathrm{cm}^{-1}\right)\end{array}$ & $\begin{array}{l}\Delta E_{0}^{a} \\
\left(\mathrm{~cm}^{-1}\right)\end{array}$ & $\begin{array}{c}\Delta G^{*} \\
\left(\mathrm{~kJ} \mathrm{~mol}{ }^{-1}\right)\end{array}$ & $\begin{array}{c}H_{\mathrm{ab}} \\
\left(\mathrm{cm}^{-1}\right)\end{array}$ & $\begin{array}{c}\Delta G^{\mathrm{k} b} \\
\left(\mathrm{~kJ} \mathrm{~mol}^{-1}\right)\end{array}$ & $\begin{array}{c}k_{\mathrm{ET}}{ }^{c d} \\
\left(10^{10} \mathrm{~s}^{-1}\right)\end{array}$ \\
\hline$[(\text { edta }) R u-b t a-R u(e d t a)]^{4-}$ & 6900 & - & 20,64 & $\gg 750$ & $\ll 11,66$ & $\gg>5,4$ \\
\hline$[(e d t a) R u-b i m-R u(e d t a)]^{4}$ & 6670 & - & 19,95 & 820 & 10,14 & 10 \\
\hline$\left(\mathrm{NH}_{3}\right)_{5} \mathrm{Ru}-\mathrm{bta}-\mathbf{R u}(\mathrm{edta})$ & 5530 & 1250 & 24,86 & $>865$ & $<14,51$ & $>1,7$ \\
\hline$\left(\mathrm{NH}_{3}\right)_{5} \mathbf{R u}-$ bim-Ru(edta) & 5620 & 1370 & 26,00 & 850 & 15,83 & 1,0 \\
\hline$\left[\left(\mathrm{NH}_{3}\right)_{3} \mathrm{Ru}-\mathrm{bta}-\mathrm{Fe}(\mathrm{CN})_{5}\right]^{-}$ & 6735 & 1530 & 30,33 & 1675 & 10,30 & 9,4 \\
\hline$\left[\left(\mathrm{NH}_{3}\right)_{5} \mathrm{R}\left(\mathrm{u}-\mathrm{bim}-\mathrm{Fe}(\mathrm{CN})_{5}\right]^{-}\right.$ & 6920 & 2340 & 37,06 & $>1900$ & $<14,33$ & $>1,9$ \\
\hline$c i s-\left[C l(b p y)_{2} \mathbf{R u}-b t a-R u(b p y)_{2} \mathrm{Cl}\right]^{2+}$ & 6850 & - & 20,49 & 780 & 11,16 & 8,9 \\
\hline$c i s-\left[C l(b p y)_{2} \mathrm{Ru}-b \mathrm{im}-\mathrm{Ru}(\mathrm{bpy})_{2} \mathrm{Cl}\right]^{2+}$ & 7520 & - & 22,49 & 922 & 11,46 & 7,9 \\
\hline trans-[(bta) $\left(\mathrm{NH}_{3}\right)_{4} \mathrm{Ru}-\mathrm{bta}-\mathrm{Ru}(\mathrm{edta}) \Gamma$ & 5810 & 810 & 22,56 & 870 & 12,15 & 4,5 \\
\hline trans $-\left\{\{(\text { edta }) R u-b t a-\}_{2}\left(\mathrm{NH}_{3}\right)_{4} \mathbf{R u}\right\}^{2-}$ & 5730 & 810 & 22,32 & 940 & 11,08 & 6,9 \\
\hline
\end{tabular}

${ }^{a}$ Em princípio, a barreira termodinâmica $\Delta E_{0}$ (que é uma aproximação de $\Delta G^{\circ}$ ) para sistemas assimétricos de classe II poderia ser estimada a partir do espectro de intervalência do complexo de valência mista, por meio de um rearranjo na Eq. 38 , isto é, $\Delta E_{0}$ (teórico) $=\left[\nabla_{\text {mảx }}-\left(\Delta \bar{\nabla}_{1 / 2}\right)^{2}\right] / 2310$. Contudo, sabe-se que o valor experimental é normalmente $30-40 \%$ superior que o valor calculado pela expressão de Hush. ${ }^{70}$ Portanto, para se evitar que o valor de $\Delta E_{0}$ seja subestimado (o que provocaria uma diminuição no valor de $\Delta G^{*}$ e, conseqüentemente, um aumento na magnitude da constante de transferência de elétrons), o melhor é ernpregar as aproximações experimentais para se determinar o seu valor a partir da diferença de potenciais redox $\Delta E_{1 / 2}$, conforme procedimento adotado nesta tese;

${ }^{b} \Delta \mathrm{G}^{*}=\Delta \mathrm{G}^{*}-H_{\mathrm{ab}}$;

${ }^{\circ}$ Como as unidades de energia se encontram normalizadas pela quantidade de matéria (mol), então a constante de Boltzmann ( $k_{\mathrm{B}}$ ) deve ser substituída pela constante dos gases $(R)$ na Eq. 35 ;

${ }^{d}$ Embora o modelo clássico de Marcus-Hush possa, em princípio, ser aplicado na determinação de $k_{\mathrm{ET}}$ de todos os sistemas estudados, vale lembrar que, no caso dos sistemas de classes III ou II/II, a teoria de Hush não se aplica adequadamente na determinação de $H_{\mathrm{ab}}$, incluindo um erro intrínseco nos valores de $\Delta G^{*}$. No caso dos sistemas assimétricos, a maior fonte de incerteza em $k_{\mathrm{ET}}$ decorre da estimativa aproximada de $\Delta E_{0}$. 


\section{Referências}

1. Leigh, G. J., Ed. Nomenclature of Inorganic Chemistry: Recommendations 1990; International Union of Pure and Applied Chemistry; Blackwell Science; Cambridge, 1990.

2. Ferreira, A. M. C.; Toma, H. E.; Massabni, A. C. Quim. Nova 1984, 7, 9.

3. Cohen, E. R; Taylor, B. N. Rev. Mod Phys. 1987, 59, 1121.

4. DeLaeter, J. R. Pure Appl. Chem. 1991, 63, 975.

5. Adams, R. N. Electrochemistry at Solid Electrodes; Marcel Dekker; New York, 1969.

6. Bard, A. L.; Faulkner, L. R. Electrochemical Methods: Fundamentals and Applications; Wiley; New York, 1980.

7. Barbara, P. F.; Meyer, T. J.; Ratner, M. A. J. Phys. Chem. 1996, 100, 13148; e referências citadas.

8. Young, R. C.; Keene, F. R.; Meyer, T. J. J. Am. Chem. Soc. 1977, 99, 2468.

9. Bazhenova, T. A.; Lobkovskaya, R. M.; Shibaeva, R. P.; Shilov, A. E.; Shilova, A. K.; Gruselle, M.; LeNy, G.; Tchoubar, B. J. Organomet. Chem. 1983, 244, 265.

10. (a) Taube, H.; Myers, H.; Rich, R. L. J. Am. Chem. Sac. 1953, 75, 41 18. (b) Taube, H.; Myers, H. J. Am. Chem. Soc. 1954, 76, 2103.

11. Gordon, B. N.; Williams, L. L.; Sutin, N. J. Am. Chem. Soc. 1961, 83, 2061.

12. Creutz, C.; Taube, H. J. Am. Chem. Soc. 1969, 91, 3988.

13. Creutz, C.; Taube, H. J. Am. Chem. Soc. 1973, 95, 1086.

14. Fleischer, E. B.; Lavallee, D. K. J. Am. Chem. Soc. 1972, 94, 2599.

15. Tom, G. M.; Creutz, C.; Taube, H. J. Am. Chem. Soc. 1974, 96, 7828.

16. Sutton, J. E.; Sutton, P. M.; Taube, H. Inorg. Chem. 1979, $18,1017$.

17. Sutton, J. E.; Taube, H. Inorg. Chem. 1981, 20, 3125.

18. Marcus, R. A. Discuss. Faraday Soc. 1960, 21.

19. Marcus, R. A. Annu. Rev. Phys. Chem. 1964, 15, 155.

20. Marcus, R. A.; Sutin, N. Biochim. Biophys. Acta 1985, 811, 265.

21. Marcus, R. A. Angew. Chem., Int. Ed. Engl. 1993, 32, 1111.

22. (a) Hush, N. S. Trans. Faraday. Soc. 1961, 57, 557. (b) Hush, N. S. J. Electroanal. Chem. 1999, 460, 5.

23. Hush, N. S. Prog. Inorg. Chem. 1967, 8, 391.

24. Hush, N. S. Electrochim. Acta 1968, 13, 1005.

25. Hush, N. S. Coord. Chem. Rev. 1985, 64, 135.

26. (a) Dogonadze, R. R; Levich, V. G. Dokl. Akad. Nauk USSR 1959, 124, 123. (b) Dogonadze, R. R. Dokl. Akad Nauk USSR 1960, 1108. (c) Dogonadze, R. R. Dokl. Akad. Nauk USSR 1960, 1368. (d) Dogonadze, R. R.; Levich, V. G. Dokl. Akad. Nauk USSR 1960, I33, 158 (e) Levich, V. G. Adv. Electrochem. Electrochem. Eng. 1966, 4, 249.

27. (a) Rehm, D.; Weller, A. Isr. J. Chem. 1970, 8, 259. (b) Julliard, M.; Chanon, M. Chem. Rev. 1983, 83, 425.

28. Lewis, N. A. J. Chem. Educ. 1980, 57, 478.

29. (a) Taube, H. Adv. Inorg. Chem. Radiochem. 1959, I, 1. (b) Taube, H. J. Chem. Educ. 1968, 45, 452. (c) Taube, H.; Gould, E. S. Acc. Chem. Res. 1969, 2, 321. (d) Taube, H. Pure Appl. Chem. 1970, 24, 289. (e) Taube, H. Comment. Inorg. Chem. 1981, l, 17. (f) Taube, H. Angew. Chem., Int. Ed. Engl. 1984, 23, 329. (g) Taube, H. Science 1984, 226, 1028.

30. (a) Taube, H. In Mechanisms of Inorganic Reactions; Advances in Chemistry Series (14); American Chemical Society; Washington, DC, 1965, p 107. (b) Taube, H. Electron Transfer Reactions of Complex Ions in Solution; Academic Press; New York, 1970. (c) Taube, H. In Tunneling in Biological Systems; Chance, B., Devault, D. C., Frauenfelder, H., Marcus, R. A., Schrieffer, J. R., Sutin, N., Eds.; Academic Press; New York, 1979, p 173.

31. Taube, H. In Electron Transfer Reactions: Inorganic, Organometallic, and Biological Applications; Isied, S. S., Ed.; Advances in Chemistry Series (253); American Chemical Society; Washington, DC, 1997; Vol. 253, p 1.

32. (a) Haim, A.; Sutin, N. J. Am. Chem. Soc. 1965, 87, 4210. (b) Haim, A.; Sutin, N. J. Am. Chem. Soc. 1966, 88, 434. (c) Haim, A.; Sutin, N. J. Am. Chem. Soc. 1966, 88, 5343.

33. (a) Sutin, N. In Inorganic Biochemistry; Eichhorn, G. L., Ed; Elsevier; New York, 1973; Vol. 2, p 611. (b) Sutin, N. Acc. Chem. Res. 1982, 5, 275. (c) Sutin, N. Adv. Chem. Ser. 1991, 25. 
34. Sutin, N. Prog. Inorg. Chem. 1983, 30, 441.

35. Newton, M. D.; Sutin, N. Annu. Rev. Phys. Chem. 1984, 35, 437.

36. Brunschwig, B. S.; Sutin, N. Coord. Chem. Rev. 1999, 187, 233

37. (a) Haim, A. J. Am. Chem. Soc. 1963, 85, 1016. (b) Haim, A. J. Am. Chem. Soc. 1966, 88, 2324. (c) Haim, A. Inorg. Chem. 1966, 5, 2081. (d) Haim, A. Inorg. Chem. 1968, 7, 1475. (e) Haim, A. Inorg. Chem. 1970, 9, 426. (f) Haim, A. Acc. Chem. Res. 1975, 8, 264. (g) Haim, A. Prog. Inorg. Chem. 1983, 30, 273.

38. Haim, A. Adv. Chem. Ser. 1997, 253, 239.

39. (a) Ram, M. S.; Haim, A. Inorg. Chem. 1991, 30, 1319. (b) de Oliveira, L. A. A.; Dellaciana, L.; Haim, A. Inorg. Chim. Acta 1994, $225,129$.

40. Kochi, J. K. Angew. Chem., Int. Ed. Engl. 1988, 27, 1227; e referências citadas.

41. (a) Mulliken, R. S. J. Am. Chem. Soc. 1950, 72, 600. (b) Mulliken, R. S. J. Am. Chem. Soc. 1952, 64, 811. (c) Mulliken, R. S.; Person, W. B. Molecular Complexes; Wiley; New York, 1969.

42. (a) Turro, N. J. Modem Molecular Photochemistry; Benjamin/Cummings; California, 1978; Cap. 9. (b) Sutin, N.; Creutz, C. Pure Appl. Chem. 1980, 52, 2717. (c) Kavarnos, G. J.; Turro, N. J. Chem. Rev. 1986, 86, 401.

43. Meyer, T. J. Prog. Inorg. Chem. 1983, 30, 389.

44. (a) Balzani, V., Ed. Supramolecular Chemistry; Reidel; Dordrecht, 1987. (b) Balzani, V.; Scandola, F. Supramolecular Chemistry; Ellis-Hordwood; New York, 1991.

45. Fox, A. M.; Chanon, M., Eds. Photoinduced Electron Transfer; Elsevier; Amsterdam, 1988.

46. Juris, A.; Balzani, V.; Barigelletti, F.; Belser, P.; von Zelewsky, A. Coord. Chem. Rev. 1988, 84, 85; e referências citadas.

47. Balzani, V.; Scandola, F. Supramolecular Photochemistry; Ellis-Horwood; Chichester, UK; 1991.

48. (a) Ulstrup, J.; Jortner, J. Chem. Phys. 1975, 63, 4358. (b) Jortner, J. J. Chem. Phys. 1976, 64, 4860. (c) Hopfield, J. J. Biophys. J. 1977, 18, 311.

(d) Beratan, D. N.; Onuchic, J. N. Adv. Chem. Ser. 1991, 71. (e) Beratan, D. N.; Betts, J. N.; Onuchic, J. N. Science 1991, $252,1285$. (f) Balabin, I. A.; Onuchic, J. N. J. Phys. Chem. 1996, 100, 11573. (g) Gehlen, J. N.; Daizadeh, I.; Stuchebrukhov, A. A.; Marcus, R. A. Inorg. Chim. Acta 1996, 243, 271. (h) Lopezcastillo, J. M.; Jaygerin, J. P. J. Phys. Chem. 1996, 100, 14289. (i) Amaut, L. G.; Formosinho, S. J. J. Photochem. Photobiol., A 1997, 111, 111. (j) Kharkats, Y. I.; Ulstrup, J. Chem. Phys. Lett. 1999, 303, 320.

49. Chance, B.; Devault, D. C.; Frauenfelder, H.; Marcus, R. A.; Schrieffer, J. R.; Sutin, N., Eds. Tunneling in Biological Systems; Academic Press; New York, 1979.

50. (a) Wherland, S.; Gray, H. B. Proc. Natl. Acad. Sci. U. S. A. 1976, 73, 2950. (b) Addison, A. W.; Cullen, W. R.; Dolphin, D.; James, B. R., Eds. Biological Aspects of Inorganic Chemistry; Wiley; New York, 1977. (c) Isied, S. S. Prog. Inorg. Chem. 1984, 32, 443. (d) Johnson, M. K.; King, R. B.; Kurtz, D. M.; Kutal, C.; Norton, M. L.; Scott, R. A., Eds. Electron Transfer in Biology and the Solid State: Inorganic Compounds with Umusual Properties; Advances in Chemistry Series (226); American Chemical Society; Washington, DC, 1990. (e) Therien, M. J.; Chang, J.; Raphael, A. L.; Bowler, B. E.; Gray, H. B. Structure and Bonding 1991, 75, 109. (f) Lloyd, E.; Chapman, K.; Chapman, S. K.; Jia, Z. S.; Lim, M. C.; Tomkinson, N. P.; Salmon, G. A.; Sykes, A. G. J. Chem. Soc., Dalton Trans. 1994, 675. (g) Scott, J. R.; Fairris, J. L.; Mclean, M.; Wang, K. F.; Sligar, S. G.; Durham, B.; Millett, F. Inorg. Chim. Acta 1996, 243, 193. (h) Gray, H. B.; Winkler, J. R. J. Electroanal. Chem. 1997, 438, 43. (i) Harris, M. R.; Davis, D. J.; Durham, B.; Millett, F. Biochim. Biophys. Acta 1997, 1319, 147. (j) Isied, S. S. In Electron Transfer Reactions: Inorganic, Organometallic, and Biological Applications; Isied, S. S., Ed.; Advances in Chemistry Series (253); American Chemical Society; Washington, DC, 1997, p 331. (k) Sun, J.; Wishart, J. F. Inorg. Chem. 1998, 37, 1124. (l) Malmstrom, B. G.; Wittung-Stafshede, P. Coord. Chem. Rev. 1999, 186, 127. (m) Wilker, J. J.; Dmochowski, I. J.; Dawson, J. H.; Winkler, J. R.; Gray, H. B. Angew. Chem., Int. Ed. Engl. 1999, 38, 90.

51. Bolton, J. R.; Mataga, N.; McLendon, G., Eds. Electron Transfer in Inorganic, Organic, and Biological Systems; Advances in Chemistry Series (228); American Chemical Society; Washington, DC, 1991.

52. Gray, H. B.; Winkler, J. R. Annu. Rev. Biochem. 1996, 65, 537.

53. (a) Turro, N. J.; Barton, J. K.; Tomalia, D. A. Acc. Chem. Res. 1991, 24, 332. (b) Arkin, M. R.; Stemp, E. D. A.; Turro, C.; Turro, N. J.; Barton, J. K. J. Am. Chem. Soc. 1996, 118, 2267. (c) Kirschdemesmaeker, A.; Lecomte, J. P.; Kelly, J. M. Top. Curr. Chem. 1996, 177, 25. (d) Turro, C.; Evenzahav, A.; Bossmann, S. H.; Barton, J. K.; Turro, N. J. Inorg. Chim. Acta 1996, 243, 101. (e) Hall, D. B.; Barton, J. K. J. Am. Chem. Soc. 1997, 119, 5045. (f) Netzel, T. L. J. Chem. Educ. 1997, 74, 646. (g) Stemp, E. D. A.; Arkin, M. R.; Barton, J. K. J. Am. Chem. Soc. 1997, 119, 2921. (h) Xiong, Y.; Ji, L. N. Coord. Chem. Rev. 1999, 186, 711. (i) Stemp, E. D. A.; Holmlin, R. E.; Barton, J. K. Inorg. Chim. Acta 2000, 297, 88

54. Stemp, E. D. A.; Barton, J. K. Met. Ions Biol. Syst. 1996, 33, 325. 
55. Clarke, M. J. In Electron Transfer Reactions: Inorganic, Organometallic, and Biological Applications; Isied, S. S., Ed.; Advances in Chemistry Series (253); American Chemical Society; Washington, DC, 1997, p 349.

56. Ulstrup, J. Charge Transfer Processes in Condensed Media; Springer-Verlag; Berlin, 1979.

57. (a) Cannon, R. D. Electron Transfer Reactions; London, 1980. (b) Eberson, L. Electron Transfer Reactions in Organic Chemistry; Berlin, 1987. (c) Astruc, D. Electron Transfer and Radical Processes in Transition Metal Chemistry; VCH; New York, 1995.

58. Kavarnos, G. J. Fundamentals of Photoinduced Electron Transfer; VCH; New York, 1993.

59. Hush, N. S. J. Electroanal. Chem. 1999, 470, 170.

60. Piepho, S. B.; Krausz, E. R.; Schatz, P. N. J. Am. Chem. Soc. 1978, 100, 6319

61. Piepho, S. B.; Krausz, E. R.; Schatz, P. N. J. Am. Chem. Soc. 1978, 100, 2996.

62. (a) Wong, K. Y.; Schatz, P. N.; Piepho, S. B. J. Am. Chem. Soc. 1979, 101, 2793. (b) Piepho, S. B. Nouv. J. Chim. 1980, 4, 639. (c) Schatz, P. N. In Mixed-Valence Compounds; Brown, D. B., Ed.; Proceedings of the NATO Advanced Study Institute (58); D. Reidel Pub. Co.; Dordrecht, Holland, 1980, p 115. (d) Wong, K. Y.; Schatz, P. N. Prog. Inorg. Chem. 1981, 28, 369. (e) Reimers, J. R.; Hush, N. S. Chem. Phys. 1996, 208, 177. (f) Boukheddaden, K.; Varret, F. Chem. Phys. 1997, 216, 373. (g) Rezvani, A. R.; Bensimon, C.; Cromp, B.; Reber, C.; Greedan, J. E.; Kondratiev, V. V.; Crutchley, R. J. Inorg. Chem. 1997, 36, 3322. (h) Borras-Almenar, J. J.; Coronado, E.; Ostrovsky, S. M.; Palii, A. V.; Tsukerblat, B. S. Chem. Phys. 1999, 240, 149.

63. Piepho, S. B. J. Am. Chem. Soc. 1990, 112, 4197.

64. (a) Mayoh, B.; Day, P. J. Am. Chem. Soc. 1972, 94, 2885. (b) Mayoh, B.; Day, P. Inorg. Chem. 1974, 13, 2273. (c) Ratner, M.; Ondrechen, M. Mol. Phys. 1976, 32, 1233. (d) Lauher, J. Inorg. Chim. Acta 1980, 39, 119. (e) Burdett, J. E. Comment. Inorg. Chem. $1981,1,85$.

65. Zhang, L.-T.; Ko, J.; Ondrechen, M. J. J. Phys. Chem. 1989, 93, 3030.

66. Brown, D. B., Ed. Mixed-Valence Compounds: Theory and Applications in Chemistry, Physics, Geology, and Biology; Proceedings of the NATO Advanced Study Institute; D. Reidel Pub. Co; Dordrecht, Holland, 1980.

67. Goffer, Z. Archaeological Chemistry; Wiley; New York, 1980.

68. Robin, M. B.; Day, P. Adv. Inorg. Chem. Radiochem. 1967, 10, 247.

69. Allen, G. C.; Hush, N. S. Prog. Inorg. Chem. 1967, 8, 357.

70. Creutz, C. Prog. Inorg. Chem. 1983, $30,1$.

71. Crutchley, R. J. Adv. Inorg. Chem. Rad. 1994, 41, 273.

72. Ward, M. D. Chem. Soc. Rev. 1995, 24, 121.

73. Woodward, J. Philos. Trans. Roy. Soc. London 1724, 33, 15.

74. (a) Cowan, D. O.; Levanda, C.; Park, J.; Kaufman, F. Acc. Chem. Res. 1973, 6, 1. (b) Cowan, D. O.; Kaufman, F. J. Am. Chem. Soc. 1977, 99 , 6623.

75. Haim, A. In Electron Transfer Reactions: Inorganic, Organometallic, and Biological Applications; Isied, S. S., Ed.; Advances in Chemistry Series (253); American Chemical Society; Washington, DC, 1997, p 239.

76. (a) Shepherd, R. E.; Chen, Y.; Zhang, S. S.; Lin, F. T.; Kortes, R. A. In Electron Transfer Reactions: Inorganic, Organometallic, and Biological; Isied, S. S., Ed.; Advances in Chemistry Series (253); American Chemical Society; Washington, DC, 1997 ; Vol. 253, p 367. (b) Aquino, M. A. S. Coord. Chem. Rev. 1998, 170, 141. (c) Chatterjee, D. Coord. Chem. Rev. 1998, 168, 273.

77. Wu, Y.; Pfennig, B. W.; Sharp, S. L.; Ludwig, D. R.; Warren, C. J.; Vicenzi, E. P.; Bocarsly, A. B. Coord. Chem. Rev. 1997, $159,245$.

78. Hicks, C.; Fan, J. W.; Rutenberg, I.; Gafney, H. D. Coord. Chem. Rev. 1998, 171, 71.

79. Garcia, C. G.; De Lima, J. F.; Tha, N. Y. M. Coord Chem. Rev. 2000, 196, 219; e referências citadas.

80. (a) Batista, A. A.; Porcu, O. M.; Nascimento, O. R.; Barbosa, V. M.; Oliva, G. J. Coord. Chem. 1993, 30, 345. (b) Yeomans, B. D.; Humphrey, D. G.; Heath, G. A. J. Chem. Soc., Dalton Trans. 1997, 4153. (c) Dinelli, L. R.; Batista, A. A; Wohnrath, K.; de Araujo, M. P.; Queiroz, S. L.; Bonfadini, M. R.; Oliva, G.; Nascimento, O. R.; Cyr, P. W.; MacFarlane, K. S.; James, B. R. Inorg. Chem. 1999, 38, 5341. (d) Wohnrath, K.; de Araujo, M. P.; Dinelli, L. R.; Batista, A. A.; Moreira, I. D.; Castellano, E. E.; Ellena, J. J. Chem. Soc., Dalton Trans. $2000,3383$.

81. Laidlaw, W. M.; Denning, R. G. J. Chem. Soc., Dalton Trans. 1994, 1987.

82. Balzani, V.; Juris, A.; Venturi, M.; Campagna, S.; Serroni, S. Chem. Rev. 1996, 96, 759; e referências citadas.

83. Elliott, C. M.; Der, D. L.; Ferrere, S.; Newton, M. D.; Liu, Y. P. J. Am. Chem. Soc. 1996, 118, 5221.

84. De Cola, L.; Belser, P. Coord. Chem. Rev. 1998, 177, 301.

85. Joulié, L. F.; Schatz, E.; Ward, M. D.; Weber, F.; Yellowlees, L. J. J. Chem. Soc., Dalton Trans. 1994, 799.

86. Whittle, B.; Everest, N. S.; Howard, C.; Ward, M. D. Inorg. Chem. 1995, 34, 2025. 
87. (a) Ward, M. D. Inorg. Chem. 1996, 35, 1712. Keyes, T. E.; Forster, R. J.; Jayaweera, P. M.; Coates, C. G.; McGarvey, J. J.; Vos, J. G. Inorg. Chem. 1998, 37, 5925. (b) Shukla, A. D.; Whittle, B.; Bajaj, H. C.; Das, A.; Ward, M. D. Inorg. Chim. Acta 1999, $285,89$.

88. (a) Sedney, D.; Ludi, A. Inorg. Chim. Acta 1981, 47, 153. (b) Constantino, V. R. L.; de Oliveira, L. F. C.; Santos, P. S.; Toma, H. E. Transition Met. Chem. 1994, 19, 103. (c) Rawson, J. M.; Winpenny, R. E. P. Coord. Chem. Rev. 1995, 139, 313. (d) Das, N. N.; Das, R. Polyhedron 1997, 16,2135 .

89. Chou, M. H.; Creutz, C.; Sutin, N. Inorg. Chem. 1992, 31, 2318.

90. Rein, F. N.; Toma, H. E. Polyhedron 1998, 17, 1439.

91. (a) Matsumoto, K.; Matsumoto, T.; Kawano, M.; Ohnuki, H.; Shichi, Y.; Nishide, T.; Sato, T. J. Am. Chem. Soc. 1996, 118, 3597. (b) Moreira, L. D.; Franco, D. W. Adv. Chem. Ser. 1997, 253, 255. (c) Samanta, R.; Munshi, P.; Santra, B. K.; Lahiri, G. K. Polyhedron 1999, $18,995$.

92. Moreira, I. D.; De Lima, J. B.; Franco, D. W. Coord. Chem. Rev. 2000, 196, 197.

93. Moreira, I. S.; Franco, D. W. In Electron Transfer Reactions: Inorganic, Organometallic, and Biological Applications; Isied, S. S., Ed; Advances in Chemistry Series (253); American Chemical Society; Washington, DC, 1997, p 255.

94. Toma, H. E.; Araki, K. Coord. Chem. Rev. 2000, 196, 307.

95. (a) Frank, M.; Nieger, M.; Vogtle, F.; Belser, P.; Vonzelewsky, A.; Decola, L.; Balzani, V.; Barigelletti, F.; Flamigni, L. Inorg. Chim. Acta 1996, 242, 281. (b) Collin, J. P.; Gavina, P.; Heitz, V.; Sauvage, J. P. Eur. J. Inorg. Chem. 1998, 1. (c) Demadis, K. D.; E1-Samanody, E. S.; Coia, G. M.; Meyer, T. J. J. Am. Chem. Soc. 1999, 121, 535.

96. Seddon, E. A.; Seddon, K. R. In The Chemistry of Ruthenium; Clark, R. J. H., Ed.; Elsevier Science Pub.; Amsterdam, 1984.

97. Jortner, J.; Pullman, B., Eds. Tunneling; Reidel; Dordrecht, 1986.

98. (a) Szabo, A.; Ostlund, N. S. Modern Quantum Chemistry: Introduction to Advanced Electronic Structure Theory; McGraw-Hill; New York, 1989. (b) Levine, I. N. Quantum Chemistry, $4^{\text {a }}$ ed.; Prentice-Hall; Englewood Cliffs, 1991

99. (a) Lowe, J. P. Quantum Chemistry; Academic Press; Boston, 1993. (b) Schatz, G. C.; Ratner, M. A. Quantum Mechanics in Chemistry; Prentice-Hall; Englewood Cliffs, 1993.

100. Atkins, P. W.; Friedman, R. S. Molecular Quantum Mechanics; 3rd ed.; Oxford University Press; Oxford, 1997.

101. Richardson, D. E.; Taube, H. Coord. Chem. Rev. 1984, 60, 107.

102. Richardson, D. E.; Taube, H. Inorg. Chem. 1981, 20, 1278.

103. Kaim, W.; Kasack, V. Inorg. Chem. 1990, 29, 4696

104. (a) Karki, L.; Lu, H. P.; Hupp, J. T. J. Phys. Chem. 1996, 100, 15637. (b) Bublitz, G. U.; Boxer, S. G. Annu. Rev. Phys. Chem. 1997, 48, 213. (c) Bublitz, G. U.; Laidlaw, W. M.; Denning, R. G.; Boxer, S. G. J. Am. Chem. Soc. 1998, 120, 6068. (d) Vance, F. W.; Slone, R. V.; Stern, C. L.; Hupp, J. T. Chem. Phys. 2000, 253, 313.

105. Marcus, R. A.; Sutin, N. Comment. Inorg. Chem. 1986, 5, 119.

106. (a) Libby, W. F. J. Phys. Chem. 1952, 56, 863. (b) Libby, W. F. J. Chem. Phys. 1963, 38, 420.

107. Cannon, R. D. Chem. Phys. Lett. 1977, 49, 299.

108. Hupp, J. T.; Neyhart, G. A.; Meyer, T. J. J. Am. Chem. Soc. 1986, $108,5349$.

109. Neyhart, G. A.; Hupp, J. T.; Curtis, J. C.; Timpson, C. J.; Meyer, T. J. J. Am. Chem. Soc. 1996, 118, 3724.

110. (a) Toma, H. E.; Takasugi, M. S. J. Solution Chem. 1983, 12, 547. (b) Toma, H. E.; Takasugi, M. S. J. Solution Chem. $1989,18,575$.

111. Toma, H. E.; Takasugi, M. S. Polyhedron 1989, 8,941.

112. Timpson, C. J.; Bignozzi, C. A.; Sullivan, B. P.; Kober, E. M.; Meyer, T. J. J. Phys. Chem. 1996, 100, 2915.

113. (a) Mayer, U.; Gutmann, V.; Gerger, W. Monatsh. Chem. 1975, 106, 1235. (b) Gutmann, V. Electrochim. Acta 1976, 21, 661. (c) Gutmann, V. The Donor-Acceptor Approach to Molecular Interactions; Plenum; New York, 1980. (d) Gutmann, V.; Resch, G.; Linert, W. Coord. Chem. Rev. 1982, 43, 133 .

114. (a) Stranks, D. R. Discuss. Faradoy Soc. 1960, 29, 73. (b) Meyer, T. J.; Taube, H. Inorg. Chem. 1968, 7, 2369. (c) Endicott, J. F.; Kumar, K.; Ramasami, T.; Rotzinger, F. P. Prog. Inorg. Chem. 1983, 30, 141. (d) Cotton, F. A.; Wilkinson, G. Advanced Inorganic Chemistry; $5^{\mathrm{B}}$ ed.; Wiley; New York, 1987; p 1308.

115. Hupp, J. T.; Neyhart, G. A.; Meyer, T. J.; Kober, E. M. J. Phys. Chem. 1992, 96, 10820.

116. Powers, M. J.; Meyer, T. J. J. Am. Chem. Soc. 1978, 100, 4393.

117. Brunschwig, B. S.; Ehrenson, S.; Sutin, N. J. Phys. Chem. 1986, 90, 3657.

118. Sullivan, B. P.; Curtis, J. C.; Kober, E. M.; Meyer, T. J. Nouv. J. Chim. 1980, 4, 643.

119. Neyhart, G. A.; Timpson, C. J.; Bates, W. D.; Meyer, T. J. J. Am. Chem. Soc. 1996, 118, 3730 
120. Curtis, J. C.; Sullivan, B. P.; Meyer, T. J. Inorg. Chem. 1983, 22, 224.

121. Blackbourn, R. L.; Hupp, J. T. J. Phys. Chem. 1988, 92, 2817.

122. Kober, E. M.; Goldsby, K. A.; Narayana, D. N. S.; Meyer, T. J. J. Am. Chem. Soc. 1983, 105, 4303.

123. Nelsen, S. F.; Adamus, J.; Wolff, J. J. Am. Chem. Soc. 1994, 116, 1589.

124. Dubicki, L.; Ferguson, J.; Krausz, E. R. J. Am. Chem. Soc. 1985, 107, 179.

125. (a) Joachim, C.; Launay, J.-P. Chem. Phys. 1986, 109, 93. (b) Webb, R. J. H., P. M.; Wittebort, R. J.; Sorai, M.; Hendrickson, D. N. Inorg. Chem. 1992, 31, 1791. (c) Dong, T.-Y.; Huang, C.-H.; Chang, C.-K.; Wen, Y.-S.; Lee, S.-L.; Chen, J.-A.; Yeh, W.-Y.; Yeh, A. J. Am. Chem. Soc. 1993, 115, 6357. (d) Das, A.; Maher, J. P.; McCleverty, J. A.; Badiola, J. A.; Ward, M. D. J. Chem. Soc., Dalton Trans. $1993,681$. (e) Pierce, D. T.; Geiger, W. E. Inorg. Chem. 1994, 33, 373.

126. Woitellier, S.; Joachim, C.; Launay, J.-P. Chem. Phys. 1989, 131, 481.

127. Metcalfe, R. A.; Dodsworth, E. S.; Lever, A. B. P.; Pietro, W. J.; Stufkens, D. J. Inorg. Chem. 1993, 32, 3581.

128. Lindoy, L. F. The Chemistry of Macrocyclic Ligand Complexes; CUP; 1989; 117.

129. (a) Archut, A.; Azzellini, G. C.; Balzani, V.; De Cola, L.; Vogtle, F. J. Am. Chem. Soc. 1998, 120, 12187. (b) Vogtle, F.; Plevoets, M.; Nieger, M.; Azzellini, G. C.; Credi, A.; De Cola, L.; De Marchis, V.; Venturi, M.; Balzani, V. J. Am. Chem. Soc. 1999, I2I, 6290.

130. Archut, A.; Vogtle, F.; De Cola, L.; Azzellini, G. C.; Balzani, V.; Ramanujam, P. S.; Berg, R. H. Chem.-Eur. J. $1998,4,699$.

131. (a) Neyhart, G. A.; Meyer, T. J. Inorg. Chem. 1986, 2S, 4808. (b) Loeb, B. L.; Neyhart, G. A.; Worl, L. A.; Danielson, E.; Sullivan, B. P.; Meyer, T. J. J. Phys. Chem. 1989, 93, 717.

132. (a) Launay, J.-P.; Tourrelpagis, M.; Lipskier, J. F.; Marvaud, V.; Joachim, C. Inorg. Chem. 1991, 30, 1033. (b) Marvaud, V.; Launay, J. P. Inorg. Chem. 1993, 32, 1376.

133. Haga, M.; Ano, T.; Kano, K.; Yamabe, S. Inorg. Chem. 1991, 30, 3843.

134. (a) Lewis, N. A.; Obeng, Y. S. J. Am. Chem. Soc. 1989, 111, 7624. (b) Roberts, J. A.; Hupp, J. T. Inorg. Chem. 1992, 31, 157. (c) Hupp, J. T.; Dong, Y. Inorg. Chem. 1994, 33, 4421.

135. Zhang, X. K.; Kankel, C. R.; Hupp, J. T. Inorg. Chem. 1994, 33, 4738.

136. Naklicki, M. L.; Crutchley, R. J. Inorg. Chim. Acta 1994, 225, 123.

137. Sauvage, J. P.; Collin, J. P.; Chambron, J. C.; Guillerez, S.; Coudret, C.; Balzani, V.; Barigelletti, F.; Decola, L.; Flamigni, L. Chem. Rev. 1994, 94, 993.

138. (a) Barigelletti, F; Flamigni, L.; Balzani, V.; Collin, J.-P.; Sauvage, J.-P.; Sour, A.; Constable, E. C.; Thompson, A. M. W. C. J. Am. Chem. Soc. 1994, 116, 7692. (b) Wagner, R. W.; Lindsey, J. S. J. Am. Chem. Soc. 1994, 116, 9759.

139. De Cola, L.; Balzani, V.; Barigelletti, F.; Flamigni, L.; Belser, P.; von Zelewski, A.; Frank, M.; Vögtle, F. Inorg. Chem. $1993,32,5228$.

140. (a) Bissell, R. A.; de Silva, A. P.; Gunaratne, H. Q. N.; Lynch, P. L. M.; Maguire, G. E. M.; Sandanayake, K. R. A. S. Chem. Soc. Rev. 1992, 187. (b) Goulle, V.; Harriman, A.; Lehn, J.-M. J. Chem. Soc., Chem. Commun. 1993, 1034.

141. (a) Carter, F. L., Ed. Molecular Electronics; Marcel Dekker; New York, 1987. (b) Bard, A. J. Integrated Chemical Systems: A Chemical Approach to Nanotechnology; Wiley; New York, 1994. (c) Astruc, D. Acc. Chem. Res. 1997, 30, 383. (d) Aviram, A.; Ratner, M., Eds. Molecular Electronics: Science and Technology; Annals of The New York Academy of Sciences (852); The New York Academy of Sciences; New York, 1998. (e) Ziessel, R.; Hissler, M.; El-Ghayoury, A.; Harriman, A. Coord Chem. Rev. 1998, 180, 1251. (f) Tour, J. M.; Kozaki, M.; Seminario, J. M. J. Am. Chem. Soc. 1998, 120, 8486.

142. Petty, M. C.; Bryce, M. R.; Bloor, D., Eds. An Introduction to Molecular Electronics; Oxford University Press; New York, 1995.

143. Balzani, V.; Credi, A.; Venturi, M. Coord. Chem. Rev. 1998, 171, 3.

144. Harriman, A.; Ziessel, R. Coord Chem. Rev. 1998, 171, 331.

145. (a) De Silva, A. P.; Gunaratne, H. Q. N.; Gunnlaugsson, T.; Huxley, A. J. M.; Mccoy, C. P.; Rademacher, J. T.; Rice, T. E. Chem. Rev. 1997, 97, 1515. (b) Stufkens, D. J.; Vlcek, A. Coord. Chem. Rev. 1998, 177, 127. (c) De Silva, A. P.; Fox, D. B.; Huxley, A. J. M.; Mcclenaghan, N. D.; Roiron, J. Coord. Chem. Rev. 1999, 186, 297.

146. Kalyanasundaram, K.; Gratzel, M. Coord Chem. Rev. 1998, 177, 347.

147. Beer, P. D.; Gale, P. A.; Chen, G. Z. Coord. Chem. Rev. 1999, 186, 3.

148. (a) Edmonds, T. E. Chemical Sensors; Blackie; Glasgow, UK, 1988. (b) Dürr, H.; Bouras-Laurent, H., Eds. Photochromism: Molecules and Systems; Elsevier; Amsterdam, 1990. (c) Kahn, O. Molecular Magnetism, Chapter 4; VCH; New York, 1993. (d) Czarnik, A. W. Acc. Chem. Res. 1994, 27, 302. (e) James, T. J.; Limnane, P.; Shinkai, S. Chem. Commun. 1996, 281. (f) Atwood, J. L.; Holman, K. T.; Steed, J. W. Chem. Commun. 1996, 1401. 
149. (a) Lehn, J.-M. Angew. Chem., Int. Ed. Engl. 1988, 27, 89. (b) Lehn, J.-M. Angew. Chem., Int. Ed Engl. 1990, $29,1304$.

150. (a) Miller, J. S. Adv. Mater. 1990, 2, 378. (b) Miller, J. S. Adv. Mater. 1990, 2, 495. (c) Miller, J. S. Adv. Mater. 1990, 2, 601. (d) Vonzelewsky, A.; Belser, P.; Hayoz, P.; Dux, R.; Hua, X.; Suckling, A.; Stoecklievans, H. Coord Chem. Rev. 1994, 132, 75. (e) Philp, D.; Stoddart, J. F. Angew. Chem., Int. Ed. Engl. 1996, 35, 1155. (f) Ashton, P. R; Ballardini, R.; Balzani, V.; Constable, E. C.; Credi, A.; Kocian, O.; Langford, S. J.; Preece, J. A.; Prodi, L.; Schofield, E. R; Spencer, N. Chem.-Eur. J. 1998, 4, 2413. (g) Chambron, J. C.; Sauvage, J. P. Chem.-Eur. J. 1998, 4, 1362. (h) Fox, M. A. Acc. Chem. Res. 1999, 32, 201. (i) Belser, P.; Bernhard, S.; Blum, C.; Beyeler, A.; De Cola, L.; Balzani, V. Coord Chem. Rev. 1999, 192, 155

151. Giuffrida, G.; Campagna, S. Coord. Chem. Rev. 1994, 135, 517.

152. Toma, H. E. An. Acad. Bras. Cienc. 2000, 72, 1.

153. (a) Schneider, J.; Dür, H., Eds. Frontiers in Supramolecular Organic Chemistry and Photochemistry; VCH; Weinheim, Germany, 1991. (b) Vögtle, F. Supramolecular Chemistry; Wiley; Chichester, UK, 1991. (c) Fabbrizzi, L.; Poggi, A., Eds. Transition Metals in Supramolecular Chemistry; Kluwer; Dordrecht, 1994. (d) Zeng, F. W.; Zimmerman, S. C. Chem. Rev. 1997, 97, 1681. (e) Boulas, P. L.; Gomez-Kaifer, M.; Echegoyen, L. Angew. Chem., Int. Ed. Engl. 1998, 37, 216. (f) Flamigni, L.; Barigelletti, F.; Armaroli, N.; Collin, J. P.; Sauvage, J. P.; Williams, J. A. G. Chem.-Eur. J. 1998, 4, 1744. (g) Kumar, R. K.; Goldberg, I. Angew. Chem., Int. Ed. Engl. 1998, 37, 3027. (h) Ward, M. D.; White, C. M.; Barigelletti, F.; Armaroli, N.; Calogero, G.; Flamigni, L. Coord. Chem. Rev. 1998, 171, 481. (i) Willner, I.; Kaganer, E.; Joselevich, E.; Durr, H.; David, E.; Gunter, M. J.; Johnston, M. R. Coord. Chem. Rev. 1998, 171, 261. (j) Ballester, L.; Gutierrez, A.; Perpinan, M. F.; Azcondo, M. T. Coord. Chem. Rev. 1999, 192, 447. (k) Kaschak, D. M.; Johnson, S. A.; Waraksa, C. C.; Pogue, J.; Mallouk, T. E. Coord. Chem. Rev. 1999, 186, 403. (1) Macdonnell, F. M.; Kim, M. J.; Bodige, S. Coord. Chem. Rev. 1999, 186, 535.

154. Atwood, J. L.; Davies, J. E. D.; Macnicol, D. D.; Vögtle, F., Eds. Comprehensive Supramolecular Chemistry; Pergamon; Oxford, 1996.

155. Venturi, M.; Credi, A.; Balzani, V. Coord. Chem. Rev. 1999, 186, 233.

156. Lehn, J.-M. Supramolecular Chemistry: Concepts and Perspectives; VCH; Weinheim, 1995.

157. Ward, M. D. Chem. Ind 1997, 640.

158. Launay, J.-P.; Coudret, C. Ann. N. Y. Acad. Sci. 1998, 852, 116.

159. (a) Reimers, J. R.; Hush, N. S. Inorg. Chem. 1990, 29, 3686. (b) Reimers, J. R.; Hush, N. S. J. Phys. Chem. A 1999, $103,3066$.

160. (a) Ribou, A.-C.; Launay, J.-P.; Takahashi, K.; Nihira, T.; Tarutani, S.; Spangler, C. W. Inorg. Chem. 1994, 33, 1325. (b) Fraysse, S.; Coudret, C.; Launay, J.-P. Eur. J. Inorg. Chem. 2000, 1581.

161. Masui, H.; Freda, A. L.; Zerner, M. C.; Lever, A. B. P. Inorg. Chem. 2000, 39, 141.

162. Haga, M. A.; Ali, M. M.; Koseki, S.; Fujimoto, K.; Yoshimura, A.; Nozaki, K.; Ohno, T.; Nakajima, K.; Stufkens, D. J. Inorg. Chem. 1996, 35, 3335.

163. Chao, H.; Ye, B. H.; Zhang, Q. L.; Ji, L. N. Inorg. Chem. Commun. 1999, 2, 338.

164. Hossain, M. D.; Ueno, R.; Haga, M. Inorg. Chem. Commun. 2000, 3, 35.

165. (a) Lowery, M. D.; Hammack, W. S.; Drickamer, H. G.; Hendrickson, D. N. J. Am. Chem. Soc. 1987, 109, 8019. (b) Curtis, J. C.; Roberts, J. A.; Blackbourn, R. L.; Dong, Y. H.; Massum, M.; Johnson, C. S.; Hupp, J. T. Inorg. Chem. 1991, 30, 3856. (c) Dong, Y.; Hupp, J. T.; Yoon, D. I. J. Am. Chem. Soc. 1993, 115, 4379. (d) Lau, K. W.; Hu, A. M.-H.; Yen, M. H.-J.; Fung, E. Y.; Grzybicki, S.; Matamoros, R.; Curtis, J. C. Inorg. Chim. Acta 1994, 226, 137.

166. Coia, G. M.; Demadis, K. D.; Meyer, T. J. Inorg. Chem. 2000, 39, 2212.

167. Crossley, M. J.; Burn, P. L. J. Chem. Soc., Chem. Commun. 1991, 1569.

168. (a) Woitellier, S.; Launay, J.-P.; Spangler, C. W. Inorg. Chem. 1989, 28, 758. (b) Tour, J. M.; Wu, R.; Schumm, J. S. J. Am. Chem. Soc. 1991, 113, 7064. (c) Kugimiya, S.; Lazrak, T.; Blanchard-Desce, M.; Lehn, J.-M. J. Chem. Soc., Chem. Commun. 1991, 1179. (d) Thomas, J. A.; Jones, C. J.; McCleverty, J. A.; Collison, D.; Mabbs, F. E.; Harding, C. J.; Hutchings, M. G. J. J. Chem. Soc., Chem. Commun. $1992,1796$.

169. (a) Mock, W. L.; Pierpont, J. J. Chem. Soc., Chem. Commun. 1990, 1509. (b) Saika, T.; Iyoda, T.; Honda, K.; Shimidzu, T. J. Chem. Soc., Chem. Commun. 1992, 591. (c) Newell, A. K.; Utley, J. H. P. J. Chem. Soc., Chem. Commun. 1992, 800. (d) Vögtle, F.; Müller, W. M.; Müller, U.; Bauer, M.; Rissanen, K. Angew. Chem., Int. Ed. Engl. 1993, 32, 1295. (e) Gilat, S. L.; Kawai, S. H.; Lehn, J.-M. J. Chem. Soc. $1993,1439$.

170. (a) Rebek, J. Acc. Chem. Res. 1984, 17, 258. (b) Gourdon, A. New J. Chem. 1992, 16, 953.

171. Goldhaber-Gordon, D.; Montemerlo, M. S.; Love, J. C.; Opitek, G. J.; Ellenbogen, J. C. Proc. IEEE 1997, 85, 521.

172. (a) Joachim, C. New J. Chem. 1991, 15, 223. (b) Samanta, M. P.; Tian, W.; Datta, S.; Henderson, J. I.; Kubiak, C. P. Phys. Rev. B: Condens. Matter 1996, 53, R7626. (c) Magoga, M.; Joachim, C. Phys. Rev. B: Condens. Matter 1998, 57, 1820. 
173. Andres, R. P.; Bein, T.; Dorogi, M.; Feng, S.; Henderson, J. I.; Kubiak, C. P.; Mahoney, W.; Osifchin, R. G.; Reifenberger, R. Science 1996, $272,1323$.

174. (a) Dhirani, A.-A.; Zehner, R. W.; Hsung, R. P.; Guyot-Sionnest, P.; Sita, L. R. J. Am. Chem. Soc. 1996, 118, 3319. (b) Bumm, L. A.; Arnold, J. J.; Cygan, M. T.; Dunbar, T. D.; Burgin, T. P.; Jones, L.; Allara, D. L.; Tour, J. M.; Weiss, P. S. Science 1996, $271,1705$. (c) Reed, M. A.; Zhou, C.; Muller, C. J.; Burgin, T. P.; Tour, J. M. Science 1997, 278, 252.

175. McConnell, H. M. J. Chem. Phys. 1961, 35, 508.

176. (a) Franzen, S.; Goldstein, R. F.; Boxer, S. G. J. Phys. Chem. 1993, 97, 3040. (b) Moser, C. C.; Page, C. C.; Farid, R.; Dulton, P. L. J. Bioenerg. and Biomembr. 1995, 27, 263.

177. (a) Homlin, R. E.; Danliker, P. J.; Barton, J. K. Angew. Chem., Int. Ed. Engl. 1995, 34, 352. (b) Meade, T. J. Met. Ions Biol. Syst. 1996, 32 , 453.

178. Cygan, M. T.; Dunbar, T. D.; Arnold, J. J.; Bumm, L. A.; Shedlock, N. F.; Burgin, T. P.; II, L. J.; Allara, D. L.; Tour, J. M.; Weiss, P. S. J. Am. Chem. Soc. 1998, 120, 2721.

179. Purcell, S. T.; Garcia, N.; Binh, V. T.; II, L. J.; Tour, J. M. J. Am. Chem. Soc. 1994, 116, 11985.

180. (a) Finklea, H. O. Electroanal. Chem. 1996, 19, 109. (b) Hsu, C. P.; Marcus, R. A. J. Chem. Phys. 1997, 106,584

181. Pourbaix, M. Atlas of Electrochemical Equilibria in Aqueous Solution; 2nd ed.; Permagon Press; Oxford, 1974.

182. (a) Babcock, G. T.; Wikström, M. Nature 1992, 356, 301. (b) Malmström, B. G. Acc. Chem. Res. 1993, 26, 332. (c) Tommos, C.; Babcock, G. T. Acc. Chem. Res. 1998, 31, 18.

183. Cukier, R. I.; Nocera, D. G. Annu. Rev. Phys. Chem. 1998, 49, 337; e referências citadas.

184. Spencer, S. J.; Blaho, J. K.; Lehnes, J.; Goldsby, K. A. Coord. Chem. Rev. 1998, 174, 391; e referências citadas.

185. (a) Birge, R. R. Annu. Rev. Phys. Chem. 1990, 41, 683. (b) Scherl, M.; Haarer, D.; Fisher, J.; DeCian, A.; Lehn, J.-M.; Eichen, Y. J. Phys. Chem. 1996, 100, 16175.

186. (a) Moyer, B. A.; Meyer, T. J. Inorg. Chem. 1981, 20, 436. (b) Johnson, C.; Henderson, W.; Shepherd, R. E. Inorg. Chem. 1984, $23,2754$.

187. (a) Vlcek, A. A. Prog. Inorg. Chem. 1963, 5, 211. (b) Osteryoung, J. J. Chem. Educ. 1983, 60, 296. (c) Mabbott, G. A. J. Chem. Educ. 1983, 60, 697. (d) Kissinger, P. T.; Heineman, W. R. J. Chem. Educ. 1983, 60, 702. (e) Heinze, J. Angew. Chem., Int. Ed. Engl. 1984, $23,831$.

188. Evans, D. H.; O'Connell, K. M.; Petersen, R. A.; Kelly, M. J. J. Chem. Educ. 1983, 60, 290.

189. (a) Campbell, J. A.; Whitaker, R. A. J. Chem. Educ. 1969, 46, 90. (b) Barnum, D. W. J. Chem. Educ. 1982, 59, 809.

190. Angus, J. C.; Lu, B.; Zappia, M. J. J. Appl. Electrochem. 1987, 17, 1.

191. Werner, A. Berichte 1907, 40, 765.

192. Fraser, R. T. M. In Werner Centennial; Kauffman, G. B., Ed.; Advances in Chemistry Series (62); American Chemical Society; Washington, DC, 1967, p 295.

193. (a) Penland, R. V.; Lane, T. J.; Quagliano, J. V. J. Am. Chem. Soc. 1958, 80, 527. (b) Nakamoto, K.; Fujita, J.; Murata, H. J. Am. Chem. Soc. 1958, 80,4817

194. (a) Hohman, W. H. J. Chem. Educ. 1974, 5I, 553. (b) Jackson, W. G.; Lawrance, G. A.; Lay, P. A.; Sargeson, A. M. J. Chem. Educ. 1981, 58, 734. (c) Jackson, W. G. J. Chem. Educ. 1991, 68, 903.

195. Phillips, W. M.; Choi, S. H.; Larrabee, J. A. J. Chem. Educ. 1990, 67, 267.

196. (a) Burmeister, J. L. Coord. Chem. Rev. 1966, 1, 205. (b) Basolo, F.; Pearson, R. G. Mechanisms of Inorganic Reactions; John Wiley; New York, 1967; p 293. (c) Burmeister, J. L. Coord. Chem. Rev. 1968, 3, 225. (d) Kauffman, G. B. Coord Chem. Rev. $1973,11,161$. (e) Balahura, R. J.; Lewis, N. A. Coord. Chem. Rev. 1976, 20, 109. (f) Jackson, W. G.; Sargeson, A. M. In Rearrangements in Ground and Excited States; de Mayo, P., Ed.; Academic Press; New York, 1980; Vol. 2, p 273. (g) Hitchman, M. A.; Rowbottom, G. L. Coord. Chem. Rev. 1982, 42, 55 .

197. (a) Bailey, R. A.; Kozak, S. L.; Michelsen, T. W.; Mills, W. N. Coord. Chem. Rev. 1971, 6, 407. (b) Buckingham, D. A. Coord. Chem. Rev. 1994, 135, 587.

198. (a) Szecsy, A. P.; Haim, A. J. Am. Chem. Soc. 1982, 104, 3063. (b) Harman, W. D.; Taube, H. J. Am. Chem. Soc. $1988,110,5403$. (c) Allgeier, A. M; Mirkin, C. A. Angew. Chem., Int. Ed. Engl. 1998, 37, 894.

199. (a) Yeh, A.; Scott, N.; Taube, H. Inorg. Chem. 1982, 21, 2542. (b) Sano, M.; Taube, H. J. Am. Chem. Soc. 1991, 113, 2327. (c) Tomita, A.; Sano, M. Inorg. Chem. 1994, 33, 5825.

200. Ooyama, D.; Nagao, N.; Nagao, H.; Miura, Y.; Hasegawa, A.; Ando, K.; Howell, F. S.; Mukaida, M.; Tanaka, K. Inorg. Chem. 1995, 34, 6024. 
201. Delmedico, A.; Pietro, W. J.; Lever, A. B. P. Inorg. Chim. Acta 1998, 281, 126.

202. da Cunha, C. J.; Dodsworth, E. S.; Monteiro, M. A.; Lever, A. B. P. Inorg. Chem. 1999, 38, 5399.

203. (a) Johnson, D. A.; Dew, V. C. Inorg. Chem. 1979, 18, 3273. (b) Alessio, E.; Faleschini, P.; Santi, A. S. O.; Mestroni, G.; Calligaris, M. Inorg. Chem. 1993, 32, 5756. (c) Boldyreva, E. V.; Virovets, A. V.; Burleva, L. P.; Dulepov, V. E.; Podberezskaya, N. V. J. Struct. Chem. 1993, 34, 602. (d) Jackson, W. G.; Jurisson, S. S.; Oleary, M. A. Inorg. Chem. 1993, 32, 445. (e) Yamanari, K.; Kida, M.; Yamamoto, M.; Fujihara, T.; Fuyuhiro, A.; Kaizaki, S. J. Chem. Soc., Dalton Trans. 1996, 305. (f) Murata, M.; Kojima, M.; Hioki, A.; Miyagawa, M.; Hirotsu, M.; Nakajima, K.; Kita, M.; Kashino, S.; Yoshikawa, Y. Coord Chem. Rev. 1998, 174, 109. (g) Fomitchev, D. V.; Coppens, P. Comment. Inorg. Chem. 1999, 21, 131. (h) Smith, M. K.; Gibson, J. A.; Young, C. G.; Broomhead, J. A.; Junk, P. C.; Keene, F. R. Eur. J. Inorg. Chem. 2000, 1365.

204. Wang, R,; Vos, J. G.; Schmehl, R. H.; Hage, R. J. Am. Chem. Soc. 1992, 114, 1964.

205. (a) Cosmano, R. J.; House, J. E. Thermochim. Acta 1975, 13, 127. (b) Buckingham, D. A.; Clark, C. R.; Liddell, G. F.; Simpson, J. Atust. J. Chem. 1993, 46, 503. (c) Boldyreva, E.; Kivikoski, J.; Howard, J. A. K. Acta Crystallogr. B 1997, 53, 394.

206. Delmedico, A.; Auburn, P. R.; Dodsworth, E. S.; Lever, A. B. P.; Pietro, W. J. Inorg. Chem. 1994, 33, 1583.

207. Dalbies, R.; Boudvillain, M.; Leng, M. Nucleic Acids Res. 1995, 23, 949.

208. Fairlie, D. P.; Angus, P. M.; Fenn, M. D.; Jackson, W. G. Inorg. Chem. 1991, 30, 1564.

209. (a) Myers, W. H.; Koontz, J. I.; Harman, W. D. J. Am. Chem. Soc. 1992, 114, 5684. (b) Delmedico, A.; Fielder, S. S.; Lever, A. B. P.; Pietro, W. J. Inorg. Chem. 1995, 34, 1507. (c) Angus, P. M.; Jackson, W. G. Inorg. Chem. 1996, 35, 7196.

210. Angus, P. M.; Jackson, W. G. Inorg. Chem. 1994, 33, 477.

211. (a) Burmeister, J. L; Hassel, R. L.; Phelan, R. J. Inorg. Chem. 1971, 10, 2032. (b) Jackson, W. G.; Lawrance, G. A.; Lay, P. A.; Sargeson, A. M. Aust. J. Chem. 1982, 35, 1561. (c) Hubinger, S.; Purcell, W. L. Inorg. Chem. 1991, 30, 3707. (d) Hubbard, J. L.; Zoch, C. R.; Elcesser, W. L. Inorg. Chem. 1993, 32, 3333. (e) Lelj, F.; Adamo, C. Theor. Chim. Acta 1995, 91, 199. (f) Cini, R.; Fanizzi, F. P.; Intini, F. P.; Natile, G.; Pacifico, C. Inorg. Chim. Acta 1996, 251, 111. (g) Angus, P. M.; Jackson, W. G. Inorg. Chim. Acta 1998, $268,85$.

212. (a) Danon, J.; Muniz, R. P. A.; Caride, A. O; Wolfson, I. J. Mol. Struct. 1967, 1, 127. (b) Gaswick, D.; Haim, A. J. Inorg. Nucl. Chem. 1978, 40, 437. (c) Zhu, N. Y.; Vahrenkamp, H. Angew. Chem., Int. Ed. Engl. 1994, 33, 2090. (d) Rievaj, M.; Bustin, D.; Riccieri, P.; Zinato, E. Inorg. Chim. Acta 1995, 228, 153. (e) Thompson, D. W.; Schoonover, J. R.; Meyer, T. J.; Argazzi, R.; Bignozzi, C. A. J. Chem. Soc., Dalton Trans. 1999, 3729.

213. (a) Basolo, F.; Burmeister, J. L.; Poe, A. J. J. Am. Chem. Soc. 1963, 85, 1700. (b) Ogino, H.; Isago, H. Chem. Lett. 1984, 561. (c) Jurisson, S.; Halihan, M. M.; Lydon, J. D.; Barnes, C. L.; Nowotnik, D. P.; Nunn, A. D. Inorg. Chem. 1998, 37, 1922.

214. (a) Murmann, R. K.; Taube, H. J. Am. Chem. Soc. 1956, 78, 4886. (b) Johnson, D. A.; Pashman, K. A. Inorg. Nucl. Chem. Lett. 1975, 11 , 23. (c) Boldyreva, E. V.; Kuzmina, S. L.; Ahsbahs, H. J. Struct. Chem. 1998, 39, 762.

215. (a) Collman, J. P.; Sun, J. Y. Inorg. Chem. 1965, 4, 1273. (b) Iyengar, R. R.; Bose, K. S.; Patel, C. C. J. Inorg. Nucl. Chem. 1975, 37 , 75. (c) Sado, M.; Ozawa, T.; Jitsukawa, K.; Einaga, H. Polyhedron 1996, 15, 103.

216. (a) Schmidt, R. R.; Losch, G. R.; Fischer, P. Chem. Ber. 1980, 113, 2891. (b) Horrocks, W. D.; Ishley, J. N.; Whittle, R. R. Inorg. Chem. 1982, 21, 3270. (c) Blackman, A. In Advances in Heterocyclic Chemistry, Vol 58; Advances in Heterocyclic Chemistry, 1993; Vol. 58, p 123. (d) Johnson, A.; Oconnell, L. A; Clarke, M. J. Inorg. Chim. Acta 1993, 210, 151. (e) Sovago, I.; Kiss, A.; Lippert, B. J. Chem. Soc., Dalton Trans. 1995, 489. (f) Boudvillain, M.; Guerin, M.; Dalbies, R.; SaisonBehmoaras, T.; Leng, M. Biochemistry 1997, $36,2925$. (g) Guo, Z. J.; Sadler, P. J. Angew. Chem., Int. Ed. Engl. 1999, 38, 1513. (h) Arpalahti, J.; Klika, K. D.; Molander, S. Eur. J. Inorg. Chem. 2000, 1007.

217. Purcell, W. L. Inorg. Chem. 1983, 22, 1205.

218. Jackson, W. G.; Lawrance, G. A.; Lay, P. A.; Sargenson, A. M. Inorg. Chem. 1980, 19, 904.

219. Armor, J. N.; Taube, H. J. Am. Chem. Soc. 1970, 92, 2560.

220. Ellis, W. R.; Purcell, W. L. Inorg. Chem. 1982, 21, 834.

221. Nelson, J. H.; Schmitt, D. L.; Henry, R. A; Moore, D. W.; Jonassen, H. B. Inorg. Chem. 1970, 9, 2678.

222. Redfield, D. A.; Nelson, J. H.; Henry, R. A.; Moore, D. W.; Jonassen, H. B. J. Am. Chem. Soc. 1974, 96, 6298.

223. Toma, H. E.; Malin, J. M. Inorg. Chem. 1973, 12, 1039.

224. Toma, H. E.; Malin, J. M. Inorg. Chem. 1973, 12, 2080.

225. (a) Toma, H. E.; Malin, J. M.; Giesbrecht, E. Inorg. Chem. 1973, 12, 2084. (b) Malin, J. M.; Toma, H. E.; Giesbrecht, E. J. Chem. Educ. 1977, 54, 385. (c) Toma, H. E.; Takasugi, M. S. Polyhedron 1982, 1, 429. 
226. Toma, H. E.; Malin, J. M. Inorg. Chem. 1974, 13, 1772.

227. Toma, H. E.; Martins, J. M.; Giesbrecht, E. J. Chem. Soc., Dalton Trans. 1978, 1610.

228. Batista, A. A.; Toma, H. E. An. Acad. Bras. Cienc. 1980, 52, 703.

229. Toma, H. E.; Batista, A. A.; Gray, H. B. J. Am. Chem. Soc. 1982, 104, 7509.

230. Toma, H. E.; Takayasu, M. M. An. Acad. Bras. Cienc. 1989, 6I, 131.

231. (a) Batista, A. A. Cinética da interação da metionina-sulfóxido e metionina-sulfona com o ion pentacianoferrato (Dissertação de Mestrado; Orientador: Toma, H. E.) Instituto de Química - Universidade de São Paulo, São Paulo, 1978. (b) Batista, A. A. Química bioinorganica dos cianoferratos (Tese de Doutorado; Orientador: Toma, H. E.) Instituto de Química - Universidade de São Paulo, São Paulo, 1982.

232. de Oliveira, L. A. A. Cinética e mecanismo de transferência de elétrons no íon pentaamin(dimetilsulfóxido)cobalto(III) (Tese de Doutorado; Orientador: Giesbrecht, E.) Instituto de Química - Universidade de São Paulo, São Paulo, 1977.

233. (a) de Oliveira, L. A. A.; Toma, H. E.; Giesbrecht, E. Inorg. Chim. Acta 1977, 22, 269. (b) de Oliveira, L. A. A.; Giesbrecht, E.; Toma, H. E. J. Chem. Soc., Dalton Trans. 1979, 236.

234. Sano, M.; Taube, H. Inorg. Chem. 1994, 33, 705.

235. Toma, H. E.; Araki, K. J. Coord. Chem. 1991, 24, 1.

236. Silva, D. O.; Toma, H. E. Can. J. Chem. 1994, 72, 1705.

237. Toma, H. E.; Alexiou, A. D. P. Electrochim. Acta 1993, 38, 975.

238. Rein, F. N. Estudo espectroscópico e eletroquímico de complexos de Ru-edta com ligantes $\mathrm{N}$-heterociclicos polifuncionais (Dissertação de Mestrado; Orientador: Toma, H. E.) Instituto de Química - Universidade de São Paulo, São Paulo, 1995.

239. Rein, F. N. Estudo da quimica dioxolenos de rutênio (Tese de Doutorado; Orientador: Toma, H. E.) Instituto de Química - Universidade de São Paulo, São Paulo, 1999.

240. Toma, H. E.; Santos, P. S.; Mattioli, M. P. D.; de Oliveira, L. A. A. Polyhedron 1987, 6, 603.

241. Toma, H. E; Giesbrecht, E.; Rojas, R. L. E. Can. J. Chem. 1983, 61, 2520.

242. Toma, H. E.; Giesbrecht, E.; Rojas, R. L. E. J. Chem. Soc., Dalton Trans. 1985, 2469.

243. Rojas, R. L. E. Estudo das interações do benzotriazol (um inibidor de corrosão) com amincomplexos de rutenio(II)/(III) e pentacianoferrato(II) (Tese de Doutorado; Orientador: Giesbrecht, E.) Instituto de Química - Universidade de São Paulo, São Paulo, 1985.

244. Nicholson, R. S.; Shain, I. Anal. Chem. 1964, 36, 706.

245. Proctor and Gamble Ltd., Brit. Pat. 652, 339 (XII-1947).

246. Walker, R. Anti-Corros. Methods Mater. 1970, 17, 9.

247. Ciba-Geigy, A. G. Ger. Pat. 1521, 758 (V-1971).

248. Ciba-Geigy, A. G. Ger., Offen 2, 155, 676 (V-1972).

249. Unilever, Brit. Pat. 1234, 468 (VI-1971).

250. (a) Walker, R. Corrosion 1973, 29, 290. (b) Walker, R. Corrosion 1975, 31, 97. (c) Walker, R. Corrosion 1976, $32,414$.

251. (a) Madsen, H. B. Stud. in Cons. 1967, 12, 163. (b) Madsen, H. B. Stud. in Cons. 1971, 16, 120.

252. (a) Griess, P. Ber. Dtsch. Chem. Ges. 1882, 15, 1878. (b) Auwers, K. Ber. Dtsch. Chem. Ges. 1938, 7l, 604. (c) Specker, H.; Gawrosh, H. Ber. Dtsch. Chem. Ges. 1942, 75, 1338.

253. O'Sullivan, D. G. J. Chem. Soc. 1960, 3653.

254. Cordes, M. M.; Walter, J. L. Spectrochim. Acta A 1968, 24, 1421.

255. (a) Rubim, J. C. Uso do espalhamento Ramam intensificado pela superficie no estudo de inibidor de corrosão (benzotriazol) adsorvido em eletrodos (Dissertação de Mestrado; Orientador: Sala, O.) Instituto de Química - Universidade de São Paulo, São Paulo, 1982. (b) Rubim, J. C.; Gutz, I. G. R.; Sala, O. J. Mol. Struct. 1983, 101, 1. (c) Rubim, J. C.; Gutz, I. G. R.; Sala, O.; OrvilleThomas, W. J. J. Mol. Struct. 1983, 100, 571. (d) Rubim, J. C. Chem. Phys. Lett. 1990, 167, 209. (e) Rubim, J. C.; Kim, J. H.; Henderson, E.; Cotton, T. M. Appl. Spectrosc. 1993, 47, 80 .

256. Escande, A.; Galigné, J. L.; Lapasset, J. Acta Crystallogr. B 1974, 30, 1490.

257. (a) DelBene, J.; Jaffe, H. H. J. Chem. Phys. 1968, 48, 1807. (b) DelBene, J.; Jaffe, H. H. J. Chem. Phys. 1968, 48, 4050. (c) DelBene, J.; Jaffe, H. H. J. Chem. Phys. 1968, 49, 1221. (d) DelBene, J.; Jaffe, H. H. J. Chem. Phys. 1969, 50, 1226. (e) Escande, A.; Lapasset, J.; Faure, R.; Vincent, E. J.; Elguero, J. Tetrahedron 1974, 30, 2903.

258. Rondeau, R. E.; Rosenberg, H. M.; Dunbar, D. J. J. Mol. Spectrosc. 1968, $26,139$.

259. Pugmire, R. J.; Grant, D. M. J. Am. Chem. Soc. 1971, 93, 1880. 
260. (a) Wilson, R. F.; Joe, F. L. J. Inorg. Nucl. Chem. 1960, 15, 255. (b) Wilson, R. F. Z. Anorg. Allg. Chem. 1962, 318, 233. (c) Sotofte, I.; Nielsen, K. Acta Chem. Scand. A 1981, 35, 733. (d) Sotofte, I.; Nielsen, K. Acta Chem. Scand A 1981, 35, 739. (e) Sotofte, I.; Nielsen, K. Acta Chem. Scand. A 1981, 35, 747. (f) Sotofte, I.; Nielsen, K. Acta Chem. Scand A 1983, 37, 891. (g) Sotofte, I.; Nielsen, K. Acta Crystallogr. A 1984, 40, C309. (h) Sotofte, I.; Nielsen, K. Acta Chem. Scand A 1984, 38, 253. (i) Sotofte, I.; Nielsen, K. Acta Chem. Scand. A 1984, 38, 257. (j) Aleksandrov, G. G.; Babin, V. N.; Kharchevnikov, A. P.; Struchkov, Y. T.; Kochetkova, N. S. J. Organomet. Chem. 1984, 266, 109. (k) Moore, D. S.; Robinson, S. D. Adv. Inorg. Chem. 1986, 30, 1. (l) Hursthouse, M. B.; Short, R. L.; Robinson, S. D. Polyhedron 1986, 5, 1573. (m) Moore, D. S.; Robinson, S. D. Adv. Inorg. Chem. 1988, 32, 171. (n) Olby, B. G.; Robinson, S. D.; Hursthouse, M. B.; Short, R. L. Polyhedron 1988, 7, 1781. (o) Bajaj, H. C.; Vaneldik, R. Inorg. Chem. 1990, 29, 2855. (p) Olby, B. G.; Robinson, S. D.; Hursthouse, M. B.; Short, R. L. J. Chem. Soc., Dalton Trans. 1990, 621.

261. (a) Reedijk, J. In Comprehensive Coordination Chemistry; Wilkinson, G., Gillard, R. D., McCleverty, J. A., Eds.; Pergamon Press; Oxford, 1987; Vol. 2. (b) Steel, P. J. Coord. Chem. Rev. 1990, 106, 227.

262. Constable, E. C.; Steel, P. J. Coord. Chem. Rev. 1989, 93, 205.

263. (a) Guss, J. M; Merritt, E. A.; Phizackerley, R. P.; Hedman, B.; Murata, M.; Hodgson, K. O.; Freeman, H. C. Science 1988, 241 , 806. (b) Godden, J. W.; Turley, S.; Teller, D. C.; Adman, E. T.; Liu, M.-Y.; Payne, W. J.; LeGall, J. Science 1993, $253,3104$.

264. Sundberg, R. J.; Martin, R. B. Chem. Rev. 1974, 74, 471.

265. (a) Haga, M. Inorg. Chim. Acta 1983, 75, 29. (b) Hatzidimitriou, A.; Gourdon, A.; Devillers, J.; Launay, J.-P.; Mena, E.; Amouyal, E. Inorg. Chem. 1996, 35, 2212. (c) Iwamoto, M.; Alessio, E.; Marzilli, L. G. Inorg. Chem. 1996, 35, 2384. (d) Clarke, M. J.; Bailey, V. M.; Doan, P. E.; Hiller, C. D.; Lachancegalang, K. J.; Daghlian, H.; Mandal, S.; Bastos, C. M. Inorg. Chem. 1996, 35, 4896. (e) Geremia, S.; Alessio, E.; Todone, F. Inorg. Chim. Acta 1996, 253, 87.

266. Ohno, T.; Nozaki, K.; Haga, M. Inorg. Chem. 1992, 31, 548.

267. Reddy, K. B.; Cho, M. O. P.; Wishart, J. F.; Emge, T. J.; Isied, S. S. Inorg. Chem. 1996, 35, 7241

268. Clarke, M. J.; Stubbs, M. Met. Ions Biol. Syst. 1996, 32, 727.

269. (a) Clarke, M. J. Ruthenium and Other Non-Platinum Metal Complexes in Cancer Chemotherapy; Springer-Verlag; Germany, 1989 ; Vol. 10. (b) Keppler, B. K. Metal Complexes in CancerChemotherapy; VCH; Germany, 1993.

270. McNamara, M.; Clarke, M. J. Inorg. Chim. Acta 1992, 195, 175.

271. Dhubhghaill, O. M. N.; Hagen, W.; Keppler, B. K.; Lipponer, K.-G. L.; Sadler, J. L. J. Chem. Soc., Dalton Trans. $1994,3305$.

272. Sundberg, R. J.; Bryan, R. F.; Taylor, I. F.; Taube, H. J. Am. Chem. Soc. 1974, 96, 381

273. Clarke, M. J.; Taube, H. J. Am. Chem. Soc. 1975, 97, 1397.

274. (a) Shepherd, R. E. J. Am. Chem. Soc. 1976, 98, 3329. (b) Johnson, C. R.; Shepherd, R. E. Synth. React. Inorg. Met.-Org. Chem. 1984, 14, 339.

275. Walters, M. A.; Spiro, T. G. Inorg. Chem. 1983, 22, 4014.

276. Jones, C. M.; Jonhson, C. R; Asher, S. A.; Shepherd, R. E. J. Am. Chem. Soc. 1985, 107, 3772.

277. Gross, R.; Kaim, W. Inorg. Chem. 1986, 25, 4865; e referências citadas.

278. (a) Isied, S. S.; Kuehn, C. G. J. Am. Chem. Soc. 1978, 100, 6754. (b) Szeczy, A. P.; Haim, A. J. Am. Chem. Soc. 1981, $103,1679$.

279. Parise, A. R.; Baraldo, L. M.; Olabe, J. A. Inorg. Chem. 1996, 35, 5080.

280. Tha, N. Y. M. Reatividade de ligantes na química dos cianoferratos (Tese de Doutorado; Orientador: Toma, H. E.) Instituto de Química Universidade de São Paulo, São Paulo, 1981.

281. Glockle, M.; Kaim, W. Angew. Chem., Int. Ed. Engl. 1999, 38, 3072.

282. (a) Toma, H. E. Influências das interações de transferência de elétrons no comportamento dos complexos de pentaaminrutênio(II) e de pentacianoferrato(II) com ligantes insaturados (Tese de Doutorado; Orientador: Malin, J. M.) Instituto de Química - Universidade de São Paulo, São Paulo, 1974. (b) Toma, H. E. Cianoferratos: correlação de estrutura, reatividade e intervalência (Tese de Livre Docência) Instituto de Química - Universidade de São Paulo, São Paulo, 1979.

283. Ford, P.; Rudd, D. F. P.; Gaunder, R.; Taube, H. J. Am. Chem. Soc. 1968, 90, 1187

284. Tfouni, E. Coord Chem. Rev. 2000, 196, 281; e referências citadas.

285. Treadway, J. A.; Meyer, T. J. Inorg. Chem. 1999, 38, 2267.

286. (a) Mukaida, M.; Okuno, H.; Ishimori, T. Nippon Kagaku Zasshi 1965, 86, 589. (b) Yoshino, Y.; Uehiro, T.; Saito, M. Bull. Chem. Soc. Jpn. $1979,52,1060$.

287. Shimizu, K.; Matsubar.T; Sato, G. P. Bull. Chem. Soc. Jpn. 1974, 47, 1651. 
288. Vogt, L. H.; Katz, J. L.; Wiberly, S. E. Inorg. Chem. 1965, 4, 1157.

289. Brauer, G. Handbook of Preparative Inorganic Chemistry; 2nd ed.; Academic Press; New York, 1965; Vol. 2; 1511.

290. (a) Gleu, V. K.; Breuel, W. Z. Anorg. Allg. Chem. 1938, 197. (b) Gleu, V. K.; Breuel, W. Z. Anorg. Allg. Chem. 1938, 237. (c) Gleu, V. K.; Breuel, W. Z. Anorg. Allg. Chem. 1938, 335.

291. Sullivan, B. P.; Salmon, D. J.; Meyer, T. J. Inorg. Chem. 1978, 17, 3334.

292. Hansen, L. D.; West, B. D.; Baca, E. J.; Blank, C. L. J. Am. Chem. Soc. 1968, 90, 6588.

293. Waiba, H.; Isensee, R. W. J. Org. Chem. 1961, 26, 2789.

294. Zwickel, A. M.; Creutz, C. Inorg. Chem. 1971, 10, 2395.

295. Lim, H. S.; Barclay, D. J.; Anson, F. C. Inorg. Chem. 1972, 11, 1460.

296. Toma, H. E.; Sernaglia, R. L. Talonta 1995, 42, 1867.

297. Sullivan, B. P.; Conrad, D.; Meyer, T. J. Inorg. Chem. 1985, 24, 3640.

298. (a) Dobson, J. C.; Helms, J. H.; Doppelt, P.; Sullivan, B. P.; Hatfield, W. E.; Meyer, T. J. Inorg. Chem. 1989, 28, 2200. (b) Hua, X.; Lappin, A. G. Inorg. Chem. 1995, 34, 992.

299. Felix, F.; Ludi, A. Inorg. Chem. 1978, 17, 1782.

300. Das, A.; Bajaj, H. C. Polyhedron 1997, 16, 1023.

301. (a) Chatterjee, D.; Bajaj, H. C.; Das, A. Inorg. Chem. 1993, 32, 4049. (b) Bajaj, H. C.; Das, A. Polyhedron 1997, 16, 3851. (c) Forlano, P.; Cukiernik, F. D.; Poizat, O;; Olabe, J. A. J. Chem. Soc., Dalton Trans. 1997, 1595. (d) Chatterjee, D. Polyhedron 1999, $18,1767$.

302. Sawyer, D. T.; Roberts Jr., J. L. Experimental Electrochemistry for Chemists; John Wiley \& Sons; 1974; p 212.

303. (a) Taqui-Khan, M. M.; Ramachandraiah, G. Inorg. Chem. 1982, 21, 2109. (b) Baar, R. B.; Anson, F. C. J. Electroanal. Chem. 1985, 187, 265. (c) Khan, M. M. T.; Siddiqui, M. R. H.; Hussain, A.; Moiz, M. A. Inorg. Chem. 1986, 25, 2765. (d) Khan, M. M. T.; Hussain, A.; Ramachandraiah, G.; Moiz, M. A. Inorg. Chem. 1986, 25, 3023. (e) Zhang, S. S.; Shepherd, R. E. Inorg. Chem. 1988, 27, 4712. (f) Zhou, J. H.; Xi, W.; Hurst, J. K. Inorg. Chem. 1990, 29, 160.

304. Britton, H. T. S.; Robinson, R. A. J. Chem. Soc. 1931, 458, 1456.

305. Espenson, J. H. Chemical Kinetics and Reaction Mechanisms; 2nd ed.; McGraw-Hill; New York, 1995.

306. Brown, E. R.; Large, R. F. In Techniques of Chemistry - Physical Methods; Weissberger, A., Rossiter, B. W., Eds.; Wiley-Interscience; New York, 1971; Vol. I; Part II-A: Electrochemical Methods.

307. Matsumoto, F. M. Eletrodos quimicamente modificados com filmes de pentacianoferratos (Tese de Doutorado; Orientador: Toma, H. E.) Instituto de Química - Universidade de São Paulo, São Paulo, 1995.

308. Stewart, J. J. P. In Reviews in Computational Chemistry; Boyd, D. B., Lipkowitz, K. B., Eds.; VCH, 1991; Vol. 1, p 45.

309. Zerner, M. C. In Reviews in Computational Chemistry; Boyd, D. B., Lipkowitz, K. B., Eds.; VCH, 1991; Vol. 2 , p 313.

310. (a) Ridley, J. E.; Zemer, M. C. Theor. Chim. Acta 1973, 32, 111. (b) Ridley, J. E.; Zemer, M. C. Theor. Chim. Acta 1976, 42, 223. (c) Bacon, A. D.; Zerner, M. C. Theor. Chim. Acta 1979, 53, 21. (d) Zerner, M. C.; Loew, G. H.; Kirchner, R. F.; Mueller-Westerhoff, U. T. J. Am. Chem. Soc. 1980, 102, 589.

311. Hehre, W. J.; Radom, L.; Schleyer, P. V. R.; Pople, J. A. Ab Initio Molecular Orbital Theory; Wiley-Interscience; New York, 1986.

312. Allinger, N. L. J. Am. Chem. Soc. 1977, 99, 8127.

313. Matsubara, T.; Creutz, C. Inorg. Chem. 1979, 18, 1956.

314. Okamoto, K.; Hidaka, J.; Iida, I.; Higashino, K.; Kanamori, K. Acta Crystallogr. C 1990, 46, 2327.

315. Shepherd, R. E.; Taube, H. Inorg. Chem. 1973, 12, 1392.

316. Toma, H. E.; Creutz, C. Inarg. Chem. 1977, 16, 545.

317. Katz, N. E.; Creutz, C.; Sutin, N. Inorg. Chem. 1988, 27, 1687.

318. Creutz, C.; Kroger, P.; Matsubara, T.; Netzel, T. L.; Sutin, N. J. Am. Chem. Soc. 1979, 101, 5442.

319. Salaymeh, F.; Berhane, S.; Yusof, R.; Delarosa, R.; Fung, E. Y.; Matamoros, R.; Lau, K. W.; Zheng, Q.; Kober, E. M.; Curtis, J. C. Inorg. Chem. 1993, 32, 3895.

320. Callahan, R. W.; Brown, G. M.; Meyer, T. J. Inorg. Chem. 1975, 14, 1443.

321. Reimers, J. R.; Hush, N. S. Adv. Chem. Ser. 1990, 226, 27.

322. Meyer, T. J. Acc. Chem. Res. 1978, 11,94.

323. Newton, M. D. Chem. Rev. 1991, 91, 767. 
324. (a) Chang, J. P.; Fung, E. Y.; Curtis, J. C. Inorg. Chem. 1986, 25, 4233. (b) Creutz, C.; Chou, M. H. Inorg. Chem. 1987, 26, 2995. (c) Saleh, A. A.; Crutchley, R. J. Inorg. Chem. 1990, 29, 2132. (d) Mao, W. L.; Qian, Z.; Yen, H. J.; Curtis, J. C. J. Am. Chem. Soc. 1996, $118,3247$. (e) Zeng, J.; Hush, N. S.; Reimers, J. R. J. Am. Chem. Soc. 1996, 118, 2059. (f) Hush, N. S.; Reimers, J. R. Coord. Chem. Rev. $1998,177,37$.

325. Marcus, Y. Chem. Soc. Rev. 1993, 22, 409.

326. Toma, H. E.; Santos, P. S. Can. J. Chem. 1977, 55, 3549.

327. Yeh, A.; Haim, A. J. Am. Chem. Soc. 1985, 107, 369.

328. Burewicz, A; Haim, A. Inorg. Chem. 1988, 27, 1611.

329. Olabe, J. A.; Haim, A. Inorg. Chem. 1989, 28, 3277.

330. Huang, H. Y.; Chen, W. J.; Yang, C. C.; Yeh, A. Inorg. Chem. 1991, 30, 1862.

331. Lin, C. L.; Hung, K.; Yeh, A.; Tsen, H. T.; Su, C. C. Inorg. Chem. 1999, 38, 411.

332. Almaraz, A. E.; Gentil, L. A.; Baraldo, L. M.; Olabe, J. A. Inorg. Chem. 1996, 35, 7718.

333. Nakamoto, K. Infrared and Raman Spectra of Inorganic and Coordination Compounds; $5^{\mathrm{a}}$ ed.; Wiley-Interscience; New York, 1997.

334. (a) Wilmshurst, J. K. Can. J. Chem. 1960, 38, 467. (b) Sacconi, L.; Sabatini, A.; Gans, P. Inorg. Chem. 1964, $3,1772$.

335. Fairey, M. B.; Irving, R. J. Spectrochim. Acta 1966, 22, 359

336. Allen, A. D.; Senoff, C. V. Can. J. Chem. 1967, 45, 1337.

337. Herington, E. F.; Kynaston, W. J. Chem. Soc. 1955, 3555.

338. Cutin, E. H.; Katz, N. E. Polyhedron 1991, 10, 653.

339. Isied, S. S., Ed. Electron Transfer Reactions: Inorganic, Organometallic, and Biological Applications; Advances in Chemistry Series (253); American Chemical Society; Washington, DC, 1997.

340. (a) Shriver, D. F.; Atkins, P. W.; Langford, C. H. Inorganic Chemistry; Oxford University Press; Oxford, 1990; Cap. 15; p 474. (b) Huheey, J. E.; Keiter, E. A.; Keiter, R. L. Inorganic Chemistry: Principles of Structure and Reactivity; 4a ed.; HarperCollins College Pub.; New York, 1993; Cap. 13; p 543.

341. Morino, L. A.; Toma, H. E. Talanta 1984, 31, 224.

342. Araki, K.; Toma, H. E. J. Electroanal. Chem. 1991, 297, 301.

343. (a) Dwyer, F. P.; Goodwin, H. A; Gyarfas, E. C. Aust. J. Chem. 1963, 16, 42. (b) Bosnich, B.; Dwyer, F. P. Aust. J. Chem. 1966, 19, 2229. (c) Dwyer, F. P.; Goodwin, H. A.; Gyarfas, E. C. Aust. J. Chem. 1963, 16, 544.

344. (a) Fergusson, J. E.; Harris, G. M. J. Chem. Soc, A 1966, 1293. (b) Bryant, G. M.; Fergusson, J. E. Aust. J. Chem. 1971, $24,275$.

345. Bryant, G. M.; Fergusson, J. E.; Powell, H. K. Aust. J. Chem. 1971, $24,257$.

346. (a) Godwin, J. B.; Meyer, T. J. Inorg. Chem. 1971, 10, 471. (b) Brown, G. M.; Weaver, T. R.; Keene, F. R.; Meyer, T. J. Inorg. Chem. 1976, 15 , 190.

347. Adeyemi, S. A.; Miller, F. J.; Meyer, T. J. Inorg. Chem. 1972, 11, 994.

348. Weaver, T. R.; Adeyemi, S. A.; Brown, G. M;; Eckberg, R. P.; Hatfield, W. E; Johnson, E. C.; Murray, R. W.; Untereker, D.; Meyer, T. J. J. Am. Chem. Soc. 1975, 97, 3039.

349. Ives, D. J. G.; Janz, G. J. Reference Electrodes: Theory and Practice; Academic Press; New York, 1961.

350. (a) De Armond, M. K.; Carlin, C. M. Coord. Chem. Rev. 1981, 36, 325. (b) Vlcek, A. A. Coord. Chem. Rev. 1982, 43, 39.

351. Garcia, E.; Kwak, J.; Bard, A. J. Inorg. Chem. 1988, 27, 4377.

352. Roffia, S.; Casadei, R.; Paolucci, F.; Paradisi, C.; Bignozzi, C. A; Scandola, F. J. Electroanal. Chem. 1991, 302, 157.

353. Lever, A. B. P. Inorganic Electronic Spectroscopy; 2nd ed.; Elsevier; Amsterdam, 1985.

354. Kalyanasundaram, K. Coord Chem. Rev. 1982, 46, 159.

355. (a) Tokel-Takvoryan, N. E.; Hemmingway, R. W.; Bard., A. J. J. Am. Chem. Soc. 1973, 95, 6582. (b) Saji, T.; Aoyagui, S. J. Elecroanal. Chem. Interfacial Electrochem. 1975, 58, 401.

356. (a) Heath, G.; Yellowlees, L.; Braterman, P. Chem. Phys. Lett. 1982, 92, 646. (b) Bugnon, P.; Hester, R. E. Chem. Phys. Lett. $1983,102,537$.

357. (a) Nakamoto, K. J. J. Phys. Chem. 1960, 64, 1420. (b) Gondo, Y. J. Chem. Phys. 1964, 41, 3928.

358. (a) Krumholz, P. J. Am. Chem. Soc. 1953, 75, 2163. (b) Williams, R. J. P. J. Chem. Soc. 1955, 137. (c) Palmer, R. A.; Piper, T. S. Inorg. Chem. 1966, 5, 864. (d) Bosnich, B. Inorg. Chem. 1968, 7, 178. (e) Hanazaki, I.; Nagakura, S. Inorg. Chem. 1969, 8, 648.

359. Brandt, W. W.; Dwyer, F. P.; Gyarfas, E. C. Chem. Rev. 1954, 54, 959.

360. (a) Schilt, A. A. J. Am. Chem. Soc. 1960, 82, 3000. (b) James, B. R.; Parris, M.; Williams, R. J. P. J. Chem. Soc. 1961, 4630. (c) Day, P.; Sanders, N. J. J. Chem. Soc. A 1967, 1530. 
361. Meyer, T. J. Pure Appl. Chem. 1986, 58, 1193.

362. Meyer, T. J. Acc. Chem. Res. 1989, 22, 163.

363. Kalyanasundaram, K.; Grätzel, M. Coord. Chem. Rev. 1986, 69, 57.

364. Long, C.; Vos, J. G. Inorg. Chim. Acta 1984, 89, 125.

365. Vos, J. G.; Haasnoot, J. G.; Vos, G. Inorg. Chim. Acta 1983, 71, 155.

366. Hage, R.; Prins, R.; Haasnoot, J. G.; Reedijk, J.; Vos, J. G. J. Chem. Soc., Dalton Trans. 1987, 1389.

367. Sullivan, B. P.; Salmon, D. J.; Meyer, T. J.; Peedin, J. Inorg. Chem. 1979, 18, 3369.

368. Haga, M. Inorg. Chim. Acta 1980, 45, L183.

369. Ernst, S. D.; Kaim, W. Inorg. Chem. 1989, 28, 1520.

370. Barigelletti, F.; Decola, L.; Balzani, V.; Hage, R.; Haasnoot, J. G.; Reedijk, J.; Vos, J. G. Inorg. Chem. 1989, $28,4344$.

371. (a) Hopfield, J. J.; Onuchic, J. N.; Beratan, D. N. Science 1988, 241, 817. (b) O'Regan, B.; Grätzel, M. Nature 1991, 353, 738. (c) Collin, J. P.; Harriman, A.; Heitz, V.; Odobel, F.; Sauvage, J. P. J. Am. Chem. Soc. 1994, 116, 5679

372. (a) Rillema, D. P.; Callahan, R. W.; Mack, K. B. Inorg. Chem. 1982, 21, 2589. (b) Curtis, J. C.; Bernstein, J. S.; Meyer, T. J. Inorg. Chem. 1985, 24, 385. (c) Hage, R.; Dijkhuis, A. H. J.; Haasnoot, J. G.; Prins, R; Reedijk, J.; Buchanan, B. E.; Vos, J. G. Inorg. Chem. 1988, $27,2185$. (d) Bignozzi, C. A.; Roffia, S.; Chiorboli, C.; Davila, J.; Indelli, M. T.; Scandola, F. Inorg. Chem. 1989, 28, 4350. (e) Kalyanasundaram, K.; Nazeeruddin, M. K. Inorg. Chem. 1990, 29, 1888. (f) Scandola, F.; Bignozzi, C. A.; Chiorboli, C.; Indelli, M. T.; Rampi, M. A. Coord. Chem. Rev. 1990, 97, 299. (g) De Cola, L.; Belser, P.; Ebmeyer, F.; Barigelletti, F.; Vogtle, F.; von Zelewsky, A.; Balzani, V. Inorg. Chem. 1990, 29, 495. (h) Strouse, G. F.; Schoonover, J. R.; Duesing, R.; Meyer, T. J. Inorg. Chem. 1995, 34, 2725. (i) Serromi, S.; Campagna, S.; Denti, G; Keyes, T. E.; Vos, J. G. Inorg. Chem. 1996, 35, 4513.

373. Kaim, W.; Kohlmann, S. Inorg. Chem. 1990, 29, 1898.

374. (a) Ohno, T.; Nozaki, K.; Ikeda, N.; Haga, M. In Electron Transfer in Inorganic, Organic and Biological Systems; Bolton, J. R., Mataga, N., McLendon, G., Eds.; Advances in Chemistry Series (228); American Chemical Society; Washington, DC, 1991, p 215. (b) Ohno, T.; Nozaki, K.; Haga, M. Inorg. Chem. 1992, 31, 4256. (c) Nozaki, K; Ohno, T.; Haga, M. J. Phys. Chem. 1992, 96, 10880. (d) Haga, M.; Ali, M. M.; Maegawa, H.; Nozaki, K; Yoshimura, A.; Ohno, T. Coord. Chem. Rev. 1994, 132, 99. (e) Haga, M.; Ano, T.; Ishizaki, T.; Kano, K; Nozaki, K.; Ohno, T. J. Chem. Soc, Dalton Trans. 1994, 263.

375. (a) Hage, R. Coond. Chem. Rev. 1991, 111, 161. (b) Hage, R.; Haasnoot, J. G.; Nieuwenhuis, H. A.; Reedijk, J.; Wang, R. Y.; Vos, J. G. J. Chem. Soc., Dalton Trans. 1991, 3271. (c) Keyes, T. E.; Vos, J. G.; Kolnaar, J. A.; Haasnoot, J. G.; Reedijk, J.; Hage, R. Inorg. Chim. Acta 1996, 245, 237. (d) Hage, R.; Lempers, H. E. B.; Haasnoot, J. G.; Reedijk, J.; Weldon, F. M.; Vos, J. G. Inorg. Chem. 1997, 36,3139

376. Hage, R.; Haasnoot, J. G.; Reedijk, J.; Wang, R. Y.; Vos, J. G. Inorg. Chem. 1991, 30, 3263.

377. (a) Krentzien, H.; Taube, H. J. Am. Chem. Soc. 1976, 98, 6379. (b) Krentzien, H.; Taube, H. Inorg. Chem. 1982, $21,4001$.

378. (a) Hupp, J. T.; Meyer, T. J. Inorg. Chem. 1987, 26, 2332. (b) Haga, M.; Matsumura, T.; Yamabe, S. Inorg. Chem. 1987, $26,4148$.

379. (a) Murrell, J. N. J. Am. Chem. Soc. 1959, 81, 5037. (b) Murrell, J. N. Quart. Rev. (London) 1961, 15, 191. (c) Bender, C. J. Chem. Soc. Rev. 1986, 15,475 .

380. Solomon, E. I.; Lever, A. B. P., Eds. Inorganic Electronic Structure and Spectroscopy. Methodology; Wiley; New York, 1999; Vol. I.

381. Creutz, C.; Newton, M. D.; Sutin, N. J. Photochem. Photobiol., A 1994, 82, 47.

382. (a) Atkins, P. W. General Chemistry; Scientific American; New York, 1990. (b) Skoog, D. A.; West, D. M.; Holler, F. J. Fundamentals of Analytical Chemistry; $7^{\mathrm{a}}$ ed.; Saunders College Pub.; Fort Worth, 1996.

383. (a) Willard, H. H.; Merritt Jr., L. L.; Dean, J. A.; Settle Jr., F. A. Instrumental Methods of Analysis; $7^{\mathrm{a}}$ ed.; Wadsworth Pub. Co.; California, 1988. (b) Atkins, P. W. Physical Chemistry; $4^{\mathrm{a}}$ ed.; Oxford University Press; Oxford, 1990.

384. Ford, P. C. Coord Chem. Rev. 1970, 5, 75.

385. Stritar, J. A.; Taube, H. Inorg. Chem. 1969, 8, 2281.

386. Baxendale, J. H.; Rodgers, M. A. J.; Ward, M. D. J. Chem. Soc. A 1970, 1246

387. Stasiw, R.; Wilkins, R. G. Inorg. Chem. 1969, 8, 157.

388. Gale, R.; McCaffery, A. J. J. Chem. Soc., Dalton Trans. 1973, 1344. 